SB107 Hylander H85

man

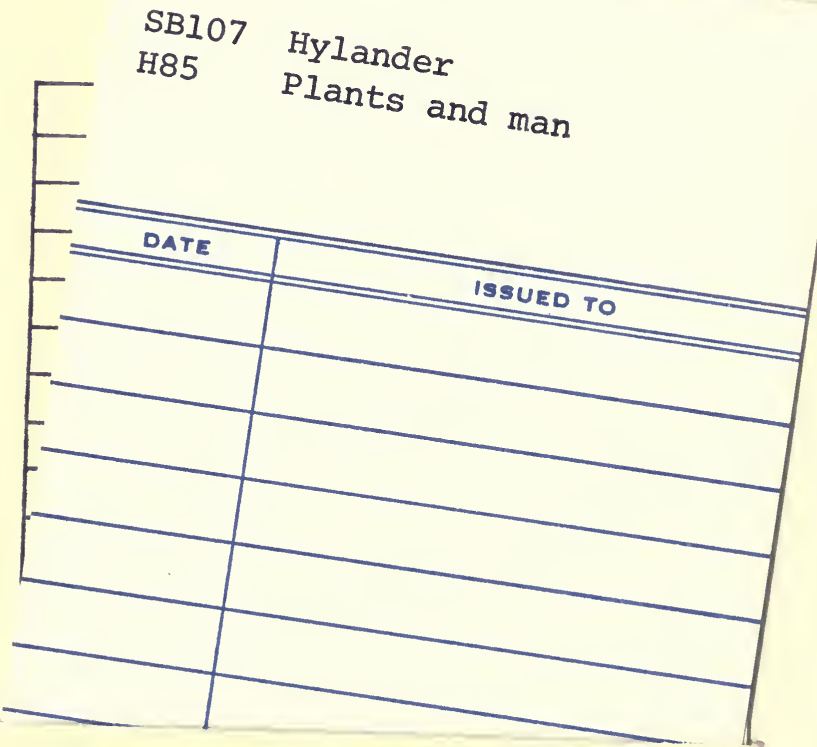

Roresta institute

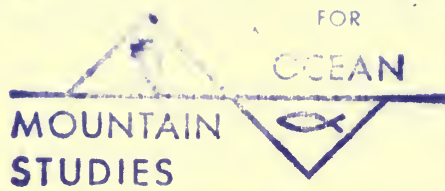

STUDIES

CARSON CITY, NEVADA 9701 
Poresta institute

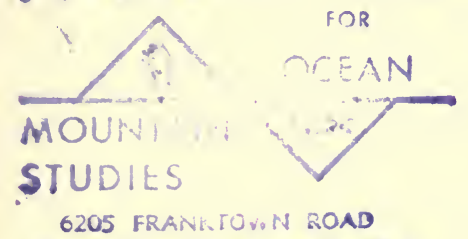

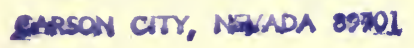

From the collection of the

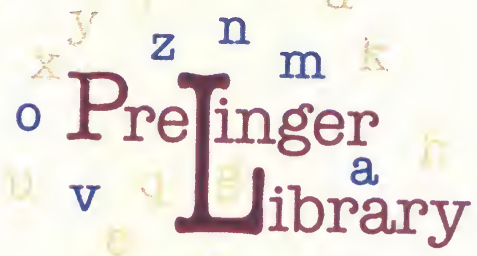

$t=p$

San Francisco, California

2008 

Plants and Man 


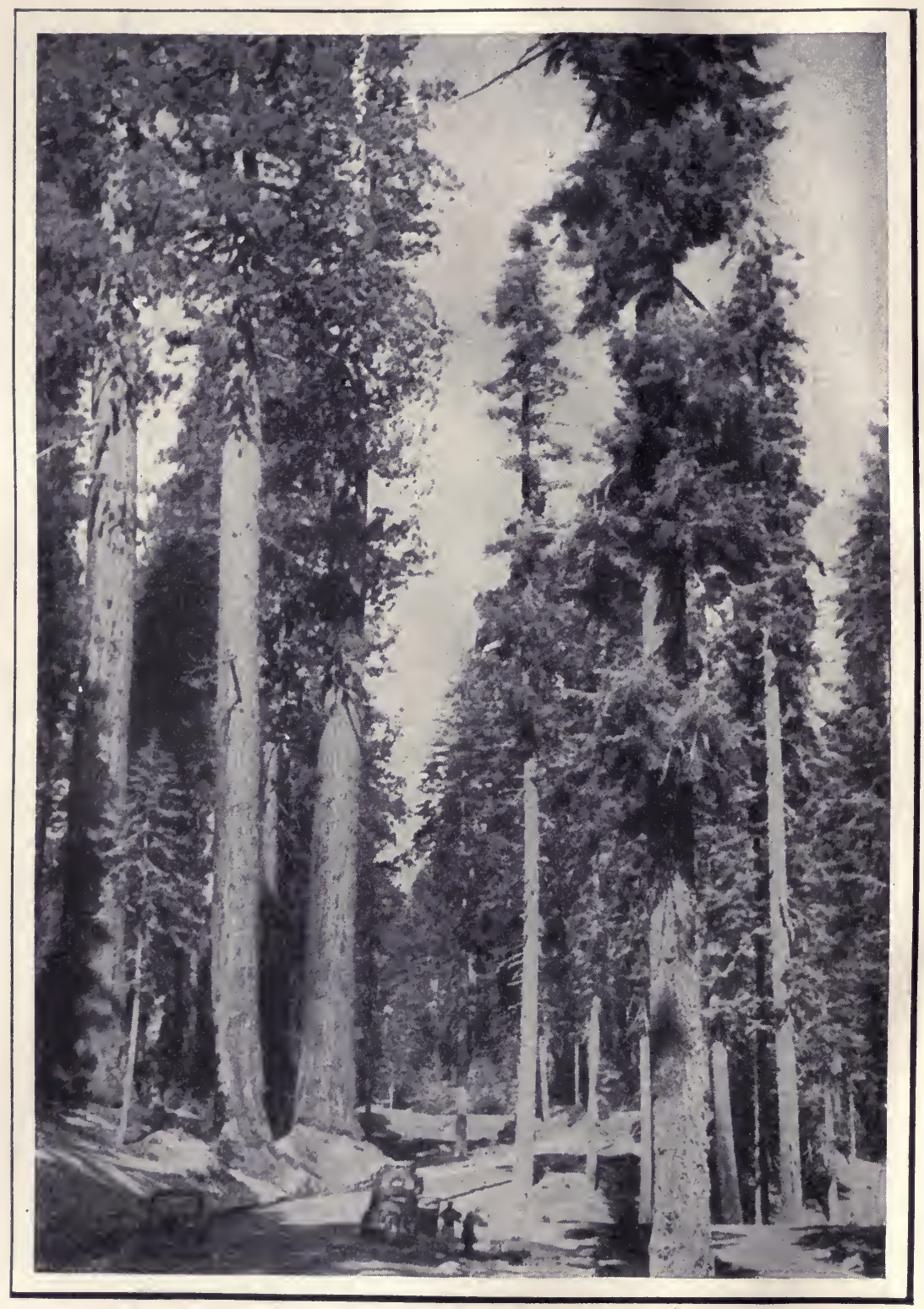

A majestic forest of Sequoias, firs and pines in Sequoia National Park, California. 


\section{Plants and Man}

by

CLARENCE J. HYLANDER

Associate Professor of Botany,

Colgate University

and

ORAN B. STANLEY

Instructor in Botany,

Colgate University

$\wedge$

Poresta institute

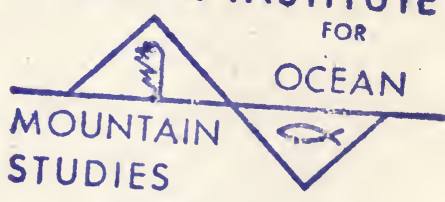

15 FRANKTOWN ROAD

CARSON CITY, NEVADA 89701

\section{THE BLAKISTON COMPANY}

Pbiladelpbia 
Copyright, 1941, by The Blakiston Company

PRINTED IN U. S. A.

BY THE MAPLE PRESS COMPANY, YORK, PA. 


\section{PREFACE}

When an additional book appears in a field well provided with existing texts, a few words of explanation are in order.

In the first years of a liberal arts college program, in Junior Colleges, and in Teacher Training Colleges, there has appeared a need for introductory texts which give the student a survey of certain fundamental concepts and their relationship to human existence, as a part of the cultural education which will enrich the lives of our citizens of tomorrow. Textbooks written with this aim are, however, not numerous. The majority of elementary texts have been written for the purpose of preparing the student for later specialization in that particular subject. Such books include by necessity much technical knowledge prerequisite for understanding advanced details in that field; but often this is irrelevant and uninteresting for the student who does not plan further specialization in the subject. In fact, the student may well be repelled by the content or organization of many existing elementary texts even though he may have had a spark of interest in the subject to begin with. It is a challenge to all college subjects which have any cultural or practical value to meet this trend in education by presenting courses which are ends in themselves rather than stepping stones for those who wish to devote more academic time or their entire lives to that particular field.

Perhaps no science has been so consistently bound by traditional presentation as elementary botany. Most of the existing texts include information of little interest and doubtful value to the average citizen, information that is often of theoretical interest only to the professional botanist, and information organized in a routine and stereotyped fashion as typical of texts of the last century as of today. Botany can be presented as a vital cultural subject, correlated with numerous everyday experiences of the student. 
PLANTS AND MAN has as one of its aims an appeal to the general interests of the average student, which will enrich his experiences with plants and plant products, and which will give him a sound appreciation of the importance of plants in human affairs. With this in mind, much that is of theoretical importance to botanists and which has little significance in our daily lives, has been omitted. On the other hand, some aspects of plant activities and structures have been dealt with in detail because of their association with products used by man.

However, PLANTS AND MAN is not merely an economic botany. The study of plants from the viewpoint of man is obviously associated with economic relationships; but an-understanding of the utilization of various parts of the plant body, and of our dependence upon various plant activities, is furthered by a comprehension of anatomical, physiological and taxonomic details of plant life which make these economic uses possible. Also unlike most economic botany approaches, harmful relations of plants with one another and with man are stressed as well as the customary useful ones; this involves a discussion of heterotrophic plants and plant pathology.

Nature study is often an aspect of plant life neglected in botany texts. This approach to botanical science, long a part of the curriculum in secondary schools, has been overlooked as a part of college botany courses-even though most students are interested in the out-of-doors and welcome an opportunity to become acquainted with plant personalities in the field. Several chapters on the plant aspects of nature study have been included in the present volume, introducing the student to the fundamental taxonomic approach to identification of common trees, shrubs and flowers both native to the United States and introduced as ornamentals. This makes the text of value to prospective teachers who plan to go into secondary school work. Science has become an integral part of the program from first grade through high school; in the lower grades most of the elementary science has to do with nature study and various botanical topics such as plant foods, textiles, uses of wood, etc. A botany course which emphasizes a study of plants in the laboratory, with microscope and herbarium sheet, offers little help to 
the future teacher who will be confronted with a need for acquaintance with the living plants of our environment. Plant life and plant products figure largely in the experience of school children, and can become an interesting part of the science program provided the teacher is adequately prepared to direct such work.

With these aims in mind, the authors have organized the subject matter of PLANTS AND MAN into six parts, each dealing with a basic relationship of plant life to human existence.

Part One introduces the student to the more important aspects of elementary botany, pertinent to the topics taken up in the remainder of the text. The first chapter discusses elementary biological information essential to the concept of a plant organism. Chapters two and three summarize in evolutionary treatment the essential facts from morphology, anatomy, physiology and ecology dealing with the maintenance of life in the plant organism, and the reproductive methods used by plants in perpetuating themselves. Chapter four briefly outlines the basic elements of plant taxonomy and the consideration of the most important phyla of the plant kingdom. Chapter five concludes this part of the book with a preview of the various inter-relationships between plants and man, some of which constitute the remaining chapters of Parts Two through Six.

Part Two continues the consideration of plant foods and other organic products, introduced in chapters two and three. The methods by which such organic products are elaborated, the origin of plants cultivated for their products, and the various ways in which plants are used as foods, food accessories and beverages comprise chapters six through fourteen.

Part Three continues the consideration of the supporting tissues developed by plants, introduced in chapter two. The development of the plant skeleton, the identification of woody plants (Angiosperm and Gymnosperm trees native to the United States), the conservation of our forest resources, the production and use of wood and fibers comprise chapters fifteen through twenty.

Part Four develops the idea of the formation of secretions in plants, and man's use of both plant secretions and excretions; 
this includes a discussion of latex plants, drug plants and industrial uses of plants taken up in chapters twenty one through twenty three.

Part Five deals with the harmful aspects of the activities of colorless plants, discussing in chapters twenty four and twenty five the pathogenic bacteria and the parasitic fungi, with their economic importance in destroying useful crop plants.

Part Six impresses upon the student the enjoyment of plant life by making. him familiar with the wild flowers and the ornamental plants.

It is hoped that the selection of subject matter and its organization into the present volume will make available material hitherto scattered through various elementary and advanced texts, and may inspire the introduction of a semester course which will appeal to the cultural interests of the general student, acting as a survey of plant science and building at the same time a substantial foundation for further botanical study, while emphasizing the importance of appreciating the various relations of PLANTS AND MAN.

Hamilton, New York

Clarence J. Hylander Oran B. Stanley 


\section{CONTENTS}

Preface

Part One . THE NATURE OF THE PLANT WORLD

1-Two Patterns of Life . . . . . . . . . . . 3

2-The Evolution of the Plant Body . . . . . . 23

3-The Evolution of Plant Reproduction . . . . 49

4-The Variety of Plant Life . . . . . . . . 83

5-The Inter-relations of Plants and Man. . . . 110

Part Two . . . PLANTS AS FOODS AND BEVERAGES

6-Plant Manufacture of Food . . . . . . . 129

7-The Origin of Cultivated Plants . . . . . . 142

8-Vegetable Foods . . . . . . . . . . . 154

9-The Cereal Fruits . . . . . . . . . . . . 167

10-Legumes, Berries and Small Fruits . . . . 180

11-The Orchard Fruits. . . . . . . . . . . . 193

12-Sugar-producing Plants : . . . . . . . . . 216

13-Food Accessories and Spices . . . . . . . . 224

14-Beverage Plants . . . . . . . . . . . . . 234

Part Three PLANTS AS SOURCES OF WOOD AND FIBERS

15-The Plant Skeleton. . . . . . . . . . . . 247

16-The Gymnosperm Trees. . . . . . . . . 256

17-The Angiosperm Trees . . . . . . . . . . 279

18-Wood and Its Uses. . . . . . . . . . . 311

19-Conservation and Management of American

Forests . . . . . . . . . 331

20-Fiber-producing Plants . . . . . . . . 345

Part Four. . PLANT SECRETIONS AND EXCRETIONS

21-Latex-producing Plants . . . . . . . . . 359

22-Drug Plants. . . . . . . . . . . . . . 370

23-Industrial Uses of Plants. . . . . . . . . . 383 
Part Five . . . . . . PLANTS AS PARASITES 24-Bacteria and Disease . . . . . . . . 403 25-Fungi and Plant Disease. . . . . . . . . 413

Part Six . . . THE ENJOYMENT OF PLANT LIFE 26-American Wild Flowers. . . . . . . . . . 435 27-Ornamental Plants. . . . . . . . . . . 474

Glossary . . . . . . . . . . . . . . . . 493

Index. . . . . . . . . . . . . . 505 
Part One

THE NATURE OF THE

PLANT WORLD 



\section{Chapter 1}

\section{TWO PATTERNS OF LIFE}

It is a familiar fact that the living world which surrounds us and of which we are an integral part consists of two kinds of organisms, each of which has developed a pattern of living successful in its own way. One is represented by the animal kingdom which, since it displays so many characteristics similar to our own, we are likely to think of as being more or less typical of all life. But the three quarters of a million species which constitute the animal kingdom are the end-product of an experiment with only one pattern of existence; we can not appreciate fully the potentialities and importance of living things by limiting our knowledge of life to the animal kingdom. The other pattern of living has been developed by plants, with a resulting diversity of a quarter of a million species. The more familiar members of both kingdoms have attained a degree of complexity which obscures fundamental similarities, giving the casual observer the impression that a wide gulf exists between a plant and an animal. It is hard to believe, at first sight, that seaweeds have much in common with the fish swimming among them, or deer with the grass upon which they are grazing. But to the biologist these two patterns of life show many similarities indicating a common origin in the geologic past. Before we attempt to define a plant, or to isolate the basic differences which underlie the two kingdoms, it might be well to consider a few of the more important traits that plants and animals have in common.

\section{Protoplasm}

Life as we know it is always found in conjunction with a physical basis of PROTOPLASM, the tangible substance out of which all living things are made. Plant and animal protoplasm are essentially alike in appearance and composition-there is little 
difference in this respect between the living substance of an oak tree and that of a dog. Under the microscope this protoplasm is a grayish material of a semi-liquid consistency and a granular or foamy appearance, largely composed of water. Suspended in the watery portion are numerous kinds of proteins - compounds of carbon, hydrogen, oxygen and nitrogen plus a few salts. The two most significant facts about protoplasm are that it is a mixture of proteins and that these exist in a colloidal condition. Proteins, the most complex of chemical substances known to man, are made up of amino acids which combine in several hundred thousand different ways; the wide range in characteristics of living things is thought to be due, in part at least, to the possible combinations of proteins which make up the protoplasm of different species. Colloids, which are suspensions of minute particles of one substance in another, even when of a non-living nature, exhibit in a simple fashion characteristics such as growth which are usually considered more typical of living things. Common colloids are smoke, milk and gelatine. When a drop of copper salt is placed in a potassium ferrocyanide solution, a colloidal membrane forms between the drop and the solution, growing by the addition of materials from either side. The colloidal nature of protoplasm makes possible fluctuations from a jelly-like to a liquid condition, and important surface tension phenomena which are vital in many protoplasmic activities.

No one knows for a certainty how or when protoplasm first evolved from the non-living and inorganic materials of the earth's crust. There is little doubt, however, that the first manifestations of life were extremely simple ones, perhaps naked masses of protoplasmic jelly floating about in prehistoric seas, taking in the necessary elements for protoplasm-building through their colloidal membranes and living in a much more primitive fashion than living organisms do today.

\section{The Unicellular Organism}

Long before the beginning of the fossil record, protoplasm developed the ability to encase itself in a wall more durable than the protoplasmic membrane, and within this protective 
armor it was able to exist under many adverse conditions of dessication and physical contacts which would have been fatal to naked protoplasm. By far the majority of organisms today consist of protoplasm thus organized into units or CELLS. Not only are plants and animals alike in being made up of protoplasm, but both have the protoplasm organized into cellular units. The success of this step upward in the evolution of life is attested by the fact that there still are many thousands of microscopic

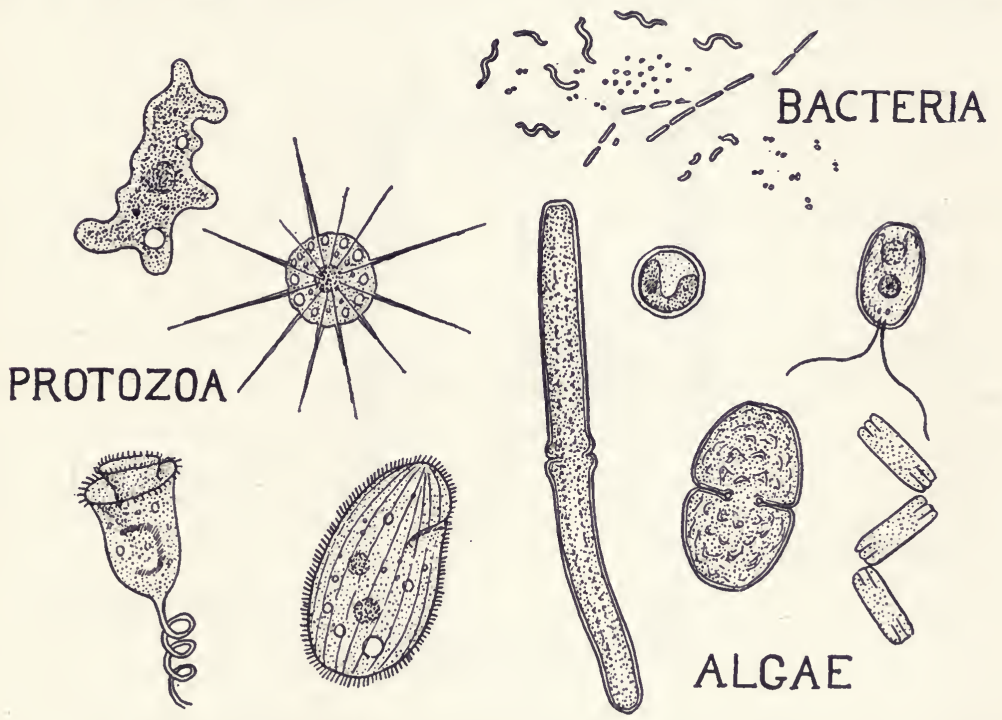

FIG. 1.-A drop of water from a stagnant pool reveals a microscopic world of unicellular organisms including bacteria, protozoa and algae.

plants and animals which live in the unicellular condition, the whole body being restricted to the dimensions of a single cell. Such are the Protozoa in the animal kingdom, of which familiar representatives are the simple Amoeba or the more complex Paramecium, both carrying on all the activities typical of an animal within the limits of a single cell. Plant species of this simple type of body organization are also common. A drop of water from a stagnant pool (fig. 1) reveals a microscopic world of Protozoa and unicellular plants; the colorless rods and spheres of bacteria, the boat-shaped cells of yellowish diatoms, and 
hundreds of different shaped cells suffused with bright green pigment, characteristic of the species belonging to the Green Algae.

Study of these unicellular organisms or of a single cell from the body of a more complex plant or animal reveals the fact that a cell is a highly organized mass of protoplasm, separated from the environment by its protective cell wall (fig. 2). This wall is a non-living structure secreted by the protoplasm; it is not uniform in nature, the cell wall of plants having evolved along

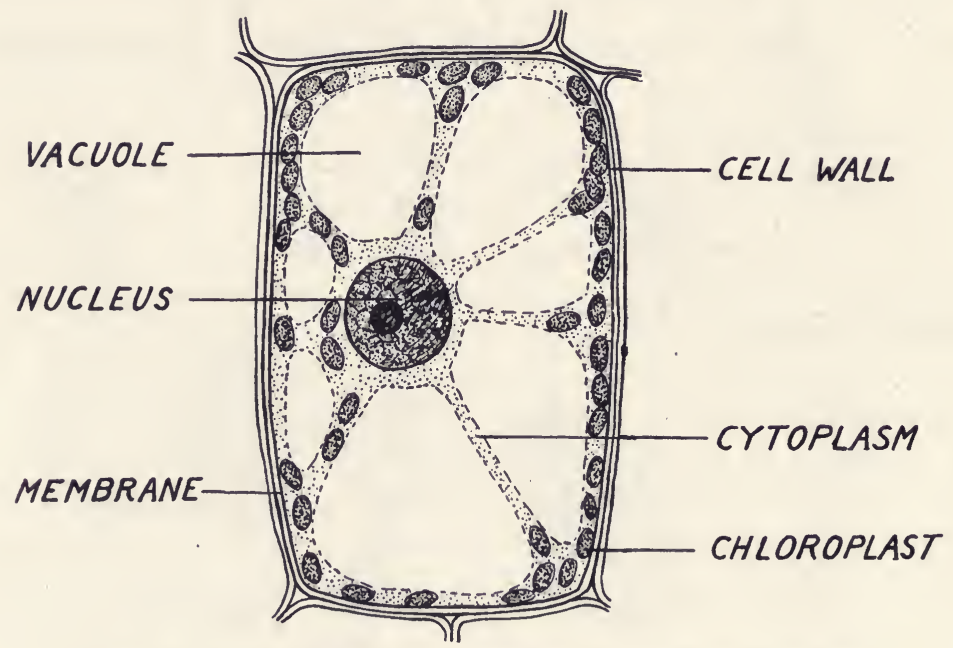

FIG. 2.-A cell is a highly organized mass of protoplasm.

slightly different lines from that of animals. The animal cell wall is of protein nature and very pliable, while that of a plant is of cellulose and often extremely rigid. Within the cell wall, the protoplasm is often exceedingly complex, various portions taking on special functions. Most important of these protoplasmic structures are the nucleus, the cytoplasm and the various protoplasmic membranes. The NUCLeus is a rounded and dense mass of protoplasm, often near the center of the cell, which exercises a directive influence over the activities of the entire cell; cells deprived of their nuclei do not act normally and usually do not live long. The nucleus is also important in heredity, for in it is 
located the chromatin material which acts as the carrier of inherited traits from one generation to the next. The CYTOPLASM constitutes the bulk of the cell, and is that portion of the protoplasm surrounding the nucleus; it is generally more liquid in consistency and in some plant cells can be seen carrying on a slow streaming movement. It is in the cytoplasm that the living activities of the organism take place, such as manufacture or digestion of food, respiration and excretion. The cytoplasm contains numerous inclusions some of which are living and some not. The living inclusions, known as plastids, are chiefly specialized bits of cytoplasm which are self-perpetuating. Plastids are characteristic of plant cells and have important functions. The prevailing green color of vegetation is due to the presence of plastids known as chloroplasts, which contain the green pigment, chlorophyll. Other plastids of an orange, yellow, or red hue (chromoplasts) are commonly found in fruits and flowers. Colorless plastids (leucoplasts) act as depositors of starch for storage purposes. Non-living inclusions are chiefly food particles, waste products and water vacuoles. The latter are reservoirs of water which look like small globules and frequently contain materials in solution. Plant cells as a rule have much larger vacuoles than animal cells have; sometimes the vacuoles occupy so much of the cell that the cytoplasm merely lines the cell wall. In addition to the cytoplasm and nucleus, there are the various MEMBRANES which separate the different kinds of protoplasm. A nuclear membrane separates the nucleus from the cytoplasm, and a plasma membrane separates the living protoplasm from the non-living cell wall.

\section{The Multicellular Organism}

In the early history of life the cell was the organism. But just as naked protoplasm proved less satisfactory in the relentless struggle for existence than protoplasm organized into cells, the single-celled organism had to yield to the potentialities of organisms made up of many cells united with one another. The multicellular condition offers many advantages, among them the possibility of attaining greater size, of adaptation to a wider variety of habitats, of greater specialization of functions. Division 


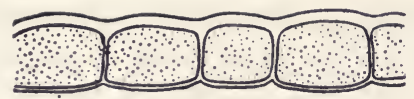

SIDE VIEW

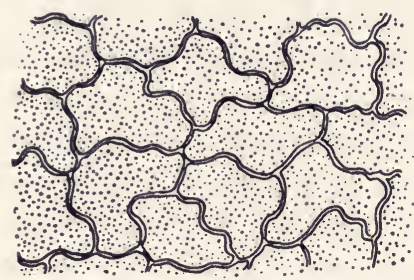

SURFACE VIEW

EPIDERMIS

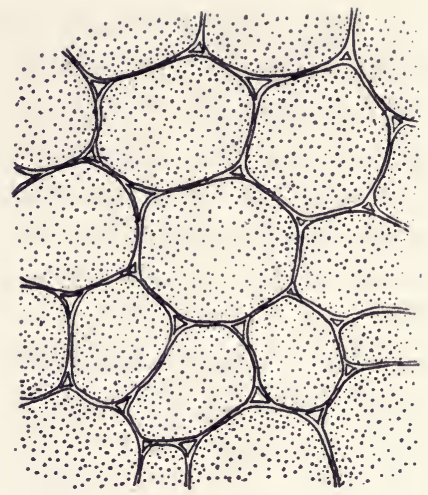

\section{PARENCHYMA}
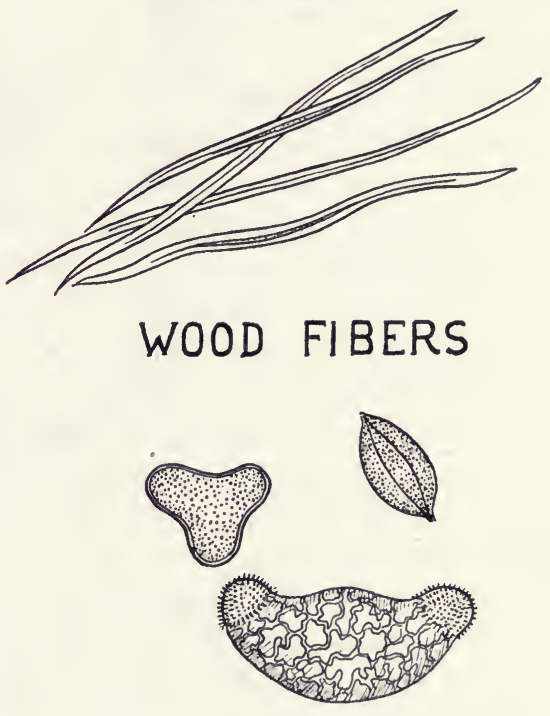

SIEVE TUBE VESSEL

\section{VASCULAR TISSUES POLLEN GRAINS}

FIG. 3.-Various types of plant tissues include: epidermis, parenchyma, vascular tissues, supporting tissues (wood fibers), reproductive tissues (pollen grains). 

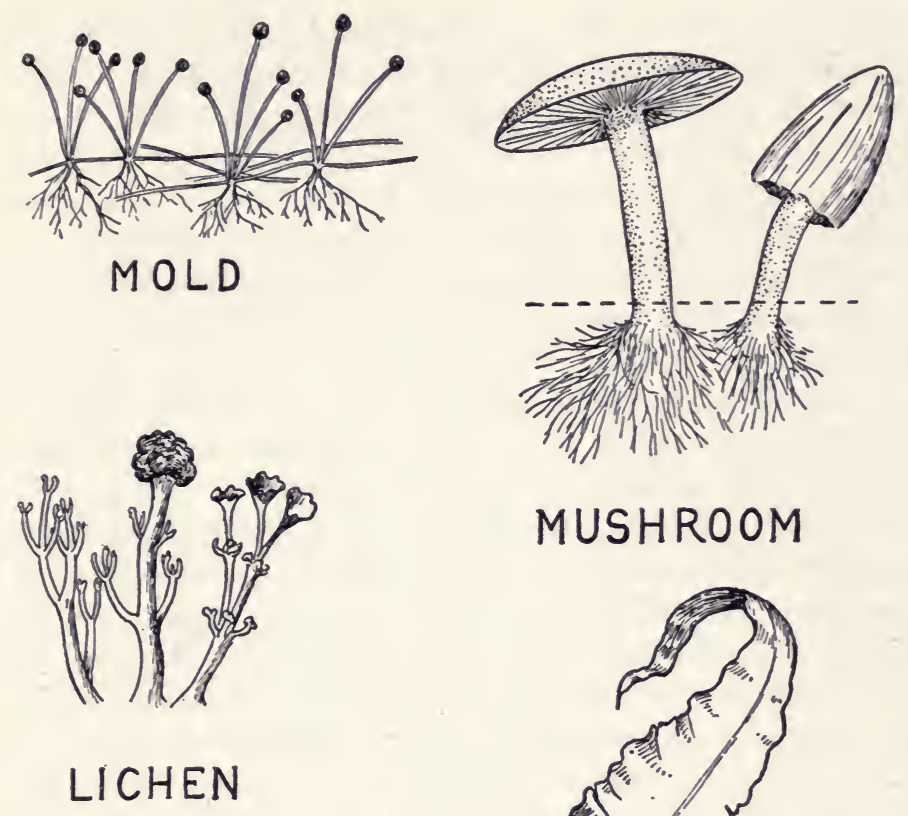

\section{MUSHROOM}
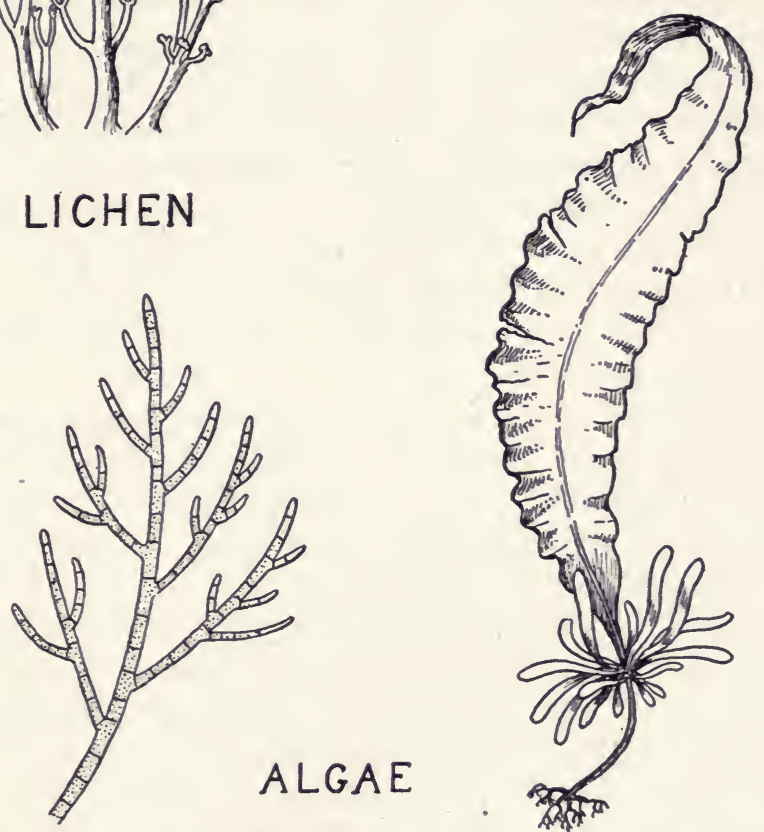

FIG. 4. - The thallus type of plant body is typically seen in molds, mushrooms, lichens, algae. 
of labor among the cells of a multicellular body brings about a more efficient carrying on of all the life functions; a structure designed for protective purposes, for example, can act as such far better than another which is fitted for absorption of water. In the evolution of multicellular plants, some groups of cells specialized in protective duties, others absorbed water or gases, still others assumed the responsibility of manufacturing food. A large group of cells having a similar structure and carrying on similar special functions is known as a TISSUE, but although the bodies of plants and animals may thus be built up of numerous tissues, the cell remains the unit of structure and function. The activities of the organism as a whole is merely the sum total of all the activities of the individual cells. All of the higher groups of animals and plants are built up of tissues; examples of such tissues among animals are muscles, nerves, glands and bones. In the plant kingdom there are a few main types of tissues (fig. 3). The outer protective cells of leaves, flowers and fruits is epidermal tissue; parenchyma tissue of relatively unspecialized cells makes up the bulk of leaves, flowers, fruits and young stems; vascular tissues conduct water and the minerals and foods dissolved in it; supporting tissues act as skeletal elements. In full-grown woody plants vascular and supporting tissues comprise the bulk of the roots, trunks and branches.

Many of the lower plant and animal groups include organisms which have not gone far beyond the tissue stage of body organization. Such are the simpler marine invertebrates - the corals and sponges. In the plant kingdom this condition is the rule among the pond-scums and seaweeds (algae), and among the mushrooms and molds (fungi). A plant body characterized by only a few different tissues co-ordinated in a primitive fashion is known as a THALLUS; for this reason the algae and the fungi are often referred to as thallus plants or thallophytes (fig. 4).

As division of labor proved to be a successful evolutionary advance, specialization progressed beyond the union of cells into tissues. Groups of tissues with some organic connection and concerned with the same general function formed greater cell aggregates known as ORGANS. Familiar organs in the animal kingdom are the heart, lungs and stomach. Plants also have ad- 


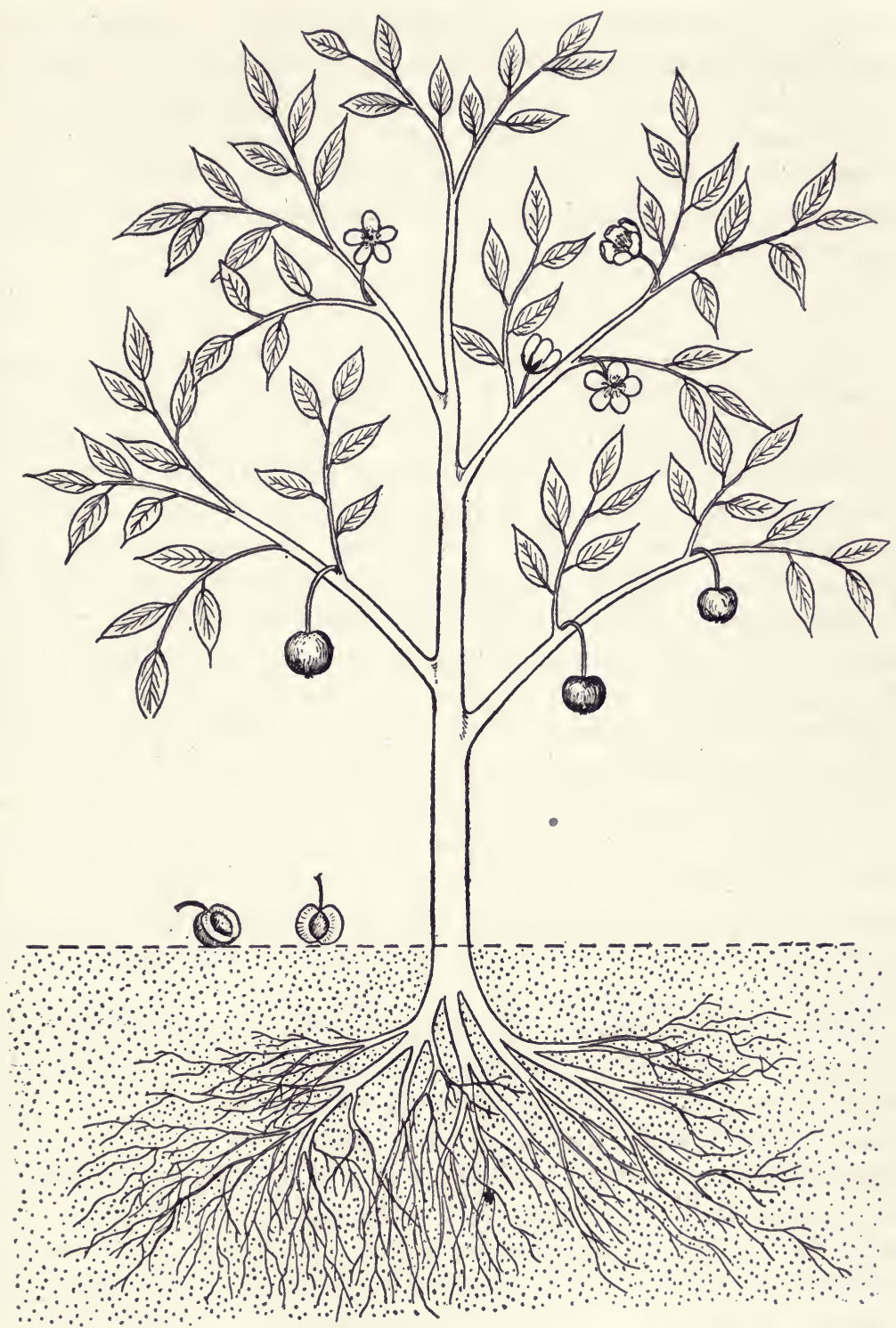

Fig. 5. - The organs of a flowering plant include roots, stems, leaves, flowers, fruits and seeds. 
vanced to the organ-type of body plan (fig. 5). Trees, shrubs and other flowering plants have a body built up of six types of organs, each with one or more definite functions to perform in the economy of the life of the whole plant. These are the roots, stems, leaves, flowers, fruits and seeds. The particular nature and activity of each of these will be taken up in detail in the next two chapters.

\section{Metabolism}

The common protoplasmic basis and cellular organization of both plants and animals is an indication of their biological kinship from the structural viewpoint. But there are also numerous similarities in the activities taking place in the protoplasm and within the cells. All living material is strikingly different from the non-living world by being able to grow, to reproduce and to adapt itself to changing environmental conditions. In the performance of these living processes protoplasm takes in substances from the environment, transforms and utilizes them. To be alive means a consumption of materials and energy, with a consequent dependence upon some sort of fuel. The only fuel which can be utilized for energy release by plants or animals is that found in compounds of carbon and hydrogen combined to form either carbohydrates, fats or proteins. It is this organic fuel which constitutes food, and food is a primary requisite of all living things. That animals must eat in order to live is well known to all; but the fact that plants need food is not as widely appreciated.

The series of physical and chemical changes taking place in protoplasm during the securing and utilizing of food is known as METABOLISM; metabolic activity is fundamental to the life of all plants and animals (fig. 6). It is a dual process, with a constructive and a destructive phase. In its constructive phase metabolism involves securing food and assimilating it into protoplasm, resulting in growth or storage of food for future consumption. In its destructive phase the food is oxidized with a consequent release of potential energy and the excretion of waste products. This oxidation phase of metabolism can be compared with burning wood, both being the result of the union of oxygen with a 
carbon compound. The rapid oxidation when fuel is burned in a furnace or an engine is combustion; the slower oxidation taking place during cell metabolism is termed respiration. Just as few people think of plants as needing food, it is commonly not appreciated that plants need air and must breathe. Cell breathing or respiration in the plant world is a less vigorous and less obvious process than among animals, since plants need less oxygen and carry on a less rapid rate of respiration than do the more active animal organisms. With the energy of the fuel made available

\section{DESTRUCTIVE PHASE \\ CONSTRUCTIVE PHASE}

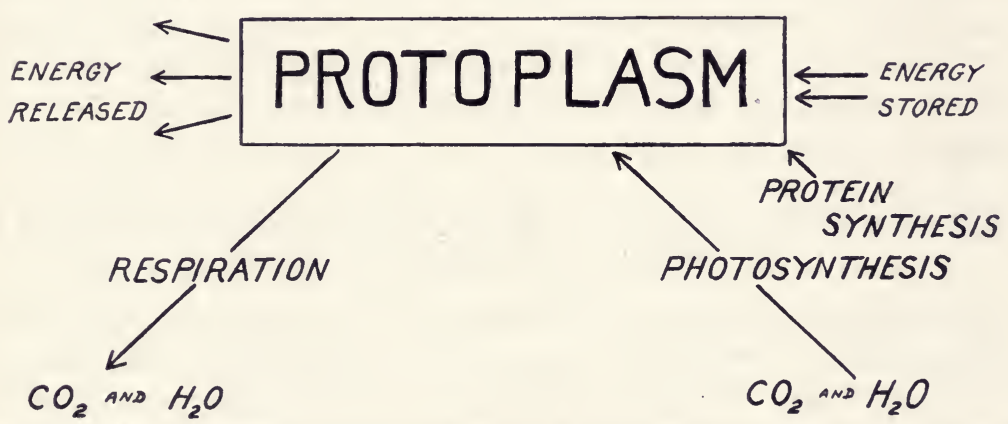

FIG. 6.-Metabolism is a dual process, with a constructive and a destructive phase.

by respiration, all of the vital activities of protoplasm can take place.

In the constructive phase of metabolism, there is a marked difference between the plant and the animal cell. The two kingdoms separated along diverging pathways millions of years ago, in their methods of securing food. Ancestors of both may have been simple unicellular organisms capable of extracting inorganic materials from the environment and synthesizing them into organic ones as food for protoplasm. Such a type of metabolism is termed AUTOTROPHIC, indicating an ability to transform common inorganic substances such as water, air and a few 
minerals into food. There are some autotrophic bacteria living today which may represent this simple type of constructive metabolism, showing the method by which the first living things lifted themselves out of the realm of the non-living into that of organic compounds and protoplasmic colloids. These are the iron and sulphur bacteria found in stagnant pools. Their protoplasm has the ability to oxidize iron or sulphur compounds and to thus release small amounts of energy. With this energy at their disposal, the bacteria decompose water and carbon dioxide, substances which diffuse easily into the cell. The carbon dioxide of the atmosphere is the sole source of the carbon utilized by the plant cell; and the water is the only source of the hydrogen needed. Out of the atoms of carbon, hydrogen and oxygen thus released from these two compounds, the bacterial protoplasm synthesizes a simple carbohydrate such as sugar. This is the simplest form of constructive metabolism, often referred to as carbon synthesis. It can be represented in equation form as follows:

carbon dioxide + water + energy (secured from oxidation of sulphur) = food (sugar) + oxygen.

The sugar is used as a basis for further elaboration into other carbohydrates and fats, or may be transformed into proteins by the addition of nitrogen, phosphorus and sulphur secured by the absorption of their salts. From proteins new protoplasmand more life - can be constructed.

As protoplasm increased in complexity and new structures made their appearance, this primitive type of metabolism gradually gave way to the more specialized types characteristic of the majority of living plants and animals. It is in this constructive phase of metabolism that we find the most basic difference between the two. We have already discovered some minor ones, such as differences in the cell wall and cell contents. The cellulose wall results in the more rigid aspects of plant bodies with their lessened ability to move about; and the cytoplasmic inclusions give vegetation their characteristic colors. But the feature which has determined to a great extent all of the superficial differences between the two kingdoms is the result of two 
different ways of securing food during constructive metabolic activity. Plants have perfected the autotrophic type found in primitive fashion among the sulphur and iron bacteria, manufacturing food out of inorganic substances absorbed from the environment. Animals have lost this ability (assuming that they once had it) and have specialized in HETEROTROPHIC metabolism, i.e., a dependence upon ready made organic compounds as food. This is ingested rather than absorbed, usually through a mouth opening; after ingestion it is digested and made fit for absorption and assimilation into animal protoplasm. This characteristic makes all animal life dependent upon such autotrophic organisms as green plants, which are the alchemists living on the border between the non-living and the living world, capable of continually transforming substances from the former into organic materials characteristic of life.

Perfection of autotrophic metabolism has resulted in an ability to tap far greater reserves of energy than those released by oxidizing sulphur or iron. A vast amount of energy continually reaches the earth in the form of sunshine. Even though man has long known of the billions of potential horsepower which thus daily reaches us in the form of ordinary sun's rays, he has been unsuccessful in constructing solar engines to capitalize this power. The autotrophic green plants are able to harness this immense stream of energy, by a process which seems relatively simple. There appeared, sometime during the early evolution of plants, a green pigment, chlorophyll. CHLOROPHYLL is composed of carbon, hydrogen, oxygen, nitrogen and magnesium; it is without doubt the most important compound known to man. Produced by plant protoplasm in the presence of sunlight, when an integral part of living protoplasm it acts as a screen to intercept solar radiation. With this energy captured during daylight hours the cells can carry out the difficult feat of rearranging the atoms of water and carbon dioxide, which is a necessary step in the synthesis of food. Chlorophyll may have been, at first, diffused through the cytoplasm as is the case with the presentday Blue-green Algae (see p. 86). But in time cellular specialization resulted in the localization of the chlorophyll in special plastids, the chloroplasts. These chlorophyll-bearing structures, 
usually elliptical in shape, are found in the cells which make up the green parts of plants, notably the leaves. Since solar radiation affords tremendous sources of easily available energy, the synthesis of carbon compounds by autotrophic green plants far surpasses in amount and efficiency that of the colorless autotrophic ones such as the bacteria. Green plants have multiplied and increased in diversity until today they comprise the most conspicuous part of the earth's vegetation-evidence of the success of this pattern of living.

This constructive phase of metabolism in green plants is known as PнотOSYNTHESIS, and is a relatively simple process when one considers the far-reaching effects of its activities. It involves the utilization of solar energy by means of chlorophyll associated with protoplasm, so that carbon dioxide and water, absorbed into the plant cell, can be transformed into the complex organic molecule of glucose. During the process oxygen is released as can be seen from the following chemical equation for photosynthesis (compare with that of the autotrophic bacteria previously given on p. 14).

$$
6 \mathrm{CO}_{2}+6 \mathrm{H}_{2} \mathrm{O}+\text { solar energy }=\mathrm{C}_{6} \mathrm{H}_{12} \mathrm{O}_{6}+6 \mathrm{O}_{2}
$$

Expressed otherwise, six molecules of carbon dioxide and six molecules of water are decomposed and rebuilt by the chlorophyll-protoplasm combination, with the aid of sunlight, into a single molecule of sugar (glucose) and six molecules of oxygen. Thus during the photosynthetic process, in addition to manufacturing food, green plants give off oxygen as a by-product, in this way purifying the air for all organisms depending upon oxygen for respiration. All plants which lack chlorophyll are heterotrophic, ${ }^{*}$ and all animals are dependent upon photosynthesis for their very existence. The importance of photosynthesis to man in the production of food crops is obvious in the development of agriculture.

\section{Secondary Differences between Animals and Plants}

The animal type of metabolism, lacking the ability to synthesize food, has become specialized in its own way for the securing

* With the exception of the autotrophic bacteria already described on page 14. 
of food by eating it. Either the organic material is secured directly from green plants, resulting in herbivorous habits, or indirectly by eating the herbivorous animal. This animal way of securing the necessary material for constructive metabolism has brought with it many of the more obvious differences between plants and animals. Plants are generally thought of as stationary organisms, while animals are typically capable of motion. This stationary nature of plant life is the result of their method of procuring food, being able to absorb air, water and the needed minerals in solution without moving about in search of them. To be able to move is in itself no advantage, since it uses up energy and valuable food reserves as well as necessitates complex tissues and organs to bring about locomotion. Considered in this way the inability of plants to move about is not an imperfect condition in which the tree, for example, is inferior to the squirrel scampering along its branches, but rather the perfection of a special and satisfactory method of food-getting. Since they cannot live by the absorption of inorganic materials, land animals are unable to survive by rooting themselves in one spot; the food they require would hardly come into their open mouths while they lay in wait for it. Animal locomotion is a means to an end and when an animal can get its food by standing motionless it becomes as stationary as a plant; witness the sedentary animals of the sea such as corals, barnacles and sea anemones which depend upon ocean currents to waft dissolved organic debris or minute plants into their mouths.

This dependence of animal metabolism upon locomotion has resulted in many secondary differences between plants and animals. Animals seem more conscious of their surroundings, react more directly to stimuli, and in general "feel" more obviously than plants. Among the vertebrate animals this has resulted in the development of complex nervous systems and, ultimately, intelligence. Plants lack nervous systems and brains, quite possibly, because they never needed them. Consciousness of one's surroundings is imperative only for an organism searching for food; sense organs help in locating the food; a co-ordinated neuromuscular system aids in securing it. Locomotion, sensation and nervous activity primarily were developed as a means to this 
end, to better satisfy the inherent demands of heterotrophic animal metabolism. Plants have protoplasm which is also sensitive and irritable, but have developed these characteristics to only a slight extent and have survived in the struggle for existence without them. Plants feel, but in a limited sort of way; plant protoplasm is sensitive to gravity, pressure, chemicals in solution, temperature, light-any factors in the environment which are important in the living routine of the plant organism. Any of these may bring about a response on the part of the plant, which though slow and inconspicuous is still essentially a response to a stimulus.

\section{Growth and Reproduction}

There are other activities of protoplasm which indicate a kinship between the two kingdoms of life, of which we might mention growth and reproduction. When a cell has assimilated more food than it needs, it uses some of it to increase the amount of protoplasm within the cell; but soon the cell reaches its maximum and very definitely circumscribed proportions. At this point the cell divides in half, a new cross wall forms, and two cells result. This growth of an organism by cell division is the method by which all plants and animals increase in size as they develop from minute beginnings to maturity. The acorn becomes a massive oak by cell division. There are slight variations in this process in the two kingdoms, however. Animal growth results in more definite and limited proportions characteristic of each species, while the size of a plant varies within wider limits. In addition, certain parts of the plant body have unlimited growth. This is true of the growing tips of roots and stems and of the growth ring beneath the bark of woody plants. The latter is a layer of potentially immortal cells which causes growth in diameter, bringing about possibilities of annual increase in girth limited chiefly by the restrictions of the environment. Some Sequoias (fig. 7) have been growing for over five thousand years and may continue to do so for another five thousand. Such unlimited growth gives plants the ability to live to far greater age than animals can, many common trees exceeding a century of life. Another variation in the growth process is associated with the 
production of organs. Most animals develop a definite number of organs, while among flowering plants there is an indefinite number. The number of leaves, flowers or fruits produced by a tree is not consistent for all members of the same species.

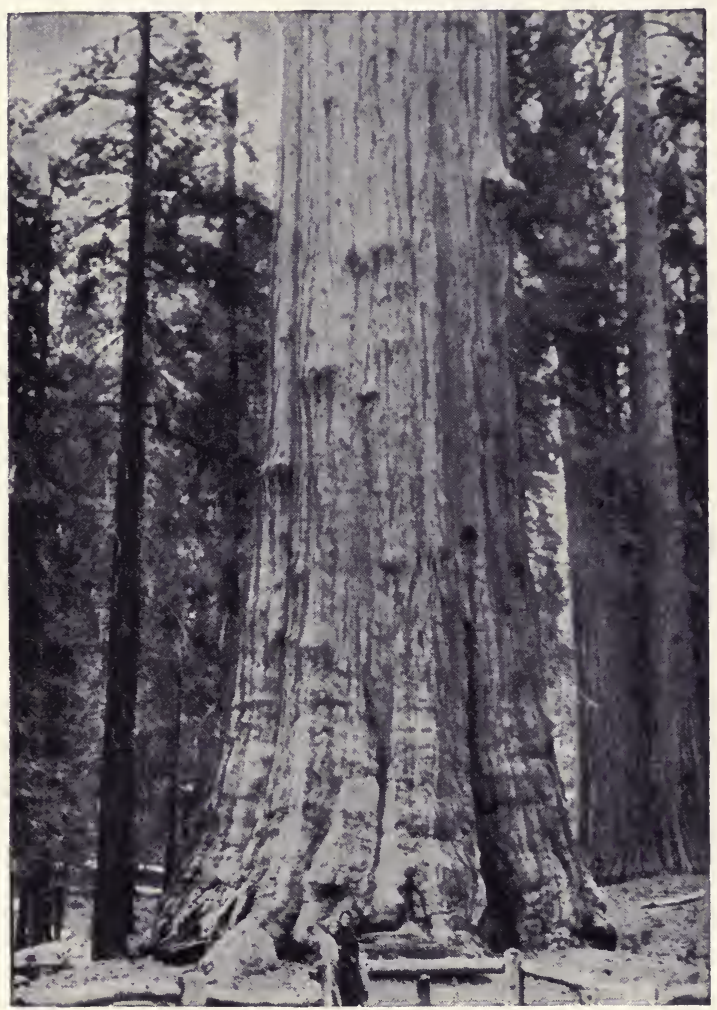

Fig. 7.- Some Sequoias have been growing for over five thousand years and may continue to do so for another five thousand. General Sherman tree in Sequoia National Park.

Reproduction is basically the same for both plants and animals, being merely an extension of the growth process, with the new cells separating from the parent and developing into independent organisms. These reproductive units are usually single cells bearing within themselves all the characteristics of the parents, which appear as the cell grows by cell division and 
forms specialized tissues and organs by cell differentiation. When each reproductive cell develops into a new organism by itself, there is only one parent and the process is termed ASEXUAL REPRODUCTION. Asexual reproductive cells, or spores, are far more common among plants than animals for reasons which will be discussed in Chapter 3. On the other hand many organisms produce reproductive cells which must unite in pairs in order to live, the fused cells forming a single cell which then proceeds to develop into a new organism. This is the essence of SEXUAL REPRODUCTION, the two cells being known as egg and sperm. Sexual reproduction involves bringing the sperm and the egg together so that fusion can take place, a process which is possible for animals with their powers of locomotion but obviously difficult for stationary land plants. Except for the seaweeds and simple land plants, sexual reproduction with motile sperm cells is not as highly developed among plants as among animals.

With these facts in mind it is possible to better appreciate the fundamental similarities and differences in the plant and animal pattern of living. We have seen that both types of organisms have much in common; the physical basis of protoplasm, organized into cells made up of cell walls, nuclei and cytoplasmic parts; the division of labor in the formation of tissues and organs; basic activities such as metabolism, growth and reproduction. Differences between the two kingdoms are not so much differences in fundamental structures or functions as in different ways of accomplishing the same result. Most important are the two types of constructive metabolism - the autotrophic food manufacture of green plants and the contrasting heterotrophic dependence of animals upon ready-made organic compounds. Associated with this basic difference is the presence of chlorophyll, with the resulting prevalence of the green color in plants; and the more obvious ways in which we think of animals and plants as being unlikein the ability to move about, to be conscious of the surroundings, to feęl and to think. As will be evident when the activities of plants are discussed more in detail, this plant pattern of existence has been just as successful in its own way as the more familiar one of the animal kingdom. 
It has been a long and devious road from the first divergence of life along the two patterns of living to the present day complexity of the living world. As evolution progressed, the members of both kingdoms became increasingly different from one another, but there has always been a dependence of heterotrophic organisms upon green plants since they alone held the secret of the conversion of sunshine, air, water and a few common minerals of the earth's crust into food. This has brought about a web of inter-relations between plant and animal species which has profoundly influenced the evolution of both. Plants have always been the pioneers and the vital mainstay of animal and human life. They were the advance guard to colonize the land as organisms left their aquatic birthplace to venture upon dry land. After a few members of the plant kingdom had secured a foothold on the previously barren rocky areas, numerous animal species followed. Even today mosses and lichens are the pioneers in populating bare rock areas and lifeless cliffs; to be followed by an increasing assemblage of grasses, ferns, shrubs and trees which get a foothold in what humus these pioneers leave behind them. As soon as the mat of vegetation becomes complete a new world of insects, worms, and numerous vertebrates can populate the region which now offers them food and shelter. Where plants go, animals may follow; thus plants determine where and how animals shall live. In fact the kind of animal life is directly correlated with the evolving character of the plants in the same region. Hoofed animals go with grasses, as do broad grinding molar teeth. Perhaps one reason we as primates have arms with prehensile hands instead of four legs like a horse is that our ancestors lived among trees; climbing could not become a characteristic activity of prairie-dwelling species.

With the universal dependence of animals upon plants for food, man is no exception to the rule when his existence is dependent upon the products of forests and farms. On the whole, the autotrophic pattern of living has been, and always will be, a tremendous asset to mankind. It can not be said that the reverse is also true; the greatest enemy of the plant world is often man himself. Wasteful and unappreciative of the benefits to be derived from a correct relationship with plant life, he has often destroyed, 
with short-sighted policy, what should naturally have been useful and enjoyable. The purpose of this book is to make possible an intelligent understanding of how plants live and in what ways their living is of importance to man, so that there may be a fuller enjoyment and wiser use of "the other half" of this living world. 


\section{Chapter 2}

\section{THE EVOLUTION OF THE PLANT BODY}

As a result of the preceding discussion on the essential nature of a plant organism, we can define a plant as an organized mass of protoplasm which secures its food either by manufacturing it from inorganic substances absorbed from the environment (autotrophic metabolism) or by absorbing it from the surroundings (heterotrophic metabolism); in addition, like all living things, a plant is capable of growth, response and reproduction. Every plant known to botanists has these characteristics; but as a result of millions of years of experimentation, various types of plant bodies have evolved, each fitted to carry on these typical plant activities under different circumstances and with varying degrees of efficiency. It is our problem in this chapter to reduce the great variety of body types to those which represent progressive stages in adaptation of the plant pattern of existence to a wide range of living conditions.

Most vital of all processes is the securing of food. In all cases this is obtained from the environment by direct absorption through cell walls and plasma membranes in marked contrast to the animal method of ingestion with consequent digestion and absorption into the body cells. The absorption of inorganic materials from the environment and their synthesis into food is a typical activity of all green plants, which therefore form the useful majority of our forest and crop plants. Most important of all the food-manufacturing functions of plants is the process of photosynthesis. This requires an adequate supply of raw materials and sunlight, at temperatures favorable to protoplasmic activity. Coincident with the necessary intake of carbon dioxide and water is the need of oxygen for respiration. Also fundamental in the absorptive phases of plant metabolism is the intake of nitrates, sulphates, phosphates and other salts 
needed in elaborating proteins from carbohydrates. Excretion of wastes is also important in the economy of the plant organism, though this takes place to a lesser extent in plants than in animals. Added to these basic activities concerned with the intake and outgo of materials, the plant grows and increases in size, protects itself against unfavorable environmental factors, and adjusts itself to a varying environment.

In carrying out these maintenance functions, green plants present a variety of structural modifications. There is a great range in body size from the microscopic and unicellular algae. to the giant Sequoias, even though both carry on all of the maintenance activities essential to plant life. The range from simplicity to complexity, in both structure and function, which exists among living plants may represent the evolutionary sequence through which plant life passed as it became more complex with increasing specialization of functions. Considering a progressive series of plant body types, chosen from living species, we can visualize the probable stages through which plant life passed in the evolution to its present-day complexity.

This series, from the viewpoint of the maintenance organs and activities of green plants, can be represented by six types of plant body: (1) the unicellular body, as seen in a desmid plant; (2) the multicellular aquatic plant body without any division of labor as seen in the pond scum Spirogyra; (3) the multicellular aquatic plant body with some degree of division of labor, as seen in the kelps such as Laminaria; (4) the body of a primitive land plant, the liverwort; (5) the body of a more advanced land plant, the moss; 6 ) the most complex type of all plant bodies, a woody land plant such as a maple tree.

\section{The Unicellular Plant Body}

Green plant metabolism is reduced to its simplest terms in the bodies of the one-celled aquatic plants, of which a DESMID will be taken as representative. These minute algae are microscopic free-living organisms dwelling among the leaves and stems of submerged vegetation or floating about in the waters of ponds and lakes. A drop of water from such a habitat reveals a world of these minute plants and their relatives (fig. 8). The cell is char- 
acterized by a constriction in the middle; in the cytoplasm are two large green chloroplasts, important parts of the desmid protoplasm. Frequently vacuoles are present. As the desmid plant floats about in the sunlit water, it is surrounded by an environment which furnishes all of the essentials for its existence. One of the raw materials for photosynthesis is always present, since water permeates the entire cell due to its ability to pass through the cell wall. Carried with the water into the protoplasm

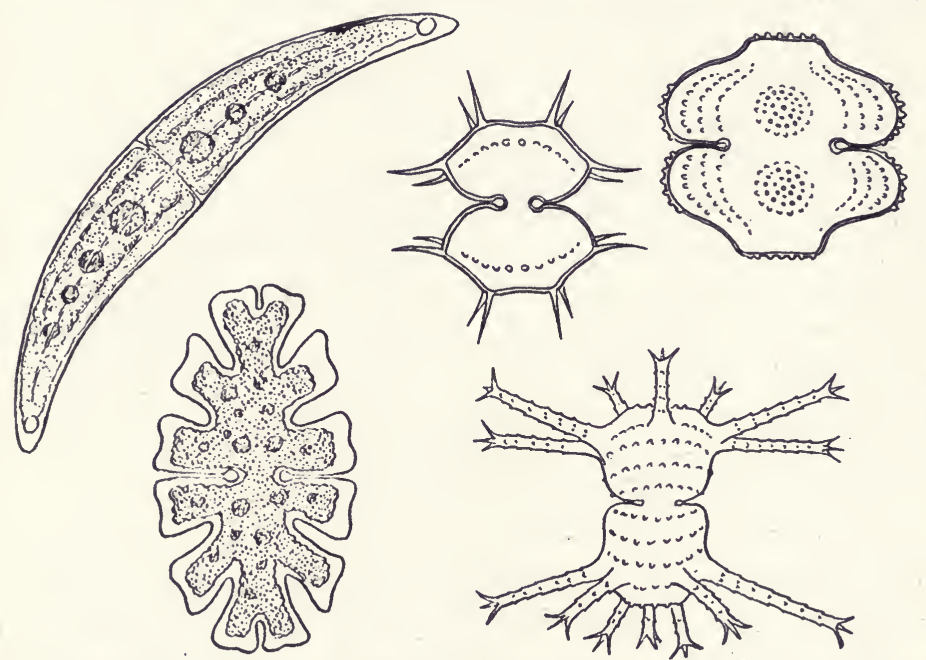

Fig. 8.-Desmids are minute plants living among leaves and stems of submerged vegetation or floating in surface waters of ponds and lakes.

is dissolved air, containing the carbon dioxide also needed for photosynthesis-as well as the oxygen required for respiration. Thus all the inorganic materials needed for food manufacture are continuously available. The chloroplasts, intercepting the sunlight which penetrates into the water, effectively aid cell protoplasm in the decomposition of carbon dioxide and water, and their recombination in the form of glucose. Some of this sugar passes in solution to various parts of the cell where it may be used as fuel during respiration or may be transformed into starch, cellulose or fat. Dissolved nitrates and other necessary salts pass into the cell in the same fashion as the carbon dioxide. With the addition of the 
nitrates, phosphates and sulphates the glucose can be converted into proteins and the latter in turn into new desmid protoplasm. As this cytoplasmic activity continues some of the oxygen released by photosynthesis is used up by respiration; but an active cell, on sunny days, liberates more oxygen than can be used by respiration with the resulting passage of oxygen out of the desmid cell into the water of the environment. At night, however, photosynthetic activity ceases so that oxygen has to pass into the cell to continue the respiration process. This balance between the oxygen released by photosynthesis and that used up in respiration is quite variable, depending upon the rate of food consumption and food formation. This same variable balance holds true for the carbon dioxide; ordinarily, in the daytime, the amounts of this gas given off by respiration are used up at once within the cell by the photosynthetic process, so that actually, in the hours of sunlight, respiration does not result in the giving off of carbon dioxide to the environment. At night, or during periods of photosynthetic inactivity, the carbon dioxide is given off to the surroundings just as in animal respiration. Such a balance between the oxygen and carbon dioxide taken in and given off holds true for all green plants, aquatic or terrestrial.

Of the other fundamental activities essential to plant existence, those of growth and protection are as simple as those concerned with metabolism. The size of the cell is limited, so that when this maximum volume is attained, excess protoplasm formation results in a splitting of the cell to form two new desmids; growth and asexual reproduction in this case being closely related processes. Protection against dessication is unnecessary for aquatic plants since they are continually bathed in a watery environment. Protection against physical injury is well taken care of by the rigid cell wall which, in many species, develops spines and sharp projections which undoubtedly discourage hungry aquatic animals. This life of a desmid plant is typical of all green members of the plant kingdom, with the fundamental demands of existence uncomplicated by numerous cells, tissues and organs. It is an existence characterized by an ability to solve all of life's pressing problems in an elemental and simple fashion. 


\section{The Multicellular Plant Body without Division of Labor}

In a POND Scum such as Spirogyra (fig. 9) we find a multicellular aquatic plant with no division of labor among the cells which make up the organism. Each filament of the thread-like plant is made up of a number of cells in a single row, attached end to end. Young plants consist of a few cells and may be attached to the substratum by the basal cell which acts as a holdfast. Older plants consist of hundreds of cells, and are generally floating. All of the cells which make up the Spirogyra plant look

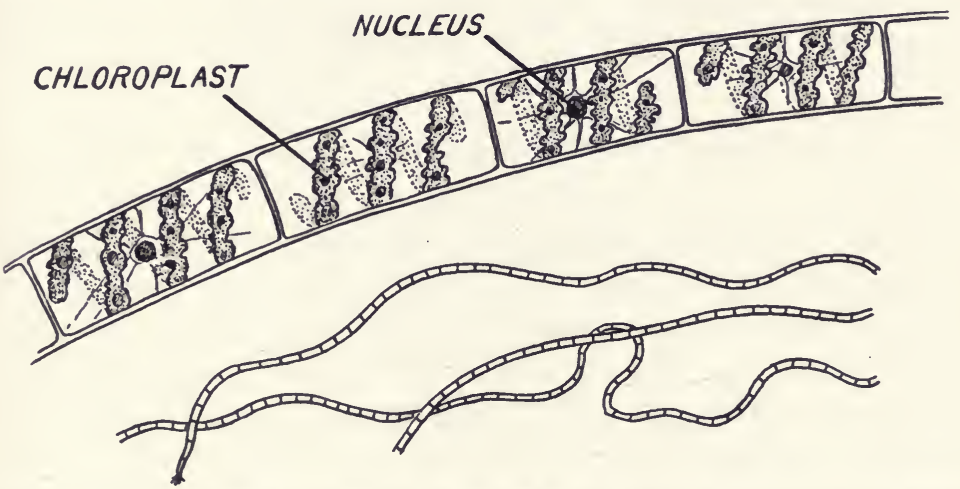

FIG. 9.-In a pond scum such as Spirogyra we find a multicellular aquatic plant with no division of labor among the cells; upper drawing an enlarged portion of the plant seen in lower drawing.

alike and carry on the same functions, so that for practical purposes it is simply a number of individuals - each similar to a desmid cell-which have remained united after cell division. The greater part of each cylindrical cell consists of a water vacuole filled with cell sap, a thin layer of cytoplasm separating it from the cell membrane and cell wall; strands of cytoplasm extend inward and surround the central nucleus. This cytoplasmic layer contains one or more band-shaped chloroplasts which form bright green spirals around the cell wall. These carry on photosynthesis in the same manner as the chloroplasts of the desmid. Each cell of the filament independently takes in its own carbon dioxide, oxygen and minerals from the aquatic 
medium with which every cell is in contact, and waste products pass outward in the same way. When excess protoplasm has been formed within a cell, it develops a transverse wall and cell division results in two cells where formerly there had been one. Growth of the plant as a whole is the result of this increased number of cells. Some materials in solution diffuse from one cell to its neighbor but no cell is dependent upon this means of support. No special protective walls are developed; when a cell or group of cells has been injured and dies, the fragments form new filaments by the customary cell division. In its life activities, even though it is multicellular and macroscopic in size, Spirogyra does not differ essentially from the microscopic and unicellular desmid.

\section{A Multicellular Thallus Plant with Some Division of Labor}

In those aquatic plants known as KeLPs (fig. 10) the multicellular body shows an increase in complexity with a beginning of division of labor. Kelps are brownish-green seaweeds which live in cool oceans, often forming meadows along the sea bottom below low tide mark. The body of a typical kelp, such as Laminaria, is made up of millions of cells forming a massive thallus which sometimes attains a length of a hundred feet or more. There is a definite division of the body into three parts; a root-like basal holdfast, a slender stem or stalk, and an expanded blade. Being aquatic, the kelps like the desmids and pond scums can absorb all of the necessary substances for autotrophic metabolism from the surrounding medium. There are two important differences, however. Only a small proportion of the cells of the kelp's body is in contact with the water, so that these must form a medium of exchange of substances between the water and the remaining cells of the thallus. Furthermore, all of the cells do not contain chloroplasts; such cells are located for the most part in the blade where photosynthetic activity is centralized. The restriction of photosynthetic tissue to certain parts of the plant body becomes more and more marked as we proceed to the higher plants, so in this respect the kelps introduce a new element in the construction of the plant body. The stem is made up of outer protective cells and an inner strand of elongated cells which conduct mate- 
rials after a primitive fashion. Attachment to the substratum is the special duty of the holdfast cells, which however have no absorptive functions. The great size of these kelps - they are the largest thallus plants-is due in part to this beginning of tissue differentiation. The life of a kelp is basically the same as that of

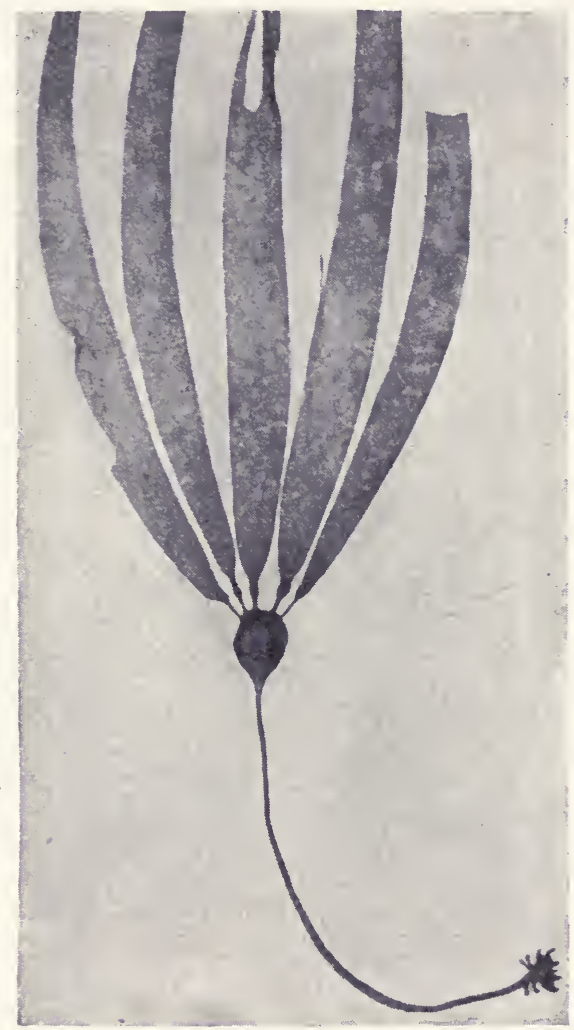

Fig. 10. - The body of a kelp is a thallus with division into a root-like holdfast, a flexible slender stalk, and an expanded (often subdivided) blade.

Spirogyra, except for the mutual inter-dependence of the thallus cells. Carbon dioxide, water and salts diffuse in through the epidermal layers and pass eventually to the photosynthetic cells. After food manufacture the excess glucose passes out from the green cells to all parts of the plant, to be used as needed. Since 
protein synthesis does not depend upon chlorophyll or sunlight, much of this soluble sugar is utilized by every cell in making new protoplasm. Stem growth in diameter is the result of the activity of a growth zone beneath the epidermis where cell division continually takes place. The growth of the blade is similarly the result of cell division, often resulting in such a large surface that it becomes frayed and broken by waves and ocean currents. In contrast to the pond scums, the kelps have a more definite shape and more limited growth. The tough, leathery outer epidermal layers function well for protection, preventing dessication of the underlying tissues when the kelp is by chance left stranded at low tide - an experience which would be fatal to a desmid or to a pond scum.

\section{A Primitive Thallus Land Plant}

The transition from an aquatic to a terrestrial mode of living imposed severe demands upon the plant body. In all three of the preceding plants the body is able to secure easily the essential inorganic materials from the surrounding water; into which the plant may also excrete waste substances. There is little need for an impervious epidermis to prevent loss of water from the protoplasm, or for supporting tissues. Hundred-foot kelps are buoyed by the water to such an extent that they need no skeletal support as required by a land plant of equal size. But life on land brings with it problems associated with securing water and dissolved minerals, with developing protective tissues, and with production of a skeleton if the plant is to attain any size.

LiverWORTs (fig. 11) are a group of simple land plants living in the shaded and moist habitats of wooded ravines and stream banks. These plants are more or less transitional in structure between the green thallus plants of ponds and oceans and the more highly organized flowering plants. Marchantia, a typical liverwort, has a flattened and ribbon-like body a few inches in length which clings closely to the ground. It is a thallus plant, having no differentiation into roots, stems or leaves. However it exhibits a certain amount of tissue differentiation-greater than in the kelp - and is characterized by some of the modifications which are necessary for land living. It has a compact multi- 
cellular body, the bulk of whose cells are protected from dessication by a special epidermal covering. The important contact with the earth, source of the life-sustaining water and minerals, is secured by numerous hair-like rhizoids which serve the double purpose of anchorage and absorption. Being prostrate in habit, Marchantia and all liverworts have no supporting tissue. Division of labor among the cells results in greater inter-dependence among the cells of the thallus than is found in any of the preced-

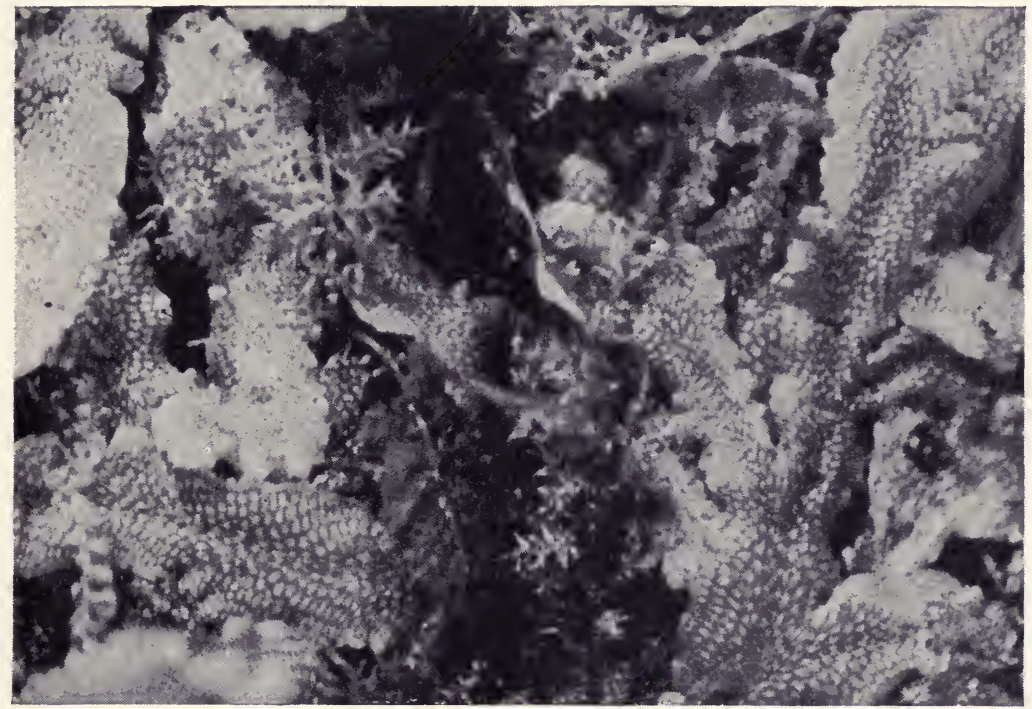

Fig. 11.- Liverworts are a group of simple land plants living in the shaded and moist habitats of wooded ravines.

ing types. The cells with chloroplasts are found immediately beneath the epidermal layer; below this photosynthetic tissue (fig. 12) is a layer of storage cells, larger in size and with fewer chloroplasts. On the undersurface of the epidermis develop the rhizoids which lack chloroplasts and act as absorptive cells. Throughout the body there exist numerous connecting air spaces which permit free passage of water and gases from one cell to another. The daily life of the liverwort is only slightly different from that of its aquatic relatives. The water arrives at the photosynthetic cells by diffusion from the lower cells of the thallus, 
into which it has passed from the rhizoids. Carbon dioxide and oxygen diffuse into the plant over the entire epidermis or through special pores in the surface.

For successful living in a greater variety of land habitats than that found in Marchantia, further structural specialization is necessary, with a more efficient functioning of the absorptive and photosynthetic tissues. Roots take the place of rhizoids and the

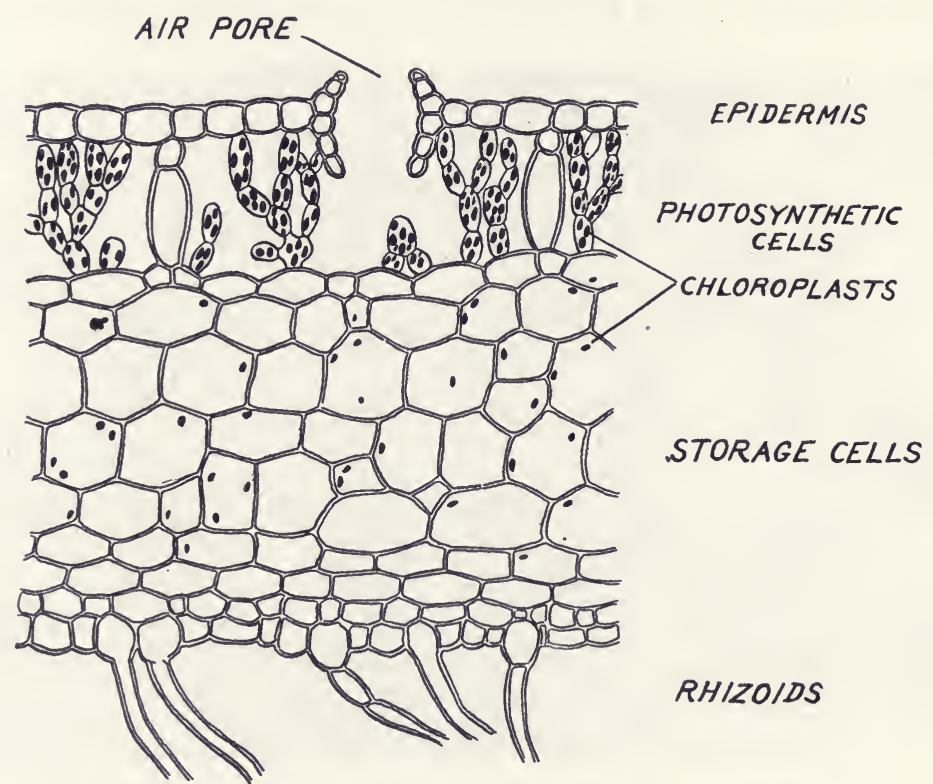

FIG. 12.-Division of labor in Marchantia results in a protective epidermis, photosynthetic cells, storage cells and absorptive rhizoids.

photosynthetic tissues are collected in expansions of the body known as leaves. Skeletal and conductive tissues are important in the stems, which by necessity connect the roots with the leaves as well as support the latter. The leaf becomes the most characteristic plant organ; in fact many may consider leaves the identifying feature of a plant. Each leaf is an organ made up of tissues specialized in carrying on photosynthesis; it is the last word in the evolution of that part of the green plant concerned with constructive metabolism. Thallus plants and liverworts have no leaves, 
but among the mosses, near relatives of the liverworts, leaf-like organs appear.

\section{A Primitive Leafy Land Plant}

Many mosses prefer to grow in damp and shaded situations similar to those chosen by liverworts, but they are able to live also in sunnier and drier habitats, since they are structurally better fitted for terrestrial life. Mosses have stems on which grow leaflike organs which contain most of the chloroplast-bearing cells. The basal end of the stem develops rhizoids similar to those of Marchantia. Still lacking, however, are the true roots and the vascular stem tissues found in the fern, and seed plant groups. This deficiency has predestined mosses to being a small and insignificant portion of our vegetation.

The HAIRY-GAP MOSS of fields and roadsides (fig. 13) is typical of the group. Each individual plant is rarely more than a few inches in height, and grows in close association with numerous other individuals to form a compact mossy turf. There are three divisions to the moss body. In contact with the earth is a mass of filamentous rhizoids, threads of colorless cells whose function is the same as in the liverworts. The rather frail stem is made up of closely packed cells lacking chloroplasts, and showing only slight

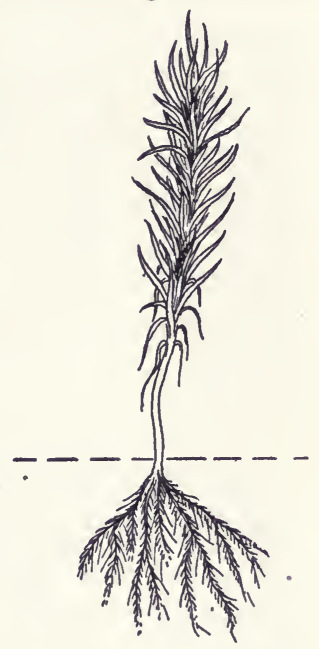

FIG. 13.-Hairy cap moss has a frail stem clothed with leaf-like outgrowths, and possessing absorbing rhizoids. specialization for support or conduction. The leaves are hardly true leaves as we understand them in terms of those found on trees and flowering plants. They are simple outgrowths from the stem, made up of chloroplast-bearing cells. The maintenance activities of a hairy-cap moss plant are practically the same as those of Marchantia. Water passes from the rhizoids by intercellular diffusion through the stem to the leaves, or directly from the environment into the rather unprotected leaf cells. Carbon dioxide and other gases pass into the leaf cells from the atmos- 
phere. Mosses can be considered as representing a body plan in which the erect habit and some specialization of tissues have appeared. But many improvements were necessary before plants could successfully colonize the variety of habitats of mountains, plains and deserts which they occupy today. Adequate tissues to protect the plants against water loss, special conductive channels to form a vascular system, and skeletal tissues had to appear. The first to develop these were the ferns and their relatives the horse-tails and club-mosses; in the geologic past these plants were the dominant forms of land vegetation, forming the first forests. But the culmination of adaptation for land living is to be seen in the seed plants, which have superseded the fern group in the struggle to cover the earth's surface with vegetation. Since fundamentally the ferns are like the seed plants in their maintenance structures, only the latter need to be considered. Of these the maple tree can be considered as representative of the entire group.

\section{A Woody Land Plant}

In the MAPLE TREE the constructive metabolic work is localized in the foliage, of which each leaf is in reality a factory specializing in the manufacture of sugar. The entire body plan of the tree is designed to place the foliage in the most advantageous position for carrying on its work and to provide the factories with the necessary raw materials. Sunlight being essential for photosynthesis, one of the main functions of the trunk is to raise the foliage to the light so that each of the thousands of individual leaves can get its share of solar energy; thus there is a network of branches and stems which entails skeletal tissue in order to provide a framework which can rise far into the air and support tons of weight. To best expose the leaves to the light the plant body must often raise the foliage a considerable distance from the earth. Since the earth is the sole source of the water and mineral salts, the trunk and branches assume a second function in addition to support; through their conductive channels the materials taken in by the absorptive system pass freely to the leaves; more freely than would be true it the water and dissolved salts had to diffuse slowly from cell to cell in their course from roots to leaves. The 
absorptive duties are assumed by the underground portion of the maple tree which forms a network ramifying for hundreds of feet in all directions underneath the surface of the soil; the ultimate branches of this root system act as millions of tiny hairs taking in the water needed for plant maintenance. At the same time, the root system anchors in place the otherwise top-heavy mass of foliage and branches. Thus there is the fundamental division of the tree into leaves (photosynthetic region), stems (supporting

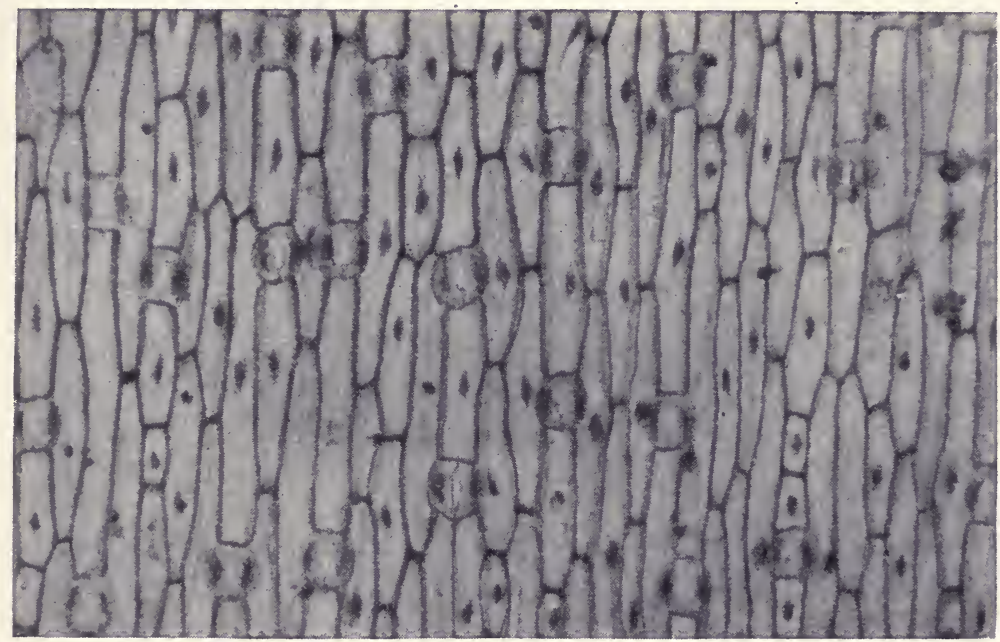

Fig. 14.-A surface view of a leaf epidermis shows a firmly packed layer of colorless cells, interrupted by the air pores, or stomates.

and conducting region), and roots (absorptive and anchorage region). In each of these, the cells differ considerably in structure and function depending upon the special activities resulting from this division of labor.

The LEAVES of the maple, like those of most flowering plants, are broad and thin in order to expose a maximum amount of surface to the light. Each leaf is a compact mass of green cells protected above and below by an epidermis and traversed by a network of supporting veins. The epidermis (fig. 14) is made up of colorless cells which do not interfere with the transmission of light to the green cells beneath; their chief function is to keep the 
underlying tissue from drying out. In many cases this is effectively brought about by a thickened and waxy outer layer known as a cuticle. Since an entirely impervious epidermis would prevent the necessary exchange of gases with the atmosphere, the epidermis is perforated by many small pores (stomates) which act as automatic valves, the size of their openings varying with the dryness of the atmosphere and thus regulating the loss of water by evaporation. Through the stomates the carbon dioxide and oxygen can circulate freely between the photosynthetic cells

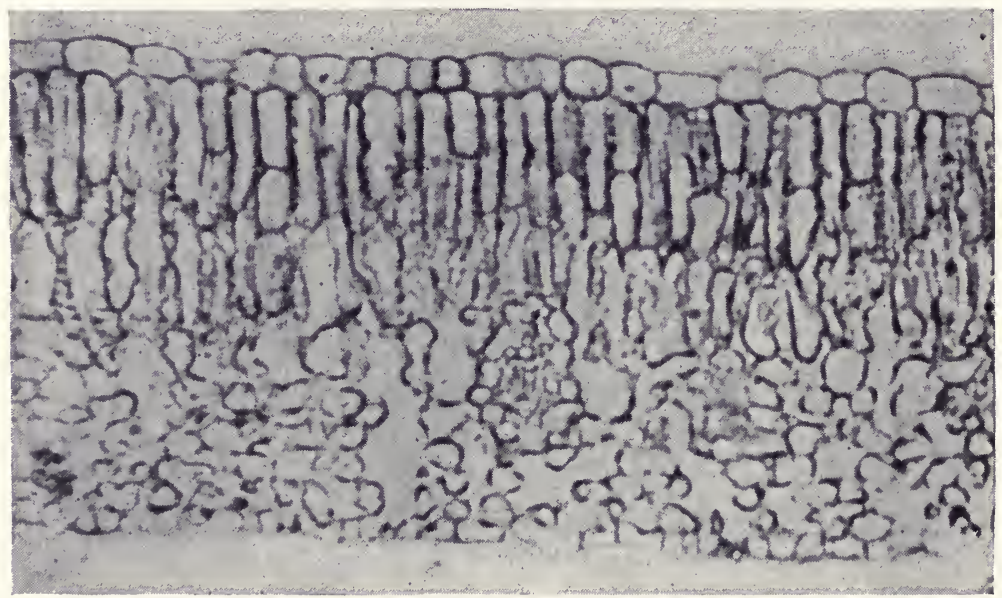

FIG. 15.-Between the upper and lower epidermis lie the parenchyma cells which contain chloroplasts (small black dots in cells) and thus carry on photosynthesis.

and the air. This water loss through the leaves, technically known as transpiration, presents one of the greatest problems to land plants. Openings are necessary for the gaseous exchanges associated with photosynthesis and respiration; yet the plant can not select which gases will pass out, so that transpiration becomes a necessary evil. Reduction of transpiration loss by desert plants has been brought about by various adaptations such as hairy coat to the leaves, stomates in depressions, or elimination of the leaves entirely as in the cacti.

Between the upper and lower epidermis (fig. 15) lie the parenchyma cells which carry on photosynthesis. The upper 
layers consist of closely packed cylindrical cells, each gorged with a dozen or more chloroplasts; it is this tissue which gives leaves their green color. The parenchyma cells found between these and the lower epidermis are more irregular in shape, have fewer chloroplasts and are surrounded by connecting air spaces into which the stomates open. The veins are vascular channels, made up of elongated conductive cells, which form a circulatory network among the parenchyma cells; the terminal portions of each vein are in actual contact with a parenchyma cell.

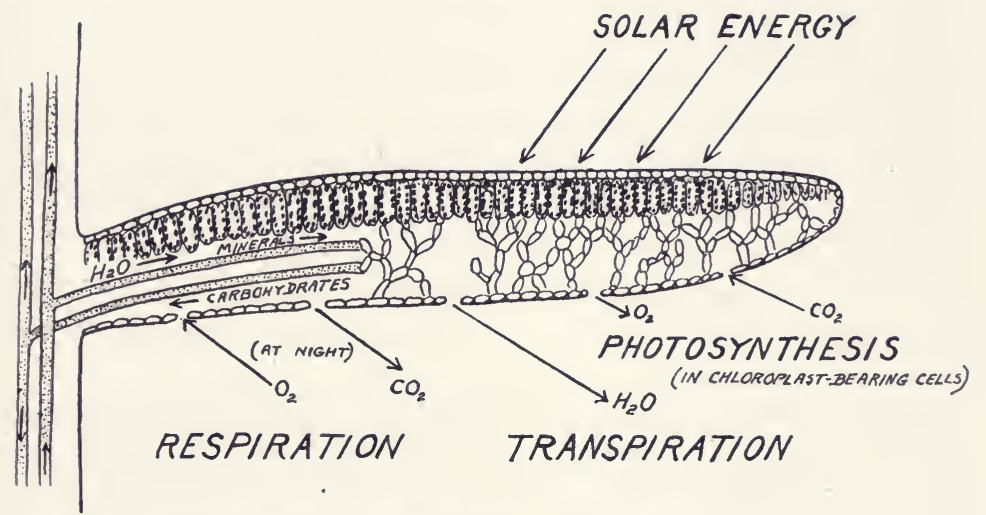

PROTEIN SYNTHESIS (IN EVERY CELL)

FIG. 16.-Numerous activities take place in a living leaf during daylight hours.

Every day, from sunrise to sunset, leaves are scenes of continuous activity (fig. 16). Carbon dioxide, diffusing in through the stomates from the atmosphere, passes through the air spaces of the parenchyma and eventually enters a chloroplast-bearing cell. At the same time water, flowing upward through the vascular channels from the roots, passes into smaller and smaller veins until it too enters a chloroplast-bearing cell. With these raw materials, secured from the distant air and the more distant soil, each green cell then carries on the same process that took place in the unicellular desmid plant. Glucose diffuses out of the photosynthesizing cell through other channels in the same veins and in time passes into every cell of the tree, to be used for respiration, protein and protoplasm building, or storage. The 
oxygen which is a by-product of this process, if not completely used up within the plant by respiration, passes out of the cells and into the atmosphere via the stomates. A more detailed description of food manufacture is taken up in Chapter 6.

From this we can see the importance of leaves to a plant. In undifferentiated plants where chloroplasts occur in every cell and where there is little dependence of one part of the plant body upon another, the loss of a portion of the body is of little consequence. But the whole life of the maple tree depends upon the activity of the leaves; every cell lacking chloroplasts - which includes most of the roots, stems and branches, flowers, fruits and seeds - is dependent upon the food-manufacturing leaf cells. Therefore the loss of leaves, due to insect defoliation or fungus attack, becomes a serious matter. The dependence also works the other way. The leaves must rely upon stem growth to obtain sufficient light and upon co-operation of root and stem to bring to them the raw materials upon which the life of the leaves themselves depend. The leaves are helpless and can not themselves stay alive, if deprived of roots and stems.

The intake of water and dissolved salts from the environment occurs through other highly specialized portions of the maple tree. The ROoTs are subterranean organs with a structure suited for their dual role of absorption and anchorage. The actual tip of each ultimate branch of the root system consists of actively growing cells which bring about continuous growth and elongation of the root; this takes place, however, in a far different medium than that surrounding the growing tip of the stems. The root tip has to force its way through the ground, past and around soil particles with contours so harsh as to easily injure living cells. To obviate this, the growing cells of the tip produce a buffer root-cap of cells which are continually replaced as they wear away. Behind the root-cap and the root tip of growing cells, the cells become differentiated into three regions (fig. 17); a single layered epidermis, a cortex of irregular and large parenchyma cells, and a central cylinder of conductive and supporting cells. In none of these regions of the root are there chloroplast-bearing cells. The outer epidermis, unlike that of the leaf, is not specialized as an impervious protective coat, for through it all materials 


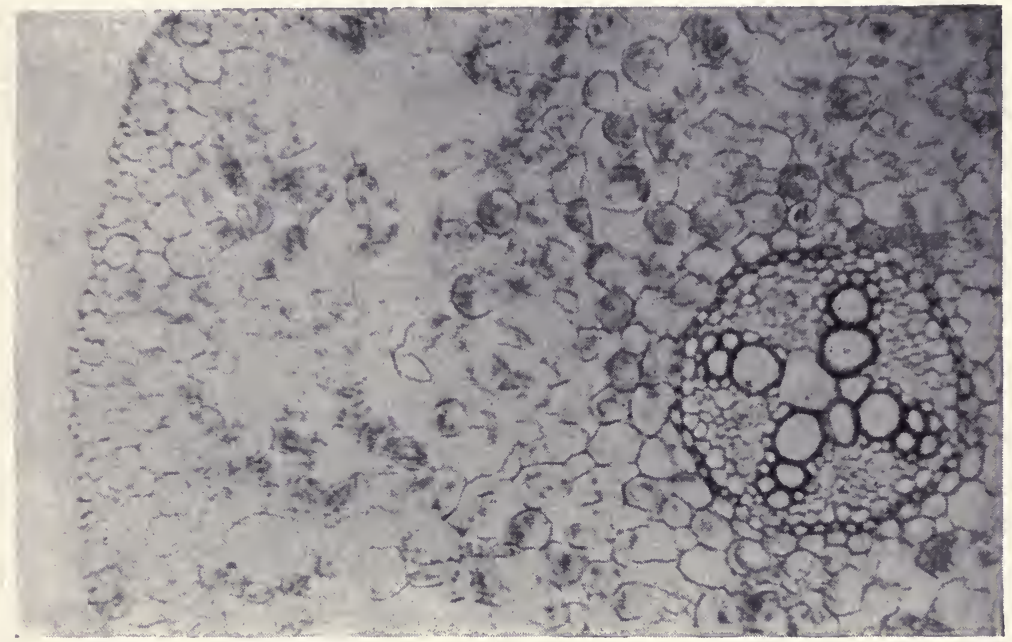

Fig. 17.-A young root is differentiated into three regions: a single-layered epidermis, a spongy cortex and a compact central cylinder of conducting and supporting cells.

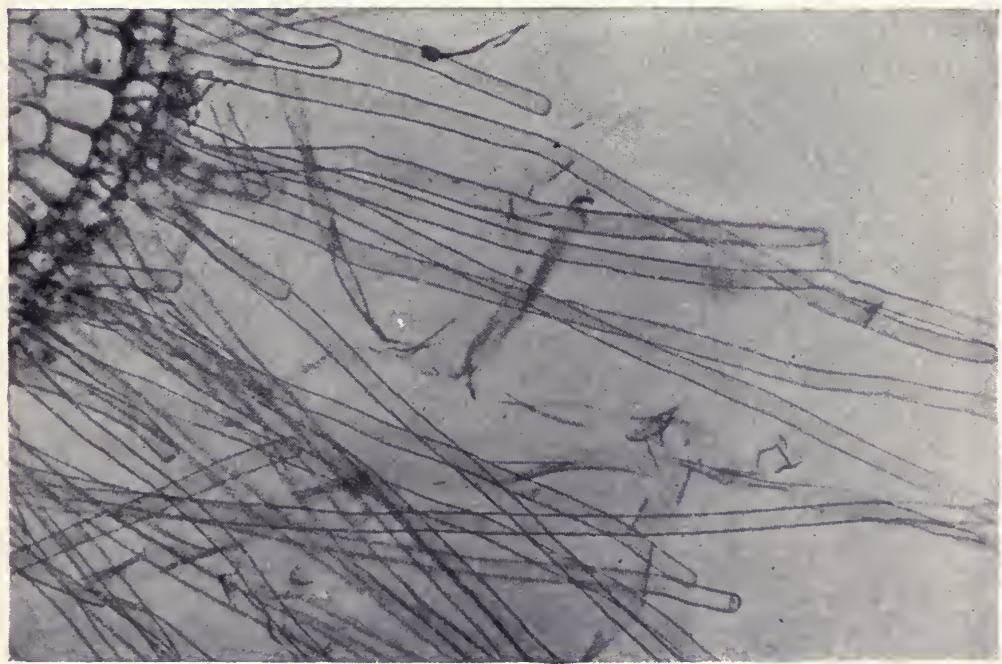

Fig. 18.-Root hairs are slender epidermal outgrowths which increase the absorptive surface of roots. 
must pass if they are to enter the vascular system. It is the most important part of the root from the standpoint of absorption. Outgrowths of the epidermal cells appear a short distance behind the root-cap extending for an inch or two along the root surface. These outgrowths, known as ROOT HAIRs, (fig. 18) are slender filaments which increase considerably the absorptive surface of the epidermis and which are able to penetrate the soil in the spaces between the soil particles. Root hairs are evanescent structures, living for only a day or two; new root hairs are produced in the zone nearer the root tip as old ones wither away in the region farther from the tip. Water passes into the protoplasm of the root hair by osmosis, and at the same time any mineral salts in solution enter the cell by dialysis. Once in the cell sap of the root hair cells, the water and salts pass from cell to cell in the cortex until finally these materials reach the central cylinder. Here are two kinds of conductive channels; radiating from the center of the root are groups of thick-walled water conducting cells into which the water and minerals pass. The water conducting cells, or XYLEM, form a continuous vascular system through the stem to the veins of the leaves. Alternating with the xylem strands and thus not interfering with the passage of water into them from the root hairs, are groups of smaller food conducting cells known as PHLOEM. The function of these vascular channels is conduction of manufactured food from one part of the tree to another, bringing soluble carbohydrates especially from the leaves to the stems and roots. In addition to its conductive function, the central cylinder can withstand the lengthwise tension to which roots are subject, due to the thickened woody cell walls of the xylem. In older roots certain changes occur in these structures; epidermis is replaced by bark and a ring of growth cells produces annual increase in thickness of the woody tissues.

There is no sharp distinction internally between the root and the stem. At the surface of the ground the root system becomes the STEM, with little marked difference in appearance. A young stem has epidermis but this is a short-lived tissue found commonly only in recent growth of the tree. In older stems and in the trunk, the epidermis is replaced by bark as in the underground parts of the tree (fig. 19). The cork cells which make up bark are a 
far more efficient protective tissue, against both water loss and physical injury, than simple epidermal cells. Within the bark and considered a portion of it, is the cortex, a continuation of the cortex of roots. The cortex of the trunk occupies proportionally much less space and is an inconspicuous tissue. Just

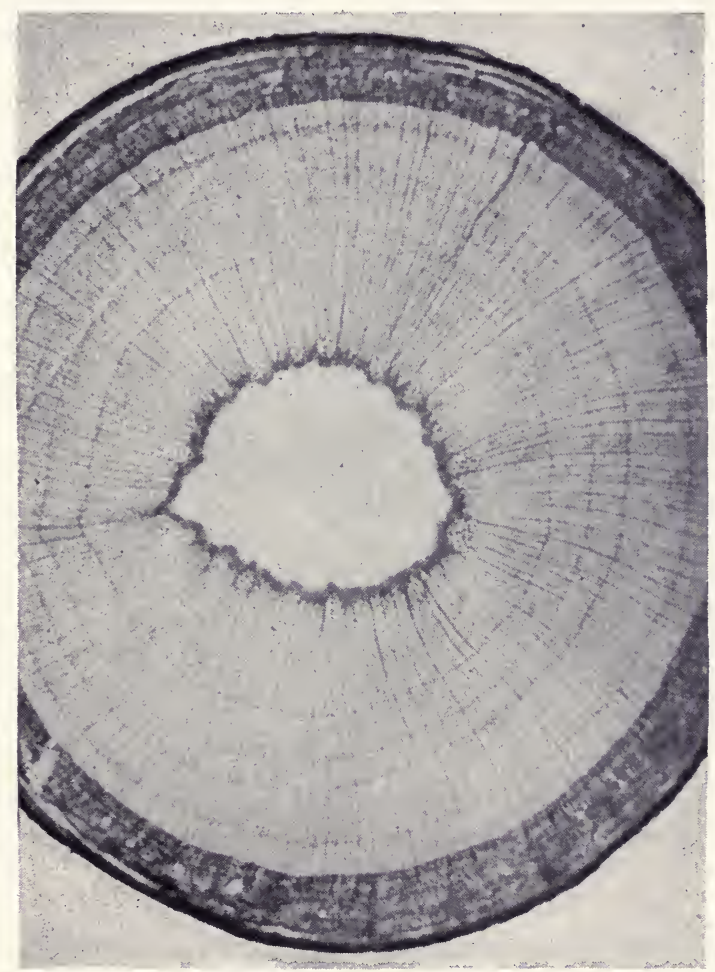

FIG. 19.-A stem typically consists of an outer zone of bark and cortex (dark area), a cylinder of wood cells marked by annual rings, and a central pith of variable size.

inside the cork and cortex tissues of the tree lies the inner bark and sap wood, a zone of living cells which forms a ring around the more central part of the trunk (fig. 20). This is the conductive and growing part of the stem, continuous with the conductive channels of the central cylinder of the root. The PHLOEM tubes, 
instead of being in scattered groups, form a continuous ring just inside the cortex; in them most of the circulation of sugar and other soluble plant foods take place. The water conducting channels form a second ring of cells on the inside of the phloem zone; they are continuous with the XYLEM of the root and that of the leaf veins. Between the two is a narrow zone of growth cells - the САмBIUM - which keep dividing as long as the tree lives, bringing about increase in diameter of the trunk by forming new phloem cells and new xylem cells. The remainder

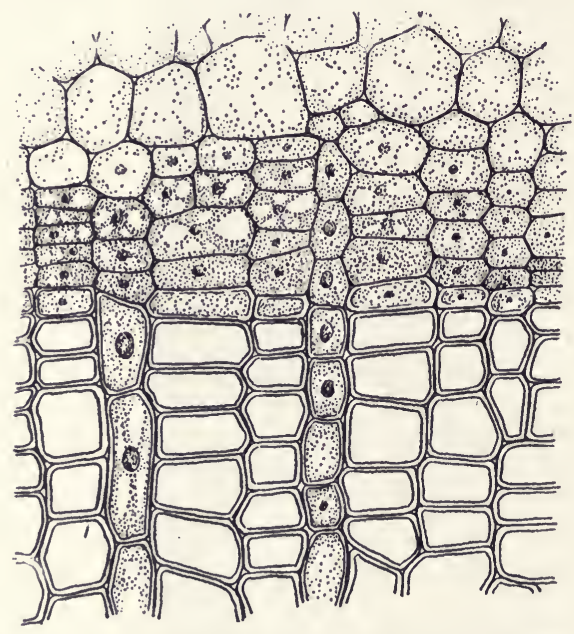

CORTEX

PHLOEM (Food DUCTS)

CAMBIUM

XYLEM (WATER DUCTS)

FIG. 20.- Inside the bark and cortex tissues of a tree trunk lies the sap wood, a zone of living cells which act as the conductive and growing portion of the stem.

of the maple tree trunk consists of wood. Wood makes up most of the tissue within the cambium ring since it is produced in association with the water-conducting channels. There are two kinds of wood cells. Long tubes, made up of cylindrical cells placed end on end and known as vessels, conduct the water; scattered among the vessels are the more slender cells with thickened walls known as fibers. These form the skeletal rather than the conductive elements of the trunk. Both the vessels and fibers which make up most of old trunks and branches are dead cells. Living waterconductive cells are found only in the immediate vicinity of the 
cambium ring beneath the bark. The skeletal tissues which characterize woody plants are discussed more in detail in Chapter 15, and their economic importance is the subject matter of Part Three in its entirety.

Growth of roots and stems takes place at the tips, where special growing points are made up of cells which are continuously dividing to form new cells, the latter soon becoming differentiated into the tissues which make up the full-grown root or

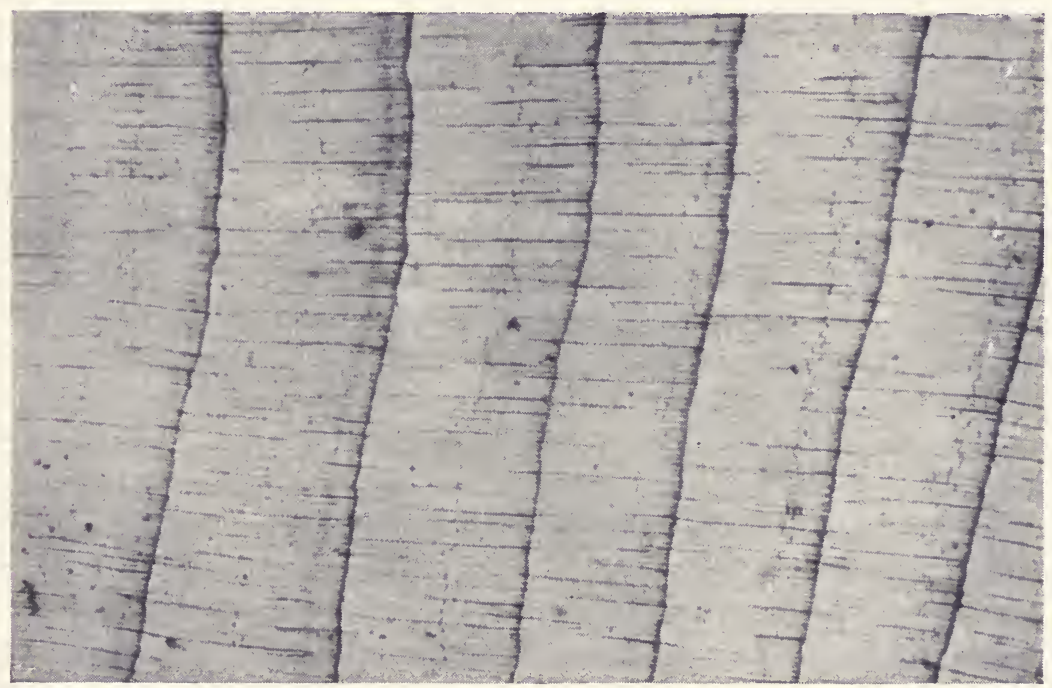

Fig. 21.-The demarcation between (summer and spring) wood of successive seasons results in annual "rings."

stem. Growth in diameter is the result of the activity of the cambium cells. In many plants living in climates with alternating warm and cold, or wet and dry, seasons, the cambium cells do not grow continuously. During the warm, or wet, season conditions are such that they actively divide and form new phloem cells on their outer surface and new xylem cells on their inner face. As the season progresses, fewer and fewer vessels are formed in the xylem or wood, and more fibers. Thus the "spring wood" is lighter colored and more porous, as compared with the denser and less porous "summer wood" (fig. 21). During the winter, or 
dry season, cambium activity ceases entirely. When renewed growth takes place the next spring, the wood presents a marked contrast to that of the previous autumn which is contiguous with it, having more and larger vessels and fewer fibers; it is this line of demarcation between the summer wood of one season and the spring wood of the next which results in an annual ring, of which one is usually formed per year in the trunk of the tree.

In a tree, then, we see the climax of organization of the plant body. But with all its organs and tissues and elaborate specialization, the tree does not carry on any metabolic activities different from those characteristic of a desmid or a liverwort; such structural complexity has become necessary because of the competitive demands of land living. Soil is the part of the environment containing water and the necessary minerals; therefore the tree must have a part of its body in intimate contact with this source of raw materials - the result being the root system. The utilization of sunlight, on the other hand, necessitates photosynthetic tissues exposed to the air, which is likewise the source of carbon dioxide and oxygen in this part of the tree's environment. Hence the aerial portions of the tree, making up the foliage. Connecting these two important parts of the plant body, the stems, branches and trunks become the arteries of conduction as well as the sinews of support. The entire tree is a beautifully designed organism with every part having a structure and an appearance correlated with its special duty in the general maintenance of the tree's existence.

\section{The Colorless Plant Body}

There are many plants, of varying degrees of body complexity, which lack chlorophyll; therefore they can not carry on photosynthesis and lead the independent existence of autotrophic green plants. Neither can they carry on the simple type of autotrophic metabolism without chlorophyll, characteristic of the sulphur and iron bacteria. These heterotrophic bacteria and fungi, like animals, are unable to live on inorganic materials; unlike animals, they absorb their organic food from the environment rather than ingest it. This means a dependence upon carbohydrates, fats and proteins produced by or existing in auto- 
trophic organisms. Since there is no dependence upon sunlight, they frequently abound in shaded and dark habitats where photosynthetic plants could not live. Such plants have no leaves, stems or roots; the majority are microscopic or small in size, with little tissue specialization and hence belong to the thallus plant group. Their maintenance activities center about the securing of food, and as a result the plant body is designed for the absorption of organic materials from the surroundings.

The absorption of food is brought about in one of two ways. A SAPROPHYTE is a heterotrophic plant which secures its organic material from the bodies of dead organisms or their excreta, or from the debris of plant life known as humus. Saprophytes are often scavengers and usually not detrimental to man. In some cases, as among the decay bacteria, the saprophytes are actually of great value in the continual cycle of food elements in nature. PARAsites on the other hand absorb the organic material directly from the bodies of living animals and plants; this often disturbs the normal activities of the host and causes its death. Plant parasites are man's deadliest enemies, causing the majority of human diseases and diseases of animals, as well as plant diseases which take an expensive annual toll among our crop plants. This aspect of the relationship of plants to man is more fully treated in Chapters 24 and 25.

Other maintenance activities of saprophytes and parasites are similar to those of the green plants; respiration, excretion, growth, protection against unfavorable factors in the environment. A consideration of three body types-bacteria, molds and mushrooms - chosen from the thousands of heterotrophic plants will suffice to show the range in body complexity.

BACTERIA are the smallest organisms known to man, some species being only $1 / 250,000$ of an inch in length. They are unicellular colorless plants found in liquid or semi-liquid environments. In contrast to the desmid cell, the bacterial organism has an exceedingly simple structure (fig. 22). A thin cell wall may at times develop a thick gelatinous sheath or capsule for protective purposes; within this, the protoplasm is not clearly organized into nucleus and cytoplasm, the chromatin material being scattered throughout the cell. Few cytoplasmic structures are dis- 
cernible. One of the most distinctive features of the bacteria is their characteristic shape, some being spherical, others rodshaped and still others spiral. Whether saprophyte or parasite, the bacterial cell absorbs its food from the surrounding environment; the protoplasm produces enzymes, similar in function to those found in animal bodies, which are excreted into the environment. Acting upon the complex organic compounds of plant or animal protoplasm, these enzymes break them down into simple sugars or amino acids, which are absorbed into the

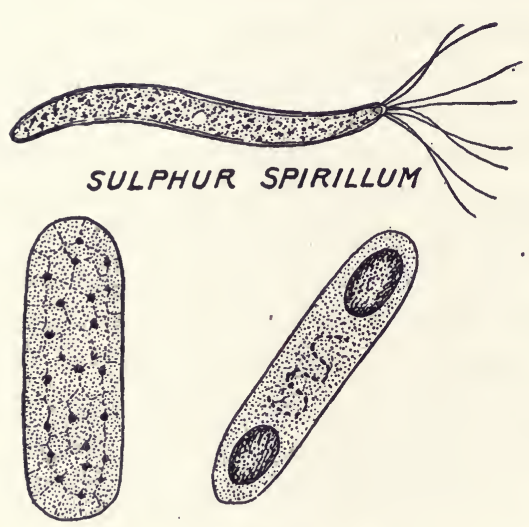

BACILLUS (DIAGRAMMATIC)

BACILLUS

\section{FORMING SPORES}

Fig. 22.-In contrast with the desmid cell, the bacterial organism has an exceedingly simple structure with diffused nuclear material. cell and then used for respiration, storage or growth. Because of this dependence upon organic substances, bacteria and other heterotrophic plants are not found in environments characterized only by inorganic materials. This accounts for their scarcity in clear lakes or on bare earth surfaces, and for their abundance in stagnant pools with decaying bodies of plants or animals, on food and in the tissues of living organisms. Destructive metabolism within the bacterial cell involves respiration with the release of carbon dioxide, water and vital energy, though some species have a special type of respiration with no need for oxygen. Growth is by cell division, as in the desmid cell. The capsule or sheath, already described, is an effective protective structure; because of this, bacterial cells are often difficult to destroy.

Molds are multicellular colorless plants roughly comparable to some of the seaweeds. They are far smaller in size, most molds forming a felt-like coating over organic materials. Some are aquatic, and some terrestrial. Division of labor has resulted in two parts to the mold's body. The general mass of colorless and 
multicellular filaments make up the bulk of the mold, but these are dependent upon root-like tufts of absorbing filaments which penetrate the substratum and absorb organic materials (fig. 23). The mold carries on the same type of existence as does the bacterial cell, with the added complications associated with a multicellular body. A mold growing on the surface of a piece of bread is continually absorbing carbohydrate and other organic material through its rhizoids; this food passes slowly through cell after cell, eventually reaching every cell of the body. With ample food, the newly formed protoplasm stimulates cell division, so that growth of the mold is the result of an increase in the number of cells.

Mushrooms attain greater size than molds, reaching the greatest size of any heterotrophic plant. But even with this greater size, there is not much more division of labor in the plant body, and little tissue specialization. A common field mushroom (fig. 24) consists of an almost entirely subterranean maintenance portion; the above-

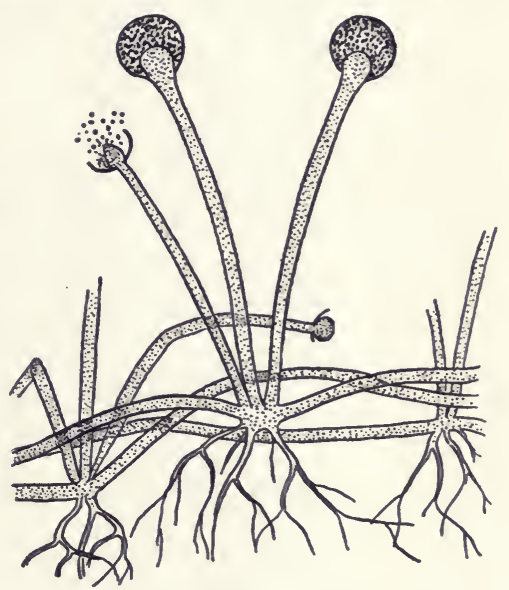

Fig. 23.-Division of labor in a mold plant has resulted in a mass of colorless vegetative filaments with root-like absorbing outgrowths. ground and familiar structure with stalk and cap is in reality the reproductive outgrowth from the subterranean vegetative body. This body is a mass of unspecialized cells, of a filamentous nature and similar to that of the mold. From these, absorptive filaments penetrate the humus or other source of organic material. Metabolic activity, involving food getting and utilization, is the same as that taking place in the mold.

Even with their lack of complex maintenance tissues or organs, the heterotrophic plants have become numerous and of great economic importance. It is said that for every two selfsustaining green plants there is a saprophytic or parasitic species depending upon them for sustenance. Since these destructive 
members of the plant world must be kept in check in order to allow the more constructive ones to thrive, it is as vital to understand how these plants live as to comprehend the activities of the

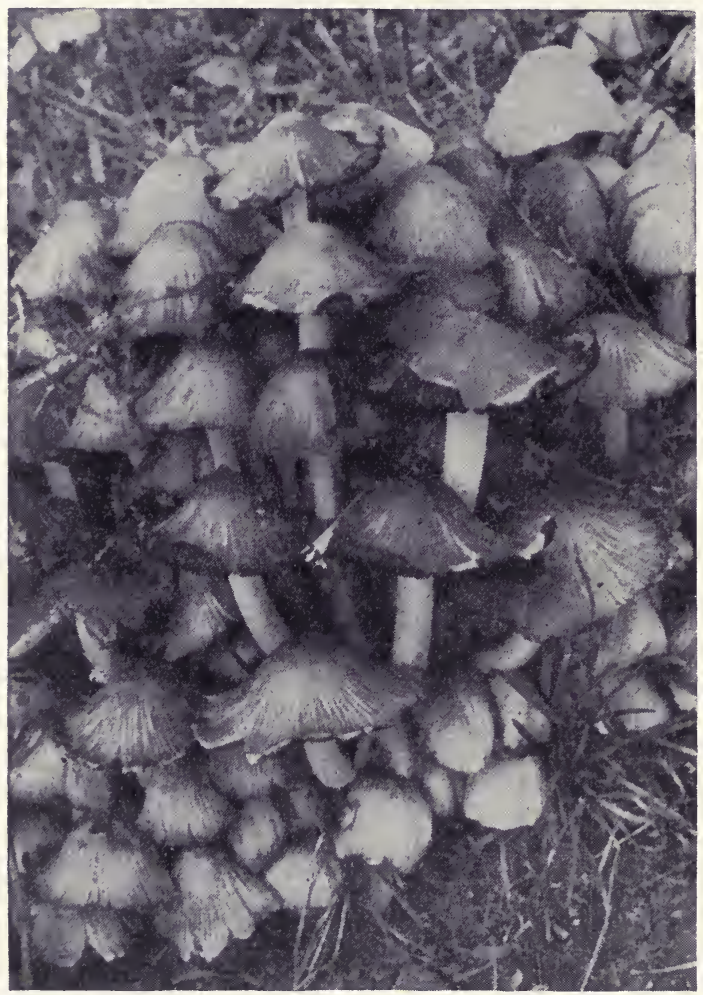

FIG. 24. - The common mushroom consists of a subterranean vegetative body, with the visible stalks and caps in reality only the reproductive organs.

more familiar green plants. Once man has learned how these parasites subsist, he can attempt to control them, furthering the growth of useful species by restraining or eliminating the harmful heterotrophic ones. 


\section{Chapter 3 \\ THE EVOLUTION OF PLANT \\ REPRODUCTION}

As plant bodies evolved from the unicellular condition to the large and complex forms of trees and other flowering plants, division of labor resulted not only in the localization of various maintenance functions in special organs such as roots, stems and leaves; but also in a segregation of reproductive abilities in definite portions of the plant. In place of the primitive condition whereby any part of the plant could reproduce the entire organism, special cells, tissues and organs were set aside for reproductive purposes. This restriction of reproductive powers has its culmination in such complex structures as flowers, seeds and fruits.

The numerous types of reproduction found in the plant kingdom are but variations of the two basic methods of asexual and sexual reproduction described in the first chapter. The asexual method was undoubtedly the first to appear, and from it evolved primitive sexual types of reproduction as well as the more complex asexual and sexual habits of land plants. As in the study of the maintenance activities of plants, it will be convenient to limit our attention to a few significant types which are representative of the important stages in the evolution of plant reproduction. These include (1) reproduction in unicellular plants, (2) reproduction in multicellular thallus plants, (3) the reproductive cycle of a moss, (4) the reproductive cycle of a fern, (5) the reproductive cycle in the little club moss, (6) the reproductive life history of a Gymnosperm, or cone-bearing seed plant, and (7) the reproductive life history of an Angiosperm, or flowering seed plant.

In such a series there is evident an increasing adaptation of plant reproduction to conditions of terrestrial life, especially in 
regard to specialization of fertilization methods, in dispersal of spores during asexual reproduction, in protection and nourishment of the embryo within a seed, and in dispersal of the young plants through development of fruits.

\section{Reproduction in Unicellular Plants}

As might be expected, the simplest form of reproduction is found among the unicellular plants. This is an asexual reproductive process known as Fission, closely related to growth; both

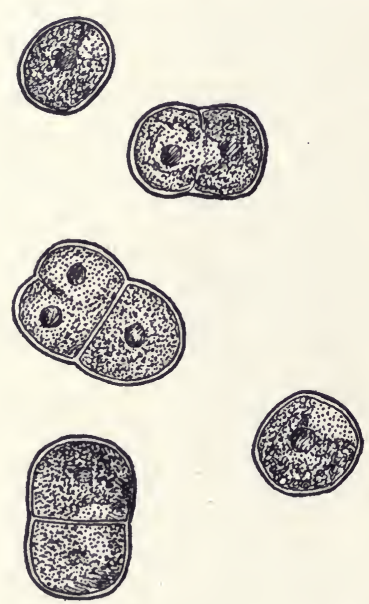

Fig. 25.-Protococcus plants grow and reproduce by the simple process of cell division. processes being the result of cell division. Protococcus, a microscopic unicellular green plant related to the desmids, lives in colonies on the bark of trees, where it often forms a conspicuous green coating. After the plant has elaborated sufficient food materials to enable the cell to attain its maximum dimensions, it undergoes cell division (fig. 25). The nucleus first passes through a complex cycle, dividing its chromatin material into equal portions at opposite ends of the cell. Then the cytoplasm around one of these daughter nuclei becomes separated by a cross wall from that in the other half of the cell surrounding the other nucleus. Thus each half of the original cell becomes a new cell, entirely surrounded by a cell wall and containing a nucleus. If these cells were to remain attached to each other after cell division, it would be a growth process; and if repeated at intervals would result in a multicellular body. But instead, these two new cells separate from each other and a new generation of two individuals results. This type of reproduction by fission represents the first attempts of life to perpetuate itself, and the entire cell organism takes part in the process. After reproduction by fission, the parent cell loses its identity in the formation of the two new organisms. 
Such reproduction by fission is also characteristic of the entire group of the bacteria. Because of the simplicity of the process, it can take place at frequent intervals, sometimes several times an hour. This accounts for the rapid increase in bacterial populations when these unicellular heterotrophic plants become established in a favorable nutrient medium such as blood.

\section{Reproduction in Multicellular Thallus Plants}

In the transition to multicellular life, some plants attempted to retain the individuality of every cell, not only in the accom-

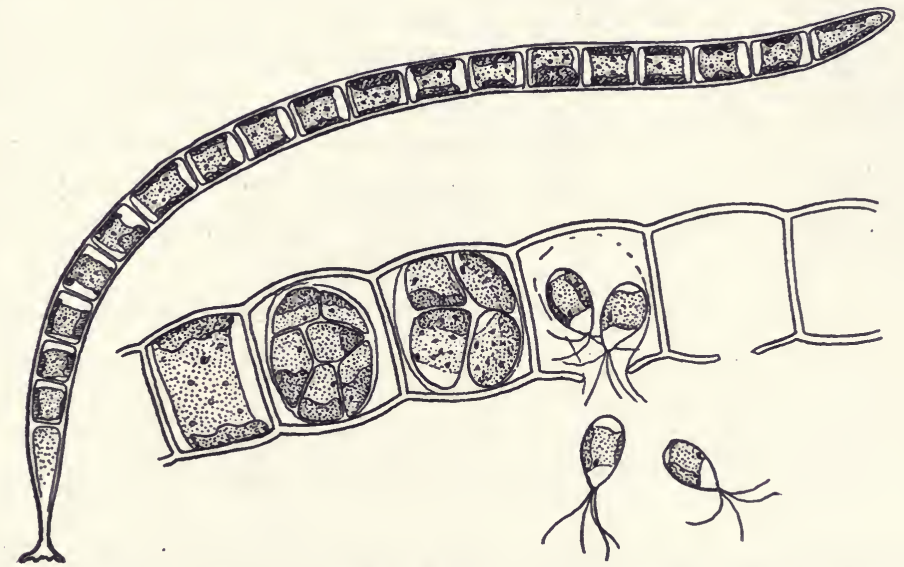

FIG. 26.-Ulothrix cells can undergo division to form small motile bodies known as zoospores.

plishment of all maintenance activities (cf. p. 27) but also in the ability of every cell to reproduce the entire plant. In such cases each cell undergoes a modified sort of fission, its contents breaking up into one or more units known as SPORES, which are asexual reproductive structures possessing the ability of growing into new organisms upon separation from the parent. Some spores have become highly specialized for their reproductive function, being protected by thick cell walls which aid in keeping the germ of protoplasm alive during unfavorable environmental conditions, as excessive heat or cold, or dryness. Under suitable conditions of temperature, food supply, etc. the spore bursts its re- 
straining wall and the protoplasm, by cell division, develops into the new plant.

In other thallus plants (pond scums and seaweeds) spores are frequently produced which are capable of swimming about independently; such motile spores are known as zoospores. In the pond scum Ulothrix, which is somewhat similar to Spirogyra,

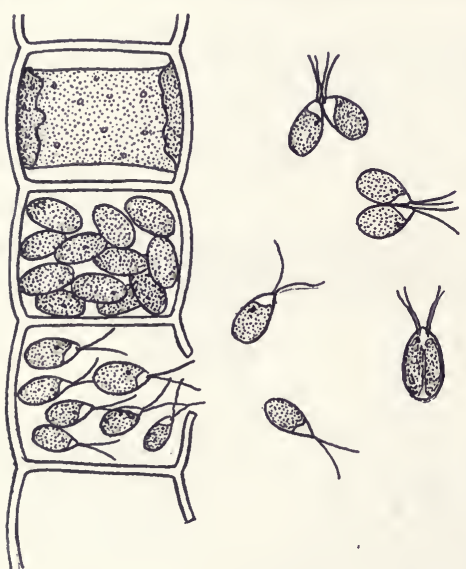

FIg. 27.-Ulothrix cells can also form motile bodies known as gametes which must fuse in pairs before germination. each cell may participate in the reproductive process. The cell contents undergo division to form several pear-shaped zoospores (fig. 26), each with four hair-like flagella which by their vibration bring about locomotion of the cell through the water. Since the zoospore can thus swim away from the parent filament, dispersal is brought about coincident with reproduction.

Further specialization in asexual reproduction occurs in algae such as the kelps (Laminaria) where the zoospores are not produced by every cell of the thallus but in certain cells which have assumed this particular function; these special cells form spore sacs, and are known as SPORANGIA. In all plants other than the thallus species, spores are always produced in multicellular sporangia.

Reproductive variation among the algae, in itself of little significance to man, is of theoretical importance because it shows how sexual reproduction may have evolved from primitive asexual types. Returning to our Ulothrix plant, we discover that zoospore formation often alternates with another type of reproductive activity. The contents of a cell undergoes division to form a number of motile cells which are smaller than the zoospores. Upon escaping from the cell they swim about just as zoospores do; but before they exhaust themselves they unite with one another in pairs to form fused cells (fig. 27). Each fused cell 
can grow into a new Ulothrix plant, but a solitary motile cell cannot. This may not seem of momentous consequence, yet this new type of reproductive behavior has crossed the border line between asexual and sexual reproduction. For the essence of sexual reproduction is the union of two cells to form one, from which the new organism develops. Such cells which must fuse before they can develop into new organisms, are known as gametes. The gametes of Ulothrix are the simplest and least

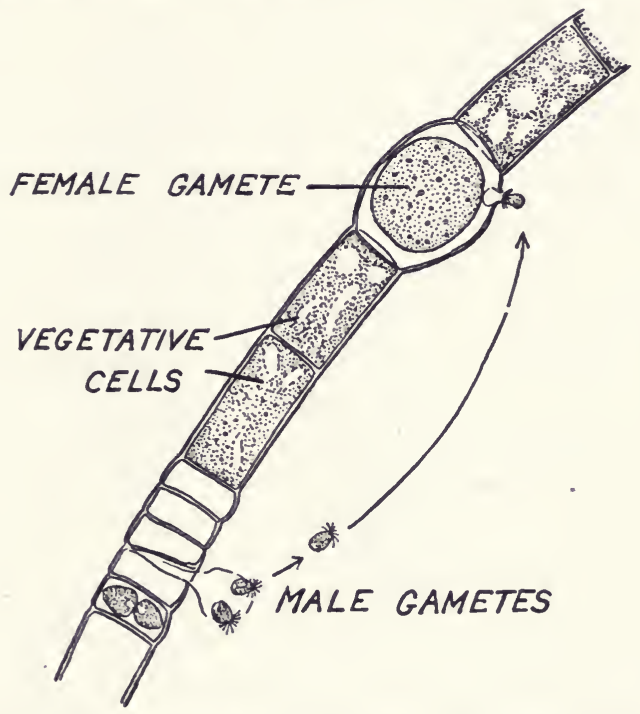

FIG. 28.- In an Oedogonium plant certain cells of the filament transform their contents into large female gametes while other cells form smaller male gametes.

specialized of sexual reproductive cells and the process of their uniting is the simplest form of sexual reproduction. Its possible origin (from zoospores developing the habit of fusing) indicates the probable transition from asexual to sexual reproduction.

We have seen that spores, by further division of labor, are often produced in special cells or groups of cells, the sporangia. In the same manner gametes tend to become produced in special gamete-forming parts of the plant. These in many cases become definite sex structures and when made up of complex tissues, become sex organs. The gametes themselves also become dif- 
ferentiated, exhibiting differences in appearance and behavior. This can be seen in another pond scum, Oedogonium (fig. 28). Certain cells of the filament transform their protoplasmic contents into single large gametes, each of which completely fills the cell and is incapable of leaving it. Such a large immotile gamete is not only a potential reproductive cell but also a storehouse of reserve food. Other cells of the Oedogonium filament produce smaller gametes which possess flagella and look more like the gametes of Ulothrix. When released from the cell, these motile gametes swim about and eventually one of them chances to find the opening provided in the cell which contains the large gamete. Entering through this, the small gamete fuses with the larger one to form a single cell. The large immotile gamete is known as an EGG, and the small motile gamete is a SPERM. In all higher plants, as well as in animals, sexual reproduction is by gametes of this type. The fusion of the two gametes thus seen in a primitive fashion in Oedogonium is known as fertilizationthe goal of every sexual reproductive act. It is a step farther in specialization, beyond the fusion of similar gametes. The fertilized egg, released by the breaking down of the cell wall surrounding it, undergoes cell division and grows into a new plant.

Even greater specialization is to be seen in the brown and red seaweeds, where the gametes are produced in special structures, rather than in ordinary vegetative cells. These structures are known as sex organs, and one-the female sex organ-produces the eggs, while the other, or male sex organ, produces the sperms. The egg remains in the female sex organ, motility being characteristic of the male gamete only.

\section{The Reproductive Cycle of a Moss}

Reproduction among land plants is a modification of the inherited pattern laid down in the foregoing primitive types of reproduction. But the transition to land living made certain changes imperative in both sexual and asexual reproduction, to adapt plants to an environment where movement of reproductive cells could take place only with great difficulty. Asexual reproduction by swimming spores, for example, is possible only in a liquid medium; thus spore formation on land must involve im- 
motile light spores capable of resisting dessication and of being carried about in the air. The land environment proved a stumbling block to motile gametes also; with the result that swimming sperms were gradually supplanted by male cells carried through a special structure to the egg cell. Sexual reproduction by motile sperm cells has persisted in several of the lower groups of land plants-typically among the mosses and ferns. Asexual reproduc-

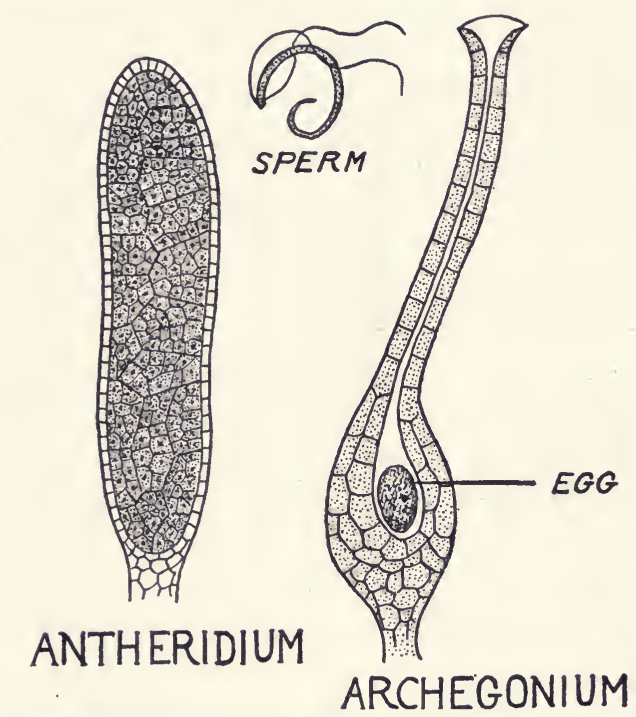

FIg. 29. - The club-shaped antheridia of a moss are packed with male gametes or sperm; the flask-shaped archegonia produce the female gametes or eggs.

tion by spores, however, is so obvious in these groups that they are often spoken of as "spore plants."

A typical moss plant is a rather delicate and frail organism, made up as we have seen (see p. 33) of a stem, photosynthetic leaf-like organs, and rhizoids. The reproductive phase of the moss life history begins with the formation of sex organs; these are hidden among the leaves at the tip of the stem. In some species the male and female structures are found on the same plant, in others they occur upon different plants. This tendency to separate the sexes becomes more frequent in the higher plants. 
The club-shaped male sex organs, or ANTHERIDIA, are packed with hundreds of minute coiled sperm cells; the flask-shaped female organs, or ARCHEGONIA, have swollen bases each of which contains a single egg cell (fig. 29). After a rain, or any accumulation of moisture on the moss, the sperms are released and swim

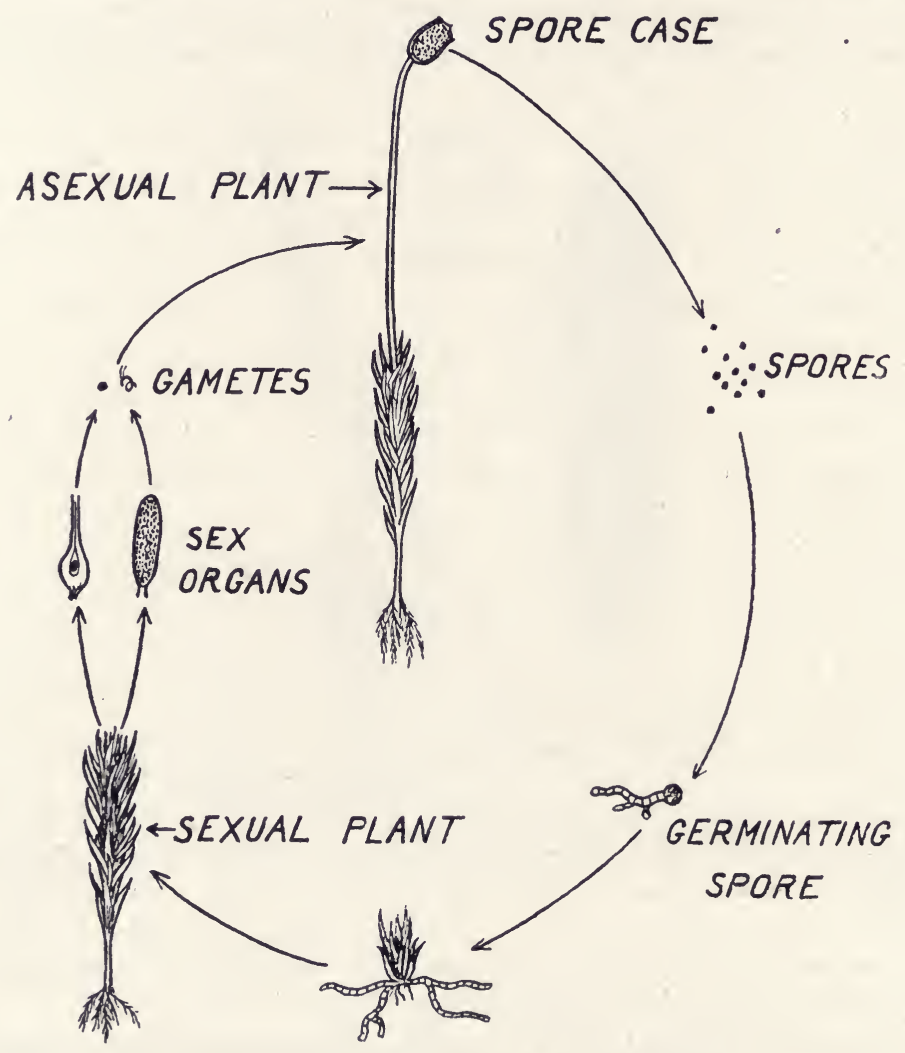

Fig. 30.-The life history of a moss plant.

to the tip of the archegonium. There the sperm finds its way through the passageway in the neck of the female sex organ, eventually reaching the egg and uniting with it. The fertilized egg, remaining in place at the tip of the moss plant, now begins growing into a new generation. But this new plant is entirely different in appearance from the parent. It is leafless and brown 
(therefore unable to carry on autotrophic metabolism), and grows up from the leafy green moss plant as a parasite. When mature, it produces a capsule at its tip in which many thousands of small spores are produced. Each spore, carried to a new environment by the wind, germinates into another leafy green moss plant like its grandparent (fig. 30).

Such a cycle of asexual and sexual reproduction is known as alteration of generations, and the sexual plant is referred to as a GAMETOPHYTE, the asexual plant as a SPOROPHYTE. In the life history of any plant going through alternation of generations, a spore always develops into a gametophyte while a fertilized egg grows into a sporophyte. In the moss, dispersal of new plants occurs during the asexual reproductive phase with the scattering of the spores.

\section{The Reproductive Cycle of a Fern}

This alternation of a sporophyte with a gametophyte is carried out with increasing specialization of the sporophyte, in the FERns. The familiar leafy fern plant begins its reproductive phase by the development of sporangia, either on the under side of the leaves or on special parts of the plant (fig. 31). Each sporangium consists of a stalk and a spherical capsule filled with spores. Since the fern reproduces asexually in this way, unlike the leafy moss plant, it is a sporophyte.

After a spore has fallen to the ground, it germinates into a new fern generation which is as different in appearance from the parent fern plant, as the new moss generation is from its parent. This fern plant, developing from the spore, is a gametophyte known as a PROTHALlus - a flattened and heart-shaped plant attached to the ground by tufts of rhizoids on its under surface (fig. 32). Among the rhizoids are the archegonia and antheridia, the former flask-shaped with necks protruding beyond the prothallus, the latter barrel-shaped structures made up of relatively few cells. When there is sufficient moisture, the sperm cells swim to the archegonia and fertilize the eggs. Like the fertilized egg of the moss gametophyte, that of the fern does notgrow into another plant like its immediate parent. Instead, remaining in place, the fertilized egg develops into an embryo which soon 


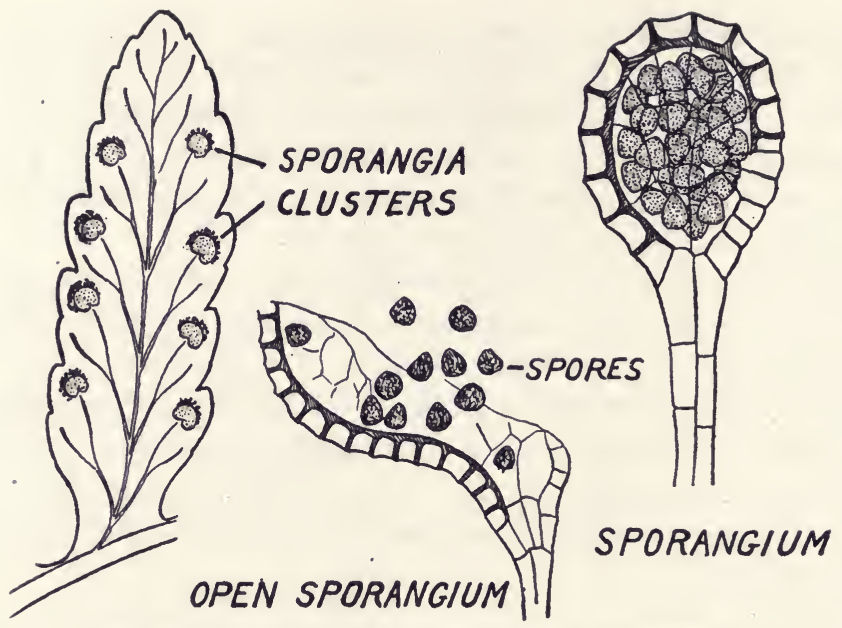

FIG. 31.-The familiar leafy fern plant begins its reproductive phase by the development of sporangia, each sporangium consisting of a stalk and a capsule filled with spores.

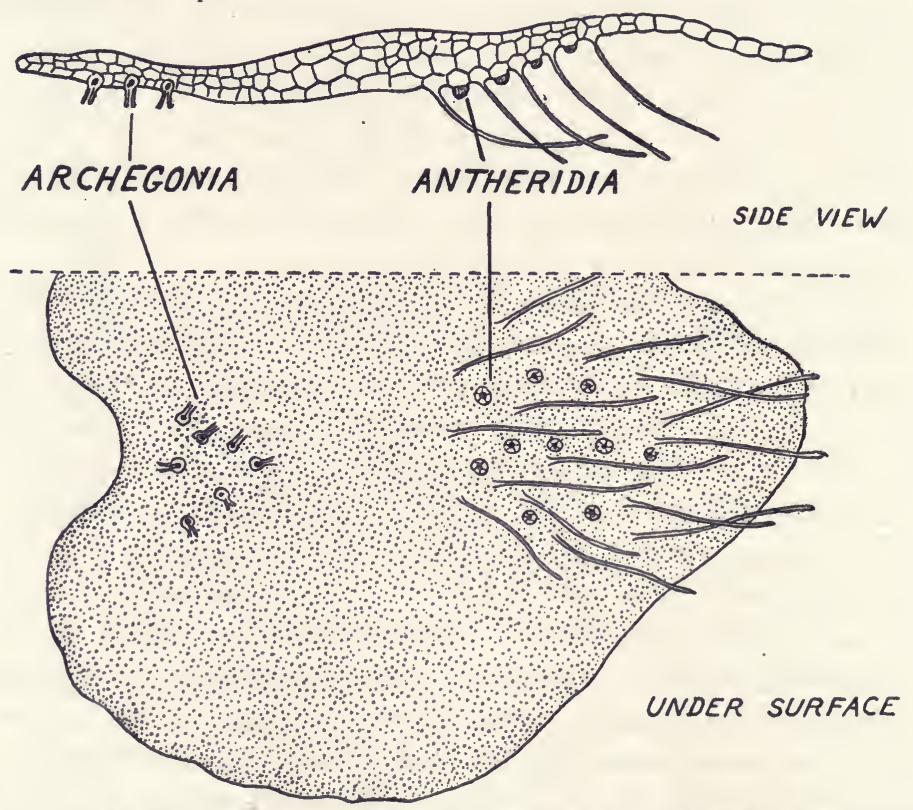

Fig. 32.-The fern gametophyte, or prothallus, is a flattened heart-shaped plant of minute size, attached to the earth by tufts of rhizoids. 
assumes the root-stem-leaf habit of the familiar fern sporophyte (fig. 33) while still attached to the prothallus. As soon as the roots begin to function and growth has resulted in a few leaves, the new plant becomes autotrophic and takes care of itself; the prothallus, having fulfilled its important function, withers and dies.

The alternation of generations in the fern (fig. 34), as in the moss, depends upon the sporophyte for dispersal of new plants. Also, as in the moss, the spore always grows into a gametophyte (the prothallus) which is green and independent. The most notable difference is that in the fern, the sporophyte has become green and independent also instead of being a parasite upon the gametophyte. This ability of the sporophyte to take care of itself by photosynthesis is one of the major innovations which has enabled plants to so thoroughly cover the land.

\section{The Reproductive Cycle in the Little Club Moss}

Reproductive habits of the higher plants are of immeasurable importance, since we are dependent upon their reproductive

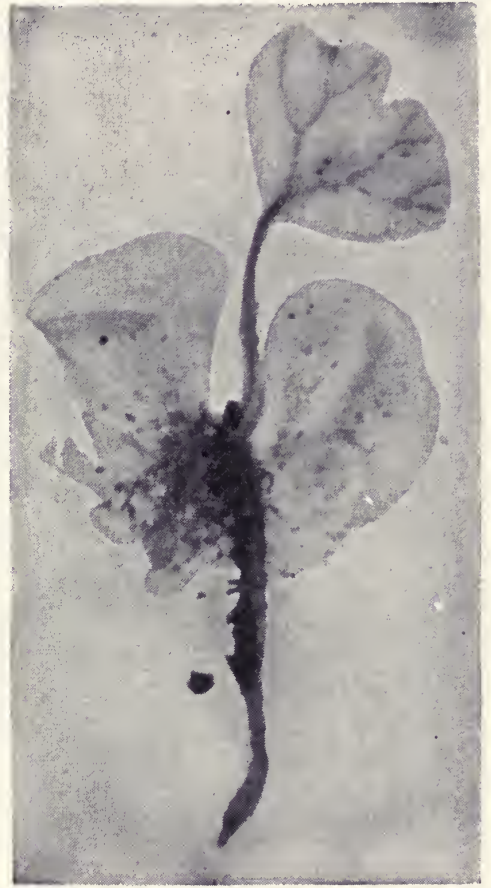

Fig. 33.- Young fern sporophyte, with embryonic leaf, growing out of heart-shaped gametophyte. The dark area on the gametophyte is the mass of rhizoids with soil particles adhering to them. habits for the majority of our foods - their fruits and seeds. In addition, the esthetic appeal of plants to gardeners and horticulturists is largely due to the production of flowers; and the flower is merely the highest expression of a reproductive organ in the sporophyte. An understanding of the formation of flowers, fruits and seeds is therefore an important aspect of any elemen- 
tary consideration of plant life, as well as necessary to control the amounts and types of seeds and fruits produced. One will appreciate flowers all the more for a knowledge of how they function. Flower and seed production would be difficult to comprehend without the preceding survey of the stages which constitute

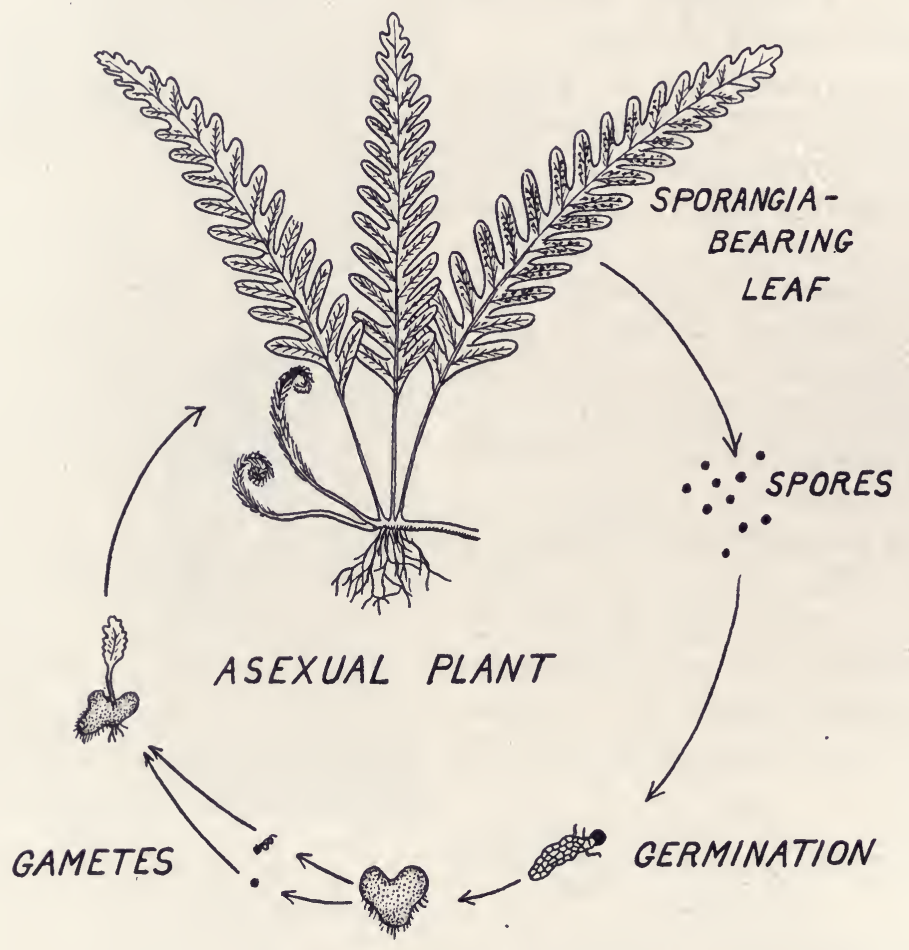

\section{SEXUAL PLANT}

Fig. 34.-The life history of a fern plant:

the basis of evolution of reproductive habits in the simpler plants; an evolutionary sequence which begins with fission in the unicellular algae and culminates in flowers, seed formation and ingenious methods of fruit dispersal.

A SEED is an embryo sporophyte, protected within various coats and surrounded by stored food upon which it can feed 
when it awakens from its dormant state. The origin of the seed habit, which has become the most successful reproductive advance following the independence of the sporophyte, can be traced back to insignificant beginnings. All of the very primitive plants which originated the seed habit have become extinct; but among the fern group there are living a few species which give us a picture as to how the seed habit might have originated.

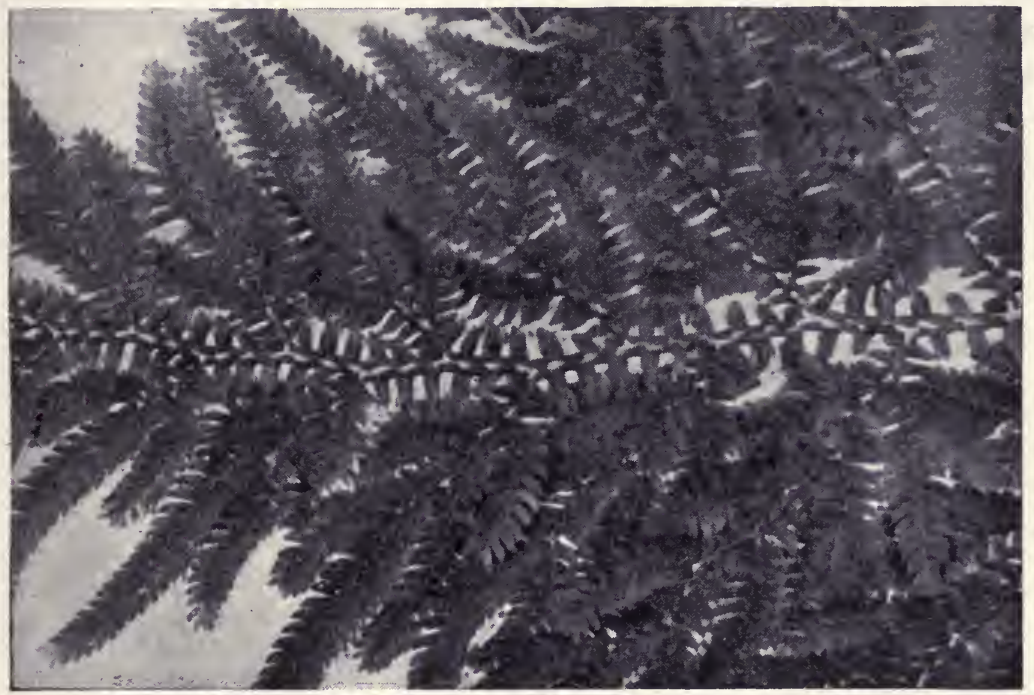

Fig. 35.-The little club moss sporophyte is a plant of small size with minute overlapping leaves.

One of these is the LITTLE GLub moss (Selaginella), whose reproductive cycle includes several noteworthy innovations.

Most of the ferns, in their asexual generation, produce only one kind of spore, which germinates into a single kind of prothallus. But the little club moss sporophyte-a plant of small size, with overlapping leaves covering the branching stems (fig. 35)-develops two kinds of sporangia. Some sporangia produce a few large spores, known as MEGASPOREs; in other sporangia are formed thousands of very small spores - the MICROSPOREs. These spores are different not only in size, but also in behavior. The microspores grow into male prothalli and thus produce only 
sperm cells, while the megaspores develop into female prothalli producing only eggs. Another striking comparison lies in the fact that the gametophytes are microscopic, lack chlorophyll, and pass their entire existence within the confines of the microspore or megaspore wall (fig. 36). The microspore, while still in the sporangium, grows into the simple few-celled male gametophyte, which at maturity produces antheridia and sperm cells. At the same time the megaspore, also while still in its sporangium, develops within itself the tiny female gametophyte with a few archegonia.

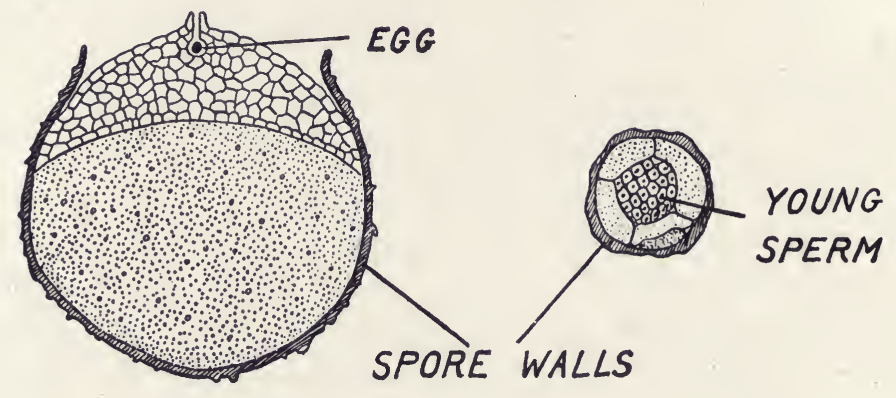

\section{FEMALE PLANT MALE PLANT}

Fig. 36.-Male and female gametophytes of the little club moss never get outside of the spore walls.

When the sporangium containing the microspores bursts open, the powdery microspores, containing the invisible male prothalli, are scattered through the air. Some fall on the other type of sporangia, which have opened and exposed the megaspores; these also have opened to expose the portion of the female gametophyte bearing the archegonia. When this happens, the microspore wall breaks open, the sperm cells are released from the male prothallus and swim through the film of water-which must be present if fertilization is to take place - to the nearby female gametophyte in the megaspore. Fertilization is thus the result of a process which brings the entire male plant to the female one, eliminating the necessity for a long and perilous 
journey on the part of the sperm. The fertilized egg, while still in the megaspore, grows into an embryo sporophyte with rudimentary roots and leaves. When the megaspore drops to the ground, the embryo is well on its way to becoming a new spore-

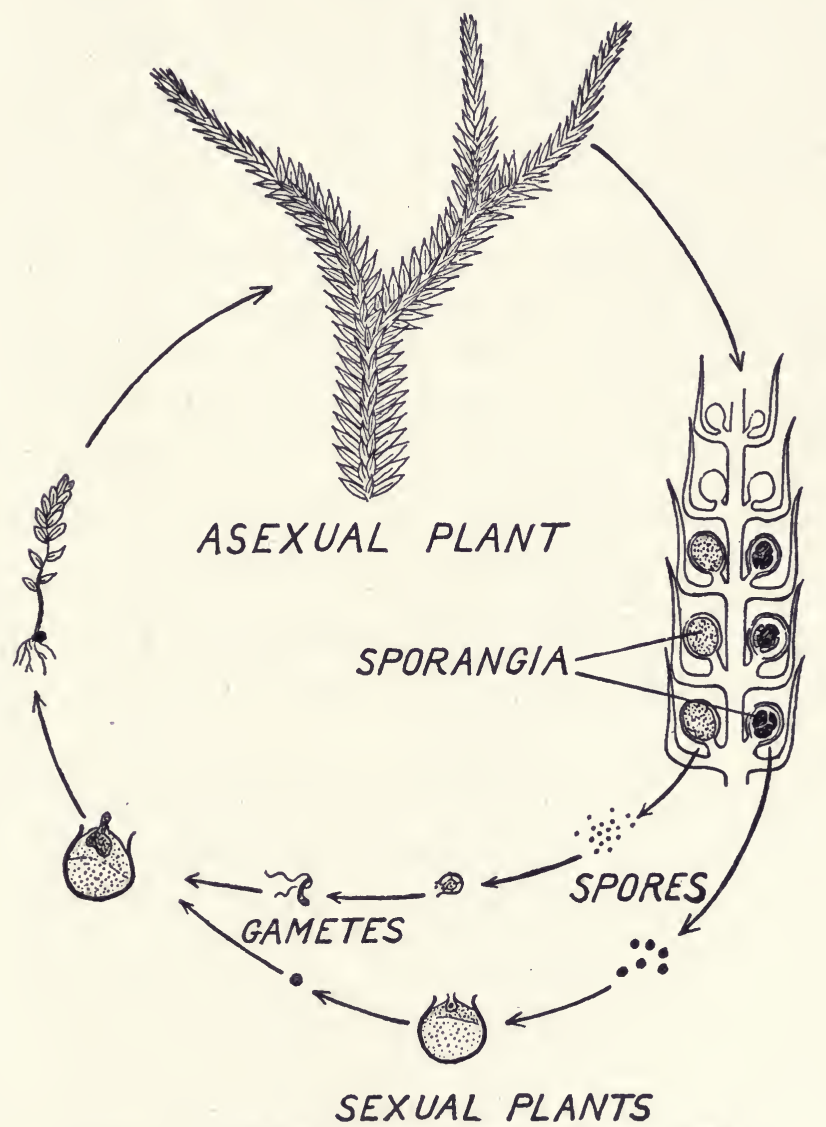

FIg. 37.-The life history of the little club moss.

producing generation. During alternation of generations in the little club moss (fig. 37), the gametophyte has become reduced to an insignificant heterotrophic parasite within the reproductive tissues of the sporophyte. 
The significance of the innovations found in the little club moss lies in the resemblance of its microspores to the pollen grains of the seed plants, which are merely highly specialized microspores. The ovules found in the pistil of a flower are likewise specialized sporangia producing megaspores. Thus when pollination takes place, there is a transfer of the microspores with their minute male prothalli to the megaspores containing their microscopic female plants. The details of this process, with the structures resulting, will be made clear as we consider the reproductive life history of a Gymnosperm such as the pine tree.

\section{The Reproductive Cycle of a Cone-bearing Seed Plant}

The PINE can be considered typical of the whole group of primitive seed plants (Gymnosperms) in which alternation of generations results in the production of two kinds of spores as in the little club moss, in an independent green sporophyte as in all the ferns, and in a parasitic gametophyte as in the little club moss. Improvements center about the special reproductive organs which produce the spores, known as cones; the novel method by which dependence upon motile sperm is eliminated, resulting in the formation of a pollen tube; and the protective and nutritive tissues which surround the embryo sporophyte, resulting in the seed.

Cones are familiar structures found on many Gymnosperm trees such as the spruces, firs, cedars and pines. These cones are the reproductive organs produced by the sporophyte generation, which is the tree itself. Taking a pine as an example, we find that the sporophyte develops two kinds of cones (fig. 38). One of these is the large cone composed of overlapping scales, amidst which the seeds appear. Seeds are always the product of sexual reproduction, and therefore develop from fertilized eggs which appear only on the female prothalli; since female prothalli (gametophytes) are produced only within the megaspores, such seed-bearing or "female" cones are in reality cones bearing large spores. The other kind of cone is much smaller and less conspicuous; oval in outline, they grow in clusters near the tips of the branches, usually higher up on the tree than the seed-bearing cones. These are sometimes called "male" cones because they 
develop sporangia filled with microspores, which grow into male prothalli.

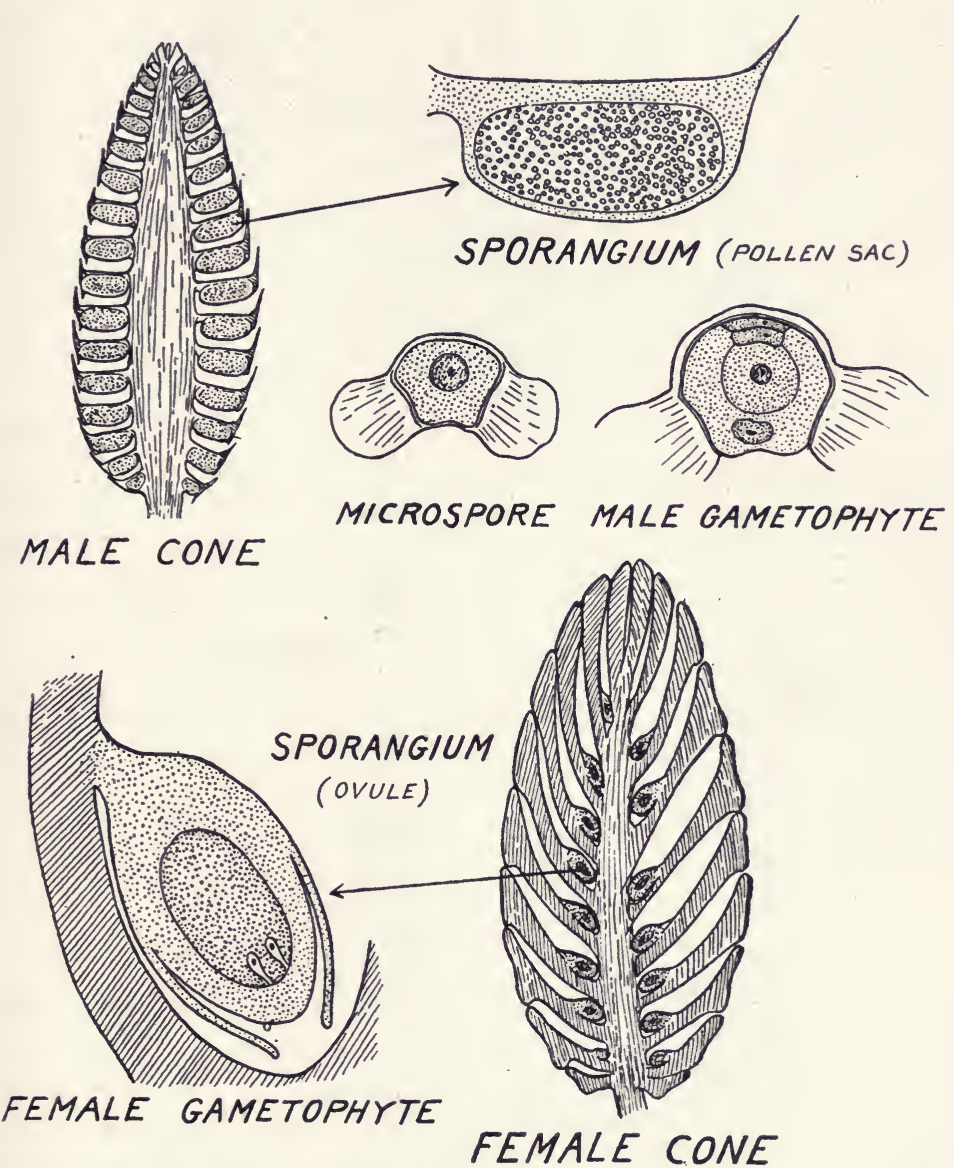

FIG. 38. - The pine sporophyte develops two kinds of cones; one produces small spores which germinate into male gametophytes and the other produces large spores which germinate into female gametophytes.

Reproduction begins when the male cones release their microspores, often in clouds which float in the air like dust particles. Carried by gravity or wind, a few chance to alight on the female cones. A microspore which has fallen among the scales of the 

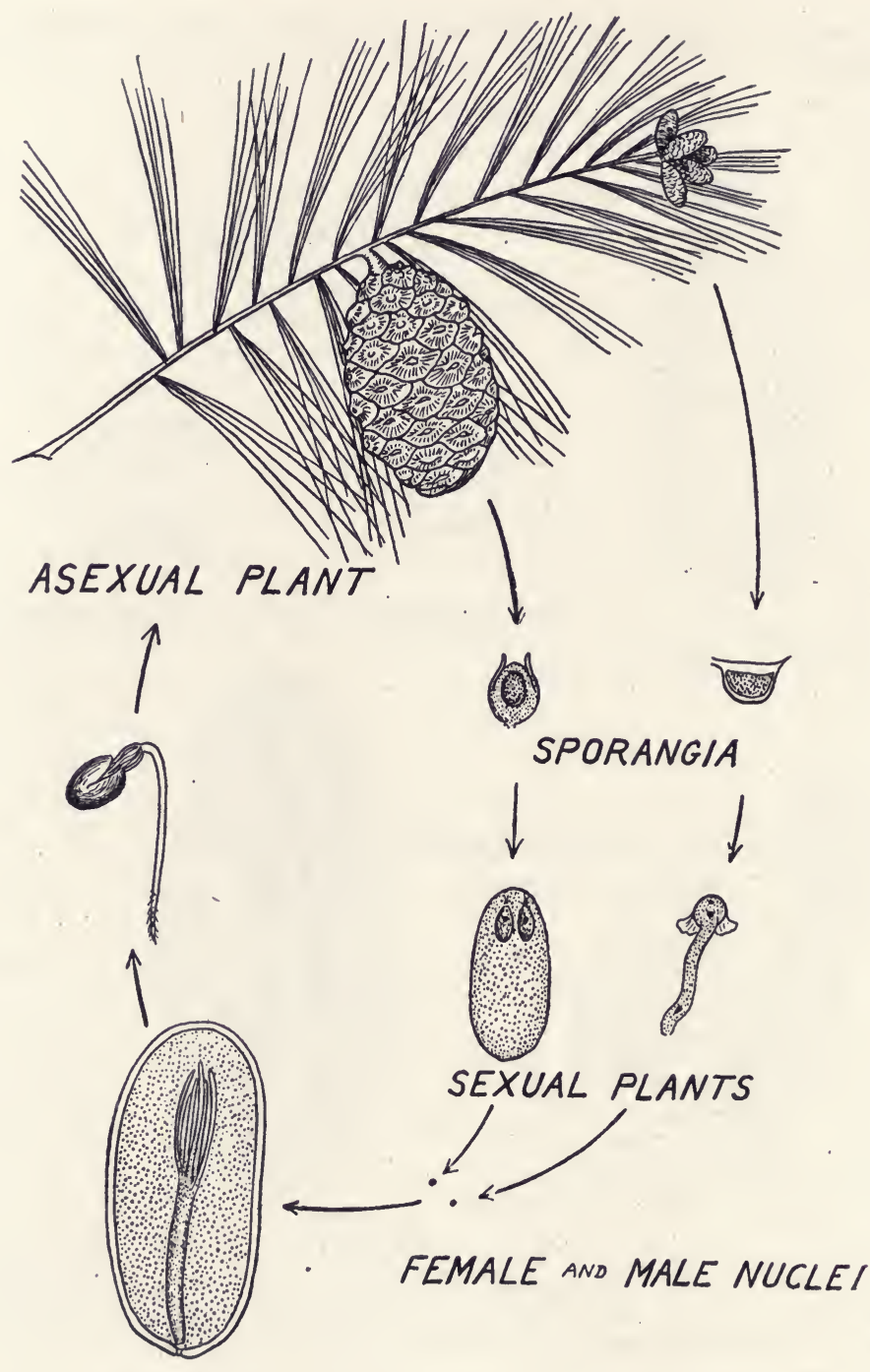

SEED

FIG. 39.-The life history of a pine tree. 
female cone may find itself in close proximity to the megaspore; at this same time the microspore contents have formed a fewcelled male prothallus, part of which bursts through the microspore wall and forms a finger-like pollen tube. The pollen tube eats its way through the tissues of the female prothallus to the egg cell, forming a passage way for the male cell which takes the place of the motile sperm. This male cell eventually finds the egg nucleus and then fertilization takes place. All of these events in the sexual phase of alternation of generations are hidden from view within the sporangium on a scale of the female cone.

From this point on the fertilized egg rapidly forms a minute embryo pine tree with rudimentary root, stem and leaves. At a certain period growth stops and the embryo becomes dormant. While these events are taking place, the integument or coat of the sporangium has been developing into a tough hard covering to protect the embryo; all together form the seed. As the scales of the female cone separate, these seeds float to the ground, in some cases being carried short distances by the wind as a result of wing-like expansions developed by the integument. The dormancy of the seed is broken when warmth, moisture and other conditions necessary for germination are present. The embryonic pine then resumes growth, bursts through the seed coats, thrusts its roots into the earth, spreads its foliage to the sun, and starts life as a new sporophyte generation (fig. 39).

\section{Reproduction in a Flowering Seed Plant}

In a typical Gymnosperm such as a pine, the reproductive organ of the sporophyte - the cone-has but one function: the production of the microspores and megaspores which culminate the asexual cycle in alternation of generations. The cones are not particularly adapted for any special means of ensuring the transfer of the microspores (pollen) to the megaspores, gravity or wind being relied upon to bring this about.

In the Angiosperms (see p. 101) the reproductive organ of the sporophyte is the flower. In many cases this still has the single function of producing the reproductive cells, the plant depending upon the wind to carry the pollen in a hit-or-miss fashion from one plant to another. An example of such a wind-pollinated 
flower is the GATKIN (fig. 40), a cone-like reproductive organ of which the hairy "pussy" of the willow is representative. Catkins are usually yellow or green in color and of inconspicuous size; they are the type of flower found on many trees such as the oaks, poplars, willows, birches and hickories. Male catkins produce pollen (microspores) in special sporangia-bearing structures known as STAMENs; while the female catkins develop ovules (sporangia producing megaspores) in highly specialized structures known as PIsTiLs. Wind pollination, as in the Gymnosperms; results in the chance transfer of a pollen grain to the pistil, where

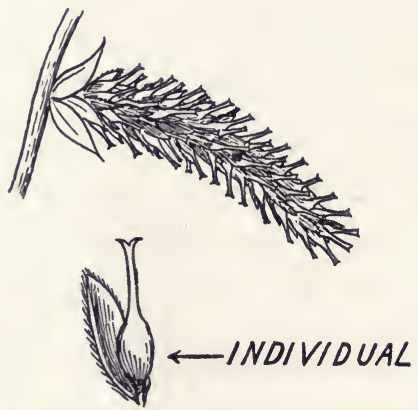

FEMALE (PISTILLATE)

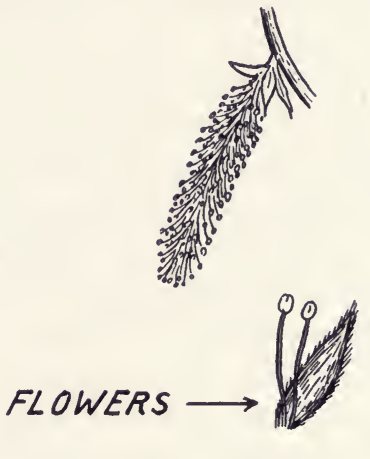

MALE (STAMINATE)

FIG. 40.-Catkins are clusters of wind-pollinated flowers which lack conspicuously colored floral parts.

the male prothallus germinates, produces a pollen tube and the union of the male and female cells takes place in the ovule. The seeds develop in the female catkins as in the pine.

A catkin, however, does not conform to the popular idea of a flower, even though it fulfills the most essential function of a flower-the production of the reproductive cells. Flowers are generally considered to be brightly colored, often fragrant, portions of the plant body. This is because many Angiosperms which comprise our woody shrubs, garden and house plants, and orchard trees have come to rely upon another pollination method than that by wind. The transfer of pollen from stamen to pistil is brought about by animals in a more reliable manner; special 
flower parts serve to attract the animals for this purpose, acting as colorful and conspicuous signboards to arrest the attention of the animals. Frequently these attracting structures of the flower are so large and prominent that they seem the most important part, obscuring the stamens and pistils which are the real reproductive organs. Thus the FLOWER has come to serve a dual purpose; in addition to the primary function of producing pollen and ovules, in stamens and pistils, it has as its duty also the attraction of animals who unwittingly carry pollen from one flower

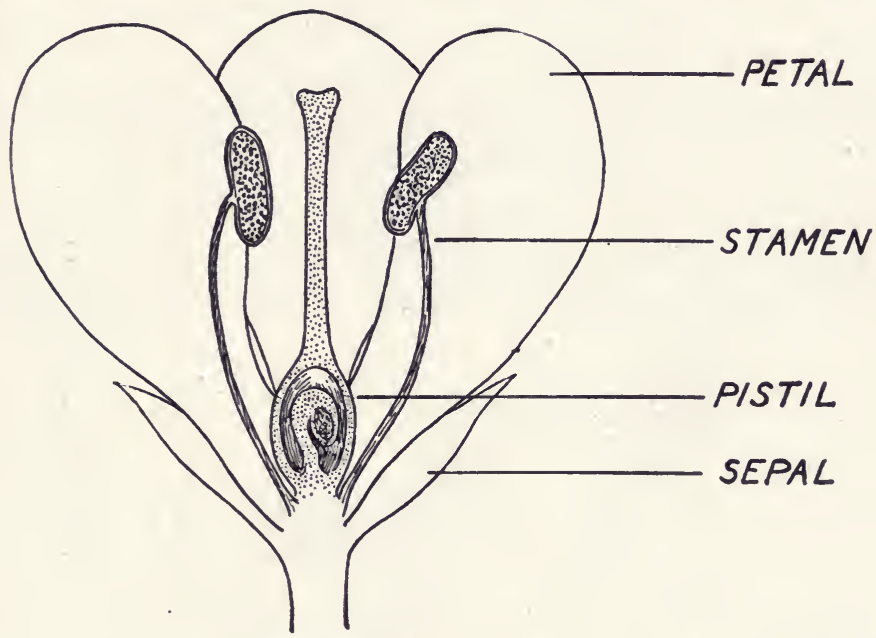

FIG. 41.-A complete flower consists of petals, forming a whorl known as the corolla; sepals, forming another whorl known as the calyx; stamens; and pistils.

to another (fig. 41). If flowers do not depend upon animals for pollination, they lack these brightly colored parts; but no flower can lack the stamens and pistils if it is to serve the purpose for which flowers have evolved-reproduction.

Flowers have developed a variety of devices for the attraction of pollinating agents; chief of these are the petals. Petals originally were leaves which through evolutionary history have lost their chlorophyll and in most instances have become white or colored. The whorl of petals which encircles the central pistil and stamens is known in its entirety as the corolla. In the most 
simple and perhaps primitive condition, the petals are of equal size and distinct from each other, forming a symmetrical corolla. This condition is well illustrated in the buttercup, magnolia,
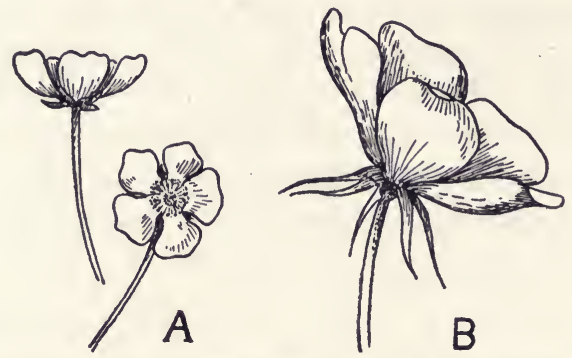

FIG. 42.- In many flowers the petals are of equal size and separate from each other, as in the buttercup (A) and the wild rose (B).

poppy and wild rose (fig. 42). In other cases some petals are larger than others, forming an asymmetrical corolla as in the pea and orchid families. Another common condition is the fusion of

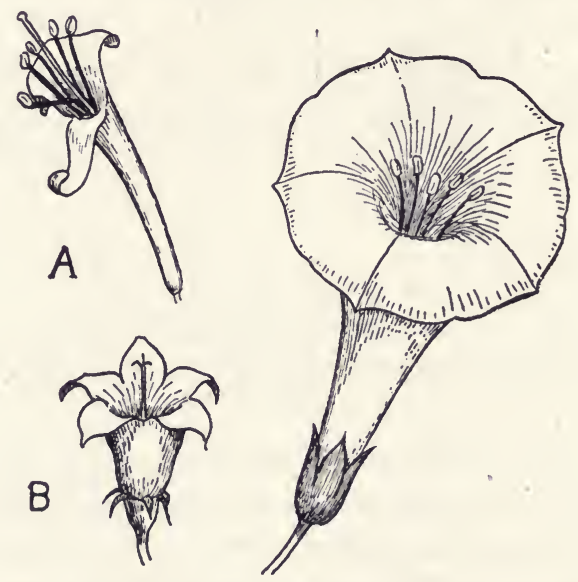

Fig. 43. - In some flowers the petals are fused to form a funnel-shaped corolla, as in the honeysuckle (A), bluebell (B), and wild potato vine (C).

the petals to form a tubular corolla as in the morning glory (fig. 43). Sometimes flowers with such fused corollas are so minute that individually they would escape the notice of animals; these . are clustered in compact heads to form the "composite" flower 
of the daisy or dandelion, where each flower-in the popular sense - is in reality made up of thousands of tiny strap-shaped or tubular flowers which form the ray and the disc of the flowerhead (fig. 44). Composite flowers form those spectacular blooms of the plant kingdom - the chrysanthemums and dahlias.

Outside of the corolla, many flowers produce another whorl of leaf-like green structures-the sepals. Sepals are collectively known as the GALYX, whose chief function is to protect the flower

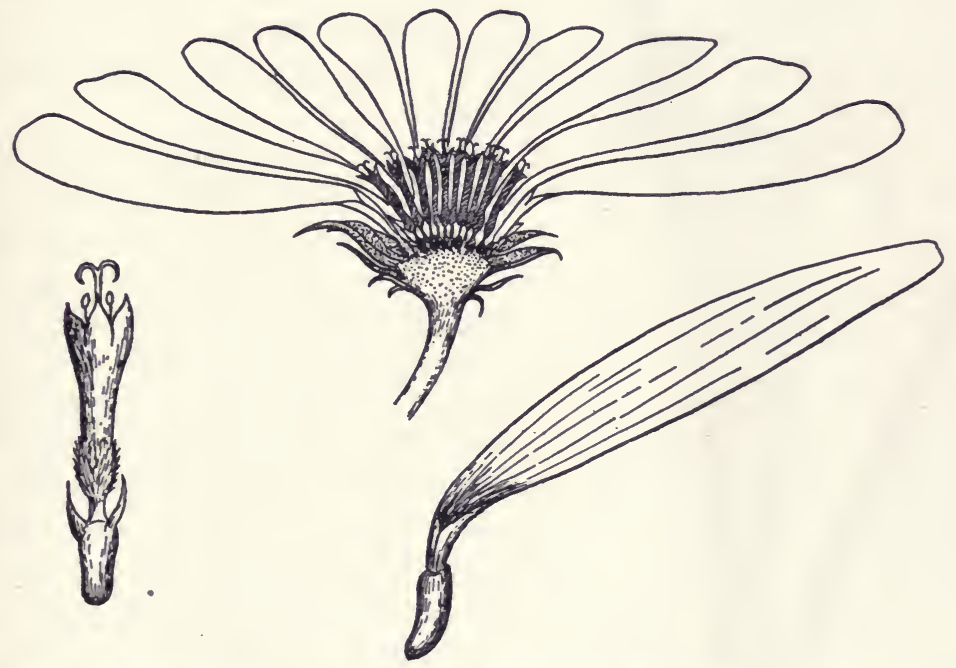

DISC FLOWER

RAY FLOWER

FIG. 44.-Composite flowers are grouped in heads, often as in the sunflower differentiated into ray flowers and disc flowers.

when in oud and to support the corolla. But in many cases the sepals have assumed the function of attraction, and then resemble petals. Among the anemones, clematis and cowslip, for example, the flowers lack petals and colored sepals take their place. In the common four o'clock, likewise, there are no petals, the fused calyx being colored to attract insects.

In other cases, additional structures are pressed into service by the flower for the function ordinarily assumed by the corolla. Bougainvillea has small inconspicuous flowers, but they are 
surrounded by showy leaf-like BRACTS, purple or red in color, which are often mistaken for petals. Dogwood trees have conspicuous white bracts beneath the clusters of small, yellowish flowers; while the poinsettia "flower" is in reality red leaves beneath an insignificant group of yellowish flowers. In the jackin-the-pulpit (fig. 45) and the calla lily, the flowers lack both petals and sepals; in the former case a green and brown bract (the

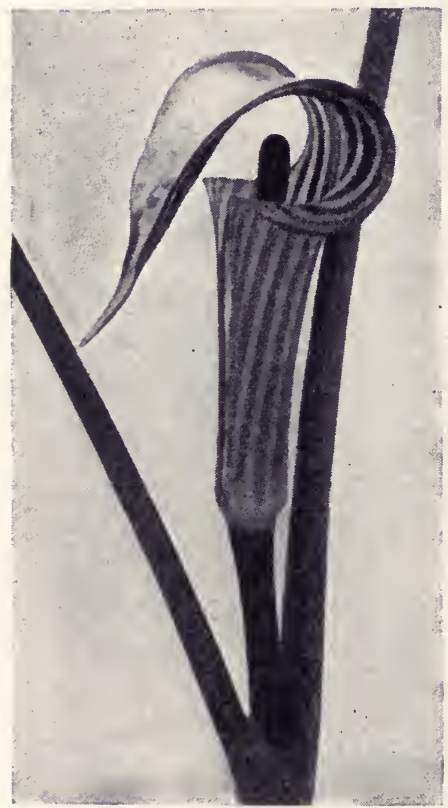

Fig. 45.-In some cases, as in the Jack-in-the-pulpit, additional structures are pressed into service to attract insects; the "pulpit" is a special form of leaf known as a spathe. pulpit) surrounds and arches over the flowers; in the latter, a broad white bract spreads out beneath the base of the axis bearing minute flowers.

Reproduction begins with the formation of the microspores and the megaspores, as in the Gymnosperm. Using the APPLE TREE as an example, we see that the flowers have unfolded an arresting set of petals which succeed in attracting insects in search of honey. The microspores (fig. 46) develop in sporangia which appear as sacs in the STAMENs, the latter corresponding roughly to the scales of the male pine cone. When mature, the spores are released through breaks in the tip of the stamen, so that they frequently form yellow powdery masses on the outside of the stamen. While the apple blossom is expanding its fragrant corolla as an open invitation to the insect world, the contents of the pollen (or mature microspores) are undergoing changes of an important nature. Male nuclei develop, taking the place of motile sperm or male cells; there is no trace of the male prothallus cells such as there is in the pine. Thus when the pollen is shed, each grain has passed into the male prothallus stage with its mature male "cells" in the form of nuclei. 
An insect, in brushing past the stamen, catches some of the dry pollen on his hairy legs, and flies on in search of nectar; in doing so he may brush off some pollen on the pistil of the same or another flower. By doing so, he is transporting the male sexual

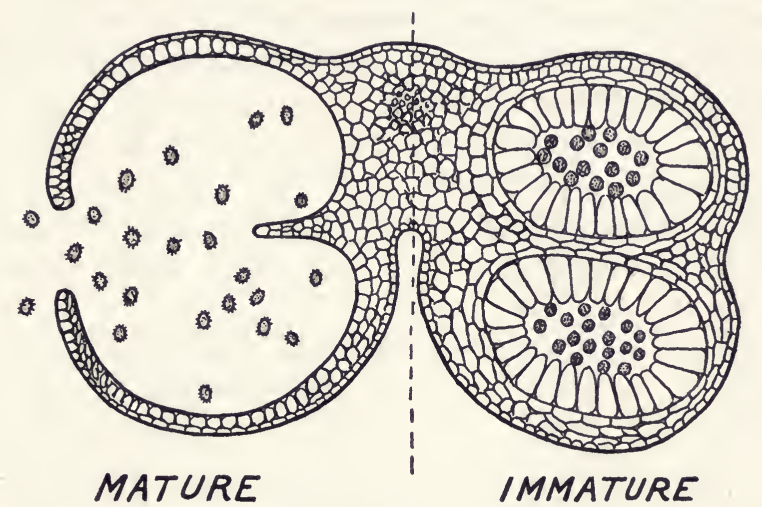

Fig. 46.-Microspores (pollen grains) develop in sacs in the stamens.

generation to the PISTIL. This latter organ is a flower part quite different from anything found in the female cone of the pine. There the sporangia containing the megaspores developed on the surface of the cone scale; but in a flower, the sporangia (ovules)
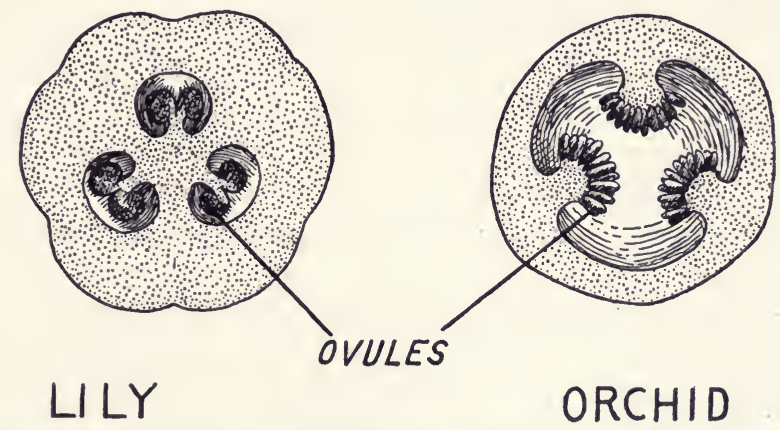

FIG. 47.-The ovules in the pistil are sporangia producing megaspores.

are produced within the tissue of the pistil. Within the ovule (fig. 47), the megaspore produces a vestigial female prothallus as well as a functional egg. After pollination has taken place, the pollen grain germinates on the top of the pistil, producing a pollen tube 
which grows down through the pistil to its enlarged base (the ovary) where the ovule is located (fig. 48); this takes from a few hours to several months, varying with the different types of flowers. Once the pollen tube has reached the vicinity of the egg, a male nucleus moves down through the tube, unites with the egg, and fertilization takes place. At this point, a new sporophyte generation has come into existence.

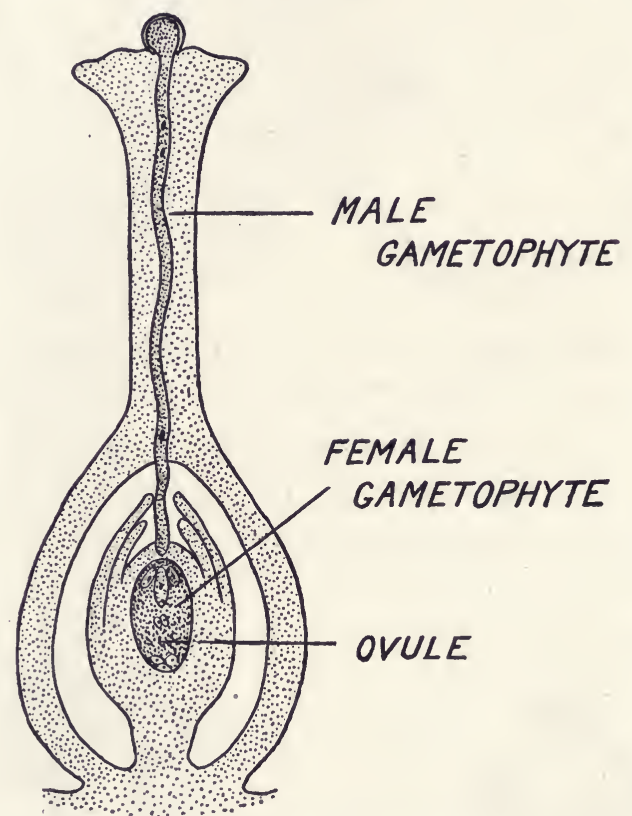

Fig. 48.-Diagram of pollination and development of the gametophytes.

In the meantime, superficially the apple blossom looks as if nothing has taken place. All the stages intervening between pollination and fertilization take place in the pistil, involving hidden microscopic male and female prothalli; the sexual generations have been reduced to degenerate parasites living within the reproductive organs of the sporophyte. But after fertilization, changes take place in the flower. The petals wither and fall off, having played their role in reproduction. The fertilized egg, remaining in place, grows into an embryo with three well- 
defined parts. There is a rudimentary foliage shoot known as the PLUMULE, an equally rudimentary root known as the RADICLE, and two seed-leaves or Cotyledons (fig. 49). Those Angiosperms in which the embryo develops two cotyledons, as in the apple, are known as Dicots; in other Angiosperms the embryo produces but one cotyledon, this group being known therefore as the Monocots. Lilies, orchids, palms, grasses are Monocots; while oaks, roses, buttercups, daisies are representative Dicots.

Other changes in the flower include a withering away of the top of the pistil. But the most vital changes take place in the ovary of the pistil. Here the embryo sporophyte is rapidly in-

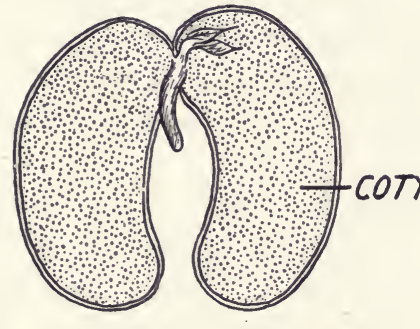

BEAN (OPENED)

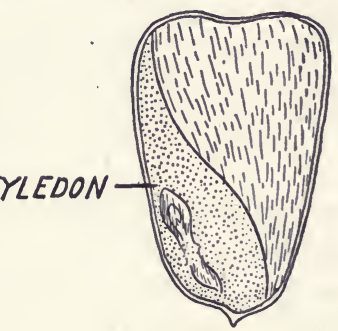

CORN (SECTION)

FIg. 49.- Some seeds contain embryos with two cotyledons, as occurs in the Dicot seed plants (bean); others contain embryos with a single cotyledon, as in the Monocot group (corn).

creasing in size, therefore requiring a considerable supply of food which must come from adjacent tissues in the ovule. While the embryo was developing from the fertilized egg, the female prothallus cells became a storehouse for reserve food, known as the ENDOSPERM. The growing embryo now begins to penetrate this endosperm region of the ovule, absorbing food from it. In most of the Monocots the embryo ceases absorption and growth before the endosperm is entirely consumed, so that when the embryo becomes dormant it is surrounded by the remaining endosperm. In the Dicots, the usual condition is that the embryo advances into the endosperm until it is all used up; some of this absorbed food is stored in the cotyledons of the embryo which thus become large fleshy structures. The integument of the ovule forms a protective covering to the embryo, both together forming one 
of the organs resulting from fertilization-the sEED. A seed, therefore, generally consists of a protective coat, an embryo, and stored food either outside the embryo as endosperm, or in the cotyledons of the embryo itself. Just as the sexual generations leading up to fertilization in the apple blossom are invisible, the formation of the seed-hidden within the ovary tissues - is an invisible process also. A familiar seed is the shelled peanut; the brown papery covering is the seed coat, the two halves of the peanut are the cotyledons gorged with reserve food, and the rest of the embryo is almost invisible since the plumule and radicle are tucked in between the prominent cotyledons. Every seed contains within itself an embryo plant in a compact, well protected, and well nourished form; capable of remaining dormant for decades or of germinating as soon as favorable conditions present themselves. It is the culminating triumph of reproduction among land plants.

Another post-fertilization change which takes place in our apple blossom, as in all flowers, is the formation of the FRUIT. Because the ovules of a Gymnosperm are borne superficially on cone scales, the seeds have no additional protective structures formed around them. But in the Angiosperm the ovule is buried in the ovary of the pistil; thus the matured ovule, or seed, is from the beginning surrounded by additional tissues capable of protecting, or aiding in the dispersal of, the seed. Fruits with few exceptions always contain seeds and can appear only after production of flowers. So the sequence of events which begins with the production of a flower and pollination, terminates in the formation of a seed within a fruit.

The fruit has become an important organ in the life history of a flowering seed-plant; dispersal of the seed is almost as important as the dispersal of the pollen. Among the Gymnosperms both are taken care of in a primitive way by the wind. Among many Angiosperms fruits have become structurally adapted for more efficient means of wind dispersal as well as dispersal by water, by mechanical devices, and by animals.

Wind dispersed fruits are generally small, light in weight, and dry (fig. 50). Some have flattened wings, as in the maple and ash, which aid them in gliding through the air, while others-for 
example clematis and dandelion-have feathery appendages which sustain them in the air for great distances. Water-dispersed fruits are not common; the most typical case is that of the coconut. This fruit develops an abundance of fibrous light material which does not absorb water, and acts as a life-preserver for the contained seed which is the coconut of commerce.
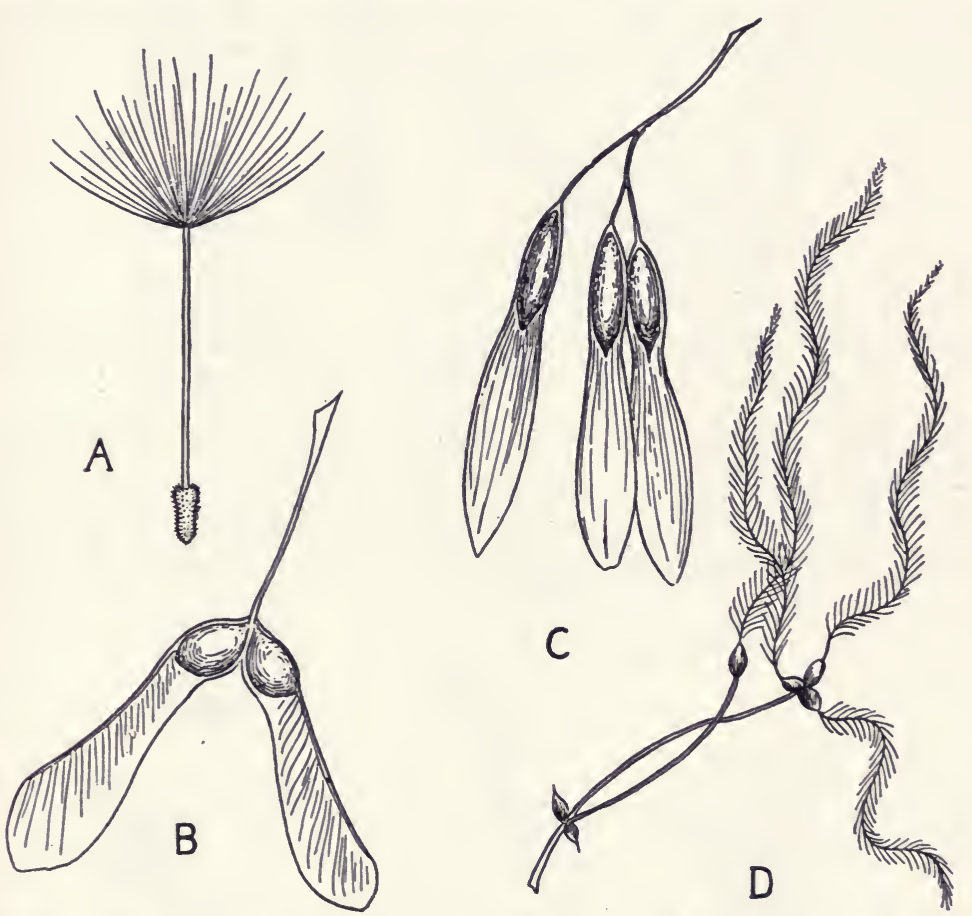

FIG. 50.-Wind-dispersed fruits are generally small, light and dry; typical are those of dandelion (A), maple (B), ash (C) and clematis (D).

More ingenious is the production of fruits which involve an explosive or propulsive mechanism for the ejection of the seeds (fig. 51). In the touch-me-not, the fruit is an elongated capsule whose wall separates at maturity into lengthwise sections while remaining attached at the tip. When an object happens to touch the tip of this capsule, it releases the segments, which uncurl rapidly and act as sling-shots in throwing the seeds in all direc- 
tions. Among members of the pea and bean family, the drying of the pod often results in a twisting and breaking of the fruit so that the seeds (the peas or beans) are forcibly ejected. Few of the wind-

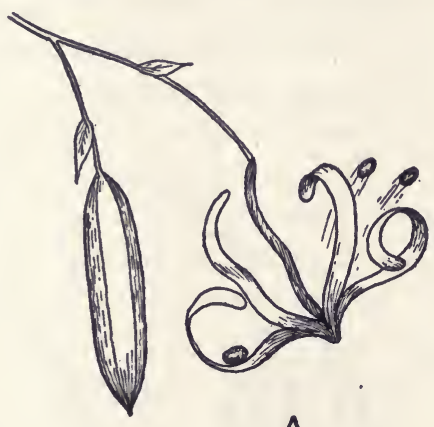

A

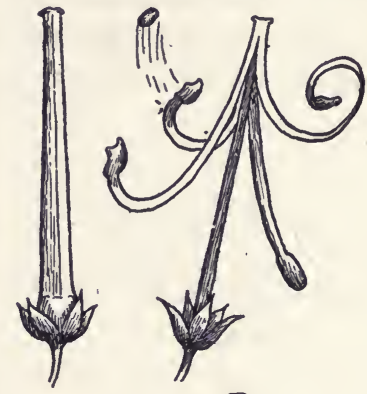

B

Frg. 51.- Some fruits involve explosive or propulsive mechanisms for seed dispersal, as in touch-me-not (B) and wild geranium (A).

dispersed, water-dispersed or mechanically-operated fruits have become of economic importance as foods for man, since in most cases the fruit is dry, small, and possesses little if any stored food. The exception is found among the cereals, but in reality the food
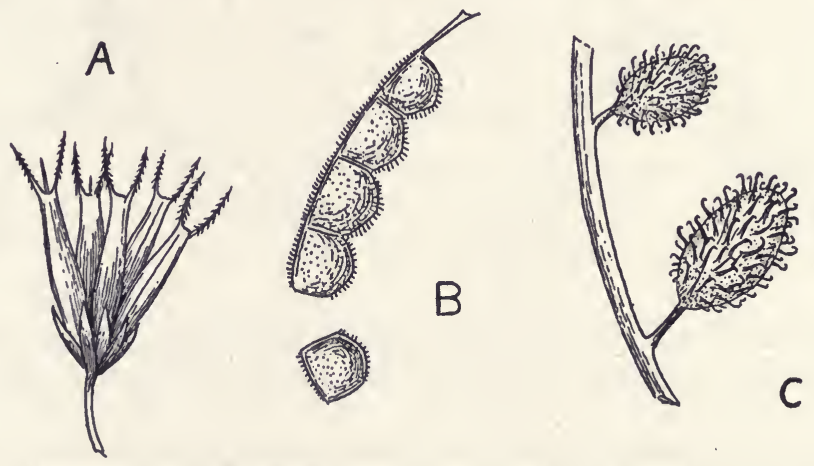

FIG. 52.-Many animal-dispersed fruits have hooks or barbs for attachment to animals; examples include beggar ticks (A), tick trefoil (B), burrs (C).

value in this case depends upon the seed rather than the fruit which is thin-walled, dry and an insignificant part of the grain.

Animal dispersed fruits have succeeded in a variety of ways in using animals for seed distribution. In some cases these fruits are 
small and dry with hooked or barbed outgrowths which catch in an animal's fur (fig. 52). Fruits with such spines and hooks are numerous, as anyone knows who has taken a hike through the woods in autumn and returned with his clothing covered with tenacious burrs and ticks; a proof of the effectiveness of this method of fruit dispersal.

Of greater interest to man, since they include the majority of our edible fruits, are those which-like the fruit produced by the

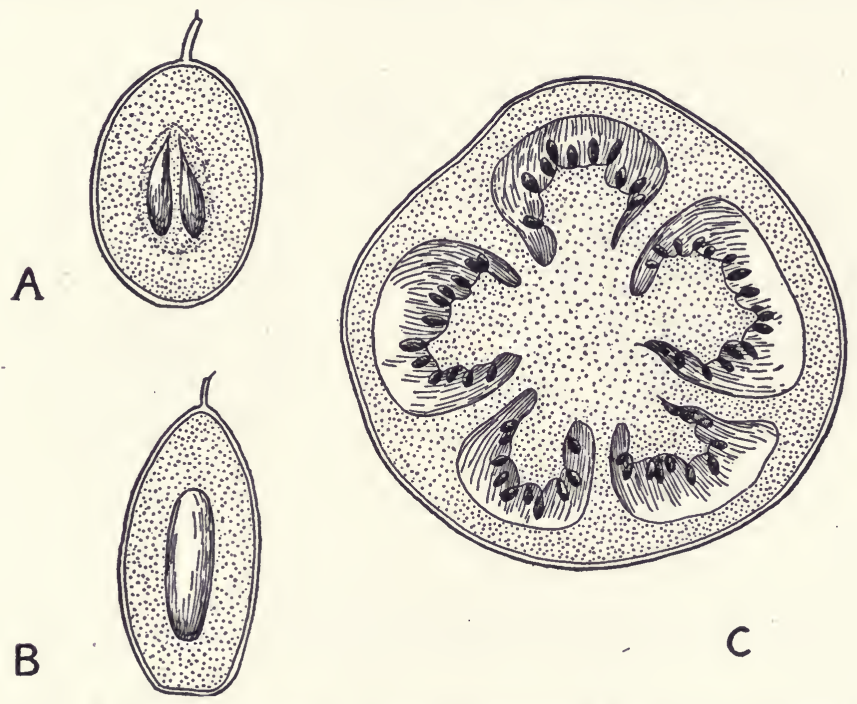

Fig. 53.-A berry is a fleshy animal-dispersed fruit with the seeds buried in soft pulp which is often edible; such is found in the grape (A), the date (B), and the tomato $(\mathrm{C})$.

apple blossom - become large and fleshy in order to act their part as a lure to get animals to eat them and thus bring about seed dispersal. In such fleshy fruits, the ovary and sometimes adjoining flower parts, grow into colorful and edible organs whose chief function is to induce a curious animal to eat them. Thus our habit of eating fruit is definitely associated with the universal scheme of things, perfected for the purposes of seed dispersal. In many fruits, the seeds are so large or so well protected by a hard wall, that the animal discards them after eating 
the fleshy portion of the fruit. In other cases, the seeds, safe within their seed coats, are seldom harmed by a temporary sojourn in the animals's alimentary canal.

The commonest type of fleshy fruit is known as a BERRY, which botanically consists of seeds (or a seed) surrounded by a predominantly fleshy wall (fig. 53). In the date fruit, the berry is one-seeded. In the grape, there are several seeds. In the tomato the numbers of seeds may run into the hundreds. The banana is a berry with the minute seeds forming specks along the longitudinal
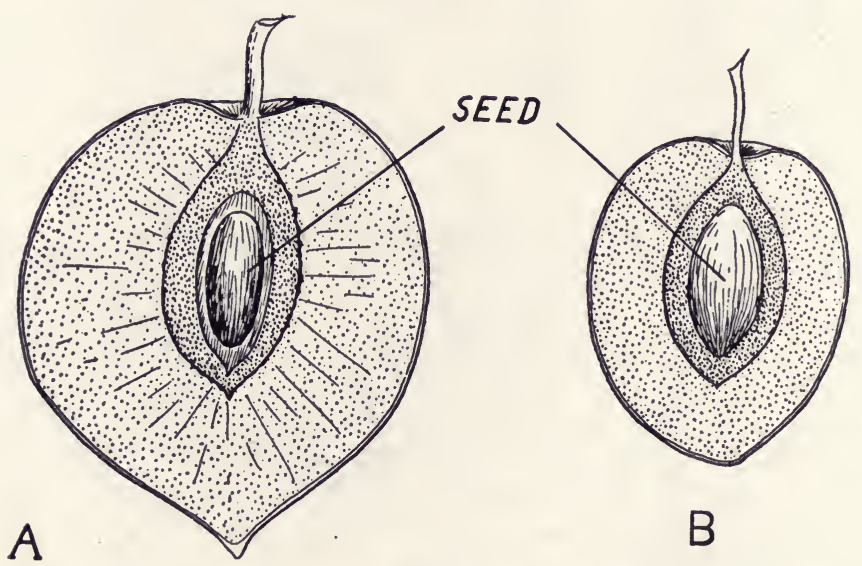

FIG. 54.- In the drupe fruit the outer portion remains soft and fleshy while the inner portion becomes hard and forms a pit or stone, as in the peach (A) and the plum (B).

axis. In some modified berry fruits, a portion of the outer ovary wall becomes thickened to form a rind, as in the citrus fruits. The DRUPE (fig. 54) is another type of fruit; in this case only the outer wall remains fleshy, while the inner part of the ovary becomes hard and stony. This kind of fruit is typical of the cherries, olives, peaches, and plums. Other types of fruits will be discussed in the chapters on fruits used as food.

With the dispersal of the apple seed, the final step in the reproductive cycle of the apple tree is completed (fig. 55). The embryo sporophyte, having been dormant thru the winter, is awakened into renewed activity as the environment produces favorable temperature and moisture conditions. Germination 

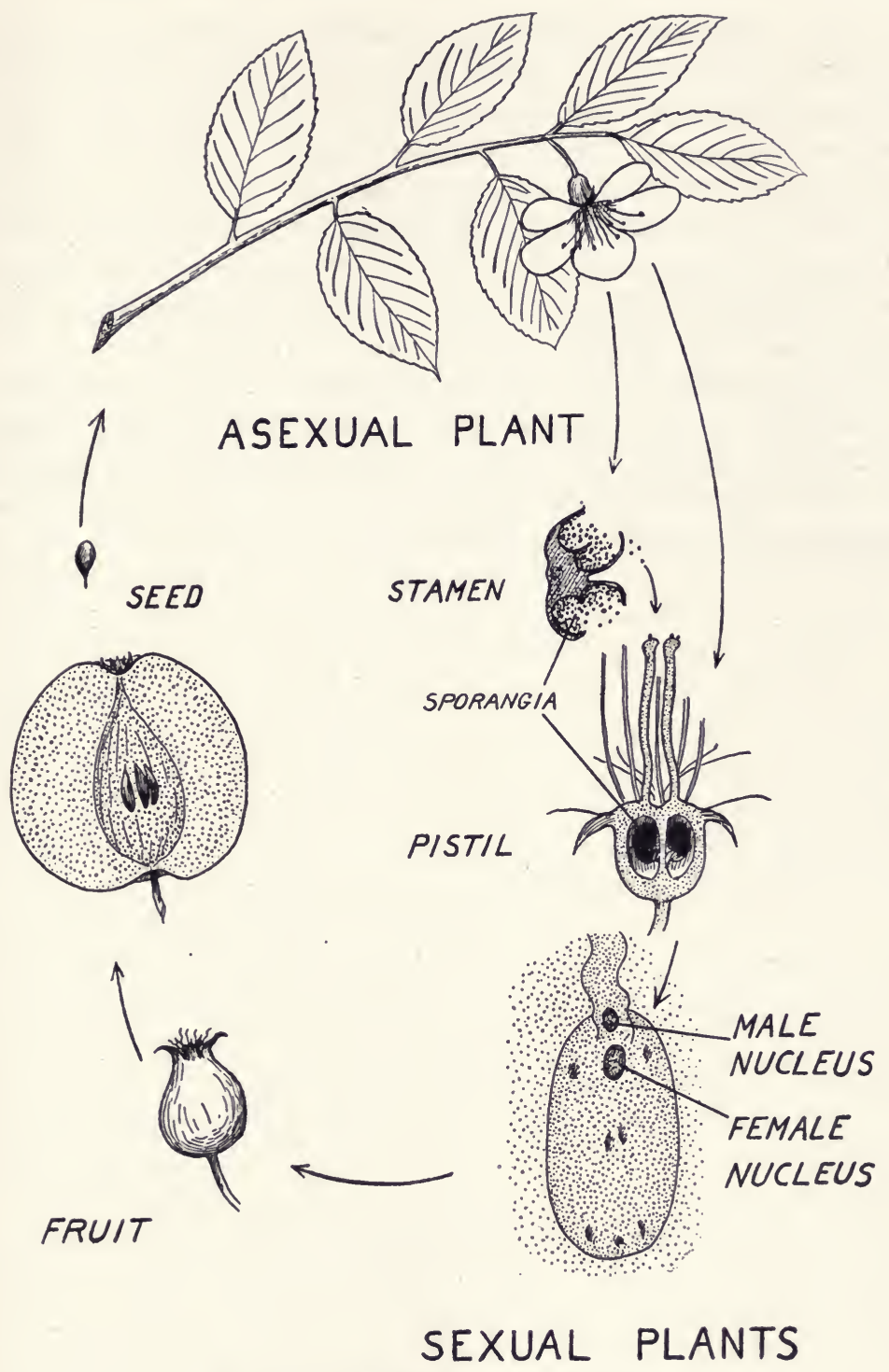

Fig. 55.-Life history of an apple tree. 
then takes place, resulting in the embryo bursting through its seed coats; the plumule grows upward, above the cotyledons which become green and temporarily make food for the young plant until the true leaves are ready for this task; the radicle penetrates the earth and assumes absorptive functions typical of roots. In a few weeks, the young sporophyte has entirely broken its dependence upon the parent thru the food stored in the cotyledons or in the endosperm. It can now carry on all of the maintenance functions described in the previous chapter.

In the seed habit, the Angiosperms have achieved a reproductive advance among plants comparable to that found among mammals; in both cases, it has been the exceedingly painstaking care of the embryo which has been an important factor in the attainment of supremacy in their respective kingdoms. 


\section{Chapter 4}

\section{THE VARIETY OF PLANT LIFE}

At first sight, the vegetation which makes up our grasslands and forests, our fields and gardens appears to be a bewildering variety of millions of plants. A little observation, however, reveals the fact that many of these plants look much alike even though no two plants are exactly the same. Almost unconsciously we think of a plant as belonging to a certain "kind," which is what the botanist means when he says that it belongs to a definite species. A sPEcIEs is a group of individuals which resemble each other so closely that their similarities far outnumber any minor differences which may exist. Once we have seen one or two individuals of a species, we have a fair idea of what all the individuals of that species will look like, wherever we meet them. In referring to a species, we use a double name to designate it; a tree is a sugar maple or a white pine, and a flower is a New England aster or a swamp buttercup.

The plant kingdom consists of some two hundred and fifty thousand species, but the great majority of these rarely enter into our daily lives. Only a thousand or two, at most, constitute the dominant part of our native plant life, or are used by man. The more common of these species will be described in Chapters 16, 17, 26, and 27.

Since science implies an orderly arrangement of facts, a scientific study of plants must include some systematic method of classifying these species. This is done by grouping species with numerous characteristics in common into an assemblage which is based upon relationship. For example, the white pine, red pine and pitch pine are three distinct species each with its particular characteristics; the white pine has five leaves in a cluster, the pitch pine has three, and the red pine has two. On the other hand, 
all three have the leaves in the form of needles grouped in clusters; a common bond of relationship which makes it possible to group them all as pines. Such a group of related species is known as a GENUS (plural, GENERA). Other common genera are the oaks, maples and daisies; each a group of closely related kinds of plants. In common terminology, when a double name - such as white pine - is applied to a plant, the last name refers to the genus, the qualifying adjective to the species. Common names, however, are often indiscriminately applied to several different plants or may be local appellations known only in a restricted area. Botanists have found it necessary to give species and genera scientific names which are always associated with a published and exact description of the plant. A plant may have a dozen common names, and in fact frequently does; but it has only one scientific name, which is the same the world over. The scientific name is also a double one, but in this case the genus name comes first, instead of last. Thus the white pine is Pinus strobus, Pinus being the name of the pine genus, and strobus referring to the species known as white pine. The pitch pine, similarly, is Pinus rigida.

A study of the characteristics of all plant genera shows that some are quite like each other and are obviously closely related; the pines, spruces and firs have more traits in common than they have with the maples. Such a group of related genera is known as a FAMILY. And carrying the grouping further on the basis of biologic kinship, an association of related families is known as an ORDER; related orders are grouped into a CLASS; related classes into a PHYLUM (plural, PHYLA). The phylum is the largest unit used in classifying organisms, just as the species is the smallest.

The larger the units of classification, the more obvious are the characteristics by which they are differentiated from each other. Differences among species, on the other hand, are often to be detected only by professional botanists. It is easier, for example, to tell two different genera-such as oaks and maples-from each other, than to tell a red oak from a black oak (two different species). Likewise it is easier to recognize the differences between the pine family, which includes the firs and spruces, and the cypress family, which includes the cedars and junipers; than to differentiate between a spruce and a fir, each of which is a genus. 
A phylum is generally made up of species with some common conspicuous and unique characteristic, such as the phylum of the fungi, all of which lack chlorophyll.

The characteristics which are used as the criteria of plant relationships, and by which plants are grouped into species, genera, etc. are of two types. One type is associated with metabolic activities and the vegetative structures of the plant; the other is connected with differences in reproductive structures and habits.

Vegetative characteristics which differentiate plants include (1) the presence or absence of chlorophyll; (2) the relative complexity of the plant body, whether unicellular, multicellular with little division of labor, or multicellular with complex organs; (3) the anatomy and habits of stems; and (4) the anatomy and types of leaves, with their varying habits (deciduous or evergreen, for example). Many vegetative characters are untrustworthy guides, since such organs as stems and leaves vary greatly among members of the same species, frequently responding to slight environmental changes.

Reproductive differences, being less often the result of environmental influences, are more constant. Such characteristics involve (1) the type of reproduction present, whether sexual or asexual; (2) the character of the sporophyte or gametophyte generation; (3) the type of reproductive organ, whether sporangium, cone or flower; and (4) the type of associated reproductive structure, such as fruits or seeds. Differences among species of flowering plants are usually found to be restricted to variations in flower structure (number, position and character of stamens or petals), kind of fruit produced, or seed characteristics.

On the basis of such criteria as these, species are grouped into genera, genera into families, families into orders, orders into classes and classes into phyla. Since the orders and classes are of interest chiefly to the botanist, and often are such highly artificial units that there is considerable difference of opinion as to just what they should include, the emphasis in this discussion will be placed upon genera, occasional families, and phyla. There are approximately a dozen phyla in the plant kingdom; eight of these will be discussed in the present chapter. 
Five phyla are often grouped together and known as the thallus plants, or Thallophytes, since they are all characterized by a relatively simple thallus body devoid of true roots, stems or leaves; in no case do they produce flowers, fruits or seeds. The phylum Schizophyta includes the simplest and most primitive plants, such as the bacteria. The three phyla Chlorophyta, Rhodophyta and Phaeophyta include those species which form the bulk of the flora in both fresh and salt water. The Mrcophyta is made up of the chlorophyll-deficient thallus plants commonly known as the fungi.

The remaining three phyla are characterized by a more complex vegetative and reproductive organization. These, in contrast with the preceding predominantly aquatic or microscopic plants, are of larger size and comprise the major part of the land vegetation. The phylum BRYOPHYTA is made up of plants such as the mosses, which have a rather imperfect vegetative body, as far as adaptation to terrestrial life is concerned; while the phylum Pteridophyta includes the ferns and their relatives, among which the sporophyte body develops true roots, stems and leaves. The most complex group of plant species constitutes the phylum SPERMATOPHYTA, characterized by reproductive habits involving flowers or cones, and seeds.

\section{The Thallus Spore Plants}

The thallus spore plants, or Thallophytes, include many inconspicuous species rarely observed by the average person. A great number are microscopic, living their lives unseen in bodies of water; others, though of larger size, exist beneath the surface of the lakes and oceans.

The simplest and yet the most iniquitous of all plants belong to the phylum ScHizopHYTA, characterized by a simple cell structure in which a true nucleus is lacking and limited to asexual reproductive habits by fission. The 2500 known species are grouped into two classes, in one of which chlorophyll is present, in the other it is absent. The former comprises little-known slimy water plants known as Blue-green Algae (fig. 56) while the latter includes the Bacteria. 
The remainder of the thallus plants include some phyla with chlorophyll-bearing species and others which lack the chlorophyll. All have a more complex cell structure and body organization than the Schizophyta. The green thallus phyla are almost entirely restricted to aquatic habitats, being unable to survive dessication resulting from living beyond the reach of spray or high tides. These phyla form the variety of pond scums and blooms which appear in streams and ponds, as well as the numerous seaweeds which colonize the oceans. Many are microscopic and unicellular; a few are massive and resemble land plants

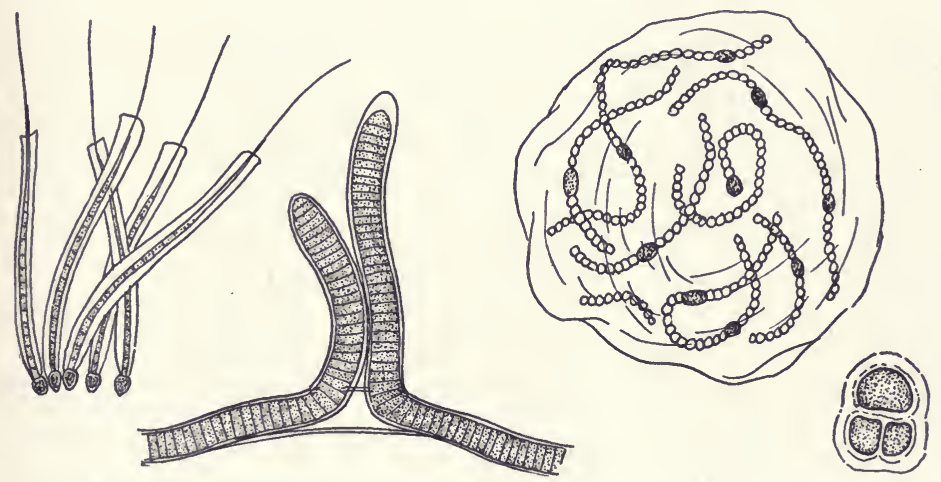

Fig. 56.-Blue green algae are slimy water plants closely related to the bacteria.

in form and size; but the majority are delicate individuals built up on the filamentous body plan. The distinction between the various phyla of these green Thallophytes is based upon the presence or absence of auxiliary pigments which often obscure the chlorophyll. In the Chlorophyta the green color is very evident, the chlorophyll being associated with no other pigment; these plants are therefore known as the Green Algae. A brown pigment, fuco-xanthin, gives an olive-brown or black tinge to the plants of the Phaeophyta, which are appropriately known as the Brown Algae. And the red pigment, phycoerythrin, found in the Rhodophyta often obscures the chlorophyll to such an extent that the plants appear rose-red or purple in color, and are called the Red Algae. 
The phylum Chlorophyta or Green Algae, occurs in both fresh and salt water, comprising some 5000 species. Many of the fresh water forms are filamentous like Ulothrix and Spirogyra while others are unicellular as are the desmids (see p. 24). In the oceans the Green Algae are those seaweeds which grow around high tide mark; some are filamentous and mossy in appearance while others form expanded blades which float like torn leaves in

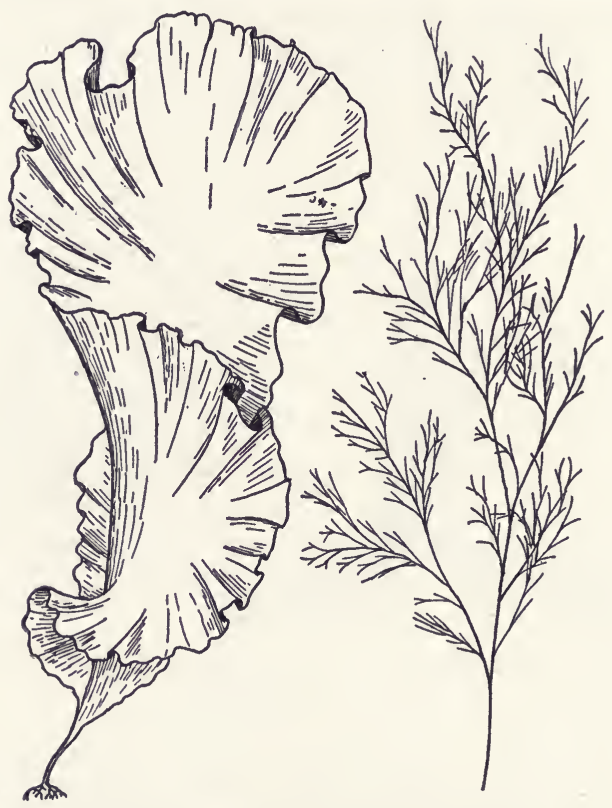

FIg. 57.-Green algae are common seaweeds about high tide mark; some are hair-like and mossy, others form thin sheets.

quiet harbors (fig. 57). Green Algae are of little economic importance except as food for fishes and other aquatic animals.

There are less than 1000 species in the phylum PhaEophyta or Brown Algae, which however are the dominant plants in the region from low tide mark to depths of fifty and sixty feet. Those that inhabit the rocks around low tide mark include the slippery olive-brown seaweeds familiar to every one who has prowled along rocky shores; of these the common rockweed or bladderwrack with its swollen bladders is typical. Others have a habit 


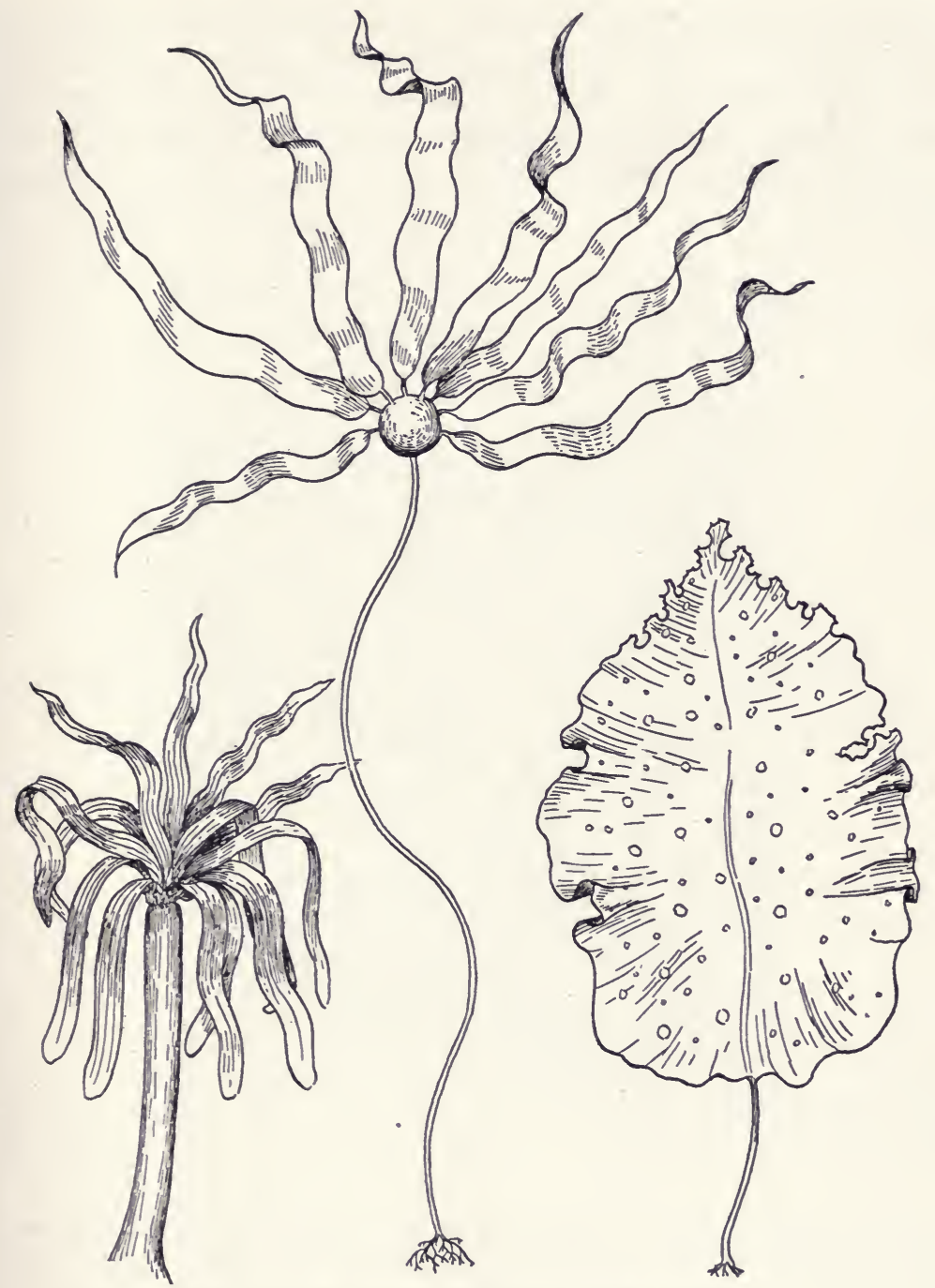

Fig. 58.-Kelps are the largest thallus plants. 
resembling higher plants, such as the gulf weed which forms drifting mats of vegetation and comprises part of the Sargasso Sea. Still others attain considerable size, as is the case among the Kelps which are the largest thallus plants, many of them growing to a length of several hundred feet and thus equalling the height of many trees (fig. 58). Kelps are the only seaweeds that are

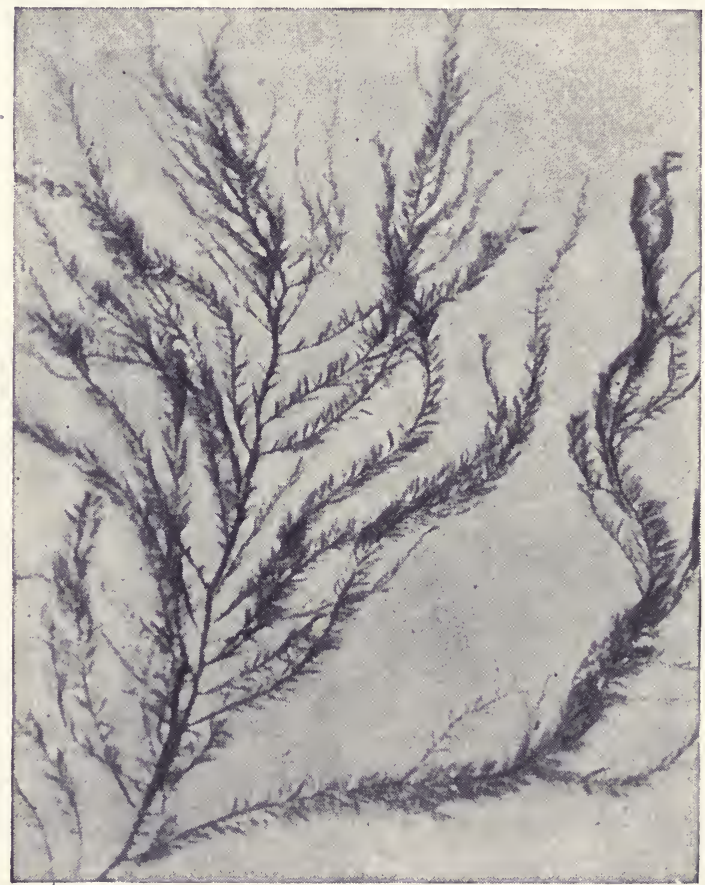

FIG. 59. - The Red Algae are delicate in appearance and often of ornamental form.

farmed much as land crops are; beds of kelp in the Pacific Ocean are harvested and from them are secured the iodine and potassium salts in which these species are particularly rich. Kelps and other brown seaweeds are often used for fertilizers, and in Japan they are even prized as food delicacies.

The phylum RHoDophyTA or Red Algae grow at the greatest depth in the oceans, from low tide mark to the limit of light 
penetration. The 2000 species which constitute this phylum are more delicate in appearance than the fleshy and massive Brown Algae and many of them have exquisitely intricate and ornamental body forms (fig. 59). They are rarely seen except torn loose from their holdfasts after a storm; when, washed up on the beaches, they are only tattered remnants of their former graceful selves. One papery and fragile genus (Porphyra), purplish in color, is cooked and eaten in the British Isles where it is known as laver. Dulse is another genus (Rhodymenia) also used as food in Great

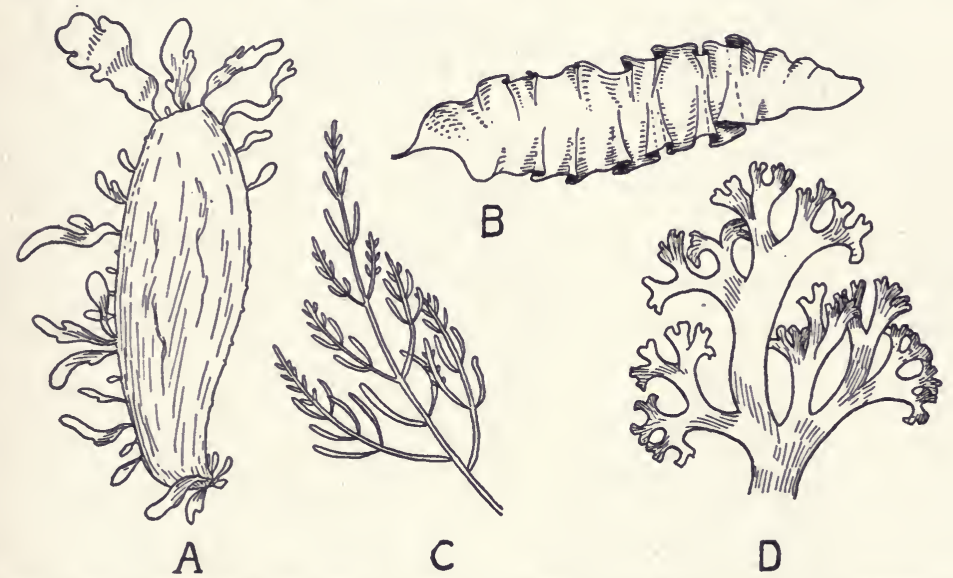

FIG. 60.- Red algae of economic importance include dulse (A), Porphyra (B), the agar seaweed (C), and Irish moss (D).

Britain. Irish Moss (Chondrus) is one of the few seaweeds collected along the Atlantic coast of the United States for commercial purposes; being made into a gelatinous product for curing leather and sizing cloth. Commercial agar, or vegetable gelatine, is made from a red alga known as Gelidium (fig. 60).

Over 20,000 species of thallus plants lack chlorophyll and hence must live as saprophytes or parasites; these are grouped into the phylum MrcophyTA, popularly known as the Fungi. The phylum is subdivided into classes on the basis of the type of reproductive structures developed during sexual and asexual reproduction. One group, the Algae-like Fungi, has a simple vegetative body resembling the filamentous algae; among them 
we find the bread molds, the mildews, and a few plant parasites (figs. 23, 61). Reproduction is both sexual and asexual, in the latter case involving simple spores in rather unspecialized
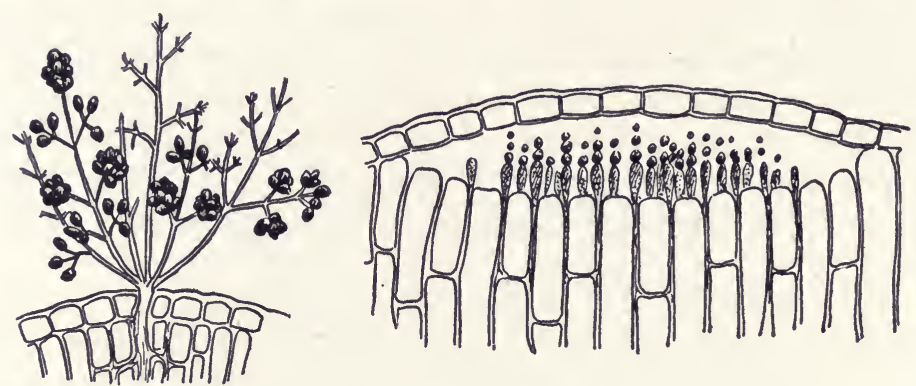

Fig. 61.-The algae-like fungi include molds (see fig. 23) and mildews, here shown growing in leaf tissues.

sporangia. Another group, the Ascus Fungi, has a more specialized vegetative body and reproduces asexually by special sac-like structures known as asci in which are a small and definite number
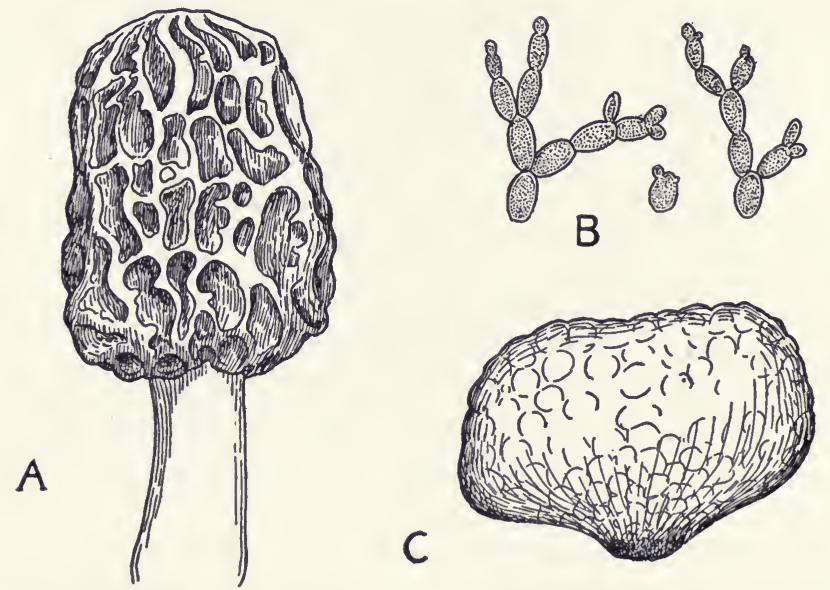

FIG. 62.-Useful ascus-fungi include morel (A), yeast (B), and truffles (C).

of spores. Some of the Ascus Fungi are harmless saprophytes; a few are useful such as Yeast, Truffles and Morels; but many are harmful plant parasites and cause a great number of plant diseases (fig. 62). Plant diseases are treated at greater length 
in Chapter 25. A third group of the Mycophyta is the BasidiumFungi which includes the bracket fungi and the mushrooms. These produce spores on special structures known as basidia, found on the "cap" of the common mushroom (figs. 24, 63). The remaining group of the Mycophyta comprises the $\mathrm{Li}$ chens, unusual plants exemplifying a condition known as symbiosis. Part of the lichen body is composed of fungus filaments, part of unicellular green algae.

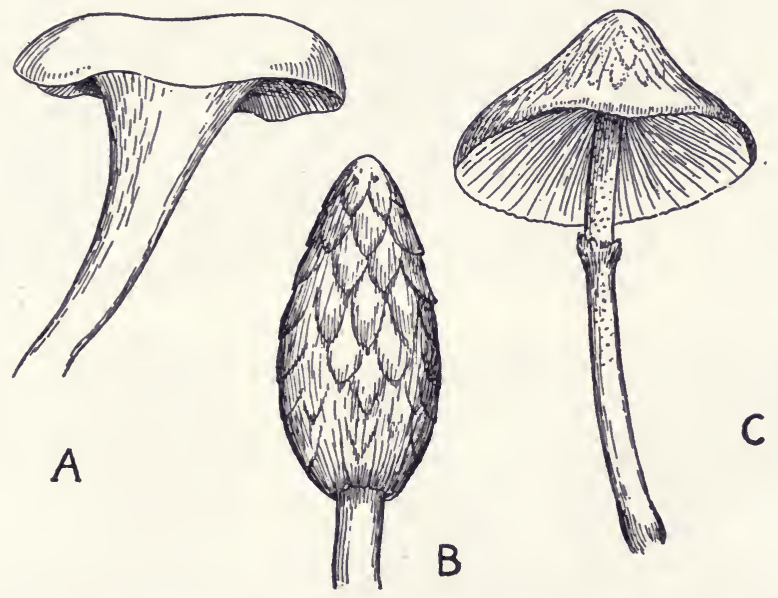

Fig. 63.-Common mushrooms include false chantrelle (A), shaggy mane (B) and parasol mushroom (C).

These two kinds of plants live amicably together, profiting by each other's activities. Lichens are gray-green plants capable of living on bare rock or tree trunks; and in damp cool climates such as northern New England they form an abundant epiphytic flora (fig. 64).

\section{The Leafy Spore Plants}

As was discussed in Chapter 2, the migration of plants to the land was dependent upon the development of a body adapted to terrestrial living conditions. Among existing land plants there is considerable variation in the complexity of the vegetative and reproductive organs, ranging from the inconspicuous mosses to the woody seed plants. Those species which are grouped into 

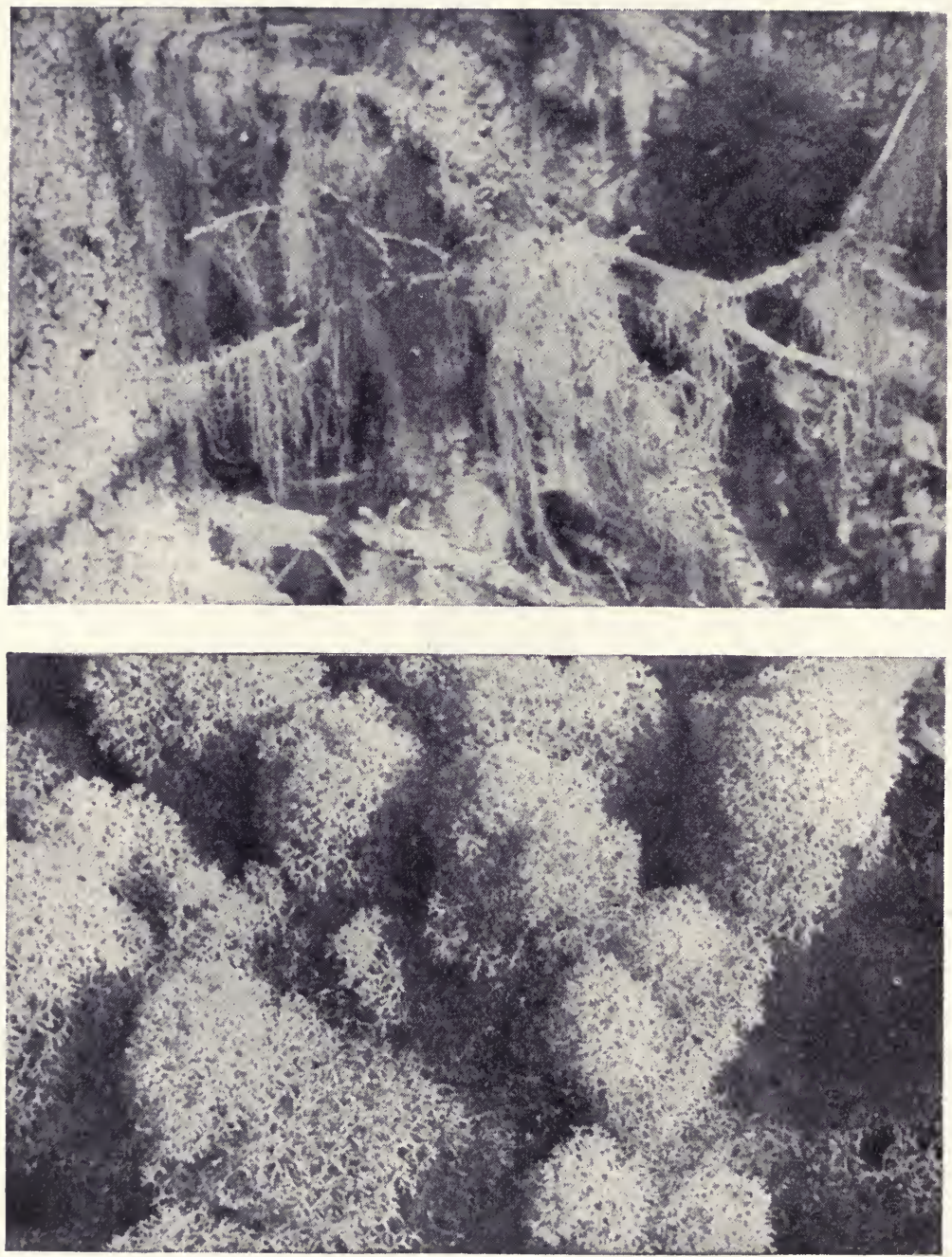

Fig. 64.- Lichens are gray-green plants capable of living as epiphytes on branches of trees (Old Man's Beard, above), or of growing on rock and bare earth (Reindeer Lichen, below.) 
the two phyla of the leafy spore plants have the simplest types of plant bodies.

The phylum BRYOPHYTA consists of some 17,000 species of small plants which can well be called the amphibians of the plant world, since they prefer to live in semi-aquatic habitats. Theirs are the least complex organs of any land plants, and in their life history (see p. 55) occurs an alternation of a green independent gametophyte with a parasitic colorless sporophyte. At least 12,000 of the species are included in the group of Bryophytes known
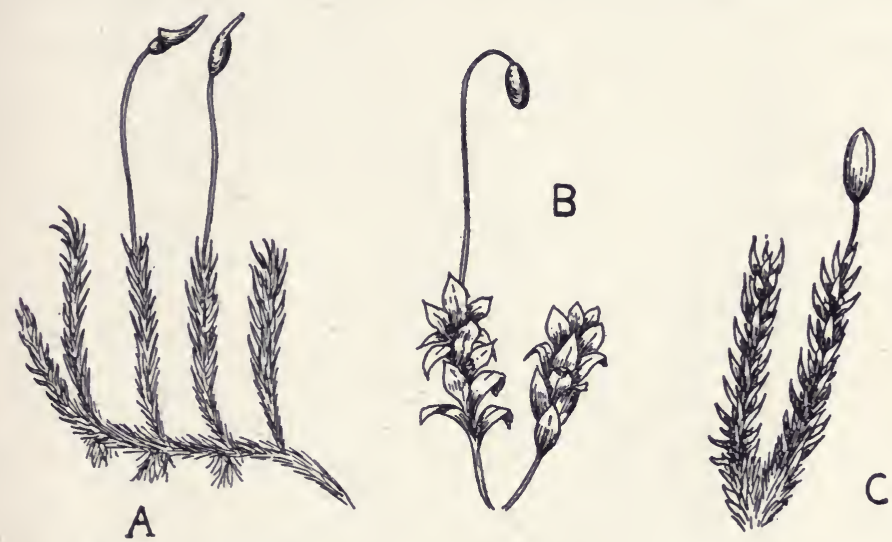

FIG. 65.-Mosses are predominantly small plants; common examples are crane's-bill (A), Mnium (B), and rock moss (C).

as Mosses (fig. 65), which are predominantly small plants a few inches in height and with the habit of growing in closely packed masses. The "leaves" which appear on the erect stems are not structurally true leaves, being only a few cells in thickness and made up of a homogeneous tissue of unspecialized cells. However, superficially they resemble leaves. Mosses lack roots, absorbing their water and minerals as we have seen through rhizoids. The only genus of any economic importance is peat moss, whose deposits are used as fuel.

The other group of Bryophytes is known as the Liverworts. They are generally prostrate and creeping plants with no leaflike organs as in the mosses (fig. 66). Many liverworts consist of forking thalli with little greater tissue specialization than that of 
some of the seaweeds. They form matted growths on damp rocks and stumps in shaded ravines and wet woods. Liverworts represent a type of plant body intermediate between the thallus spore plants and the ferns. None of them is of economic importance.

The phylum PTERIDOPHYTA includes less than half as many species (about 6000) as are found in the Bryophyta. These are, however, greater in size and more familiar, including the ferns, club-mosses, horse-tails, ground-pines and scouring-rushes. In prehistoric times they were more dominant than now, as proven by the numerous fossil remains. During the late Paleozoic Era, Pteridophytes formed vast forests, many species growing to the
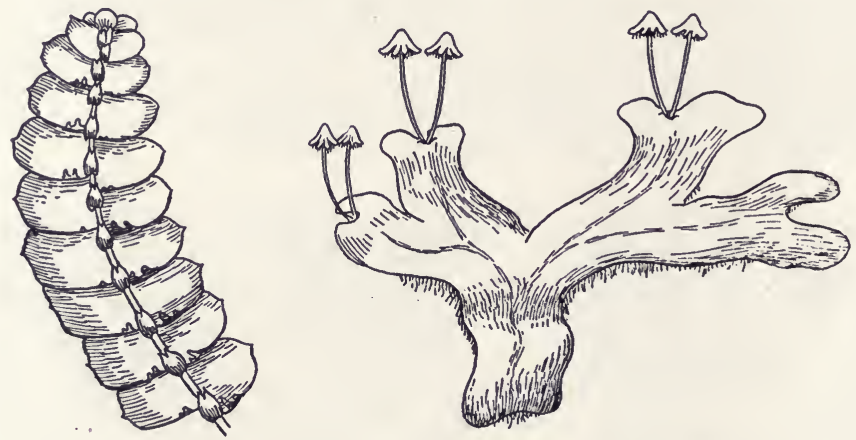

Fig. 66.-Liverworts are creeping or matted plants.

size of trees. Today only a few species are tree-like, as exemplified by the tropical tree ferns. Pteridophytes are characterized by a highly complex sporophyte which is green and independent, made up of true roots, stems and leaves; and an inconspicuous gametophyte which is also green and independent but of the thallus type of organization (see p. 30).

One group of the Pteridophyta is the True Ferns, with about 5000 species (fig. 67). These are plants, for the most part, with subterranean stems and large, often intricately subdivided, leaves. Since the rather delicately constructed leaves are not suited for exposure to sun and dry. winds, most fern species live in damp shaded habitats, being typically plants of the deep woods where the air is continually moist. Some, as the Christmas fern, are evergreen and keep their leaves amid winter snows. Others are 
deciduous - the cinnamon, royal, and interrupted ferns - and prefer swampy woods and stream margins. A few colonize tree trunks and boulders, as does the polypody fern. Growing to the greatest height of any native species, the brake fern has a threeparted leaf which often grows to be five or six feet tall.

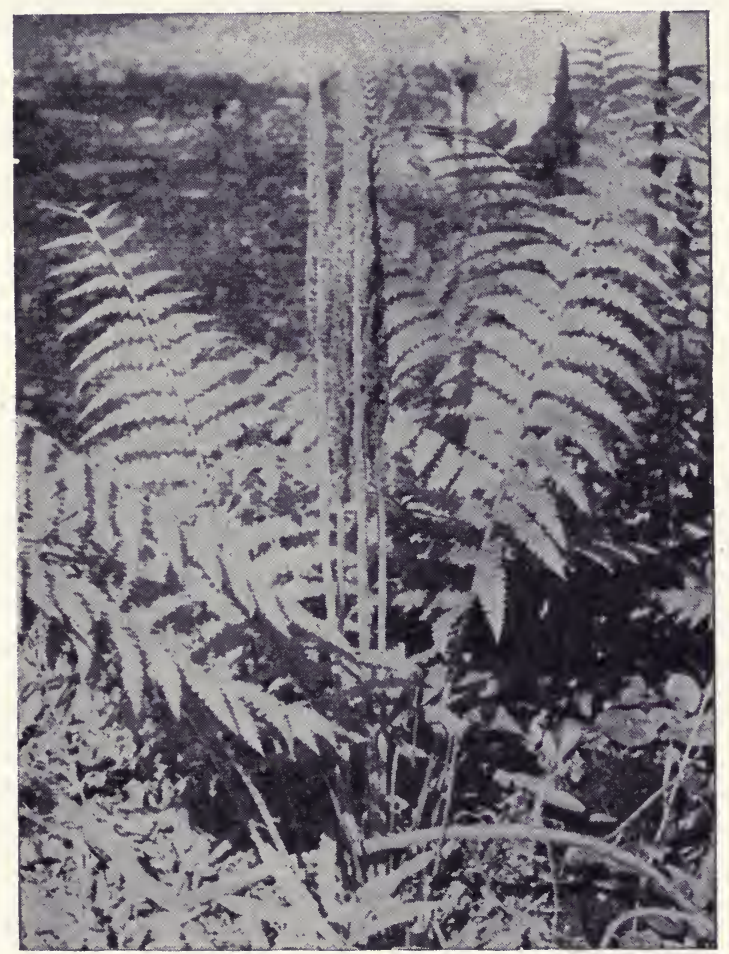

Fig. 67.- The true ferns are plants with subterranean stems, large and often intricately compound leaves. The cinnamon fern produces special spore-bearing leaves in the center of the foliage cluster.

Another group of the Pteridophyta is the Club-mosses (fig. 68) with about 1000 species. These are creeping or erect plants of woods and fields, smaller in size than the True Ferns and with minute scale-like leaves closely overlapping on the stems, resembling the leaf-habit of some conifers. Gound-pine is a species which looks like a miniature evergreen tree; creeping-pine and 
ground cedar form sinuous growths close to the earth; and the numerous club-mosses grow stiffly erect with shining dark green leaves. Some of the species are used as Christmas greens.

A third group is the Horse-tails (fig. 69) with less than 50 species. One of their characteristics is a segmented stem lacking leaves; these photosynthetic organs have become reduced to whorls of small scales while the stems are green and carry on

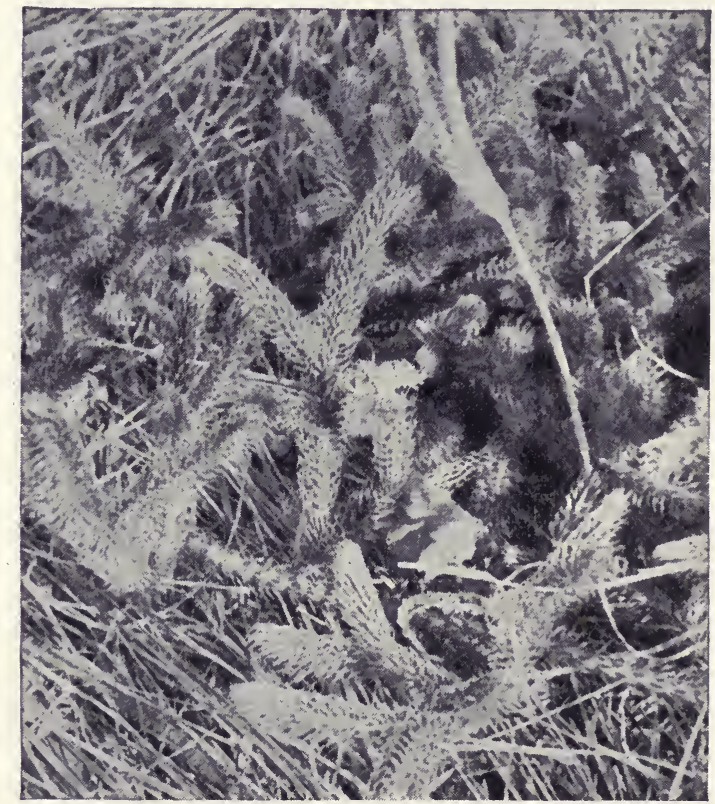

FIG. 68.-Creeping pine is a fern relative with minute scale-like leaves.

photosynthesis. The horse-tails are usually swamp-dwelling plants rarely more than a few feet in height. Scouring-rushes have cylindrical stems which lack the whorls of lateral branches characteristic of the horse-tails. This entire group, as well as that of the club-mosses, differs from the true ferns in having the spores produced in terminal cone-like structures.

Pteridophytes today are of little economic importance, except as ornamental plants. In the geologic past, however, their 
abundant remains accumulated in vast prehistoric swamps to form the organic deposits which later turned to coal and thus became important sources of fuel.

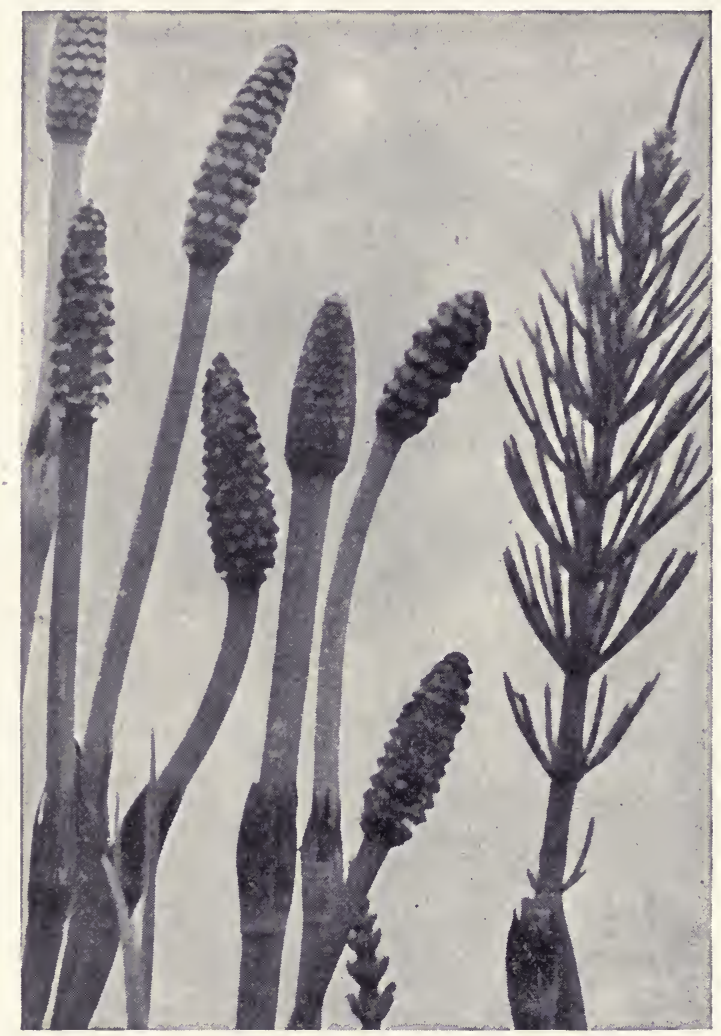

Fig. 69.-The horse-tails are fern relatives with segmented green stems, lacking leaves. Reproductive stems on left, terminated by cone-like structures producing the spores.

\section{The Naked-seed Plants}

All of the preceding phyla of plants, irrespective of the complexity of their maintenance organs, reproduce by structures which are protected little or not at all against environmental factors. But in this last phylum we are to consider-the SPERMATOPHYTA - the embryo is always developed within that protec- 
tive and nourishing organ, the seed. The evolutionary significance of the seed habit is clear when we discover that over half (about $160,000)$ of all the plant species can be grouped into this phylum, and that land vegetation is made up almost exclusively by them.

The Spermatophyta or Seed Plants are subdivided into two classes. One group, or class, of less than 1000 species, includes the
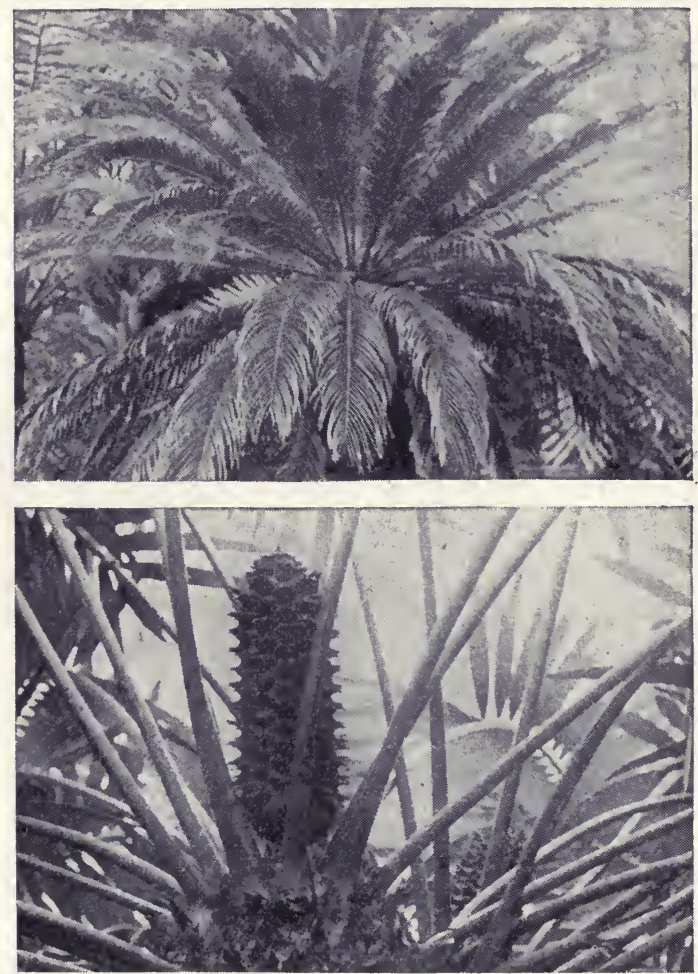

Fig. 70.-Cycads are semi-tropical low-growing Gymnosperms with fern-like leaves and cone-like reproductive structures.

more primitive members in which the seeds are produced on exposed cone scales. These are the Gymnosperms, in which no fruit surrounds the seed, and which are therefore called the nakedseed plants. The other group, made up of the remaining species of the phylum, is that of the Angiosperms, in which the seed lies within a protective fruit (see p. 76). 
The Gymnosperms as a class are chiefly woody shrubs and trees of an evergreen habit, with the sporophyte reproducing by cones. They differ among themselves in the size and shape of the leaves, and in the types of cones produced. Of the sixteen or eighteen families which comprise the class, five are extinct, representing the most primitive type of seed plants, unable to survive to the present day in competition with more specialized species. A few other families include a small number of uncommon genera, of little economic significance. The Cycad Family, for example, is made up of semi-tropical species of low-growing trees with pithy palm-like trunks and terminal clusters of large fern-like leaves (fig. 70); one species known as the sago palm, native to southern Florida, is considered a food plant by the Seminoles who make flour from its underground starchy stem. Another family includes the single species of the maidenhair tree, an Oriental species with wedge-shaped deciduous leaves often grown for ornamental purposes in eastern cities.

The most familiar of the Gymnosperm families are known as conifers. * These are important forest trees as indicated in Chapters 16 and 18. The Pine Family includes those species with needle-like leaves as are found typically among the pines, firs, spruces and hemlocks. One member of the family-the larch-is unusual in being deciduous. Smaller shrubby evergreens are found in the Yew Family, represented by the common yew; this family has needle-like leaves, but fleshy and berry-like cones instead of dry scaly ones. The species with small, overlapping scale-like leaves are found in the Cypress Family, which includes our native cedars and junipers as well as many of the shrubby ornamental evergreens used as foundation plantings around houses and public buildings. Some of the largest trees in the world are found in the Redwood Family, which also includes the bald cypress of our southern swamps.

\section{The Fruit-seed Plants}

The class of the Angiosperms includes, in addition to all of the flowering plants, many species which do not have flowers in the popular sense of the term. But all produce fruits of a sort, fleshy or

* For illustrations of conifer families, see Chapter 16. 


\section{DICOT}
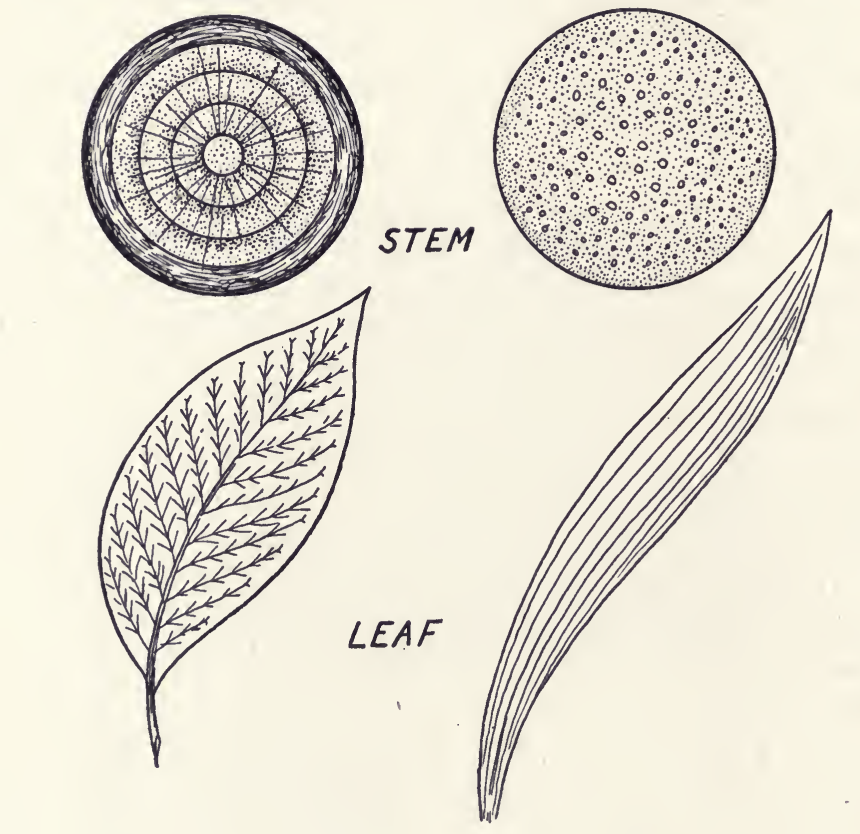

STEM

MONOCOT
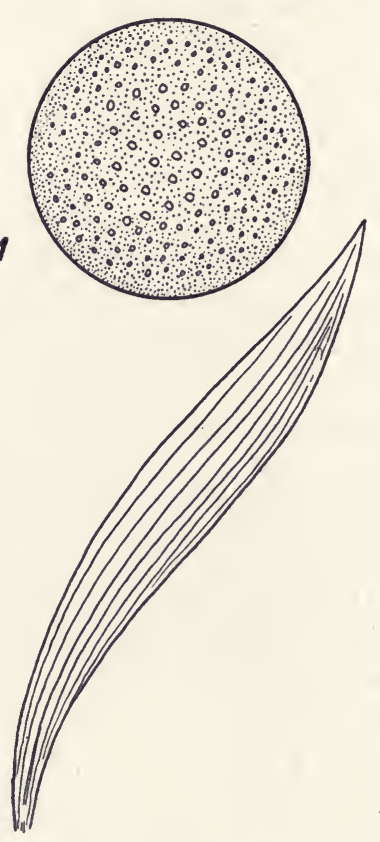

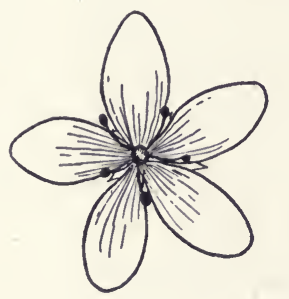

FLOWER
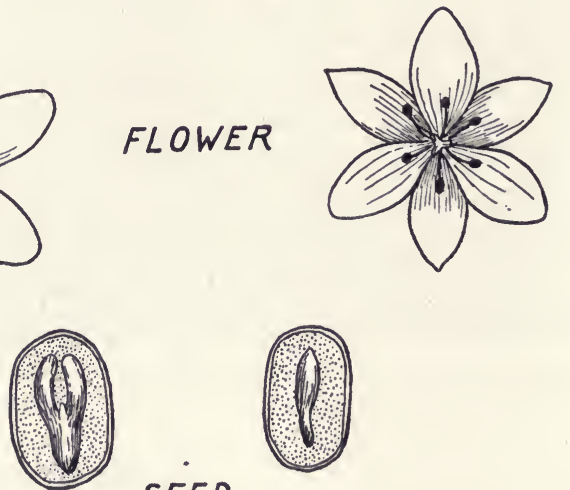

SEED

Fig. 71.-Angiosperms are made up of two sub-groups, the Monocots and the Dicots; these differ in vegetative and reproductive structures. 
dry, conspicuous or small, to protect the seed and aid in its dispersal. As a convenience in classifying this large assemblage of species, Angiosperms are customarily subdivided into two subclasses on the basis of reproductive and vegetative differences. One sub-class is known as the DICOTs, since there are two cotyledons in the seed (see p. 75); but plants belonging to this subgroup also have other features in common. Their flowers usually have the petals, sepals and stamens in fours or fives; their leaves

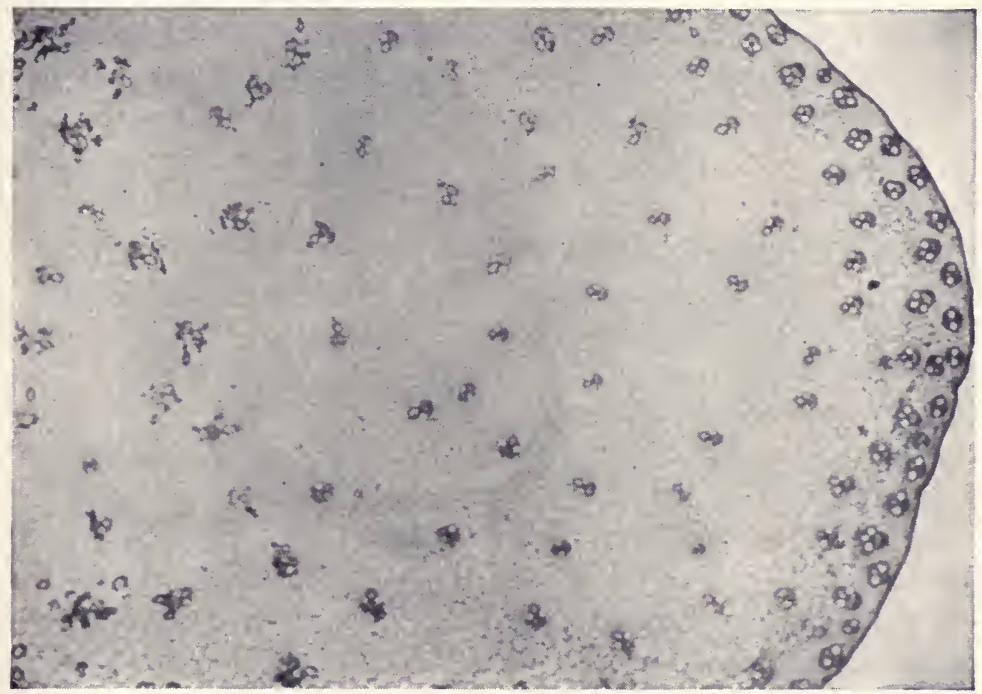

Fig. 72.-Monocots, such as corn, have pithy stems with scattered bundles of conducting cells.

are usually broad and netted-veined; and their stems are capable of producing wood and annually increasing in diameter, forming annual rings (fig. 71). The other sub-class - the monocors-includes those species with a single cotyledon in the seed; leaves that are usually long, slender and parallel-veined; flower parts in threes or sixes; and pithy stems lacking the ability to increase annually in diameter (fig. 72).

The DICOTs are considered by most botanists to be more primitive than the Monocots, and to represent simpler stages in floral evolution. This sub-class is made up of 100,000 to 125,000 
species (it is difficult to get exact estimates in any of the groups larger than the family), among which are found all our broadleaved and deciduous trees. On the basis of flower structure the Dicot families fall within three well defined groups; (1) those in which the flowers lack petals and sepals or possess undifferentiated ones when present, and thus are chiefly wind-pollinated; (2) those in which the petals and sepals are separate from each other, forming a corolla and calyx of clearly defined segments; (3) those in which the petals are fused to form a tubular corolla, and the sepals are similarly fused to form a funnel-shaped calyx.

In the first group* there are about 20 common families and some 20,000 species. Among them are the catkin plants, found in the Willow, Walnut, Birch and Beech Families; in which are found many of our important hardwood trees. Also in this group are some herbaceous families of general interest, such as the Mistletoe; Pepper, Buckwheat and Pink Families. Few are of ornamental value since the flowers are inconspicuous or small in the majority of species.

In the second group of the Dicots we find the greatest number of families (about 100) and species (some 50,000). Many native and ornamental flowers are found in the Buttercup, Water Lily, Poppy, Violet, Saxifrage, Rose and Mallow Families. A few families include native trees, such as the Magnolia, Rose, Maple, Horse Chestnut and Holly Families. Food plants are numerous in this group, headed by the Pea and Rose Families (see Chapters 8, 9 and 10), and including the Mustard, Rue and Grape Families. All of the citrus fruits are members of the Rue Family. In this group is also the Cactus Family, one of the most interesting of the succulent families.

The third group is made up of those species with the most highly evolved flowers found among the entire Dicot sub-class; here some 35,000 species are found distributed through about 50 families. Trees and food plants are relatively fewer than in the other two groups; but because of the complex flower, more species are cultivated as ornamental garden plants. Ornamental shrubs such as the rhododendrons and azaleas are found in the Heath

* For additional illustrations of Dicot trees see Chapter 17; for herbaceous Dicots, see Chapters 26 and 27. 
Family, while annual flowers are numerous in the Primrose, Mint and Composite Families. Food plants are found in the Huckleberry, Morning Glory, Potato and Goud Families.

The sub-class of моNосотs is conspicuous for the absence of tree species, which is to be expected from their type of stem structure; it abounds in tropical members, many of them of spectacular leaf and flower characteristics. About 35,000 species of Monocots are grouped into some 30 families. There are numerous
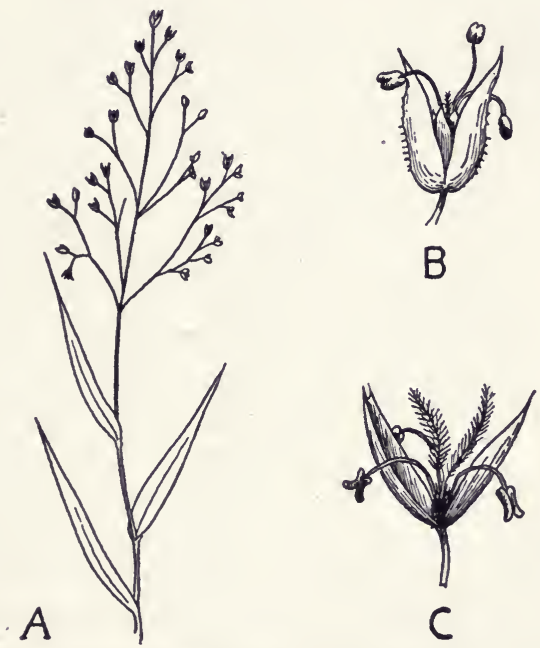

FIG. 73.-Grasses have developed a highly specialized type of wind-pollinated flower; Kentucky blue grass (A), timothy (B), wheat (C).

families of aquatic plants, used in garden pools and aquaria; these include the Cat-tail, Pondweed, Arrowhead, Tape-grass, Duckweed and Water Hyacinth Families. Some of these have minute wind-pollinated flowers, as in the Cat-tails where the tiny brownish flowers are clustered into cylindrical spikes; while others have conspicuous and beautiful blooms as the Pickerel Weeds, Water Hyacinths and Arrowheads.

The Monocots include one of the most widespread and valuable of all plant groups - the Grass Family. Grass species have developed a highly specialized type of wind-pollinated flower (fig. 73) which lacks the usual colored corolla. An effective habit of 
living gregariously has made it possible for them to populate almost exclusively the central plains of the United States to form one of the dominant features of our vegetation-the prairies. All of the cereal grains as well as sugar cane belong to the Grass Family.

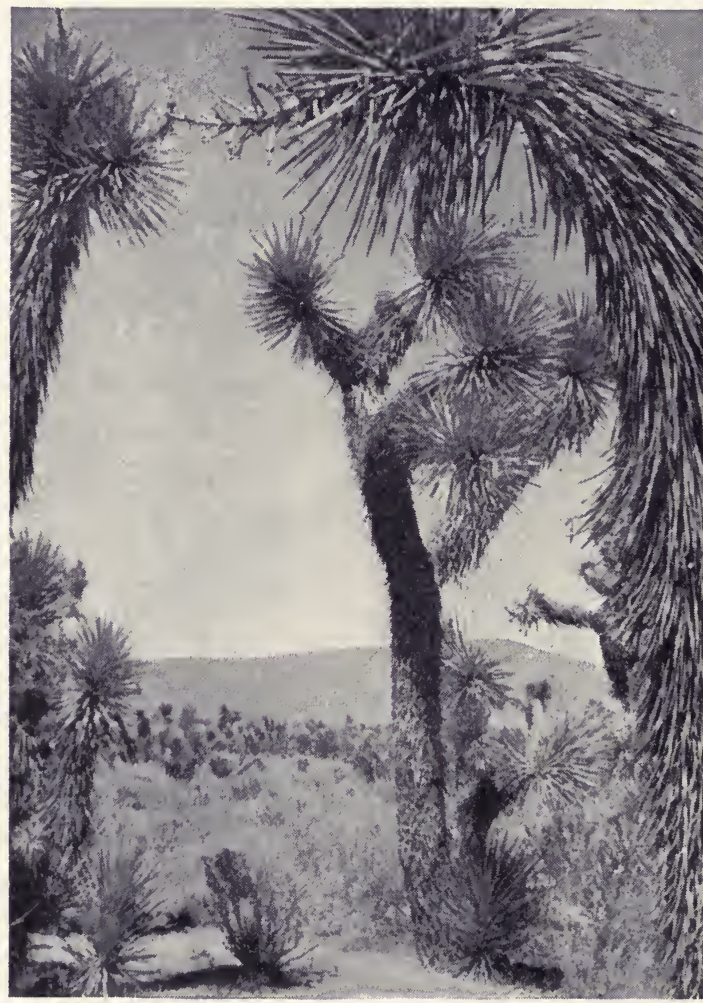

FIG. 74.- Joshua trees are members of the Lily Family which are grotesque denizens of our arid southwest.

Two of the most conspicuously flowered families of the entire phylum are found in the Monocot sub-class; they are the Orchid and the Lily families. In the latter are the few trees which grow on our southwestern deserts, the Joshua Trees or Tree Yuccas (fig. 74). The Palm Family is the only family which has persisted in 
the tree habit, including many tropical species which are of economic importance. One of the largest flowers in the plant kingdom is produced in the Arum Family, by an East Indian genus known as Amorphophallus; this relative of the common

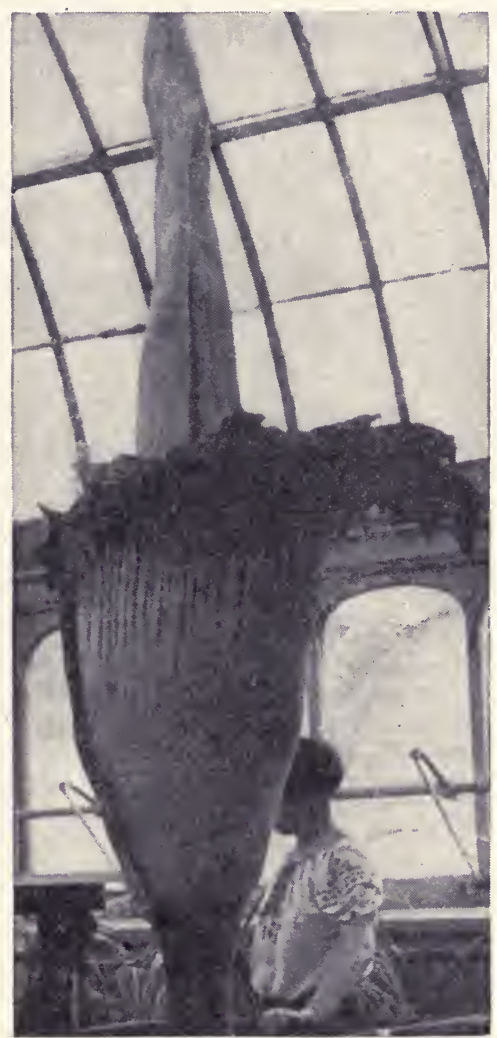

Fig. 75.-The Amorphophallus plant produces the largest flower in the plant kingdom-four to six feet in diameter and eight feet or more in height.

Jack-in-the-pulpit produces a flower four to six feet in diameter and six to eight feet in height (fig. 75).

A Summary of Plant Classification

Phylum Schizophyta: thallus plants with and without chlorophyll-Blue-green Algae and Bacteria. 
Phylum Ghlorophyta: chlorophyll-bearing thallus plants with no accessory pigment-Pondscums and Green Seaweeds.

Phylum Phaeophyta: chlorophyll-bearing thallus plants, aquatic and chiefly marine, with fucoxanthin obscuring the chlorophyllBrown Seaweeds, Kelps.

Phylum RhoDорнутA: chlorophyll-bearing thallus plants, aquatic and chiefly marine, with phyco-erythrin obscuring the chlorophyll-Red Seaweeds.

Phylum Mycophyta: chlorophyll-deficient thallus plants, chiefly terrestrial-Molds, Mildews, Mushrooms.

Phylum BRYOPHYTA: amphibious land plants with green independent gametophytes and parasitic sporophytes, no true roots or leaves - Liverworts, Mosses.

Phylum Pteridophyta: more completely terrestrial plants with green and independent sporophytes as well as gametophytes; true roots, stems and leaves but no seedsFerns, Club-mosses, Horse-tails.

Phylum Spermatophyta: most highly evolved land plants, with dominant green sporophytes and microscopic parasitic gametophytes; true roots, stems and leaves; seed habit.

Class Gymnosperms: exposed ovules and seeds; no fruits Cycads, Maidenhair Tree, Conifers.

Class Angrosperms: imbedded ovules and seeds in fruits.

Sub-class Dicotyledonous Plants (Dicots):

Representative Families-

Walnut Family

Elm Family

Beech Family

Pink Family 
Buttercup Family

Cactus Family

Rose Family

Pea Family

Mallow Family

Heath Family

Mint Family

Composite Family

Sub-class Monocotyledonous Plants (Monocots):

Representative Families-

Grass Family

Lily Family

Palm Family

Arum Family

Orchid Family 


\section{Chapter 5}

\section{THE INTER-RELATIONS OF PLANTS AND MAN}

Very few species of plants or animals live in complete biologic isolation, carrying on the maintenance and reproductive activities described in preceding chapters uninfluenced by the presence of other living things. In fact, in any habitable area the plant and animal populations form a maze of inter-relationships in which one species is inextricably caught in a web of life which involves many others. It is almost impossible to destroy or remove a single species from a locality, or introduce a new one, without producing far reaching effects upon numerous and often totally unrelated groups of organisms.

Some of these relationships involve only plants, such as that of the semi-parasitic mistletoe deriving its existence while attached to the limb of a sycamore, or that of the forest trees forming a shaded floor where mosses and ferns can thrive in the damp twilight. Other relationships involve only animals as is the case of the food-chains linking carnivorous animals and their prey, or parasitic tapeworms with the mammals whose intestinal tract they are inhabiting. Such relations, of which there are many, often result in profound structural and physiological changes during the evolution of the organisms involved. But the interrelations which occupy our attention in this chapter are primarily those showing the mutual inter-dependence of plants and animals, and plants and man. Since man, in his biologic heritage, is a member of the animal kingdom, it is relevant to discover the fundamental relations of plants to animals, and thus realize why certain relationships exist between plants and man.

There are three fundamental ways in which the plant and animal kingdoms influence each other. First and most obvious, is the dependence of all animal life upon green plants as a basic 
source of food. Secondly is the dependence of green plants (and therefore indirectly all animals) upon colorless plants for a continual supply of the inorganic materials needed for protoplasm building. And thirdly is another obvious relationship as a result of which both green plants and animals are preyed upon by parasitic heterotrophic plants.

\section{Green Plants as a Food Supply}

One of the most vital of inter-relations in the web of life is that in which one species acts as food for another species. As we have seen in Chapter 2, green plants because of their autotrophic habits are independent of the animal kingdom. It is not the same for animals, however. They must secure their food in organic form-as carbohydrates, fats or proteins-from the bodies of other organisms. This means an ultimate dependence upon some autotrophic species as a food supply. The very existence of the entire animal kingdom therefore depends upon the presence of green plants! In lakes and oceans the algae synthesize carbohydrates and proteins from the water and the salts dissolved in it. Protozoa and minute invertebrates feed upon the algae; fishes eat the protozoa and tiny invertebrate animals, only in turn to be eaten by larger fishes. Thus a food chain links the lowly algae with sharks and other aquatic vertebrates. Vegetation is also necessary to assure the existence of land animals, the herbivorous forms feeding upon plant life, subsequently to be eaten by the carnivorous species. There the sequence of food-linkages may lead from the mighty lion to the insignificant grasses which he tramples under foot. The primate group is predominantly vegetarian, feeding upon succulent stems, storage roots, fruits and seeds. When man diverged from his primate relatives he bore with him this appetite for plant foods, in search of which he ranged the woods and fields. Civilized man improved upon this method of getting his food by developing the science of agriculture.

\section{Green Plants and Our Oxygen Supply}

Supplies of the various substances necessary for life are not unlimited; animals consume great quantities of oxygen during the 
respiratory phase of their metabolism, green plants use up definitc amounts of carbon dioxide and nitrates in their synthesizing activities while manufacturing food. Why does not the supply of oxygen, carbon dioxide and nitrates ever become exhausted? The answer to this reveals a natural cycle of the elements in question, in which organisms are mutually very helpful-one organism returning to the environment what another organism removes from it.

Oxygen is essential in order to have respiration continue; without respiration as a means of liberating the potential energy of food all multicellular life would be eliminated from the face of the earth. Since animal species are continually removing oxygen from the atmosphere, it would not be long before all the available oxygen would be used up. That this does not happen is due to the fact that when green plants are carrying on photosynthesis, oxygen is released as a by-product (see p. 16). Green plants are the depositors, animals the chief withdrawers, of oxygen in the cosmic bank account. Our forests and meadows are therefore more than so many feet of lumber or so much fodder for cattle. They keep the air continually fresh by renewing the oxygen supply at the same time they are removing the carbon dioxide which, if accumulated in quantity, would in itself bring an end to all animal life on the earth.

\section{Importance of Decay Bacteria}

Other relatively unknown and unappreciated inter-relations of plants with animals involve a new kind of eternal triangle; in this case, green plants, animals and bacteria. As plants and animals grow and reproduce, generation after generation, the increase in the bulk of protoplasm thus produced is tremendous; and since protoplasm is made up of definite elements, the increase in volume of protoplasm is proportionate to the decrease in the amount of the substances used up in making that protoplasm. Two elements in particular-carbon and nitrogen-are thus being continually withdrawn from the environment to be made into protoplasm; the source of the former being carbon dioxide, of the latter, nitrates. It is not difficult to realize that, unless the carbon and nitrogen can eventually return to the environ- 
ment, the available supply of these two elements will eventually become exhausted since no natural inorganic process produces them in sufficient quantity to be of use. Millions upon millions of tons of protoplasm exist in living bodies alone; to which must be added the billions of tons which have gone into the bodies of past plants and animals.

Carbon dioxide is taken in during photosynthesis and from it carbohydrate foods are manufactured. Without carbon, there could be no food, and no life. The amount of carbon dioxide in the world is definitely limited; the .03 per cent present in the atmosphere is equivalent to about six tons over each acre of earth's surface. Some crops such as sugar cane extract many tons of carbon from the air above each acre in a growing season. At the average plant consumption rate, it has been estimated that all the carbon dioxide in the atmosphere would be used up in thirty five years. Since life has been a going concern for many millions of years, and no danger of a carbon shortage is present today, there must be some way in which nature balances the consumption and production of carbon dioxide. Respiration returns small amounts to the air, but in such insignificant quantities that this would only defer the day when all the carbon dioxide would be depleted. It is at this point that the bacteria and some fungi enter the picture (fig. 76). There is a natural process known as decay, which is considered by many to be a nuisance if not a danger, since it causes the destruction of foods and other useful articles containing organic substances. Decay is the result of the activity of colorless plants, chiefly bacteria. These ubiquitous organisms are found practically everywhere; and as soon as life leaves a body, the bacteria start their work as scavengers and decompose the remains. This is done so efficiently that we can walk for miles through a forest in which life has gone on for centuries, but find few traces of these organisms that have lived. Decay bacteria, while living according to their saprophytic type of metabolism upon the organic substances of the dead body, thus become the world's number one scavengers. But they perform an even greater service; for during the process, carbohydrates and fats are broken down into the carbon dioxide and water from which they were made. Wood, for example, is one of 
the most abundant of plant tissues; in it are locked up vast amounts of carbon. When the wood decays (which indicates that the colorless plants are at work), the cellulose is changed to glucose and organic acids, and eventually into carbon dioxide and water. The carbon molecules are returned to circulation, to be used over again by green plants in another carbon cycle.

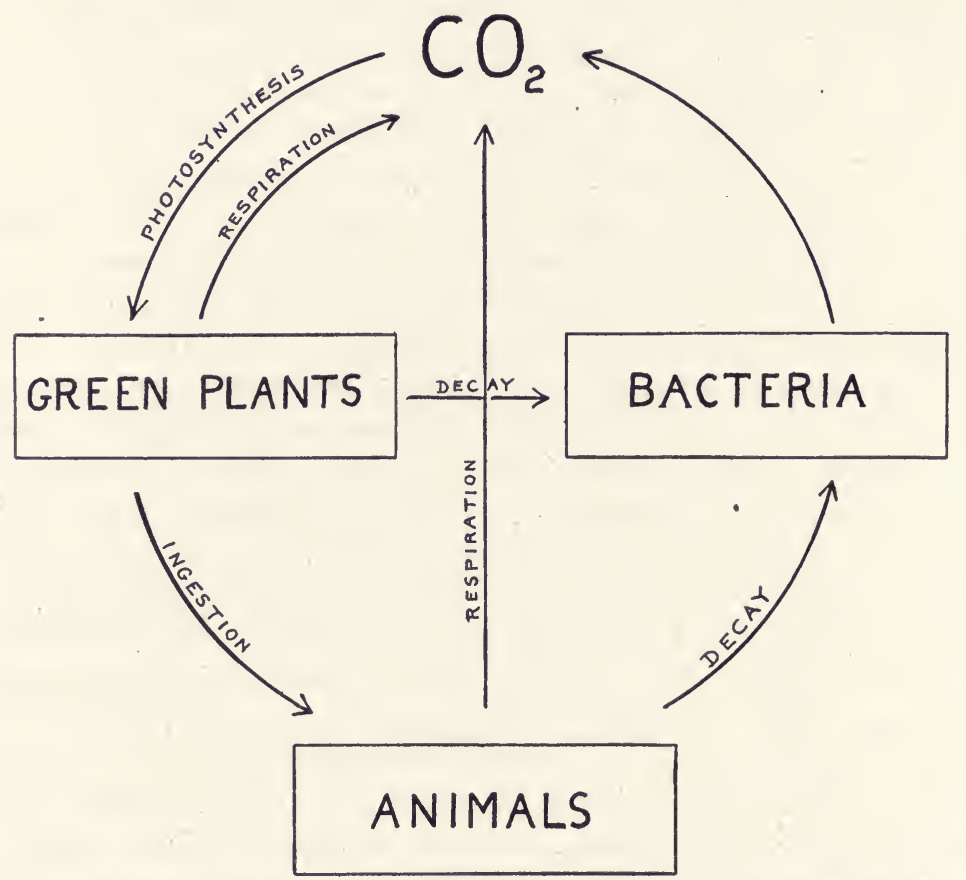

FIG. 76.-Bacteria are important in the cycle of carbon which occurs in nature.

Thus if there were no decay, life would come to a standstill through deficiency of carbon. In the carbon cycle, the colorless plants are the depositors in the universal account, while the green plants are the spenders; animals look on interestedly since their own existence depends upon the continual amounts that the green plant spenders can withdraw.

Just as there is a limited amount of carbon in nature, so is there a definite quantity of nitrogen available for protein synthesis. Four fifths of the atmosphere is nitrogen gas, but few plants 
and no animals can make use of this. The nitrogen must be in the ground in the form of nitrates. Green plants remove tons of the available nitrates from the soil each growing season, so that eventually - as in the case of extraction of carbon dioxide from the atmosphere - the supply becomes depleted. This is evident in run-down farms where no more crops can be grown because the nitrates have been exhausted and must be replaced by fertilizers

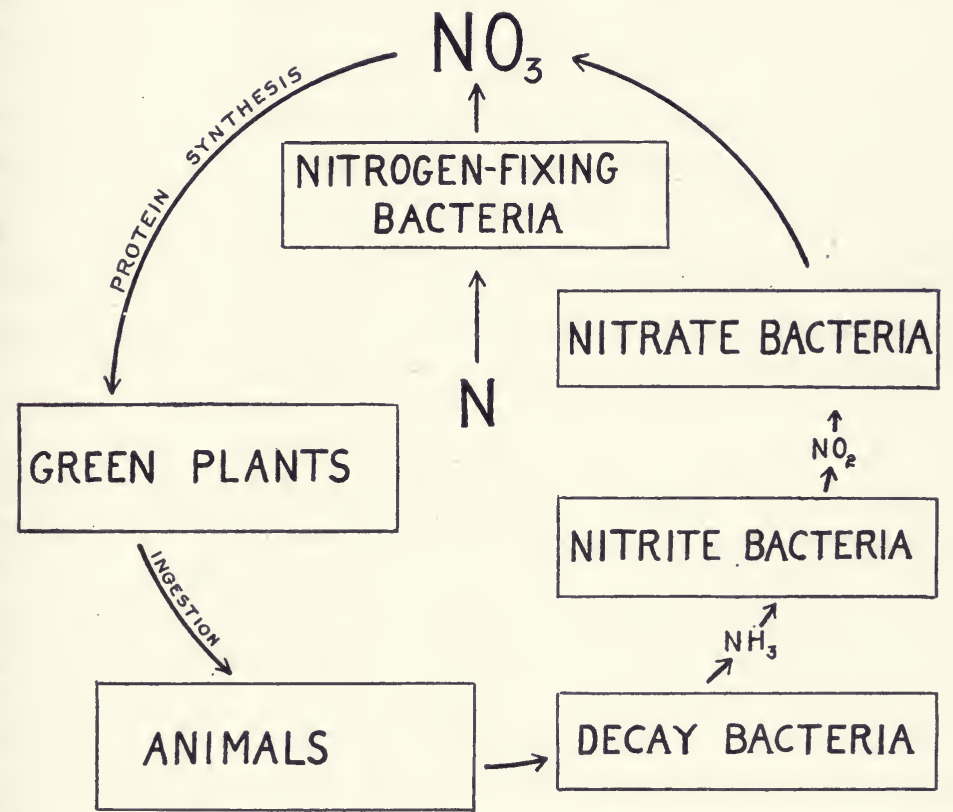

Fig. 77.-Bacteria are also important in the cycle of nitrogen.

before crops can again be grown in the same soil. Nature continually re-fertilizes the soil from the remains of dead plants and animals, again using the colorless plants in the cycle. Decay bacteria which can "feed upon" proteins (the organic substances which contain the nitrogen) decompose the plant or animal remains with the evolution of ammonia as a waste product. The ammonia is oxidized by two sets of bacteria which can utilize this compound in their metabolic processes-the nitrite and nitrate bacteria-and thus produce nitrates. The nitrates thereupon are 
ready to be used again by other green plants in their synthesis of proteins (fig. 77). Another phase of the nitrogen cycle involves certain species known as nitrogen-fixing bacteria, which can extract the nitrogen from the air and "fix" it as a nitrate. Some of these bacteria are free-living in the soil, subsisting upon carbohydrate debris which is used as the source of energy to fix the nitrogen. Others live in nodules on the roots of various plants related to the peas, beans, clover and alfalfa; when the host plant dies and becomes part of the soil humus, these nodules decompose and add nitrates to the soil. Since soils can be enriched in this way by "green manure," it is possible to alternate crops so that such nitrate-depositing plants make up for the other plants which withdraw the nitrates from the soil. Here again the depositors in the account are the bacteria, the spenders are the green plants; but also again animals are most interested bystanders, since their protoplasm is derived from plant protoplasm, and the latter depends upon nitrogen for its formation.

\section{Parasitism}

Another way in which plants influence the lives of animals presents a less cheerful picture. The colorless plants are parasites as well as saprophytes, and as parasites they gain their sustenance from living plants and animals. In some cases this does not harm the host organism, yet in many instances it results in the common enemy of all living things-disease. As a result animals which do not die of old age or by accident usually fall prey to one of hundreds of species of bacteria. Plants themselves are also the prey of these minute assassins, though in this case it is the fungi rather than the bacteria, which are the chief offenders.

Man does not stand apart from this maze of inter-relations, some of which are beneficial and some harmful. Dependent upon green plants for his foods and food accessories, his beverages and his drug plants, man has developed this relationship into a complete dependence upon agriculture and allied activities. Dependent also upon the bacteria, he has learned to use them in keeping his soils rich in nitrates. But like his fellow animals, his body at the same time is continually being attacked by hosts of other bacteria which are attempting to use him in their food 
cycle; because of this, medical and bacteriological sciences have come to be important human activities.

However, man has formed other relationships with plants, as a result of his civilized mode of existence. Rather than becoming more independent of these green allies, he has increased his dependence upon them, and is beginning to realize that they can be merciless foes as well as helpful friends. A few of these relationships will be suggested in the balance of the chapter.

\section{Plant Relations Beneficial to Man}

Many of the ways in which plants are of importance in the lives of animals have been elaborated upon an extensive scale by man, with an exploitation of those species possessing useful characters. At the same time new relationships, resulting from the demands of civilization, have developed which make our dependence upon plant life even greater than that of many animals.

Still most important of these is man's reliance upon plants as a basic source of food. By a slow and at times costly method of trial and error, man learned which plants were fit to eat and which parts of the plant were most edible. After the existence of certain food plants became common knowledge, man evolved methods of growing these near to where he lived instead of depending upon their chance occurrence in nature. The story of the origin and domestication of food plants is one of the most fascinating episodes in the conquest of our environment. With the advent of agriculture, man could cease his daily search for food and settle down to more civilized tasks. This dependence upon plants extended to his domesticated animals which he used for food or as beasts of burden. The presence of good grazing areas, therefore, was almost as important to him as his own food plants.

The thallus members of the plant kingdom have never been of importance as food for man. We have seen that some of the red seaweeds are eaten in various countries, notably the British Isles and Japan; but for the most part the phyla of the Green, Red and Brown Algae are of little value in this respect. The fungi are better known as food plants; though mushrooms can claim the distinction of being edible plants more because of their unusual 
and delicate flavor than by the presence of nutrients in their tissues, which are chiefly composed of water. The Greeks and Romans prized mushrooms as food delicacies, and through successive ages various peoples have held them in high esteem. Today they are the only thallus plants to be commercially cultivated for eating purposes. This is the safest method of securing mushrooms, for eating wild species is dangerous unless one is sure of the identification of the edible and poisonous varieties. There are some two hundred edible species, the best known being the puffballs, morels, truffles, chantrelles, chicken and field mushrooms. Lichens are relatively indigestible because of the bitter acids they contain, but several genera are eaten by animals and people of some races. Reindeer lichen is the chief food of semiarctic land mammals, and a related genus known as iceland moss contains a starchy food eaten by the inhabitants of Iceland. Of historical importance is the lichen Lecanora found in northern Africa and western Asia, which was the "manna" of the Israelites.

The leafy spore plants are of negligible food value, since mosses and ferns contain insufficient nutrient material to attract animals or man. It is quite different, however, with the leafy seed plants (Spermatophyta). Because of their greater size and more efficient maintenance organs, as well as their habit of storing food in roots, stems, fruits and seeds, many of these have become staple adjuncts of the human diet.

The vegetative parts of a plant are of importance as foods, in proportion to the degree in which they are used as storage organs. Ordinary plant tissues, being made up of cellulose-walled cells, are indigestible and of little nutrient value. Among the few Gymnosperms whose vegetative parts have food value, we have already noted the starchy underground stems of the sago palm (see p. 101); few other species in the class are of any food importance. Among the Angiosperms, on the other hand, there are many species with edible roots, stems or leaves. The storage of food in the roots of beets, carrots, radishes, turnips and sweet potatoes have made these plants useful as vegetables. In addition there are many other species whose roots store food-usually starch-and which have been used by various peoples as foods. Digging for roots is one of the most primitive ways of 
getting dinner. Less frequent is the storage of food in stems and leaves. The underground stem of the white potato is the most important edible stem; other edible stems and leaf bases include celery, rhubarb and asparagus. Leaves, being short-lived structures, are rarely used as food storage organs; but though low in nutrient value, they are prized as vegetables because of their crisp succulence and high vitamin and mineral content. Edible leaves or buds include spinach, water cress, cabbage, lettuce and onion.

The reproductive process in seed plants has resulted in organs of great significance as foods. Gymnosperms have no fruits, but their seeds are in many cases tasty and edible. The seeds of the piñon and other pine species are known as pine nuts; they have been eaten for centuries by the Indian and Mexican population of our Southwest, who also grind them into a meal. Angiosperms, chiefly because of their fruit habit, are of much greater food importance. Popularly known as vegetables are such fleshy fruits as tomatoes, peppers, egg plant, squash and cucumber; while fruits in both the botanical and popular sense include the various berries, grapes, melons, apples, pears, plums, cherries, peaches, citrus fruits and numerous tropical species including pineapples, bananas, figs and dates. Seeds often constitute the most nutritious part of a fruit, as in the nuts and the cereal grains. In the legumes (peas and beans) the pod, which is the fruit, is sometimes eaten with the seeds, though the latter possess most of the stored food in their fleshy cotyledons. Only a few flowers are used as foods, most familiar being the artichoke and the cauliflower.

The importance of plants as foods constitutes the subject matter of the chapters in Part Two, where also are considered those substances found in plants which are necessary food adjuncts: the sugars produced in the sugar cane and sugar beet; the stimulants found in the coffee, tea and cacao plants; and the spices secured from a great variety of plant species.

Other ways in which plants and man have formed inseparable associations have been the outgrowth of human needs and desires above those of our animal relatives. Some of these relations depend upon the presence of fibers or other supporting tissues. Various kinds of strengthening fiber cells, chiefly developed in 
stems and leaves, have been found useful by man in numerous ways. Since the days of primitive man, the wood fibers comprising the trunks of woody Gymnosperms and Angiosperms have furnished suitable material out of which to build shelters, household articles, and conveyances for transportation on land and on water. Wood and wood products can claim an importance second only to plant foods. Other fibers, of a more flexible nature, have long been used for weaving clothing materials and other textile products; such pliable fibers are derived mainly from flax, cotton, hemp, sisal and jute plants. Fibers from herbaceous plants were used early in the history of civilization for making paper, the best known being the Egyptian papyrus plant; in more recent times the fibers from woody plants have become the

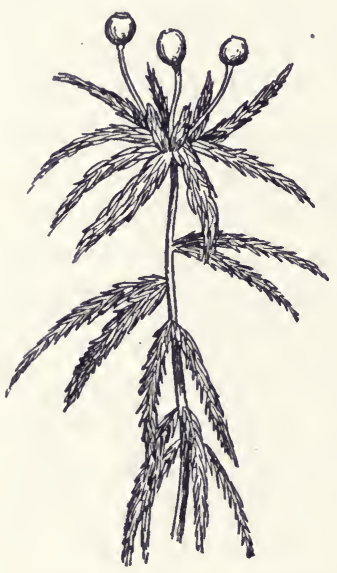

Fig. 78.-Peat moss accumulates in bogs and can be used as fuel. chief source. These aspects of man's utilization of skeletal elements in the plant body are more fully treated in Part Three.

The cellulose character of plants makes them an excellent fuel, since cellulose (like all carbon and hydrogen compounds) is very combustible. For heating and lighting his cave dwelling, early man undoubtedly found wood the most available material. Even today, wood ranks at the top of the list of common fuels. If woody stems, or the remains of non-woody plants, chance to lie on the surface of the ground, they are soon consumed by decay bacteria and the oxidizable compounds of the plant body are returned to the atmosphere as carbon dioxide and water. Whatever potential energy such plants may have contained is thus lost for man's use. However, if such plants happen to fall under water, they escape the action of the decay bacteria. Mosses and ferns, for example, often grow in or near swamps and ponds; when they die, their remains settle to the bottom of the water and form deposits of muck-in reality a water-soaked humus. The cellulose materials in their tissues retain their potential energy, since it is not released by the action of bacteria or fungi. 
Peat moss (Sphagnum) (fig. 78) is particularly prone to this habit, accumulations of old peat moss being exhumed, dried and then used as fuel.

During previous geologic eras vast swamps existed on many continents, particularly in what is now eastern United States. The dominant plants in these swamps were the Pteridophytes, some of which grew to be trees (fig. 79). The leaves, stems and spores of these ferns accumulated under the water, forming
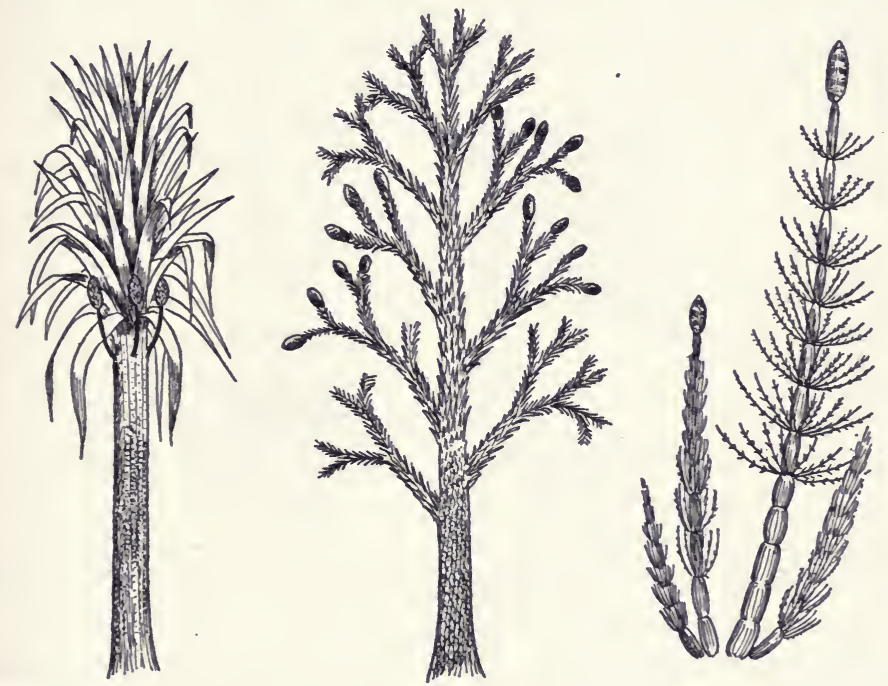

Fig. 79.-Prehistoric swamp forests included fern-relatives which grew to tree size.

deposits of organic matter in which the potential energy of the cellulose substances lay hidden. With the passage of millions of years, layers of sedimentary rocks formed over the swamp remains. The plant debris then became changed into bituminous coal, and this-if subjected to pressure while aging - became anthracite. Today we are using the deposits as subterranean storehouses of fossil energy which originally came from solar radiation intercepted by chlorophyll and transformed into plant tissues. Every time we get heat by burning a piece of coal, we are releasing the sunlight which shone upon the earth in 
the Paleozoic Era. Thus plants form a link between us and the far distant past. Coal is a more efficient fuel than wood since the water which interferes with complete combustion of wood has been removed in coal by the process of compression.

In more recent times another fuel substance has risen to importance. Petroleum, like coal and wood, is a compound of carbon and hydrogen, and therefore combustible. The exact origin of petroleum is still unknown, but one quite possible explanation is that petroleum deposits are the result of the accumulation of plant remains containing reserve oil as a storage material. Such plants are the diatoms (fig. 80), whose cells con-
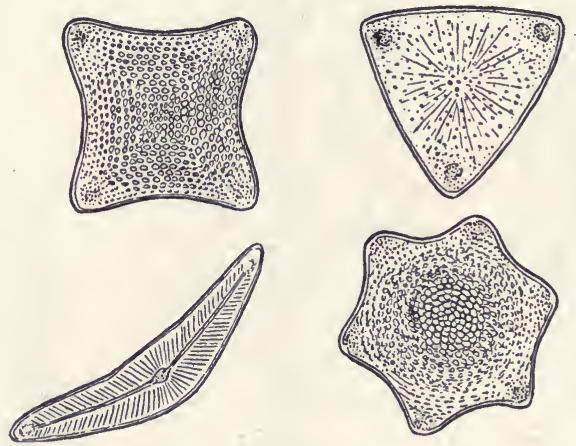

Fig. 80.-Diatoms, minute floating algae, are considered to be a source of some petroleum deposits.

tain small globules of oil. When these microscopic plankton organisms die, they sink to the bottom of the sea and escape decay under conditions similar to those found in the coal-forming swamps. But in this case the potential energy, instead of being locked up in cellulose, is in the oily compound known today as petroleum. Thus when we use gasoline to propel our automobiles; we may be releasing solar energy which a half a billion years ago filtered through some prehistoric sea, to be caught by tiny diatom plants. If petroleum originated in this way, then practically all of man's power is derived from solar energy intercepted by chlorophyll-bearing plants and stored in the organic compounds which have resisted decay.

Plants, like animals, produce secretions in special cells or groups of cells known as glands, and also give off waste products 
which are excretions. Many of these secreted and excreted plant substances have been found useful by man; this will be more clear after reading Part Four. Latex is a plant secretion with elastic qualities which, in the familiar form of rubber, has become an important plant product upon which many modern industries depend. Other industrial uses of plants include the manufacture of plastics and cellulose products, of varnishes and resin products, and of the various tannins, dyes and volatile oils.

Plant life is beneficial to man in many indirect and rarely appreciated ways. We have already discussed the importance of green plants in keeping constant the oxygen balance in the air, and of colorless plants in the cycle of carbon and nitrogen. Other less obvious relationships are those in which vegetation controls soil erosion, floods and water supplies.

Recently the importance of plants in erosion control has been vividly brought to our attention. Continuous high winds have a surprising lifting power and can remove surface soil if it is unprotected by vegetation. In the prairie states, where the dominant plants are grasses, the level expanses are frequently subjected to high winds. These have little effect on the soil as long as it is covered by a mat of grass, whose intertwined roots and stems effectively hold the soil in place. Farmers in this area, during the first world war, plowed thousands of acres of land previously covered with buffalo grass in order to grow sufficient wheat to supply the abnormal demand. When the overseas market for our cereal grains ceased to exist, these surplus "marginal" lands were abandoned. But man had upset the natural balance of plant life, and the buffalo grass did not come back onto these unused fields. Unusually high winds at this particular time then took a toll of the surface soil, removing it in clouds of dust which darkened many states, making an uninhabitable dust-bowl of what formerly was grasslands. Only a slow and laborious replanting of these thousands of square miles with grasses capable of living in such an environment will keep the soil where it belongs.

Barren soil is also easily eroded by rain which removes the topsoil. Rainfall, when it comes suddenly and in great amounts, runs off the surface of the ground and, carrying with it soil particles, forms gullies wherever a hillside is unprotected by 
grass or other vegetation. Such a run-off of the rainfall has several far reaching and disastrous consequences. One is the swelling of the streams and rivers so that floods result; another is the small amount of rainfall that can soak into the ground and remain there as ground water, to seep into springs and thus keep our reservoirs filled with pure drinking water. If, on the other hand, the soil is covered with vegetation, much more of the rainfall goes into the ground, since the roots form a spongy network which absorbs the water at the same time that it prevents erosion of the soil. Removal of forests at the headwaters of any river system usually causes periodic floods farther down the course of the main river.

Another beneficial aspect of our inter-relations with the plant world is associated with the esthetic appeal of plants. Most of us have a deep-seated liking for the companionship of plants; we like their comforting shade, their fragrance, their colorful blossoms; we like to have trees and flowers around us, whether in elaborate gardens or in window boxes and pots. Millions of dollars are spent annually by taxpayers for plants which beautify their public streets and parks. Ornamental plants help to make urban living more tolerable; garden clubs flourish best, it seems, in large cities. Few of us would deliberately choose to live in a region in which there is no plant life at all; and the attractiveness of many recreational areas-whether golf clubs, fishing and hunting preserves, state or national parks-depends upon the character of the vegetation. Life without plants, entirely apart from their dollars-and-cents value, would be much less pleasant. This aspect of plant appreciation forms the subject matter of Part Six of this text.

\section{Plant Relations Harmful to Man}

Plants are not, unfortunately, entirely beneficent in their relations with animals and man. Because of their inherent metabolic shortcomings, the colorless plants have always been a menace to self sustaining green plants and to animals. Most harmful of the colorless plants, from the human viewpoint, are the microscopic bacteria which cause diseases. In size and structure they are insignificant organisms; yet they are one of the few 
groups of living things which has seriously threatened the survival of various races of mankind. In Part Five, this relation of plants to man is considered more in detail.

In the same part is taken up the warfare which plants wage among themselves. A sunlit meadow or a quiet forest gives an impression of peace and goodwill, suggesting that plants are far removed from the life-and-death struggles which characterize animal lives. But underneath its placid exterior the plant world is rife with the struggle for existence. The greatest battles are those fought between the green plants and the hosts of colorless
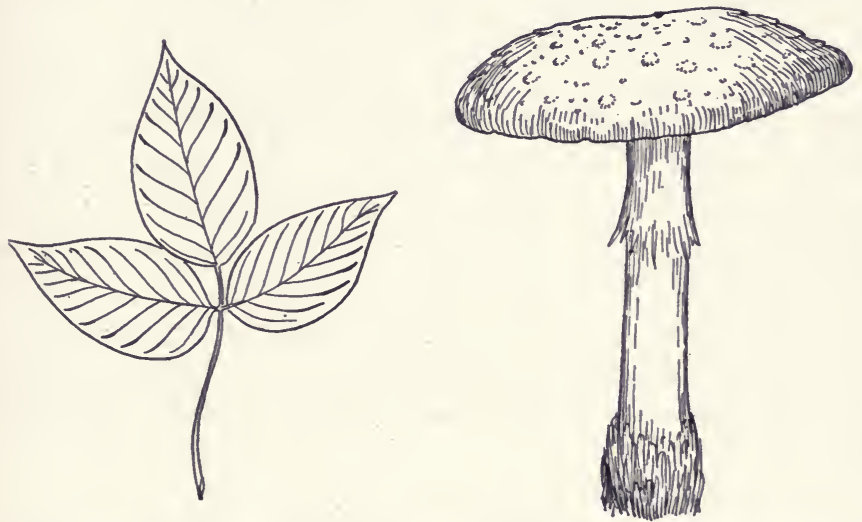

Fig. 81.-Poisonous plants include poison ivy and the Amanita mushroom.

fungi waiting to parasitize them. Microscopic fungus spores, carried through the air, penetrate the stomates of a leaf or fissures in the bark, and once within the host plant, germinate into invisible parasites which will live their entire lives at the expense of the photosynthetic host. Such fungus-caused diseases are numerous, sometimes threatening extinction of a species as happened in the blight which attacked the eastern chestnut trees. Plant diseases, in fact, are even more numerous than those of human beings; but the average person is not aware of them except when the host plant is a valuable crop. It is in these instances that the warfare between fungi and green plants becomes important to man. Often he must step in to lend aid to his green allies lest they become vanquished in the struggle. The 
constant battle to save valuable plants enlists the services of an army of trained specialists, an entire government department, and requires annual expenditures of millions of dollars.

Other harmful kinds of plants are those which produce poisons (fig. 81). These are remarkably few, in comparison with the total number of useful or harmless plants. Most of them are found among the mushrooms; the most familiar examples being the various species of Amanita. Some of these produce powerful toxic substances which can cause human death. A few of the Angiosperms likewise produce poisons, usually in the fruits or seeds. Many of these poisons, such as that found in the opium poppy, are used as drugs and have considerable medicinal value. In other cases the poisonous substances are merely annoying, as in the irritating oils produced by the vegetative parts of poison oak, poison ivy or poison sumac (all members of the genus Toxicodendron). When a plant is not poisonous, yet persists in growing where it is not wanted, it becomes one of those pernicious weeds which frequently makes cultivation of desired plants a constant battle. Botanically, there is no distinction of a weed; in many cases the plant considered a weed in one locality becomes - usually because of its rarity - a prized ornamental in another.

In this and the preceding chapters we have discussed the general considerations of what a plant is, how plants are structurally fitted to get a living and reproduce their own kind, the variety of plants which exist and the outline of their importance to man. With this as an introduction we can proceed to a more detailed consideration of certain aspects of these relations between plants and man. 
$\mathcal{P}_{\text {art }} \mathcal{J}_{w o}$

PLANTS AS FOODS

AND BEVERAGES 



\section{Chapter 6 \\ PLANT MANUFACTURE OF FOOD}

One of the most remarkable characteristics of living things is their ability to produce constant sources of energy within themselves, and to create matter with the resultant tremendous increase in bulk. A tiny seed, weighing an ounce or two, takes root in the soil and in time becomes a forest giant with tons of foliage on its branches and more tons of wood in its trunk. Where does all this come from, in a place where there was no visible matter before? At the same time, living involves work and therefore requires energy, even among plants. This is dramatically displayed by the seedling which germinates in a crevice of a boulder, eventually growing to such size that it splits the rock in two. From where does this energy come?

The answer to both questions is the same: the energy and the substance originates in FOOD. Foods can be defined as those chemical compounds which can be used by living things for energy, or out of which protoplasm can be constructed through growth. Thus one of the most fundamental relations of organisms to their environment is the securing of this all-important food.

\section{Glucose: the Basic Food}

Foods belong in three chemical categories: carbohydrates, fats and proteins. All three are compounds of carbon and hydrogen and oxygen; and all are distributed throughout the bodies of plants and animals, but in varying amounts and suited to various purposes. Carbohydrates and fats are commonly the chief sources of energy, while proteins are especially useful in the creation of new protoplasm through growth. Fats and proteins are secondary foods, being derived from the simpler carbohydrates; fats can be elaborated by either plants or animals, but only plants can change carbohydrates into proteins. Thus 
of the three foods, carbohydrates are essential for the existence of the others.

We have already seen that the first carbohydrate manufactured by choroplasts is glucose, and that this glucose can be synthesized only by plants (see p. 16). Since all of the other carbohydrates are derived from glucose, the world's entire food supply is dependent upon this one process of photosynthesis, and this one chemical compound. GLucose $\left(\mathrm{C}_{6} \mathrm{H}_{12} \mathrm{O}_{6}\right)$ is also known as dextrose, grape sugar or corn sugar. It is found in abundance in fruit juices and honey. It is commercially produced from corn starch, to form the familiar corn syrup. Glucose is only $60 \%$ as sweet as cane sugar, and is much easier to digest; the latter (sucrose) must be converted into glucose by digestive enzymes before being absorbed into the circulatory system. Thus invalids and persons with poor digestions are fed glucose-sweetened foods rather than those with the usual sugars.

\section{The Carbohydrate Foods}

From glucose, the simple carbohydrate resulting from photosynthesis, plants elaborate numerous other carbohydrate foods (fig. 82). Carbohydrates make up the bulk of the dry weight of a plant, and appear to be more important in plant functions than among animals. The glucose may be utilized directly by the plant as a source of energy, or may be converted into numerous other compounds used for specific purposes by various parts of the plant. These compounds include other sugars, starch, cellulose, dextrins, gums and pectins.

There are three other sugars which originate from glucose. FRUCTOSE or fruit sugar has the same formula as glucose; it is the sweetest of all the sugars. Fructose occurs in honey and in fruit juices, but is commercially secured from the Jerusalem artichoke. MALTose or malt sugar $\left(\mathrm{C}_{12} \mathrm{H}_{22} \mathrm{O}_{11}\right)$ is rarely found in great quantities in plants; the usual source for commercial purposes is in germinating barley grains. Cane sugar or sUCROSE (also $\mathrm{C}_{12} \mathrm{H}_{22} \mathrm{O}_{11}$ ) is the most generously produced sugar, secured by man from the storage root of the sugar beet or the sap of the sugar cane stem. 
All of the sugars have numerous characteristics in common, such as sweetness, solubility in water, and readily yielded energy when oxidized. They are found dissolved in the cells, and can be easily transported from one part of the plant to another. The presence of abundant amounts of sugars in plants is often associated with low temperatures; sugars aid in the maintenance of sufficient osmotic pressure within the cells to keep the proteins

\section{STARCHES}

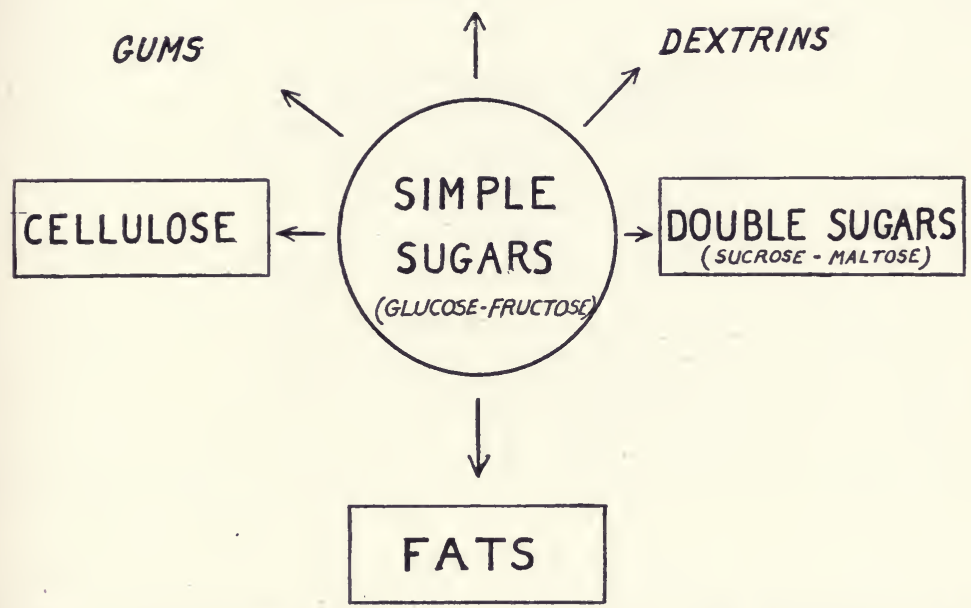

Fig. 82.-From glucose, plants elaborate numerous other carbohydrate foods as well as fats.

from being precipitated by freezing. Cool weather, for example, speeds up the transfer and storage of sugar in the sugar beet roots; cool autumns are essential for good sugar beet areas. Arctic plants have been found to contain relatively higher percentages of sugar than temperate species. And it has been recently demonstrated that feeding plants sugar makes them more resistant to low temperatures.

A common carbohydrate derived from glucose is STARCH $\left(\mathrm{C}_{6} \mathrm{H}_{10} \mathrm{O}_{5}\right)_{n}$, which is insoluble in water and therefore is not a form of energy-food capable of transportation from one part of 
the plant to another. It is used as a storage food. During photosynthetic activity, the excess glucose in a cell is stored temporarily as starch grains in the chloroplasts; this removes surplus sugar from the cell sap and eliminates possible saturation which would interfere with further sugar manufacture. At night, the starch of the chloroplasts is transformed back into glucose, through the digestive activity of enzymes, and can then pass to regions of permanent storage. In storage parts of plants, principally fleshy roots, stems, and seeds, are special colorless plastids (LEUCOPLASTS) which deposit the starch grains from the glucose in solution. $80 \%$ of the dry weight of a potato tuber is starch, which

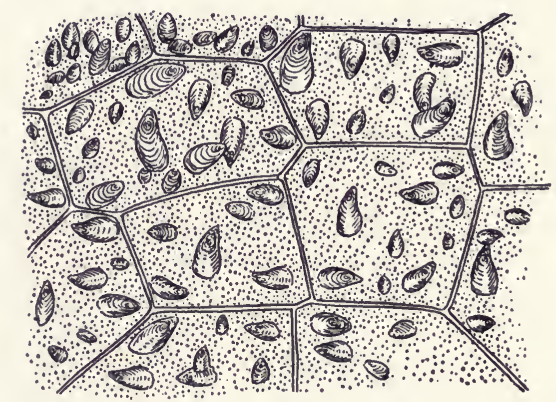

FIG. 83.-Most of a potato tuber is made up of cells filled with starch grains.

can be seen microscopically as granules gorging the cells (fig. 83). Most seeds average $60 \%$ starch. Starchy foods used by man include for the most part underground stems, fleshy roots and seeds. When eaten by animals or man, the starch has to be changed back into glucose, by the process of digestion, before it can serve as an energy food.

Another common carbohydrate derived from glucose is Cellulose $\left(\mathrm{C}_{6} \mathrm{H}_{10} \mathrm{O}_{5}\right)_{\mathrm{n}}$; this is not used by plants as a source of energy, but as a structural material in its cell walls, out of which to build its skeletal system. Wood is cellulose plus another compound, lignin - found useful by man even though indigestible. Practically pure cellulose is found in cotton fibers, which are therefore the chief commercial source of the cellulose used in industry. Cellulose is the most insoluble of all the carbohydrates; 
and is so resistant to enzyme action that few organisms can digest it except bacteria, fungi and some protozoa.

Numerous other carbohydrates, of lesser importance and less well known, are derived by plants from glucose. Dextrins are compounds intermediate between starch and maltose; they are gummy substances typified by those used in making library paste and the sticky back to postage stamps. Various GUMs, formed by the breakdown of cellulose, are used to protect stems and seeds from excessive loss of water and low temperatures. A familiar substance of this type is gum arabic. Related to the gums are the various mucilaginous substances produced commonly by numerous kinds of plants; these may act as reserve foods, may prevent excessive transpiration, or may aid in seed dispersal. The roots and flowers of the mallows produce the mucilaginous substance which forms the basis of marshmallow. In the mistletoe, the mucilage aids in seed dispersal; when a bird has eaten a berry of the mistletoe, the seeds stick to his beak. In an attempt to rub them off, the seeds are stuck firmly to a twig or a branch which will soon be the host to a germinating mistletoe parasite. Other glucose-derivatives include the PECTINs and pectin compounds produced in the cell walls of fruits; these are utilized by housewives since it is the pectin which makes the fruit juice jell. A commercial jelling compound is made from the pectins of apples.

\section{Fats and Oils}

Sugars and starches can be transformed by both plants and animals into compounds consisting of the same three elements, but these compounds - known as FATs and oILS - have greater amounts of carbon and hydrogen, less oxygen, than are found in carbohydrates. For this reason they produce greater amounts of energy when oxidized. A fat will yield two and a quarter times as much energy as a carbohydrate of the same volume. Animals store and use fats as sources of energy more commonly than plants, which utilize them chiefly as reserve foods in organs where there is a premium on space. Thus we find that most of the plants producing fats or oils use them as reserve foods in seeds in order to get as much energy as possible into a small space. 
There is no chemical difference between fats and oils; it is common practice to refer to those which are solid at ordinary temperatures as fats, and to those which are liquid at the same temperatures as oils. Fats are comparatively rare in plants while oils are very common. Oils are generally lighter than water and insoluble in it. Fats and oils are synthesized from carbohydrates through intermediate compounds such as fatty acids and glycerol; these are transformed into the more complex fats and oils by the activity of the enzyme lipase. Two common fatty acids produced by plants are formic acid, found in nettles, and acetic acid, found in vinegar. The oil first appears as droplets or vacuoles scattered through the cytoplasm of the cell. In a few plants, the oils are secreted by special plastids - the ELAIOPLASTS -which bear the same relation to fat formation as the leucoplasts do to starch production. Elaioplasts are particularly numerous in the vanilla plant and some composites. The chief commercial source of plant oils is from seeds; in this plant organ the amounts of oil vary from $4 \%$ in corn to $30 \%$ in flax, $54 \%$ in cocoa and $65 \%$ in coconuts. Familiar oils include castor oil, coconut oil, olive oil, palm oil, cottonseed oil and linseed oil.

The most common of the fats produced by plants are the WAXES - compounds resulting from the union of a fatty acid and a complex alcohol, They form the "blooms" found on leaves and fruits, which act as impervious coatings and prevent the loss of water from underlying tissues. Some plants, such as rhododendrons and magnolias, have very glossy leaves due to the abundance of wax formed on their surface. The bloom on a fruit, such as a grape or plum, is also of value in checking fungus attacks. This waxy covering prevents the rot-producing fungi from gaining entrance into the succulent fruit tissues. Strawberries picked early in the morning, for example, while this wax coat is firm and intact, rot less than those picked in late afternoon when the wax has been softened and rendered less effective by the heat of the sun.

\section{Protein Foods}

Photosynthetic glucose contains within itself all the elements -secured from air and water-necessary for forming all the 
other carbohydrates, and all the fats and oils. PROTEIns, on the other hand, are chemical compounds of the glucose elements $(\mathrm{C}, \mathrm{H}$ and $\mathrm{O})$ with nitrogen and often sulphur in addition. Thus the synthesis of proteins from carbohydrates (fig. 84) involves the intake of additional elements from the environment; these come from the nitrates, sulphates, phosphates and other minerals dissolved in soil water. The first step in the synthesis of proteins is the transformation of carbohydrates into AMINO ACIDS by the addition of nitrogen; this results from the activity of enzymes similar to pepsin of the human gastric juice. The synthesis of amino acids, which occurs only in plants, is dependent upon the absorption of nitrates from the soil. Any cell of the plant can

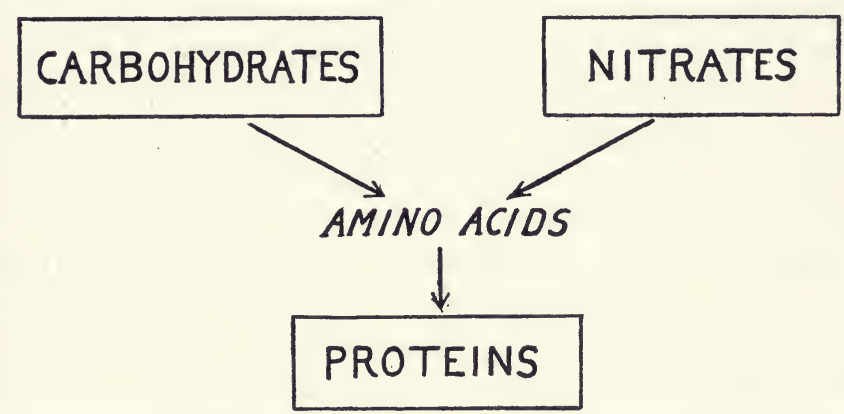

Fig. 84.-Proteins are synthesized from simple carbohydrates.

carry on this synthesis since it is independent of light and chlorophyll. Amino acids are later combined to form proteins by the addition of sulphur and in some cases phosphorus. The protein molecule is a huge and complex structure as can be seen from the atomic composition of zein, a protein found in corn, which is $\mathrm{C}_{736} \mathrm{H}_{1161} \mathrm{~N}_{184} \mathrm{O}_{208} \mathrm{~S}_{3}$.

Since proteins contain carbon and hydrogen, they can be oxidized and used as sources of energy. But they are far more valuable to plants and animals as builders of protoplasm, because of their nitrogenous character. Growth and reproduction involves formation of new protoplasm, and new protoplasm can be formed only from proteins. For this reason protein foods are particularly abundant in growing cells and in reproductive portions of plants. Plant proteins used as human food are secured 
almost entirely from the seeds of the cereals (corn, wheat, oats, rice) and of the legumes (peas and beans).

There are many different types of proteins, occurring in different forms. Some exist as part of the protoplasm of the cell, others are in solution in the cell sap, and still others are solid particles known as aleurone grains. Proteins in solution are sensitive to extreme heat or cold and, when exposed to either, frequently coagulate. Proteins can not pass through cell membranes; therefore transfer of proteins from one part of the plant to another necessitates a change to their amino acid constituents, and in this form the translocation is possible.

One group of simple proteins includes the albumins, glutelins and gliadins. Albumins are soluble in water, and are widely distributed in both plant and animal tissues, but especially abundant in cereals and legumes. Glutelins are insoluble in water, and differ from most proteins in being unaffected by heat; the commonest form exists as glutenin in wheat seeds. The gliadins are insoluble in water also; they are found chiefly in cereal seeds. The zein already referred to is a gliadin protein. In wheat flour it is the gliadin which combines with the water to form the sticky substance which holds the glutenin particles together. The resulting paste (glutenin and gliadin) is known as gluten, and gives to dough its elastic rising properties.

\section{Prgments and Other Plant Products}

Most of the activity of a green plant is concerned with the manufacture, utilization and storage of food substances; i.e., carbohydrates, fats and proteins. However, the basic carbohydrate foods are also important as the sources of numerous other complex products some of which are closely related to the sugars, others to the proteins. The most interesting of these are the ones which determine the color of plants.

Plant pigments result in a greater variety of colors than is found in the animal world; most common is CHLOROPHYLL, which gives the characteristic green hue to vegetation. Chlorophyll is an organic compound elaborated by plants, but its exact origin is not known. Chemically it is a combination of an 
acid and an alcohol, containing carbon, hydrogen, oxygen, nitrogen and magnesium. There is a striking similarity between chlorophyll and the red pigment hemoglobin which is found in blood. Both decompose to form the same products, and the chief chemical difference between the two is that chlorophyll contains magnesium and hemoglobin contains iron. Two other pigments - carotin and xanthophyll-are associated with chlorophyll. CAROTIN, reddish yellow in color, is abundantly produced in carrots, a few fruits and most orange colored flowers; chemically it is a hydrogen and carbon compound. XANTHOPHYLL, made up of hydrogen, carbon and oxygen, is more yellow than carotin. Both of these pigments frequently occur in special colored plastids, the chromoplasts. The oranges and golden-yellows of autumn foliage are due to the exposure of the carotin and xanthophyll which are not as easily decomposed by the low temperatures as the chlorophyll, which disappears as the leaf vitality wanes. If no accessory pigments are present in leavesas in the case of birches, ashes, sycamores and poplars - trees usually assume these yellow hues in autumn. The brown pigment Fucoxanthin (cf. p. 88) characteristic of the Brown Algae, is chemically related to carotin.

Some plant pigments are combinations of sugars with other substances, and are known as GLucosides. Such are the soluble anthocyan pigments found in cell sap, which are responsible for the red and blue colors found in plants. Anthocyans are abundant in the roots of beets and the outer tissues of many fruits. They depend for their formation upon the presence of sugar and of light, especially the ultra-violet end of the spectrum. Therefore fruits depend upon sunlight for development of red colors; it is a well-known fact that apples and peaches will not turn red if kept in the dark. The value of the anthocyans to the plant is not exactly known. When they occur in flowers they obviously are of value in attracting pollinating insects. In some cases the pigment may aid in screening delicate tissues from too intense sunlight; anthocyans are abundant in young foliage shoots of some trees, such as the maples. In still other cases, the pigment absorbs the sun's rays and transforms them into heat, thus protecting the plant against low temperatures. Arctic plants 
and plants of high altitudes often develop more anthocyan than plants of lower altitudes or warmer regions.

The anthocyans play an important role in autumn coloration. As the chlorophyll disintegrates and disappears, any sugar in the leaves is converted into anthocyan pigments. The reds are especially brilliant if a sudden frost, finding the sugars produced by photosynthesis still in the leaves, is followed by bright weather, since sunlight is necessary for the formation of these glucoside pigments. Plants rich in sugars, like the maples, produce the reddest autumn foliage. Ideal conditions for a predominance of reds and scarlets therefore would include (1) a sudden early frost, (2) followed by bright sunny weather (3) in a region made up predominantly of maples. These conditions are usually best fulfilled in New England, well noted for its gorgeous fall coloration.

Other substances, related to the glucosides, are known as TANnins. These are astringent substances which form insoluble compounds with tissues containing proteins; for this reason they are valuable in tanning leather. Tannins are found in great quantities in the leaves, bark and wood of oaks, hemlocks and chestnuts. Though perhaps sometimes only a waste product, tannins may be of some value as reserve foods in germinating seeds, or as bitter substances in unripe fruits, preventing animal attraction before the seeds are ready for dispersal. Their occurrence in bark suggests that they may act as antiseptic substances preventing the growth of injurious fungi. It is the excess of tannins in the leaves which gives the characteristic brown autumnal color to beeches and oaks, which are particularly rich in tannins.

Protein pigments are common among the algae. The Bluegreen Algae owe their color to the pigment PHYCOCYANIN, the Red Algae to the pigment PHYCOERYTHRIN (cf. p. 90). In the case of the Red Algae, which live at considerable depths in the oceans where only blue light is present, the phycoerythrin acts as an auxiliary photosynthetic pigment by utilizing light rays unabsorbed by chlorophyll alone.

\section{Plant Foods and Soils}

We have seen that photosynthesis produces the basic glucose and that from this all the carbohydrates and fats are elaborated 
without the addition of any other elements. Previous to this knowledge of plant physiology, men believed that the bulk of a plant was derived from materials taken out of the soil. But about three hundred years ago an interesting experiment was carried out which proved the falsity of this idea. Carefully weighed and dried soil was placed in a pot, and in this was planted a willow weighing five pounds. The pot was watered with distilled water and covered to prevent accumulation of dust. Five years later the willow was removed and found to weigh 169 pounds; but when the soil in the pot was dried and weighed again it was found to have lost only two ounces of its previous weight! Thus it was proven that plants extract most of the material for their bodies from sources other than the soil. We know today that these sources are the carbon dioxide of the air, and water.

It has long been known that plants remove some substances from the soil; only two ounces of soil were used up by the willow in the experiment just described, but the content of those two ounces is very significant. Continued growing of plants in a certain amount of soil will eventually remove certain substances essential for the life of the plant and for the manufacture of necessary plant foods. In nature such a condition rarely occurs since all the plants in an area eventually die and their bodies return to the soil what was removed during their life. Early man solved this problem of the disappearance of soil fertility by moving from one region to another after his crops had exhausted the soil.

Then man discovered that he could farm an area almost indefinitely provided he returned to the soil each season what the previous season's crop had removed. This made possible continued farming of a region by preserving its soil fertility. The importance of crop rotation and leguminous plants, in this respect, has already been noted; as has the importance of decay bacteria. Manure, wood ash and saltpeter were known to renew this fertility; though little was known of why this was so.

When the chemical nature of plant foods became known, it was possible to state which elements had to be withdrawn from the soil by plants in order to have such compounds produced. This was very evident in the nature of proteins; since these foods contained nitrogen and sulphur, the two elements must of 
necessity be secured from the soil. Analysis of plant foods and related products shows that eleven elements are present in addition to the carbon, hydrogen and oxygen found in the basic glucose. These are nitrogen, potassium, phosphorus, magnesium, calcium, sulphur, iron, manganese, boron, zinc and copper. Nutrient solutions-recently publicized as water culture of plants - have long been known to botanists; these contain all of the essential elements for plant growth, dissolved in distilled water. They usually contain definite weights of calcium nitrate, potassium nitrate, potassium phosphate, magnesium sulphate and iron phosphate.

With this more recent appreciation of what soil fertility means, it has become possible to restore to soils the amounts and kinds of chemicals withdrawn from them, in correlation with the kinds of food substances elaborated by the crop in question. Such fertilizers need include only those mineral salts which are withdrawn in great quantities by plants-chiefly nitrogen, sulphur, potassium and phosphorus. Nitrogen is returned to the soil, as we have seen, by bacteria; but it can also be put into the soil in the form of sodium nitrate, calcium cyanimide, calcium nitrate and various ammonium compounds. PHOsphorus is often restored to the soil in the form of ground bone (calcium phosphate) but this is being replaced by rock phosphates. PотAssium is replenished in the soil by addition of wood ash, seaweeds or potassium salts. Some of these substances are important in that they regulate vital plant activities, in addition to being necessary for the formation of proteins or other plant products. Phosphorus, because of its stimulation of root growth, is used for root crops such as carrots or turnips; it also speeds up the movement of carbohydrates and stimulates the formation of flowers and fruits. Potassium often determines the general health of the plant, perhaps acting as a catalyst in the synthesis of carbohydrates and proteins. Other necessary substances, such as the magnesium used in chlorophyll production, are withdrawn in such small quantities that they rarely need replacing.

From this it can be seen that green plants produce a great variety of foods and allied substances, most of which are designed specifically for use by the plants themselves. Man has 
capitalized many of these food-manufacturing processes for his own use, having discovered that the carbohydrate and protein synthesizing abilities of green plants are most essential for his own existence. But the dependence of man goes beyond the plant kingdom. No plant can produce material substance out of nothing. It is dependent upon continuous supplies of the raw materials coming from the inorganic world. Nature or man must keep the balance of reserve inorganic compounds such that plants will be guaranteed the materials out of which to elaborate the necessary organic compounds. Continual supplies of carbon dioxide and water are taken care of by nature; from them the plants can produce a continual supply of carbohydrates and fats. But for proteins and allied products, upon which protoplasm formation and thus life itself depends, the plants are dependent upon the existence of certain elements in the soil. If year after year, crops grown in a certain region are shipped elsewhere, valuable elements are being continually withdrawn; eventually the soil fertility will reach such a negligible point that crops can not profitably be grown in the region. Thus man's dependence upon plants as foods goes still farther to a dependence upon certain substances which must be present in the soil to allow food manufacture by plants; soil fertility must be kept up to a certain definite point by the addition of fertilizers. And a knowledge of just what these fertilizers must contain in order to guarantee certain crops becomes an important and practical aspect of plant biology. 


\section{Chapter 7}

\section{THE ORIGIN OF CULTIVATED PLANTS}

All of the plants known today as cultivated varieties originally existed in the wild state, although in many cases the plants have been under cultivation for such a long time - thousands of years - that they bear little resemblance to living wild relatives, nor can they with certainty be identified with their original ancestral stock. For the longer the cultivation process has continued, frequently the more unlike their wild relatives have the cultivated plants become.

Life for prehistoric man meant ranging through the forests and fields in a never ending search for plants which could satisfy his appetite, clothe him and make life more pleasant. Fruits, seeds, roots and other useful parts of wild plants were collected by early civilized man, who relied upon nature to grow the plants in her own way. From them he secured the various plant foods and allied products discussed in the preceding chapter. The prehistoric larder was filled with edible parts collected from wild plants; primitive beverages were made from other wild plants; and simple fabrics were made from fibers stripped from such native species as possessed them.

With the transition to less nomadic types of existence and the development of agriculture, man learned an easier way to get his plant products by growing the wild plants in the fields near his dwelling. Useful plants could be brought from distant and inaccessible places and cultivated near home, thus adding variety to the native species present in the immediate locality. In the carefully tended and more favorable environment, the wild plants grew to greater size and often produced more satisfactory fruits or other edible portions. At the same time, here and there in nature occurred varieties of plants with superior qualities; these choice individuals were brought to the fields and 
gardens and often served as parents for an entirely new race of cultivated plants.

Many of the food, beverage and textile plants have been under cultivation as long as there has been recorded history; some go even beyond this, so that their origin is shrouded in the mystery of prehistoric civilization. We can arrive, however, at a fairly accurate picture of the origin of most of our cultivated plants by piecing together the evidence from written descriptions and pictures left by the ancients, from the actual remains of plants found in prehistoric dwelling sites, and from a knowledge

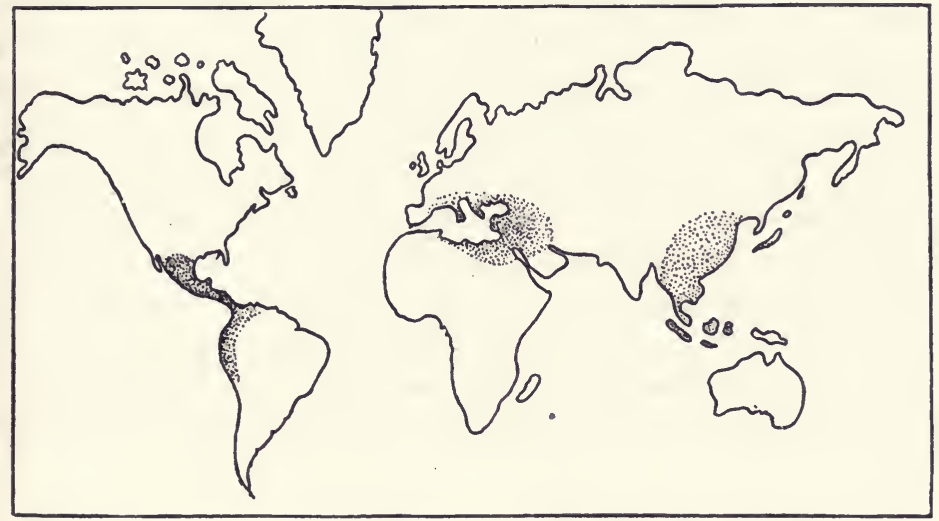

FIG. 85.-The cultivation of plants began independently in each of the three ancient centers of civilization: the Mediterranean, the Oriental and the American.

of the distribution of all the related living species of a particular cultivated plant. From these sources we can trace the course of plant migrations at the hands of man from their native homes in remote corners of the earth to our orchards and gardens, and eventually to our dinner tables.

The cultivation of plants is one of the oldest of human occupations. It began more or less independently in each of the three ancient centers of civilization-the Mediterranean, the Oriental and the American (fig. 85). Each of these civilized areas was separated for so many centuries from the others that the native species of each region had already undergone considerable change into cultivated varieties before they became known in 
other parts of the world. The plants cultivated in each region were naturally chosen from those wild species which possessed valuable products or properties. It has been only in recent times, with the development of modern means of transportation, that the cultivated plants of each of these regions have become introduced into any of the others. In some cases - as with the tomato, grapefruit, tobacco and rubber-this has happened in relatively recent times.

The Mediterranean region is the meeting place for plants originating on three continents-Europe, western Asia and northern Africa. Because of the ease of communication between these various areas, this region has been able to capitalize the cultivation of a wider range of useful species than either of the other two regions. The Oriental region (which includes Japan, China, the Malay and East Indies area) has produced relatively few cultivated vegetable and cereal plants, being most productive of fruits. The American region (North, Central and South America) has developed even fewer native cultivated plants than the Oriental region. Those that were cultivated here were unknown until after the voyages of Columbus. Little is known of the actual dates of the earliest cultivation of these American species.

\section{Cultivated Plants of the Mediterranean}

All but two of the cereal plants-maize and rice-originated in the Mediterranean region. Wheat and millet, whose ancestral homes were in Africa and Asia, were cultivated at least as long ago as 2000 B.C. Of equal antiquity is BARLEY, a native of Asia. Less ancient are OATS and RYE, which developed from species native to Eurasia at the beginning of the Christian Era (fig. 86).

This region has been very liberal with species used as vegetables in our modern diet. Longest under cultivation-dating to 2000 B.C. or earlier-have been TURNIPs and onIONS, natives of Eurasia; CABBAGE, native of Europe; and the BROAD BEAN, of Africa. Many additional vegetables were brought under cultivation in the succeeding centuries before the Christian Era: CELERY, LETTUCE and CARROTS from Eurasian species; RADISHES and BEETS 
from European ones; SPINAGH and PEAS from Asiatic ancestors. In more recent times this region has contributed HORSERADISH, PARSNIPS and PARSLEY.

\begin{tabular}{|c|c|c|c|}
\hline & EUROPE & ASIA & AFRICA \\
\hline 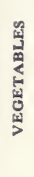 & $\begin{array}{l}\text { TURNIP-CABBAGE } \\
\text { ONION-CELERY-BEET } \\
\text { LETTUCE-RADISH } \\
\text { CARROT-PEA } \\
\text { HORSERADISH } \\
\text { PARSNIP-PARSLEY } \\
\text { ASPARAGUS }\end{array}$ & $\begin{array}{l}\text { TURNIP-ONION } \\
\text { CELERY-LETTUCE } \\
\text { PEA-CARROT } \\
\text { SPINACH } \\
\text { ASPARAGUS }\end{array}$ & BROAD BEAN \\
\hline 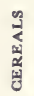 & OATS-RYE & $\begin{array}{l}\text { OATS-RYE-MILLET : } \\
\text { SORGHUM-WHEAT-BARLEY }\end{array}$ & $\begin{array}{l}\text { SORGHUM } \\
\text { WHEAT-MILLET }\end{array}$ \\
\hline $\begin{array}{l}\infty \\
\frac{\alpha}{5} \\
\frac{\alpha}{\alpha}\end{array}$ & $\begin{array}{l}\text { GRAPE-PEAR-FIG } \\
\text { ALMOND-APPLE } \\
\text { OLIVE-CHERRY } \\
\text { PLUM-STRAWBERRY } \\
\text { GOOSEBERRY-CURRANT }\end{array}$ & $\begin{array}{l}\text { DATE-FIG-MULBERRY } \\
\text { APPLE-QUINCE-PEAR } \\
\text { GRAPE-CHERRY } \\
\text { CURRANT-MELON }\end{array}$ & $\begin{array}{l}\text { WATERMELON } \\
\text { GRAPE } \\
\text { GOOSEBERRY }\end{array}$ \\
\hline 晃 & FLAX & FLAX-HFMP-COTTON & FLAX \\
\hline 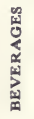 & HOPS & HOPS & COFFEE \\
\hline$\frac{0}{3}$ & \multicolumn{3}{|c|}{ POPPY-ROSE-CARNATION-LILAC } \\
\hline
\end{tabular}

FIG. 86.-A list of the cultivated plants originating in the Mediterranean region.

The Mediterranean region has been equally generous in its contribution of cultivated fruits to our menu. Almost a dozen species have been subject to cultivation for at least four thousand years. European species include GRAPES, FIGS, ALMONDS, PEARS, APPLES and OLIVES; FIGS, DATES, QUINCE and MULBERRIES originated in Asia; and Africa's gift is the watermelon. For some two or three thousand years man has cultivated the European PLUM and the Eurasian CHERRY. In the last few thousand years the European portion of this area has contributed the STRAwBERRY, GOOSEBERRY and GURRANT. Asia has yielded GURRANTS 
and cantaloups, while some gooseberries originated in Africa.

Other useful plants brought under cultivation in the Mediterranean region were textiles and beverages. FLAx can be traced back to native species found on all three continents, while HEMP originated in Asia. Both of these textile plants are of great antiquity, known to have been cultivated at least 2000 B.C. CotTon plants were cultivated independently in both the new and the old world; the old world species, originating in Asia, have been grown since the birth of Christ. Coffee-cultivated as long ago as cotton-is the beverage contributed by the Mediterranean region, tracing its ancestry to wild species of central Africa.

Flowers and other ornamental plants have an antiquity more difficult to date. TUliPS, DELPHINIUM and LARKSPURS, GERANIUMS, PANSIES, BEGONIAS and LILACS originated in the Mediterranean region at some unknown date. However the POPPY, ROSE and CARNATION can be definitely traced back to the times of the Greeks and Romans.

Thus this region, both in number of species and in value to mankind, has added considerably to our present day heritage of cultivated plants; hardly a meal is eaten but that some cereal, vegetable or fruit is used which can boast an ancestry from this meeting place of the European, Asiatic and African plants.

\section{Cultivated Plants of the Oriental Region}

The Oriental region has been less fortunate in possessing native plants suitable for use as cereals, vegetables and textiles; most of the native species have been cultivated for their fruits or used as ornamentals (fig. 87). The only cereal originating in this region is RICE; for thousands of years it has been the most important item in the diet of every Oriental. Its cultivation dates back to 3000 or 4000 B.C. TEA, of equally ancient history, is the beverage plant native to this same area. Of the vegetables originating in the Orient, the oldest (under cultivation for at least 4000 years) are the CUCUMBER and ONION; more recent is the SOY BEAN, which with rice forms the staple Oriental meal. RaDishes were also grown by the early Chinese and Japanese. 
Nature has been more liberal to the Oriental in regard to fruits. Of greatest antiquity are the APRICOT, PEACH and BANANA; all of which are supposed to have been grown as cultivated plants since 4000 B.C. The citrus fruits are considered to have become domesticated in the period between 2000 B.C. and the beginning of the Christian Era. These include the ORANGE, LEMON, GRAPEFRUIT, CITRON and LIME. More recent products of this region are the LOQUAT and KUMQUAT.

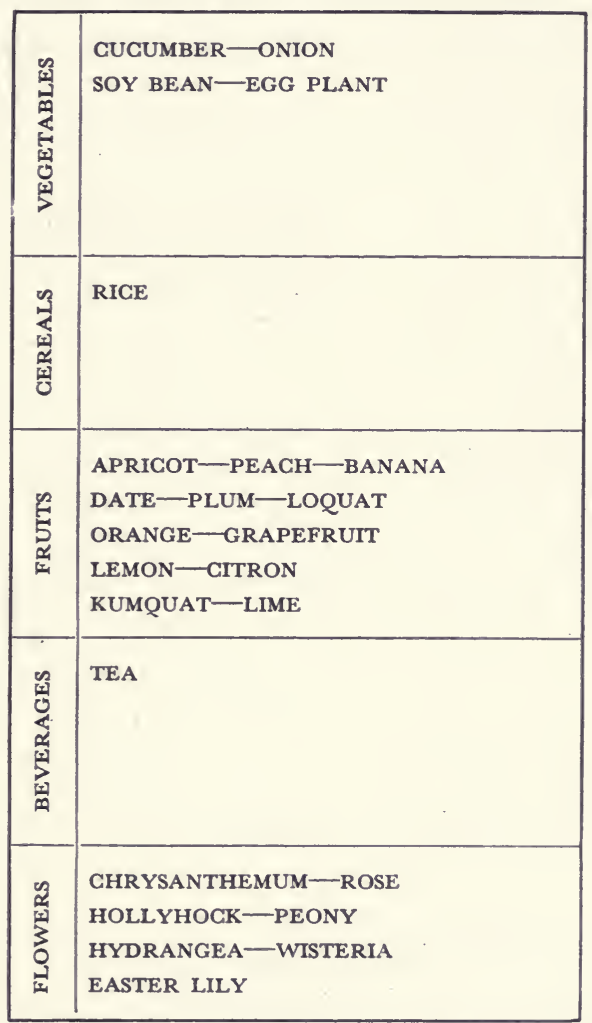

FIG. 87.-A list of the cultivated plants originating in the Oriental region.

Two of our most popular flowering ornamentals-the ROSE and the CHRYSANTHEMUM - were developed from species native to the Orient, before the birth of Christ. The Chrysanthemum is 
particularly prized by Orientals and is the national flower of Japan. Of more recent cultivated origin in this region are the AZALEA, HOLLYHOCK, HYDRANGEA, PEONY, WISTARIA and EASTER LILY.

\section{Cultivated American Plants}

It is well that Americans (using that term to designate inhabitants of the United States) do not have to depend upon native species for the variety of purposes for which we use plants. If we did, we would have no tea, coffee nor chocolate as bever-

\begin{tabular}{|c|c|c|}
\hline & NORTH AMERICA & CENTRAL AND SOUTH AMERICA \\
\hline 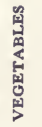 & & $\begin{array}{l}\text { SWEET POTATO-WHITE POTATO } \\
\text { KIDNEY BEAN-LIMA BEAN } \\
\text { PUMPKIN—SQUASH } \\
\text { TOMATO-PEPPERS }\end{array}$ \\
\hline 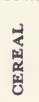 & & MAIZE \\
\hline 电 & $\begin{array}{l}\text { PLUM-CHERRY } \\
\text { CRANBERRY-BLACKBERRY } \\
\text { BLUEBERRY - STRAWBERRY } \\
\text { PERSIMMON }\end{array}$ & $\begin{array}{l}\text { COCONUT (?) } \\
\text { GUAVA-AVOCADO } \\
\text { PINEAPPLE-PERSIMMON }\end{array}$ \\
\hline 兑 & & соттоN \\
\hline 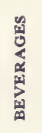 & & CACAO \\
\hline $\begin{array}{l}\frac{2}{8} \\
\frac{1}{3}\end{array}$ & DAHLIA-POINSETTIA & PETUNIA-ORCHIDS \\
\hline
\end{tabular}

FIG. 88.-A list of the cultivated plants originating in the Americas.

ages; no clothing made of cotton, linen or hemp fibers; no cereals; none of the familiar vegetables and food accessories to which we are accustomed. Our only fruits would be GRANBERRIES, BLUEBERRIES, HUCKLEBERRIES， STRAWBERRIES， BLACKBERRIES, RASPBERRIES and PERSIMMONS; unless we could eat with relish the 
tart and diminutive fruits of our native crab apples, plums and cherries. Our gardens would possess only DaHLIAS and POINSETTIAS. Although numerous plants of economic importance have originated in the new world, the great majority of these are natives of Central and South America (fig. 88).

The most important textile plant of the American region (using the term in its broadest geographical sense) is COTTON, developed in the tropical areas. Likewise from tropical America, CACAO (from which cocoa and chocolate are derived) is the new world contribution to the world's beverages. From Central and South America comes the staple cereal native to this region, MAIZE - commonly known as corn. Maize and cacao have both been under cultivation for at least 2000 years.

Vegetable foods originating in the new world include many important items of our diet. The SWEET POTATO came originally from Central America, and the white potato from South America; the former has been under cultivation the longer timeperhaps as long as maize or cacao. Other native vegetables include the KIDNEY BEAN, from which all our modern edible bean varieties have been produced; PUMPKIN, SQUASH, TOMATO, PEPPERS and LIMA BEANS.

Few cultivated fruits originated in the North American portion, except the berries and persimmons already noted. Central and South America have contributed, in addition, the PINEAPPLE and the AVOGADO.

Tropical America produced two plants which after the discovery of this continent, became of widespread importance to the human race-RUBBER and товACCO. Flowering ornamentals include PETUNIAS and most of the commercial varieties of ORGHIDS.

\section{Methods Used in Cultivating Plants}

Observant members of the human race, in their searchings for plants with useful properties, soon discovered the biologic principle that no two plants of the same species were exactly alike, or produced the same sized fruits, equally strong fibers, or beverages of identical flavor. This discovery of the universal occurrence of variations became of great importance when man 
began taking plants from their natural environment and growing them in his fields and gardens. Only those wild plants were transplanted which possessed the most desirable variations in their edible or otherwise useful parts. Some of these variations were found to be due to environmental conditions-such as amount of humus in the soil, available moisture or light; plants with such variations had no value as parental stock for cultivated plants, since such variations were not inherited by the offspring. At the same time, other variations were found to be produced independently of the environment, and to be repeated in the offspring. Thus when the early cultivators of plants also learned the other fundamental biologic truth that offspring tend to resemble their parents and to perpetuate their characteristics, they were well on their way to making plant breeding a science; even though this was centuries before the time of Mendel and the knowledge of chromosomes and genes.

The appreciation of the occurrence of variations which were heritable led to the careful selection of those wild plants whose fruits or other parts varied the most in the desired direction. Tubers, cuttings or seeds of these were chosen to start the cultivated race; and from these only the best were chosen to propagate the next season's crop. Such a process of selectionfirst from the wild plants and then year by year from among the cultivated ones-led to the elimination of those individuals with undesirable variations and to the perpetuation of those with the desirable qualities. Such selection, at first unconsciously carried out, has been the chief method by which man has produced his cultivated plants. In more recent times it has been carried out consciously and scientifically.

Scientific methods of SELECTION began in the early part of the nineteenth century. One of the first to carry out selection on a scientific basis was a gentleman farmer named LeCouteur who grew wheat on the Isle of Jersey. Becoming interested in producing a more uniform crop with more desirable grains, he began systematic selection from the varied assortment of plants in his wheat field by separating the seeds of plants with differing characteristics (such as height, size of grain, strength of stems, etc.). These seeds from plants with uniform characters were sown 
in isolated fields; each batch of seed naturally produced a more uniform crop than the heterogeneous one of the original field. This sorting out of plants was continued again in each of the new crops, plants of inferior quality being discarded and seed being chosen from the few superior plants. In time this process of selection resulted in varieties with definite heritable traits; one of these became the staple crop raised for a long time in England and France. At this same period many other plant growers in England, France and Germany were carrying out systematic selection on other crop plants. Later, in this country, such experimenters as Burbank carried on selection on a mammoth scale to produce superior plants.

The two chief methods of selection used by plant breeders today are MASS CULTURE and PEDIGREE GULTURE. In mass culture, seeds are collected from a number of individuals which show variations in the desired direction (such as larger wheat grains) and are sowed together in a given area. From the plants grown from these seeds, only the seeds of the most desirable variants are again chosen. This process is repeated for several generations until the individual plants reach the standards desired by the grower. Mass culture has been particularly successful with cotton and corn. There are objections to this method, however. It is often slow, is difficult to separate plant characteristics due to environmental factors from those due to hereditary factors, and it does not isolate the best individuals but merely raises the average for the group. Greatest objection is that this selection process must be continued indefinitely or the race deteriorates.

Pedigree culture meets some of these objections. This type of selection has long been known to animal breeders but has only recently been applied to plants. A single plant is chosen to be the parent of a new race, and seeds from it are grown in isolation to prevent chance cross-pollination with another plant. From its progeny, in turn, one most desirable individual is chosen; and by this type of selection in a few generations there may result a plant which will produce descendants with very slight variations among themselves. Such pedigree culture succeeds best with self-pollinated plants. This is the method used in preserving mutant characteristics; it has been used with great success in 
perpetuating seedless fruits, double flowers, and variegated leaves. It has been especially successful with wheat, oats, peas, beans, tobacco and potatoes.

Nature sometimes produces plants which have more conspicuous differences from others of the same species than is found in the usual variations. Such a marked heritable variation is known as a mutation; and the plant producing it is a mutant, or sport. Many of our cultivated plants originated in such natural mutants, especially among the apples. Early man discovered these sports, transplanted them to his gardens and used them as the beginning of a new line of descent. In most cases, perpetuation of the character is brought about by asexual reproduction involving the use of cuttings, bulbs or tubers, or grafting.

Within more recent times, man has not waited for nature to produce variations and mutations, but has discovered how to bring them about himself. One of the most frequent causes of variation is HYBRIDIZATION; that is, the crossing of plants with differing characteristics but belonging, in most cases, to the same species. As has been discussed in a previous chapter (see p. 72) a seed contains a plant embryo which owes its existence to sexual reproduction; half of its traits have been passed on from a "male" parent through the pollen grain, the other half from the "female" parent producing the ovule. In cross-pollinated plants, therefore, the seed (which is produced on the pistillate or "female" plant) contains some traits which bear no relation to the plant on which it is found. Hence no one can judge what the characteristics of the new plant will be by simply knowing what the seed-bearing plant was like. In nature, the pollinating parent is usually unknown and therefore the seed often germinates into a plant with unforeseen combinations of traits.

Scientific and controlled hybridization means knowing what the traits of both parents of the seed may be. As far back as 1790, a German botanist named Koelreuter took the pollen from one kind of tobacco plant and placed it upon the pistil of another variety of tobacco. This laid the foundation for the study of hybridization in breeding plants. And in the following century hybridization was used to produce as many new variations as 
possible, in order to have a greater number from which to select desirable - and often novel-combinations of traits.

Controlled hybridization makes possible the combination of several desirable traits, and means bringing into existence a plant with probable (if not certain) specifications. A droughtresistant plant with poor fruit; for example, crossed with a drought-sensitive plant bearing high quality fruit, may result in a hybrid combining drought resistance with good fruit. Luther Burbank during his lifetime "created" many new varieties in this way, especially among plums and peas. Hybridization is also of value because it results in plants with more rapid growth, larger parts and generally more vigorous constitution than either parent; such hybrid vigor is often of great importance. Burbank crossed a California walnut with the New England black walnut and produced a hybrid which grew twice as rapidly as either parent and greatly exceeded them in stature. Corn hybrids have been known to yield $50 \%$ more corn than the yield of the parents.

Thus by combining a judicious amount of hybridization with controlled selection of the offspring in every generation, patient plant breeders have been able to direct the evolution of cultivated plants. The size and color of fruits, the starch or sugar content of roots, the length of seed hairs in cotton-these are but a few of the plant characters that have been modified to man's advantage since scientific knowledge of plant heredity has made such control possible. Every year hundreds of workers are busy in genetics laboratories, in state agricultural schools and in the federal department of agriculture, with but a single aim-to improve existing varieties of cultivated plants and to create new ones. 


\section{Chapter 8 \\ VEGETABLE FOODS}

Excess food materials are stored by plants for several purposes, chief of which are to furnish future supplies of energy and growth materials, and to start the new generation in the seed with an adequate supply of food. Thus food is stored in those parts of the plant which are the longest lived. Food storage rarely occurs in such transitory organs as leaves, while roots and stems function frequently as storage organs. Underground parts of plants, such as tubers and roots, are especially well adapted for storage because of their protected position. The food stored in reproductive organs (usually fruits and seeds) is used to guarantee the growth of the embryo and to aid in its dispersal; because of the concentrated amount of food in many such organs, these parts of plants have assumed greater economic importance than vegetative organs, as sources of human food.

Vegetables in the popular sense include a widely varying number of plant parts; in this chapter the term is used to include the vegetative organs - roots, stems and leaves-used as foods or food accessories. Many fruits of the legume or berry type are considered vegetables in common parlance; these will be considered in the following chapter. The food value of the true vegetables is often low, because of the large amount of water present in vegetative organs; even so, they rank next to the cereals as a source of carbohydrate foods, which are readily digested and provide a high energy content. Proteins and fats occur in some vegetables, but in negligible quantities. Minerals and vitamins are often present in considerable quantity, and the bulky cellulose tissues give valuable roughage to our diet.

\section{Roots Used as Food}

From earliest times, roots and underground parts of plants have played an important role in sustaining human life. Such 
parts of many of our native wild plants are edible and have been used by primitive Americans on many occasions. Our cultivated root-crop plants, however, come from only four families; the Pigweed Family contributes the beet; the Mustard Family, the radish, turnip and horseradish; the Parsley Family, the parsnip and carrot; and the Morning Glory Family, the sweet potato.

The present-day wild BEET which grows along the seacoasts of Mediterranean Europe is considered the ancestral type from which the cultivated varieties have arisen. By selection, plants with fleshier and larger tap roots have been produced, in which an abundant supply of carbohydrates is stored (fig. 89). The garden beet, at first, had the white roots

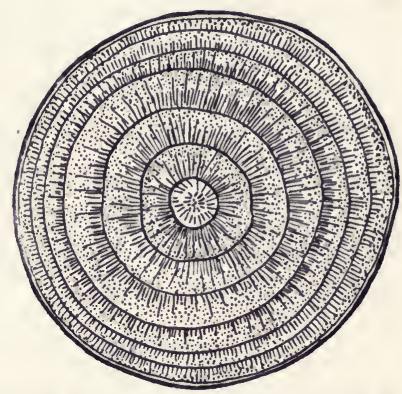

Fig. 89.-The fleshy tap root of the beet contains a supply of carbohydrates stored in alternate zones of xylem and.phloem. typical of most plants, but the red-fleshed varieties have become more popular in the last few hundred years. In the beet root, the food is stored in alternate zones of xylem and phloem pro-

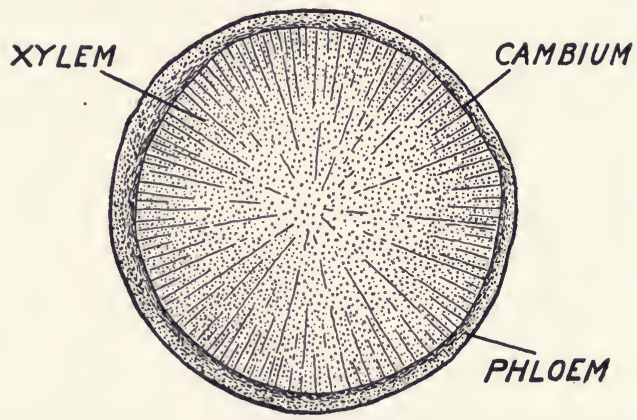

FIG. 90.-Unlike the beet, the turnip contains stored food almost entirely in the xylem portion of the root.

duced by successive cambiums, with resulting concentric rings of growth similar to the annual rings of a tree.

Turnips, like beets, are biennials forming swollen tap roots the first year and blooming the second. Originally native to 
Europe and western Asia, the turnip has become a cool-season crop throughout temperate regions. Unlike the beet, the food is stored almost entirely in the xylem portion of the root (fig. 90), outside of which is a small phloem and cortex region. The flesh of turnips varies from white to pale yellow. The cells of the xylem are not lignified like the woody tissues of many plants, hence they are soft and edible. Turnips were introduced into this country by the first settlers to come to Virginia and New England, early in the seventeenth century.

The RADISH is characterized at maturity by an elongated though smaller fleshy tap root, similar in general character to the turnip but with more food stored in the slightly larger

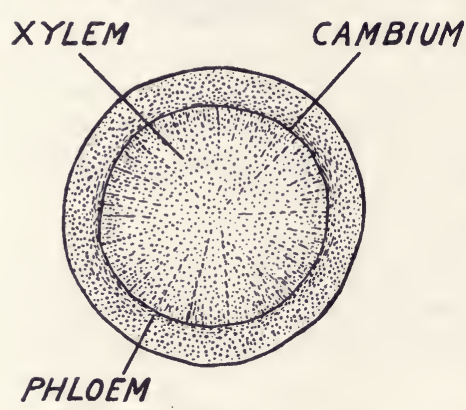

Fig. 91. -The radish is similar in general character to the turnip but has more food in the slightly larger phloem region. phloem region (fig. 91). Radishes are still found growing wild in temperate parts of the old world, from which they were brought to this country by the early English settlers. Numerous varieties have been produced with different colors of flesh and pungency of flavor.

Horseradish has a more cylindrical tap root, usually with white flesh; it has been cultivated for centuries in Europe, its native home. Unlike radishes, carrots or turnips it is not eaten as a vegetable but more usually made into a condiment after being mixed with vinegar.

Carrots, commonly found in the wild state over a large portion of the old world, have long been under cultivation in Europe and Asia. In the United States, escaped plants have made themselves at home and become wild flowers as well as troublesome weeds. The cortex and phloem region of a carrot root (fig. 92) is much larger than in the radish or turnip; in it most of the stored food is accumulated. The central xylem portion of a carrot is less nutritious and often becomes woody. Carrots vary considerably in shape, but are characteristically yellow in color due to the presence of the pigment carotin. This is some- 
times extracted and used in coloring butter; it is also a source of vitamin C. Carrots, like turnips, were introduced into Virginia and New England by the first English colonists.

The PARSNIP comes from species still found wild in the Mediterranean region, where it has been cultivated since the days of the Romans. In a parsnip root the food storage region is found in a cortex and phloem proportionately larger even than that of the carrot (fig. 93). The small xylem zone is of little importance. Escaped parsnip plants, as in the case of the carrot, have established themselves as weeds in waste places.

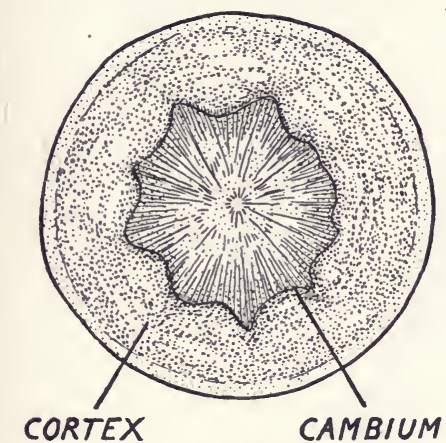

Fig. 92.- The cortex and phloem of a carrot root is much larger than that of the raddish or turnip.

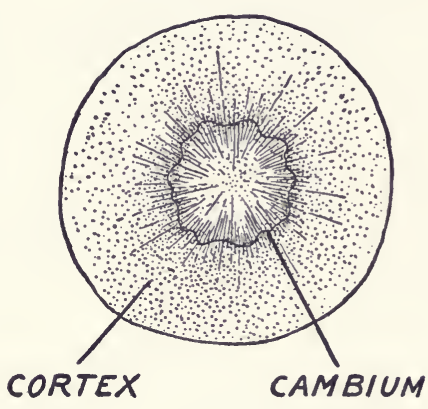

FIG. 93.-In a parsnip the food region occurs in the cortex and phloem.

The sweet potato is the American contribution to our stock of root vegetables. It is not found today in the wild state, but all of its related species are tropical American in distribution, so that the sweet potato is assumed to be a new world plant. Sweet potatoes were the plants that were first known as "potatoes"; it was much later that the term was applied to the edible tuber which since has become more widely known. Sweet potatoes were first recorded from Cuba and other islands of the West Indies, to which they had probably been transported from Central America. They belong in the same genus as the familiar morning glory, and have similar flowers and a comparable trailing habit. The thickened root has most of the food stored in the central xylem zone, as in the radish (fig. 94). Being of tropical 
origin, sweet potatoes thrive best in our southern states, where the continuous sunshine and high temperatures make it commercially worth while to cultivate as a crop. Varieties grown for northern consumption have light yellow, dry and mealy flesh; more watery varieties, softer and sweeter, are in demand in the South, where they are erroneously known as "yams." True yams are Oriental plants of an entirely different family ( $D i$ oscoreaceae) related to the lilies. A native North American species of the same genus is the wild potato vine of eastern United

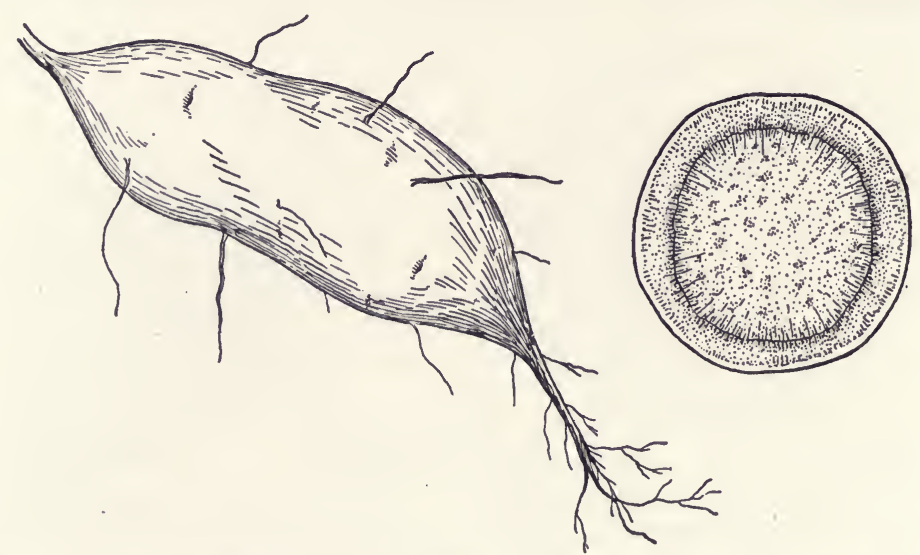

Fig. 94. - The thickened root of the sweet potato has most of the stored food in the central xylem zone.

States; this produces a huge storage root, often several feet long and weighing as much as twenty pounds. It is quite edible, when roasted; and was used as a food by the eastern Indians.

\section{Stems as Food}

Stems and leaf bases which grow entireıy above ground have never assumed great import; nce as food-storage organs; few are important food plants exce, $t$ rhubarb, a miember of the Buckwheat Family; celery, of the P. rsley Family; endive of the Composites; and asparagus of the Lily Family (fig. 95). The underground storage stem, or tuber, of the white potato (in the Nightshade Family) is the most important of all stem crops. 
RHUBARB is a large-leaved perennial with woody rhizomes which can be used to propagate the plant; the succulent and acid leaf stalks are made into pies and sauces. Over $90 \%$ of the stems is composed of water, in which are dissolved sugars and

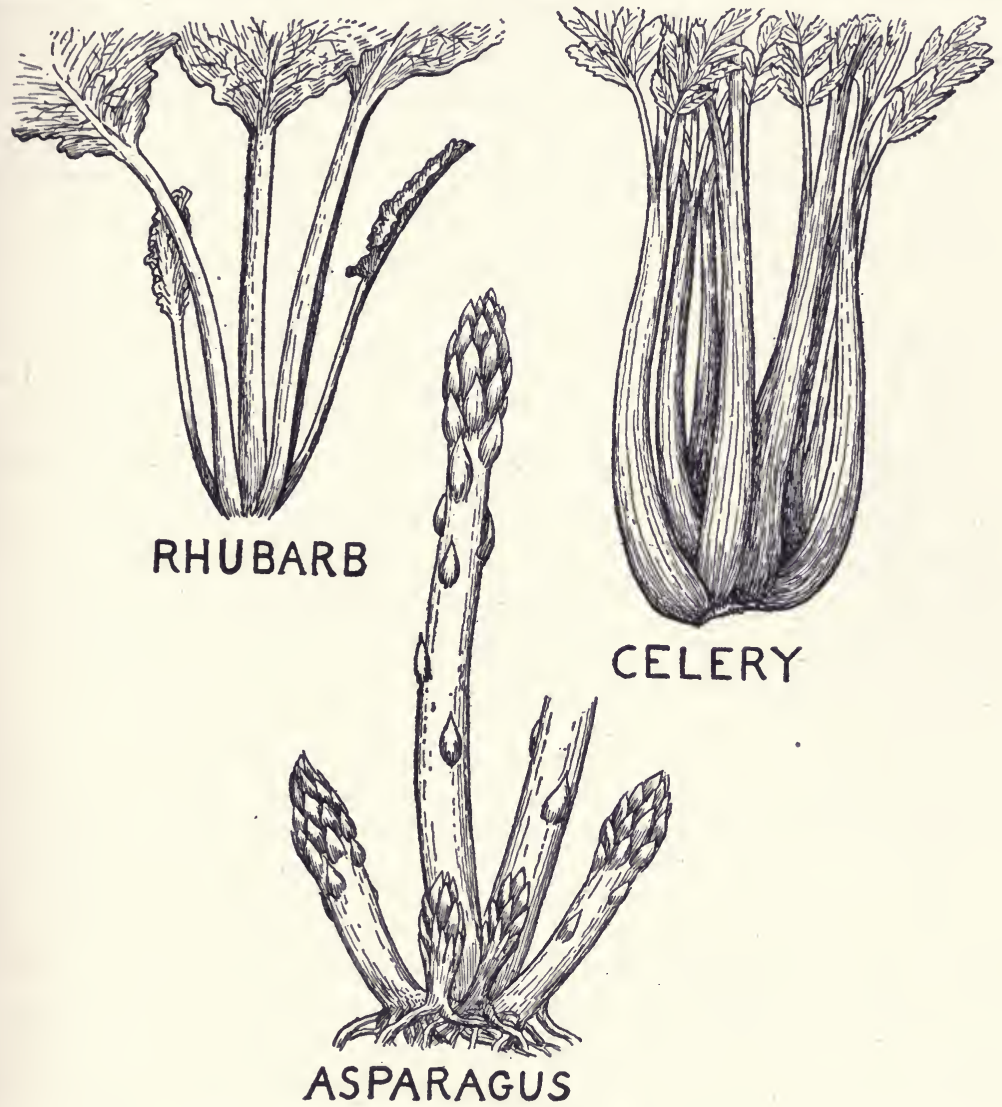

FIG. 95.-Few above-ground stems and leaf bases are important foods; exceptions are rhubarb, celery and asparagus.

salts of malic and oxalic acid. Rhubarb is still a wild plant in its native Asia.

Celery is a native of Europe, still existing in the wild state in England and the Mediterranean region, where it grows to be a rather rank and tough plant of marshes and other wet habitats. 
When cultivated, the plant is induced to form long succulent leaf stalks. As a crop plant, it requires cool moist climate, and grows best on sandy loam with plenty of available water. The green leaf stalks are blanched by covering the lower parts of the plant with earth or boards, to prevent the formation of chlorophyll. It is grown in the southern states (particularly California and Florida) as a winter crop, and in such northern states as New York and Michigan as a summer crop.

ENDIVE is one of the few composites with edible qualities, others being artichoke and lettuce. It was introduced into Greece

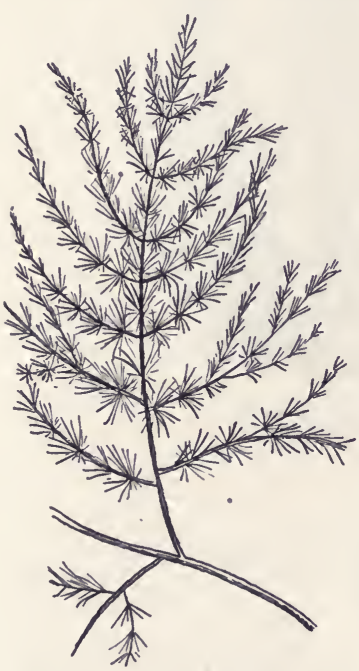

Fig. 96.- The green foliage portion of asparagus is known to florists as "asparagus fern." and Rome from its native India, and cultivated as a salad plant; recently it has become better known in the United States for somewhat the same purposes.

In the salt marshes of Europe and Asia, ASPARAGus is still found in the wild state. Like endive, it was cultivated and prized by the ancient Greeks and Romans. The perennial roots produce branching stems which are botanically interesting in that they bear no leaves but, instead, green modified branches known as cladophylls. This green foliage portion is known by florists as "asparagus fern" (fig. 96). The first new shoots to appear are thick and fleshy, forming the market asparagus. Asparagus thrives in fertile soils of moist temperate regions where there is an abundance of sunshine. Chief asparagus raising area in the United States is California; some is also grown as a crop in Massachusetts, New York, Illinois and the southeastern states. For lighter colored stalks, blanching is carried on as with celery. Dried asparagus keeps indefinitely, and some is used in this way in Europe.

Underground stems store more food than above-ground stems; this is particularly true of the white POTAтo. The underground portion of the potato plant consists of branching fibrous 
roots, and in addition slender rhizomes (which are true stems) with swollen tips growing into the familiâr tubers (fig. 97). White potatoes are therefore stems and not roots; this is evident when we realize that the eyes of a potato are really buds, and that no roots produce buds. Potato plants are usually propagated by these tubers, which will sprout after a short resting period, each eye growing into a shoot with leaves. Each tuber is made up of a thin skin, relatively narrow cortex with some starchy cells, a ring of vascular bundles and an extensive pith containing most

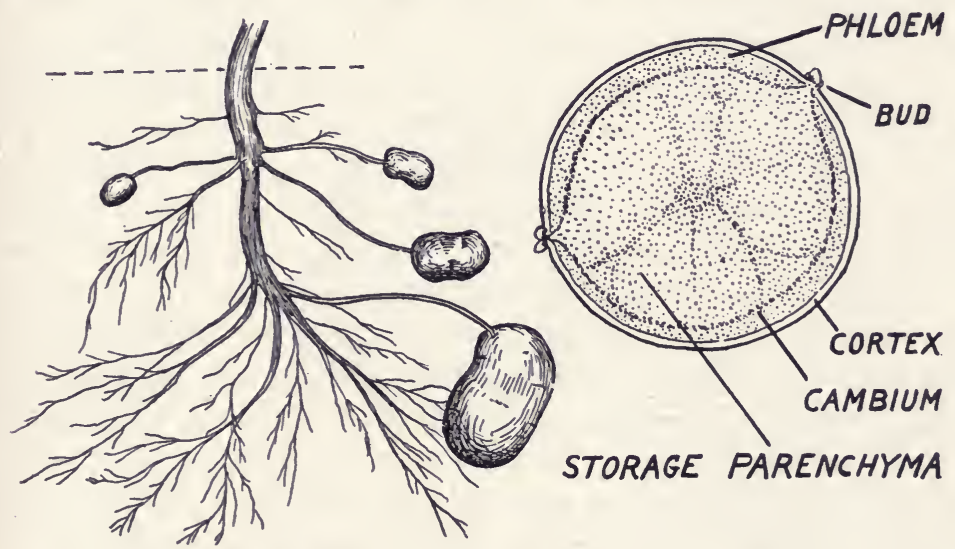

Fig. 97.- The underground portion of the potato plant consists of fibrous roots and slender rhizomes with swollen tips which grow into the tubers, or potatoes.

of the cells gorged with starch. Potatoes have a high water content $(78 \%)$, and contain about $18 \%$ carbohydrates, $2 \%$ proteins, less than $1 \%$ fat and about $1 \%$ potash. The first explorers to the New World found the natives cultivating potatoes, which are indigenous to the tropical Americas and still grow wild in Chile, Peru, Mexico and Central America. A native species occurs in the mountainous regions of New Mexico and Arizona, producing small tubers the size of marbles; this plant was prized by the Navajos and comprised a good share of their diet when other food failed. The white potato was brought to Spain by the early explorers, then found its way to England, Russia and Ireland where the potato soon become an important crop. It was brought 
back to this continent by the Irish immigrants to New England in 1719. Being native to high cool regions, potato plants thrive in northern temperate climates; they are commercially valuable crops in Maine, New York, Minnesota, Michigan, Wisconsin and Idaho. In addition to their use as food, potatoes are utilized in the manufacture of starch and alcohol.

It was the attempt to produce a better potato which started Burbank on his career as a plant breeder. After many fruitless attempts at crossing potato flowers (which usually produce sterile fruit), Burbank by chance discovered that nature did what he had failed to accomplish. In 1870 he discovered a single potato plant in his truck garden which possessed a seed-ball. He cared for these seeds until spring, then planted them; each grew into a potato plant with different traits, especially in size and quality of tubers. Two plants produced larger whiter potatoes than had ever been grown before. Burbank sold his prize tubers to a seedsman for $\$ 125$ - a fortune in his eyes at that time, since it enabled him to set out for California and his long dreamed-of work with plant breeding in that fortunate climate. On the other hand these few tubers were the beginning of the race of Burbank potatoes which in a few decades were bringing in millions of dollars to potato growers of the entire world. Today there are over five hundred varieties of potatoes under cultivation.

\section{Leaves as Food}

Although some food is stored in leaves, there is rarely sufficient to give much nutritive value to leaves as articles of human diet. Leaves are eaten chiefly for their mineral and vitamin content. Edible leaves of cultivated plants are found in the Pigweed Family-spinach and chard; the Mustard Family-cabbage, kale, Brussels sprouts, kohlrabi, broccoli and cauliflower; the Parsley Family-parsley; the Composite Family-lettuce; and the Lily Family with onions and their related varieties.

Chard is the most ancient cultivated member of the beet genus, having been grown as early as 300 B.C. in its native Mediterranean region. At first its importance lay in its storage root, as in the common beet; but selection emphasized the formation of fleshy succulent leaves at the expense of the root. The 
tender leaves and leaf-stalks of chard are used much the same as spinach. SpINACH is the commonest vegetable whose leaves are used as "greens"; originally found only in southwestern Asia, it has since become cultivated in cool moist regions throughout the world. Spinach for canning is grown in California.

One of the most diversified of plants producing leafy vegetable food is the CABBAGE species and its cultivated varieties (fig. 98).

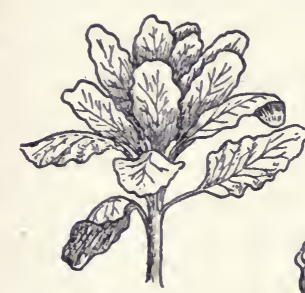

KALE

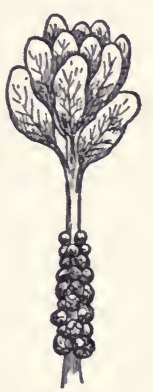

BRUSSELS SPROUTS

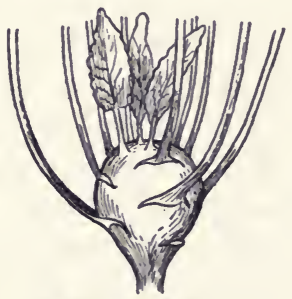

KOHLRABI

CABBAGE

\section{CAULIFLOWER}

Fig. 98.-One of the most diversified of plants producing leafy vegetable foods is the cabbage species and its varieties.

The wild ancestor is a stout and woody perennial found along the coasts of Great Britain and southwestern Europe. Its cultivation was begun by the Greeks and Romans; today it is grown practically everywhere except in the tropics. Nearest to the wild form are those varieties with a conspicuous and elongated stem such as kale and Brussels sprouts. KaLE produces numerous large leaves which are eaten like spinach; the plants themselves are very vigorous, and in England often reach a height of eight feet, with stems large enough to be used as rafters! BRUSSELS 
SPROUTS possess the peculiar habit of producing many axillary buds on the main stem, which develop into miniature cabbage heads, but more tender and delicate-flavored. In the common CABBAGE plant, the shortened stem produces a dense cluster of overlapping leaves which form a gigantic bud. There are varieties with smooth and some with wrinkled leaves, with red color as well as green. Grown throughout the world, it is sometimes known as "the poor man's vegetable" and, because of its widespread cultivation in that country, also as "the national flower of England." Like most leafy foods, cabbage is mostly water (over 90\%), with some starches, proteins and lime salts in solution. Eaten raw, it is known as slaw; fermented in brine, it is sauerkraut. Cabbage is grown in practically every state as a local crop; commercially it is produced in New York, Texas, Wisconsin, South Carolina and Florida. Kohlrabi is a variety in which the leaves form no head, and where only the enlarged turnip-like stem is eaten. Used as a human food abroad, in this country it is grown only as a stock food.

In cauliflower and broccoli the edible portion includes chiefly - flower parts. Cauliflower plants develop a large inflorescence in which the mass of flowers forms a fused head, immature when cauliflower is picked for market; a few of the leaves are usually left surrounding the flowers. Cauliflower is a cool season crop in Texas, where it is grown in late winter. BROcColi plants produce smaller heads and larger leaves; the edible portion of both leaves and flowers is green rather than blanched as in cauliflower. Both of these cabbage varieties have been cultivated for centuries, being especially prized by the Greeks.

PARSLEY, in the same family with carrots and parsnips, has also been used since the times of the ancients as a garnish and salad plant; it produces a whorl of tender dark-green leaves the first season, which are the edible portion of the plant.

LETTUCE has wild relatives living today as common roadside weeds in both the new and the old worlds. The cultivated varieties are derived from south European and western Asiatic stock. Nearly all the varieties grown today were known in Europe before the Middle Ages. Lettuce is also a cool season crop, preferring elevated plateaus and mountainous regions. Since 1900 it 
has been grown as a crop in California, Arizona, New York and Colorado; in almost every state, it is a common local vegetable. Several hundred varieties are now cultivated.

A shortened stem with closely packed thickened leaves stored with food (in reality a large bud) is known as a bulb. The onION genus (fig. 99) is one of the few bulbproducing plants with edible qualities. The garden onion has been cultivated such a great length of time (over 4000 years) that its occurrence in the wild state is now unknown. From its native home somewhere in Asia it was brought to China and India as well as the Mediterranean region. Onions grow best in cool moist climates, in sandy soils. Drying and storing the fleshy bulbs for some time before using brings out the flavor, which is due to an acrid volatile oil. Since this oil is freed by heating, cooked onions are much less strong than raw ones. Bermuda, Spanish and Italian varieties are known for their more tender flesh and milder flavor. Commercially, these are grown in Texas and California.

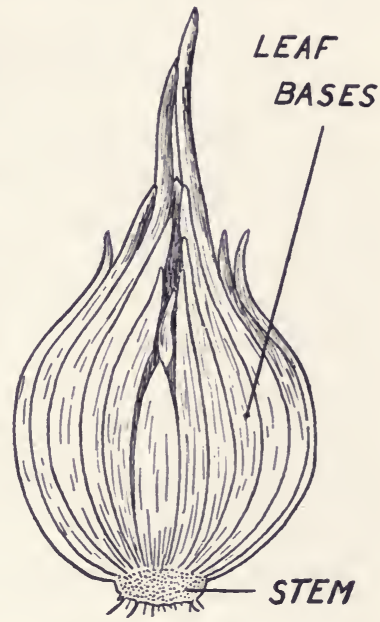

Fig. 98.-The onion genus is one of the few bulb-producing plants with edible qualities.

Many of the several hundred known species in the onion genus are native to North America, some being common weeds.

Close relatives of the onion are GARLIC, LEEK and CHIVES. Garlic develops smaller bulbs, covered with a white skin; a native of southeastern Europe, it is used as a seasoning especially in this part of the Mediterranean region. Leek is another Mediterranean species, whose thick flat leaves are used as well as its small bulbs. Chives has hollow cylindrical leaves which, with the small bulbs, are used for seasoning.

Such are the most common of the vegetative organs of plants used as foods. Some are roots, some are underground stems, others are above-ground stems and leaves. In all cases they function as storage organs for the plant, and in this way are of use to the plant itself. But what is food for a plant is also food for 
man; and there is little doubt that these easily-secured portions of plants formed a staple part of the diet of prehistoric man. With the coming of civilization, and a knowledge of plant breed-

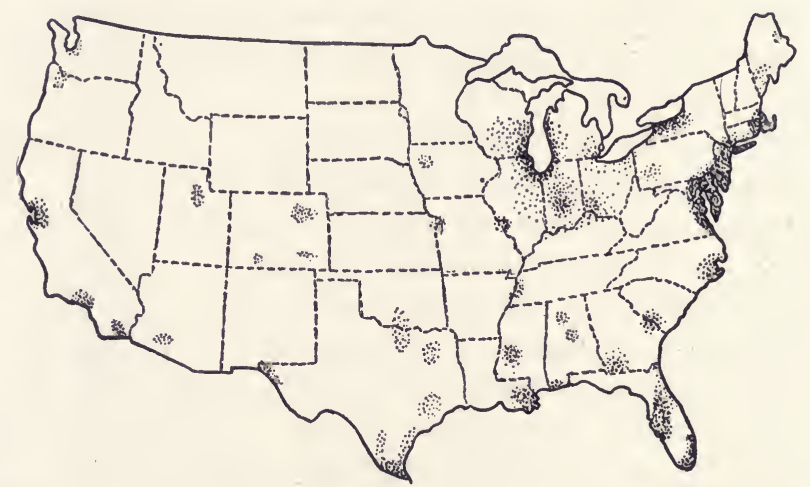

Fig. 100.-Distribution of acreage of vegetables grown for market in 1930 . ing, the original storage organs have been induced to grow in size and to increase their food content. The result is the variety of earth and leafy vegetables which we use today (fig. 100). 


\section{Chapter 9 \\ THE CEREAL FRUITS}

The storage of food in reproductive organs has been a fortunate habit of plants, from the human viewpoint; for what is food for a developing plant embryo or for a hungry animal is also food for man. Fruits, because of their high water content, actually afford small amounts of energy-giving or protoplasmbuilding material; however, they furnish an abundance of vitamins and minerals and add a pleasing variety to human diet. Seeds, on the other hand, have a low water content and store a considerable amount of nutrient material in a small space. From time immemorial seeds have played an important role in sustaining human life.

In Chapter 3 the various post-fertilization changes in a flower were discussed, with the ensuing formation of the fruit. The typical fruit develops from the enlarged ovary of the pistil while the ovules become seeds, buried in the tissue of the fruit. In some cases the maturing ovary forms a thin dry coat which protects the seeds, in other cases it becomes thick and fleshy. Thus there are two common types of fruits: dry fruits, usually adapted for dispersal by wind or mechanical means, and fleshy fruits dispersed by animals. There are numerous kinds of dry fruits (fig. 101), but only two of these are of any significance as foods. The ACHENE is considered the simplest type of dry fruit, being a small one-seeded fruit which does not split open at maturity; this is typically seen in the Buttercup Family. In a modified type of achene known as a CARYOPsis the thin-walled fruit adheres firmly to the seed coat, so that it is difficult to differentiate between fruit and seed. The caryopsis, represented by the grain or kernel found in the cereals, has become one of the most important of human foods. True NUTS are also one-seeded modified achenes. Some dry fruits contain several seeds, others many; 
of these the POD is the only type which is of food importance. A pod splits open at maturity along sutures which extend longitudinally on either side of the fruit. In some cases the pod itself is fleshy and eaten with the seeds, as in the string bean. Pod fruits are typical of the legumes (Chapter 10).

All of the preceding are sometimes known as simple fruits because they develop from the single pistil of the flower. In

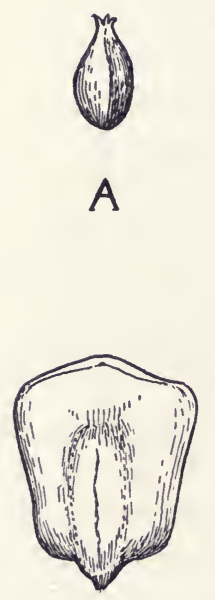

B

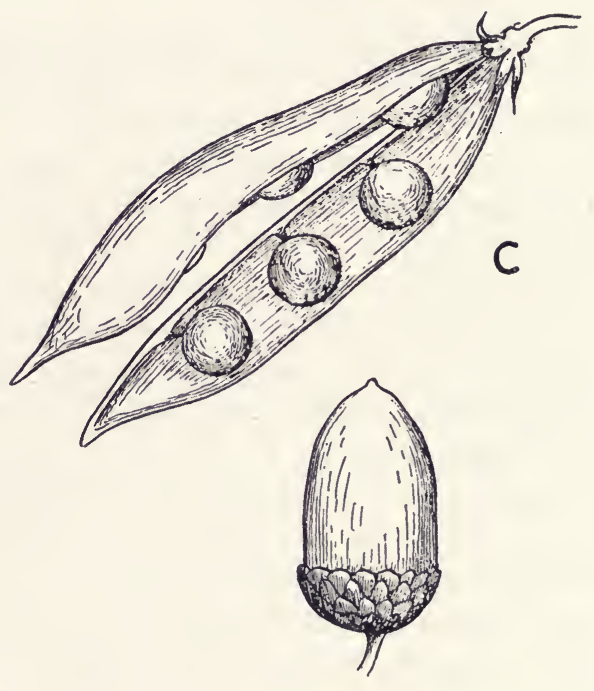

D

Fig. 101.-Dry fruits include achenes, such as that of buckwheat (A); the caryopsis, such as that of corn (B); nuts (acorn, D); and pods (pea, C).

AGGREGATE fruits more than one pistil is involved in fruit formation, so that after fertilization has taken place the ovary of each pistil develops into a small fruit side by side with those of other ovaries of the flower, on a common receptacle. Raspberries and blackberries are such fruits. In other fruits, the calyx or the receptacle aids the ovary in fruit formation; these are known as ACCESSORY fruits, typical of apples, pears, strawberries and figs.

The most important of the dry fruits, from the human food aspect, is the caryopsis of the cereal grasses. Like other members of the Grass Family, the cereals have long tapering parallel- 
veined leaves, possess a fibrous root system which often forms a matted mass, and develop a highly specialized type of windpollinated flower known as the spikelet which lacks colored petals and sepals and which produces a caryopsis fruit. Cereals thrive in regions where there is too little rainfall for woody plants and forest crops. They also grow in a wide range of climate; the cooler temperate regions are suitable to barley and rye, the warmer temperate regions to wheat, and the tropics to maize and rice. Since prehistoric times cereals have been such important food plants that they have figured largely in primitive religious festivals. The ease of planting and cultivating the crop, added to the keeping qualities and facility of transportation of the grain, have made cereals the ideal food plants on all continents for all races of man. The grains are very nutritious, being composed of a greater percentage of carbohydrates than any other plant food, at the same time containing proteins, fats and vitamins.

\section{Wheat}

WhEAT is an annual grass which has been cultivated for such a long time that its wild prototype and ancestral home are a matter of conjecture. Wheat was grown in China in 2700 B.C., and by the lake dwellers of Switzerland during the Stone Age; it was also grown by all the early civilized races in the Mediterranean region, at least 4000 B.C. A species which resembles closely the possible wild type, known as EMMER WHEAT, grows in Syria and Palestine; this is produced as a stock food in some of our western states, since it grows well even in dry mountainous regions. The original home may have been on the plateaus of central Asia. Wheat was brought to Mexico in 1529 by the Spaniards and to New England by the English in 1602.

The spikelets of wheat are clustered in groups of fifteen to twenty on a zig-zag axis, forming an elongated terminal spike. After pollination each spikelet produces the grains, or fruit. Each grain is elliptical in shape and cream, red or purple in color. The fruit and the seed coats form the husk or bran, which is particularly rich in proteins. The remainder of the grain is 
the seed proper (fig. 102) and consists of an embryo, which occupies about $6 \%$ of the seed, a relatively large endosperm region

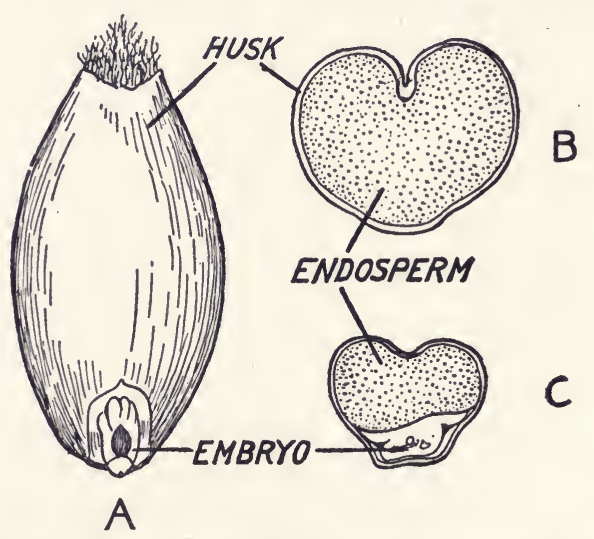

Frg. 102.-The fruit and seed coats of wheat form the husk or bran; the remainder is the seed proper, consisting of embryo and a large portion of stored food or endosperm. A, grain from embryo side; B, cross section above region of embryo; C, cross section at embryo region.

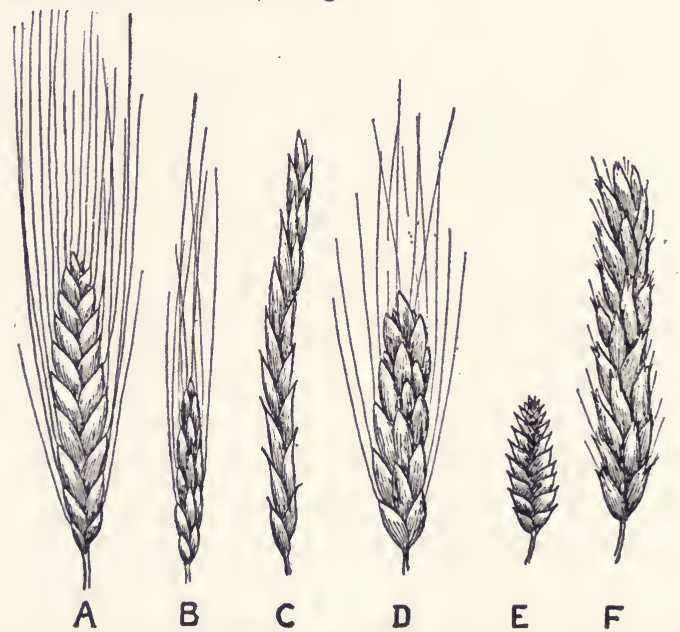

Fig. 103.-Of the numerous types of wheat, the most common include emmer (A), einkorn (B), spelt (C), durum (D), club (E) and bread (F).

rich in starch ( $85 \%$ of the seed) and an aleurone layer of cells with stored protein food, making up about $4 \%$ of the grain. 
Eight main types of wheat are known today, some comprising dozens of varieties (fig. 103). Longest under cultivation and therefore perhaps the most primitive types are the emmer, einkorn and spelt wheats characterized by grains which do not separate easily from the husks. Emmer wheat, already noted, is grown in Spain, Italy, Germany and Russia. EINKorN wHEAT thrives on poor soil, and even though a small plant with low yield, it is valuable in its ability to grow where other wheats find it difficult to survive. It has been used in southern Europe since the Stone Age; in the United States it is grown occasionally for fodder. Spelt wheAt is hardy and grows on the poorest soils;

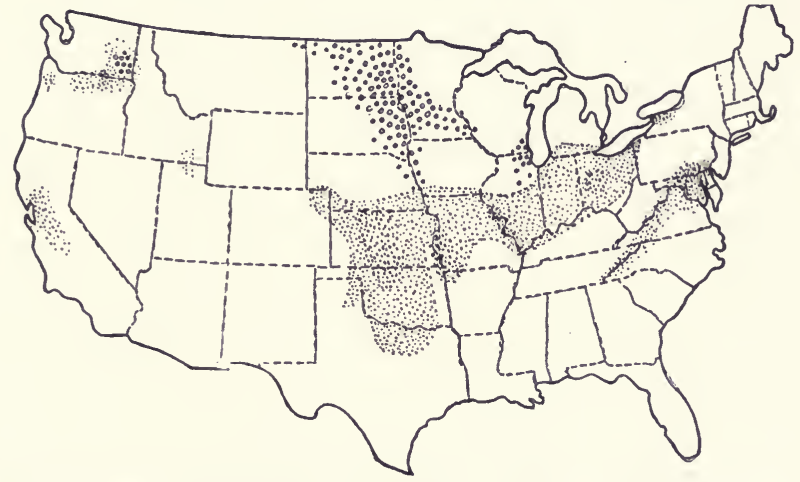

Fig. 104.-Distribution of acreage devoted to winter wheat (dots) and spring wheat (circles) in 1930.

it is a Mediterranean variety, being cultivated particularly in Spain. In the United States it is grown to only a slight extent, as a live stock feed.

The kinds of wheat cultivated in the United States are predominantly derived from the Polish, poulard, club, durum and bread wheat varieties. Polish wheat, recognized by the large papery bracts covering each spikelet, has not proven very satisfactory; the plants attain a considerable size and grow vigorously, but have a low yield of grain. The same is true of the POULARD WHEAT varieties, which are more popular in the Mediterranean countries than in the United States. Club wheAts are grown in the Rocky Mountain and Pacific coast states, mostly for pastry flour and export. Most of the American crop, however, comes 
from durum and common bread wheats. DURum wheAt has thick spikes of grains which are rich in gluten and therefore used chiefly in making macaroni and spaghetti. It is a hardy, droughtresistant variety introduced into this country from Russia and grown in the northern plains states (Minnesota and the Dakotas). Durum wheats constitute about $6 \%$ of the domestic crop (fig. 104).

There are several hundred varieties of the common BREAD WHEAT: "hard" varieties have small grains rich in proteins, while "soft" varieties have larger grains rich in starch; "spring" wheats are sowed in spring and harvested in late summer, while "winter" wheats are sowed in autumn, survive the winter and mature for an early summer harvest. Soft winter wheat, used as a pastry flour, comprises about a third of the national crop; it is grown east of the Mississippi and in the Pacific northwest. This was the variety grown in the first American wheat belt, which extended from Delaware and Maryland to New York; it was also brought into the Ohio Valley wheat region. After the Civil War, the ideal wheat-raising country of the plains was discovered, with a temperate climate and not too much rain (over thirty inches annually is detrimental to wheat), and with a suitable clay and loam soil. In the plains states, soft winter wheat is replaced by hard winter wheat and hard spring wheat. Hard winter wheats, constituting about $40 \%$ of our domestic crop, are grown in the central and southern plains region (Kansas, Nebraska and Oklahoma); the spring wheats are raised farther north in Minnesota and the Dakotas, and make up about 20\% of the annual harvest of wheat. Both these types are used in making bread flour.

The growing and harvesting of wheat has become a largescale industry with mechanical aids supplanting hand labor. On the rolling prairies of the midwest, machines plant the seed, other machines weed and plow the furrows; harvesting, threshing and transportation to the storage buildings is done by machines. On large farms the combine is used-a traveling factory which reaps, cleans, threshes, sorts the grain and even leaves it in bags along the forty-foot wide swathe cut by the machine. Some $50,000,000$ acres of American soil are under cultivation for wheat, 
producing about $600,000,000$ bushels annually. The per capita consumption of wheat is greatest in Great Britain, Canada, Australia, France and the United States; in the latter amounting to $4 \frac{1}{4}$ bushels annually. The milling of wheat results in different kinds of flour depending upon the amount of the kernel used. Standard white flour uses only three quarters of the grainthe nutritious bran, aleurone layer and embryo being removed. Whole wheat flour, in spite of its name, uses only part of the bran, but all of the endosperm. Graham flour is made from the entire kernel, and includes all of the nutrients of the bran as well as the complete endosperm and embryo. Wheat is not only milled into flour, and used in the manufacture of macaroni and spaghetti; from it is produced breakfast cereals, alcoholic beverages, industrial alcohol (cf. p. 397) and sizing starch. The wheat straw is used for packing, stuffing mattresses, making wickerwork and hats.

\section{Maize}

The New World's contribution to the cereal crops is MAIze, or "INDIAN CORN" as it was called by the first white men when they saw it under cultivation by the Indians. Since "corn" is a general term used in England and other countries to designate any hard edible seed or kernel, it is more accurate to refer to what Americans usually call "corn" by its native and more specific name of maize. The exact place of origin of maize is unknown, as is its wild prototype. A maize-like plant known as teosinte grows in Mexico, and this is sometimes considered a possible wild relative. It is probable, however, that maize originated in Central America and was carried from there by prehistoric Indian tribes north into Mexico and south into South America. Maize was being cultivated at least 2000 years ago by the Indians of our Southwest, and had become a common Indian crop as far north as the Great Lakes when the first settlers reached that region. Maize was brought to Europe by Columbus, and to Asia by the Portugese; in both regions it was found adaptable to a diversity of soils and climate, surprising in view of its tropical ancestry. 
Maize (fig. 105) is the tallest of the cereals, growing to a height of fifteen feet. Its stems, unlike those of most grasses, are solid and firm; its flowers, also different from those of most grasses, are of two kinds - staminate and pistillate. Staminate flowers, producing the pollen, are clustered on the upper parts of the plant, forming plume-like tassels. The pistillate flowers

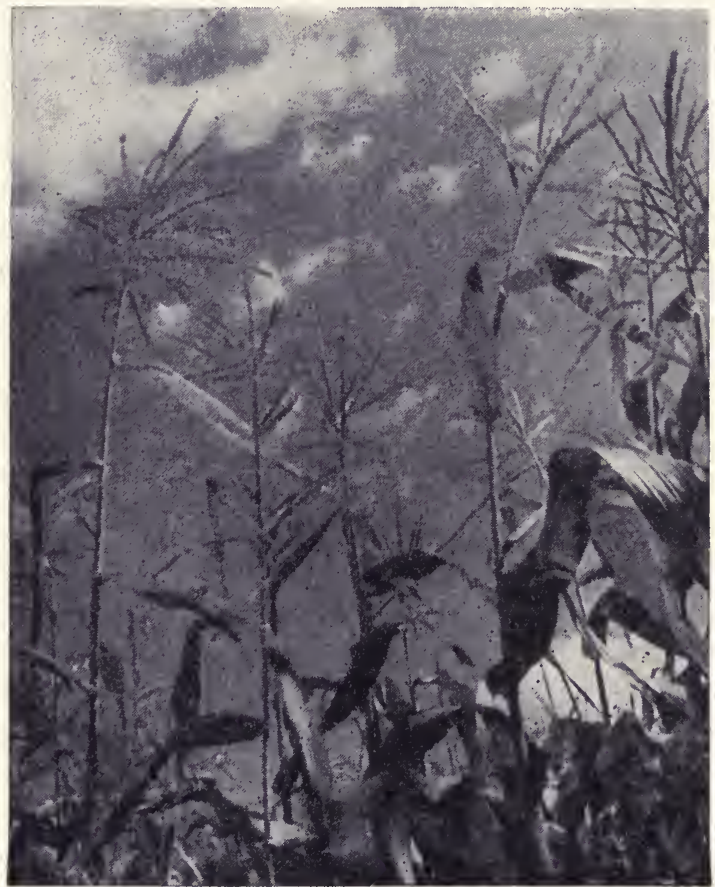

Fig. 105.- Maize is the tallest of the cereals, often growing to a height of fifteen feet; the staminate flowers form tassels at the tips of the stems.

are arranged on a thickened axis (the cob) and enclosed by leafy husks. Thread-like projections of each pistil extend beyond the husks, and are known as the "silk." In order to have fruit-formation take place, a pollen grain must fall on a strand of the silk and grow through it to the ovary, arranged with hundreds of other ovaries in rows on the cob. Each kernel of corn is therefore a separate fruit. The grains, or kernels, vary in color, shape and 
size; most familiar being the creamy yellow tooth-shaped and flattened kernel with an indented end. The embryo is tucked into one corner of the seed, endosperm occupying the remainder of it (fig. 106). The embryo is rich in oil while the endosperm contains chiefly carbohydrates.

Maize requires less moisture than wheat, though there is some difference in rainfall requirements of different varieties. It is dependent upon considerable summer sunshine and grows best in fertile riverbottom soil. Thus maize thrives in the Mississippi valley "corn belt" states of Illinois, Indiana, Missouri, Iowa, Kansas and Nebraska. There are only a few commonly cultivated types. Dent maIze is the most widely planted, its kernels having a large and starchy endosperm; it is the source of the commercial grain as well as most of the fodder and ensilage used in the United States. As a fodder plant maize is ideal for livestock, the pork industry alone using about $40 \%$ of the domestic output,

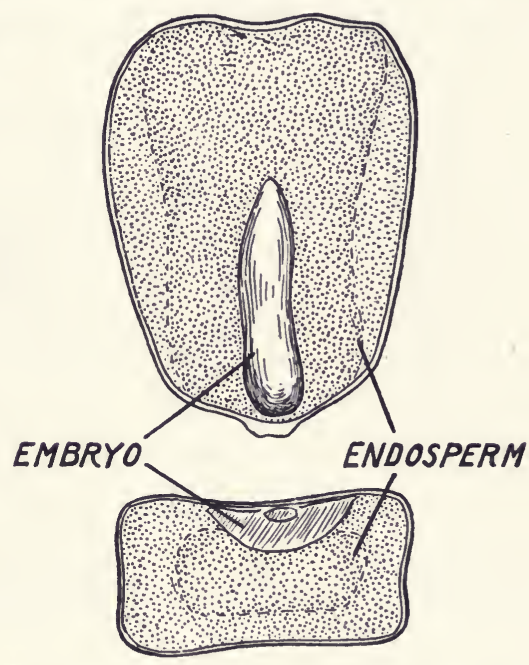

Fig. 106.-In the maize kernel the embryo is tucked in one corner and the endosperm occupies the remainder of the seed.

while cattle and horses are also fed upon it. It is said that ten pounds of maize will make one pound of beef or two pounds of pork. SwEet maIze, a variety with sugary endosperm, is capable of being grown in cooler areas than the dent varieties; it is grown for table, consumption and for canning, chiefly in the northeastern states. FLINT MAIZE is a variety with a hard outer endosperm region enclosing the softer endosperm and the embryo. This matures early and hence is grown in New England and other northern states which have a short growing season. POP MAIZE is characterized by small oval hard grains with tough coverings. This outer coat holds in the moisture 
when the grain is heated with the result that the steam formed causes an explosion which turns the kernel inside out, producing the familiar pop corn (fig. 107).

Maize is of little importance as a human food; some is made into corn meal, but being poor in gluten it does not make a coherent and satisfactory flour. Mush, scrapple and hominy are a few of the American foods which use corn meal as a basis. Some maize finds its way into prepared breakfast cereals. But

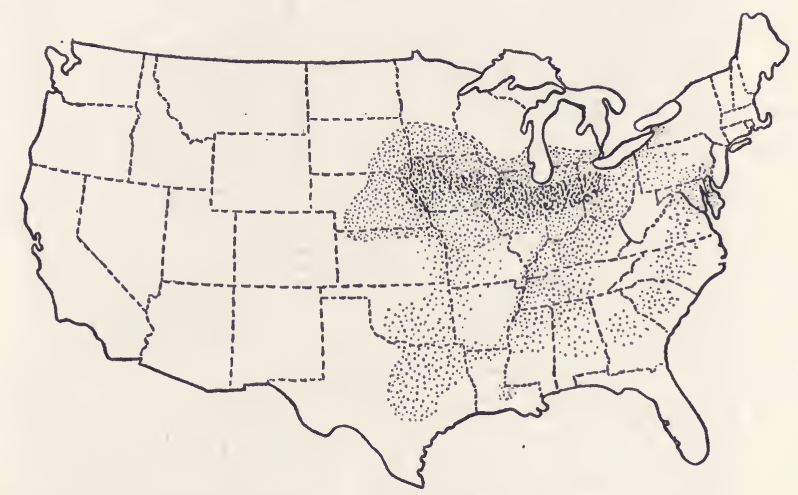

FIG. 107.-Distribution of acreage devoted to growing maize commercially (1930).

far more goes into various industrial uses (see p. 396), in making oils, starches, gums, alcohol, explosives, paper and charcoal.

\section{Rice}

RICE, the only cereal food available to tropical and Oriental countries, is a swamp-dwelling grass originally native to southeastern Asia, cultivated in China and India for at least 4000 years. From there it spread to Syria and North Africa, reaching Europe in the fifteenth century and America in the seventeenth when it was brought to North Carolina.

Rice is an annual which grows to a height of four feet, reproducing by a branching inflorescence known as a panicle, each branch terminating in a single grain with its husk (fig. 108). Rice thrives in hot moist tropical regions and is usually cultivated 
on rich soils which can be periodically flooded, since water hastens the germination of the seed. When the rice is ready for harvesting, the water is drained off the fields and stalks are piled up to dry. In the United States rice is grown in Louisiana, Texas, Arkansas and California - the Sacramento valley of the latter being particularly well fitted for its cultivation (fig. 109).

In milling rice the grain is pounded in mortars to remove the bran and the embryo; the white portion of the rice remaining is then scoured, polished and given a glossy coating of glucose and talc. Unfortunately these operations remove some of the nutritious portions of the grain; such polished rice is chiefly starchy or sugary, while whole rice includes in addition proteins, fats, and vitamins.

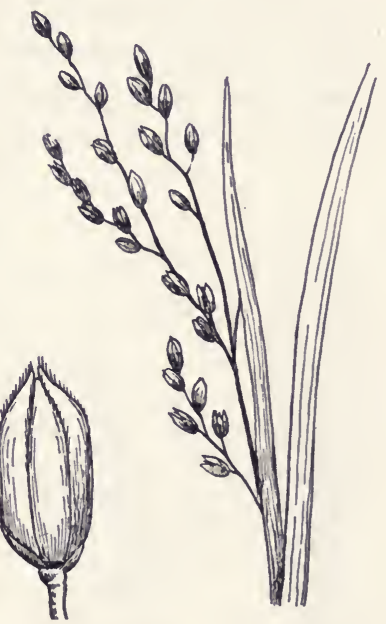

Fig. 108.-Rice has a branching inflorescence known as a panicle. The chief use of rice is for food, being eaten by over half of the world's population. But in addition it is made into the Japanese

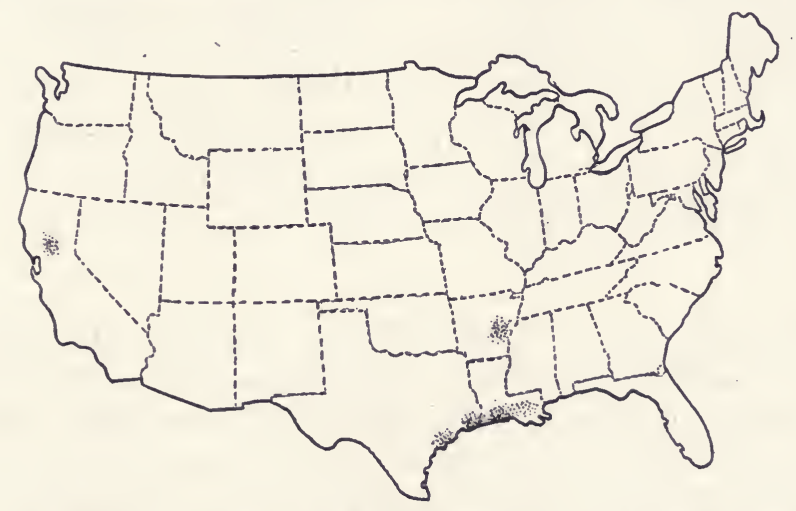

FIG. 109.-Distribution of acreage devoted to growing rice.

beverage known as saké and the straw is used in the manufacture of paper, hats and fiber board. 


\section{Barley}

Next to wheat, BARLEY is the most widely cultivated cereal crop; it is also of great antiquity, having been used for bread even before wheat. Barley, indigenous to southwestern Asia and northern Africa, was known to all the early civilizations of the

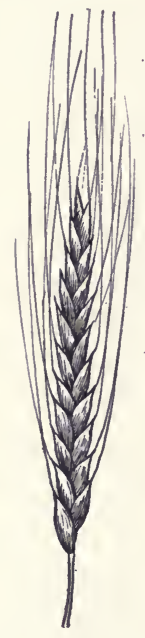

Fig. 110.-Barley plants produce spikelets with bearded bracts: grain on right, inflorescence on left.

Mediterranean region. Being an exceedingly hardy cereal, it can be grown at high altitudes in mountainous regions as well as farther north than wheat, maize or rice. The genus to which barley belongs includes several native American grasses, among them the familiar squirrel-tail grass. Barley plants seldom grow taller than three feet, and produce spikelets with conspicuously bearded bracts (fig. 110). The grains are similar in structure to the other cereals, and are often colored and enclosed in a husk. Barley contains little gluten, hence it can not be made into a light bread. Even with this handicap, until the sixteenth century it was the staple bread flour throughout northern Europe. Today most of the barley is grown in Russia and Germany. The domestic crop is raised in Minnesota and the Dakotas, to be made into malt for extracts and beverages (see p. 242).

\section{Rye}

RYE, like barley, tolerates colder climates than the other cereals. A native of the Black and Caspian Sea region of central Eurasia, rye is primarily a European crop. It resembles barley in habit, but has leaves and grains similar to wheat (fig. 111). Rye plants grow to a height of five or six feet. Cultivated rye is a cereal of relatively recent origin; for although it was known to the Greeks and Romans, it was not grown by them. Since the grain contains gluten, rye flour can be made into a rather 
heavy bread; it is still used extensively for this purpose in Russia, Germany and other Old World countries. In the United States rye is of little importance, being raised only in the Dakotas and Minnesota. Rye is also used for hay, and its straw is used in making paper and other products. The grains are used in making whiskey and alcohol.

\section{Oats}

No near relatives of the cultivated OATs are known, so its exact origin is uncertain; it may have had several ancestral homes - in Ethiopia, in the Mediterranean region or in China. Oat plants grow to a height of five feet, with open panicles like those of rice, bearing numerous spikelets which
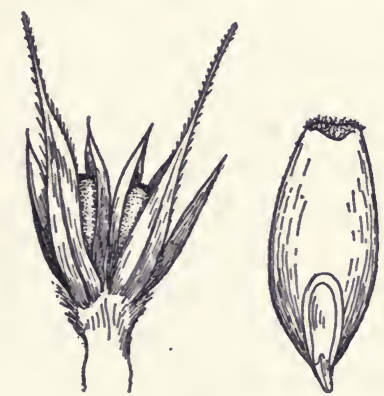

Fig. 111.-Rye resembles barley in habit but has grains similar to those of wheat; spikelet and grain figured above.

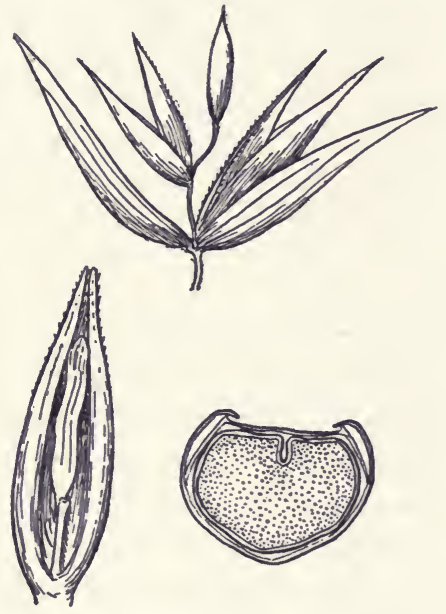

Fig. 112.-Oat plants bear open panicles like those of rice; spikelet, grain with hull, and cross section of grain figured above.

produce the grains (fig. 112). Oats are very nutritious, since they contain a considerable amount of fat and protein as well as carbohydrates. Lacking gluten, oats can not be made into a bread flour, but are used as a breakfast cereal. Three quarters of the domestic crop is used locally as feed for horses and other animals. The United States leads the world in oats production, though it is a crop also in Russia; the American crop is raised chiefly in Iowa, Illinois and Minnesota. 
Chapter 10

\section{LEGUMES, BERRIES AND SMALL FRUITS}

Somewhat intermediate between the small dry fruits of the cereals and the large fleshy fruits of the familiar orchard crops are the fruits used as vegetables or as occasional table fruits. These include the pod fruits of the legumes or Pea Family, the true berry fruits of the Nightshade and Grape Families, the modified berry fruits of the Saxifrage and Huckleberry Families, the aggregate or accessory fruits of the Rose Family, and the pepo type of fruit of the Gourd Family.

\section{The Legume Fruits}

The Pea Family, because of the nutritious food stored in the seeds of its pod-like fruit, ranks next in importance to the Grass Family in providing sustenance for practically all the races of mankind. Legumes rank with the cereals in the high protein content of their seeds; and like them, have such a low water content and impervious seed coats that the seeds can be stored for future use. In many countries the legumes take the place of meat in the diet of the poorer classes. The stored food is found in the two large cotyledons of the embryo, which form the elliptical "halves" of a kidney bean or the more hemispherical sections of a pea.

The member of the family of most ancient cultivated lineage is the BROAD BEAN which was the only bean cultivated in Europe before the time of Columbus. A native of Algeria and southwestern Asia, its flat pods and large brown seeds were familiar to inhabitants of the Old World for several thousand years before the time of Christ. Except as a forage crop, it is not grown to any extent in the United States.

Another ancient genus of legumes is the soy BEAN (fig. 113) of southeastern Asia of which over a thousand varieties have been 
cultivated in the Orient for the past several thousand years. Soy bean plants are low and bushy, producing pods and seeds which are considered by some to be the richest vegetable food known to man. Flour made from it has such a low carbohydrate and high protein content that it is an excellent food for diabetics. Being a plant of warm temperate regions, it is quite susceptible to frost. Manchuria leads the world in production of soy beans, while Illinois grows over half of the domestic crop raised chiefly for industrial purposes (see p. 394).

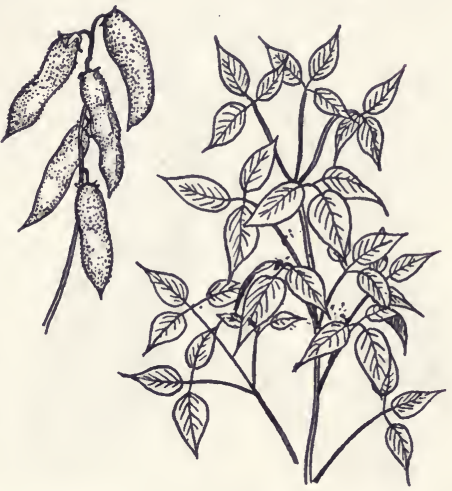

Fig. 113. - The soy bean of southeastern Asia is a low bushy plant producing small pods.

The KIDNEY or STRING BEAN (fig. 114) which is the type grown for eating and canning throughout the United States today, is a

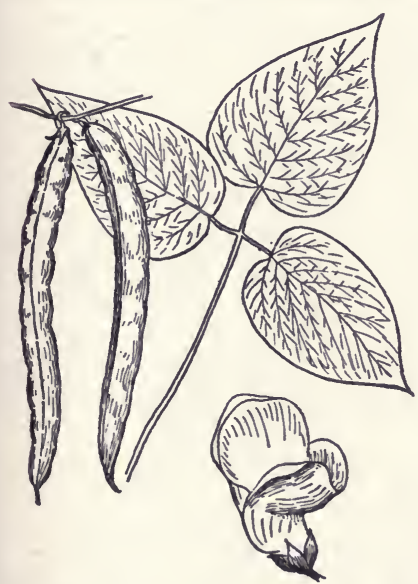

Fig. 114. - The kidney or string bean is a plant of tropical America, cultivated as our common eating bean.

plant of tropical America which was being cultivated by the Incas when the first white people came to the new world. Brought to Europe by the early explorers, it soon replaced the then common broad bean. Over a thousand varieties are known today, varying in habit from dwarf bushy plants to tall poleclimbing types, producing pods and seeds of varying texture and color, from green to yellow. Both the seeds and the pods are used as food. Beans have become an important portion of our vegetable crops23,000,000 bushels being produced in 1935.

Lima BEANs (fig. 115) are another species of the kidney bean genus, native to the tropical American region and named for the capital of Peru. Lima beans have 
broad flat pods, and contain more mealy and larger seeds than

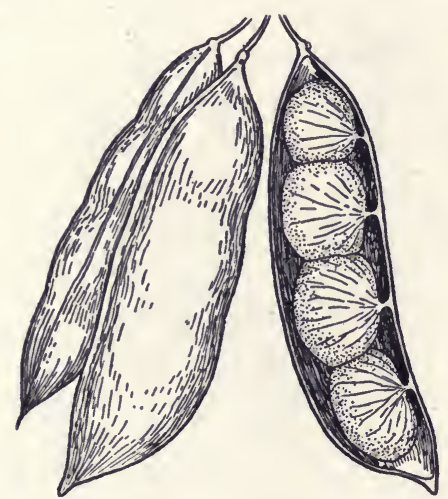

Frg. 115.-Lima beans, native to tropical America, produce broad flat pods. kidney beans.

LENTILS are bean-like plants native to southwestern Asia; they are among the most ancient of food plants, having been cultivated by the Egyptians and Greeks. The short broad pods bear lens-shaped seeds which have such a high protein content that they are often included in diets to replace meat. The chief use of lentils today is in soups.

All of the varieties of edible PEAs come from a trailing tendril-bearing vine native to southern Europe and cultivated by the Greeks and the Romans. Unlike many of the legumes, peas can stand cool summer temperatures; most of the American crop is raised in states adjacent to Canada, and in Canada itself. The less common field peas, with colored flowers and angular rather dry seeds, still grow. wild in Greece; these are grown for meal and split peas, as well as for livestock feed. The more familiar garden peas (fig. 116) with white flowers and plump sugary seeds, presumably originated in western Asia, but their wild prototype is unknown.

One of the most unusual members of the family is the PEANUT, a bushy annual of Brazil producing a shell-like pod (the "shuck" of the peanut) which must mature underground. After fertilization the flower stalk elongates and pushes the developing pod into the earth; the ovary

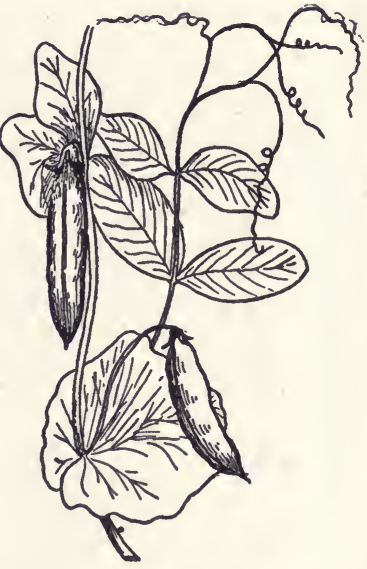

Frg. 116.-The garden pea has inedible pods, containing plump sugary seeds. of the fertilized flower would wither and fail to mature if it remained above ground (fig. 117). Peanuts grow best in sandy 
soil, in a warm sunshiny climate with moderate rainfall. The peanut was subjected to a circuitous trip before it came to North America for its intensive cultivation; it was carried from South America to the Old World tropics by Portugese sailors and thence to Virginia with the negro slaves who brought

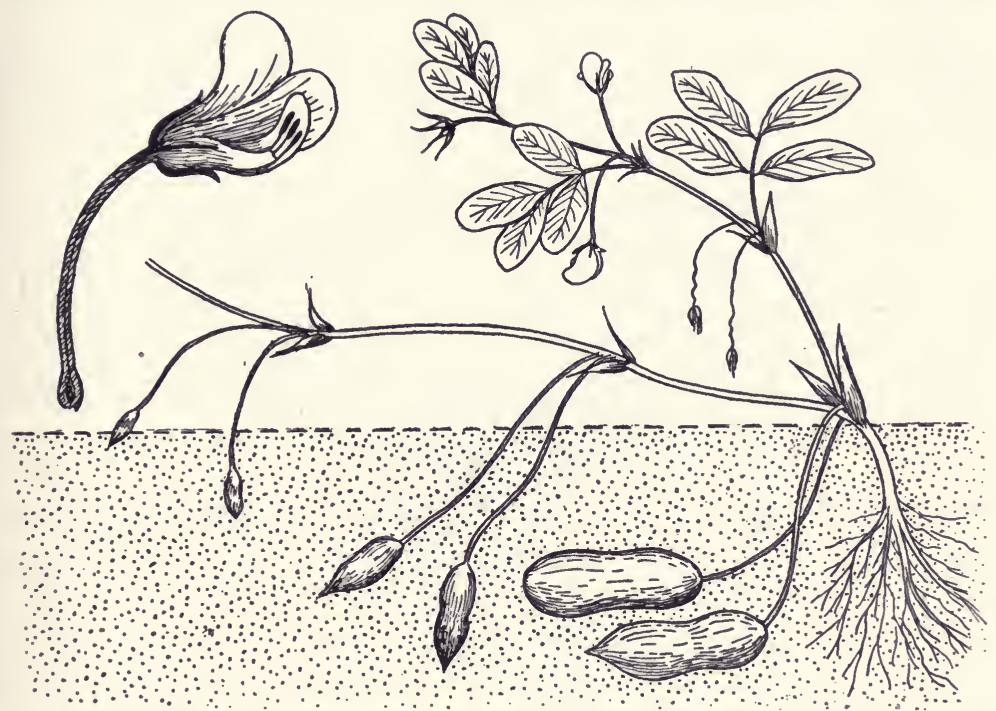

FIG. 117. - The flower stalk of the peanut, after fertilization, elongates and pushes the developing seed pod into the earth.

it with them from Africa. Georgia, which is the leading peanut growing state, produces most of our annual crop.

\section{The Berry Fruits}

Although many wild plants produce berries-and these area natural food for wild animals and humans who must depend upon uncultivated plants-few berries are of commercial crop importance because of their perishable nature. A true berry has a thin outer skin which offers little resistance to loss of water or to fungus attack, making shipment and storage difficult. Of some importance, however are the berry fruits of the Grape, the Nightshade, the Saxifrage and the Huckleberry Families. 
GRAPES were used in making wine (see p. 241) for centuries before they were grown to be eaten as a fruit; perhaps for this reason, they can boast an antiquity greater than that of most fruits. Grape seeds have been found in Egyptian tombs 3000 years old, and undoubtedly were being cultivated several thousand years before that. The grape genus includes climbing vines, common to temperate portions of both the Old and the New World; the fruit is a true berry with several seeds buried in watery pulp, developed from the ovary of the flower (fig. 118).

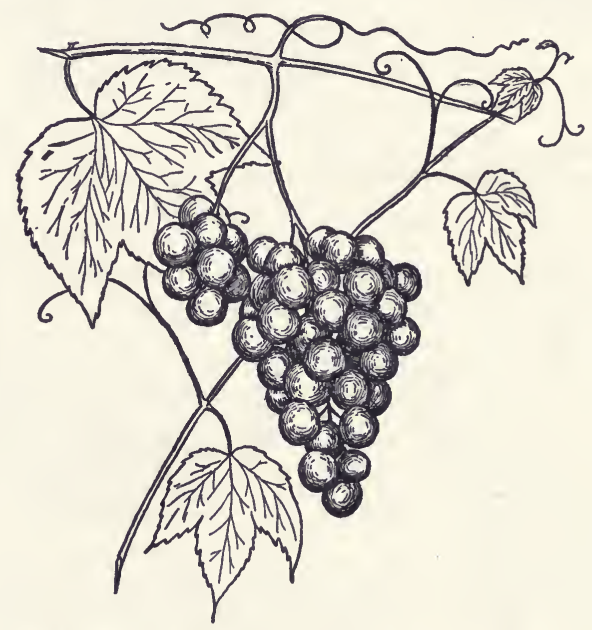

FIG. 118.-The grape genus includes climbing vines common to all temperate regions.

The European grape originated in the Caspian region of western Asia, whence its culture spread around the Mediterranean and as far as the Roman conquests could bring it. This species can be grown only in warm climates, thriving in California and some of our southern states. A variety of the European grape was brought to Mexico by the Spaniards, and from there the padres introduced it to the California missions. California is one of the largest grapeproducing areas, growing such varieties of the European grape as the Tokay for eating, the Muscat for raisins, and the ZiNFADEL for wine. Of the many native species growing wild in the United States, only the FOx GRAPE of New England has become 
cultivated. Fox grape varieties with fruits varying in color from deep purple to amber are best represented by the Concord, Catawba, Niagara and Delaware varieties. These are grown commercially chiefly in New York and Ohio. Grapes require good drainage and loose soil, thriving on hillsides. Dried currants are produced from grapes grown in Greece since 75 A.D. The growing of Muscat grapes for RAISINS has become an important industry in southern California; the grapes are gathered in trays and sun-dried for at least a week, often for a month. This curing process takes place ideally in southern California's hot dry climate.

The plants in the Nightshade Family produce a fruit which is a true berry. Some are inedible, as the purplish green fruit of the white

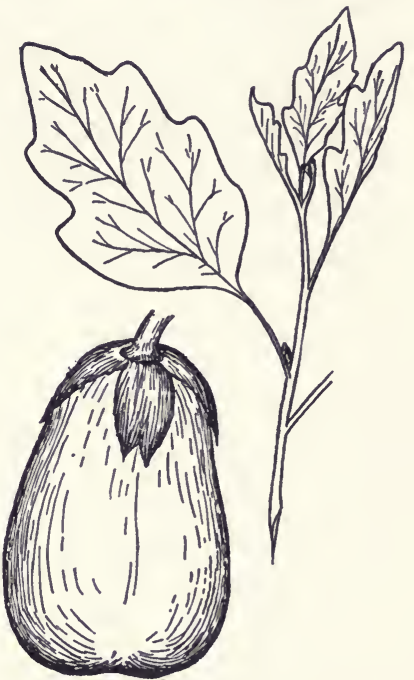

Fig. 119.-The egg plant produces a large berry which is white or purple in color. potato. However, another species in the potato genus is the EGG PLANT, native to India and widely cultivated in the tropics

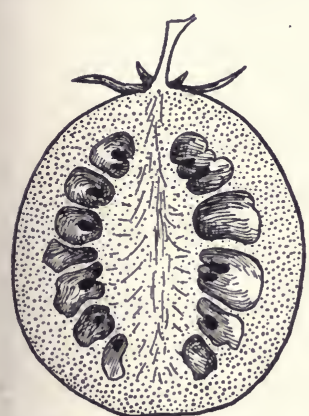

FIG. 120.-The tomato fruit is a fleshy berry containing numerous small seeds. and in our southern states (fig. 119). The arge berry, about the size of a coconut, is white or purple in color. The томato, another genus in the family, still grows wild in its native Central and South American region; it was brought to the Mediterranean region by the early explorers, and was first cultivated more as a decorative fruit (known then as the "love-apple") than an edible one. Tomato plants grow particularly well in the Mediterranean region and in the United States. The fruit is a fleshy berry with enlarged and succulent placentas, bearing small seeds (fig. 120); the color is due to the presence of two pigments, the red lycoper- 
sicin and the yellow carotin. Peppers are another genus of the Nightshade Family native to tropical America; they are not to be confused with the true pepper plant which is the source of the condiment, and belongs in another family. Peppers are pungent biting fruits (fig. 121) highly prized by southern peoples as a salad plant, or as an ingredient in Tabasco sauce and in Chili con carne. Dried and ground up peppers are known as paprika and Cayenne pepper.

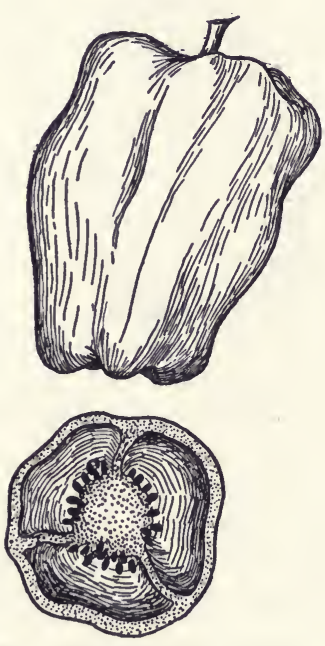

Fig. 121.-Peppers, members of the Nightshade Family, have pungent biting fruits.
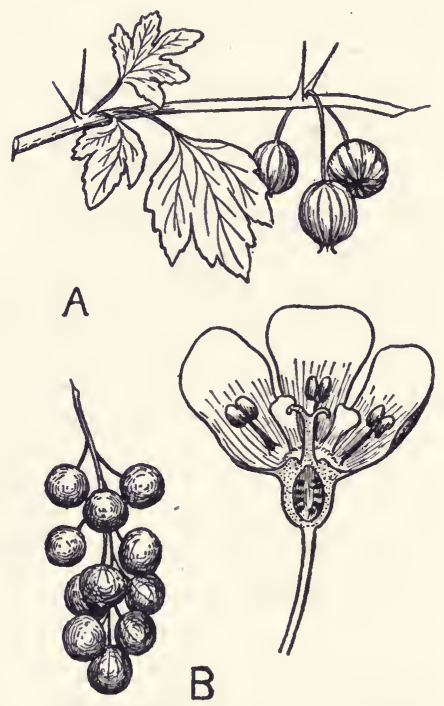

Fig. 122.-Gooseberries (A) and currants (B) are edible fruits of the Saxifrage Family.

Currants and gooseberries (fig. 122) are edible fruits of the Saxifrage Family. They are low bushy plants better adapted for living in colder climates than most edible plants; representatives of both occur in North America as well as in Europe and Asia. The cultivated currants are natives of Eurasia, where they have been grown since the Middle Ages; there are red, black and white varieties. Being very acid, currants are rarely eaten as a fresh fruit, but rather cooked into jellies and sauces. Few of the native 
American currant species are cultivated. Cultivated gooseberries are derived from species native to the cooler parts of Europe and Asia; the fruits may be red, yellow, green or white in color.

Most members of the Huckleberry Family are likewise natives of the cooler portions of the temperate regions; those with edible berries are still rudely cultivated in the wild state, and no domesticated varieties have as yet arisen. HUCKLEBERRIES and BLUEBERRIES (fig. 123) are common shrubs of eastern United States,

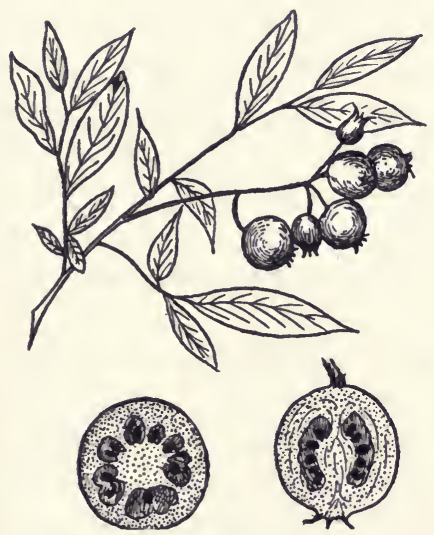

FIG. 123.-Blueberries and huckleberries are familiar small shrubs of eastern United States.

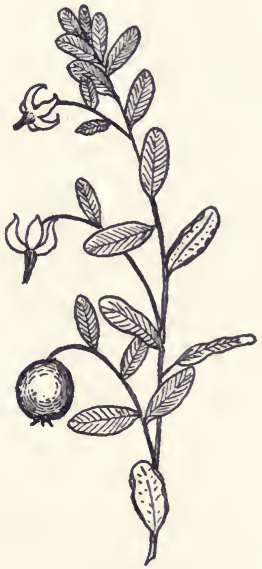

Fig. 124.-Cranberries are trailing plants common to bogs and cool habitats.

the latter growing particularly well on shallow acid soil. Wild blueberries are cultivated after a fashion, in Maine and New Brunswick, by burning over the wild stands and gathering the berries with a cranberry rake; these regions produce most of the supply for canning. Blueberries are also cultivated to a slight extent on the New Jersey sand barrens. Cranberries (fig. 124) grow as trailing plants which are native to bogs and other acid habitats throughout cooler portions of the temperate region; native species are found from New England south to New Jersey and west to Wisconsin. Originally cranberries were picked from 
wild plants, but in the last fifty years cultivation has been carried on satisfactorily in Massachusetts, New Jersey, Wisconsin and

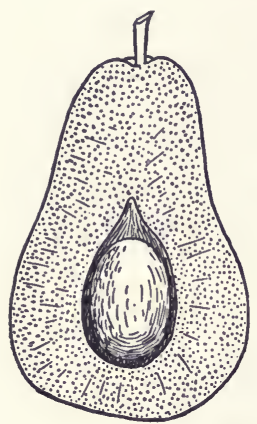

FIG. 125.-The avocado is a pearshaped fruit which botanically is a one-seeded berry.

Washington. Natural bog lands are used, flooded every winter and spring, and treated with an additional sand covering each season.

In the Laurel Family there is the bay tree genus, common to our southeastern states. One species, native to Mexico and Central America, is the Avocado. This tree is cultivated in Florida and California for its green pear-shaped fruit which is a large one-seeded berry (fig. 125). The buttery pulp which surrounds the seed has a high fat content and more proteins than any other fruit; it is used chiefly as a salad plant. It was cultivated by the Aztecs, whose original name for it (aguacate) has been corrupted into avocado.

\section{Small Fruits of the Rose Family}

Many of the so-called "berries" are not berries in the botanical sense, but rather various types of accessory or aggregate fruits. Some of these are typical of plants in the Rose Family. The STRAWBERRY is a low-growing plant which spreads in all directions by means of prostrate stems or runners. The pistils of the flower are seated on a conical receptacle, which after fertilization enlarges to form the reddish and edible portion of the strawberry, which is therefore an accessory fruit (fig. 126). The ovaries of the various pistils develop into small achenes scattered over the surface of the strawberry and mistaken for seeds. Strawberries occur throughout temperate regions in both the Old World and the New; they were known as a wild fruit to the Romans, later cultivated during the Middle Ages in France and England. Strawberries are the only small fruit which approaches the importance of the orchard fruits, ranking forth in commercial value preceded by the apple, peach and grape. The majority of the cultivated American varieties come from the western sand strawberry, native to our western coasts as well as to Mexico and Chili. 
The eastern wild varieties seldom produce large enough berries to be of economic importance.

The blackberry genus includes RASPBERRIES and BLACKBERRIES. They have coarse prickly stems or "canes" and form bushy growths which often become impenetrable thickets. The fruits are of the aggregate type, i.e., each fruit is really a composite fruit resulting from a number of small fruits being united on the same receptacle. In the blackberry the fruit cluster remains attached to the receptacle, while in the raspberry it separates from

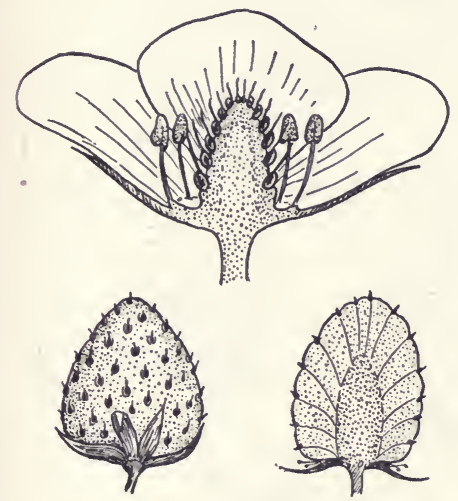

Fig. 126.-The pistils of the strawberry flower are seated on a conical receptacle which, after fertilization, enlarges to form the edible portion of the fruit.

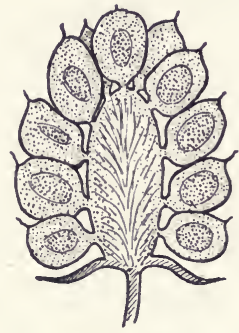

A

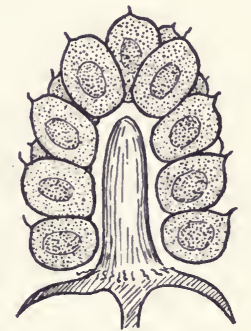

B
Fig. 127.-In the blackberry (A) the aggregate fruit remains attached to the receptacle, while in the raspberry (B) it separates from it leaving a depression in the bottom of the fruit.

it, leaving a depression in one side of the fruit (fig. 127). Blackberries are a distinctively American fruit, though species occur in Europe also. Our garden varieties are thought to have been derived from a cross between two eastern American species. A European species is the stock from which the Oregon everbearing variety has been secured. The cultivated red raspberry, on the other hand, is a European species which was grown and prized by the Romans; black raspberries are descended from native northeastern United States species. Raspberries are exceedingly hardy fruits, being capable of cultivation as far north as Alaska. Raspberries and blackberries have been crossed several times; 
the LOGANBERRY is a hybrid of the European raspberry and a California dewberry, produced by Judge Logan of Santa Cruz, California, in 1881; while the PRIMUS BERRY is a Burbank cross between the blackberry and the raspberry.

\section{The Gourd Family}

The Gourd Family is characterized by a special kind of berry fruit known as a pepo; the outer rind-like part of the fruit is developed from the receptacle of the flower and the outer part of
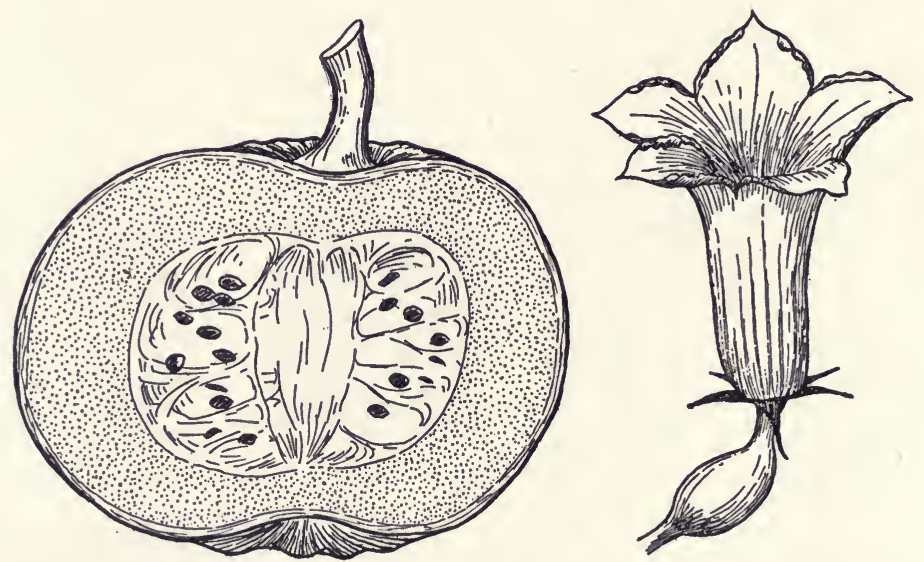

Fig. 128.- Squash and pumpkin have funnel-shaped flowers and a special kind of berry fruit with a hard outer rind and a softer inner portion surrounding the seeds.

the ovary. The inner part of the ovary, surrounding the seeds, forms the fleshy and edible part of the pepo. SQUASH and PUmPKIN (fig. 128) are both species of the same genus of native American plants cultivated by the Indians of Central America before the arrival of the Spanish explorers. They are coarse vines, producing yellow flowers and heavy fruits which lie on the ground; pumpkin specimens have been recorded with a weight of over a hundred pounds. A species native to the United States is the gourd vine or Calabazilla found in sandy places throughout the southwest.

Another cultivated genus of the family includes the CUCUMBER and MELONS (fig. 129). The cucumber, whose native home is in 
India and the East Indies, is often referred to in the early writings of the Hebrews, Egyptians and Greeks. It was not definitely
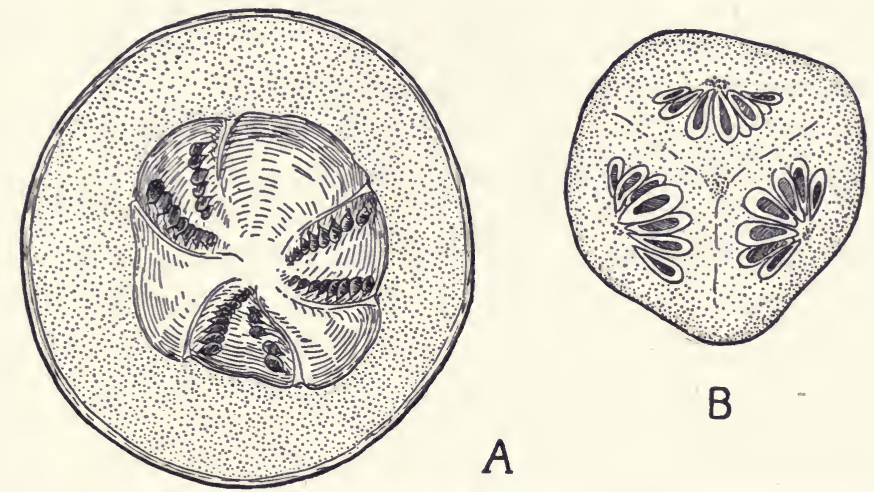

B

Fig. 129.-Another cultivated genus of the Gourd Family includes melons (A) and cucumbers (B).

under cultivation in Europe, however, until the seventeenth century. Melons are species native to Asia which were grown by

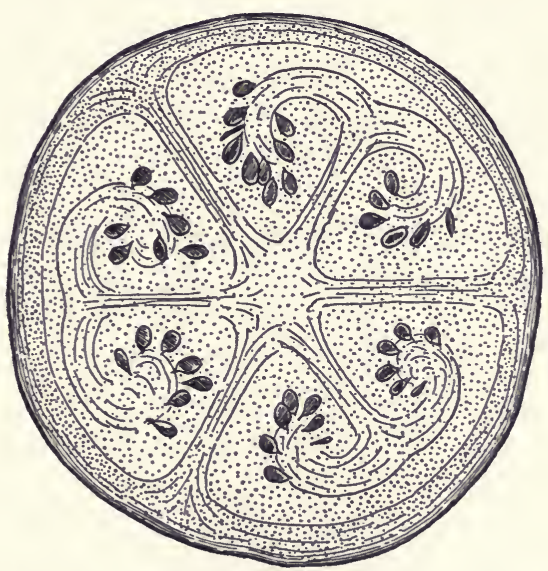

Fig. 130.-Watermelon is an African plant with an unusually large watery gourd fruit.

the Egyptians and Romans. They require a long growing season with fairly constant high temperatures; best eastern producing regions are in New Jersey, North Carolina, Maryland and Geor- 
gia; in the West, most of the melons are raised in California, Arizona and Colorado. Of the cultivated varieties, the most familiar are the winter melons (Casaba and honey-dew) with smooth hard rind and spherical shape, and the netted melons with the yellow or green flesh (cantaloupe).

The watermelon (fig. 130) is an African plant, cultivated centuries ago by the Egyptians and Chinese. Watermelons require fertile sandy soil with an abundance of sunshine, and find these requirements best fulfilled in our southeastern states. 


\section{Chapter 11}

\section{THE ORCHARD FRUITS}

Cereals, legumes and many vegetables are annuals which need to be raised from seed each season and therefore demand considerable repetition of labor every year. On the other hand, woody perennials which bear fruit for twenty or thirty years, yielding an annual crop, are obviously a great horticultural asset. Their cultivation goes back to the same distant period of human civilization as does that of a number of the cereals and vegetables. Many of the fruit trees, furthermore, originated in that part of Asia where the human race is supposed to have had its origin. Thus some of these fruits have gone with man in his migrations to new lands, from their common ancestral home. The Mediterranean region in particular, with its dry summers and mild winters, proved an ideal home for many of these introduced fruit trees. Fruit raising was as important an aspect of plant husbandry among the Egyptians, Greeks and Romans as it is today. It was early discovered that fruit trees could be cultivated in many areas unsuited for cereal or vegetable crops because of geographic or physiographic reasons, since woody perennials often thrive where herbaceous food plants can not exist.

The majority of our cultivated fruits belong to only two families of plants. First in importance is the Rose Family which, more than any other plant group, has given man a plentiful variety of edible fruits. These include the pome fruits-apple, pear and quince; and the drupe or stone fruits - cherry, plum, peach, apricot and almond. Second in importance only to these rosaceous fruits are the citrus fruits of the Rue Family-orange, lemon, grapefruit, citron and lime. There are in addition a scattering of edible fruits among various other families: the banana, coconut, date, olive, persimmon, breadfruit, fig, guava and pineapple. 


\section{The Pome Fruits}

In the formation of a pome fruit the ovary of the pistil forms a core within which are the seeds; the receptacle and calyx of the flower enlarge and envelop the core with fleshy tissue which forms the edible portion of the fruit. Thus such pome fruits as the apple, pear and quince are accessory fruits with the bulk of the fleshy portion being produced by other parts of the flower than the ovary (fig. 131).
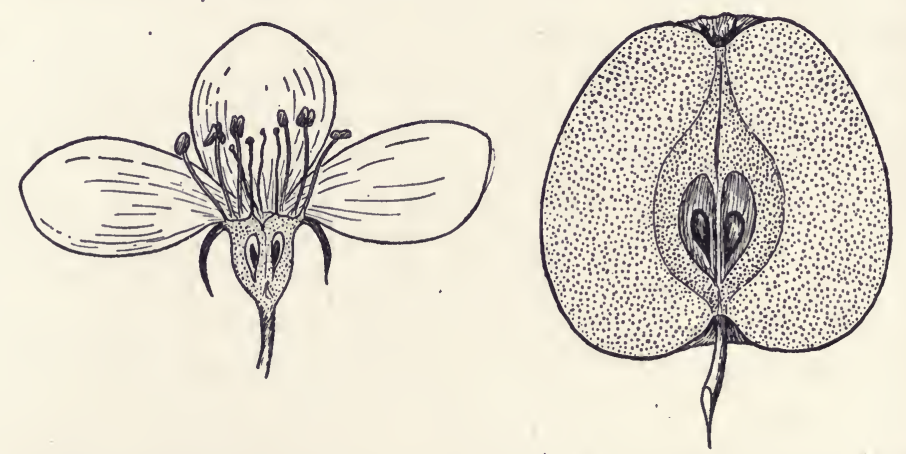

FIG. 131.- Pome fruits such as the apple are accessory fruits with the bulk of the fleshy portion produced by the receptacle and other parts of the flower.

The APPLE genus includes some twenty species of trees native to North America, Europe and Asia. Our indigenous species are all known as crab apples, and bear small bitter fruits. Few of these are cultivated, most of the orchard varieties being derived from plants native to eastern Europe and Western Asia. Apples have been cultivated for at least three thousand years; twenty two varieties were known to the Romans, and since that time there have been developed an estimated six thousand horticultural varieties. English colonists introduced the European apple into this country after they found that the native species were useless.

Apples average 80 to $85 \%$ water, with varying amounts of sugars in solution. During the ripening process original starches of the fruit change to sugar and the amount of malic acid (which 
causes sourness) decreases. Many varieties keep well even though there is such a high water content. For this reason apples were practically the only fresh fruit available in winter until the development of the citrus industry.

The apple, being pre-eminently a cool season crop, is the most widely cultivated fruit of the temperate zone; apples are grown almost everywhere except in the tropics. The chief apple growing countries are North America, western Europe, Australia, New Zealand and South Africa. Though adapted to many different soils, apples grow best on soil containing a slight amount of lime. The chief apple-producing states, in order of importance,

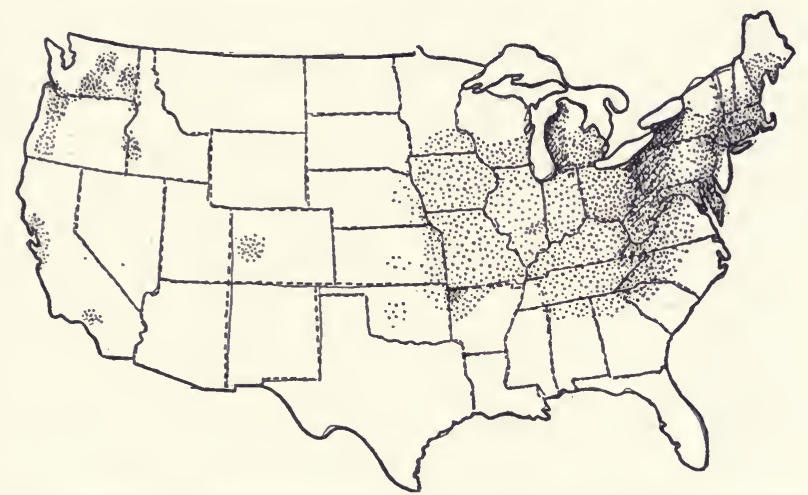

FIG. 132.-Distribution of acreage devoted to growing apples for market (1930).

are Washington, New York, Pennsylvania, California, Virginia, Michigan, Ohio and Oregon. Crops for local consumption are grown in almost every state (fig. 132).

Many of the varieties grown today were the result of chance hybridization in nature. One of the oldest American varieties is the MaIntosh, named after a Canadian farmer of Ontario who discovered this variant in some hybrid "wild" apples in the early part of the nineteenth century. From this stock, propagated by twigs and buds, the McIntosh trees have multiplied a thousand fold. The NORTHERN SPY variety originated in Bloomfield, N.Y. about 1800, while the familiar BALDwIN apple was discovered near Lowell, Mass. in 1793 by a surveyor working on a canal. The WEALTHY apple, popular in the upper Mississippi valley, ap- 
peared as a chance variety in Excelsior, Minnesota in 1894. The common CRAB APPLE is a hybrid of the orchard apple and the Siberian crab apple.

Apples, in addition to being eaten as a fresh fruit, have a variety of other uses. A large proportion of the crop is made into cider and vinegar. Conversion of cider into vinegar involves two kinds of fermentation; first, the sugary solution of the cider is converted into alcohol by the action of yeast, then the alcohol is transformed into vinegar by the activity of acetic acid bacteria. Some of the crop is also made into dried apples, used for domestic

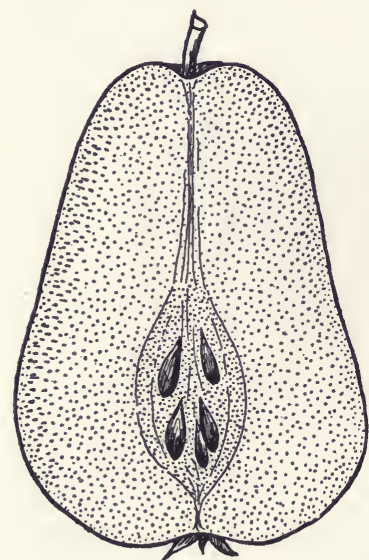

FIG. 133.-The pear is an accessory fruit like the apple. consumption and export to Germany and Holland. In making dried apples, the fruit is cored and sliced, dipped in weak salt solution, bleached with sulphur fumes and then tray-dried while hot air under pressure is passed over them. In some localities apples are used as livestock feed.

Pears are closely related to apples, being considered by some botanists to be merely different species of the same genus. Pear trees are straighter and taller than apple trees and bear white flowers which appear before the leaves. The pear is an accessory fruit like that of the apple, being derived from a fleshy receptacle which surrounds the core or enlarged ovary (fig. 133). The pear is a juicier fruit and therefore does not keep as well as apples, and is easily bruised in shipment or storage. The flesh is characteristically gritty due to the presence of minute stone cells (sclerenchyma). There are no native American species, all of the cultivated pears being derived from southern European and Asiatic plants. They are referred to in the writings of the early Egyptians, Syrians and classical authors. Pears, being less hardy than apples, have a more restricted range; the trees thrive on heavy humus soils with good drainage. The chief pear-raising country is France. In the United States pear orchards are suc- 
cessful along the seacoasts and lake margins where there is an equable climate. California, Washington, Oregon and New York raise most of the domestic crop. There are fewer varieties of pears under cultivation in this country, than of apples; the most common are the Bartlett and the Kieffer, the latter originated by a gardener of that name in Philadelphia.

The QUINCE is a small tree with round or pear-shaped fruit (fig. 134) characterized by $\mathrm{r}$ ather unpalatable yellow flesh. A native of central and eastern Asia, the quince was introduced into the Mediterranean region where it became a popular fruit with the Romans. It is grown commercially only to a slight extent in this country, chiefly

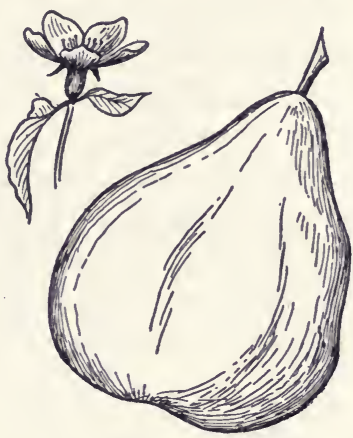

Fig. 134.-The quince fruit is rounded or pear-shaped with rather unpalatable flesh. in California, Ohio, Pennsylvania and New York. The fruit is usually canned or made into jellies and jams.

\section{The Stone Fruits}

All of the stone fruits of economic importance belong to the same genus (Prunus), a large group of some 175 species widely distributed in north temperate regions, with 20 native to the United States. The ovary forms a fruit composed of two distinct regions, the outer one fleshy and edible, the inner part hard and stony, surrounding the single large seed (fig. 135). In the cultivated varieties the fleshy portion of the drupe is more considerable and more edible than in the wild species.

Plums are small, often shrubby, trees which grow well almost everywhere in the United States except in the coldest portions. Commercial varieties have been derived from three types of plums - the native American, the European and the Japanese. There are several wild plums growing in the United States, ranging from New England to Florida and west to Colorado, producing small and bitter fruits. Cultivated varieties resulting from crossing these native species with Oriental stock are both hardy and possessed of edible fruit. Japanese plums have been 
introduced into this country relatively recently; many varieties (satsuma and Burbank) were developed by Luther Burbank after hybridizing them with our native plums. The European plum is still growing wild in its native Eurasia where it has been cultivated since the time of the Swiss lake dwellers and the Romans. This is the best known of all the plums. Introduced into the United States by the colonists, the European plum is now grown on both the Pacific and Atlantic coasts and in the Great Lakes region. Best known of the several hundred varieties which are its descendants are the green gage and the lombard plums. A particularly valuable variety of the European plum is the prune,
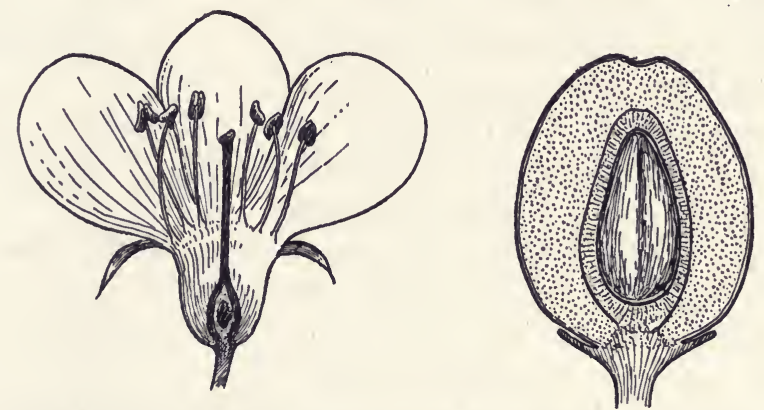

FIG. 135.-The ovary of a stone-fruit forms a fruit with two distinct regions, of which the outer one is fleshy and edible as in the cherry.

which has fruits with such a great sugar content that they can be dried and cured without removing the stones. PRUnes form the second most valuable crop in California today. The plums are gathered after they have fallen to the ground, and then dipped in boiling water or lye, sun dried in racks and finally treated with boiling water and glycerine or fruit juice to give them a glossy surface as well as to sterilize the skin. California orchards totalling over six million trees produce four hundred million pounds of prunes annually. In addition to California, Jugoslavia and France also grow a commercial prune crop.

Although there are several common native species of GHERRY, not one is of any horticultural value. Cultivated cherries are derived from two species: the sweet cherry of Europe and Asia Minor, and the sour cherry of Asia Minor. Sweet cherry trees are 
tall and long-lived, prodıcing sweet fruits of various colors but usually yellow or red; they are grown in a restricted range in states with an equable climate such as is found in New York, Michigan, California, Oregon and Washington. The sour cherry is a smaller tree with tart red fruits used chiefly for canning; sour cherry trees are grown successfully in New York and Michigan.

The PEACH (fig. 136) is a native of China, brought to Europe about 500 B.C.; previously it had been under cultivation for many centuries in the Orient. Peaches were grown in the Mediterranean region in the time of the Romans. They found their way into the United States via Mexico, where peaches were introduced by

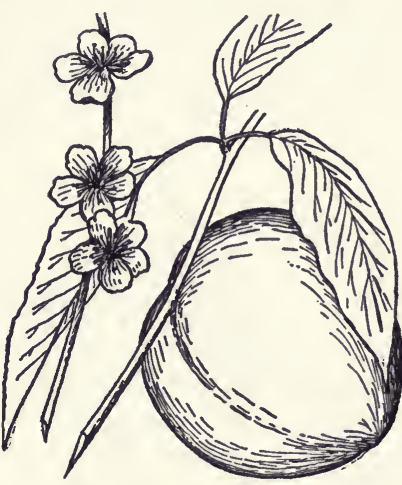

Fig. 136.-The peach has an abundance of flesh surrounding the stone with its contained seed. the Spaniards, and directly through the English colonies. Peach trees grow to be moderate sized but are short-lived and very susceptible to frost; orchards do unusually well

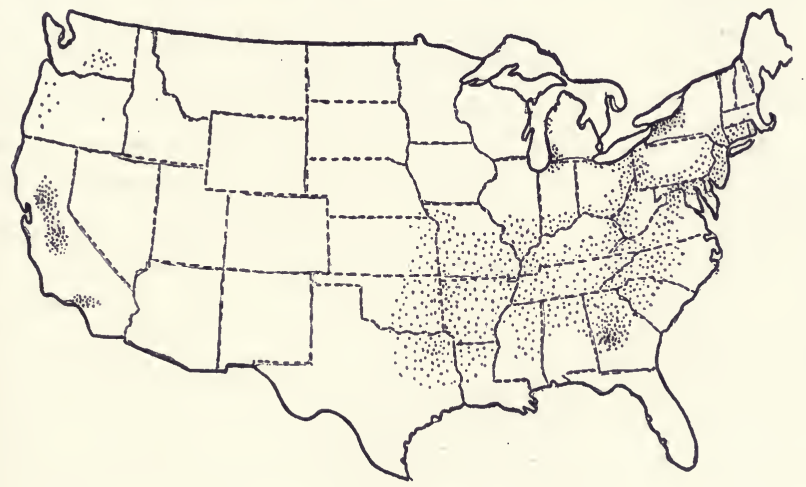

FIG. 137.-Distribution of acreage devoted to growing peaches commercially (1930).

when planted in sandy soil near large bodies of water. As in the apple, pinkish blossoms are produced before the leaves appear. Several thousand varieties are known today, of which the 
majority are grown in southern Europe, South Africa, Japan and Australia. In the United States peaches are a crop in California, Georgia, Michigan, New Jersey, Pennsylvania and New York (fig. 137). Peaches are used as a fresh fruit, but a large amount of the California crop particularly is dried or canned.

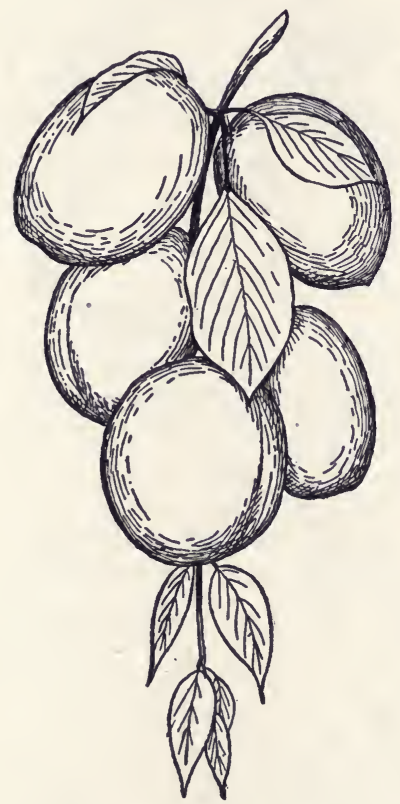

FIG. 138.-The fruit of the apricot resembles a miniature peach with a smooth-surfaced stone.

Peaches are a perishable fruit, difficult to transport or to store for long periods. The Elberta is the most commonly grown variety - a hybrid of a Chinese and a Persian species. West of the Rocky Mountains a small smoothskinned variety known as the nectarine is grown.

The APRICOT is a native of eastern Asia where it has been cultivated for 4000 years, and where it still occurs as a wild tree. It was introduced into Europe in the first century, reaching the Mediterranean after slow stages through India, Persia, Egypt and Armenia. Like the peach, the apricot is a small tree producing pinkish flowers before the foliage appears. Apricots are susceptible to frost and therefore are grown only in the warmer and protected portions of United States, China, Japan and northern Africa. The fruit (fig. 138) is like a miniature peach but with a smoother, less pitted stone. The apricot was introduced into California by the Spanish missionaries late in the eighteenth century; the climate was so well suited to them that apricot orchards soon became numerous. Today California produces all of our domestic crop, which is chiefly canned or dried for market.

The ALMOND, native of the Mediterranean region, is cultivated chiefly in Italy and Spain. Almond trees resemble peaches in shape and size, but the flowers-which appear before the leaves - are large, pink and showy. The fruit (fig. 139) is struc- 
turally like that of a peach, except that the flesh is scanty, tough and leathery while the stone is comparatively much larger. The stone, or pit, contains the almond seed which is used com-
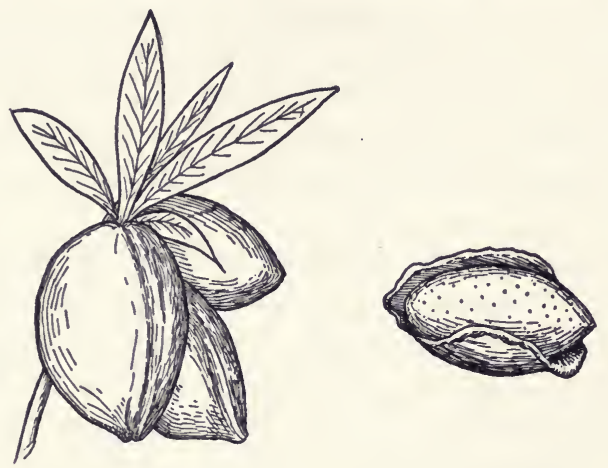

FIG. 139.-The almond fruit is structurally like that of the peach; in contrast with the latter the flesh is scanty and the stone larger.

mercially. A third of the American grown crop is raised in California. Almonds are used in confectionery and baked goods, and in the manufacture of almond oil.

\section{The Citrus Fruits}

The Rue Family, which includes all of the citrus fruits, is represented in the United States by a few native shrubs and trees; turpentine broom of the Southwest, prickly ash and hop tree of the eastern woodlands. All of the citrus species, except. the kumquat, belong to the same genus (Citrus); they are the most widely cultivated tropical fruits in the United States, growing satisfactorily in Florida, the gulf states, Arizona and California. Citrus species are thorny evergreen shrubs or small trees with aromatic foliage and flowers, producing a type of fruit whose

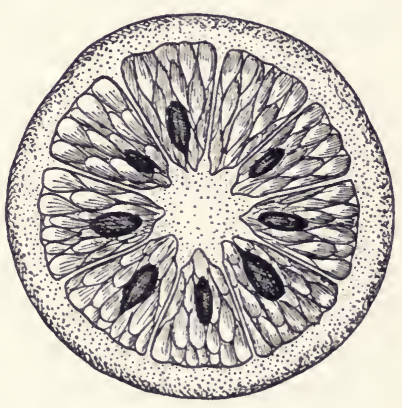

FIG. 140.-Citrus species produce a fruit with a leathery rind containing numerous oil glands. leathery rind contains numerous oil glands (fig. 140). They are 
grown best on well drained soil adjacent to the sea in a climate where the temperature ranges between 24 and 120 degrees Fahrenheit. Ripe fruit is produced continuously throughout the year, and in some cases as with the lemon, trees produce flowers, immature fruit and ripe fruit at the same time. The United States ranks first in citrus fruit crops, with the Mediterranean countries (Portugal, Spain, Italy, Palestine) second in importance even though citrus fruit culture is one of our most recent industries.

The ORANGE, hardiest member of the genus, is indigenous to the Indo-Chinese region, where two distinct species occur-the sour orange and the sweet orange. The sour orange has a reddish fruit with thick skin and sour pulp; this was the first orange to be introduced into Europe - after centuries of cultivation in China -in about the twelfth century. Orange trees were brought to Persia by the Arabs, then later to Syria, northern Africa and Spain. Sour oranges were also the first to be introduced into the New World, being brought to Florida by the Spaniards. Native Indian tribes spread this species so that groves of "wild" oranges are found around various lakes and rivers in that state. The chief use of sour orange trees is a stock on which to graft the less hardy sweet orange. The sour oranges, known as Seville oranges, are grown in Spain and the fruit shipped to England and Scotland where it is made into marmalade.

The common sweet orange tree is of moderate size, with a dense rounded head of dark green foliage and with fruit (fig. 141) of a golden-yellow color. Oranges contain 5-10\% sugars in solution, $2 \%$ citric acid and an abundance of vitamin C. In recent years they have become one of the most popular fresh fruits for year-round consumption. Sweet oranges were brought to Europe from India sometime before the fourteenth century; they were introduced into Florida before the English occupation. A sweet orange grove, dating to 1823 , is said to be the parent of all the Indian River oranges. The cultivation of sweet oranges began along the shores of lakes and rivers where the sour orange groves, already established, were used as stock on which the sweet orange was grafted. In 1894 the Florida output was four million oranges. Then came an excessively cold winter and fungus diseases which 
practically annihilated the Florida groves; the next season's crop was reduced to less than a hundred thousand oranges. But orange growing persisted, and is today an important asset to the state. Florida oranges are thin-skinned, juicy and sweet; most of them are of the VAlencia variety. Another popular type is the KING ORANGE, a species discovered in China in the eighteenth century and brought to California in 1880. King oranges, in spite of their unprepossessing appearance and thick skins, are very palatable and juicy, with a skin that separates easily from the pulp. A variety of the king orange known as the TANGERINE
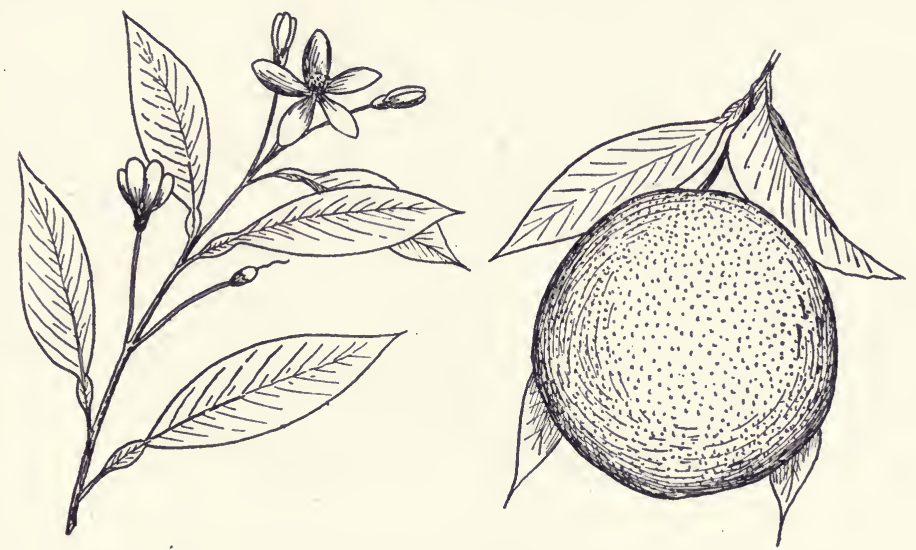

FIG. 141.-Flower and fruit of the orange.

has the pulp divided into readily separated segments; they are an important crop in Florida, the neighboring gulf states and California. Tangerines are also grown in Japan, China and southern Europe.

Orange growing began later in California than in Florida. Spanish missionaries introduced the first trees in 1804. It was seventy years later however before the first carload of fruit was shipped east of the Rockies. With the development of irrigated areas in southern California and improved means of transportation to the eastern markets, the California orange crop assumed national importance. The orange groves of that state today represent an investment of a quarter of a billion dollars. California growers depend upon two varieties; Valencias, for summer pick- 
ing (from June to November) and navels, for a winter crop. The NAVEL orange has a thick skin and excellent meaty pulp; it is a seedless variety introduced into the United States from Brazil by the Department of Agriculture. Its name is due to the formation of a smaller secondary fruit at one end, leaving a navel-like depression. Of two original trees sent to Riverside, California, in 1873, one is still standing, guarded by an iron fence. From these, some nine million descendants are now growing in California alone, producing (in 1937) fourteen million boxes of fruit.

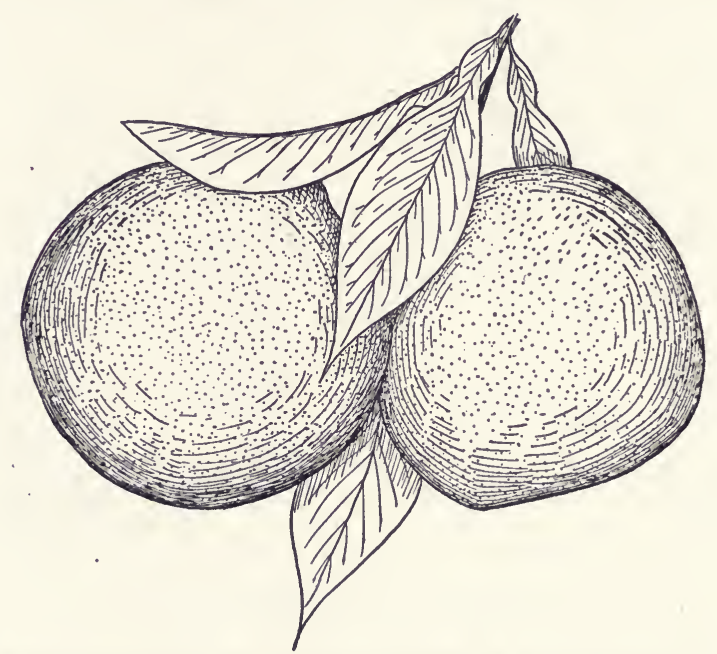

FIG. 142.-Grapefruit is the largest of the citrus fruits.

Oranges are also an important crop in many other countries with sub-tropical climates. Leading the list are Spain, Italy, Palestine, South Africa, Brazil and Japan.

GRAPEFRUIT trees grow to a larger size than oranges, reaching forty feet in height; under cultivation they are kept as lowgrowing as possible, however, to make picking the crop easier. Grapefruit (fig. 142) is the largest of the citrus fruits, sometimes reaching a diameter of six inches and a weight of ten pounds. Their popular name comes from the fact that they grow in clusters on the branches. The flesh is slightly more acid and bitter than that of oranges. No fruit has a more uncertain birthplace; 
its ancestral home is thought by some botanists to have been in the Polynesian and Malay region, by others to have been in China. Grapefruit trees were brought to Florida from the West Indies at the beginning of the nineteenth century, but they were used only as ornamentals until 1880 . The last thirty years have seen a tremendous increase in grapefruit production, with more than half of the domestic output of eighteen million boxes coming from Florida. Being more susceptible to frost than most citrus

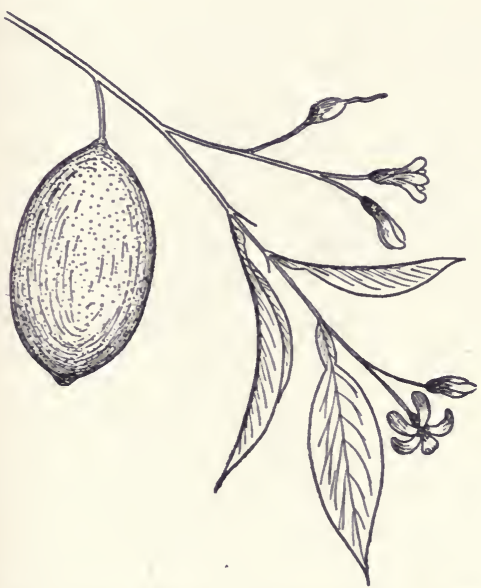

FIG. 143.-Flower and fruit of the lemon.

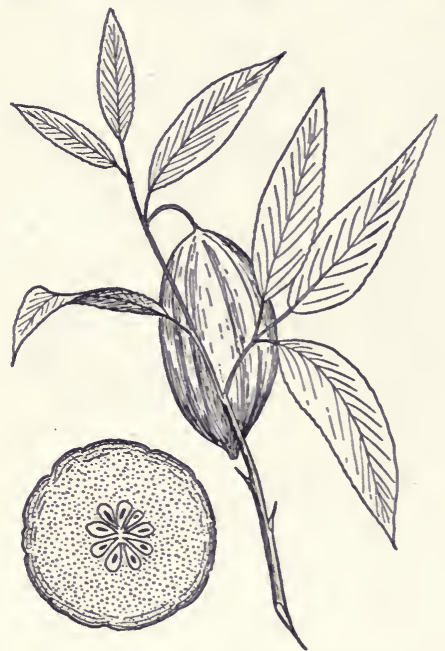

Frg. 144.-Unlike other citrus fruits, the citron has a thick rind while the pulp is small and unimportant.

fruits, grapefruit can be grown successfully only in the warmer portions of Florida, Texas, Arizona and California. They are also raised in the West Indies, India and South Africa. The chief use of grapefruit is for canning, both fruit and juice; six million cans are the annual output in California alone.

The LEMON (fig: 143), a native of southeastern Asia, was introduced into India at an early date, being brought from there to the Mediterranean where it was cultivated by the Greeks and Romans. The lemon was introduced into Spain by the Arabs in the twelfth century. Lemon trees are small in stature, rarely 
over twenty feet in height, and produce fragrant white blossoms with a purplish tinge to the outside of the petals - a contrast to the pure white orange flowers. Lemon trees are very susceptible to frost and therefore are grown most successfully only in frostfree portions of California and Florida. Italy and the United States are the chief lemon raising countries. Lemons were an important Florida crop until the fatal frost of 1895. California now leads in their production, growing about eight million boxes

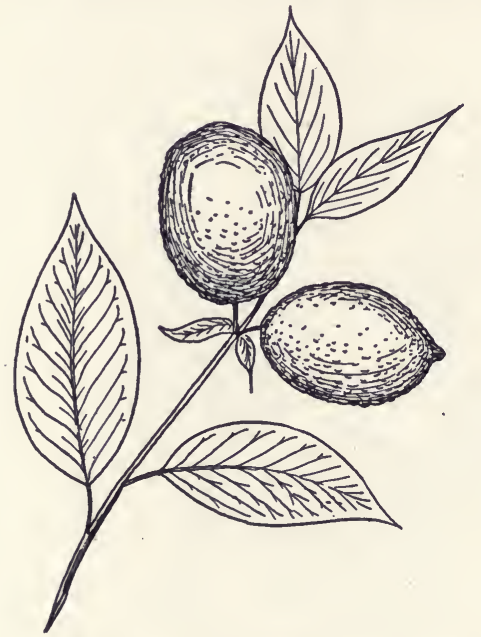

FIG. 145.-Lime fruits are small, greenish and with an exceedingly sour taste.

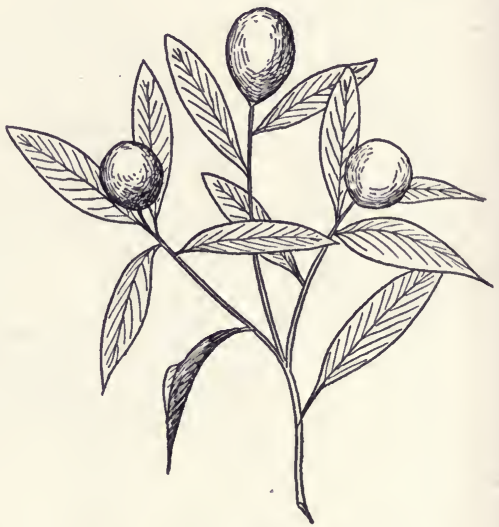

Fig. 146.-Kumquats are plum-sized fruits with spicy rinds and acid flesh.

annually. Lemons are formed on the trees during every month of the year, but the best picking is from December to March. Lemons contain less sugar and more citric acid than either oranges or grapefruit; for this reason they are used chiefly as a juice and for flavoring. The production of lemon oil is an important industry, since lemon oil ranks second only to vanilla as a flavoring substance.

The cITRon, a native of India, is the oldest of the citrus fruits, with a recorded cultivation dating to the fourth century B.C. Theophrastus describes its use in Babylon. Today citron is grown in Corsica, Greece, Sicily and the West Indies; the United States 
imports half of the world production. Citron trees are shrubby and armed with stout thorns, producing greenish yellow and fragrant fruits (fig. 144) resembling large rounded lemons; unlike other citrus fruits, the rind is thick and the pulp small and unimportant. Commercial citron is the candied rind.

LIME trees are tropical plants, often shrubby in habit, which can not tolerate low temperatures. The small greenish fruits (fig. 145) are exceedingly sour in taste, and are therefore used chiefly as juice and a flavoring substance. Limes are natives of southeastern Asia but are cultivated today in Italy, Ceylon, India, the West Indies and Mexico. Limes are grown to a limited extent on the Florida keys, the state producing 10,000 boxes annually.

Smallest and least known of the citrus fruits is the KUMQUAT, introduced into England from China in the middle of the last century. The plum-sized fruits (fig. 146) have a thick spicy rind and an acid flesh, and are eaten whole. Kumquats are hardy enough to be grown as far north as Georgia.

\section{Other Tropical Fruits}

The tropics have been particularly generous in their production of plants with edible fruits; over two hundred species grow in the Philippine Islands alone. As yet most of these are unknown and unappreciated by the white race. Most familiar are the banana, date, coconut and pineapple of the monocot families; and the fig, breadfruit, guava, olive and persimmon of the dicot groups.

The BANANA, a member of the family with the same name, of which there are no species native to the United States, is a tropical fruit indigenous to India and Malaya; it was cultivated as long ago as 1000 B.C. in Assyria. The banana plant (fig. 147) resembles a small tree, but is in reality a gigantic herbaceous plant with a subterranean stem which sends up a dozen or two large leaves whose sheathing stalks make up the "trunk." The foliage consists of a crown of leaves, each four or five feet in length. A single flower cluster is produced, which pushes its way up through the leaf bases to emerge in the center of the crown. The bunch of bananas is the fruit cluster, each fruit being a berry 
with the seeds minute black specks. After forming fruit, the banana plant dies to the ground, the subterranean stem sending up a new shoot the next growing season. Several hundred varieties of bananas are grown over a widespread tropical area, but only a few of these reach American markets. Bananas are picked green in order to be transported without injury. Ripe bananas, being rich in carbohydrates, fats and proteins, are an excellent

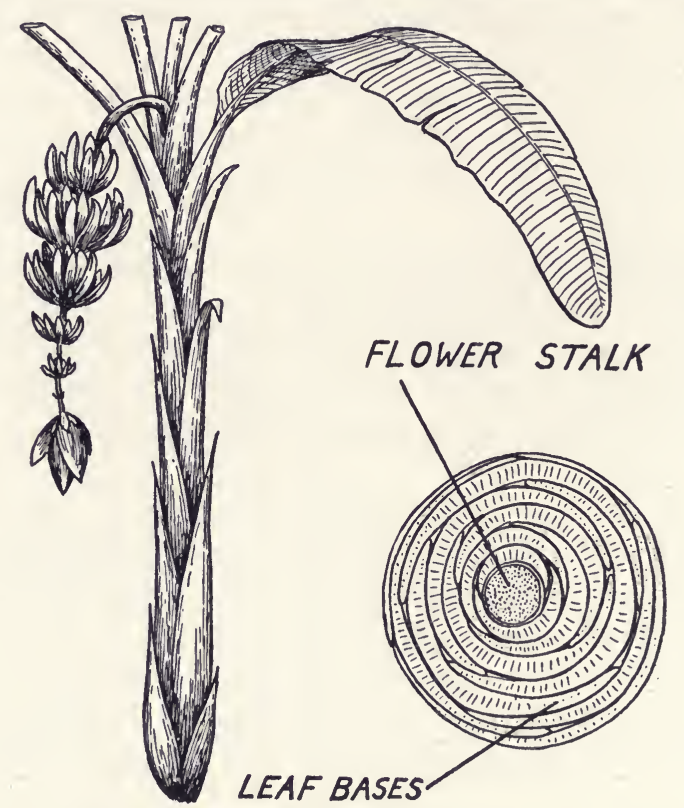

FIG. 147.-Banana plants resemble small trees but are in reality gigantic herbs bearing huge clusters of berry-fruits.

food, with a food value three times that of wheat. The American supply comes from the West Indies, Central America and Hawaii.

The Palm Family has contributed two fruits of great antiquity to the human menu-the date and the coconut. The DATE palm (fig. 148) unknown today in the wild state, is one of the oldest of cultivated plants, its history dating to 3000 B.C. Perhaps a native of India or Arabia, it was certainly cultivated in the latter country before the rise of the Mediterranean civilizations. Date palms are majestic trees reaching a height of a hundred feet, 


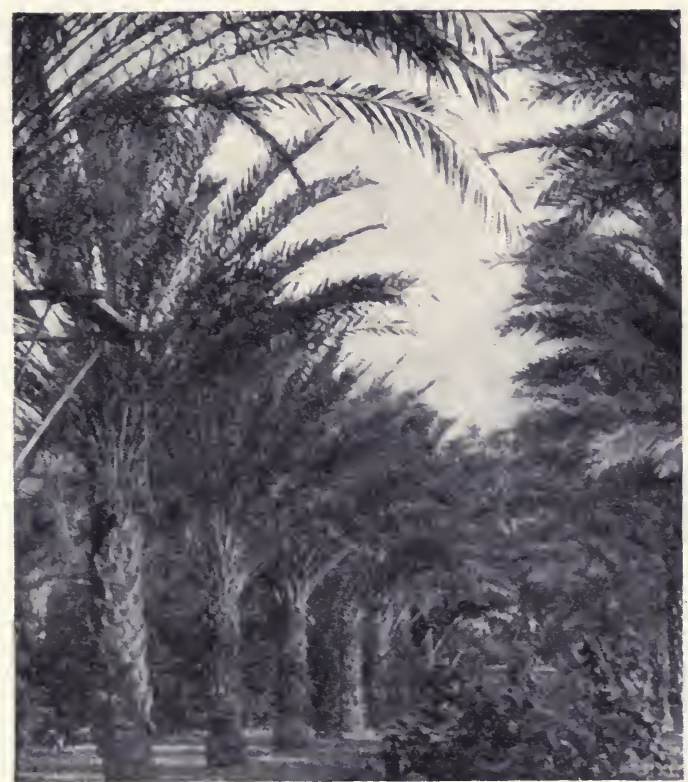

FIG. 148.-A date "garden" in southern California. The date palm is unknown today in the wild state, being one of the oldest cultivated fruit trees.
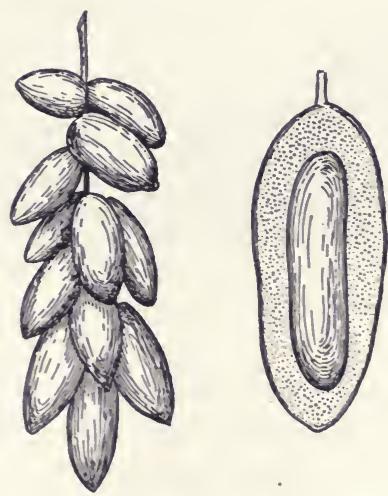

Fig. 149.-Each date is a berry with a thick and very sweet flesh surrounding the single large seed. 
with massive trunks rough with the remains of old leaf bases. The crown of foliage consists of pinnately compound leaves often twenty feet in length. Huge flower clusters consist each of thousands of small yellowish flowers, the pistillate inflorescence becoming transformed into pendant bunches of dates. Each date (fig. 149) is a berry with a thick and very sweet flesh sur-

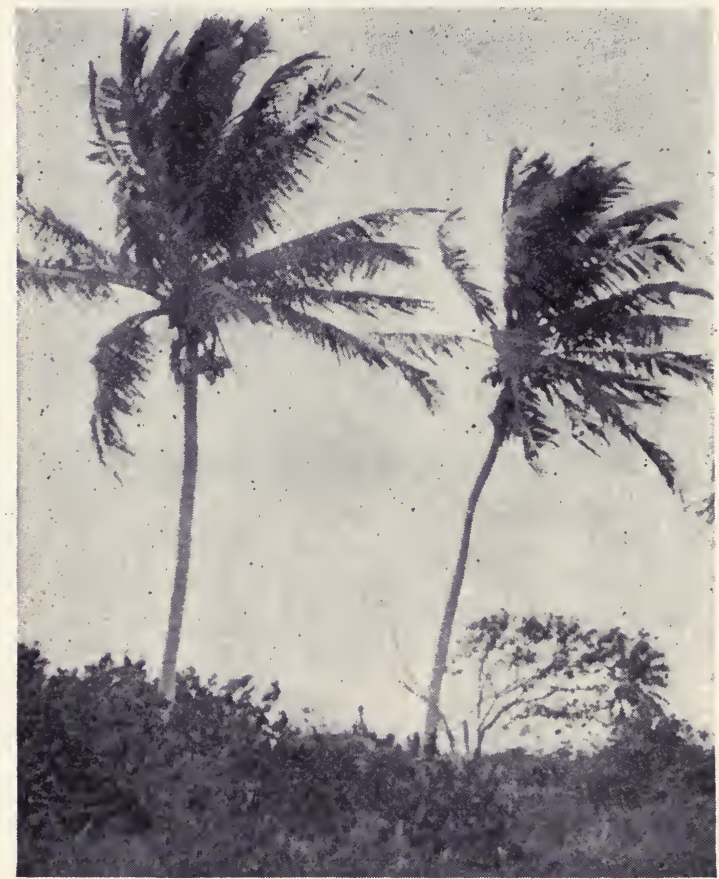

Fig. 150.-The coconut palm is the most important economic plant of the tropics; bunches of coconuts hang beneath the leaves in the palm at the left.

rounding the single large seed. Dates are red or yellow in color, turning purplish brown when ripe. They have a greater food value than most fruits; like bananas, they are rich in carbohydrates and proteins. Date palms have been known to bear fruit for over a century. Since they require less water than any other fruit tree, they have assumed great importance in desert regions where they often form groves known as oases around 
water holes. The cultivation of date palms was introduced into Florida and California by Spanish missionaries during the sixteenth and seventeenth centuries. Date "gardens" are, however, chiefly developed in the hot Coachella valley of southern California. Mesopotamia produces $80 \%$ of the world output of the commercial dried date.

The coconut palm, (fig. 150) most important economic plant of the tropics, is a tall slender tree whose smooth gray trunk is a marked contrast to the massive rough one of the date palm. The

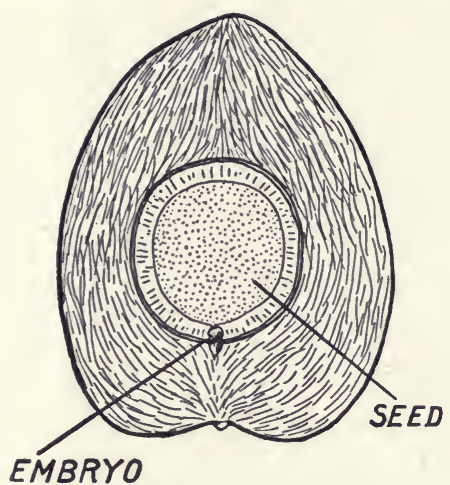

Fig. 151.-Coconut fruits are dry drupes with a fibrous brown portion enclosing the seed, which is the coconut of commerce.

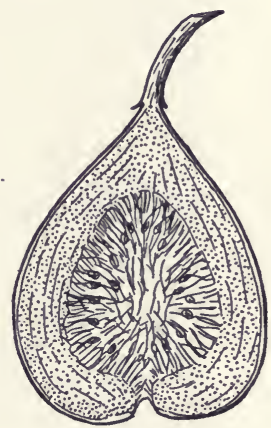

Fig. 152.-The fig fruit develops from a hollow receptacle surrounding numerous small achenes.

foliage is somewhat similar, consisting of large pinnately compound leaves. Coconut palms are ragged and wind-swept in appearance, and usually have a characteristic leaning habit. The coconut palm, no longer found in the wild state, may have originated in the Malay archipelago. But since all the other species of the coconut palm genus are native to South America, it may have originated there and been dispersed westward to the Pacific islands in prehistoric times. Today coconut palms are common along seacoasts throughout the tropics. The fruits (fig. 151) are three-sided dry drupes with a smooth rind, an outer fibrous brown portion and a hard stony inner region which forms a shell 
enclosing the seed-which is the coconut of commerce. The coconut meat and milk are the soft endosperm of the seed, while the embryo is located in the hard endosperm. The dried coconut meat, or copra, has a considerable oil content (up to $65 \%$ ); such

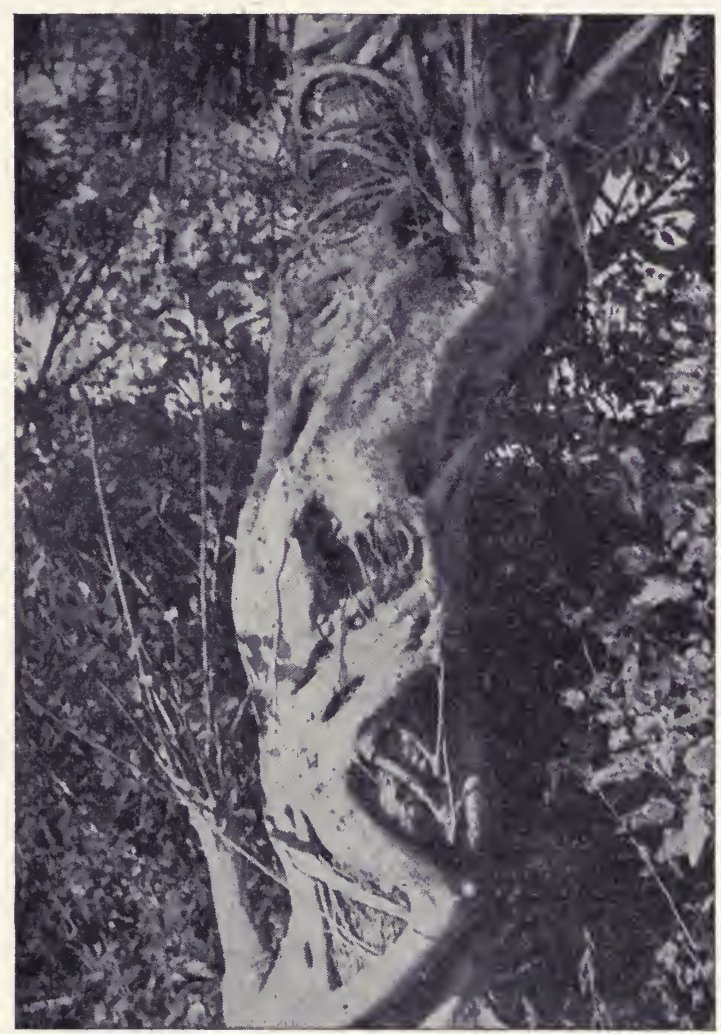

Fig. 153.-The strangling fig (Florida) is an epiphyte which eventually strangles its host to death.

dried coconut, used in confectionery and cooking, comes mostly from Ceylon. Most coconuts are gathered from uncultivated trees, although plantations are being developed in India, the Philippines, Dutch East Indies and Ceylon. In the United States fruiting trees are found in southern Florida. Other important uses of the coconut palm include the manufacture of oils and 
oil cakes, palm sugar, palm wine, roofing materials, and coirthe staple cordage of the tropics.

The Mulberry Family, which is represented in the United States by the osage orange and the mulberries, has two important tropical members. The FIG tree, originating in Arabia, has been cultivated since earliest times in the Mediterranean region. It is a shrub or small tree with a peculiar accessory fruit (fig. 152) in which the edible portion is a fleshy hollow receptacle surrounding numerous small achenes. The strangling fig (fig. 153) is an American species which grows as an epiphyte in the tropical part of Florida. The most important species is the Smyrna fig, grown in Asia Minor, Greece, Algeria, Portugal and California; this variety produces no staminate flowers and is dependent upon another variety, the caprifig or wild fig, for pollination and fruit formation. This is brought about by a tiny wasp which hatches in the

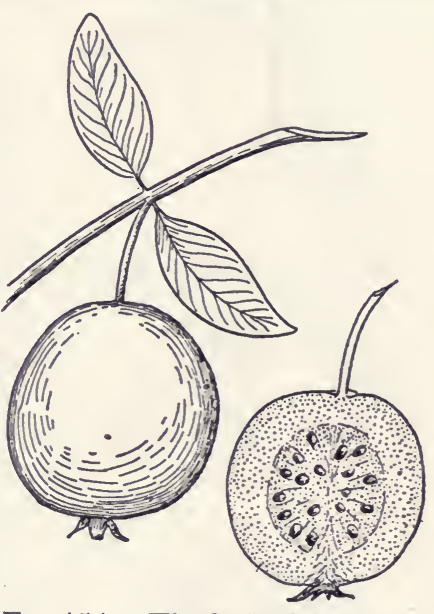

FIG. 154.-The fruit of the guava is a large yellow berry. staminate flowers of the caprifig and carries pollen with it when it emerges. Fig trees were cultivated in the mission gardens of California a century ago; but when first grown as a crop, growers were ignorant of the importance of the caprifig wasp so that fig trees produced no fruit until this necessary insect was imported, together with some wild fig trees. Figs are eaten fresh, but the majority are dried, canned or preserved. California and Texas produce most of the domestic crop, which was 35,000 tons in 1935.

The BREADFRUIT tree, another important member of the Mulberry Family, is a native of Malaya which has become widespread throughout the tropics. The prickly berry-type of fruit is an important vegetable, being eaten fresh or cooked in a variety of ways. Each breadfruit is the size of a melon, and has a fibrous yellow pulp. 
The guava is a tropical American fruit belonging in the Myrtle Family; it is a shrubby tree which was cultivated by the Incas and other early Americans. Guavas have recently become of importance as a small fruit in California and Florida, the yellow berry-type of fruit (fig. 154) being used in making jellies

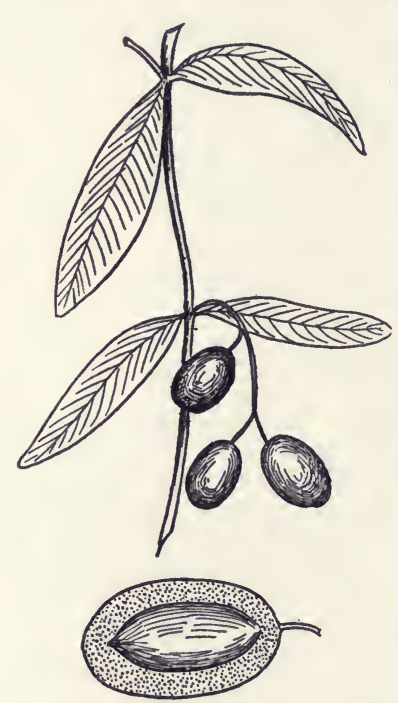

FIG. 155.-The olive, known from 1500 B.C., is an ancient Mediterranean fruit. and preserves. It is also delicious when eaten fresh, being aromatic and juicy. The olive, known from 1500 B.C. in Egypt, is an ancient Mediterranean fruit (fig. 155); it is still cultivated primarily in that region. The Olive Family is represented in the United States by our native ash trees and the cultivated Forsythia, lilac, jasmine and privet. Olive trees are small evergreens with grayish green leaves and inconspicuous flowers which produce the one-seeded stone fruits. Olives are very rich in oil, and are noted for their high food content. They are usually picked green and pickled in brine, before being eaten; a large proportion of the crop is made into olive oil. Spain, Italy and Greece are the chief olive growing countries. The United States produces about $60,000,000$ pounds of olives annually, most of them in California orchards in the central and southern parts of the state. Olives are grown to a much lesser extent in Arizona and Florida.

The PERSIMmon is native to eastern United States and China; the indigenous species, found from Texas and Florida to Connecticut, is a hardy tree but its fruit is little used. The Japanese persimmon, a tree forty feet tall, produces the edible orange-red berries which are eaten as a table fruit. Persimmons are grown in California, Texas and the gulf states.

The Pineapple Family is represented in our southeastern states by the so-called Florida moss, which is not a moss but a flowering plant with small leaves and inconspicuous flowers, draping trees of the southeastern states with festoons of grayish 
green. Florida moss is an epiphyte, living entirely on what sustenance it can get from the air. The PINEAPPLE (fig. 156), on the other hand, is an earth-growing plant with the usual root system; it is perennial, producing rosettes of bayonet-shaped, sharply pointed leaves and flower clusters in a dense head. Above the fused flower cluster there develops another, smaller rosette of foliage. The entire inflorescence forms a compound accessory

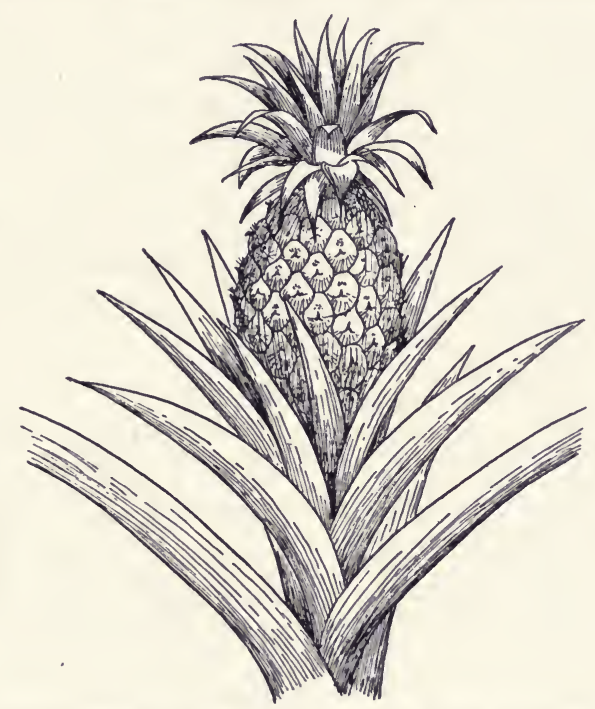

Fig. 156.-Pineapple is a perennial with a stem densely clothed with sharply-pointed leaves.

fruit, made up of fused petals, sepals, bracts and floral axes. In addition to fruit acids and sugar, pineapples contain a digestive enzyme known as bromelin. Pineapples are one of the few tropical American fruits to be developed as a commerçial crop. A native of northern South America, it was being cultivated by the natives of Peru and Mexico before the arrival of the Spaniards, who introduced it to the West Indies, Asia and Africa. Hawaii leads in the production of pineapples for canning. Cuba, Puerto Rico and Central America supply the United States with the fresh fruit. 


\section{Chapter 12 \\ SUGAR-PRODUCING PLANTS}

To the chemist, SUGAR may mean any one of a number of carbohydrates forming a sweet solution in water, and producing a colorless solid when crystallized. In everyday life sugar refers to the common sucrose, a particular type of sugar with the chemical formula $\mathrm{C}_{12} \mathrm{H}_{22} \mathrm{O}_{11}$ (cf. p. 130). Other sugars with this same formula are known to exist, but they have a different arrangement of atoms within the molecule. Similarly glucose, the first

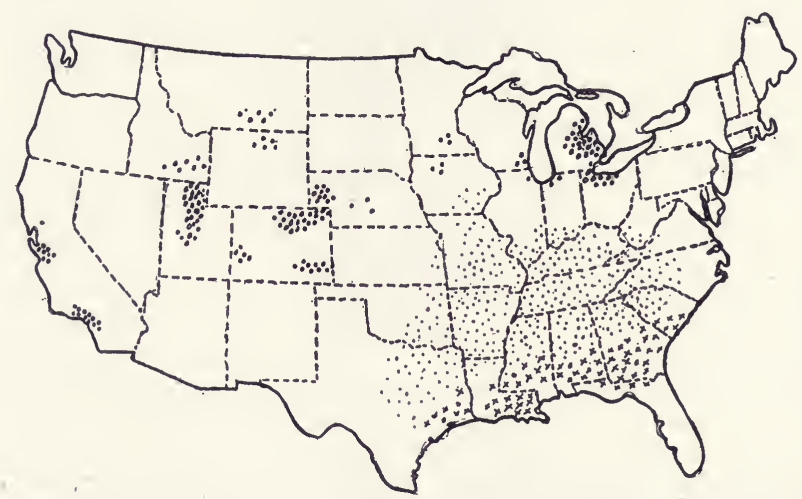

Fig. 157.-Distribution of acreage devoted to raising sugar; sorghum in dotted area, circles indicate beet area, and crosses indicate cane areas.

formed sugar in plants, is only one of several sugars with the general formula $\mathrm{C}_{6} \mathrm{H}_{12} \mathrm{O}_{6}$. As shown in Chapter 6, sugars are energy sources for growth and reproduction of plant life; but they are also important energy sources for the many and varied activities that characterize the daily life of man. Glucose can be assimilated by the human body without change, hence is manufactured in large quantities from starches (see Chapter 23) for use in feeding infants and invalids. Sucrose is assimilable with only one chem- 
ical change, while starches, fats, and proteins must undergo a more complicated series of digestive processes before they are ready to be carried out to the tissues for energy release. The inhabitants of temperate zones now consume most of the world's sugar crop, which is exceeded in value only by such crops as wheat, corn, rice, and potatoes. In spite of the fact that sugar is produced as a storage food in many different plants, our commercial supply of this commodity comes from a few plant species - sugar cane, sugar beet, various kinds of sorghum, the sugar maple, and several kinds of palms (fig. 157).

\section{Cane Sugar}

Sugar GANE is not known to exist in the wild state, hence the geographical origin of the plant is in doubt; it may well have originated in southeastern Asia, since as long ago as 327 B.C. this plant constituted an important crop in India. About a thousand years later the growing of this crop had spread to Spain and Portugal, whose seafaring adventurers were responsible for its dissemination to various tropical parts of the New World, the plant having reached the United StatesLouisiana-in 1751. About this time the sugar industry was already well established in Cuba, which is sometimes called the "world's sugar bowl" because of its large scale production of cane sugar. Today this

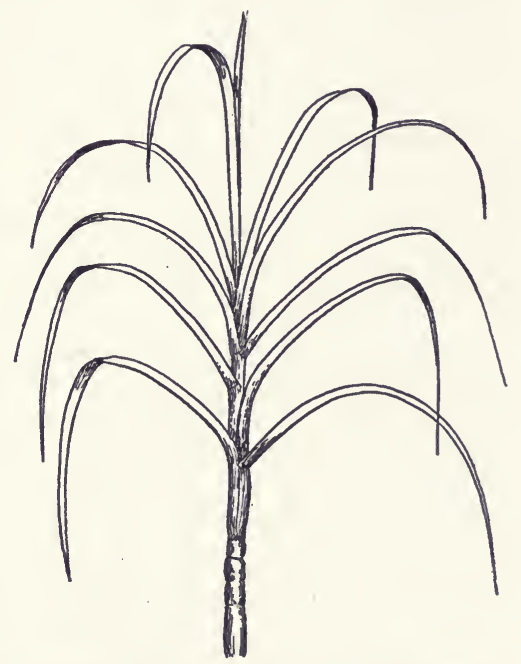

FIg. 158.- Sugar cane is a perennial grass with solid stems, growing to a height of fifteen feet. constitutes the principal export crop of tropical regions over large portions of the earth, since sugar cane flourishes in any hot moist climate. The plant itself (fig. 158) is a perennial grass which grows from six to fifteen feet high, with solid stems one to two inches in diameter. It is propagated principally by means of 
cuttings taken from the upper regions of old stems, and planted in level, deeply plowed fields, where they sprout in about two weeks. For the first few months, until the young canes are well established, constant care in weeding, cultivation, and frequent fertilization is necessary; later demands on the part of the plant are mainly for water and heat, which is abundantly supplied by tropical precipitation and sunshine. From ten to twenty months of growth, depending upon location and climate, is necessary to mature the cane crop to the desired sugar content. This is closely watched so that the cane may be cut at exactly the right time, usually found to be when the flowers of the cane are just past their prime. A delay beyond this time would give a decreased yield since sugar, stored temporarily in the stem, is transported to the developing seed where it is changed into starches and fats. The stems are cut close to the ground with a heavy knife and the underground parts left to sprout again, giving two or three more crops before replanting is necessary. Sugar cane culture in southern Louisiana, Texas and Florida is only moderately successful, since there is seldom the required length of a frost-free growing season to properly mature the cane. Frost is ruinous to cane, causing formation of undesirable by-products in the plant tissues.

Large central mills for grinding and extracting the sugar cane have now replaced many of the small, primitive, individually owned mills formerly found in sugar producing regions. Here the cane is crushed and rolled between heavy sets of rollers until it is practically dry and devoid of its sugar-containing juices; this residue is used as a fuel in the boilers of the mill, or as a raw material for the manufacture of paper and wall boards. The juice contains sucrose and other sugars, as well as numerous impurities. The latter are removed by a series of purifying processes involving straining or filtering to remove solid particles, heating with the addition of sulfur to precipitate protein substances, and of lime to neutralize acids and to precipitate other soluble substances, and finally the removal by filters of all precipitated substances. The filtered juice-clear, dark colored and containing only sugars and closely related carbohydrates-is now ready for concentration. This is brought about by boiling the juice in great open kettles or vacuum pans until the desired 
consistency is reached; at this point the sugar separates from the syrup (molasses) in the form of crystals, which are removed from the liquid by centrifuging or whirling the mass rapidly in a large perforated pan. As a result the liquid is separated from the sticky crystals which are washed with a fine spray of water, dried, and packed into containers. Crude sugar is brown in color and about $96 \%$ pure. The molasses is often boiled repeatedly to remove practically all of the crystal sugar, after which it may be used in the manufacture of rum (see Chapter 14) or industrial alcohol, in cooking or candymaking, or as a component of a valuable cattle food consisting of the pressed fibrous cane mass sweetened with the molasses, and known as molascuit.

The sugar is transported in the raw or crude form from the producing centers to the great consuming regions of the United States and Europe, where refining, the final step in its preparation for the market, takes place. In this process the crystal sugar is first washed to remove dirt, then dissolved in hot water, filtered, and passed through bone black to whiten it. The resultant clear, colorless syrup is recrystallized by boiling and centrifuging. A reduction of about $7 \%$ of the crude sugar occurs in refining, one hundred pounds of raw sugar yielding about ninety three pounds of refined sugar, and about three quarts of refined molasses. Loaf and cube sugars are produced by adding a warm sugar solution to granulated sugar and molding it either in familiar sized cubes or in larger blocks which are then sawed into cubes of the desired size. Powdered sugar is manufactured by grinding granulated or imperfect pieces of loaf sugar into a powder, then sieving through a fine mesh cloth, and finally adding a small amount of starch powder to prevent lumping. In recent years India has led in the world production of cane sugar, followed in order by Cuba, Japan, the Philippines, and Hawaii. The United States is the world's greatest user of sugar, averaging about two pounds per week per person, while Europe as a whole averages about threefourths pound per person per week.

\section{Beet Sugar}

The SUGAR BEET is the most recently exploited of man's sugar producing plants. The existence of sugar in beets was demonstrated about 1750, but no commercial development was begun 
until fifty years later when Napoleon encouraged its growth in Germany and France as a part of his economic warfare on Great Britain. With his fall from power, interest in beet sugar waned for

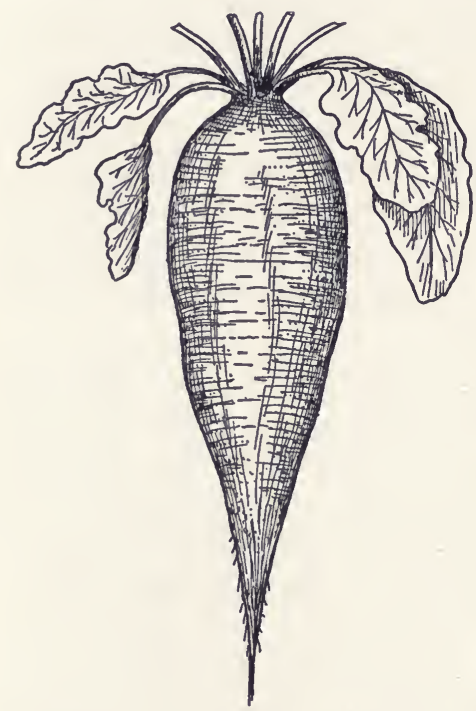

Frg. 159.-The sugar beet plant is a white-rooted variety of the common garden beet. almost thirty years, only to be revived again in the two countries mentioned where it has been increasing in importance ever since. The sugar beet industry has been carried on successfully in the United States since about 1880. The plant (fig. 159) is a whiterooted variety of the common garden beet which develops best in regions of warm summer temperatures and cool fall weather, such as exists in the northern parts of the Great Plains region and in the western mountain states. Semi-arid regions that can be irrigated, as well as naturally moist, fertile soils are suited for its growth. Sugar beets are grown in rows, from seed planted in April, and the final stand is thinned to a spacing of eight to ten inches apart. Weeding, and deep cultivation by machine, are necessary during the growth of the crop.

The plants are harvested in October, the tops removed to prevent any utilization of the sugar, and stored until ready for transportation to the mill. Here the roots are cleaned, cut into thin strips and exposed to hot running water in a series of tanks. In this way $97 \%$ of the sugar is extracted from the pulp which is then used, wet or dried, as a cattle or sheep food. The nonsoluble and soluble impurities in the raw juice are removed by being precipitated and coagulated after which the juice is filtered free of them. This process may be repeated several times, until a clear liquid is obtained which is then concentrated. The sugar is crystallized and separated by centrifuging as in the processing of cane sugar. The raw beet sugar obtained in this 
way is identical in composition and appearance to raw cane sugar. The molasses remaining after several boilings and centrifugings is used in stock foods and as a source of industrial alcohol. The beet tops are valuable both as a cattle food and as a fertilizer, and the impurities removed from the beet juices by filtration also constitute a desirable fertilizer. The great European countriesGermany, Russia, and France-lead the world in production of beet sugar at the present time. However, the United States produces over a million tons annually, mostly in Colorado, California, and Michigan. During the last twenty years, the quantity of beet sugar produced has been about one-half that of cane sugar, although at various times the production of beet sugar has equalled or even exceeded that of the rival sugar cane.

Although the two types of sugar discussed in the preceding pages completely dominate the world's sugar markets, there are several minor sources that are of sufficient interest or importance to be deserving of brief mention. The maple tree is of little or no commercial significance as one of the sugar producing plants of the world, but MAPLE SUGAR and MAPLE SYRUP constitute an important forest product in the region where the sugar maple is best developed-New England, New York, Pennsylvania, Ohio, and the Lake States. Almost entirely confined to farm woodlands, the industry is responsible for over one-half the total cash income of the average Vermont farm. Although all species of maple produce a sugary sap and are sometimes tapped, it is the sugar maple which is the dominant tree in most of the "sugar bushes" or sugar orchards found in the northeast. The production of maple sugar from these trees was discovered and developed in a crude fashion by the American Indians, whom the first white settlers found gathering the sap from cuts in the trunk, in bark or earthen vessels. The juice was concentrated by dropping hot stones into it, and converted into sugar by allowing it to freeze, with a resulting crystallization of the dissolved sugar. In present day practice, the raw sap is gathered during the early spring by hanging buckets from spouts inserted in holes bored in the trunks. These holes are about one-half inch in diameter and 
located from two to four feet above the ground. The buckets are emptied, generally twice daily, into a large tank on a sled or wagon and hauled to the evaporator. This consists of several large, shallow pans with a fire box underneath, for boiling down to the desired consistency of syrup or sugar. Very little maple sugar is produced today, most of the product being in the form of the familiar light or dark brown syrup, the lighter grades being considered more desirable, and commanding a higher price. Maple syrup produced late in the season is generally darker and has a stronger taste, which makes it undesirable.

The peaks of production of sugar and syrup, according to United States Bureau of Census records, were reached in 1859, when the records were started, and in 1918. In these years, the total production reduced to terms of sugar, was fifty two million pounds. Since 1918 there has been a steady decline in production until at the present time the annual product equals less than one-half that of the peak years.

Several varieties of the genus Sorghum, which also includes the fiber plant, broomcorn, serve as a source of SORGHUM SYRUP. Sweet sorghum, also called sorgo, is native in the tropics and subtropics, but has long been cultivated outside of its native habitat. Sorghum does not require as long a growing season as does sugar cane, hence is much more widely grown in the United States, but most of the production is in the southern states and the syrup is usually consumed near its point of origin. Sixty years ago sorghum was a much more important crop plant than today, due to the increasing production of cane sugar syrups and corn syrups. The juice obtained by crushing the stems of these sweet sorghums is evaporated in shallow pans to the desired consistency of syrup. This process yields a nutritious, distinctively flavored, dark syrup, which is widely used in cooking.

Several tropical palms yield juices which are boiled down to a syrup or sugar for local use in the regions where such plants grow. The coconut palm, wild date palm, palmyra palm, and several of the oil palms are the most used species. The date palm is tapped in much the same manner as the maple, but in other species, the tips of unopened flower clusters are cut off, and the exuding sap collected. Three quarts of this juice, known as 
TODDY, will yield one pound of sugar. Most of the world's production of PALM SUGAR is in India, where the industry is a very ancient one, but still produces over a hundred thousand tons per year. Some of this crude sugar, known as jaggary, reaches European markets.

Honey, although coming directly from bees, has its origin in the nectar of many kinds of flowering plants-particularly clover, alfalfa, buckwheat, linden, mint, and citrus fruits. This nectar consists mostly of the double sugar, sucrose, along with small amounts of the simple sugars glucose and fructose (see Chapter 6). In conversion to honey, sucrose is changed into these two last named types of sugar, and stored up in hives or nests as honey, for future use as food for the bees. Flowers that have a characteristic pleasant odor, due to their essential oils, impart a desirable taste to the honey. This substance, being almost pure sugar in its most easily digested forms, is an excellent human food. It is also used in the tobacco industry and in medicine. Beekeeping is a very old practice, and in addition to yielding honey, probably results in increased efficiency or certainty of pollination of man's agricultural crops. California, the intermountain states, New York, and the north central states lead in the United States production of honey. 


\section{Chapter 13}

\section{FOOD ACCESSORIES AND SPICES}

Spices, like perfumes, have been eagerly sought after by man since before the beginnings of recorded history. Especially in the hot climates - and this is the region which supplies most of the spices - they were used as preservatives of foods long before refrigeration was invented. Indeed, spices played such an important part in the affairs of early civilizations that they were as much in demand as gold, and much of the early exploration was the result of attempts to find other routes to spice-producing regions. A necessity of rich and poor alike, spices commanded fabulous prices, and much bloodshed occurred as the result of various countries' attempts to monopolize the European spice trade. This is said to have been originated by the Arabs, who brought their products from India to Arabia, and finally to Europe. Later the trade in spices was controlled in turn by Venice, Portugalwhich monopolized the spice traffic for two centuries-Holland, and Great Britain. The latter two empires share the present day spice trade, which though not as great as in former times, still accounts for ten to twenty million dollars worth of imports annually into the United States alone. Most spices are imported in the raw or crude form, in order to insure their freedom from adulteration, and are refined or converted to the powdered form in United States factories.

The aromatic properties of spices, like those of perfumes, are generally due to presence of essential oils or some other volatile substance within the plant tissues. Their value to the plants containing them is questionable; they probably represent byproducts of the plant's metabolism. Since some are very sharp tasting and highly irritating substances, their presence may discourage insects and other animals from feeding upon such plants. On the other hand, some of those with a pleasing odor are sup- 
posed to be of value in attracting insects to flower parts, thus insuring pollination; this is based upon the supposition that an odor which is pleasing and attractive to man's olfactory sense would register in like manner upon an insect's organ of smell.

Since spices contain practically no food value, they cannot in a strict sense be classed as foods, although their aroma, when used with foods, stimulates the appetite. Consequently spices and other flavoring materials are commonly called food accessories. During the Middle Ages, spices were regarded as being of considerable medicinal value, but today relatively few are to be found in official drug lists and these are used mainly to hide the unpleasant tastes of other drugs. A few have antiseptic properties, and many are used by the perfume and soap industries (see Chapter 23).

The classification of spices and other flavoring materials is very difficult, since so many different plant parts furnish spices that are put to similar uses. A pumpkin pie may be flavored with cinnamon from bark, nutmeg from a fruit, and ginger from a root. However, two groups are usually recognized; one comprises the spices, hard or dried plant parts that are generally added to the food in a powdered form; and the other is made up of flavoring materials, substances used whole or in the form of a liquid extract to give flavor to the food. There are hundreds of such substances used, but less than twenty - the more common ones used in the preparation of American dishes-are important enough to merit discussion.

\section{Spices}

The most commonly used spice in America is PEPPER, derived from the small, berry-like fruit (fig. 160) of the pepper plant belonging to the family of the same name. This is one of the oldest of the world's spices and long constituted the main item of trade between India, native home of the plant, and Europe. The history of pepper is the history of spices in general, control of the pepper trade having passed from one nation to another in exactly the same order as that outlined in the opening pages of the chapter. Today the pepper plant, a woody climber whose vines are trained and trimmed to facilitate gathering of the fruit, 
is cultivated in India, Ceylon, the South Sea Islands, and Africa. Spike-like clusters of small flowers mature to produce small red berry-like fruits. Upon drying, the fleshy red covering becomes black, and the entire dried fruit constitutes the commercial "pepper-corns." These are ground to yield the familiar black

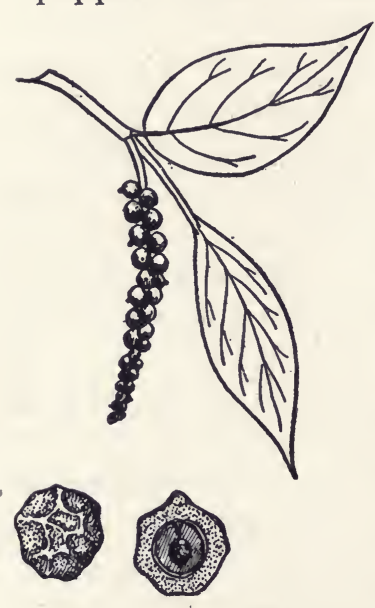

FIG. 160.-Pepper comes from small berrylike fruits whose fleshy red covering becomes black upon drying. pepper. The milder white pepper is prepared by removing, either before or after drying, the outer covering. This leaves the grayish globular seed, which yields the desired product when ground.

RED PEPPER, often known as Cayenne, chili pepper, or capsicum, is tropical America's chief contribution to the spice plants. Several plant species, members of the Nightshade Family (see fig. 121) and therefore relatives of the tomato and potato, native to the West Indies as well as tropical America, yield the orange-red fruits which are so lavishly used in the highly pungent Mexican dishes like tamales and chili con carne. The seeds as well as the surrounding narrowly cone shaped pods contain the pungent principle. The fruits are dried, and used whole or powdered. In addition to its many culinary uses, capsicum is used in medicine as a stimulant and to prevent fever, and in beverages such as ginger ale to give the desired pungency.

MUSTARDS, although grown mainly for their seeds, sometimes have their tops used as "greens" or salad herbs. Two kinds of mustard, black and white, both members of the Mustard Family, are widely grown in temperate regions of the world for the seeds. Both are annual herbaceous plants and tend to escape from cultivation, often becoming troublesome weeds. Ground seeds of both plants are used in the preparation of salad dressings, pickles, sardines, and pastes, with salt and vinegar added. In medicine, mustard and warm water are used to induce vomiting, and a volatile oil extracted from the ground seed is used as a counter- 
irritant. Although most commonly used in the ground form, mustard is frequently used in the whole seed form in the preparing of certain types of pickles.

Our common cinNaMon is obtained from a tree member of the Laurel Family and is native to Ceylon, although now grown in India, Burma, and Malaya, as well as in parts of the West Indies and South America. In the cultivation of cinnamon, young trees are cut back close to the ground and made to sprout from the roots, or produce suckers. These are fast growing, long and slender, and are cut twice a year. The bark is carefully peeled from these young, whiplike stems and scraped, after which it is rolled tightly and dried for shipment (fig. 161). Whole cinnamon, or cinnamon sticks, which are used in preparing some kinds of pickles, consists of short pieces of the rolled bark. More common is the ground cinnamon, which is one of the most popular of spices used in foods. In addition to its ordinary cooking uses,

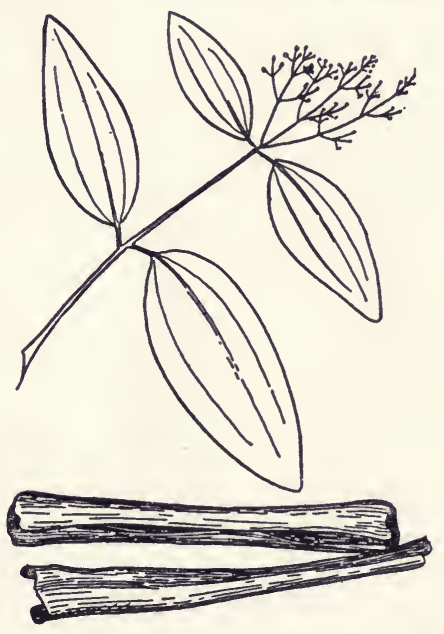

FIG. 161.-Cinnamon is a tree member of the Laurel Family; whole cinnamon consists of rolled pieces of bark from young twigs. cinnamon is widely used in the manufacture of candy, chewing gum, incense, perfumes and soaps. Medicinally, it is sometimes used as an astringent or antiseptic, but more often simply as a flavoring.

The GINGER plant is a perennial herb belonging to the Monocot plant family of that name. This family includes several other spice plants such as turmeric and cardamom, but ginger is the outstanding member of the group. Ginger is obtained from the thick rhizomes, or underground stems, which serve also as a means of propagating and spreading the plant (fig. 162). Due to the ease of dissemination, coupled with the fact that ginger will grow in any moist tropical climate, it is cultivated over a much greater area than most spices. Today its cultivation is 
almost world wide in the tropics. Preparation of ginger for commerce takes two different courses; preserved ginger, a product of southern China, is prepared by repeated boiling of young tender rhizomes in a sugar solution and finally packing in sugar. Dried ginger, a product of the other ginger producing countries, is prepared by sun drying the clean, peeled rhizomes, often followed by dusting with lime to discourage insect infestation. This is the most common type of ginger, generally reduced to a powder for use. Ginger has both an aromatic odor, due to the presence of a volatile oil, and a pungent taste, due to the presence of a resin compound (see Chapter 23). It is much used in the preparation

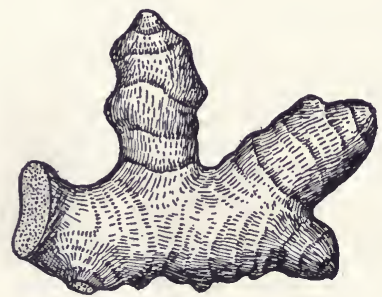

FIG. 162.-Ginger is obtained from thick rhizomes or underground stems of the plant.
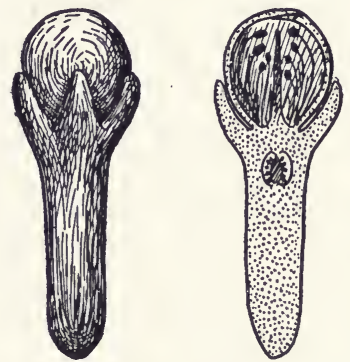

Fig. 163.-Cloves are the dried unopened flower buds of a small tropical tree in the Myrtle Family:

of pastries, pickles, garnishes for meats, and beverages. It is of some use medicinally as a digestive stimulant.

Cloves, also one of the oldest of spices, are the dried, unopened flower buds of a small tropical tree belonging to the Myrtle Family (fig. 163). Today most of the world's clove supply is produced on the small islands of Zanzibar and Pemba, off the African coast. The fresh buds are green to reddish colored, but turn to a dark brown upon drying, after they have been picked from the tree by hand. The tree is hard to reproduce and slow to grow, so that clove growing is an uncertain industry. However, the prepared spice, ground or whole, is used in a great variety of ways as a spice for cooking, in perfuming the breath or person, in beverages, and in medicine. Clove oil, obtained by 
distilling cloves with steam, has many more uses in medicine and dentistry as well as in the perfume and soap industries and in the preparation of microscope mounts of plant and animal tissues.

NUTMEG and MACE, the seed kernel and seed covering respectively of a small tropical evergreen tree native to the Spice Islands (fig. 164), were probably unknown to ancient civilization. The ripe fruit of this tree is golden yellow, looking very much like an apricot or small pear. The yellow, fleshy covering splits when the fruit is mature, revealing a bright red leathery covering over the kernel. This covering, known as the mace, is removed, flattened, and dried, to furnish ultimately the delicately flavored spice used so widely in preparing pastries, desserts, pickles, and ketchups. The kernels or nutmegs are dried, then have their seed coats removed, and finally receive a coating of lime to guard against insect attack. For use, nutmegs are grated or ground, often in the home, after which the granular product is used especially as a flavoring for custards, puddings,

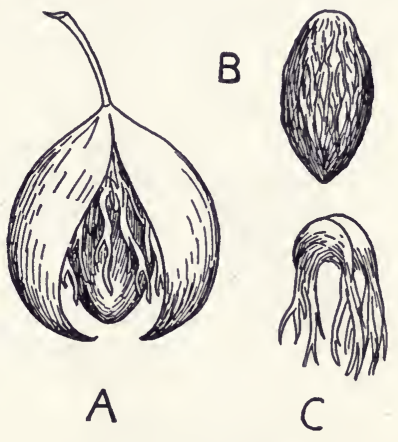

Fig. 164.-Nutmeg and mace are the seed kernel and seed covering respectively of a small tropical evergreen tree; figured above are the fruit (A), nutmeg (B), and mace (C).

pies, and beverages. Nutmeg oil, extracted from the ground product, is used in medicine and in tobacco and perfume manufacture. A fixed oil is extracted and used in soap making.

Allspice or Jamaica PePper consists of the dried unripe fruit of a small evergreen tree native to the West Indies. Jamaica produces most of the world's supply of allspice, the flavor of which resembles that of a mixture of cinnamon, cloves, and nutmeg. Allspice is collected when the small berries are mature but still green, and dried for several days during which time they become more aromatic and turn to a reddish brown color. In preparing pickles, allspice is often used whole, for most other culinary uses it is ground to a powder and used alone or in combination with other spices. The essential oil responsible for the 
aroma of allspice is sometimes extracted for use in perfumes and soaps.

\section{Flavorings}

VANILLA is undoubtedly the most popular of flavoring extracts in use today, as well as having the most interesting origin of the group. True vanilla is produced by a climbing orchid native to the hot, moist forests of Mexico and Central America. The greenish yellow flowers of the Vanilla plant, after special hand
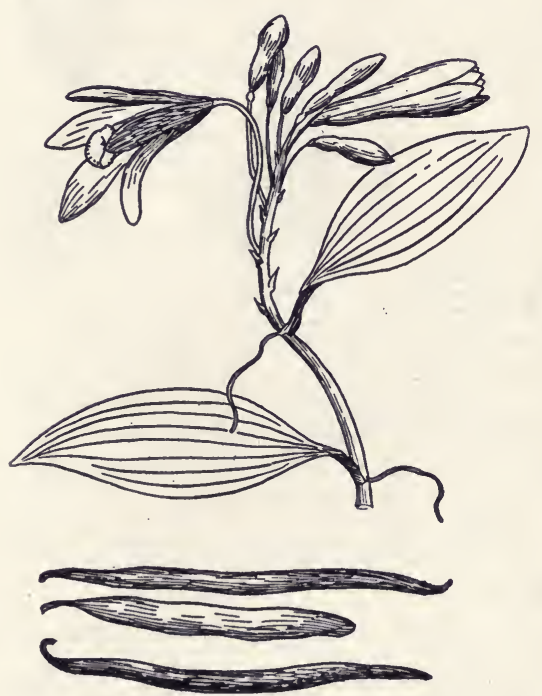

FIg. 165.-Vanilla "beans" are long thin pod-like fruits produced by a climbing orchid of the American tropics. pollination, give rise to long thin podlike fruits known as vanilla beans because of their external resemblance to bean pods (fig. 165). The crystalline flavoring substance, vanillin, is not present in the unripe fruits as they are gathered from the plant, but develops by enzyme action during a curing or sweating process after picking. During this time the yellow pods turn to a dark brown color, and tiny crystals of vanillin may appear at the surface. The final step in the preparation of vanilla is extraction of the crushed "vanilla beans" with alcohol, which dissolves out the vanillin, and is itself marketed as vanilla extract, or simply vanilla. As already mentioned, vanilla is the most universally used of the household flavorings, being commonly used in cakes, puddings, ice creams, candies, and beverages. In addition to being produced in its native home, vanilla culture has spread to the tropical Islands off the coast of South America and Africa, and in the South Seas. Much synthetic vanilla is manufactured from one of the constituents of clove oil. 
The Carrot Family contains several members whose aromatic seeds are used as flavorings. Perhaps the best known of these is ANISE, long valued by the ancients for its reputed medicinal value. This large, annual plant is cultivated in Europe, Asia, and South America for its small, grayish-brown fruits whose odor resembles considerably that of licorice. Anise seeds are widely used as flavorings in cookies, candies and cakes. The essential oil responsible for their aromatic qualities is distilled for use in beverages, perfumes, soaps, and as a flavoring in medicines.

CARAWAY seeds are brown, slightly curved, and tapering, produced by a plant native to Eurasia but commonly grown in temperate regions around the world. They are widely used in and on bread and rolls, in beverages, perfumes, and medicines.

Dill seeds, likewise produced by a native Eurasian plant that is now widely cultivated, are oval, much compressed, and light brown. These seeds, sometimes along with the leaves and stems, are used in the United States principally as a flavoring for the well known dill pickles. In the southern Mediterranean countries and Russia, the seeds and other parts of the plant are used in stews, soups, sauces, and other dishes. Dill seeds, and the volatile oil distilled from them are also used in medicinal preparations.

PARSLEY is a small herbaceous plant likewise of the Carrot Family. It has long been cultivated for its edible, aromatic leaves, which are used in this country

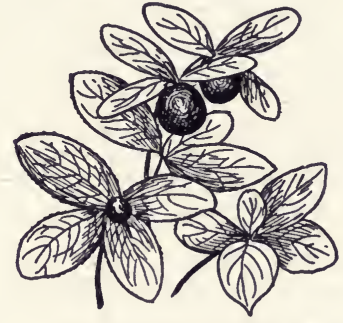

Fig. 166.-Checkerberry is the source of wintergreen oil used in flavoring. mainly as 'garnishes for meats, or as flavorings in stuffings, omelets, soups, and meat spreads. In its native Europe, parsley tops are used as a pot herb, in the same way as spinach and kale are used in the United States, and the roots are utilized as a boiled vegetable.

WINTERGREEN is a native North American flavoring material, originally coming from the leaves of the checkerberry (fig. 166) or teaberry plant, a tiny evergreen plant of eastern North America. At the present time the sweet or black birch, which contains the same substance in its young twigs and bark, has 
practically replaced the teaberry as a source of oil of wintergreen, which is steam distilled from the crushed plant material in water. This flavoring is widely used in candies and soft drinks, as well as being a constituent of numerous medicinal preparations in the forms of linaments and ointments.

The Mint Family contains a number of plants whose leaves are used as flavoring materials, or as the source of essential oils to be used in flavorings. SAGE, a small shrub native to southern Europe but widely grown for its leaves, is well known as a constituent of poultry seasonings and stuffings. It is used in the preparation of other meat products, and sometimes in soups. Oil of sage, distilled from the sage leaves, is used somewhat in perfumes and medicine.

PePpermint, the most important member of the mint family, is a European perennial which has been cultivated in the United States so long that it has escaped and become naturalized.in moist regions all over the country. It has been an important crop plant in parts of this country for over one hundred years, production centering in the moist regions of Michigan, Ohio, Colorado, and the Pacific coast states. Peppermint has a pleasing, refreshing odor and a cool taste, and is considerably used as a flavoring material in the leaf form. More important, however, is the essential oil distilled from the fresh leaves. This is much more widely used as a flavoring material, in the form of essences, for candy, chewing gums, tooth pastes, and drug preparations. It is used both internally and externally as a constituent of medicines, cough drops, nose drops, and inhalants containing the compound menthol. The perfume and soap industries likewise use considerable amounts of peppermint oil or the crystallized menthol.

SPEARMINT is much like peppermint, being cultivated in lesser amounts in the mint growing regions noted above. Like peppermint also, it is a native of Europe but is practically world wide in its present day distribution. Its flavor is like that of peppermint but considerably milder, and it is used, in both fresh and dried condition, as a flavoring for beverages, sauces, candies, chewing gums, and in various medicinal preparations. 
From the foregoing discussion of the number of plants which have become staple adjuncts of the human diet because of their pleasing flavor, it can be seen that early man was interested not only in those plants which could be used directly as foods, but also in those which could be added to foods to make eating a more pleasant pastime.

In fact, man seemed to value such food accessories as pepper, nutmeg, cloves, cinnamon and ginger far more than he did many essential foods; many voyages into unknown seas which resulted in land discoveries of the fifteenth and sixteenth centuries were prompted by a desire to secure these highly prized food adjuncts.

In somewhat the same fashion, as we shall see in the following chapter, man has held in high esteem those plants which could give him pleasing beverages. The story of tea, coffee and chocolate is also a stirring series of adventures into far lands to secure plants which essentially are not a vital part of the human diet, but which even so have come to play an important role in man's search for useful plants. 


\section{Chapter 14}

\section{BEVERAGE PLANTS}

The desire to extract substances from plants which in solution result in stimulating beverages, has led man to capitalize upon two which have a rather wide distribution in nature. One is the drug caffeine, present in the leaves and fruits of a number of tropical plants, but best known in coffee, tea and chocolate. These plants have long been used as the source of the major non-alcoholic beverages. The other is alcohol, produced by the action of yeast plants upon the fruit sugars found in various organs of the plant body. Alcoholic beverages include the wide variety of wines, beer, whiskies, brandies and other fermented or distilled beverages.

\section{Non-alcoholic Beverages}

COFFEE is the world's most important single beverage, from a commercial standpoint. The coffee plant is a native of northern Africa, whence it was transplanted to Arabia some five hundred years ago. For two hundred years the world's coffee supply came from this country; meanwhile the plant was being introduced elsewhere in the tropics, finally reaching Brazil about 1770 . The beverage was slow in becoming established in the New World, although it was in general use in Europe two hundred and fifty years ago. The use of coffee has increased in the United States to such a point that today we import over one-half of the world's entire output. It is truly a beverage of the New World, since Brazil, in an area not much larger than our state of Ohio, produces almost three-fourths of the entire world crop. The inhabitants of Sweden are the only people on earth who reportedly are greater coffee consumers than Americans.

Ninety per cent of the world's coffee comes from the seeds of an evergreen tree or tall shrub belonging to the genus Coffea of the 
Madder Family, which includes also the cinchona or quinineproducing tree (see Chapter 22). Two closely related, larger trees of this genus furnish the remainder of the commercial coffee crop. White, five parted flowers, clustered in the axils of the leaves, are borne three or four times a year; these give rise to the fruits, each of which consists of two seeds surrounded by a fleshy green covering which, as the seeds ripen, changes to red or crimson (fig. 167). The coffee tree will flourish only on a fertile

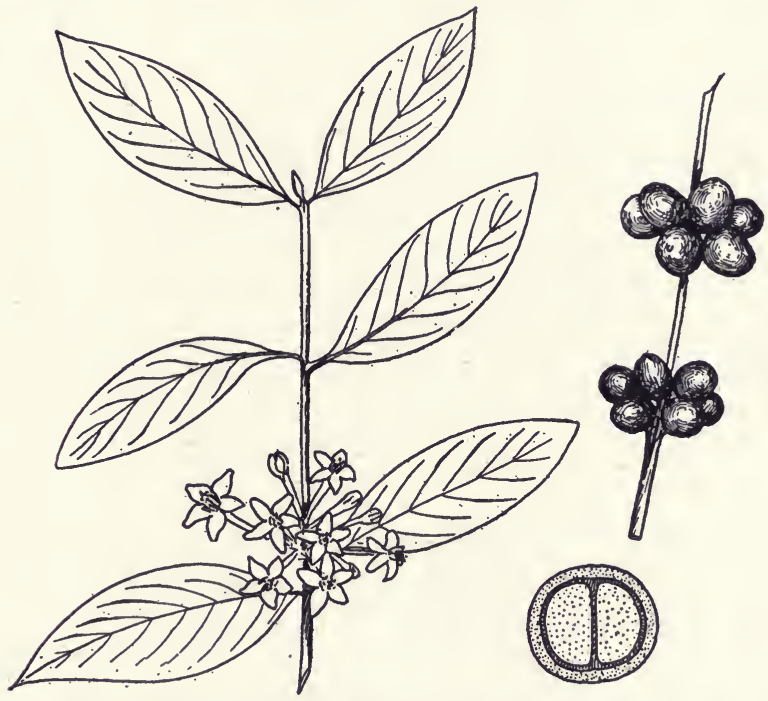

Fig. 167.-Coffee plants produce white flowers clustered in the axils of the leaves; each fruit contains two seeds surrounded by fleshy coverings.

soil in a hot moist climate. The trees, grown from seed, are planted to a spacing of six by six feet, and begin to bear when three years old. The period of best yield begins at about five years of age and continues for a twenty five year period. In harvesting coffee, the ripe berries are usually hand picked and the fleshy pulp removed either by drying and threshing the beans free from their surrounding tissues, or else by a pulping machine which removes part of the fresh pulp, after which the remainder is allowed to ferment and finally washed off. The greenish gray seeds are then dried, graded, and packed in burlap bags for 
shipment. As shortly before use as possible, the coffee "beans" in reality the seeds - are roasted, a process in which the aroma, flavor, and color of the final product is determined. Different varieties of coffee require different temperatures and times of roasting. The content of caffeine, which is the stimulating substance found in coffee and tea, varies around $1 \%$ in roasted coffee. The flavor and aroma are due to the presence of an essential oil, in addition to which coffee contains very small amounts of glucose, dextrin, proteins, and a fatty oil. The food value of coffee is negligible, hence reducing diets permit its use, without sugar and cream.

Coffee, which constitutes the chief source of income of the Brazilian people, like all of man's crops, suffers from diseases and insect pests, as well as from overproduction and low prices. The latter have caused much trouble in recent years, surplus coffee having been dumped into the ocean, and used as fuels in the producing regions. For almost fifty years the island of Ceylon was an important producer of coffee, until a plant disease in the form of a leaf rust (see Chapter 25) ruined the industry.

* $* * * *$

TEA, although not furnishing as valuable a commercial crop as coffee, is used by more people-over one-half the world's population being accustomed to its beverage use. The tea plant is a small evergreen tree or shrub three to four feet high; it was originally native to China or India, but is now grown widely in tropical or hot temperate regions. The lance-shaped leaves have a toothed margin and bear white or pink flowers (fig. 168) $n$ their axils. Since leaves are the desired product, tea plants are constantly pruned back in order to stimulate the growth of new leaf bearing shoots. Methods of cultivation of the tea plant vary with the particular variety (of which there are a thousand or more known) and the location, but all varieties require a very heavy yearly rainfall for proper growth. A great diversity of lands are used for tea culture, varying in altitude from sea level to five thousand feet, often including land that is unsuited to other types of agriculture. They range in extent from the small tea farms of China to the great plantations of Ceylon. 
The tea plants are grown from seed and then transplanted to their permanent growing place, where they become productive at three years of age, reaching full bearing at six and being productive for fifty years or more. The yield varies from two hundred to one thousand pounds of tea per acre annually. The flavor and quality of tea depends upon a number of factors such as the climate and soil of the growing region, age of the leaf, time of picking, and method of preparing the leaves. ORANGE PEKOE tea is prepared from the smallest leaves, successively

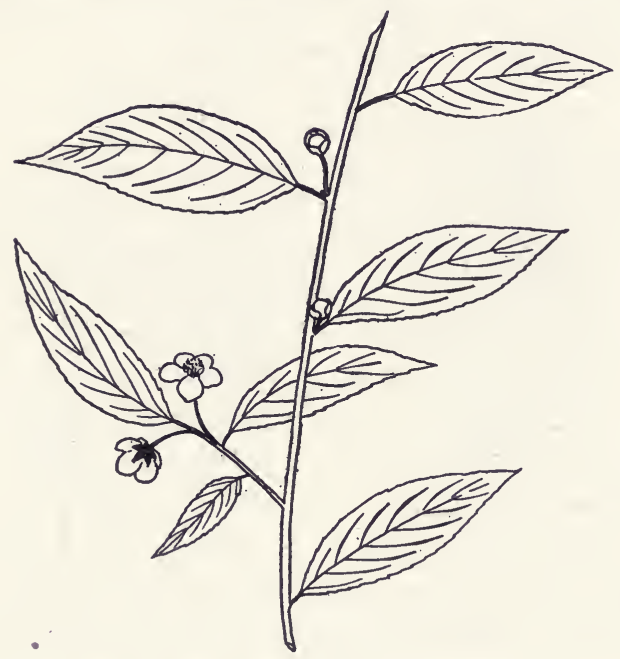

Fig. 168.-Tea plant in blossom.

larger grades of leaves yield teas known as PEKOE, PEKOE-SOUCHONG, and sOUCHONG teas. In preparing green teas from these leaves, they are allowed to remain in the sun until wilted, after which they are rolled by hand or machine, and finally fire or sun dried. Black teas are prepared by covering the rolled leaves to keep them warm and moist, thus allowing them to undergo a fermentation process after which they are dried in the usual way. The fermentation changes both the color and flavor of the leaves. Oolong tea, produced in Formosa, is intermediate between a green and a black tea, being partially fermented. Although China produces almost one half of the world's tea, very little of it is 
exported, the countries supplying the world's tea markets being British India and Ceylon, the Dutch East Indies, and Japan. The tea crop of the world is much less, by weight, than that of coffee, but nevertheless far larger quantities of beverage tea are consumed than of beverage coffee, since one pound of tea will make almost three hundred cupfuls of drink, whereas a pound of coffee will furnish about forty cups. The Orient is the great tea consuming part of the world, followed by England and her possessions. The United States uses less than one pound of tea per person each year, while Great Britain's yearly per capita consumption is between eight and nine pounds.

CocoA and chocolate are prepared from the seeds of the cacao or cocoa tree, a member of the Cacao Family which includes a large number of tropical or subtropical trees and shrubs. The cacao tree is small and sensitive to drying winds and intense sunlight, hence is of necessity grown in protected localities, often in the shade of larger trees. It is a native South American tree, and the beverage was unknown outside of this region until the visits of Spanish explorers in the sixteenth century resulted in its being introduced to Europe. However, cocoa constituted the principal beverage of Aztecs and other South American races long before this. Today, due to the great demands for the product of the cacao tree, its cultivation has spread to other tropical parts of the earth. In fact, the Gold Coast region of Africa leads in cocoa production, furnishing almost one half of the world's supply, being followed by Brazil and other South American and African sources, the two continents producing approximately 99\% of the world cocoa crop.

Cocoa trees are grown from seed, often in nurseries, and the seedlings transplanted to a spacing of four or five feet. They begin to bear in three to five years, and continue to yield for fifty years or more. Rather small flowers, borne directly on the trunk and large branches, give rise to the fruit (fig. 169) which is a cucumber shaped pod about six to twelve inches long, containing thirty to fifty flattened seeds in a sticky pulp. The fruit, which ripens in about four months, is harvested two or more times per year. After the pods are cut open, the ivory to violet colored seeds are scooped 
out and put into large fermentation boxes covered with leaves to prevent drying. Here the remainder of the pulp is liquefied and separates from the seeds, which now become reddish and aromatic. Finally, after being washed, dried, and polished, the seeds are shipped to American and European factories for manufacture into cocoa and chocolate. Here they receive another cleaning, after which they are roasted, a process which develops the characteristic flavor, at the same time decreasing the amounts of tannins-bitter, astringent substances-and increasing the proteins and fats. The roasted cocoa "beans" are broken by
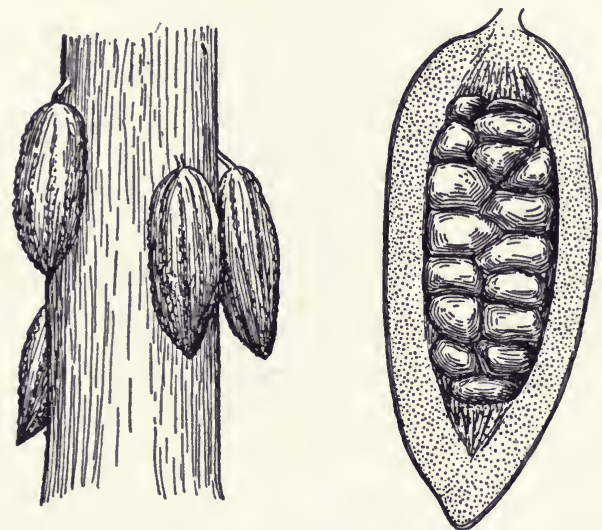

Fig. 169.-The small cacao flowers, borne directly on the trunk of the tree, give rise to cucumber-shaped fruits, each a pod containing thirty to fifty seeds in a sticky pulp.

rollers to remove the shells, and the kernels ground into an oily paste which, upon solidification, becomes the bitter chocolate of commerce. Powdered cocoa is prepared by pressing off about two thirds of the fat, which becomes cocoa butter, from the hot ground paste, and powdering the cooled residue. Sweet chocolate is prepared by the addition of sugar, vanilla, and other flavorings; milk chocolate has milk added, in addition. Cocoa butter does not become rancid, and is used as a base for many toilet preparations which come in a paste, or cream form. The United States uses more cocoa per year than any other country, despite the fact that the per capita consumption of three pounds yearly is far behind that of the Dutch people, the average consumption in 
Holland being almost eleven pounds per person yearly. In addition to containing about $1 \%$ of a gentle stimulant, theobromine, and a trace of caffeine, cocoa is really a food as well as a beverage, since it contains up to $50 \%$ of a fatty oil, and lesser amounts of starch and protein.

Another beverage plant belonging to the cacao family is the colA tree, a West African species producing seeds with a high caffeine content. The beverage, cola, is prepared by boiling the powdered seeds in water for a few minutes. The resultant infusion contains about $2 \%$ of caffeine and is very stimulating. A well known soft drink uses small amounts of cola, and coca leaves which have been extracted of their narcotic principle cocaine, discussed as a drug plant in Chapter 22. The caffeine content of a glass of this beverage is about the same as that of a cup of coffee.

Two other caffeine beverages, both used in South America, are GUARANA, made from the crushed seeds of a woody climbing plant of the Amazon valley, and Yerba maté or Paraguay tea, which is made from the leaves of various holly species growing wild and cultivated in South America.

With improvement in canning and preserving methods, fruit juices are becoming increasingly popular as beverages, in addition to their former use as appetizers before meals. There are several advantages of canned fruit juices over freshly expressed juices; they are more easily available to the user, and they are cheaper than those prepared in the home from fresh fruits. Furthermore, during seasons of overproduction in fruit growing regions, the excess fruit may be juiced and canned, rather than being placed upon an already crowded market at a much lowered price. The development of enamel-lined tin cans has greatly increased the desirability of canned fruits and vegetables in general, and has greatly simplified the process of sterilization over that originally necessary when juices especially were preserved in glass bottles. Likewise, less care is required in handling and transporting the canned products.

\section{Alcoholic Beverages}

Regardless of the favor or disfavor with which alcoholic beverages may be viewed, the fact remains that this type of 
beverage, in one form or another, is used today by all civilized and primitive peoples alike. Physiologically, alcohol is a poison which, even though it is absorbed by the blood stream and eliminated by the kidneys, while in the blood stream serves as a brain stimulant. Alcohol produces upon different individuals a great variety of effects, many of them harmful to the individual and society. Nevertheless, sugar and yeasts being as cosmopolitan as they are on the earth's surface, alcoholic beverages have been with man since before the dawn of history, and since it is impossi-

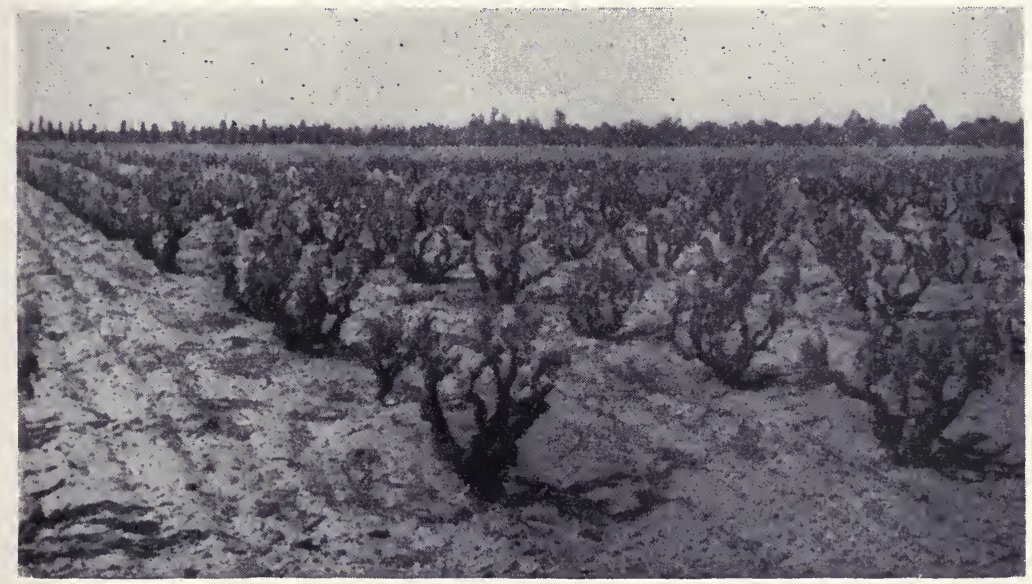

FIG. 170.-A California vineyard in early spring.

ble to prevent yeasts' manufacture of alcohol, it might be well to educate humanity to the proper use of the latter.

WinEs, in addition to being the most important of the alcoholic beverages, are also the oldest, and the cultivation of wine grapes has been carried on for hundreds of years. The European wine grape is the principal variety grown for this purpose, and as one would expect, the industry seems to center in Southern and Central Europe, though the United States, South America, and Australia all produce wines in large quantities. The grape is such a universal wine making fruit that the term wine, used without denoting any different fruit source, is taken to mean grape wine. Wines vary in their strength, flavor 
and color, according to the type of grapes used, the length of time that fermentation is carried on, and the locality and season in which they were produced. All are produced by the action of wild yeasts, which occur on the fruit skins, upon the sugar contained in the fruit. In using the sugar for its growth and multiplication the yeast plant changes it into alcohol, with the liberation of carbon dioxide gas. If wines are bottled while this process is still going on, they produce an effervescence when opened, and are known as sparkling wines, in contrast to the still wines in which the fermentation has been stopped before they are bottled. Naturally fermented wines vary between $7 \%$ and $15 \%$ in their alcohol content; wines with a higher content have been fortified with brandy or alcohol, since the yeasts are killed or rendered inactive by alcohol in concentrations above $15 \%$. France is the chief wine producing country of the world, with its famed Champagnes, burgundies, Bordeaux wines, and many other kinds known all over the earth. Germany, Italy, Spain, and Portugal also produce widely known wines. The United States is fast developing into a first rank wine producing nation (fig. 170), most of these, however, being consumed within the country. California, New York, Ohio, and Virginia lead in the production of domestic wines.

BEER has been a popular fermented beverage ever since the Middle Ages. The early beers were of a dark, muddy color, and it was not until about one hundred years ago that the German beers, lighter in color as well as alcoholic content, replaced these. Present day beer is made by "malting" a grain-generally barley-which consists of soaking it in water for one to four days, then spreading it out to begin germination, which converts the starch into sugar due to the activity of the enzyme diastase. At the proper stage of germination, the malt is dried, then ground, mixed with water to dissolve out the sugar, and the liquid portion drawn off. This is boiled with hops to give it the characteristic flavor and improve its keeping qualities, after which the mixture is fermented to the desired stage by the addition of yeast. After straining to remove sediments, the beer is stored in casks or bottles, where a slight fermentation continues, resulting in the carbon dioxide content which causes the liquid to foam when it is 
poured out. Beverages prepared in this manner contain from $3 \%$ to $7 \%$ of alcohol, in addition to some sugar, dextrin and proteins. Those fermented at the maximum temperatures are known as ales, and have a slightly higher alcohol content than those fermented at the minimum temperatures and known as beers.

Any fruit juice may develop into an alcoholic beverage if unpreserved. Thus apple, cherry and pear ciders all may become "hard" if left in the warmth. Indeed, jugs of apple cider placed in the sun have been known to blow their corks, or even burst, due to the contained carbon dioxide resulting from fermentation. MEAD, prepared by fermenting honey and water, is still used in Africa, and SAKÉ prepared by fermenting rice, is important in Japan and China where it has been used for almost three thousand years. The fermented juice of some of the thick leaved, succulent Agaves of Mexico is used under the name PULQUE.

WHISKIES, BRANDIES, RUM, and GIN are known as distilled beverages, since they are all produced by the distilling of fermented mixtures, thus resulting in beverages of very high alcoholic content. WhiskiEs are distilled from fermented cereals or potatoes. The cereals are generally malted before fermenting, to increase their sugar content. Repeated distillation of the fermented mash yields straight whiskey, which is then aged to get rid of various harsh by-products which develop during the fermenting processes. American whiskies are made from corn and rye, sometimes with the addition of some barley malt. The famous Russian vODKA is a distilled liquor equivalent to the whiskies.

BRANDIES, strictly speaking, are distilled only from the fermented juice of grapes, but the term is more generally applied to liquors distilled from any fermented fruit juice. The finest brandies, known as cognacs, are made in France, but other brandies are widely manufactured from such fruits as apples, peaches, blackberries, and apricots. GiN is distilled from fermented barley or rye, and flavored with juniper oil or other essential oils. Cheap imitations are often produced by adding flavorings to grain alcohol (see Chapter 23). Rum is distilled from the fermented juice and molasses of the sugar cane. It was a popular drink during colonial times, and was distilled in quan- 
tity in New England. Today, however, the West Indies distill considerable amounts of rum, and its use in the United States is much less than in former times. Many other distilled beverages, derived from a variety of plant products but all resulting from the action of yeasts on sugars, are known and used in various parts of the world. 
Part Three

PLANTS AS SOURCES

OF WOOD AND FIBERS 



\section{Chapter 15}

\section{THE PLANT SKELETON}

It has already been emphasized that one of the basic differences between an animal and a plant lies in the nature of the cell wall. The cell walls of plants, consisting largely of cellulose, are hard and rigid; for this reason they can give a permanent shape to the plant body in addition to serving as containers of the protoplasm. Animals, on the other hand, because of the noncellulose character of their cell walls, if cell walls are present, have the soft flesh typical of their kingdom and a body lacking a firm shape unless special supporting tissues are present. Thus all plants, due to the nature of their cell walls, possess a material with some skeletal qualities distributed throughout their bodies. But in addition, many plants have special supporting tissues which function as skeletal elements. These usually involve the addition of lignin instead of the calcium salts which form the customary strengthening substances in the animal skeleton.

Primitive multicellular plants such as the algae are predominantly found in aquatic habitats; thus the generalized skeleton formed by the cellulose walls serves all their needs for support. Kelps can grow to a length of several hundred feet even though they lack special skeletal tissues, since their bulk is partially supported by the buoyancy of the water. Special supporting tissues are likewise lacking among such simple land plants as are found in the Bryophyte phylum. Liverworts, being prostrate in habit, have little need for supporting tissues of any kind. The more erect mosses, however, need stems with some degree of rigidity. This is attained by the cellulose walls plus the turgidity of the cells themselves. TURGIDITY, which accounts for the erect nature of many plants which do not have adequately developed skeletal elements, is the distension of the cell walls due to the pressure of the abundant water within the cell. Turgidity explains the ability of many plants such as mushrooms or suc- 
culent herbaceous species to remain erect provided they have an adequate supply of water. The wilting of many garden annuals during dry periods or after they have been picked is caused by a

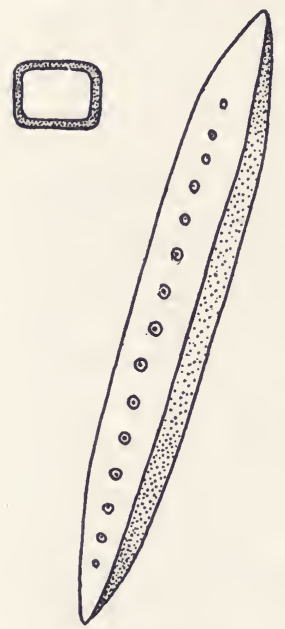

Fig. 171.-A tracheid is an elongated cell with slightly thickened and lignified walls; those of the white pine (illustrated) possess bordered pits in their walls.

Division of labor among the cells of the plant body-which has resulted in special photosynthetic, conductive and reproductive tissues - has likewise brought about special supporting tissues whose cells function primarily for skeletal purposes. Simplest of all are the tracheids of Gymnosperms, which function both for conduction and support. More specialized are the cells of such supporting tissues as collenchyma and sclerenchyma, highly developed among the Angiosperms.

\section{Tracheids}

In a typical conifer such as a pine, the bulk of the support afforded by the trunk is in the wood. Conifer wood is made up of 
the accumulated annual increments of xylem which have fulfilled their function of conduction and remain as the skeleton of the tree. This wood is a homogeneous tissue composed almost entirely of tracheids. A TRACHEID is an elongated cell, angular in cross section, with walls which are slightly thickened and lignified (fig. 171). The chief variation in the character of conifer wood is the result of the difference between tracheids formed in spring and those formed in summer. Spring tracheids have thin walls and relatively large cavities, since they function chiefly for the

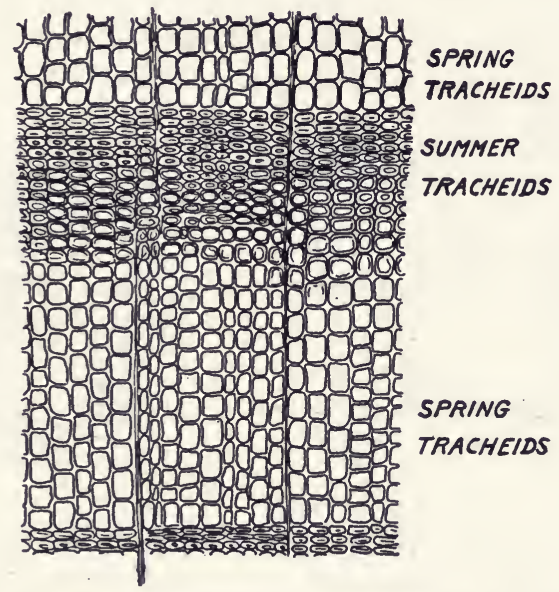

Fig. 172.- In a conifer the annual rings are due to the fact that the tracheids of the spring wood have thinner walls and larger cavities than those of the summer wood.

conduction of water and are correlated with the increased flow of sap which takes place at that time of the year. Tracheids formed in summer are conspicuously different from those formed in early spring, since they function more completely for support and less for conduction, hence have thicker walls and smaller cell cavities (fig. 172). As a result the spring wood is more open and porous than the summer wood; the demarcation between the last tracheids formed in summer and the first tracheids formed when growth is resumed the following spring is the annual ring. Conifers furnish man with a large proportion of his supplies of wood and lumber, derived from this skeletal material composed en- 
tirely of tracheids. Since tracheids have relatively thinner walls than the more specialized sclerenchyma cells of dicots, conifer wood has less solid material, volume for volume, than Dicot wood. For this reason conifers are generally known as softwoods; their wood lacks the strength and density of most Dicot woods, on the other hand the rather uniform nature of the tracheids results in a straight-grained wood which is easily worked.

\section{Collenchyma}

Collenchyma cells are the simplest of the specialized supporting tissues, being intermediate between ordinary parenchyma

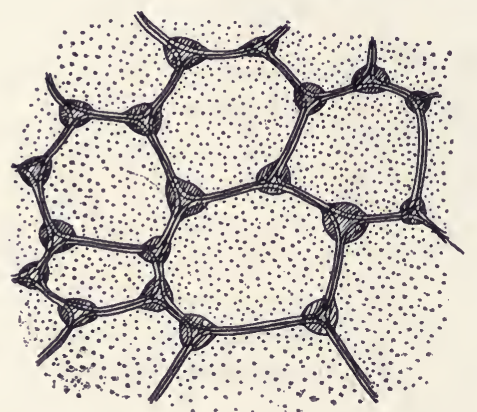

Fig. 173.-Collenchyma cells are the simplest of the special supporting tissues, being intermediate between parenchyma and sclerenchyma.

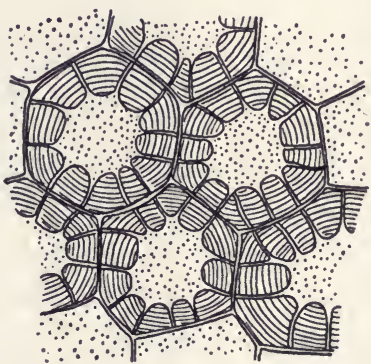

Fig. 174.- Stone cells are shorter than tracheids, and have small cavities surrounded by thick lignified walls.

and sclerenchyma. Collenchyma cells are slightly longer than broad with unevenly thickened cellulose walls, the thickening usually occurring as longitudinal strips at the angles of the cell (fig. 173). They are a temporary supporting tissue found chiefly in herbaceous stems, leaf stalks and veins of leaves where they occur as longitudinal strands.

\section{Sclerenchyma}

Sclerenchyma tissue is of two types-stone cells and fibers. STONE CELLS are the least common and least important of sclerenchyma tissues. Each stone cell (fig. 174) is shorter than a tracheid and has a much smaller cell cavity and thicker lignified walls 
which are often traversed by branching canals extending outwards from the cell cavity. Stone cells lend rigidity to the shells of nut fruits, and form the "pit" or stone of drupe fruits. They are also found in the bark of woody plants where they afford some support to this protective tissue. Both collenchyma and stone cells are of little economic importance.

Fibers are sclerenchyma cells which are greatly elongated, like the tracheids of conifer wood; the extremities of each fiber are pointed or chisel-shaped so that the cells dovetail into one another and form compact strands (fig. 175). Fibers lose their protoplasm and are therefore dead when mature. They are the most highly developed of plant supporting tissues, being flexible enough to bend under tension and strong enough to stand considerable compression. Fibers of stems are found in the pericycle zone, between the vascular bundles and the bark; in the food conducting region of the phloem; and in the xylem or wood. Fibers found in the former two regions of the stem are commonly known as BAST FIBERS, while the xylem fibers are known as WOOD FIBERS. Wood fibers are more completely lignified than most bast fibers and

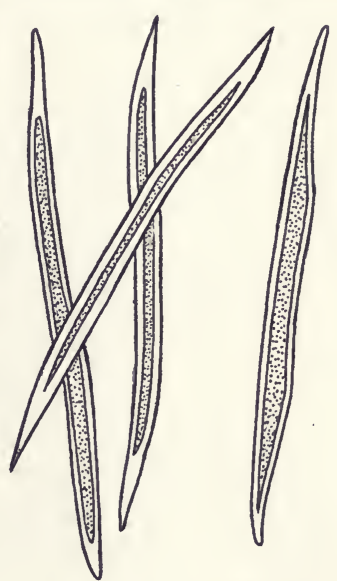

Fig. 175.-Fibers are greatly elongated sclerenchyma cells with pointed extremities; they are known as bast fibers when found in the phloem, and as wood fibers when located in the xylem. make up a large proportion of the wood of a dicot.

The fibers constituting the skeleton of a woody dicot stem are highly specialized, and completely differentiated from the conductive tissues (sieve tubes and vessels). Where the wood fibers are numerous in the xylem, the wood is dense and hard as is typically seen in the oaks or hickories. Many of the commercially important Dicot woods are of this nature and are therefore referred to as hardwoods. However some Dicots such as basswood and balsa are light soft woods because of the preponderance of thin walled skeletal elements. The grain of hardwoods, like that of conifers, is determined by the annual growth of the wood 
elements as well as by the plane in which the wood is cut. Spring wood has an abundance of large thin walled conducting vessels and few fibers (fig. 176) while summer wood has fewer vessels and many more fibers and other supporting elements. Hence the spring wood is more porous and absorbent of stains than the

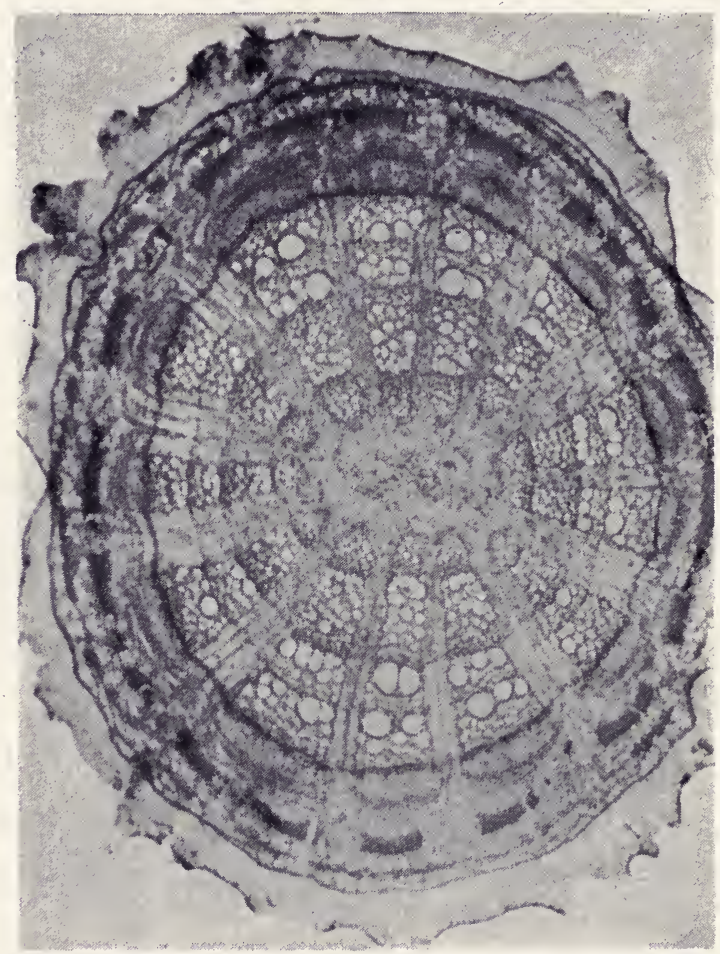

Fig. 176.-A Dicot stem has more and larger vessels, fewer fibers, in the spring wood; the summer wood by contrast seems denser, thus producing the annual ring.

denser summer wood. Grain is also influenced by the texture of the wood, as is seen in straight grained pine wood, the twisted grain of many hardwoods, and the swirling pattern found around knots.

When the fibers are found in the pericycle or the phloem they form tough strands running lengthwise of the stem. Such bast 
fibers have become of considerable economic importance as textiles. In the jute plant the sclerenchyma fibers are developed as part of the phloem. In the hemp and flax plants the bast fibers are found in the pericycle just underneath the bark. Hemp fibers may be nine feet in length and are often lignified. Flax fibers are shorter - usually one to three feet in length-and are less lignified; for the latter reason they are more pliable and suitable for weaving into cloth.

The arrangement of supporting tissues in a Dicot is such as to adequately bear the alternating stresses of compression and tension. If the only strain imposed upon a trunk were

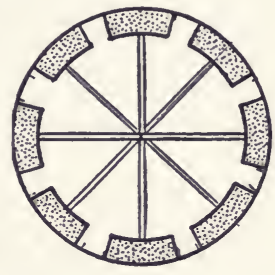
that of compression, resulting from the downward pressure of the weight of foliage and branches, the supporting tissues could be distributed throughout the trunk in almost any fashion. But in addition to supporting the weight, the trunk is continually subjected to sidewise stresses which produce a tension that becomes greater in the outermost regions of the trunk. For this reason the best distribution of the supporting tissues involves their occurrence groups or strands around the periphery of the stem. The engineering design of a tree trunk with its disposition of skeletal tissues is similar to the construction of the I-beams used in building. Such a beam is expanded upon the upper and lower surfaces where there is the greatest stress; these flanges are connected by a narrower central web which needs to bear a lesser strain. Since a plant stem has to meet lateral stresses from all directions, the groups of supporting tissues symmetrically arranged underneath the bark act as the flanges of a number of imaginary girders whose webs - the pith or parenchyma tissuescross each other at the center of the stem (fig. 177).

The distribution of supporting tissues in leaves is correlated with the fact that the upper surface of the leaves is usually under 
a tension while the lower surface is subjected to a compression strain. As in stems the greatest strain comes nearest the surfaces and the least in the center. Thus the supporting strands found in the midribs and veins of the leaves occur just under the epidermis;

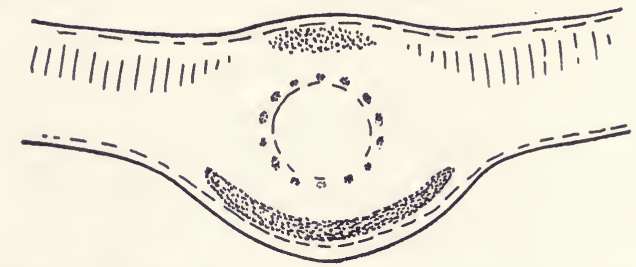

FIG. 178.- Supporting tissues in leaves are distributed to afford support where it is needed most; supporting tissues in dotted areas.

this often consists of collenchyma cells (fig. 178). In many Monocot leaves - for example the grasses - the veins have groups of sclerenchyma cells distributed just beneath the surface cells.

Monocot stems do not produce wood, since there are not the

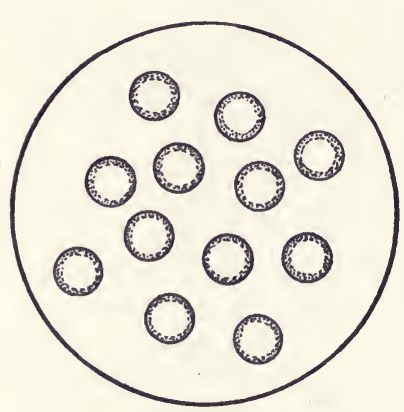

FIG. 179.-Arrangement of supporting tissues in Monocot stems often involves strands of fibers surrounding each vascular bundle. numbers of tracheids or of wood fibers found in conifers and Dicots. In Monocot stems the scattered vascular bundles are surrounded by large amounts of pith parenchyma, a contrast to the compact mass of vascular and supporting tissues forming the sap wood and heart wood of a Dicot stem. The supporting cells are found within the vascular bundles so that each of these acts like one of the rods used in making reinforced concrete. The parenchyma of the stem-which can be compared to the mass of the concreteresists compression while the skeletal strands of the bundles act like the rods in resisting tension strains imposed by lateral bending. Strands of sclerenchyma fibers may completely surround each vascular bundle, or may be disposed on their outer and inner edges (fig. 179). Such sclerenchyma fibers are usually lignified so that they 
are very coarse and stiff. These are the so-called "hard" fibers secured from various Monocot leaves such as sisal and manila hemp. The fibers from sisal hemp leaves reach a length of three or four feet, while those of manila hemp are usually less than a foot in length.

In Chapters 18 and 20 the economic significance of these skeletal elements is considered in greater detail, showing the multifarious uses to which man has put the woody tissues of trees and the fibrous elements of numerous herbaceous plants. 


\section{Chapter 16 \\ THE GYMNOSPERM TREES}

There are three principle types of land vegetation-forests, grasslands and deserts. The type predominating in a given region and the variety of the species comprising it, are dependent largely upon the fact that different geographical areas present varying environments which exclude certain kinds of plants and favor others. Two factors which vary widely over large land areas are climate, especially temperature and rainfall, and soils. Tree growth is closely correlated with ample rainfall during the warm growing season, and a winter without too dry air or high winds. Where the soils are favorable, Angiosperm trees make up the forests of warmer temperate portions of the United States, being deciduous in habit in the region between the Mississippi River and the Atlantic coast. In the cooler temperate regions, however, the common forest trees are frequently Gymnosperms of the conifer group. These are at their best on mountain slopes and highlands where the severity of winter living conditions prevents Angiosperm tree growth; they also thrive on sandy and rocky soils where most Angiosperm trees cannot grow. This fact has led to their being widely used in reforestation work, especially on rugged watershed areas where the soils are too poor to support a good growth of broadleaf or Angiosperm trees which require twice to three times as much nutrient materials in the soil.

Conifers are so dominant in occurrence and economic importance that one often thinks only of coniferous plants when speaking of the Gymnosperms. This group of cone bearing trees, though world wide in its distribution, is best developed in the cooler regions of the north temperate zone, where nearly pure forests of coniferous trees cover widespread areas. The tendency for conifers to grow in nearly pure stands greatly enhances their economic importance to man, since it facilitates the exploitation 
of individual forest products. At the same time, however, pure stands invite destruction by fire, insects and fungi more readily than do mixtures of tree species.

Conifers have a habit of growth known as excurrent (fig. 180); stem growth is all concentrated in one main axis which characteristically forms a straight, undivided central shaft about which are placed the branches. This is in contrast to the deliquescent form exhibited by most broadleaved trees, in which the main

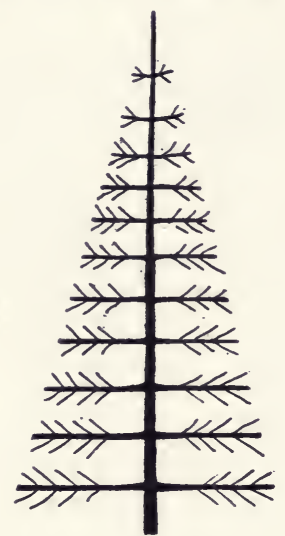

A

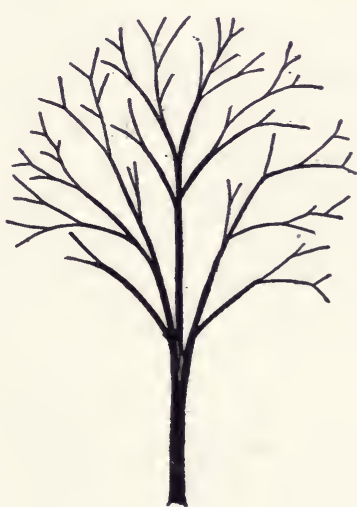

B

FIG. 180.-Trees have two types of branching, excurrent (A) and deliquescent (B); the former is typical of many conifers while the latter is characteristic of most deciduous trees.

stem is often divided several times. The concentration of wood in one central stem makes for greater ease of sawing and higher yield of lumber, since the trunks are straight and free from large knots; this is a further reason for the great importance of conifers over broadleaved trees as timber producers.

The various members of this group are spoken of interchangeably as "conifers," "softwoods," or "evergreens." The first name applies to the seed-bearing structure (cone) found in three of the four families native to North America. The term "softwood" is commonly used by lumbermen to distinguish between conifers and broad-leaved trees or "hardwoods." Very often, however, the wood of a "hardwood" (basswood or poplar) is 
considerably softer than that of a "softwood" (ponderosa or longleaf pine). Similarly, many of the "evergreens" shed their leaves during the winter (larches, bald cypress), and are in actuality, deciduous rather than evergreen. Both the evergreen and deciduous leaf habits have their advantages and disadvantages. The evergreen habit permits the tree to manufacture food during temporary warm periods in the winter season, while the deciduous tree, being leafless cannot do this. On the other hand, the evergreen leaves, though protected by wax coverings against excessive drying, may lose water faster in the drying winter winds than the roots can absorb it from the frozen soil. This is one factor contributing to the appearance of a timberline at high altitudes and in the far north.

The total number of coniferous species native to the United States is about one hundred, distributed through fifteen genera, the most common of which are the pines, spruces, hemlocks, arbor vitaes, and cedars.

\section{The Pines}

The pines (Pinus) (fig. 181) have thick, needle-like leaves which are borne in clusters of two to five, at the tips of very short branchlets which are inconspicuous and drop off when the leaves are shed, after periods of five to seven years on the tree. The cones vary greatly in size and shape but are always pendent and have thick, woody scales upon which the seeds are borne.

This constitutes the largest and most important genus of all the conifers. Excluding Mexico, North America has about thirty five native species of pines, and one or more is of importance in practically every timber producing area on this continent. Eastern North America contains twelve species, while the remaining members of the group inhabit the west.

For the most part, each species of pine has a definite number of leaves per cluster. The eastern white pine, common throughout the Northeast, has five needles in a bundle, the red pine has two, and the pitch pine has three. In most case where two species have the same leaf number, other readily recognizable criteria are available for exact determination. For example, the jack pine and red pine both have two-needled clusters, but the red 
pine leaves are four to six inches long, while those of the jack pine are only about an inch long. The eastern white, western white, and sugar pines all have their needles in fives, but their botanical ranges do not overlap, and they possess differences in length of cones and height of growth.

The EASTERN WHITE PINE referred to above has aided man immeasurably in the development of the United States. For almost three hundred years it was the principal species cut for

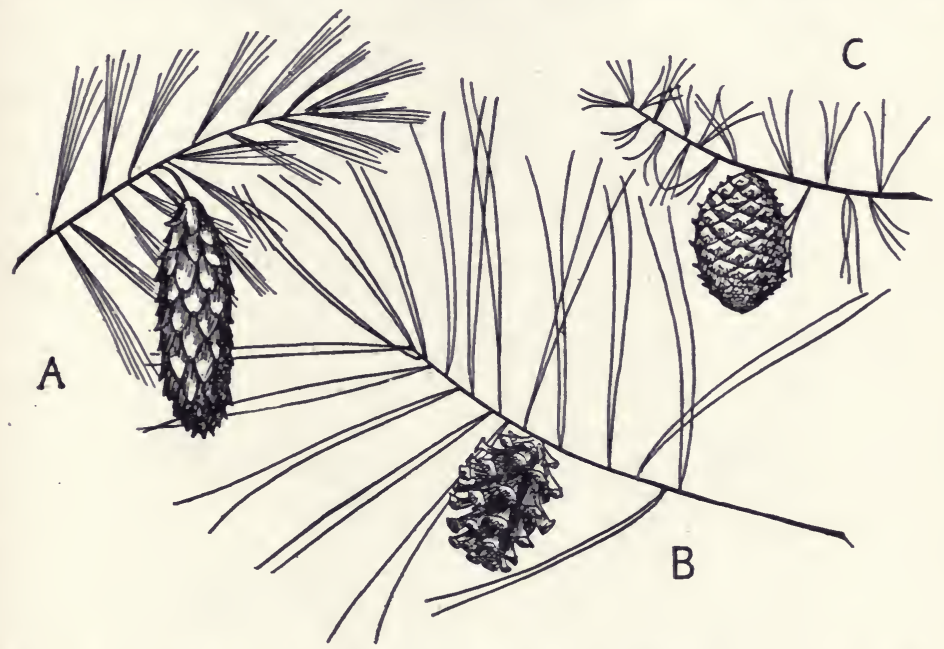

FIG. 181.-Pines have needle-like leaves in clusters; the white pine (A) has five needles in a cluster, the red pine (B) has two, and the pitch pine (C) has three.

lumber, and its sudden decline in the last fifty years is due principally to exhaustion of the once plentiful supply. It is the largest of the eastern conifers, commonly growing to a hundred feet in height and sometimes exceeding two hundred. Its best growth is made on moist sandy loam soils, although the tree will tolerate a wide variety of soil conditions. Its wood is soft and extremely even grained, due to the gradual transition from spring to summer wood. Because of its ease of propagation in the nursery, and its very rapid growth - as much as four feet per year under very favorable conditions - white pine has been widely used as a tree for planting in reforestation. However, a fungus disease, the 
white pine blister rust (see p. 430), and an insect pest, the white pine weevil, have caused a sharp drop in its importance in this respect.

The southeastern forest region, embracing the eleven South Atlantic and Gult States from Virginia to Texas, inclusive, with

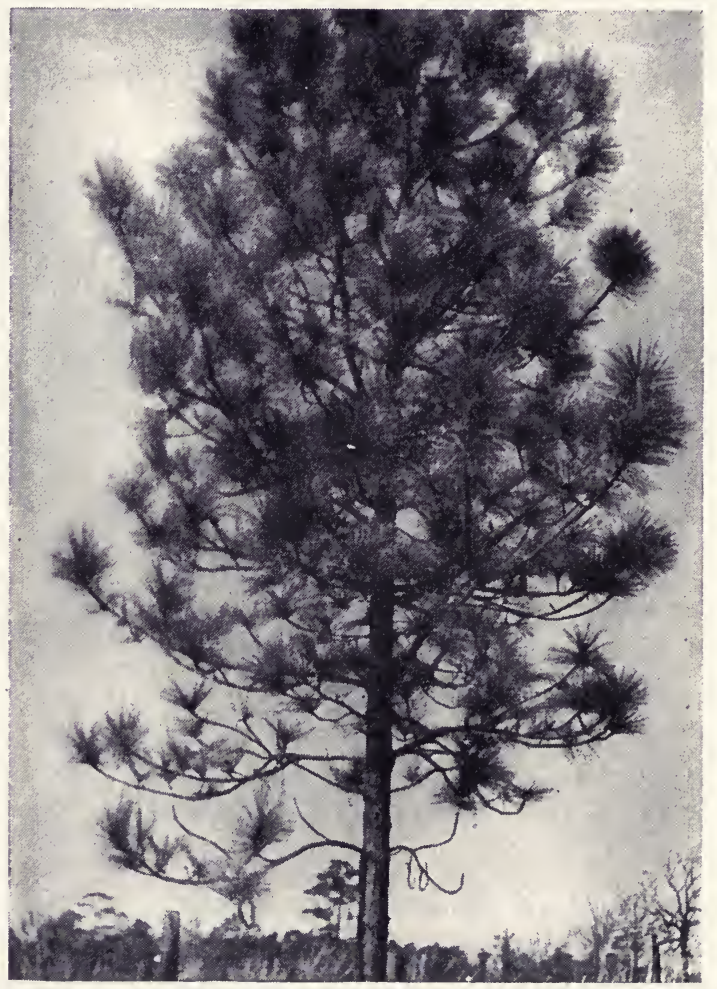

Fig. 182.-The long-leaf pine is a common tree of our southeastern coast.

Arkansas and Eastern Oklahoma is often referred to as the Southern Pine region, since it is dominated by four species of pine. The lumber of these four-longleaf, shortleaf, slash, and loblolly-is known collectively as "southern yellow pine," and for the past thirty years or more has been one of the leaders in the lumber industry. Almost one third of the total annual cut of lumber in the United States is of this group. The most important 
single species is the LONGLEAF PINE (fig. 182), which, in addition to producing lumber, is the source of naval stores (see p. 385). As its name implies longleaf pine has leaves twelve inches or more in length, borne in clusters of three. It is a fairly large tree, averaging about one hundred feet in height; its wood is hard, strong and uneven grained due to the abrupt transition between spring and summer wood. For the first five years or so of its life, the young longleaf pine makes practically no growth above ground, but sends a long taproot deep into the sandy soils upon which it characteristically grows. Following this, it enters upon a period of rapid growth, and trees twenty five years old average forty five feet in height and six inches in diameter.

In western United States we again find large areas of forest growth that are made up chiefly of members of the pine genus. The entire Rocky Mountain region, and the southern Pacific coast region, are covered with coniferous forests whose outstanding individual species are pines. In the Southern Rocky Mountain forest region are extensive forests of PONDEROSA PINE, a magnificant tree growing commonly to heights of over one hundred and fifty feet. The leaves are characteristically borne in clusters of three, although clusters of two are often found on the same tree. It is the most widely distributed pine in North America, and its lumber ranks third in importance on our American markets. It is exceedingly resistant to drought, hence comprises almost $90 \%$ of the merchantable timber stands in Arizona and New Mexico, although reaching its best development in the Pacific coast states where growth conditions are more favorable. In the Northern Rocky Mountain region it is found, in lesser abundance, in company with lodgepole pine and Douglas fir.

Sugar PINE, a five needle pine native to California and southern Oregon, is the largest American pine and one of our finest timber trees. It is closely related to our eastern white pine, and its wood has all of the desirable qualities of the latter. Heights of two hundred feet are not uncommon for this tree and diameters up to ten feet have been recorded. Its long pendant cones, up to twenty six inches in length, are recognizable at a considerable distance. The national importance of sugar pine is limited only 
by its very restricted natural distribution. This is very likely occasioned by its rather exacting nature as regards soil and temperature, since it is unable to withstand drought or extremes of temperature.

\section{The Larches}

LARGHES, or TAMARAGKS (Larix), have thin, needle shaped leaves borne in clusters of more than ten, and shed from the tree every fall (fig. 183). They are placed upon conspicuous, stubby, branchlets which persist after leaf fall and give a ragged, irregular appearance to the leafless branches. The cones are small and thin scaled.

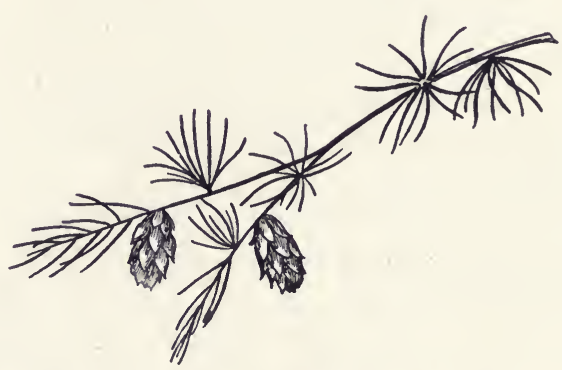

FIG. 183.-Larches have needle-like leaves borne in clusters of a dozen or more, and shed every autumn.

The larches are represented in North America by only three species. One of these, commonly known as TAMARACK, ranges from the northeastern United States northward into the Arctic circle and westward to Alaska. The other two species, WESTERN LARCH and ALPINE LARGH, are trees of rather limited distribution in the northern Rocky Mountains. The tamarack is at best only a medium sized tree, seldom exceeding seventy five feet in height and one to two feet in diameter. Almost always a slow growing tree, it is confined to swamps in the southern portion of its range, but inhabits moist uplands farther north. Western larch is a much larger species, growing commonly to heights of one hundred and fifty feet and diameters of three to four feet. In parts of Montana, Idaho, and Washington it occurs in almost pure stands; in other regions of the northern Rockies it is often asso- 
ciated with Douglas fir and various pines. Both of these larches yield hard, durable woods.

\section{The Spruces}

The SPRUCES (Picea) are characterized by solitary, short, needle shaped leaves, arranged in spirals on the branches (fig: 184). They are sharp pointed, four sided in cross section, and are placed upon prominent woody projections of the stem, which persist after the leaves have fallen making the leafless branches very rough. The cones have thin woody scales, and hang from the branches.

There are seven species of spruce native to the. United States and six of these are of some commercial importance. The red, black, and white spruces are found in the northeastern United States, the last two extending northward to

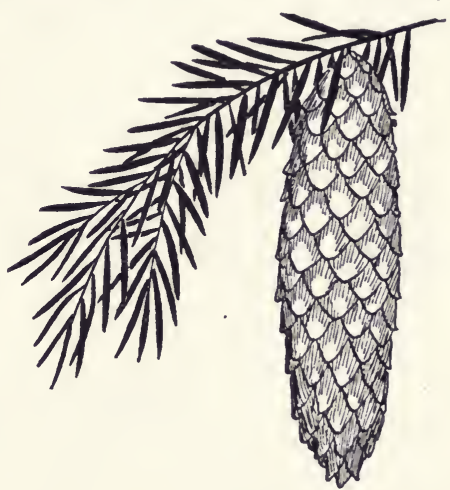

FIG. 184.- Spruces have solitary needle-shaped leaves arranged spirally along the stems. the limit of tree growth in the Arctic, and westward across Canada to the Pacific Ocean.

The RED SPRUCE and WHITE SPRUCE are of great economic importance as producers of pulpwood in spite of their medium size-sixty to eighty feet high by one to two feet in diameter. Red spruce formerly contributed most of the nation's supply of Christmas trees, and today is still widely used in this capacity in New England. Its inability to hold the leaves when cut and taken indoors is responsible for the drop in its popularity as a Christmas tree. Black SPRUCE, due to its small size, which is about one-half that of the preceding two species, is of only slight commercial importance as a pulpwood. It is characteristic of bogs and poorly drained areas, while the two larger species are found in greatest abundance on better drained lands.

Of the three western spruces, two, the ENGELMANn SPRUCE and the COLORADO BLUE SPRUCE, are typically mountain trees, the latter sparingly distributed in the central Rocky Mountain 
region, where it occurs as a fair sized tree associated with other species. The former species is one of wide range, being found at higher elevations in the Rockies from Canada southward almost to Mexico, and in the Cascade Mountains through Washington and Oregon. It is a large tree, reaching a size of one hundred and fifty feet on the better soils, found growing in extensive pure stands or in company with other coniferous trees.

\section{Douglas Fir}

The Douglas fir (Pseudotsuga) is neither a true fir, as its present common name would seem to indicate, nor a spruce as its former common name of Douglas spruce might indicate. It has sharp or blunt pointed, stalked leaves much like those of the

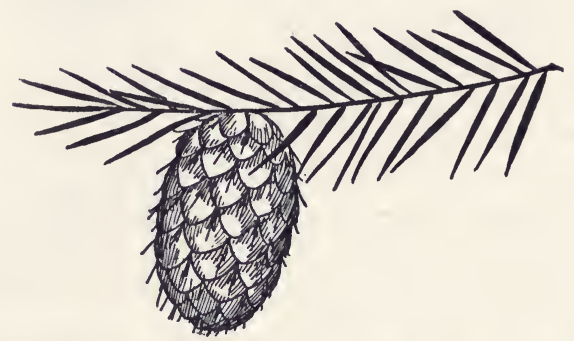

Fig. 185.-Douglas fir has needle-like leaves much like the spruces, but somewhat flattened and borne on minute projections on the stem.

spruces, but somewhat flattened and borne on minute projections of the stem (fig. 185). The cones hang from the branches, and possess three-pronged bracts which extend conspicuously beyond the cone scales.

Douglas fir, which by itself makes up almost $32 \%$ of the timber stand of the United States, rivals ponderosa pine in its widespread distribution, ranging throughout most of the Rocky Mountains from Mexico to Canada, and in all three of the Pacific coast states, where it reaches its maximum development. In fact, it exhibits such difference of form in its Rocky Mountain and Pacific Coast habitats that some consider the two forms as different species.

It is rightly called "monarch of the Pacific Northwest forests," since in this region trees not uncommonly measure three hundred feet in height and eight to ten feet in diameter. The 
largest measured tree of this species was about three hundred eighty five feet in height and fifteen feet in diameter, which would give it the record height growth for a tree in North America. When both height and diameter are considered, it is exceeded only by the giant Sequoias of California. Due largely to the presence of this giant species in both pure and mixed stands forming dense growths, the Pacific Northwest forest has the distinction of being the most heavily wooded region in the world. The great concentration of timber which is found in this region can only be appreciated when it is realized that this forest region, which represents only $13 \%$ of the commercial forest area of the United States, contains $63 \%$ of the total standing sawtimber of the country. About $80 \%$ of the standing Douglas fir is found in Oregon and Washington. Though inhabiting a wide variety of soils, best growth is made on deep, rich soils in regions where both soil and air are plentifully supplied with moisture. The largest trees are commonly five hundred years old, but trees large enough to yield saw logs may be grown in less than eighty years

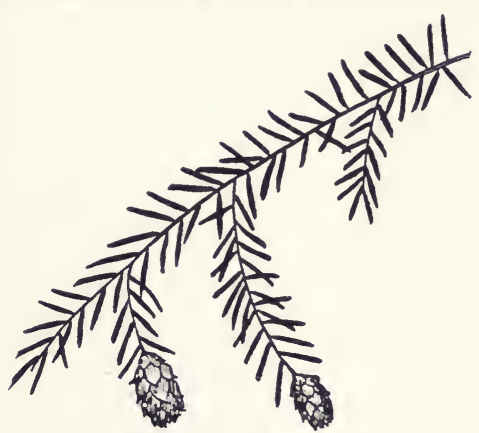

FIG. 186.- Hemlock has solitary flattened needles which are among the smallest of all the needle-leaved evergreens.

since, under favorable conditions, growth is very rapid in young trees. At the present time this species is the most important source of construction lumber and timbers, even exceeding southern pine in quantities produced.

The Douglas fir of the Rocky Mountain region is a much smaller tree, rarely exceeding a height of a hundred and thirty feet. It seems much more able to thrive under adverse conditions than does the coast form, and is commonly associated with ponderosa pine in arid parts of this region. This more resistant form is often used as an ornamental tree in the east.

\section{The Hemlocks}

Hemlocks (Tsuga) have single, spirally arranged leaves which appear as though borne in two ranks (fig. 186). They are 
short, flattened, blunt at the ends and narrowed at the base into short stalks which are attached to woody outgrowths of the stem as in the spruces. The cones are small, and hang from the branches.

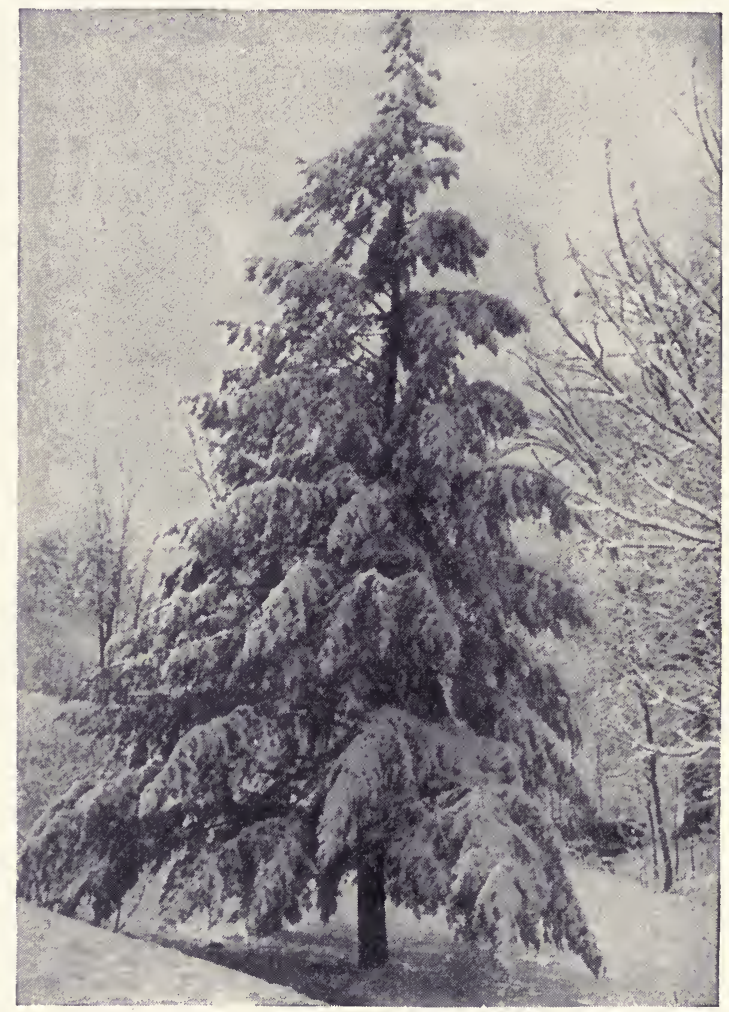

Fig. 187.-Eastern hemlock is a common tree on slopes of ravines; the excurrent type of habit indicated by this specimen is characteristic of most conifers.

There are four species of hemlock native to North America, two of which occur in the east, and two in the west. Only two of these are of appreciable present day economic importance. EASTERN HEMLOCK (fig. 187) is rather generally distributed through northeastern United States, and in the mountains reaches its southern limits in Georgia. As a rule not over seventy 
five feet in height, it may reach twice that in the favorable environment of our southeastern mountains. Hemlock is almost always found in association with other tree species, only rarely as pure stands. Young trees are frequently found making up the "understory" of a forest growth, due to the ability of hemlock to grow in suppression, beneath existing forests of other species, for long periods of time.

WeStern HeMLOCK is by far the most important, and the largest, of the four hemlocks found in North America. It is commonly over a hundred and fifty feet in height (maximum recorded height two hundred fifty nine feet, diameter nine feet), and grows in that region where most trees are giants, namely, the Pacific Northwest, where it has recently become one of the four principal timber trees. Five per cent of this country's sawtimber stand is composed by this species which is just now "coming into its own" as a tree of first rank importance in the northwest. Much of the existing western hemlock is contained in dense pure stands, though it occurs as an occasional constituent in mixture with hardwoods and other conifers. Like its associates, the Douglas fir and Sitka spruce, western hemlock makes its best growth on moist, deep soils, accompanied by a high atmospheric moisture content.

\section{The True Firs}

The true FIRs (Abies) have leaves much like those of the preceding three genera, but differ in several important respects (fig. 188). They are rounded at the apex, flattened, possess no stalks, and are not borne on projections of the stem. The thin scaled cones stand erect on the branches, where the scales fall off leaving the slender, conical, central shafts standing upright, often over the winter.

This genus is represented in North America by ten species, two of which are found in the east and the remaining eight scattered through the western forests. Members of this group have largely succeeded spruce as the nation's Christmas tree, since they do not shed their leaves when taken indoors. Their fragrance, especially true of balsam fir, further enhances their desirability. 
Of the two eastern species, but one, the BALSAM FIR, is of any commercial importance. It's range includes the northeastern United States, following the mountains of the Southeast as far as the Virginias. In Canada it is practically transcontinental in distribution, extending northward and westward to the headwaters of the Yukon. A symmetrical tree of only moderate size, rarely exceeding seventy five feet in height and two feet in diameter, it requires an abundance of moisture for proper development. Under favorable conditions growth may be fast during youth, but the span of life is short, and in older trees wood rotting fungi cause extensive damage.

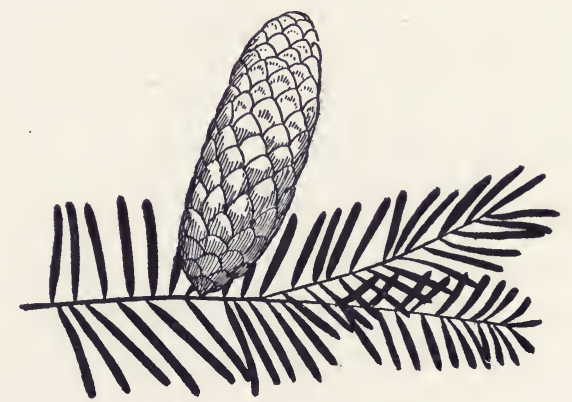

FIG. 188. - The needles of firs are rounded at the apex, distinctly flattened and often very fragrant.

Five western firs are of some economic importance; the LowLAND WHITE, SILVER, RED, and NOBLE FIRS are common in the forests of the Pacific Northwest, while the wHITE FIR is best developed in the Sierras of California. The species vary somewhat with regards to their environmental demands, but all require fairly moist soils and abundant atmospheric moisture for good growth. Their associates in the forest stands are principally Douglas fir, sugar pine, ponderosa pine, western hemlock, and Sitka spruce. It is only ten years ago that the true firs came to occupy a place of importance in the western lumber industry, and it seems certain that their importance is due to increase, since the trees are large in size, and there are large available stands remaining. Estimates place the amount of standing timber of these species at about $8 \%$ of the total timber stand, exceeded only by ponderosa pine and Douglas fir. 


\section{The Redwoods}

REDWOods and BIG TREes (Sequoia) have linear, awl-shaped, or scale like leaves (fig. 189). These may be spirally arranged or borne in two ranks. The cones are made up of thick woody scales which are wedge or shield-shaped. Since the leaves and cones grow so far above man's reach, the bark becomes a valuable identifying feature. It is reddish brown, fibrous, and deeply furrowed, on old trees reaching a two foot thickness.

The Sequoias include only two living species, both of which are confined to rather limited areas in California, in contrast to

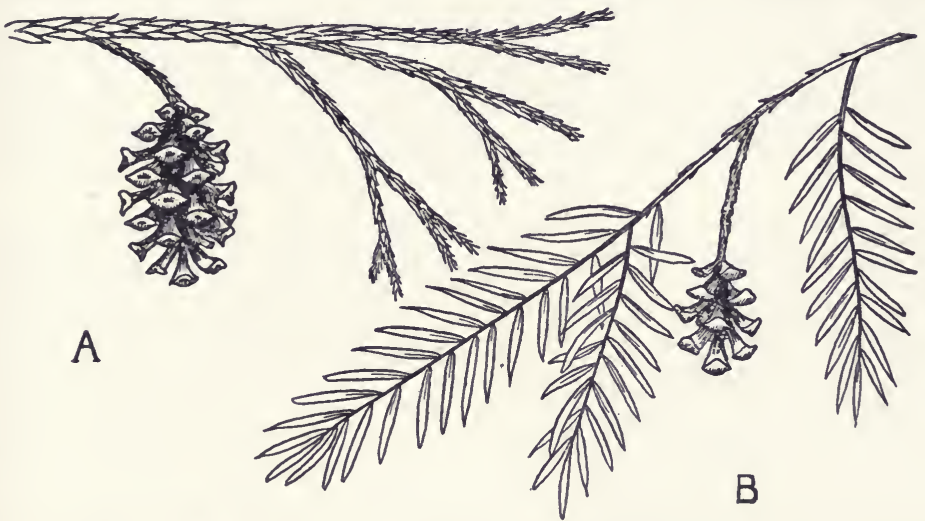

Fig. 189.- Redwoods and big trees differ in both leaf and cone characters; A, big tree; B, redwood.

their former wide distribution throughout the Northern Hemisphere. The REDWOOD, often distinguished as the coast redwood, is striking because of its great height-measured to three hundred sixty four feet,- - and its deeply furrowed, reddish brown bark, which in old trees is very highly fire resistant. Its range is confined to a strip of coast thirty miles wide and about four hundred fifty miles long, from the Oregon border southward to central California - a region visited almost nightly during the growing season by very heavy fogs. In this very limited area, however, redwood occurs in such abundance as to make up $80 \%$ of the forest growth, and constitute $3 \frac{1}{2} \%$ of all the standing timber in the United States! The tree does not reproduce itself well by seed, 
but sprouts readily from the stump, a very rare attribute of conifers. These sprouts grow very fast and reach tree size in an unbelievably short time. According to the rate at which we are using redwood at the present time, there is a hundred years supply remaining.

The BIG TREES, or Sierra redwoods, are known as the largest and oldest of living things (fig. 7). They are found only in scat-

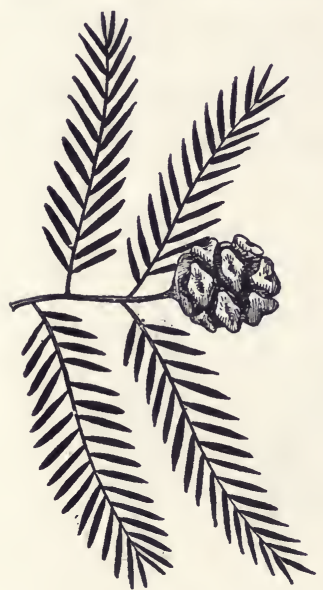

Fig. 190.-The bald cypress has short needle-like leaves arranged on either side of the stems, and shed every autumn. tered groves in a several hundred mile strip of the Sierra Nevada Mountains of California where they occupy an altitudinal range of four to eight thousand feet. Though of lesser height than redwoods (usually about two hundred fifty feet) they reach a far greater diameter, up to forty feet. They are the most majestic of trees, as they spread their massive branches over surrounding forest species which in themselves are giants but which seem dwarfed by the presence of the big trees. Ages reached by these giants have been variously recorded and reported. The oldest authentic record seems to be in the neighborhood of three thousand five hundred years, with an age of four thousand reported, but not authenticated. The wood of the big tree is brittle, but exceedingly durable. Trees which fell a thousand years ago still have sound wood, and if they occurred in greater abundance, the species would undoubtedly be of great economic importance.

\section{Bald Cypress}

The BALD CyPRESS (Taxodium) as one might guess from the name, drops its leaves each year. These are of two types; either short needle-like ones arranged in a row on each side of the branchlets, or appressed and scale-like (fig. 190). The latter condition is found mostly on branchlets bearing cones which are almost spherical and composed of thick, woody, shield-shaped scales. 

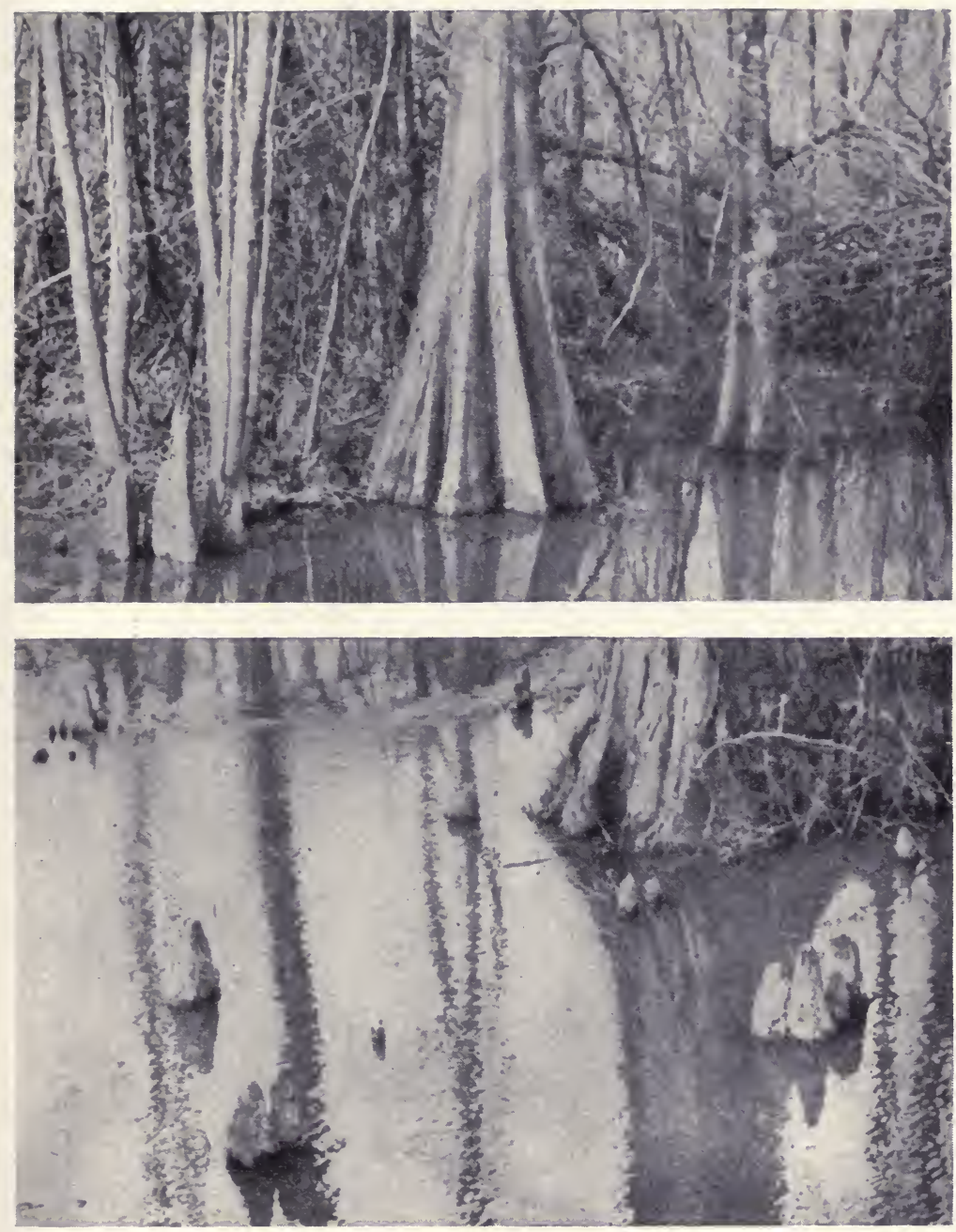

FIG. 191.-Cypress is a swamp-dwelling conifer of our southeastern states. Upper photo shows flaring, buttressed trunks; lower photo shows projecting "knees" which aerate the submerged root system. 
Only three species of the once widely distributed bald cypress genus remain, two found in the southeastern United States, and the third in Mexico. The single species that is of considerable economic importance in our country is the one bearing the group name, bald cypress. It is most typically a swamp tree, being characteristic of the deep swamps throughout the coast states from Delaware southward to Florida, westward to Texas, and northward in the Mississippi Valley to southern Illinois and Indiana. It is a fairly large tree, commonly exceeding a hundred feet or more in height, with diameters of three to five feet. The base of the trunk is characteristically much swollen and buttressed, and from the shallow widespreading surface roots arise conical growths known as "knees" (fig. 191). These knees are regarded by some botanists as an adaptation for living in water-saturated soils, air diffusing into the projecting tissues and eventually reaching the submerged root system. Although a typical swamp tree, bald cypress shows best growth on moist, well drained sites, but is excluded from the majority of such sites by its inability to compete with the more aggressive hardwood species. It has few associates in its habitat, the most common of which is tupelo gum. The seeds, because of their weight, are not well scattered by the wind, but this tree, like redwood, sprouts from the stump and considerable reproduction is secured by this means. The wood of the bald cypress is almost unbelievably durable, a characteristic which, along with its workability and attractive appearance, makes it a very valuable species.

\section{Incense Cedar}

INGENSE GEDAR (Libocedrus) has small, scale-like leaves which are borne in alternating pairs and closely overlapping on the branchlets. These are much flattened and result in the formation of flattened sprays. The cones are small-about an inch longand composed of three pairs of thin woody scales, only the middle pair producing seeds. The bark on old trees is thick, brown to reddish in color, fibrous, and deeply furrowed.

Incense Cedar (fig. 192) is found in three western statesOregon, California and Nevada-where it grows mixed with ponderosa pine, sugar pine, and white fir. The height of mature 
trees varies from a hundred to one hundred eighty feet with diameters of three to five feet. Unfortunately, large numbers of the older trees have been greatly lowered in commercial value by the attack of a fungus disease causing a rot of the heart wood.

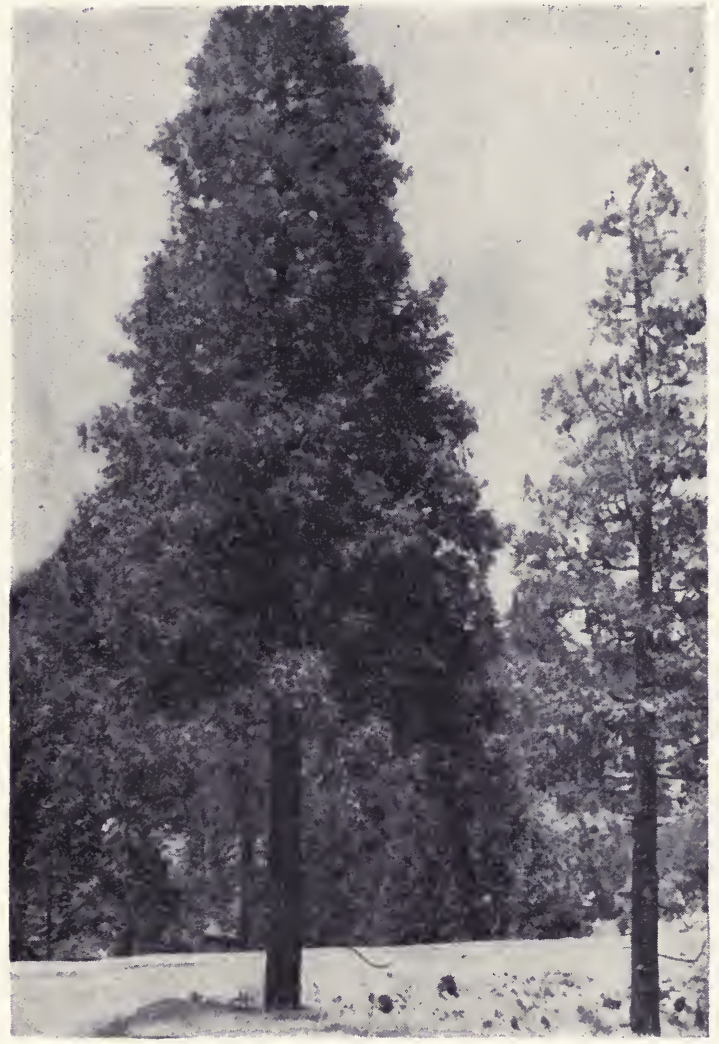

Fig. 192.-Incense cedar is a stately evergreen of our western states.

The wood is straight grained, soft, and light weight, and quite resistant to decay when placed in use:

\section{The Arbor vitaes}

The Arbor vitaes (Thuja) are unfortunately also commonly called "cedars" which leads to confusion between them and members of the cedar group to be discussed later. Their leaves 
and sprays are very similar to those of the incense cedar (fig. 193). The cones are very small, being only one-half inch long, and are made up of four to six pairs of thin leathery scales, two to three pairs of which produce seeds. The bark is very thin and fibrous, and reddish to grayish brown in color.

Only two members of the Arbor vitae genus live in North America, one native to the northeast and one to the northwest.

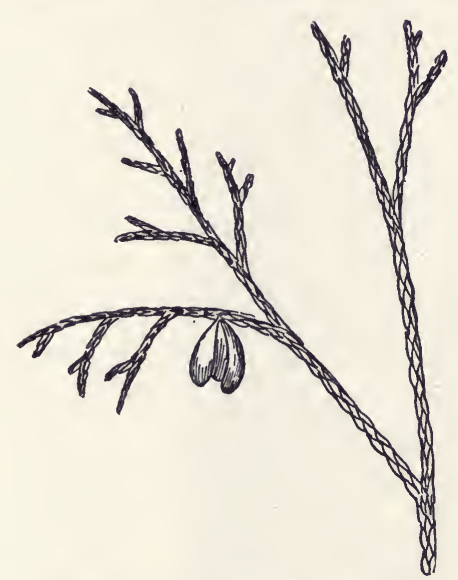

Fig. 193.-Arbor vitae has cedar-like foliage in a flattened spray.

Both are of some commercial importance. The thin fibrous bark and their shallow, spreading root systems make them very susceptable to damage by fire.

The NORTHERN WHITE GEDAR or ARBOR VITAE is the eastern representative of the genus, inhabiting a large part of the northeastern United States and Canada and extending southward to the mountains of North Carolina. It is a medium-sized tree, averaging forty feet in height and two to three feet thick, with a rather rapidly tapering stem. Growth is slow, especially in swamps where the tree is typical in parts of its range, and old trees commonly show considerable heart rot due to fungus attack, though wood is quite durable in use.

WESTERN RED GEDAR or GIANT ARbor vitAe is a much larger species, often reaching heights of two hundred feet and diameters of ten feet. It inhabits the northern Rocky Mountains and the Pacific coast from southeastern Alaska to southern California, generally preferring a moist to wet habitat for best growth. In youth, the growth is fairly rapid, and the trees reach sawtimber size in around one hundred years. The wood is valued principally for its extreme durability.

\section{Cypresses}

Cypresses (Cupréssus) have small scale-like leaves, arranged in alternating pairs and closely overlapping on the stem (fig. 194). 
They differ from other trees having this leaf habit in that the branchlets are four angled, and not flattened. The spherical cones are made up of six to ten thick, woody, pyramidal scales. The few native species are found scattered through the southwest, where two species are sawed locally for timbers.

\section{The Cedars}

The CEDARs (Chamaecyparis) are included in the cypress genus by some botanists, and many of them are known locally as

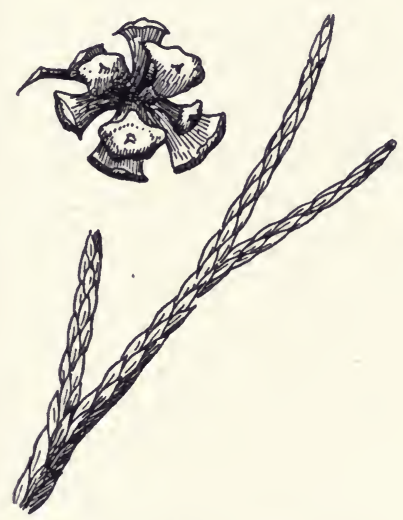

Fig. 194.-Cypress has small scale-like overlapping leaves.

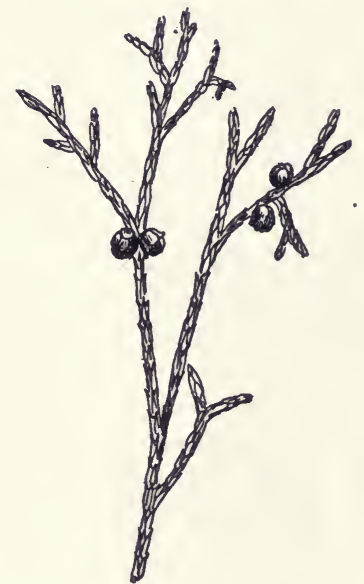

Fig. 195.-True cedars have small scale-like leaves and spherical cones.

"cypresses." The leaves are small, scale-like, arranged in alternating pairs, and closely overlapping on the stems. The branchlets may be flattened or round; thus they are seen to resemble those of the Arbor vitaes. They may be distinguished from the latter by their noticeably finer and more delicate sprays. The cones are spherical and not over one-half inch in diameter (fig. 195).

There are three species native to North America, one being a coastal species of the east, the other two limited in their distribution to the Pacific coast. SOUTHERN WHITE GEDAR, or COAST WHITE CEDAR as it is often called, is a moderately tall, slender tree. One of the most beautiful of our eastern conifers, it has several varie- 
ties which are used ornamentally. It inhabits wet fresh water swamps along the Atlantic coast from southern Maine to Florida and westward to Mississippi, thriving in situations that are unsuited to the growth of other tree species. It is of commercial importance only from southeastern New Jersey to northwestern Florida. Within its commercial range it grows in dense stands, which results in the development of a long, straight, limb-free stem making it a very desirable post and pole timber.

Of the two western species, Port Orford cedar and Alaska CEDAR, also known as LAWSON'S CYPRESS and YELLOW CYPRESS respectively, the former is confined to the coast forest region of southwestern Oregon and northern California, and the latter

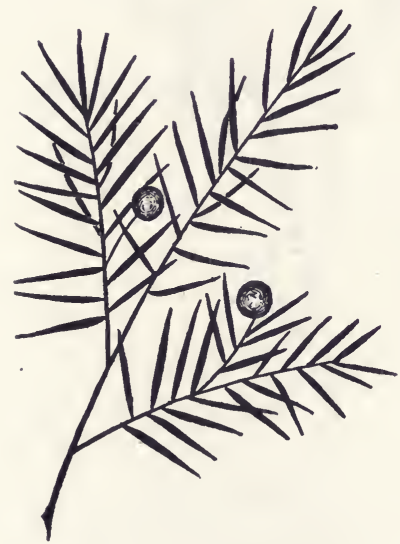

Fig. 196.-Junipers have sharply-pointed leaves and fleshy blue berry-like cones. ranges from southeastern Alaska along the coast to southwestern Oregon. Both species grow best in the presence of abundant atmospheric and soil moisture. Port Orford cedar is a fairly large tree and Alaska cedar a small or medium sized tree. They are both important forest trees within their ranges, since they supply a wood of very durable quality and act as a protection to high exposed mountainsides.

\section{The Junipers}

The Junipers (Juniperus) likewise contain some species which are known, in common parlance, as "cedars." The leaves are small and of two kinds, either scale like, arranged in alternating pairs and closely overlapping, or awl-shaped and in whorls of three (fig. 196). The branchlets are round or four angled. The fruit is a fleshy blue or blue-black, berry-like cone.

Twelve species are found in the United States, but not all reach tree proportions, and only one is of any immediate commercial importance as a timber producer. Several of the southwestern species contribute fuelwood in regions where little else in the way of tree growth exists. 
EASTERN RED GEDAR, the one important member of the group, ranges widely over the eastern United States from the Atlantic coast to the Dakotas, Nebraska and Texas, and from southern Canada to Georgia and across to Louisiana. It is a small or medium sized tree, inhabiting a wide variety of soils from good to very poor in quality, and growing very slowly. Abandoned pastures in southern New England often are characterized by scattered growths of this tree, which acts as a pioneer species in reforesting such areas. The wood is of a rather bright red color, fine grained and durable.

\section{rews}

Yews (Taxus) have short, flattened, needle-like leaves with sharp points. They are spirally arranged on the stem, but appear two ranked (fig. 197). The fruit is a berry-like structure consisting of a single seed surrounded by a bright red, fleshy covering.

Only one of the three species of yew found in the United States is of any commercial importance. It is the PACIFIC YEW, a small tree found on the Pacific coast and in the northern Rocky Mountains. The wood is fine grained, dense, rather heavy, very durable and of an attractive

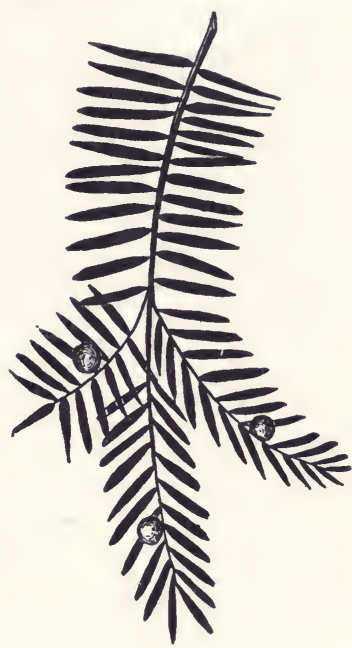

FIG. 197.-Yew has flattened needle-like leaves and bright red berry-like cones. rose-red color. Its commercial importance is definitely limited by its scarcity, and the fact that it occurs along with much larger trees whose wood is more generally useful as timber.

Another member of the group, CANADA YEW or GROUND HEMLOCK, ranges through the northeastern states and Canada. It is a low, sprawling shrub found in abundance beneath forest cover where there is considerable soil moisture present. Horticultural varieties of this, and other shrubby yews, are used as ornamentals.

Virtually every genus discussed in the preceding pages has one or more species that are familiar as ornamental trees or 
shrubs. Thus, we find the NORWAY SPRUCE, a native of Europe, widely planted in the northeast as a shade tree, and used in rows as a windbreak. The dwarf Mugho PINE is much used as a low shrub, as are many horticultural varieties of the arbor vitaes, junipers, coast white cedars and yews. Perhaps one of the most desired ornamental evergreens is the BLUE SPRUCE, which with its variety the KOSTER BLUE SPRUCE, is used throughout the northern half of our country because of its fine shape and beautiful foliage when planted alone or widely spaced. Of course many of our native forest trees are transplanted from the forest to yards and gardens, and many more are nursery grown from seed collected in the forest. Many of the Angiosperm trees are beautiful when in flower, or when the foliage turns to brilliant colors in the fall, but the evergreen Gymnosperms are stately and beautiful throughout the four seasons of the year. 


\section{Chapter 17 \\ THE ANGIOSPERM TREES}

It has already been shown that the terms "deciduous" and "evergreen" as commonly applied to Angiosperm and Gymnosperm trees respectively sometimes fail in their proper meaning. Just as there are larches and bald cypress, in reality deciduous trees, included in the evergreen group, so there are included with the deciduous trees a number of forms which are actually evergreen in that they retain their leaves for more than one year. Included among these are our common Christmas holly and the live oaks found in the southeast and on the Pacific coast. The terms "broadleaved" and "hardwood" are sometimes used synonymously with deciduous in referring to Angiosperm trees. As a group, the hardwoods are more exacting with regard to soil and moisture requirements. In a region characterized by presence of both hardwoods and conifers, the former will be found to occupy the more fertile soils. So it was that the early settlers, in selecting potential farm lands, learned to use the native forest cover as an indicator of soil fertility. Those who cleared hardwood areas raised better crops than those whose farms occupied former softwood areas.

In numbers, the trees of this group far outrank the Gymnosperms. There are some nine hundred different species of trees in the United States, $90 \%$ of which are Angiosperms. The relative importance of the two groups is most strikingly shown in the total annual lumber cut to which the hardwoods contribute but $14 \%$, the softwoods $86 \%$. This is almost in proportion to the remaining sawtimber stand in the United States, of which $89 \%$ is composed of softwoods and $11 \%$ hardwoods. These figures and facts point to the disproportionate importance of Gymnosperm and Angiosperm trees, considering the relative number of species found in each group. 
All of man's commercially important Angiosperm forest trees belong in the group of Dicots. The Monocots contain no North American tree species of importance from the standpoint of forestry although ornamental species, chiefly the palms and the tree Yuccas, are sometimes used in our southern states.

Of the twenty four tree genera discussed in the following pages, nine are characterized as catkin bearing plants. Four of

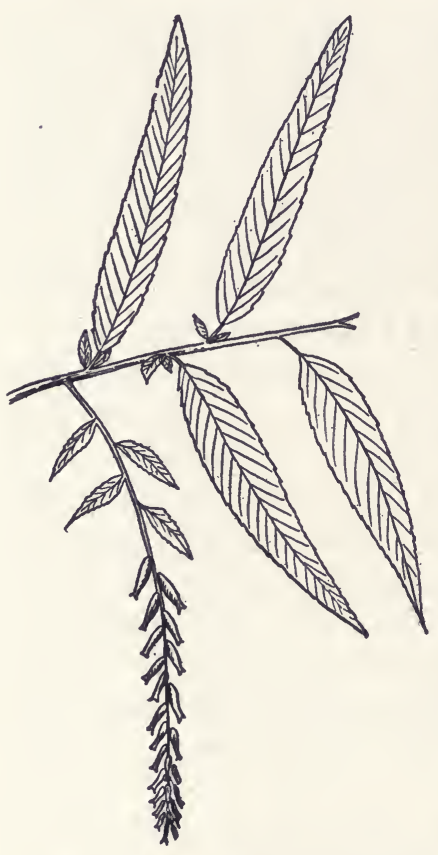

Fig. 198.-Willows have narrow elliptical leaves arranged alternately on the stem, and small flowers borne in catkins. these, the willows, poplars, birches, and alders have both staminate and pistillate flowers borne in catkins. The walnuts, hickories, beech, chestnut, and oak, on the other hand, have staminate catkins, but their pistillate flowers are solitary or in short spikes.

The fifteen genera of non-catkin bearing trees include (1) the elms and red gum, whose flowers lack petals; (2) the ashes and catalpas whose flowers have united petals; and (3) the magnolias, tulip trees, sycamore, cherries, locusts, hollies, basswoods, gums, maples, buckeyes, and dogwoods, whose flowers have separate petals.

Another method for separation of these tree groups is on the basis of leaf arrangement. The maples, buckeyes, dogwoods, ashes, and catalpas have opposite leaves; while the other nineteen have leaves alternately arranged on the twigs. In the following paragraphs, alternate leaved catkin bearing trees are first considered, followed by the alternate leaved, and finally opposite leaved, non-catkin bearing trees.

\section{The Willows}

The willows (Salix) have alternate, pointed and elliptical leaves. There are no true terminal buds on the branches; the 
lateral buds, closely appressed to the branches, are each covered by a single hood-like scale. The small flowers are borne in catkins which are conspicuous only because they appear before the leaves (fig. 198). Of the sixty five willows native to North America, only about twenty five grow to be trees; of these only a few are of importance to man. They range from the tropics northward to the

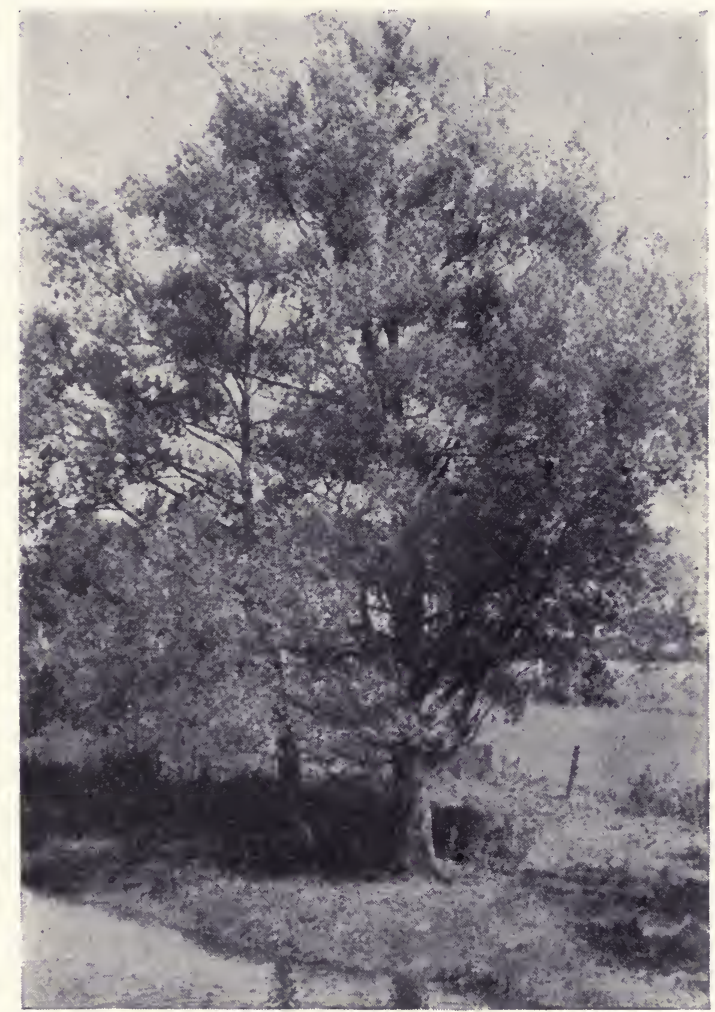

FIG. 199.-Willows are common along river banks.

limits of tree growth within the Arctic circle and all require considerable moisture, being common along stream banks, in swamps, and on springy hillsides (fig. 199).

Most of the commercial willow timber is produced by one species, the BLACK WILLOW and its varieties which range from Nova Scotia south and west to the Dakotas and Texas, including 
the entire eastern half of the United States. Most are small trees about forty feet in height and little over a foot in diameter, but the southern forms reach heights of over one hundred feet with diameters up to four feet. It is extremely rapid growing, reaching maturity in about sixty years, and having a light, soft and weak wood. Because of its rapid growth and its dense root system, this and other tree willows are widely used for planting along stream banks and levees where it is essential that the soil be firmly anchored against the erosive forces of running water.

\section{The Aspens, Cottonwoods, and Balsam Poplars}

This genus (Populus) includes fifteen tree species, less than half of which are of commercial importance. The leaves are alternate, oval to triangular, sometimes toothed or lobed, and generally have long stalks which are often flattened in cross
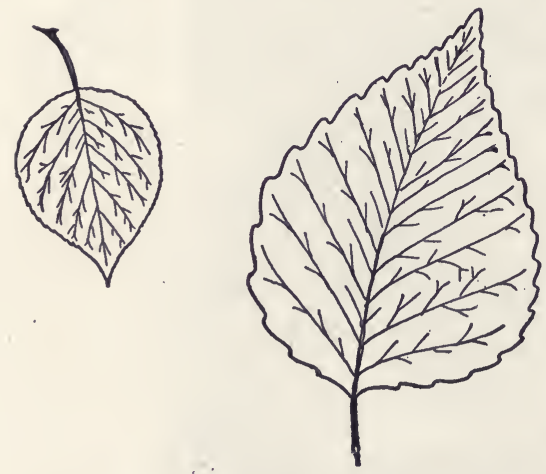

Fig. 200.-Poplars have. longstalked leaves, alternately arranged on the stem.

the southern Rocky Mountains, and the Ohio valley. The leaves are broadly circular in outline, pointed, with minute, rounded teeth, and a laterally flattened stalk which causes them to "tremble" in the slightest breeze. It is usually a small tree not over sixty feet in height, extremely fast growing and short lived with a light, soft, weak, close-grained wood. Similar in all commercial respects to the trembling aspen is the LARGETOOTH ASPEN, which differs botanically in having its 
leaves set with coarse teeth, growing to a slightly larger size, and having some minor differences in bark color. Both of these trees are of more silvicultural than commercial value, since they rehabilitate burned over areas in the north, forming a temporary forest cover and allowing the more valuable forest trees-spruces, pines, and yellow birch-to become established under their protective influence.

The BALSAM POPLAR grows to be a larger tree than the preceding two species, commonly reaching a size of eighty by two feet. Its northern range is much like that of trembling aspen, but its southern limits are reached in northeastern United States, the Lake States, and the northern Rocky Mountains. The leaves are longer and more taper-pointed than the preceding, and the leaf stalks are round in cross section. Balsam poplar wood is similar to that of the aspens.

The EASTERN COTTONWOOD has broadly triangular and coarsely toothed leaves. It becomes a large tree, often well over one hundred feet in height, and is the most important of the eastern poplars. It ranges from the south Atlantic coast northwestward across southern Canada to the Rocky Mountains, southward to the Rio Grande and Gulf of Mexico. A fast growing, short lived tree, it matures in less than seventy five years and thereafter deteriorates rapidly. The wood is light, soft, and weak, and warps badly in drying. The drought resistance of cottonwood when once established led to its being widely used as a tree for shade and ornament in the arid regions of the west.

The Northern BLACK CotTonwood is the largest of American poplars and is the largest broad-leaved tree in the Pacific Northwest, where it sometimes reaches heights of over two hundred feet. Its range is limited to the Pacific Coast area from Alaska to California, extending eastward into Montana and Idaho. The leaves are long-triangular in shape, with fine, rounded teeth. The wood is soft and fine grained.

\section{The Birches}

The BIRChEs (Betula), numbering about ten tree species, have alternate leaves that are egg-shaped to triangular in outline, and toothed (fig. 201). There are no terminal buds, and lateral 
buds have several overlapping scales; birch flowers are borne much like those of poplar and willow, except that the pistillate flowers form 'a short, spike-like catkin instead of the longer, more drooping type found in the former groups. The bark on some species separates into characteristic thin, papery layers, while on others there are conspicuous horizontally elongated lenticels, as in the cherries.

Three of the birches - the yellow, black, and paper-are important for their hard, strong, close grained woods which are put to a wide variety of uses. All three are considered as medium

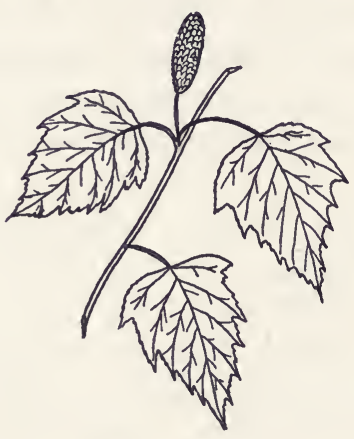

A

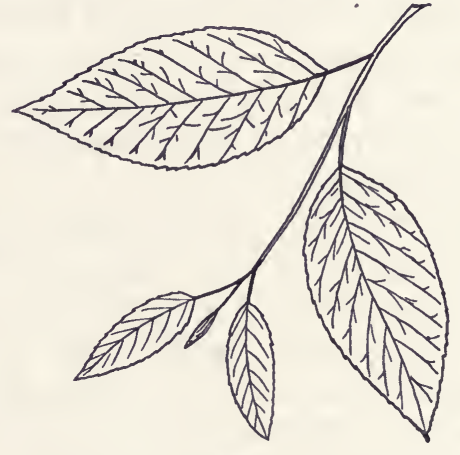

B

Fig. 201.-Birches have triangular or oval leaves; the staminate flowers are borne in drooping catkins while the pistillate form shorter cone-like structures. A is gray birch, B, black birch.

sized trees commonly attaining heights of eighty feet, and the leaves all have the same long-oval shape, more or less taperpointed at the ends. YELlOW BIRGH is the most important of the three and produces almost three-fourths of all the timber sold as "birch." It ranges from Newfoundland southwestward to eastern Minnesota, thence southeastward to northern Indiana and Ohio, and southward in the mountains to Georgia. The young twigs and inner bark contain oil of wintergreen, which fact will serve to identify it from all other birches except the black birch from which it may be readily separated by its yellow, satin-like bark which peels off in thin papery curls.

BLACK BIRGH ranges from southern Maine westward to central Iowa, southward to Virginia, the Carolinas, and Georgia. The 
heartwood is a dark reddish-brown and is frequently finished to imitate mahogany. Oil of wintergreen may be distilled from the twigs and bark.

PAPER BIRCH is the most widely distributed of the North American birches, ranging widely over the northern half of the continent. Besides being useful for its wood, paper birch is valuable as a pioneer tree species in the reforestation of burned over areas, especially in the far north. It is fast growing, but short lived, and is sometimes grown for ornamental purposes. The white, paper-like bark peels off in thin sheets on the older trees and permits ready identification.

\section{The Alders}

Alders (Alnus) have alternate egg-shaped or oval, usually irregularly toothed leaves which arise from stalked buds (fig. 202). Male alder flowers are much like those of the birches, but the female flowers are in the form of a short spike which matures into a leathery, cone-like fruit. Of the six tree species, only one is of sufficient size and abundance to be commercially important. This is the RED ALDER, which inhabits the Pacific coast forests from southern Alaska to southern California and is the most

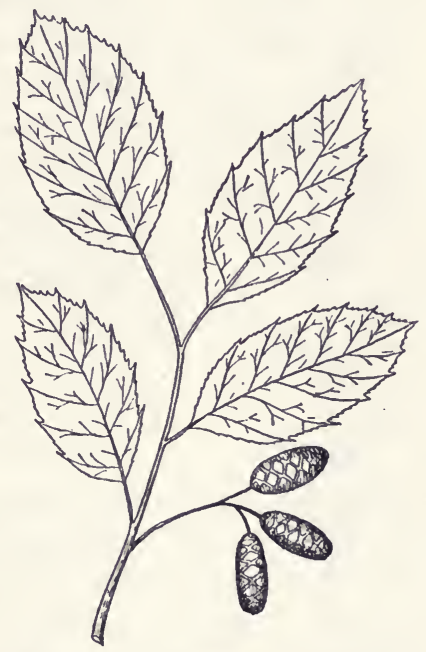

FIG. 202.-Alders have irregularly-toothed, oval leaves. important hardwood tree in this area. It is ordinarily a mediumsized tree but is sometimes found growing to a height of one hundred thirty feet. It occurs in mixture with the important conifers of this region, and is a very rapidly growing species. The wood is a pale reddish brown, somewhat like cherry in grain.

\section{The Walnuts}

The walnuts (Juglans) possess alternate, compound leaves consisting of nine to twenty three lance-shaped, pointed leaflets borne on stout twigs (fig. 203). The terminal buds are covered 
with a few scales but often appear naked. Their male flowers are like the willows, but the female flowers occur in short spikes of a few flowers each maturing to form a round nut, enclosed in a tough, semifleshy coat which persists after the fruit is ripe. There are five native species, two of which are of economic importance. Of outstanding importance is the BLACK WALNUT, one of the most valuable of North American woods, which ranges from

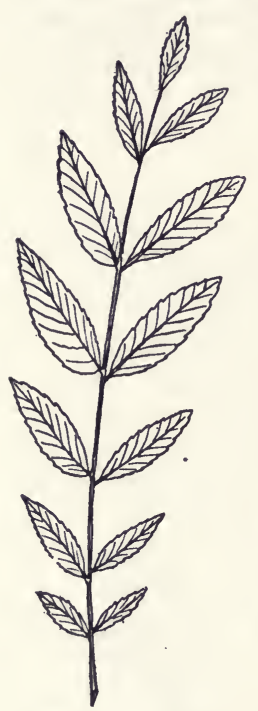

FIG. 203.Walnut species have compound leaves. southern New England westward to Minnesota and Nebraska, southward to Texas and the Gulf states. It is generally a medium sized tree though known to reach a size of one hundred fifty by six feet. The leaves are one to two feet long, and composed of fifteen to twenty three leaflets attached to a stout central stalk. It is best developed on the deep, rich, moist soils of the Ohio river valley, and produces one of the most highly prized ornamental woods in North America. The fruit of this tree is often sold locally and is much in demand in certain sections of the East.

The BUTTERnUT, or WHITE WALNUT, ranges through an area similar to that of the black walnut, except for northward extensions to New Brunswick and eastern South Dakota, and southern and western limits which are considerably more restricted. The leaves are apt to be longer but composed of fewer leaflets than those of black walnut. It is a rather small tree over most of its range, often with a poorly developed trunk and heavy limbs, the wood of which is far inferior to that of black walnut.

\section{The Hickories}

The Hickories (Hicoria) like the walnuts have alternate, compound leaves with fewer leaflets-usually five to seventeen on each leaf (fig. 204). Hickory flowers are similar to those of the walnuts but the fruit is a spherical nut enclosed in a leathery or woody husk which splits at maturity into four sections. There are 
almost twenty species of hickories in the United States, part of which are known as "true hickories," while the others are known as "pecan hickories." The "true hickories" include six species of importance, among them SHAGBARK, SOUTHERN SHAGBARK, and BIGLEAF SHAGBARK hickories; MOCKERNUT; FALSE PIGNUT, and PIGNUT hickories. All of these are generally medium sized trees, with leaves composed of five to seven leaflets, the wood very heavy, hard, tough, and elastic. All are quite valuable as timber producing trees and the first three produce the hickory nuts of commerce. All, except the southern shagbark, range over a considerable portion of the Eastern United States.

The "pecan hickories" are characterized by a greater number of leaflets (five to seventeen) than the preceding group. One species, the PECAN hickory, is a large tree ranging through the south central United States. Its timber is of secondary importance, but it is the producer of our pecan nuts, and has been

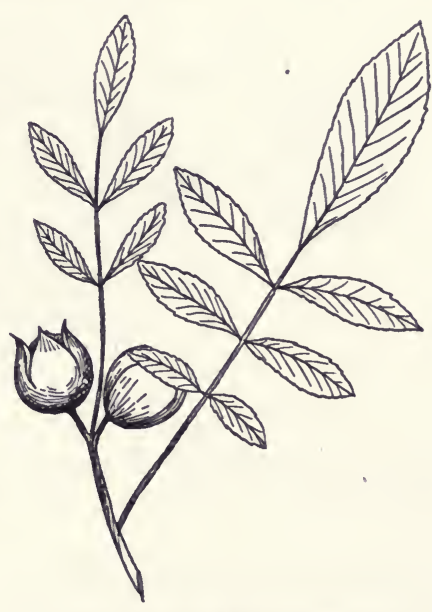

Fig. 204.-Hickories have compound leaves also, but with fewer leaflets than the walnuts.

widely planted for that purpose. BITTERNUT hickory is common from the Atlantic coast to the Great Plains, and from southern Maine, New York, Michigan and Minnesota to the Gulf coast. It is a rapid growing, medium-sized tree whose wood is hard, heavy, and elastic.

\section{The Beech}

BeEch (Fagus) is represented in North America by a single species. The alternate and sharply toothed leaves are elliptical in shape and of a firm, papery texture. The long, pointed buds are covered with numerous scales. Staminate beech flowers are borne in spherical heads, while female flowers occur in two- to fourflowered spikes, giving rise to the fruit, ("beech nut") a pyramidshaped nut enclosed in a bur covered with slender spines (fig. 
205). The smooth, blue-gray bark is a distinguishing feature for trees of all ages. It ranges from the Atlantic coast westward to Wisconsin, Illinois, Louisiana and eastern Texas, and from northern Florida to New Brunswick and is one of the most common trees of the eastern hardwood forest, reaching a fairlv large size,

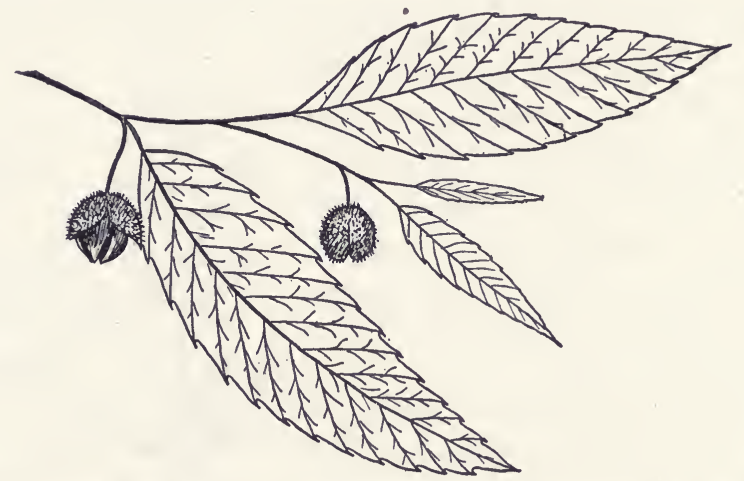

Fig. 205.-Beeches have sharply-toothed leaves and pyramid-shaped nuts borne in small burrs.

often one hundred feet or more. The wood is hard, strong, and tough, but is not durable in contact with the soil.

\section{The Chestnut}

The CHestnut (Castanea) is the only important native member of its genus, although several other species, known as chinquapins, are found in the south. The leaves of chestnut are similar to those of beech, except for their large size and more prominent incurved teeth (fig. 206). The staminate flowers are borne in a long catkin, while the pistillate occur in clusters of two to five; the fruit is the familiar large, rounded nut, enclosed in a bur covered with sharp, branched spines.

Chestnut was one of our very valuable timber species, ranging widely from southern Maine to Indiana, south to Mississippi and Virginia, until the advent of the chestnut blight at the beginning of the century. The past thirty five years have seen it reduced from the position of a dominant species throughout large parts of the East to an almost extinct tree (see page 424). Its fast growth, 
large size, great durability, and ease of reproduction (by stump sprouts) made it a favorite for many uses. The large, edible nut was formerly roasted and sold in considerable quantities. There is good reason to believe that a disease-resistant hybrid (resulting from a cross with the Japanese chestnut) will be developed, but replacement as a forest species, if possible, will be far in the future, since the place of dominance once held by American chestnut in the eastern forests has been taken over by other species, many of them inferior in value.

\section{The Oaks}

The OAKs (Quercus) constitute by far the largest group of hardwood trees in the world. They number between two and three hundred species, and many more if hybrids are included; sixty of these attain tree size in the United States. The alternate leaves are either deciduous or

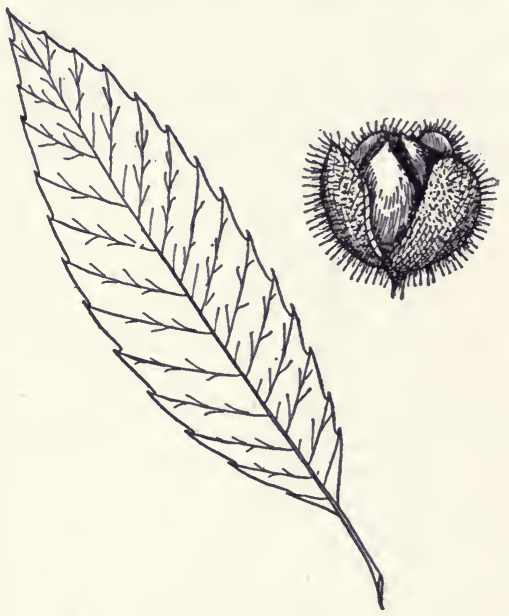

FIG. 206.-Chestntus have sharply-toothed pointed leaves and rounded nuts in large prickly burrs. evergreen, and extremely variable in size and shape, often on the same tree. The leaf margins exhibit a wide variety of characteristics, being deeply or shallowly lobed, notched, toothed, or smooth. The buds, both terminal and laterals, are characteristically clustered at the ends of the twigs. Male flowers are borne in drooping catkins; the female solitary or in few flowered spikes which give rise to the fruit, an acorn or nut partly enclosed by a scaly cup.

In addition to being the largest group, the oaks are by far the most important group of hardwoods in North America. Annually they furnish more native timber than any other group of broadleaved trees, being surpassed only by the conifers. In addition to their wood being of great value, the bark of certain species is important as a source of tannins, and the world's cork supply is produced by two European oaks. From the standpoint of their 
woods and the uses to which they are put, the oaks may be divided into two large groups, the white oaks and the red oaks. Members of these groups range throughout the United States. The hardwood forests of the midwestern United States are so conspicuously populated with oaks that they are often thought of as being primarily oak forests.

The WHITE OAK GROUP (fig. 207) contains the largest and most valuable of the oaks. They are distinguished by their generally white or light colored wood, and by their leaves which are lobed,

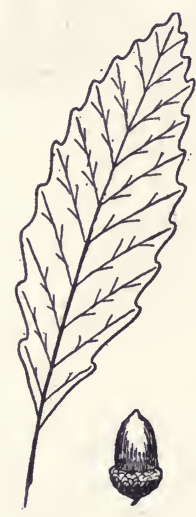

A

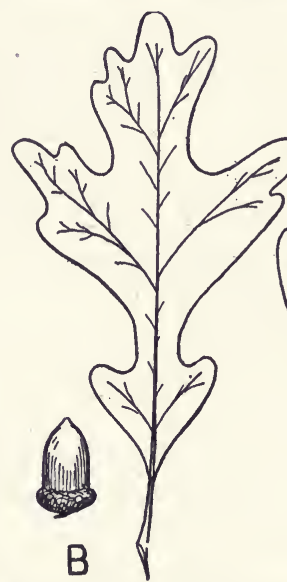

B

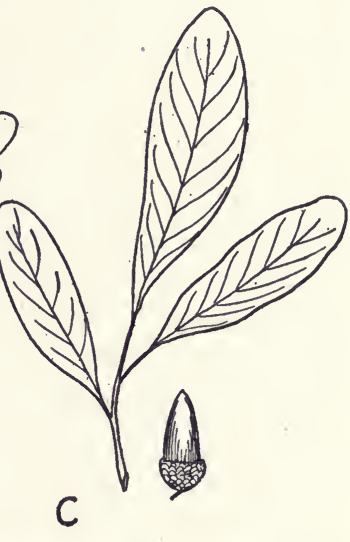

C

Fig. 207.-The white oak group of trees includes white (B), chestnut (A), and live $(\mathrm{C})$ oaks.

notched, or toothed, but never bristle-tipped. The wood is extremely close grained, heavy, hard and durable. To this group belong, as eastern representatives, four species often referred to as the "white oaks proper". and five species known collectively as chestnut oaks. The former contains the large sized and common WHITE and BUR OAKS, and the medium sized OVERCUP and POST OAKs, all of which range widely over the eastern United States. Also eastern are the chestnut oaks which include the CHESTNUT, SWAMP WHITE, SWAMP GHESTNUT, GHINQUAPIN, and LIVE OAKS. The first named is a small tree, the remaining four are medium sized trees and the last named is an evergreen oak which retains its leaves over the winter. The latter species is confined to the south 
Atlantic and Gulf coastal plains, the other four range widely over the eastern and northeastern United States. The only western white oak of outstanding importance is the OREGON WHITE OAK which is a medium sized tree found in the Pacific coast region from British Columbia to California. Several relatively unimportant species of live oaks belonging in the white oak group are found in the southwest.

The RED OAK GROUP (fig. 208) contains those trees whose leaves are bristle-tipped, and whose woods are dark brown or
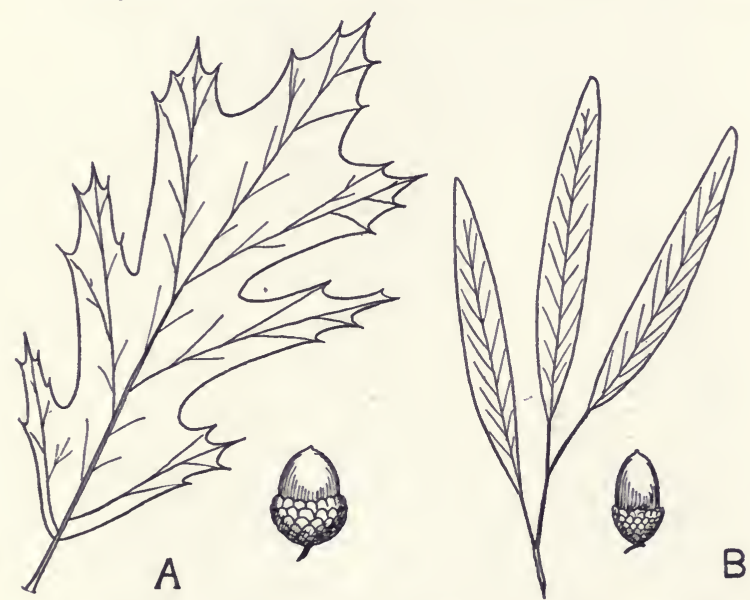

FIG. 208.-The red oak group of trees includes black (A) and willow (B) oaks.

reddish brown in color. The eastern members of this group are divided into the "red oaks" and the "willow oaks." Though ranging throughout the eastern United States, the red oaks are probably best developed in the south where one commonly finds the large sized SHUMARD RED, SOUTHERN RED, and GHERRY BARK OAKS. More generally distributed are the medium sized NORTHERN RED, SGARLET, PIN and NutTAll oaks, and the large BLAGK OAK. The "willow oaks" have smaller leaves which resemble somewhat those of the willow. They are mostly medium sized trees, although one, the wILlOw OAK, attains a large size on favorable soils in certain parts of its range. The LAUREL OAK is semi-evergreen, retaining its leaves during the winter but dropping them 
before the new leaves appear in the spring. The other two, the SHINGLE and WATER OAKS, are mostly small to medium sized deciduous trees.

The only western red oak of importance as a timber tree is the GALIFORNIA BLACK OAK which is found along the coast and extending over the west slopes of the Cascade and Sierra ranges in Oregon and California. It is usually a medium sized tree, although it may reach heights of one hundred feet on the best soils. Also belonging to this group, though of little economic importance, are the west coast live oaks.

\section{The Elms}

The ELMS (Ulmus) are represented by six native species, all of which have alternate, mostly elliptical, double toothed, short

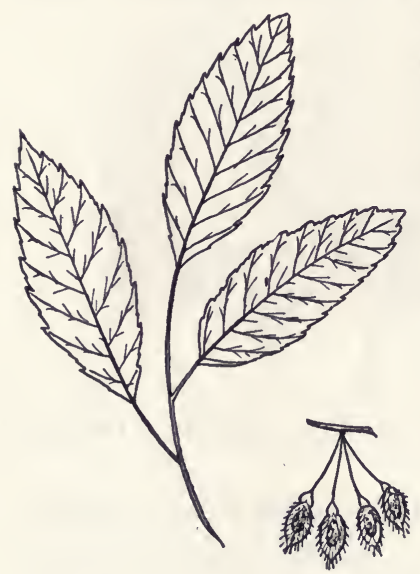

FIG. 209.-Elms have elliptical toothed leaves and winged fruits. stalked leaves, the twigs in some species covered with cork (fig. 209). There are no true terminal buds, and the lateral buds are covered with numerous overlapping scales. The small, inconspicuous flowers appear before the leaves unfold, and the fruit is a flattened, oblong or round single seed, surrounded by a thin papery wing.

This genus includes three species which are of interest because of their usefulness to man. Their woods are all much the same as regards properties and uses, being very hard, tough, difficult to split, coarse-grained, with brown heartwood and light colored sapwood. Pernaps the most important, at least the best known, is the American, or White elm whose range extends from Newfoundland to Florida and westward to Texas and Saskatchewan. Its broad, spreading, vase-shaped crown when grown in the open, makes it easier to identify from a distance than any other North American tree (fig. 210). It is a large tree, and height measurements up to one hundred twenty feet have been re- 
corded. In forest grown trees, the trunk may rise sixty feet before branching. It makes its best growth on moist, well-drained bottom-land soils, although it grows commonly in a great variety of situations from swampy areas to dry hilltops. As an ornamental and shade tree, it has been more widely planted in the east than almost any other kind of tree. At present the existence of our

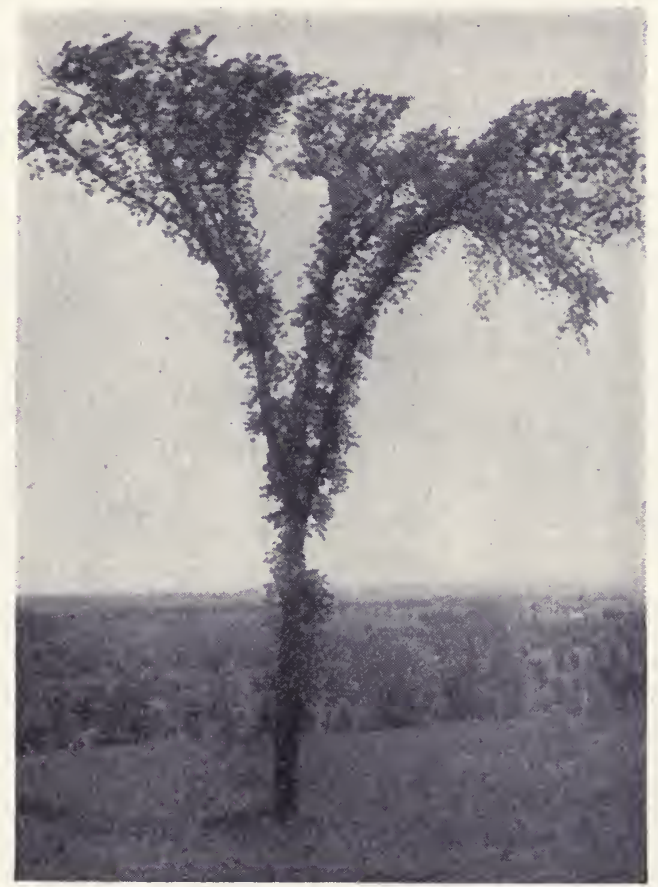

Fig. 210.-The elm is a graceful deciduous tree of wide range in the United States. Its deliquescent habit is typical of most Angiosperm trees.

American elm is being threatened by an introduced fungus disease, the Dutch Elm Disease which, if not eradicated, may deprive future generations of this tree both as an ornamental and as a timber producer.

The SLIPPERY, or RED ELM, is similar in general appearance to the white elm, but tends to have the lower part of the trunk more clear of branches. It is a smaller tree than white elm, and may be 
distinguished from it by the mucilaginous inner bark, and by the leaves which are rough above, while those of American elm are smooth on top. The range of this tree is similar to that of the preceding, except that it is more limited in its northeastward and northwestward extensions.

The ROCK ELM is likewise a medium sized tree, but in contrast to the two preceding species, has a well-defined main trunk persisting for a considerable distance into the crown. For this reason, it has been more highly regarded by the lumberman, and the never large supply has been badly depleted. It occupies a broad belt from northern New England and southern Canada southward and westward to Tennessee, Illinois, Nebraska and Kansas.

\section{The Red Gum}

RED GUM, or SWEET GUM (Liquidambar) is the single native species of its genus. The leaves are alternate and star-shaped,

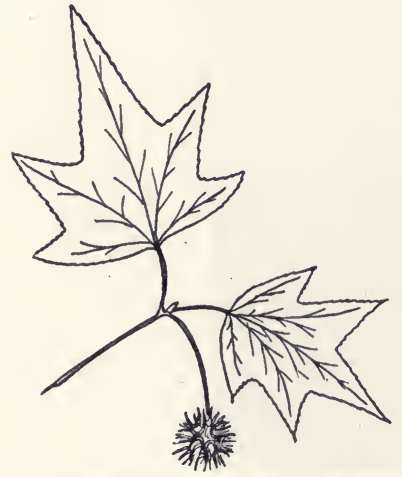

FIG. 211.-Red gum has star-shaped leaves. finely toothed and have a pleasingly aromatic odor when bruised (fig. 211). The several scaled terminal and lateral buds are borne on rather stout twigs with star-shaped pith, the older ones often possessing corky wings. Red gum flowers are small and inconspicuous, and the fruit is a long stalked, spherical head of woody, spiny capsules, each of which generally bears one fertile seed. It ranges throughout the southeastern United States from central Florida westward to Texas and Oklahoma and northward to southern Illinois, Indiana, and Ohio, southeastern Pennsylvania to southwestern Connecticut. In its most favorable habitats, red gum sometimes reaches a height of one hundred fifty feet and a diameter of five feet. It is one of the most important commercial hardwood species in the United States, and is found growing mixed with other hardwood species particularly in swamps and moist river bottoms in the south. Ordinarily considered a fastgrowing tree during youth, though this characteristic may be 
influenced by the quality of the habitat, red gum reaches maturity in two to three hundred years, and undoubtedly lives beyond that age. The wood is grayish to reddish brown, moderately hard and heavy, either straight-grained or with interlocking grain. Because of the attractive star-shaped leaves, which turn a brilliant crimson in the autumn, the species is used as an ornamental in the milder portions of the northern United States.

\section{The Magnolias}

The GUGUMber tree and magnolias (Magnolia) are especially well known for their large, showy flowers, which in some species

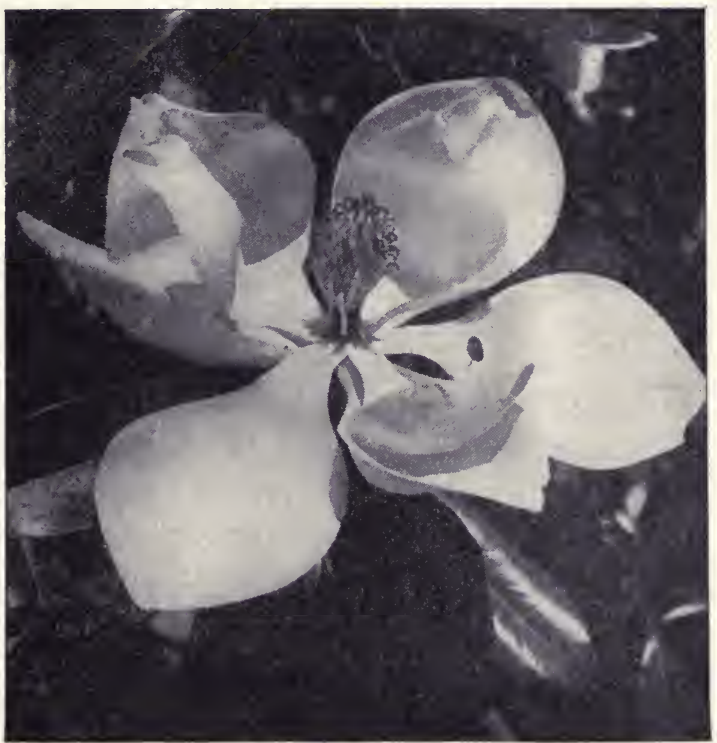

Fig. 212.-The Magnolia is a native southeastern tree well known for its large and conspicuous flowers.

grow to be a foot in diameter (fig. 212). Of nine species found in North America, some are deciduous and some evergreen. The alternate, sometimes waxy or shiny leaves are oval or elliptical in shape, with entire or wavy margins; they are among the largest of Angiosperm leaves, their size varying from six inches in some species up to thirty inches in others. The twigs are rather stout, 
with large terminal buds which show a single outer scale, often covered with short silky hairs. The seeds, borne in a conelike fruit, possess a pulpy outer layer which attracts birds and aids in their dispersal.

The group includes but one species, the GUGUMBER TREE, which is important for its timber. It ranges from central New York southward to the gulf states, and westward to Ohio, Indiana, Illinois and Arkansas, being of commercial importance in Tennessee, Kentucky, and the Carolinas. It is a medium to large sized tree, reaching one hundred by four feet on moist, fertile soils where it grows mixed with other hardwood species. The wood is light, close grained, soft and brittle, and not distinguished from that of yellow poplar in the lumber trade.

Several other magnolias reach small tree size in the warmer

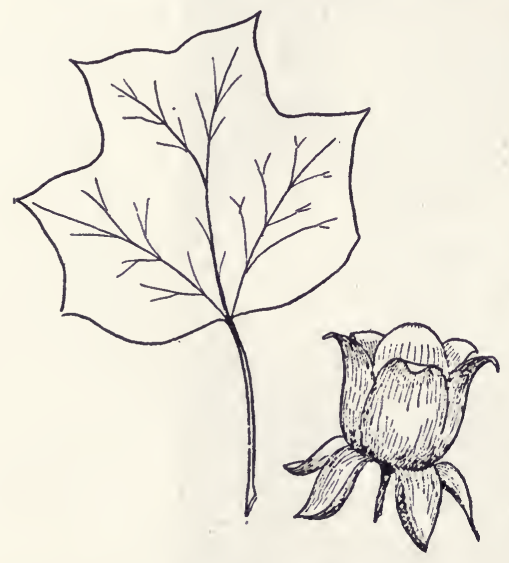

FIG. 213.-Tulip trees have fourlobed leaves and showy flowers. parts of the United States and are used as shade and ornamental trees in such regions.

\section{The Tulip Tree}

The TULIP TREE, Or YELLOW POPLAR (Liriodendron) is the only North American member of its genus; one other species is native to central China (fig. 213). Its leaves are alternate, nearly circular in outline but four lobed, and broadly notched or almost flattened at the tip. The twigs are rather stout, smooth and lustrous, with a terminal bud shaped somewhat like a duck's bill. The flowers are very showy, and tulip-like in appearance, giving rise to a cone-like fruit composed of many winged seeds.

The tulip tree reaches a height greater than that of any other native broad-leaved tree, growing to be two hundred feet high and twelve feet in diameter. The trunk is straight and clear of branches for a considerable distance above the ground, adding to its commercial value. The species ranges widely in the Eastern 
United States, being found from southern New England westward and southward to Illinois, Arkansas, Louisiana, and the gulf states, including northern Florida, and reaching its maximum size and abundance in the lower Ohio river basin and on mountain slopes in Tennessee and North Carolina. It is a fairly rapid-growing tree and probably lives to be three hundred years old. On account of the very showy flowers, tulip tree is widely used as an ornamental species in the East, but because of very tender roots, is quite difficult to transplant successfully. The wood is light in weight, soft, weak and straight grained. The thin layer of sapwood is nearly white, while the heartwood is pale greenish yellow or brown.

\section{The Sycamores}

The sycamores (Platanus) have alternate, simple leaves, bright green above and paler beneath, with three to five large toothed

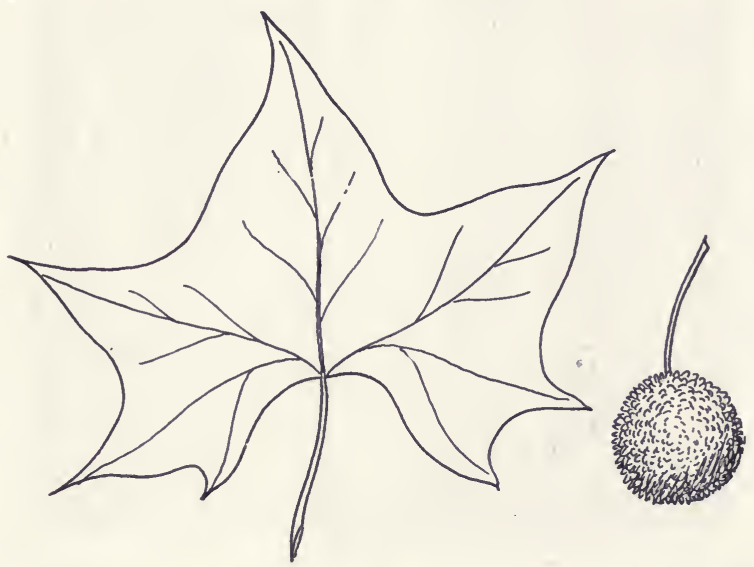

Fig. 214.-Sycamores have leaves with three to five broad lobes, and spherical fruits.

lobes. The twigs are conspicuously zigzag, lacking a terminal bud, and with the conical lateral buds covered by a single caplike scale. The individual, minute, flowers are borne in spherical heads, giving rise to the spherical fruit made up of numerous single seeds, each surrounded at the base by a ring of hairs which aids in their dissemination by the wind (fig. 214). The bark on 
young trunks or large limbs flakes off, leaving the light colored inner bark exposed, and giving the limbs and trunk a characteristically mottled appearance.

One commercial species, the SYCAMORE or PLANE TREE, ranges widely from southern Maine to northern Florida, and from

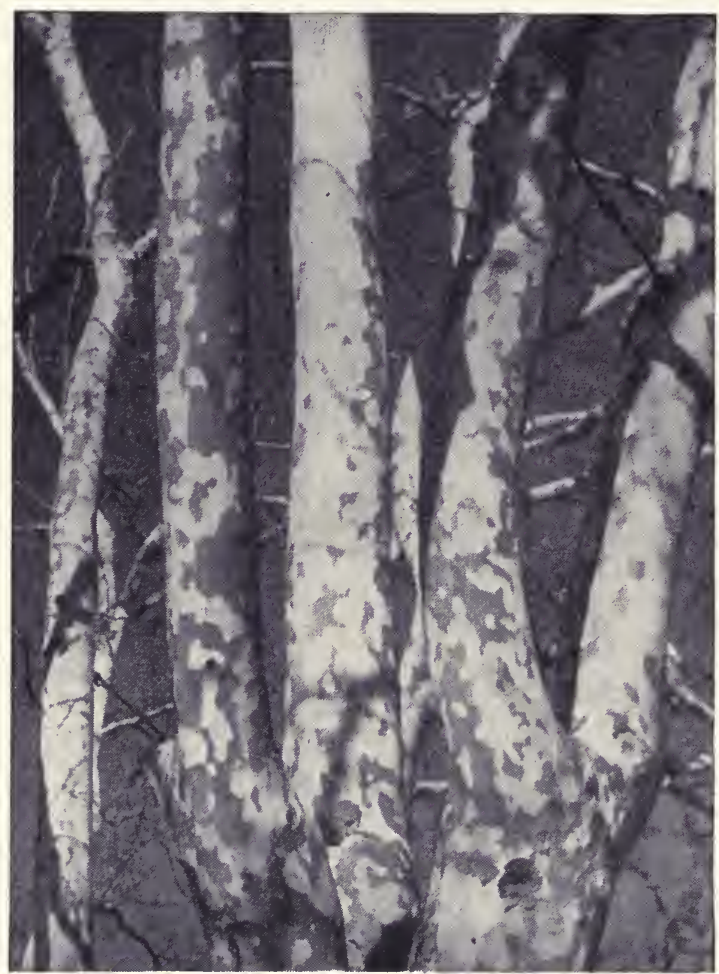

Fig. 215.-The mottled bark of the sycamore is a conspicuous feature of this common deciduous tree.

southern Michigan to southwestern Texas. It is one of the largest of eastern hardwood trees, reaching a maximum size of one hundred seventy five by fourteen feet, and having a probable life span of six hundred years. The mottled bark (fig. 215) and open spreading crown afford an easy means of distinguishing this tree from its associates on riverbank and bottom-land habitats. The 
largest and best-developed sycamores are found in the Ohio and Mississippi river basins. The wood is hard, heavy, weak, and light reddish brown with pale yellow sapwood, having a grain that is often interlocked and difficult to split. Sycamore is occasionally planted as an ornamental, but its prolific seed habit causes some discrimination against it in this capacity.

\section{The Cherries}

The CHERRIES (Prunus) include over twenty species that are found in our forests. They have alternate, simple leaves which vary in shape from lance-shaped to oval, with finely toothed margins (fig. 216). The twigs have a pronounced bitter taste and possess several-scaled terminal buds. The small white flowers give rise to familiar small fleshy stone fruits. The bark is reddish brown to black, often with conspicuous lenticels which are light colored and horizontally elongated like the birches.

BLACK CHERRY is the only wild cherry to be considered as a timber species, ranging throughout the entire eastern half of the United States and southern Canada. It is ordinarily a tree of medium size, sometimes reaching a maximum of one hundred by five feet on rich, moist soils where it occurs mixed with other hardwood species. Growth is very rapid under favorable conditions and an age of two hundred years is probably reached by the old growth

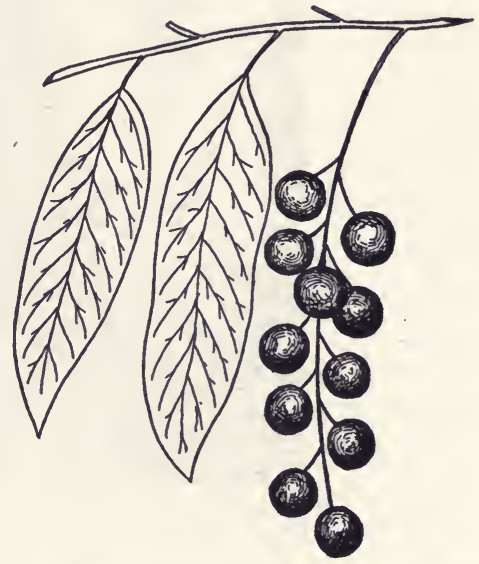

Fig. 216.-Cherry trees have lance-shaped or oval leaves and attractive flowers; the fruits are often in clusters. trees. Although not outstanding with regard to quantity of wood produced, black cherry is one of the most valuable of the eastern hardwoods because of the high ornamental value of its wood, which is moderately hard and heavy, strong and close grained, consisting of a light to dark reddish brown heartwood and a thin yellow sapwood. 
Other cherries have been considered in the chapter dealing with orchard fruits.

\section{The Locusts}

The Locusts include two closely related genera. The HONEY LOCUST (Gleditsia) genus is represented by three native species, all of which have alternate and compound leaves. They are borne on stout, zigzag twigs which are armed with very stout, sharp, three-branched thorns. Terminal buds are absent, and

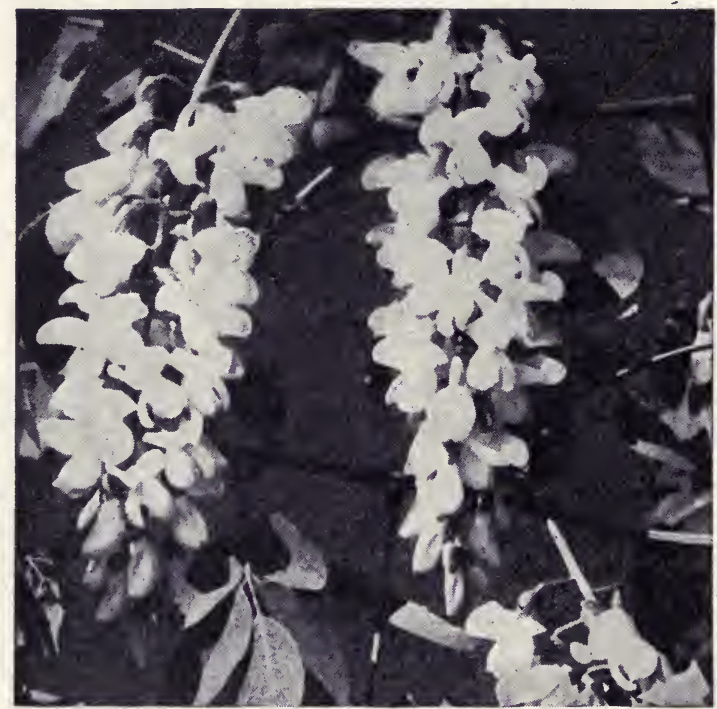

Fig. 217. - The locust has pendant clusters of showy and creamy-white flowers.

the lateral buds are partly buried in the bark and located just above the leaf scars. As the trees mature, the bark often develops clusters of long, many-branched thorns. The spikelike clusters of flowers are small and greenish white, giving rise to a several seeded pod-like fruit. One commercial species, the honey locust, ranges from the mountains of western Pennsylvania westward to eastern Nebraska, and southward to eastern Texas and the mountains of Alabama and Georgia. It is usually a mediumsized tree, but may reach dimensions of one hundred forty by six feet, with a short trunk and spreading, open crown. This 
fast growing species reaches its best development in the open or in mixture with other bottom-land hardwoods in the southern parts of its range, where it is of secondary commercial importance. The wood is hard, coarse-grained and strong, very durable in contact with the soil. It is very hardy when planted as an ornamental, and is widely used as such, its armed branches making it a highly effective hedge tree.

The BLACK LOCUST (Robinia) is one of a group of about twenty trees and shrubs whose leaves are like those of the honey locust, borne on twigs armed with short, stout thorns placed one on each side of the leaf scar. Terminal buds are lacking and the lateral buds are small and imbedded in the twig under the leaf scar. The creamy white flowers (fig. 217) are borne in showy clusters which later mature to form the brown flat pod-like fruits with their hard-coated, bean shaped seeds. Black locust was originally restricted in its range to central Pennsylvania southward to northern Georgia in the Appalachian Mountains, also spots in southern Illinois, Indiana, and western Arkansas, but at present the tree is naturalized over most of the area east of the Rockies. It is a medium-sized tree with a maximum measurement of one hundred by three feet, and when grown on good soils has a clear straight trunk. It is a very fast growing tree and during its youth will average two to four feet a year height growth on good soils. The wood is very hard, strong, and durable; and for this reason the tree has been widely planted in the United States and Europe for timber, but unfortunately it has a very serious insect pest in the form of the locust borer which has led to a more sparing use of black locust for forest planting in some sections.

\section{The Hollies}

The HOLLy (Ilex) group contains about six native species which reach tree size. The leaves are alternate and simple, and may be either persistent or deciduous, with smooth, smalltoothed, or long spiny toothed margins. Holly flowers are small and greenish-white, giving rise to the characteristic red or black berry-like fruit which consists of a single seed surrounded by a fleshy covering. 
One important tree member, HOLLY, is typically a southeastern species, ranging from extreme southern Illinois and Indiana southwestward to southern Texas, and northeastward to Massachusetts, its southern limits being south central Florida. It is usually a small tree about forty feet in height, attaining maximum dimensions of one hundred by four feet, with a short, straight trunk. It is a slow-growing tree, reaching maturity at about one hundred fifty years of age, with light, close-grained, weak wood. Its ornamental value far outranks that of its timbers, and great quantities of the evergreen leaves and berries are used annually as holiday decorations.

\section{The Basswoods}

The BAsswoods or LINDENS (Tilia) are common trees of the eastern United States, there being almost twenty species. Their

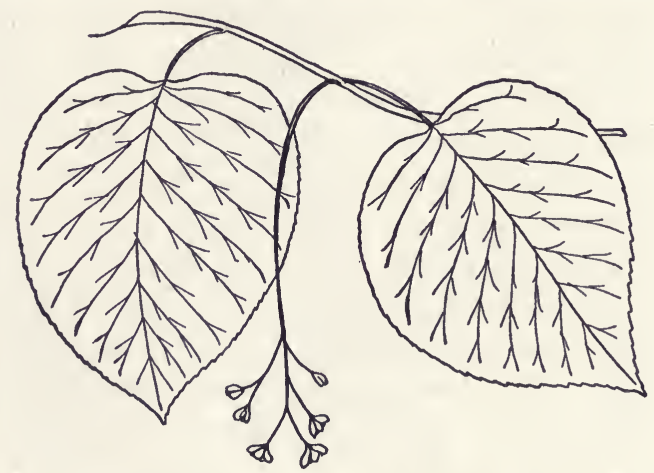

FIG. 218.-Basswood leaves are often almost circular in outline.

leaves, borne alternately on the twigs, vary in shape from almost circular to egg shaped (fig. 218). The twigs are sometimes zigzag, lack terminal buds and have divergent lateral buds. Pale yellow flowers are borne in clusters, attached to a narrow bract which aids in the dispersal of the woody, globular fruits. One important species, the common BAsswood, ranges from New Brunswick to Delaware in the east, and westward to Manitoba, the Dakotas, and Kansas. Basswood is a large tree, sometimes reaching a size of one hundred twenty by four feet, and is best developed in the southern part of its range, where it occurs in mixture with 
other hardwoods on deep, rich, soils. Seed crops are produced irregularly, and germination is delayed or uncertain, most of the basswood reproduction being from stump sprouts, which develop when the old trees are cut. Rapid growth by both seedlings and sprouts results in trees maturing in slightly over one hundred years. The wood is soft, light, moderately strong and evengrained, with light brown to nearly white heartwood and thick white sapwood. The inner bark is fibrous, being sometimes manufactured into cordage, and the flowers yield a nectar which is especially fine for bees.

\section{The Gums}

Tupelo, or Gum (Nyssa) consists of six eastern species. Their leaves are alternate, simple, and oval in shape, often with wavy or coarsely toothed margins. The small, greenish white flowers are solitary or borne in clusters, giving rise to purple oval fruits.

The gums include two trees of importance for their timber products, the TUPELO GUM ranging from southern Virginia to Texas along the Atlantic and Gulf coastal regions, and extending northward in the Mississippi valley to southern Illinois; and the BLACK GUM which ranges more widely, extending from southern Maine to central Florida on the east, and from southern Michigan to eastern Texas on the west. Both are large trees and reach their best development in southern swamp lands and along moist river bottoms. Tupelo gum occurs in almost pure stands, or mixed with cypress, while black gum does not occur in any quantity in one locality, being found generally mixed with other hardwood species. On rich, moist soils the gums grow rapidly, but in swamps the growth is slower. Their wood is medium heavy, fairly hard, and difficult to split, with a yellow to brownish gray heartwood and paler sapwood.

\section{The Maples}

MAPLES (Acer) numbering about thirteen native species, have opposite, simple or compound, leaves (fig. 219). The simple leaves are palmately veined and lobed; the compound ones are three parted or pinnately divided. The small, red or yellow flowers give rise to the familiar two seeded winged fruits. 
Of the six commercially important maples, five are trees of the eastern United States, ranging from Southern Canada southward to the Gulf states and from the Atlantic coast to the Great Plains region. Outstanding in importance among these are the SUGAR MAPLE and the BLACK MAPLE which furnish the hard maple of the lumber trade. Both are large trees with maximum dimensions of one hundred thirty by five feet, those forest grown having clear, straight trunks, while open grown trees branch near the ground to produce dense, rounded crowns. They are long-lived trees, and if not injured by fires or grazing, will reach ages of
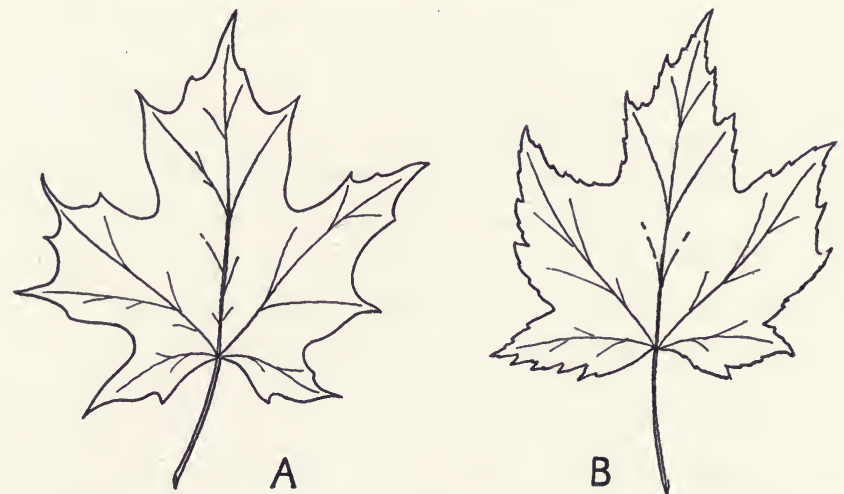

Fig. 219.-Two common maples are the sugar maple (A) and the red maple (B).

three hundred years. The wood of both is hard, close-grained, and strong; the heartwood light reddish brown in color, the sapwood white.

RED MAPLE and SILVER MAPLE are medium-sized trees, and furnish the "soft maple" of commerce. Both are fast growing trees which reach maturity early and rarely live to be one hundred fifty years old. They are also alike in that they reach their best development on swamp- or bottom-lands, although red maple is at home on all sorts of soils, even to sterile, dry, hilltops. The wood is medium-hard and close-grained, with pale brown heartwood and a thick layer of white sapwood. The AsH-LEAvED, or BOX-ELDER MAPLE is of little commercial value, being generally a small tree with soft, light wood. All of these native maples are widely used as ornamental and shade trees, the red maple 
because of its fast growth and brilliant red fall foliage coloration, the silver maple because of its incised leaves and silvery older branches. The Norway MAPle, native of Europe, and several dwarf JAPANESE MAPLES have been introduced as ornamentals.

The only western maple of commercial interest is the BIGLEAF MAPLE which ranges from southeastern Alaska south along the coast to southern California. It extends inland to the west slopes of the Cascade Mountains in Washington and Oregon, and is found on the west slopes of the Sierras in California. One of the few commercial hardwoods found on the Pacific coast, it inhabits a variety of soils, but does best on rich river-bottom lands where it reaches a size of one hundred by four feet or more. Its habit of growth is much like that of the eastern maples, under forest conditions developing a long, straight, branch free trunk. The wood is similar in quality to that of the eastern hard maples; in addition to which burls, often developed on the old trees, have become much in demand for manufacture into fancy veneers in recent years, and have led to an increase in the importance of this species.

\section{The Buckeye and Horse Chestnut}

Members of this genus (Aesculus) have large opposite, palmately compound leaves, each made up of five to nine leaflets. The stout twigs produce large, terminal buds from which emerge, in addition to the leaves, conspicuous upright clusters of showy flowers (fig. 220). The fruit is a large leathery or spiny single seeded structure. The BUCKEYE is a native American tree; the HORSE CHESTNUT, widely used as an ornamental, is a naturalized tree in parts of the east, where it was brought many years ago from its native Greece.

YELLOW BUCKEYE is the only member of moderate commercial importance. Its range includes the central portion of the eastern United States, and it is best developed on deep fertile soils of the western Appalachians and in the Ohio river valley, where it grows to be a medium sized tree. Growth is rapid and the trees mature in around seventy years, although ages greater than this are probably reached. The wood is light, soft, and close grained, the heartwood yellow in color. 


\section{The Dogwoods}

The DOGWOODS or CORNELS (Cornus) number about eighteen species of which four reach tree size. The leaves are generally opposite with entire or finely toothed margins (fig. 221). Small

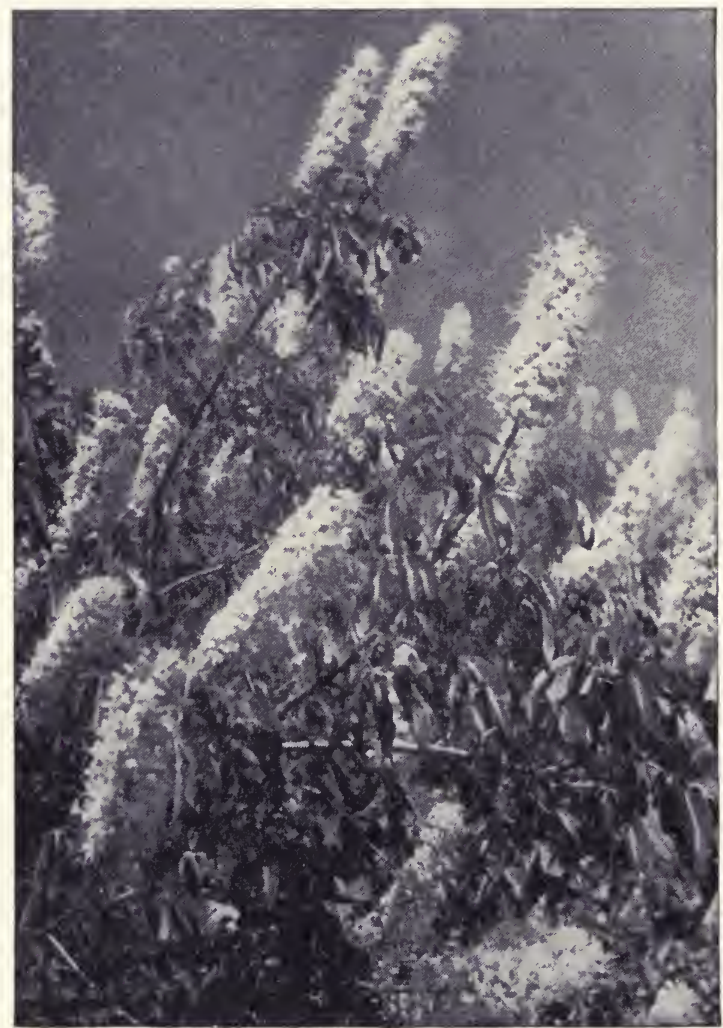

Frg. 220.-Buckeye is a small tree with large erect clusters of showy white flowers.

yellowish flowers are borne in heads, in some species surrounded by showy, white or pink, bracts which are mistaken for petals. The fruit is a one-seeded, commonly red, fleshy berry.

Two members are of slight commercial importance, the FLOWERING DOGWOOD which ranges from southern Maine to 
Florida and from southern Michigan to eastern Texas, and the PACIFIC DOGWOOD which ranges along the coast from British Columbia southward to California. Both are small trees whose short, tapering trunks are topped by large-limbed,

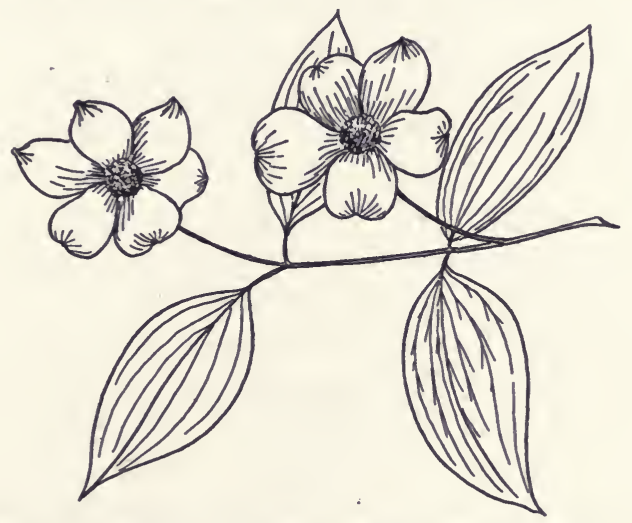

Fig. 221.-Dogwood trees have opposite oval leaves, and small yellow flowers in compact heads surrounded by large showy bracts.

bushy crowns. Their woods are hard, heavy, close grained, and pinkish brown; and both trees are prized and widely planted as ornamentals.

\section{The Ashes}

The Ashes (Fraxinus) are represented in North America by almost twenty species, all having opposite, compound leaves. Greenish flowers are borne in dense clusters and ripen into single-seeded, winged fruits (fig. 222).

The ashes include six species deserving of mention as timber producing trees, five of which are predominantly eastern in their ranges and

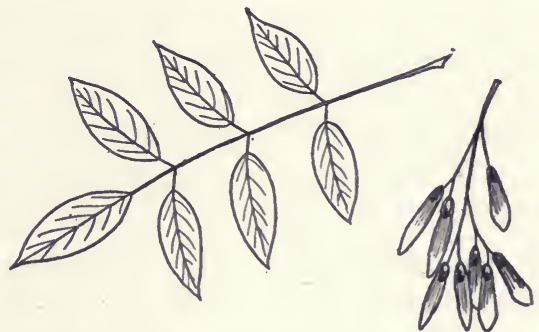

Fig. 222.-All of the ash species have opposite compound leaves. one which is a Pacific coast tree. WhItE ASH is the largest and most abundant of American ashes. Inhabiting deep, 
fertile soils in association with other hardwoods, it ranges from Nova Scotia westward to southeastern Minnesota and southward to eastern Texas in the west, and northern Florida in the east. It is a large tree, growing rapidly during its youth, and producing a light brown heartwood and pale sapwood which is hard, tough, close grained, and free from taste or odor.

RED ASH extends farther west in its northern range than the white ash, but not so far south, entering Northern Mississippi, Alabama and Georgia. It is at best a medium-sized tree with a short, often poorly formed trunk, and is common as a scattered tree along the borders of swamps or on stream banks. The wood is similar to that of white ash but inferior to it.

GREEN ASH is botanically a variety of the red ash and is often confused with it. Its range is much greater, extending from Maine to Saskatchewan and southward to Delaware, northwestern Florida, eastern Texas, northeastern New Mexico, northern Arizona, and Utah. Green ash is more important commercially than red ash, being a larger tree, and is very hardy to climatic extremes, having been widely used for planting in the plains states and Canada. Its wood is similar in properties and uses to that of white ash and is not distinguished from it in the lumber trade.

BLACK ASH is a typically northern tree, extending westward from southern Newfoundland to southern Manitoba, and southward to eastern Iowa, southern Ohio, and Delaware. It is a small to medium-sized tree with a poorly shaped trunk, occurring on moist to wet soils, in mixture with other hardwoods and conifers along stream banks and the borders of swamps. The wood is of a much poorer quality than that of the other northern ashes, and is frequently known as "brown ash" in the lumber trade.

BLUE ASH ranges from southern Michigan south to northern Alabama and west to eastern Kansas, Oklahoma, and Arkansas. It is a medium sized tree, reaching a maximum height of over one hundred feet on the better soils where it is often accompanied by white ash. Its rather restricted range and rare occurrence limit its commercial importance, since its wood is similar to that of white ash, not being distinguished from it by the lumber trade.

OREGON ASH is a timber tree of secondary importance in the Pacific northwest. Commonly a tree of moderate size, 
it is capable of growing to heights of over one hundred feet under the most favorable conditions, which include a rich, moist, welldrained soil. Associated trees on such sites include several of the important hardwood and coniferous species mentioned on previous pages. Growth is rapid during youth, barring undue suppression, then slows gradually until maturity is reached at about two hundred years. The wood has the same general qualities and uses as that of the more important eastern ashes.

\section{The Catalpas}

This genus (Catalpa) numbers but two species in the United States. Both have very large, oval, mostly entire leaves, which are

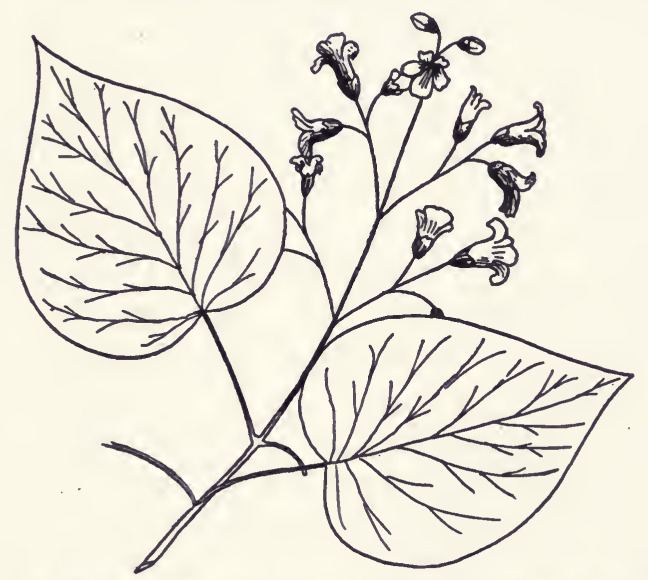

FIg. 223.-Both the leaves and the flowers of the catalpa are large and showy.

arranged in opposite pairs or in whorls of three on the stout, rough twigs. Terminal buds are absent, and the leaf scars are circular, raised at the edges with a depressed center. Their showy flowers are white, often spotted with purple, and borne in large clusters (fig. 223). The fruit is a long, pod-like capsule which splits to free the numerous winged seeds.

The two species, COMMON CATALPA and HARDY CATALPA, are small trees native to the southern and gulf states. Their woods are light, soft, coarse grained, and very durable in contact with the soil, but their small size and inability to withstand rigorous 
climates decidedly curtails possible economic importance. Their ornamental value probably surpasses their timber value, since both are widely planted for foliage and flowers in the United States and in Europe.

In this and the preceding chapter, consideration has centered upon the variety, characteristics, and distribution of the important trees of the United States. The following chapter is devoted to the more important wood products derived from these trees. For other forest tree products, the reader is referred to Chapters 21,22 , and 23 , dealing respectively with latex-producing plants, drug yielding plants, and industrial uses of plants. 


\section{Chapter 18 \\ WOOD AND ITS USES}

From earliest Colonial times the forest industries have played a most important part in the wealth and welfare of the American people. The forest and woodworking industries employ over a million workers, and the building industry, which depends largely upon forest products, employs more than two million more. In Washington and Oregon, where the forest industries account for an income of $\$ 250,000,000$ annually, $12 \%$ of the total employment is accounted for by them. In the past, the forest has served mainly as a source of lumber and fuel, and while it is true that these two products still make up about $75 \%$ of the total volume of wood used, they by no means exhaust the category of forest products. Indeed, the waste from the lumber industry alone supports a host of minor forest industries. Formerly about $66 \%$ of the total volume of standing timber cut annually was wasted. About one-third of this amount was left in the woods in the form of stumps, tops, branches, broken trunks, and decayed logs from improper storage. Losses in manufacture, in the form of bark, sawdust, slabs, edgings and trimmings, etc. accounted for two-thirds of the total waste. Recent years have witnessed great progress in reducing these classes of waste.

Woods waste is being reduced by the cutting of lower stumps, and closer utilization of the tops, which increases the length of the felled trunk and often gives an extra log.length, while care in the felling of trees prevents breakage of logs. In felling the giant trees of the Pacific coast area, it is often necessary to build a bed of limbs and brush upon which to fell the tree in order to prevent breakage, which would occur if the massive trunk were to fall upon a large rock or across another log.

Manufacturing wastes are being reduced by using thinner saws which reduce less of the wood to sawdust, remanufacturing 
slabs, edgings, and defective lumber into smaller articles, such as boxes, crates, tool handles, and toys; and the utilizing of sawdust and shavings, as fuel, insulating materials, and for conversion into pulp for paper and fiber boards.

Popular prejudice to fungus-stained or wormy lumber is being overcome, and in instances where the strength or usability of such materials is not impaired they may be used as panelling, particularly in club, office, and dining rooms. The decorative effects of such materials are highly desirable.

Most forest products are derived from the woody trunks of trees, which require felling, cross cutting, and perhaps further conversion in the woods. Other products such as rubber, turpentine and rosin, and maple sugar come from the sap or growing parts of the tree and are taken continuously over a period of years from the standing trees.

For purposes of discussion, forest products are here classified into five main subdivisions as follows:

1. Construction materials such as lumber, cross ties, posts, poles, and piling.

2. Chemical derivatives such as naval stores, rubber, dyes, tannins, maple sugar, pulp, and distillation products. With the exception of the last two named products, this group is reserved for discussion in Chapters 21, 22, and 23.

3. Containers such as slack and tight cooperage, crates, boxes, veneers, and baskets.

4. Furniture.

5. Miscellaneous products such as fuelwood, excelsior, cork, toys, novelties, etc.

\section{Construction Materials}

LUMBer.-Of the country's total timber cut about $51 \%$ is used for lumber. Hardwoods make up about one-fifth of this amount, with softwoods contributing the remainder. Practically every tree species mentioned in the two preceding chapters finds its way, in some form, to the nations lumber markets (figs. 224, 225). About three-fourths of all lumber is used for general construction, building purposes, and millwork such as 


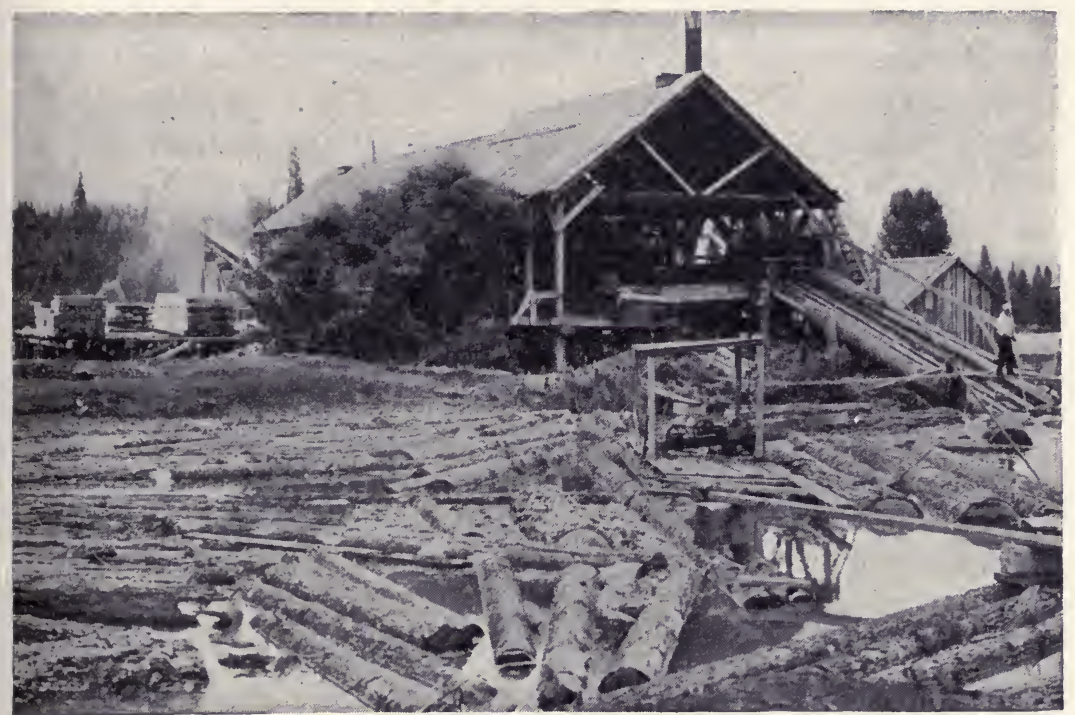

Fig. 224.- - Log pond and slip, Trout Lake, Washington. (Courtesy U. S. Forest Service.)

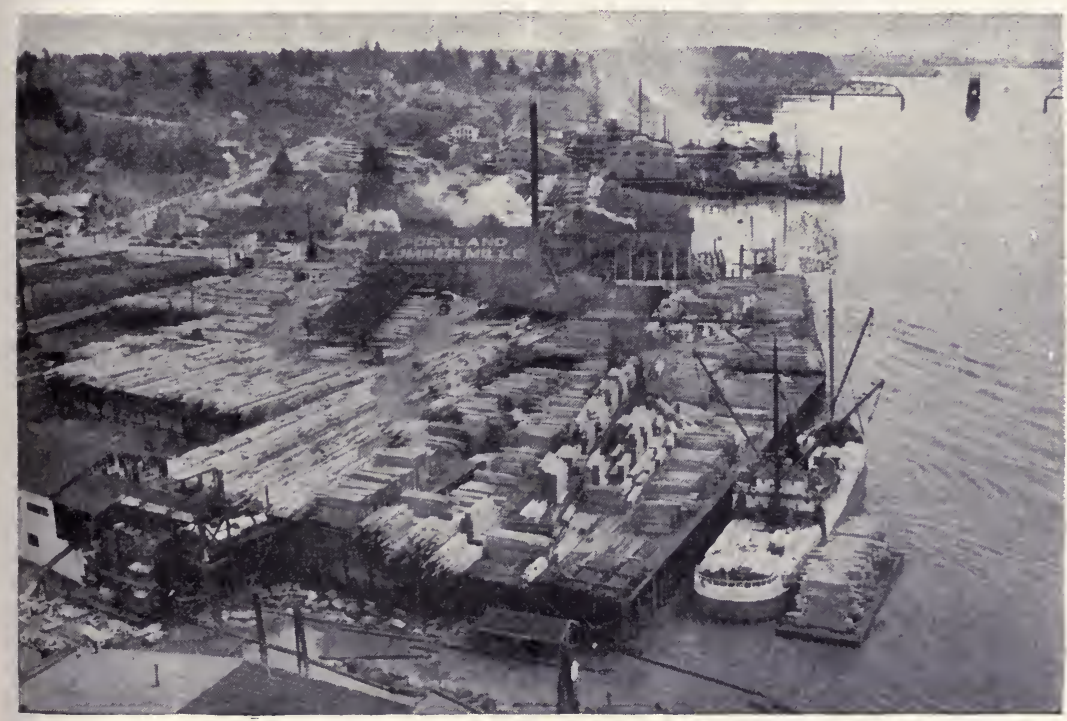

Fig. 225.-Lumber mill dock, Portland, Oregon. (Courtesy U. S. Forest Service.) 
doors, sash, and interior trim. The remainder is manufactured into boxes, crates, furniture, vehicles, and railway cars.

CRoss TIEs. - The amount of wood used annually for railroad ties is exceeded only by that used for lumber and fuelwood. In normal years as many as seventy five million cross ties have been used, but this amount has been lowered recently, due partly to the increasing use of preservative treated ties which need replacing less often than the previously untreated ones. In the latter condition a normal life of five to eight years could be expected; treated, they serve twenty to thirty years. Most of the cross ties used in the United States are of oak, southern pine, and Douglas fir. Other species used to a much lesser extent include redwood, western red cedar, cypress, tamarack, western larch, western and eastern hemlock, lodgepole pine, red and tupelo gums, beech and maples.

Hewed ties are cut from felled trees in the woods, being faced on two sides with an axe. There is consequently a greater variation in size, depending upon size of trees, than in sawed ties. For this reason, and because slabs from the latter may be used for manufacture of other products (whereas the chips from hewed ties are waste) and the greater ease of treating sawed ties with preservatives, there has been an increasing production of the sawed type.

Poles AND PILING.-Our electric light and power transmission lines, and telephone and telegraph systems of communication normally require about three million poles per year for replacements and new installations. This represents an annual expenditure of about $\$ 10,000,000$.

Chestnut was formerly one of the most important species used for this purpose, but it is steadily decreasing in importance because of its susceptibility to the chestnut blight (see p. 424). The cedars, including western red, northern white, and southern white, are all important pole species, since their woods are very durable even in an untreated condition. Southern pine is extensively used in the treated condition, having an estimated life of forty years. In the Eastern United States, about three-fourths of all poles used are supplied by the southern pines. The most common sizes of poles are from sixteen feet with four inch tops 
to fifty feet with eleven inch tops. Because of their smaller diameters and greater lengths, poles are logged separately from saw logs. Felling is usually done in the winter and the poles are peeled of their bark in the woods during the spring or early summer, after which they are removed from the woods to be seasoned prior to preservative treatment or use.

Great quantities of pilings are used, particularly in seaboard regions, for docks, wharves and piers. Grade crossing eliminations, highway bridges and railroad trestles demand large amounts throughout the country. In general, the same species are used for both poles and piling, the latter demanding greater strength and straightness in order to drive properly without splitting, but less durability, since much of the piling is driven underground where decay and insect damage are negligible factors. Piling is cut as close as possible to the point where it is to be used. When piling of lengths greater than a hundred feet is required, it is of Douglas fir, since this is the only species capable of supplying this size, of the necessary quality.

FENCE POSTS. - Estimates place the number of fence posts used annually, most of them on farms and ranches, along highways and railroads, at about $600,000,000$. In general, the farm woodlot is the greatest producer of posts, though in some parts of the country considerable quantities are produced as an incidental product on large logging operations. They offer great opportunity for efficient forest utilization, since many of them are produced from tops which are too small for saw logs, and from thinnings in young growing forest stands. The leading species, used because of their outstanding durability, include eastern and western red cedar, redwood, cypress, mulberry, black locust, and Osage orange. A second group would include chestnut, honey locust, white oak, northern and southern white cedar, catalpa, and bur oak. Butt-treating the posts with a preservative greatly increases their life, and makes it possible to use many of the much less durable woods, not mentioned above.

Shingles. - In spite of the increased use of so-called "fireproof" composition roofing materials in the last twenty years, shingle manufacture continues to be an important forest industry. It is claimed that with proper manufacture, seasoning, and use, 
the wooden shingle is best for dwelling use because of its cheapness, long life, and attractive appearance. By far the outstanding shingle wood is western red cedar, which is the source of nearly all the shingles made in the United States. Eastern white cedars, redwood and cypress also make very good shingles.

Western red cedar shingles usually come from large-sized trees which are logged with other species. The cedar logs are sorted from other species in the woods and sent to shingle mills. Here they are sawed into the desired length for shingle bolts, and split to a size suitable for the shingle machine, where they are carried past a very sharp circular saw. This power-driven carriage has a reciprocal action which provides for a tapered shingle, in both up and down directions at alternating strokes of the machine. Then the shingles are "edged" (that is, the sides are made parallel to one another and at right angles to the ends), sorted, and packed into bundles.

Split shingles, or shakes, were extensively used during early Colonial times, but today are produced and sold commercially on only a small scale in the far west. They are made principally from sugar pine, redwood, and western red cedar.

MINE TIMBERs.- Ranking sixth in amount of wood consumed yearly, the annual mine timber output is valued at about $\$ 28,000,000$. The 6,500 mines in the United States all require timbers for safety of operation. Most of the mine timbers are round, hewed, or split; sawed wood in. the form of timbers, plank, and lumber being much less used. For many years local timber supplies were depended upon as a source of mine timbers, but especially in the important coal and metal mining regions, these supplies have been depleted. As a result it is necessary to haul in desirable woods, or use local inferior species. The kind of wood used varies widely, depending upon proximity of the mining center to the various timber producing areas. Thus in the soft coal mines of Illinois and Indiana, hardwoods from the region immediately south, and southern pine from further away, are the woods used. Oak, because of its strength and durability, is the most commonly used of all tree species, making up almost onehalf of all mine timbers. In the copper and other metal mines of 
the northwest, Douglas fir, western larch, ponderosa and lodgepole pines are used.

The lengths and other specifications for mine timbers vary with local conditions and requirements. The production of such timbers is usually a separate business, though closely associated with small sawmill operations in the mining districts, where it results in more complete utilization of the tree, since pieces as small as two inches in diameter are used. Unfortunately, farm woodlands sometimes have their young, rapidly-growing stands of trees clear cut for mine timbers. Because of the warm, damp atmosphere of most mines, wood decay is very rapid in untreated timbers. Consequently preservative treated timbers are widely used in the more permanent parts of the mine, with untreated woods used in the temporary branches and tunnels.

\section{Chemical Derivatives}

Wood consists of a groundwork of cellulose, an organic chemical substance which is readily converted into sugars. This cellulose is cemented together in the form of cells by lignin and infiltrated with gums, tannins and resins. These must be removed from wood pulp before rayon, cellophane, white paper or many other cellulose products can be manufactured.

Chemical derivatives of wood have increased greatly in importance among forest industries as more has been learned concerning the chemistry of the basic substances composing the wood. They are due to become increasingly important as more knowledge is gained and as complete utilization of wood becomes more imperative.

WOOD PULP AND PRODUGTS MANUFAGTURED FROM IT.-The pulp and paper industry is one of the ten largest industries in the United States, $4 \%$ of the total timber cut being pulp wood. In Eastern Canada it is the most important single industry. Paper manufactured entirely or in part from wood pulp constitutes $90 \%$ of all American made paper. The wood pulp industry is in a constant state of change, due to the large amount of successful research being conducted to determine methods and species adapted to pulping. Early in the development of the pulp 
industry basswood was the leading species used. Then spruce became the leader because of its even, long, strong fibers, freedom from excessive pitch and colored substances, and great availability. It has held the lead for many years, but at the present its position is being challenged by the southern pines. These species (longleaf, shortleaf, slash, and loblolly) have for some time been of importance in the manufacture of Kraft papers, widely used as bags and wrapping papers. Due to their excessive amount of pitch and their yellow color, they were not adapted to the production of newsprint or other light colored papers. Continued research has resulted in the perfection of methods whereby the

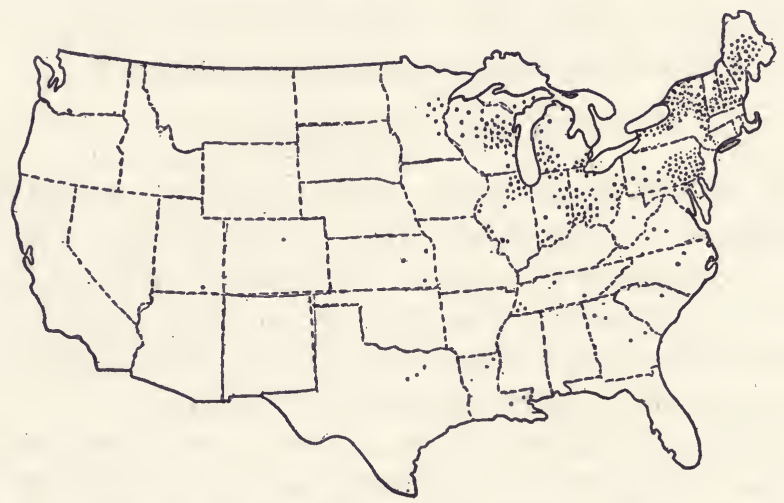

FIG. 226.-Distribution of paper and pulp mills in the United States.

southern pines can be successfuly manufactured into newsprint. This growing pulp industry in the south may greatly change the economic conditions of the region, in addition to offering a cheap domestic source of pulp which has been imported in increasing quantities during recent years. In addition to spruce and southern yellow pine, other species used include hemlock, poplar, balsam fir, jack pine, white fir, beech, birch, maple, larch, gum, and several others of minor importance at present.

The industry has long been centralized in the northeast (fig. 226) but, as stated above, there is a decided development in the south, and also in the Pacific northwest, where large amounts of sawmill waste are being utilized by a fast growing pulp industry. 
There are four principal methods of converting wood into pulp, three of which are chemical processes, and one a mechanical process. These include the sulphite, sulphate, groundwood and soda processes.

The sulphite process. - The principal woods used in this process are spruce, hemlock and balsam fir, which are brought to the mill in the form of four foot bolts or logs. If these have not been barked or peeled in the woods, this is the first step of the mill procedure. They are then reduced to small chips by a mechanical chipper, after which they are cooked, under high pressure and temperature, in an acid solution consisting of sulphurous acid and calcium bisulphite. This solution removes all non-cellulose materials, which make up about $50 \%$ of the weight of the wood, from the pulp, so that the final product is pure cellulose. The non-cellulose fraction is at present a large source of waste, which may some day be used. Following an eight to fifteen hour cooking period, the pulp is washed free of chemicals, screened, and compressed into sheets for transport to the paper mill.

The sulphate process. -This process produces pulp which is manufactured into the Kraft papers, so called because of their great strength. The principal woods used in the manufacture of sulphate pulp are southern yellow pine, jack pine, and hemlock. They are prepared as in the preceding process, being reduced to chips which are cooked under pressure in an alkaline solution of caustic soda and sodium sulphide for one to four hours after which the pulp is washed, screened and dried in sheets.

The groundwood process.-This is non-chemical in nature and consists of grinding the logs or bolts into a pulp by holding them against the surface of a rapidly revolving grindstone. Large amounts of water are sprayed on the stone to keep the pulp from overheating during the grinding. This is the cheapest form of pulp conversion, and results in a low grade pulp, which alone would make a very weak, inferior type of paper. It is used, with the addition of sulphite pulp, for newsprint paper, also for wall papers, wall boards, and wrapping papers. The original chemical constituents of the wood remain in the final pulp product, with the result that yellowing and discoloration occur with exposure to air and light, being due to oxidation of substances which in 
chemical pulps are dissolved out by chemical action. The principal wood used in this process is spruce, with smaller amounts of hemlock and balsam fir.

The soda process. - The soda process uses mostly poplar, Douglas fir, gum, and small amounts of beech, maple, and birch. The chips are cooked in a solution of caustic soda for four to six hours, after which the pulp is washed, screened, and compressed. This process yields a soft, weak, bulky fiber which is mixed with sulphite for strength and used for manufacture into book and magazine papers.

In the conversion of pulp to paper, the pulp, together with all the materials that are added to make up the particular paper, is placed into large beating machines which separate and spread the fibers. A rosin compound, or sizing, is added to make the fibers resistant to wetting; fine clay, or filler, to make a smooth paper; and dyes to give the paper its desired color. The final step in the manufacture of paper is the spreading of a thin suspension of pulp, about $99 \%$ water, on a moving endless belt of wire cloth which drains off most of the water, leaving a thin wet mat of fibers. This wet sheet is compacted by passing through a series of steel and rubber rollers (fig. 227), and dried by passing between and around numerous steam heated drying cylinders. Finally the sheet is run between heavy steel rollers, known as calenders, which give it a smooth finish. This paper machine is the most expensive piece of machinery in the industry, a large one often costing a million dollars or more. Some of the large newsprint machines are capable of turning out a sheet almost twenty feet wide at the rate of a thousand feet per minute.

FIBER BOARDS.-Many types of fiber, wall, or building boards are in use today, a number of which are of wood composition. These are made of pulp, pulp screenings, shredded bark, compressed shavings, etc. Such boards are put to a wide variety of uses, including principally partitions, ceilings, sheathing, drawer bottoms, doors, shelving, store fixtures and trunks.

RAYON.-For many years cotton linters were used in the manufacture of rayon, or artificial silk, but today it is made almost entirely from wood which is cheaper and more readily available. The manufacture and use of rayon has increased 

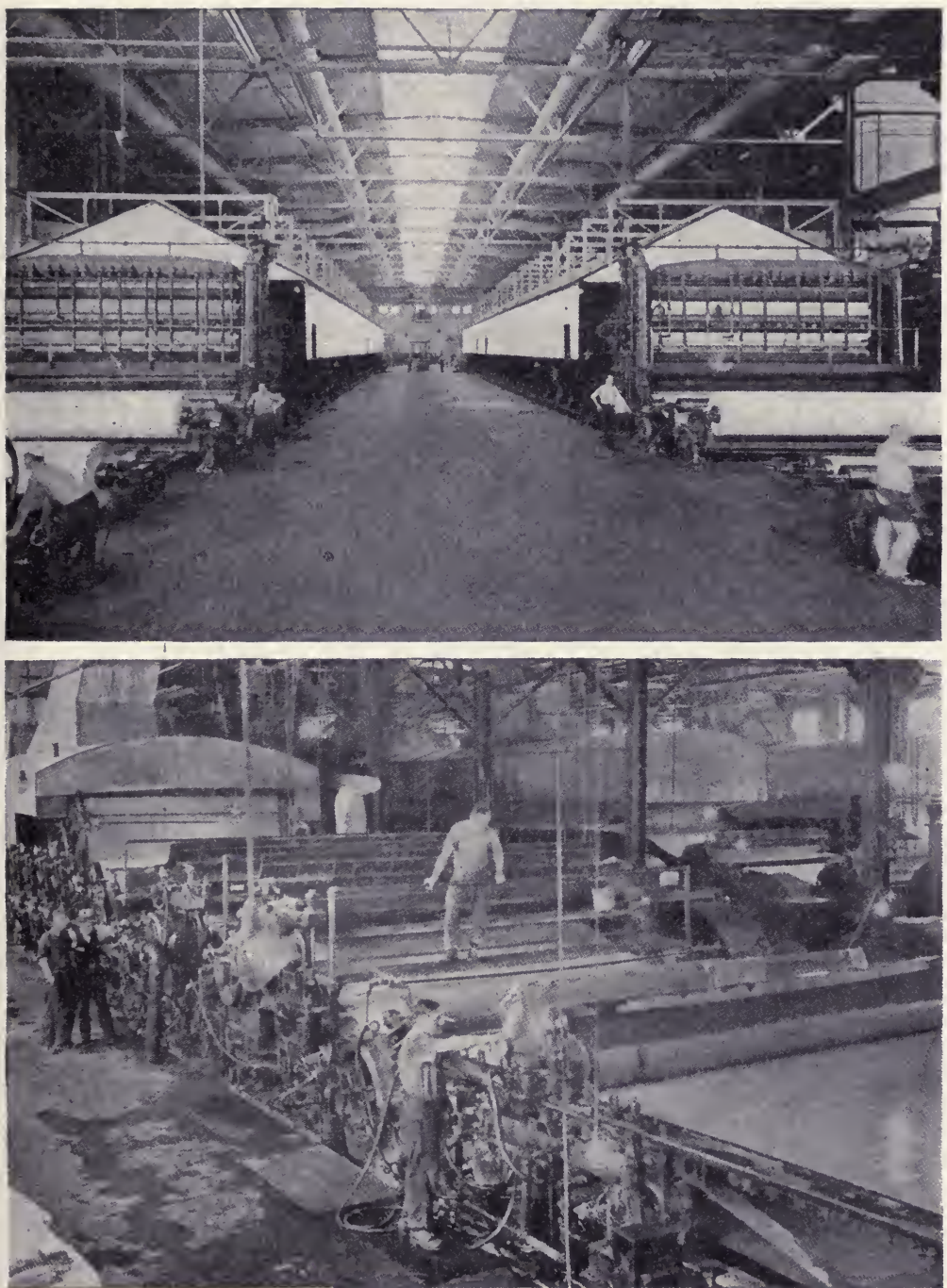

Fig. 227.-Lower photo: Wet end of rolls of paper machine. Upper photo: Dry end of rolls. (Courtesy News Print Service Bureau.) 
greatly during recent years. It is lustrous, of a soft texture, and of a constant color, and can be used to advantage in combination with cotton, silk, satin, and wool. The manufacture of rayon is intricate and complicated, there being four different processes by which it is made. There are about twenty five factories in the United States, which is the worlds principal producer and user of rayon. Further discussion of this product, as well as the one following, are to be found in Chapter 23.

Plastics. - The field of wood plastics is relatively new and undeveloped among the forest industries. It consists of the molding of pulp or cellulose products under great pressure to yield a hard substance which will not shrink or swell with moisture changes. With the great volume of previously mentioned sawmill and woods waste that is available at low cost for production of plastic products, it is reasonable to believe that in the future this industry will yield many products used in art, architecture, building construction, novelties, and other useful commodities. The nature of the processes by which plastics are produced is further elaborated in Chapter 23.

HARDWOOD DisTILlation PRODUCTS.-The process of converting wood into charcoal has been carried on for as long as there is recorded history. Of course, it is only in recent times that the gases, which pass off from the carbonizing wood in the form of dense, heavy, black smoke, have been of economic value. The northern hardwoods, maple, beech, and birch, are the most desirable, but oak and hickory are also very important, and as a result the industry centers mainly in the Lake States, New York, Pennsylvania and Tennessee. The annual consumption of wood by the hardwood distillation industry is between one-half and one million cords, or about six-tenths of one per cent of all timber cut. In the process of manufacture, the wood is cut to fifty inch lengths, loaded on small metal trucks, and run directly into large iron ovens. The wood is heated, by fires built beneath the ovens, for twenty two to twenty four hours, during which time all gases are driven off and condensed into large tanks. After completion of the heating process, the charcoal is moved into a set of cooling ovens for twenty four hours, then into the open air to cool for forty eight hours. Caution is necessary in cooling the charcoal 
because, if not properly cooled, fire is likely to occur. The crude distillate collected from the wood is refined to lime acetate or acetic acid, and wood alcohol. The lime acetate is mostly used as a source of acetic acid and acetone, which are consumed mainly by the textile and leather industries. The wood alcohol finds its main use as a solvent, largely in the paint and varnish industry. It is also used in the manufacture of dyes, formaldehyde, photographic films, and medicinal preparations. Most of the charcoal is used in the steel industry to produce a high grade of steel from iron ore. It is also used somewhat as a fuel, and in some medicinal compounds.

SofTwOoD Distillation PRODUCTs.-This industry is an outgrowth of the hardwood distillation industry, but yields entirely different products due to the differences in the structure and chemical composition of the raw materials. The industry is confined to the coastal regions of the southeast, since this is the source of the woods used almost entirely, namely longleaf and slash pines. About $80 \%$ of the wood now used consists of stumpwood, which is removed by blasting or pulling, generally eight to ten years following logging, and $20 \%$ of lightwood, a highly resinous, knotty waste material. There are two processes of distillation used with these raw materials, the destructive process, and the steam and solvent process. The former heats the wood, in four foot lengths, in ovens, driving off the gases which are condensed and refined as wood turpentine and pine tar. The wood itself is converted to charcoal. In the steam and solvent process, the wood is ground into small pieces and then steamed to remove turpentine and some pine oil, after which the residue is extracted with gasoline to remove rosin. There is incomplete utilization of the extracted wood chips in this process, though some of it is manufactured into a fiber board.

\section{Wood Containers}

Cooperage.-All wood containers made of staves and ends or heads held together by bands or hoops, are known as cooperage, which is separated into two broad divisions, slack, and tight cooperage. These divisions are based upon differences in woods used, manufacture, and qualities of the containers included in 
them. Slack cooperage includes barrels, tubs, buckets, and churns, used mostly for the shipment of dry or solid substances such as flour, sugar, chemicals, powdered milk, vegetables, lime, rosin, cement, fruits, hardware, and china. Tight cooperage is made to contain liquids, such as wines, whiskey, beer, syrup, turpentine, chemicals, and meat products. White oak, because it is very hard and impermeable, yet workable, is by far the leading tight cooperage wood. Due to the great demands made upon white oak for this purpose, it is becoming scarce and expensive to use. Substitute woods, which must be paraffined to protect against leakage, include red oak, red gum, and white ash.

Slack cooperage, which must be primarily light in weight and cheap since it competes with cardboard and paper containers, utilizes such woods as the less desirable oaks, red, tupelo, and black gums, maple, elm, ash, beech, birch, basswood, cottonwood, southern yellow pines, Douglas fir, and ponderosa pine.

Three separate processes of manufacture are required for the production of the component parts of cooperage. The staves are knife cut, or sawed (the latter method being preferred because of reduced waste) from bolts or split short log lengths brought in from the woods. They are then dried, either in kilns, or by piling so as to admit free air circulation, in a drying shed. The headings for barrels are built up of boards sawed from wood bolts of the desired length, and the wooden hoops, 95\% of which are elm, are cut or sawed from planks or thick boards. In recent years, metal hoops have been used in increasing quantities, displacing the wooden hoops. In order to save on transportation, the three parts of cooperage are very often shipped, unassembled, to the point of use, where they are assembled and filled.

VenEers AND PLYWOOD.-Veneers, or thin sheets of wood, have been used by man for hundreds of years. Until about fifty years ago, they were made of highly ornamental woods which were too expensive to be used in the form of solid boards in the manufacture of furniture. In recent years, however, veneers cut from inexpensive, or low grade woods have found widespread use for crates, containers, baskets, trunks, battery separators, and most recently plywood. The last named consists generally of three, 
five, or seven layers, or plies, of veneer glued together with the grain of individual sheets laid at right angles to one another. In this way a product far stronger than a single board of like thickness is obtained. Plywoods are manufactured in thicknesses of from one thirty second of an inch up to one and one-fourth inches, the most commonly used form being a one-fourth inch, three ply sheet. Plywoods are widely used in the manufacture of car and trailer bodies, containers, and for interior finish, in place of plaster and wall paper. Ornamental, as well as common woods, are used in the plywood industry.

There are three general methods of making veneers. The largest volume of wood is converted into veneers by the rotarycut method, in which a continuous slice of wood is cut from a log of given length by rotating it against a stationary knife which "peels" the log down to a five inch core. Practically all tree species that grow to be over a foot in diameter are used for rotary cut veneers.

Sliced veneers are produced by moving a log rapidly downward past a stationary knife, a slice being removed each time the log passes. This method is slightly more wasteful than the rotary cut method, but the sheets may be cut to desired sizes and grains matched. Oak, mahogany, Spanish cedar, rosewood, and other beautifully grained woods are cut by this method. Most wasteful process of producing veneers is the sawing method, in which successive thin sheets of wood are sawed from a log by a special, thin-edged, circular saw. Only the finest ornamental woods, with grains that are to be matched, are produced in this manner. Uneven-grained woods, burls, stumps, and knotted woods which would split or tear if knife cut, are used.

Boxes and Crates.-The manufacture of these containers is closely associated with the lumber industry, since the raw materials are often supplied in the form of lumber. The importance of this seemingly minor industry can only be appreciated when it is realized that about $15 \%$ of the annual timber cut is used in producing such wooden containers. There are about seven hundred box factories, constituting a $\$ 100,000,000$ industry, in the United States. Even though substitute materials are replacing wooden boxes in some uses, great quantities are still in demand 
for the packing of citrus fruits, apples, pears, canned goods, vegetables, and fish. Practically every wood species mentioned in the preceding chapters, except black walnut, cherry, ash, hickory and locust, is used for box shooks, as the parts are called, or crating materials. The leading species are southern pine, ponderosa pine, northern and western white pines, hemlock, spruce, gums and yellow poplar. Much mill waste in the form of slabs, edgings, trimmings, defective boards, and low grades of lumber are utilized in the manufacture of wood containers.

\section{Furniture}

In several states the remanufacture of lumber and veneers into furniture constitutes an important industry, since most of our furniture is of domestic make. This is manufactured mostly of native American woods, the few foreign woods being used in the form of fancy or beautifully grained veneers overlaid on domestic wood cores. It is a curious thing that much public opinion, in the past, has held veneered furniture to be inferior to that built of solid woods. While it is true that much antique furniture is of solid walnut, cherry, or mahogany, such pieces do not last as well under the abuse of temperature and humidity extremes found in modern homes as do pieces manufactured of built up veneers. Especially with fancy-grained woods, burls, crotch and swirl figures, birds-eyes, and the like, warping and cracking is almost unavoidable in large solid pieces such as those needed for table tops and cabinet sides. However, a thin slice of such a beautiful wood glued under pressure to a base already built up of three or four cross-grained wood sheets, will resist all but the most violent changes of moisture and temperature.

Oak and maple lead in the manufacture of American furniture, because of the abundant supply of these woods in the forests of the United States, as well as for their strong and durable character. Both are capable of taking natural finishes, as well as finishes to imitate other woods. Oak sawed on the radial section, exposing in surface view the broad, light staining wood rays is known as "quartered oak," and was in great demand twenty five years ago, but present day oak furniture uses 
more oak wood cut to expose these rays in cross sectional view. Maple is widely used in the manufacture of chairs and bedroom furniture. Fancy maple grains, birds-eye, curly, and burl maples, are used as veneers, but most of the maple furniture is of a solid construction, since maple is an even grained wood which does not warp or crack badly when it has been properly seasoned and finished. Hard, or sugar maple is most used, but the soft, red, or swamp maple is used to some extent in the south.

The two most valuable American ornamental woods are black cherry and black walnut. Sound, large trees of these species are eagerly sought after by lumbermen and furniture manufacturers, but the supply is very limited. Especially prized are the fancy-figured woods of these trees which are sawed into thin veneers and matched for table tops and cabinet and chest fronts.

Gumwood, or red gum, has been widely used in recent years as a substitute for walnut, sometimes under the name of satin walnut. The wood has a fine, close grain, enough lacking in character so that it may be stained to imitate other woods, among them - in addition to walnut-mahogany, maple, and birch.

Birch wood is much used, in the form of straight-grained lumber, for the solid parts of the better grades of furniture. It has, in addition to a sparkling, even grain, the strength necessary to make substantial, wear-resistant furniture. Some woods of uneven grain, which are sliced into veneers and called "curly birch," are used in bedroom and high grade kitchen furniture.

There have been times when it seemed that metal furniture was finding favor with the public, and might partly replace wooden furniture; but today, except for metal beds, furniture of wood construction is still leader in the field. There are many reasons for this, some of them being the natural warmth of wood, as contrasted with the chill of metal; the quietness of wood parts moving against one another; the lightness and strength of wood, and its resistance to deep mars and dents. The use of metal has been stressed in "fireproof" construction, but properly treated wood is more fire-resistant than sheet metal. As long as wood is abundant and cheap, it will lead all other substances as a furniture material. 


\section{Miscellaneous Products}

EXCELSIOR.-This widely used packing material, mattress and upholstery stuffing consists of thin shreds of a light-colored, soft, wood cut from bolts of varying lengths by the action of knives and sharp fine steel teeth. The leading woods used, in order of their importance and desirability, are basswood (which is most desirable but very limited in quantity), aspens and poplars (which make up $50 \%$ of excelsior wood), yellow pine, yellow poplar, white pine, willow, and white cedar.

Products From SAWDUST AND SHAVINGS.-As previously mentioned, an enormous quantity of sawdust and shavings, formerly disposed of in waste burners at a considerable cost, is finding profitable use along many and varied lines. One of these uses is in the production of wood flour, which is manufactured largely from sawdust by grinding between stones. It is used in the manufacture of many forms of wood plastics, artificial carvings, explosives, wall paper, linoleums, fiber boards, lamp shades and numerous other articles.

Sawdust is widely used as such for its absorbent and insulating qualities, and mixed with chips, shavings, and wood scraps it is used as a fuel in localities where sawmills are abundant, especially on the west coast. Recently developed machines compress shavings and sawdust, under high pressure into short log form for fireplace use. This form of fuel is known as briquettes.

Dimension stock.-This consists of small wood cuttings, especially hardwoods, used in the manufacture of tool handles, vehicle and implement parts, and furniture. It may be cut from lumber stock, but is being increasingly derived from sawmill waste in the forms of slabs, edgings, trimmings, and low grade or defective lumber, hence is important in furthering complete and efficient utilization of wood. The leading woods used are ash, hickory, maple, oak, elm, locust, basswood, southern pine, and Douglas fir.

FuelwOod.-Next to lumber, fuelwood is the most important wood product of the American forests, constituting almost 30\% of all wood products. Its importance has decreased with increasing use of coal and electricity, and seems likely to continue on 
the decline as rural communities are electrified. Fuelwood is one of the important means of utilization for logging waste left in the woods. Many farm woodlands are maintained as such for their fuelwood alone; the regions of greatest importance as producers of fuelwood being, in order, the South, Pacific Northwest, Lake States, and Northeast. Charcoal, or carbonized wood, is obtained by heating wood in absence of air. It may be produced in outdoor charcoal pits, holes dug in the earth and filled with wood scraps to be ignited. These are covered with straw, leaves, and earth, and allowed to burn slowly, with only a small amount of air admitted, for eight to twenty one days, depending upon the amount of wood contained. Most of the present day charcoal is produced in the processes of hardwood and softwood distillation.

Cork.-When this term is mentioned, one thinks first of bottle stoppers, although this use of cork accounts for only about $4 \%$ of the country's cork utilization, most of which is for insulation, with gaskets and linoleum using about one-fourth of the total. The world's cork supply comes from the western Mediterranean area, mostly Spain and Portugal, where it is harvested as the bark of the cork oak, a small bushy tree which grows in open groves of thirty to sixty trees per acre. The first-formed cork is rough and deeply furrowed, so that it cannot be used except for conversion into ground cork, to be remanufactured into cork composition products. This virgin cork is removed from the tree with care as new crops of high quality cork become available at intervals of eight to ten years if the trees are properly cared for. After collection from the tree, cork is air-seasoned and then boiled and scraped free of the rough outer portions, after which it is flattened, dried, and shipped to the manufacturing centers. There are many grades of cork, depending upon the uses for which the particular quality of cork is fitted.

There are many products of the forest other than wood, detailed discussion of which is omitted here. A large number of these come not from trees themselves, but are found growing under the protection of the forest canopy. Throughout the Appa- 
lachian mountain region in our Eastern states, thousands of ornamental plants are removed for planting in yards, for decorations indoors during the holiday season, and for use by florists in making flower displays. Notable among such plants are the azaleas, mountain laurel, rhododendrons, ferns and leucothoe or fetter bush. The Christmas season results in the removal of about twenty million "Christmas trees" annually. A wide variety of species are used, including in the Northeast, balsam fir and spruce, in the West, Douglas fir and several of the true firs, and in the South several kinds of pines.

Thus, obviously, the cutting and utilization of forest trees for all these products must be undertaken with a proper knowledge of forest conservation and perpetuation through wise and judicious use. The following chapter is devoted to discussion of the proper methods of conserving our forest resources. 


\section{Chapter 19}

\section{CONSERVATION AND MANAGEMENT OF AMERICAN FORESTS}

No country in the world has been endowed with such a wealth, in quality and quantity, of forest tree growth as has the United States. Originally possessed of a forest area greater than any other country except Russia, we have a far greater diversity of tree species than that country, with a resultant variety of forest industries. This natural resource is all the more important because it is renewable when properly cared for, so that it actually is a case of being able to "eat one's pie, and have it, too"'

When the first white settlers landed on the New England coast they found a forest which stretched unbroken across the Appalachian mountains to beyond the Mississippi river. Similarly a great belt of forest growth was found to exist along the Pacific coast and in the Rocky mountains. The forests of the eastern states are made up of both coniferous and deciduous trees, with deciduous forest predominating; while those of the west are almost entirely coniferous. The broad expanse of land between these forest areas is occupied by grasses which form the Great Plains, an area of scanty rainfall in which tree growth does not survive in competition with the grasses.

\section{Extent of United States Forests}

The Eastern Forest is commonly divided into five regions: the New England, the Middle Atlantic, the Lake States, the Central States and the Southeastern regions (fig. 228).

The New England FOREST REgion includes the five New England states, and is composed in the north of spruce-fir forests with some hardwoods, and in the south of a predominantly hardwood forest in which birch, beech, maple, and hemlock 
stand out conspicuously. The Middle Atlantic Regionincluding New York, Pennsylvania, New Jersey, Maryland, and Delaware - is predominantly a hardwood forest region, except for the highlands of northern New York which are covered by spruce and fir. The common hardwoods of this region are those mentioned above, with oaks and yellow poplar in addition in the southern part. The LAKe States-Michigan, Wisconsin and Minnesota - are a stronghold for white, red, and jack pines in the north, with a broad band of birch, beech and maple extending from west to east, south of the pine belt, and an oak-hickory belt occupying the southern part of the region. The Central States

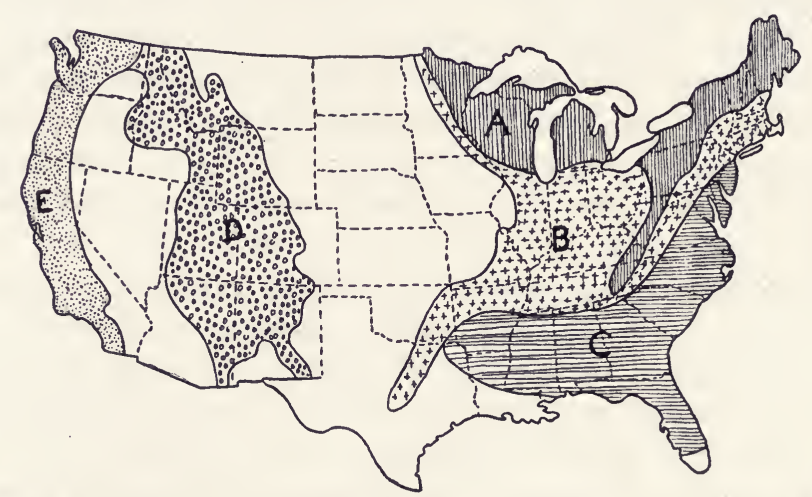

FIG. 228.-Forest Areas of the United States: A, northern coniferous; B, central hardwoods; C, southern pines; D, Rocky Mountain forest; E, Pacific forest.

REGTON, often called the Central Hardwoods region, includes the eight central states from West Virginia to Missouri and Iowa, inclusive, and from Tennessee to Lake Michigan. The southeastern part of this region is predominantly one of oaks and yellow poplar, while the northwestern part is mostly oak and hickory, with a mixture of many other hardwoods such as maple, beech, elm, ash, and walnut. The Southeastern REgion, sometimes called the "Southern Pines" region, includes the eleven South Atlantic and Gulf states from Virginia to Texas, plus Oklahoma and Arkansas. The forest growth of this region is of a very diversified character. In traveling through this region from north to south, one encounters three rather distinct types of forest: first, a 
hardwood forest dominated by oaks and yellow poplar, next an oak-pine forest, and finally in the southern half of the region, a pine forest made up of longleaf, slash, loblolly, and shortleaf pines. In the lowlands adjacent to the Mississippi river are forests composed of red and tupelo gums and cypress, while Eastern Texas and Oklahoma have forest areas of oak-pine and oakhickory composition.

The Western Forest is made up of three principal regions. The forests of the NORTHERN ROCKY MOUntain.region, including Montana and Idaho, are made up principally of lodgepole, ponderosa, and western white pines, and western larch, with different species of spruce and fir than those found in the east occurring at high elevations in the mountains. The Southern Rocky Mountain REgion includes Arizona, New Mexico, Colorado, Utah, Nevada, Wyoming, and western South Dakota. Here the forest growth is very diversified but the outstanding trees are ponderosa pine, lodgepole pine, and Engelmann spruce. The Pacific CoAst Region, including the states of Washington, Oregon and California, possesses the most heavily forested spots on earth. In Washington and Oregon the dominant species east of the Cascade mountains is ponderosa pine; west of the mountains the forest growth is dominated by Douglas fir, but with many other species, notable among them Sitka spruce, ponderosa pine, and several true firs. The California forests are dominated by sugar pine, with redwood (along the coast), incense cedar, and Jeffrey pine contributing materially to the forest cover.

\section{Location and Utilization of Timber Supplies}

From this description of our forest regions, one concludes that most of our forest area is in the eastern United States. This is exactly the case; three-fourths of our forests are in the east, with only one-fourth west of the great plains. This distribution is very desirable, since most of the timber consumption centers about the eastern industrial areas. However, this vast eastern forest area today contains only about one-fifth of the total standing sawtimber, while the other four-fifths of the nations large size timber is in the far west. The Pacific coast region, with only $13 \%$ of the United States forest area possesses $63 \%$ of the nation's standing 
sawtimber. From these figures may be gained some idea of man's depletion of the forest areas easily within his reach (fig. 229). Perhaps it was a far sighted deity that placed the nations storehouse of timber in the most inaccessible regions! At the present time successful efforts are being made to utilize more fully, and wisely, these timber resources, and many of our once flourishing eastern timber lands which through unwise use had been reduced to a non-productive status, are being rebuilt as productive areas, thus insuring to the population of the east a readily accessible and economical source of wood. The cries of "timber famine," raised by some of the early leaders of forest conservation in order to arouse public sentiment, have been regarded with scorn by

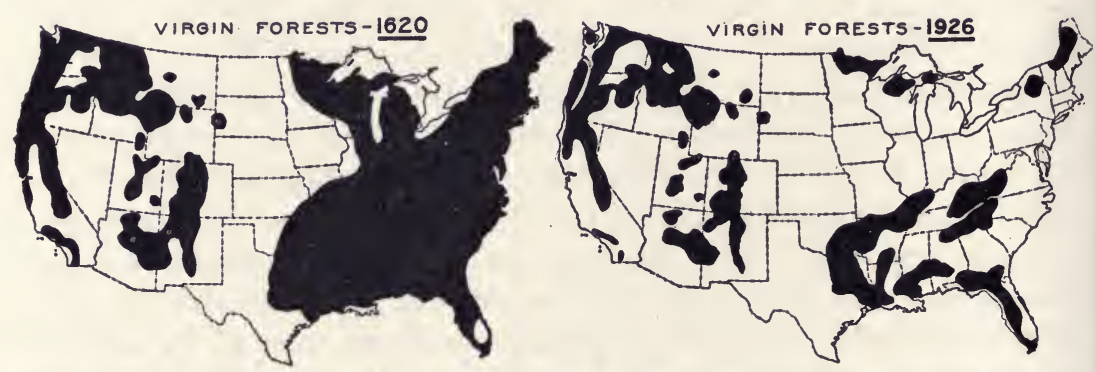

FIG. 229.-Original forest area and present forest area of the United States. 1620-1926. (Courtesy U. S. Forest Service.)

some individuals, but it seems to have been the alarm that awakened a public, now conservation-minded, to the fact that their "forest budget" was badly out of balance. Having thus examined our forest areas and the need for perpetuating them, let us now look into some of the methods necessary to insure standing timber for future generations of Americans.

\section{Reproducing the Forest}

Forests, if properly cared for, will reproduce themselves naturally (fig. 230). It often happens, however, that ruthless and unwise lumbering practices leave a forest in a non-productive condition. If such a forest is in an accessible area where timber is valuable, or if the presence of a forest growth is vital from the standpoint of watershed protection and erosion control, 
then it is desirable to resort to some method of artificial reproduction. This is also the only sure way of getting discarded agricultural lands back into a desirable forest growth in a reasonable amount of time. Artificial reproduction of forest lands has certain advantages. Reproduction is immediate, since there is no waiting

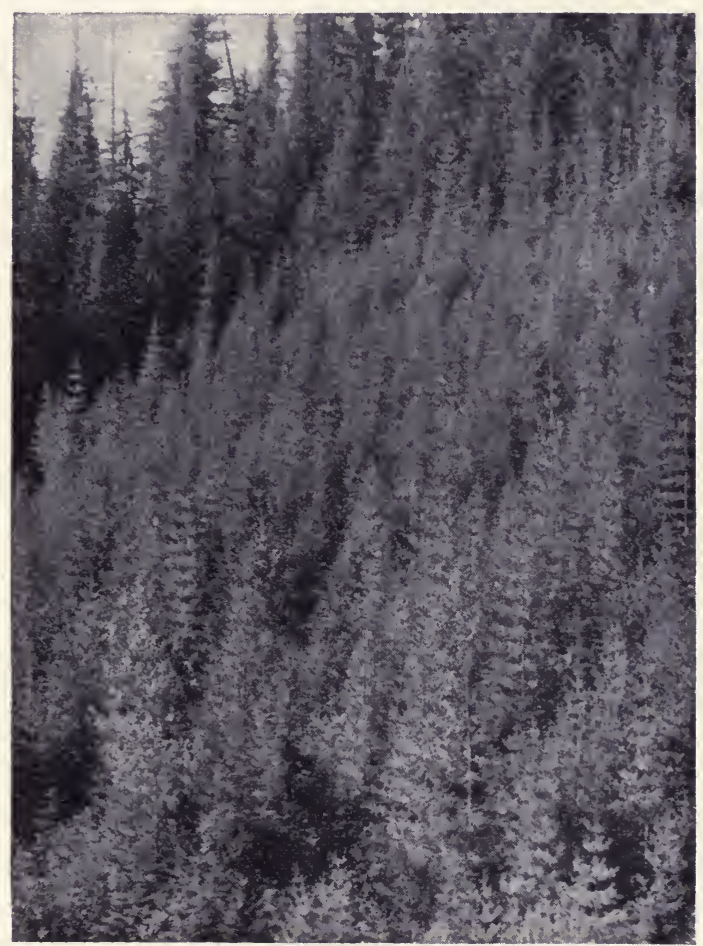

FIG. 230.- Timber management and natural reforestation, Couer d'Alene National Forest, Idaho. (Courtesy U. S. Forest Service.)

for a good seed year (in some tree species this occurs only once in five to seven years). It is possible to control the kind of trees to be grown, rather than taking natural tree species determined by chance; only species that are of value for products desirable in that particular locality need be grown. A fully stocked forest is more certain, since the trees can be planted closely enough to insure full coverage of the soil. 
While artificial reproduction in the form of seeding a potential forest area is sometimes practiced, the planting of two or three year old nursery grown stock is much more reliable, even though considerably more expensive. In the latter method, the young trees are ordinarily planted six feet apart in each direction; thus an acre would contain about twelve hundred trees. A spacing of this sort insures early meeting of the crowns or tree tops, with a resultant complete soil protection and an ultimate forest that yields straight, limb free logs. Intermediate thinnings will be necessary in the life of such a forest, but these will sometimes yield a profit by producing cordwood, pulpwood, posts, and poles, as well as cause the remaining trees to add a maximum of trunk growth each year.

If care has been used in selecting tree species well suited to the environment, succeeding generations of forest trees may be secured by methods of natural reproduction. These involve the removing of the mature timber crop in such a way as to favor natural seeding of the area from seed trees left standing in, or adjacent to, the cut-over area. In the case of some hardwood tree species the stumps will give rise to sprouts, known as coppice, if cutting is properly done. Coppice growth is much faster than seedling growth, since root systems of the parent trees are already well established and able to supply soil nutrients abundantly, in addition to containing stored food materials which give the young sprouts vital energy for early growth. Coppice reproduction is often supplemented by seedling reproduction, since ability of the parent stumps to produce successive sprout crops is rather definitely limited.

There are several advantages of natural reproduction, chief among which is its low cost. Artificial reproduction by planting costs from six to fifteen dollars per acre, while on the other hand natural reproduction involves only the leaving of a few seed trees which represent almost a negligible investment. Thus it is well adapted to remote and inaccessible forest areas where planting is financially impossible until far in the future, when timber will command a much higher price than it does today. A naturally reproduced forest stand is composed of tree species which have been successful in meeting the demands of their particular 
environment. In other words, they have been "tried and proven" by nature; there is no question as to their ability to produce a satisfactory forest growth.

\section{Protecting the Forest from Injurious Agencies}

Rapid growth and the maturing of a forest stand is possible only when such a forest is afforded adequate protection against the numerous destructive forces that are constantly threatening its well-being. This phase of forestry is known as forest protection, and treats of the protection of forests against all such destructive agencies as fire, insects, fungi, wind, sand dunes, and grazing. One or more of these agents is likely to threaten every forest stand during the greater part of its life. Indeed it sometimes seems almost miraculous that a forest will grow to maturity in the face of so many dangers. Large amounts of money are spent each year in the task of safeguarding our young and mature forest growths. Sometimes one hears these vast financial outlays criticized as unnecessary, the argument being advanced that our finest existing forests were produced by nature alone, without man's assistance. This is quite true, but they were also produced without man's interference; it has often been said that man, with plow and fire, is the worst enemy of the forest. Furthermore, man often is not content to accept the kinds of trees that naturally would grow best together, so that he creates a kind of forest growth which, under natural conditions, would not survive. Finally, nature, though ultimately producing the finest forests, is very wasteful in the process. Such forest areas may have experienced heavy and repeated losses due to lightning fires, insect outbreaks, and ravages of disease before the now visible forest matured. As long as there was no civilization, and no demands for the products of the forest, such losses were of no consequence, but present day civilization has a use for forest products and will not countenance avoidable wastes of useful raw materials. As these resources become more valuable, greater care and cash outlay will be justified since the returns will likewise be greater.

Fire is commonly regarded as the worst enemy of forests: certainly it is the most spectacular in its method of destruction. In the past, forest losses by fire in the United States have almost 
equalled those amounts actually cut for use. The Tillamook fire of 1933 in western Oregon burned for ten days and destroyed eight times as much timber as was cut in the Pacific Northwest region during the previous year. Not only do forest fires burn up valuable standing timber, but what is even more important, they prevent the natural and satisfactory reproduction of the forest, thus destroying future, as well as present forests. Fires burn the valuable nutrient materials out of the surface soil layers, impoverishing such soils and making more difficult the reestablishing of a forest cover. Such soils are much more open to washing by water, or erosion, which results in loss of the surface soil and its resultant deposition in stream channels and reservoirs, thus decreasing their capacity for water, and resulting in overflow and flooding. In addition to all the above mentioned losses is the loss of human life and property in fires. The Peshtigo fire of 1871, in Wisconsin, resulted in over fifteen hundred deaths; and the Hinckley fire of 1894, in Minnesota, resulted in the loss of over six hundred lives.

Smokers, incendiaries, and camp fires are responsible for approximately one-half the total forest fires. Lightning, the only natural cause of fire, starts about two-fifths of the fires. Although the number of fires has increased during the last twenty five years, due to the increasing use of the forest by the public, it is encouraging to note that the losses due to fires have generally decreased because of the more adequate protection given to the forests. Increased efficiency in detecting and suppressing forest fires will aid further in decreasing losses of this kind, but education and cooperation of the forest-using public is also vitally necessary. It is easy for a camper to extinguish his cigarette before dropping it, or to put out his campfire before leaving it; but it is not easy for a forest fire guard to make a special trip, by truck and on foot, to suppress the fire if it is detected in time; or for an army of men to spend weeks controlling the fire if detection is delayed, the forest is very dry, or a strong wind is fanning the flames into the tops of the trees.

Forest insect pests, although resulting in much less dramatic effects than fire, constitute a serious problem in forest management. They cause a damage to forests and forest products which 
is estimated at $\$ 100,000,000$ annually. Insécts attack and cause malformation or destruction of buds, flowers and seeds, leaves, bark, wood, and roots. Such forest products as furniture, dwellings, posts and poles are destroyed or weakened. Many of these insect pests are native to our American forests, and under normal conditions of nature, are held fairly well in check by their natural enemies-parasites, predators, and climatic factors. Occasionally, however, a series of years favorable to the rapid propagation of a particular pest results in the building up of an abnormally large population. This condition is known to entomologists as an "outbreak." It is only by careful study of life histories and requirements of the many and various destructive forest insects that such outbreaks may be forecast or recognized before they have reached peak proportions. Then necessary control measures can be applied to check the damage; these include removal and burning of insect-infested trees and general cleaning up of logging debris which would favor conditions for insect multiplication. Special methods of growing and maintaining forest stands also help in preventing undue insect damage. An example of such a silvicultural method of control is seen in the planting of white pine beneath a light cover of hardwoods in order to protect it from damage by the white pine weevil. Especially destructive are introduced insect pests, since they are not suppressed by the natural checks which existed in their native environment. Sometimes insectivorous birds and rodents do not readily accept these newcomers as items in their diet, so that the insects breed and multiply unmolested in their new home. The gypsy and browntail moths, Japanese beetle, and European pine tip moth are familiar examples of such introduced pests.

Fungus diseases of forest trees are caused by heterotrophic plants (see Chap. 25), which, being colorless, must secure their food at the expense of green plants and in so doing cause disease and deterioration of the host. All parts of forest trees, of all ages, are subject to attack by wood-rotting or disease producing organisms-leaves, stems, and roots, as well as fruit, being invaded. In the case of root and stem diseases, entrance is usually gained through breaks in the bark of the stems or roots, which may be 
caused by the eating habits of insects, natural pruning of branches, fire scars, injuries by grazing animals or careless logging operations. In the case of leaf diseases, entrance is usually by way of the stomata of the leaves. Such diseases do their worst damage on the evergreen coniferous trees, since these retain their leaves for periods of three to seven years and are dependent upon them during that time for photosynthesis. The persistent nature of such leaves allows attacking organisms to work back through them to the twigs and branches. In the case of deciduous trees, leaf diseases are not of much consequence, since the leaves are normally shed before invasion has progressed far enough to interfere with food manufacture. The fungus rarely penetrates beyond the leaf, so that even repeated attacks interfere but little with the normal functions of deciduous trees.

As examples of particularly interesting tree diseases are the following diseases of seedlings, stems, and leaves. Seedling DISEASES, which attack very young trees, are a constant threat in the nursery growing of forest tree species. Outstanding in this group is the damping-off disease, which is caused by several species of fungi which live in the soil, ordinarily utilizing dead plant remains as food. They are, however, also capable of becoming parasitic upon very young seedling stems of all kinds of forest trees, causing a break in the continuous water supply between roots and leaves, and eventually resulting in death of the plants.

STEM DISEASES of forest trees are probably more numerous and more harmful in natural forest growth than any other type of disease. One of the outstanding diseases of this group is the chestnut bark disease, or chestnut blight, which was introduced from Europe and Asia, and has practically exterminated this once valuable and dominant eastern forest tree. Attack by this parasite results in a killing of the cambium and inner bark, and ultimately the tree itself. White pine blister rust causes the development of a large spindle-shaped swelling or canker on the stem of its host with the death of all parts beyond the canker, and soon the entire tree, especially if it is a young specimen. It has caused widespread damage to the eastern and western white pines, and now threatens the California sugar pine, unless adequately controlled. 
The Dutch elm disease results in a plugging of the water conducting elements in the sapwood of elms, with resulting wilt and death of leaves, branches, and finally the tree. It was introduced from Europe ten years ago, and threatens the elm with a fate similar to that of the chestnut. Wood rotting fungi, though not causing a speedy death are responsible for great losses, especially in over mature timber, or timber in which growth is rapidly diminishing due to age. In such timber, the annual amount of wood added by growth is generally offset by the loss of an equal amount through decay caused by various wood rots. Thus there is lost each year a large volume of wood in standing timber and likewise in manufactured wooden products which are used in environments favorable to decay. While usually not directly responsible for death of forest trees, these organisms do cause a mechanical weakening of trees which predisposes them to windfall and breakage by snow and ice.

Among LEAF DISEASES of coniferous trees, the rusts are probably the most damaging. In addition to destroying the leaves, rusts often spread to twigs, branches, stems, and fruit. The pines, spruces, hemlocks, firs, cedars, and larches are all subject to leaf diseases of this sort. Among deciduous trees, the tar spot of maple and willow is one of the commonest diseases. It may be found as well developed, black splotches often one-fourth inch in diameter on leaves of maple and willow in late summer or fall, just before the foliage is shed.

Further discussion of diseases of forest trees, as well as those of mans other important plants, will be found in Chapter 25, which deals exclusively with plant diseases.

\section{Harvesting the Timber Crop}

As pointed out before, the time to make provision for natural reproduction of the forest is at the harvesting of the timber crop, technically referred to as logging. In former days logging was carried out with the idea expressed in the old slogan "cut and get out." Today, however, far-sighted lumbermen and timber owners log their forests with care, and thus are spared the expenses of paying taxes upon unproductive forest areas as well 
as being assured of future returns upon their investment. The ideal lumbering operation is one which carefully selects the trees to be removed on a basis of size, vigor, and distribution in the stand; requires care in the cutting of low stumps, in the felling of trees so as to leave undamaged the succeeding timber crop, and in the removing of the logs from the forest. Slash, or logging debris, is burned at the proper time, or dragged and distributed so as to facilitate early decay; left untreated in the forest, slash constitutes a serious fire hazard in many regions. Caterpillar tractors for assembling logs prior to transportation by truck, railroad, or water, have largely replaced the old and more destructive method. This consisted of long cables, rigged to a tall spar tree and stretched out in all directions for two thousand feet or more, from which were suspended pulleys and cables used to drag or swing the logs to the assembling point. This method, as formerly practiced, was very destructive to young trees left standing in the forest. Tractor logging is much less damaging; in fact the exposure of mineral soils by the tractor tread often provides the best kind of seed bed for germination of certain tree seeds.

\section{Indirect Benefits of the Forest}

Man is so inclined to measure the value of objects in his environment in terms of direct financial returns that he often overlooks some very valuable assets of the forest, aside from their direct value as producers of timber and other primary forest products. Many of these "other benefits" of the forest may become of primary importance locally.

One of the most important non-commercial uses of the forest is in the form of watershed protection. Forests retard the surface run-off of rainfall, protecting the soil from erosion and resulting in a regulated stream flow. Even in regions whose climate or soil will not grow commercial timber, a scrub forest, or brush cover, should be maintained for watershed protection. The value of such cover was strikingly shown in the case of a fire in a southern California canyon which destroyed the brush cover. Shortly thereafter a cloudburst resulted in a flood originating in this 
canyon with a resultant loss of property and lives. An adjoining canyon whose vegetative cover was intact showed a run-off of only a small fraction of that in the burned-over canyon, and caused little damage.

In many parts of the country, especially the West and South, millions of domestic animals, mainly cattle, sheep, and hogs, are grazed in the open forest growth predominating in certain localities. Under conditions of properly controlled grazing, the forest growth can be maintained at the same time, and such areas made to produce both forest products and forage. The national government receives millions of dollars annually for the grazing privileges in National Forests.

Forests are becoming more important yearly as propagating areas and homes for wildlife. Most of our beneficial forms of wild life spend a part or all of their lives in the shelter of the forests, or in the streams running through forest areas. These are becoming increasingly important from the recreational standpoint, as year after year more citizens turn to hunting, fishing, camping, and hiking as a means of diversion from the hurry and strain of civilized living. Good highways, and the increasing use of autos as transportation brings most people within reach of some forest recreational area. The prime assets of many National Parks - both from the recreational and scenic viewpoints-lie in their forests; this is especially true of Sequoia and Yosemite National Parks.

Forests generally tend to ameliorate climatic extremes, causing forested areas to be cooler in the hot summers, and warmer in the winter. By lessening the amount of wind movement, they retard drying and tend to conserve soil moisture. Early settlers in the Great Plains appreciated this benefit, and planted extensive windbreaks about their fields and homes. The greatly increased shelterbelt planting in the western Great Plains during recent years is the result of scientific studies which have shown the absolute value of forest growth as a factor in the control of local climate.

With all of these indirect benefits of the forest in mind, as well as those direct benefits discussed in the preceding chapter, the American public should give its wholehearted cooperation in 
the matter of forest protection, and in the matter of increasing development of a sustained-yield type of forestry. Such a cooperation in act and spirit will assure, for future generations of American citizens, the multitude of forest benefits which we and our ancestors have enjoyed and used, though we have not always used them with wisdom and discretion. 


\section{Chapter 20 \\ FIBER-PRODUCING PLANTS}

Food and clothing were to primitive man, as they are to present day civilization, two of the prime necessities of life. Although man's first garments were of animal skins, he early sought a type of clothing that was lighter in weight, cooler, and more pliable. Thus the use of several of our present-day plant fibers have their beginnings lost in antiquity. As civilization progressed, demands for fibrous products became greater, and the number of plants used as sources increased, until today there are probably well over a thousand species used, since in the Philippines alone there are seven hundred and fifty such plants.

Plant fibers may be classified in a variety of ways: according to their use as textile fibers, brush fibers, etc.; according to the part of the plant in which they occur, as stems, leaves, etc.; or according to the groups of plants in which they occur, as Monocots or Dicots. The classification used here groups the fiber sources with regard to Dicot or Monocot nature, and subdivides these groups upon the basis of the plant parts from which they come.

\section{Fibers from Dicot Stems}

FLAX may well be man's oldest textile plant; five thousand years is a moderate estimate of its antiquity as a cultivated plant. In value of its products, flax is exceeded only by cotton, which, however, it surpasses in quality of textile fabric. Flax plants grown for fiber are slender, little-branched annuals with small white or blue flowers and fine leaves, growing to a height of around three feet (fig. 231). They grow best on moist fertile soils, in cool humid regions; such conditions are especially present in the northern European countries of Russia, Belgium, Germany, 
and Ireland, which lead the world in flax culture. Until forty years ago, almost every United States farmer grew fiber flax for his own use, but this has been largely discontinued, and at the present time no commercial fiber flax crops are grown in the United States.

Flax fibers are located in the thin bark which covers the stem,

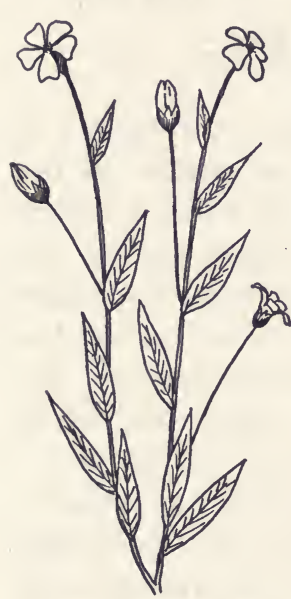

FIg. 231.-Flax plants are. slender annuals with small white or blue flowers. and consist of tough strands, sometimes three feet long, made up of cells with heavy cellulose walls. The plants are usually harvested by pulling, and then either submerged in water or allowed to lie in the field exposed to dew, rain, and snow until bacterial decomposition has loosened the fibers from the bark and wood. The debris is then removed from the fibers by the rolling and beating action of special machines after which the fiber is combed and straightened, either by hand or machine. Long straight fibers are spun into thread used for high grade linen fabrics, while short and tangled fibers (tow) are used in flax yarns and in coarse fabrics. Linen threads, fabrics, and yarns are famous for their great strength, which increases when they are wet. Linen fabrics conduct heat more rapidly than others, and therefore are more desirable for summer clothing, the body heat being easily dissipated into the surrounding air.

HemP is also a very ancient cultivated plant, though probably not as old as flax. It was introduced into Europe from China about 1500 B.C. and the industry today centers in Russia, Italy, and Hungary. In this country small amounts are produced in Wisconsin and Kentucky.

The hemp plant is a tall hollow-stemmed annual which grows to be sixteen feet high (fig. 232). Its flowers are small, maturing to form the hemp seed which yields a fatty oil. The dried flower tops yield a powerful narcotic drug which is discussed in 
Chapter 22. Hemp for fiber does best in a mild humid climate and a rich moist soil, maturing its fiber in about four months.

Hemp fiber, like flax, occurs in strands beneath the bark. Its extreme length-three to nine feet-and its great strength and durability, are responsible for its value. The cellulose of the cell walls is impregnated with a stiffening substance, lignin, which prevents the fiber from having the elasticity and flexibility of flax. In the harvesting of hemp, the plants are cut and dried, after which the fibers are separated by the same methods empolyed in separating flax fibers. On account of its great strength, hemp was formerly much used for ropes and ship riggings, but is . no longer so widely used in this capacity, being replaced by manila. It is used in the manufacture of coarse textiles, sailcloth, webbing, bags, and tarpaulins, where its dark color is not objectionable. The short fibers, or tow, are used for packing pumps and engines, caulking seams in boats, and to a slight extent as an upholstery stuffing. In recent years the use of hemp has fallen off considerably due to

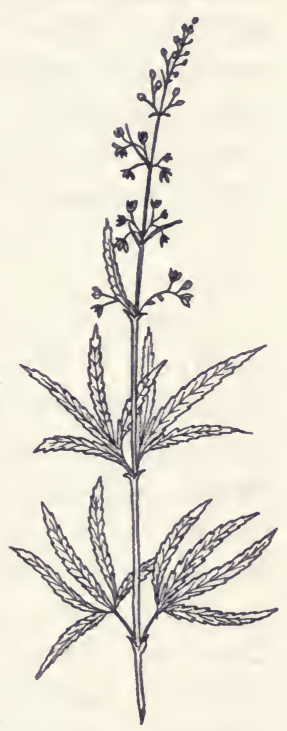

FIG.

232.-

Hemp plants are tall annuals with inconspicuous flowers. increasing use of cheaper fibers such as jute, manila, and sisal.

JuTE fiber is obtained from several woody annual plants belonging to the Basswood Family. Most important is India jute, a plant reaching heights of ten to twelve feet. It is grown mostly in rich, river bottom soils that are often overflowed at high water, in the warm humid climate of India. Plants are harvested by cutting or pulling about four months after planting, while the yellow flowers are still in blossom. The softer stem tissues are rotted out in pools or running water, and the fibers are then loosened from the bark by whipping on the waters' surface. After several rinses, the fiber is wrung out of the water and allowed to dry on bushes or poles. The fibers have considerably more lignin 
than either flax or hemp, hence are quite stiff; their length and abundance in the stems, along with their cheapness and ease of spinning, make them valuable. They are not very strong, and deteriorate rapidly when exposed to moisture. In spite of its perishable nature, jute is the world's leading material for use as burlap bags, covers for cotton bales, potato sacks, linoleum and carpet backing, brown twines, and tarpaulins.

RAmie, or China grass, is a fiber plant belonging to the nettle family. It is a perennial plant, producing from two to four crops of canes annually in southeastern Asia, where it has been used since primitive times. It is a plant of warm climates, requiring a fertile, well-drained soil; cultivation on an experimental scale has been carried on in California and the southern states. The fibers, located beneath the outer bark layer, are fine; very long and lustrous, possess a high durability and a strength greater than that of any other fiber. The only objection to ramie is the difficulty with which it is extracted from the plant-a process involving mostly hand labor. The canes are peeled of their bark and the outer green tissues stripped or scraped from the fibrous parts by hand. The fibers thus left are heavily coated with gum, which must be removed by repeated washing in water and drying in the sun. Studies are being made to find a simpler degumming process, which at the same time will improve the pliability and cohesive qualities of the fiber. In its natural condition, ramie is so smooth as to prevent its manufacture into textiles requiring great strength. In Asia, and parts of Europe, it is used for the manufacture of dress goods, underwear, upholstery, and paper.

\section{Fibers from Dicot Fruits}

The two fibrous products included in this group arise as a dense hairy covering of seeds, within the seed pod or boll as it is known in cotton. They originate as outgrowths of the epidermis of the young developing seeds.

CotTon is the world's most important fiber plant, constituting the greatest industrial crop as well as being one of man's oldest cultivated plants (fig. 233). Several species of the cotton plant 
are known and cultivated, but the bulk of the world's supply comes from two species, known as upland cotton and Sea Island cotton. Since all cottons are of tropical origin-India, South and Central Americas, and the West Indies-they are grown successfully only in regions of high temperature and long growing season. It has long been the chief crop of the southern United States, which produces over one-half of the world's supply, followed by India, China, and Egypt. Cotton grows best on a deep fertile soil, but some varieties will do well in less favorable
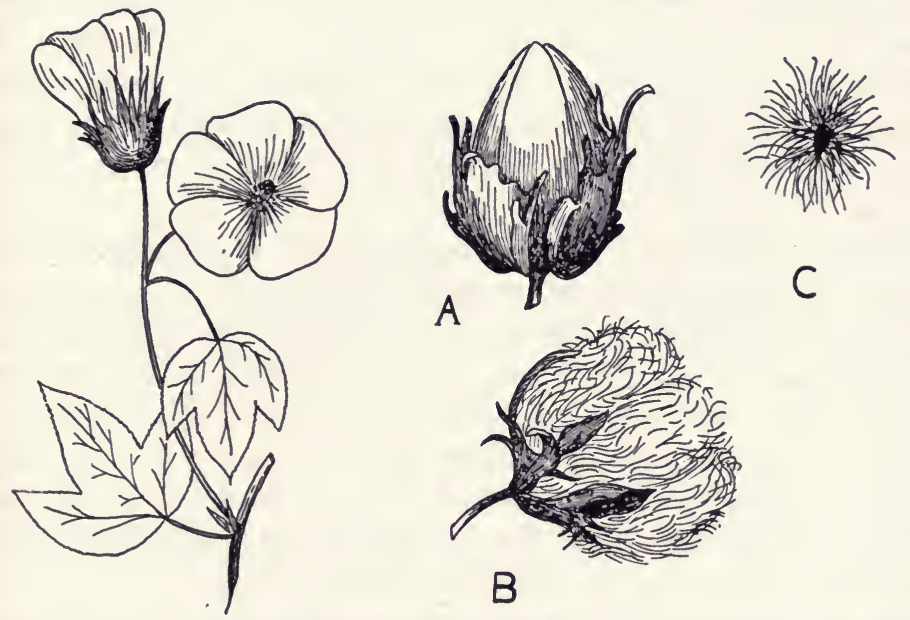

A

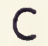

Fig. 233. - Cotton plants produce large white flowers and fruits with a fibrous covering to the seeds; $A$ and $B$, the fruit; $\mathrm{C}$, the seed.

soils if the moisture content is suitable. In its native state, the cotton plant grows as a perennial shrub or small tree, but when grown as a crop plant it is treated as an annual. Sea Island cotton, so called because Columbus found it growing in the West Indies, has the longest fiber, but is more exacting in requirements than upland cotton. American production of this variety centers in the coastal regions of South Carolina, Georgia, and Florida. Upland cotton, which makes up $99 \%$ of the United States cotton crop, probably originated in Central America. Its fibers are shorter, but it is easily cultivated and gives a high yield in the southern region extending from Texas to the Atlantic coast. 
The lint, as cotton fiber is called, matures in about six months, at which time the bolls split open, exposing it along with the enclosed seeds, and allowing the entire mass to be picked out by hand. Very recently there has appeared on the market a mechanical cotton picker which is driven through the fields and picks the cotton far more quickly than a number of human pickers manage. Rain at the time of picking may seriously affect the cotton crop, since the fibers rot easily when wet. Being practically pure cellulose, cotton takes very little nutrient material from the soil; therefore, cotton crops have been grown repeatedly, sometimes for as long as forty years, on the same area. This, however, is a bad practice for reasons other than soil nutrition; it especially favors the increasing hazards of insects and disease, which are ever present dangers to all cultivated crops, but even more so to cotton.

Before cotton, as it comes from the field, is manufactured into textiles, several processes known collectively as ginning and milling are involved. In the ginning of cotton the fiber is removed and separated from the seeds, after which it is baled and transported to the cotton mills. Here it is given a final cleaning to remove any fragments of bolls or other foreign matter, and then extracted of its short fibers which are not used for textile manufacture. Finally the long lint is combed to straighten and distribute the fibers evenly, and spun into thread.

The chief use of cotton is in the manufacture of textiles of all kinds. Since the growth of the automobile industry, cotton has become an important constituent in rubber tire fabrics. Absorbent cotton, used in surgery and in the manufacture of cellulose products discussed in Chapter 23, is prepared by removing chemically the outer oily layer of the cotton fiber. In this condition it will absorb almost twenty times its own weight of water. The short fibers or linters, the seeds, and the stalks, which formerly were waste products, today constitute some of the most valuable products of the cotton plant. Fiber boards and paper from the stalks; oil, stock food and fertilizer from the seeds, and cellulose products from linters are only part of the important by-products of the cotton industry. 
The silk-like floss produced on the seeds of the KAPOK tree is the most valuable of the materials used for padding and stuffing (fig. 234). The original home of this tree was in tropical America, but it is now grown in Asia and Africa. The United States imports this fiber mostly from Java, Ceylon, and the Philippines. The mature kapok tree is short-stemmed and broad crowned, with a spreading, buttressed base, and will produce annually about a thousand seed pods which yield about ten pounds of fiber. This cotton-like floss is light brown to whitish in color; very light, fluffy, elastic, and impervious to water. For the latter reason it is
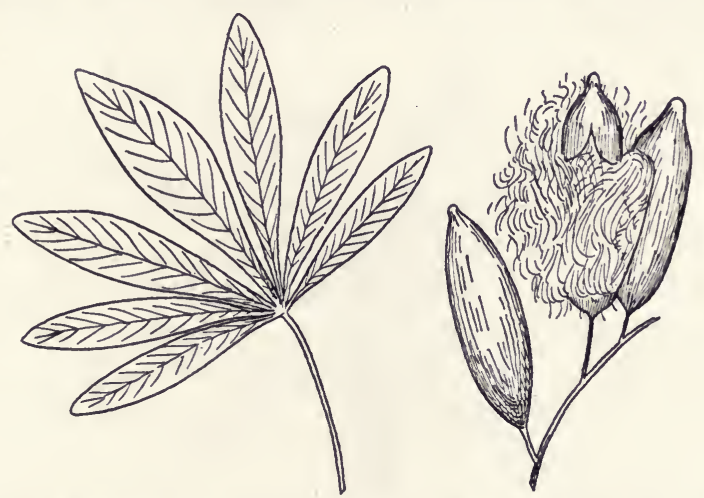

Fig. 234.-Kapok seeds have a silky-haired covering, useful to man because of its imperviousness to water.

used as a life preserver filling; a small cushion stuffed with kapok will keep a person afloat for many hours. Kapok seeds are used as a source of oil for soap making and food purposes.

\section{Fibers from Monocot Leaves}

Fibers of this group come from very large leaves or leaf-bases, where they occur as long strands of stiff-walled cells associated with the conducting tissues.

MANILA HEMP, or ABACÁ, as it is often called, is a strong, valuable fiber which is obtained from several species of wild plantain or banana (fig. 235). The principal source is a bananalike species grown mainly in the Philippines, where it constitutes the chief crop. Manila hemp plants demand a warm humid 
climate and a rich moist soil-conditions which exist everywhere in these islands. Plants are grown from seed or cuttings and the first crop can be gathered in about three years; subsequent crops can be secured at intervals of three to four years.

The fibers, individually six to twelve inches long, are removed in six to twelve foot strands by stripping the outer layers from the large, sheath-like leaf bases, where the fibers occur as a tough rind beneath the outer cell layers. The strands are then scraped to remove associated tissues, and dried. It is shipped to the United States in large bales, and here manufactured into cables and ropes. Due to its elasticity and strength, which is even greater

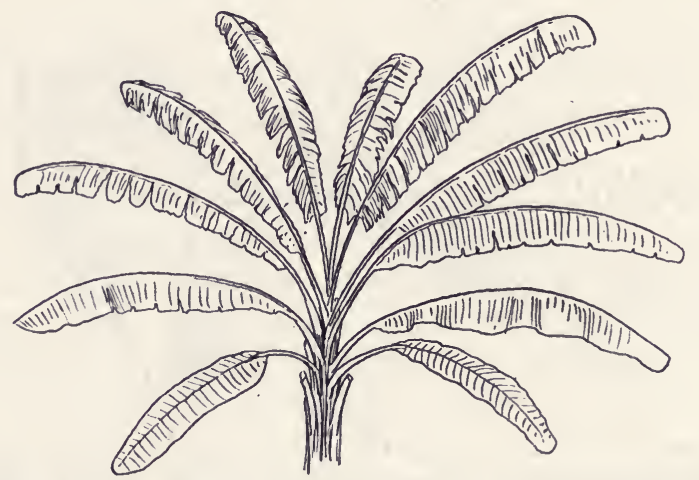

Fig. 235.-Manila help fibers are obtained from the leaf bases of the large leaves.

than that of hemp, manila has replaced most other fibers for use in manufacture of cordage. Hats, heavy paper and binder twine are outlets for the fiber; it is especially suitable for marine cables, since neither salt nor fresh water harm the fiber.

The sisal fibers - henequen, sisal, and istle-all come from Mexican plants known as Agaves, which are stemless perennial plants with basal clusters of fleshy, sharp-pointed leaves. They are closely related to the century plants grown in the southern United States as ornamentals. All are drought resistant plants, thriving on dry sterile soils where other crops could not survive. The plant is reproduced by means of sprouts which arise at the 
bases of old plants; these are planted out, often in soils that are too rocky to be plowed, and allowed to grow, with little or no cultivation, until they are about seven years old, when crops of leaves are first cut from the plants. Today sisal is grown in Florida, Africa, Java, Sumatra, India, and Haiti. The fibrous product is located in the leaves, from which it is removed by hand or machine, then cleaned, dried, and shipped to the manufacturer. Sisal fibers are used mainly in binder twine; fibers from some species contributing to the manufacture of lariats, coarse sacks, and similar products. The fibers are weak and heavy, hence they are not suitable for cables, ropes, rigging, etc.

$$
\text { * * * * * }
$$

As its name indicates, New Zealand hemp comes from a native New Zealand plant, a member of the lily family, now widely cultivated throughout the tropics and even in temperate regions. It is grown as a fiber plant in California, and elsewhere in the United States as an ornamental. The fiber comes from the leaves, which may be as much as eight feet long and eight inches wide, containing up to $20 \%$ of fiber. When removed from the leaves, the fibers are softer and more flexible than manila, and have a high luster. New Zealand hemp is used to some extent for cloth, mostly for binder twine, tow lines, and cordage where it is often mixed with other Monocot leaf fibers mentioned above.

Panama hats are made from the leaves of a stemless tropical American palm, cultivated in Colombia and Ecuador. Young leaves are collected, split into thin strips, cleaned, bleached, and hand woven to form the hat. The leaves of the Puerto Rican hat palm are similarly used to make the so-called Puerto Rican hats. Both of these hats are far more durable and of a finer texture than the ordinary straw hats, which are made from braids or straw plaits of wheat, rice, rye, or barley straw especially grown for that purpose.

\section{Fibers from Monocot Stems}

The "stems" of many Monocot trees are composed largely of persistent leaf stalks. However, there are two groups of plants, 
one a group of climbing palms known as RATTANS, and the other a group of giant grasses called BАмвоOs, which furnish very pliable, woody products widely used in the manufacture of chair seats, baby carriages, hampers, and other light pieces of furniture.

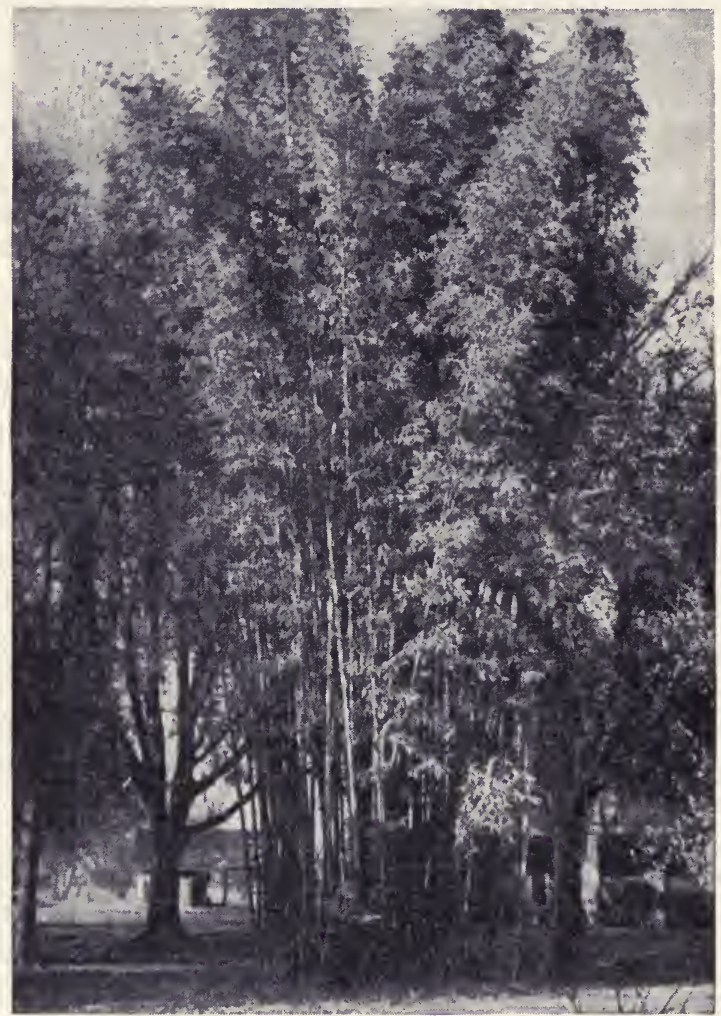

Fig. 236.-Bamboos are giant grasses which furnish man with useful pliable stems.

Rattans are found in the hot humid forests of the East Indies and elsewhere in tropical Asia. Their stems are long, flexible and strong. A large quantity is shipped to the United States and Europe, where it is used either whole or split, in the manufacture of the above-named articles.

Bamboos (fig. 236) often reach heights of one hundred feet or more and a diameter of a foot. They occur in most tropical 
countries, especially in the hot humid regions of southeastern Asia. Stems of numerous species are used by the natives for all types of construction, and are exported to other countries for manufacture into fishing rods, furniture, baskets, brushes, and many other objects.

\section{Fibers from Monocot Flowers and Fruits}

Broomcorn, also a member of the Grass Family, is a member of the sorghum genus, other members of which are discussed in Chapter 12 as sugar producing plants. The seed head of broomcorn is made up of a cluster of long straight seed bearing branches which constitute the brush, or valuable part of the plant. Most of the United States broomcorn is grown in the Mississippi valley. Harvesting of broomcorn is carried out before the seed has formed, by cutting the stems a few inches below the heads, after which they are sorted for quality, threshed, and dried, later to be manufactured into brooms of all kinds.

Although not properly included in this section, another grass, known as BROOMROOT, is widely used in the manufacture of cheap brushes. This is a perennial plant found especially in the mountainous regions of Mexico, where it is exploited by the natives for its coarse wiry roots at all seasons of the year. After the plants have been dug, their roots are washed, dried, cut from the tops, and sorted for baling and shipment.

The COCONUT PALM contributes a fiber known as GOIR which is the rough, brownish fiber derived from the husks of its fruit, the coconut. In order to loosen the fibrous material, unripe coconuts are soaked in salt water for several months, after which the fiber is beaten free from the rest of the tissues, washed, and dried. The resultant fiber is very resistant to mechanical wear and wetting, so is widely used in the manufacture of doormats, upholstery stuffing, coarse textiles, and cordage. Most of the coir which finds its way into the world markets is from India and Ceylon, although it is produced for native use throughout a much larger area in the tropics. 

Part Four

PLANT SECRETIONS

AND EXCRETIONS 



\section{Chapter 21 \\ LATEX-PRODUCING PLANTS}

In many plants there occurs a white or colored emulsion known as LATEX, which consists of a watery liquid holding in suspension within it a variety of minute particles or globules of other chemical substances. When exposed to the air, or subjected to chemical treatment, these latex substances usually separate or coagulate. Their actual value to the plant has not been definitely determined, but since latex coagulates upon exposure to air, which happens only when wounding of the plant occurs, it may well be a protective device which prevents drying of plant tissues and entrance of parasitic organisms under such conditions.

Rubber is by far the most important latex product known to man at the present time. Over fifty species of plants are known to yield rubber, not all of them in the form of latex, as will be pointed out later; but only a few species are of commercial importance at present. Rubber is the youngest of the world's major crop plants; it has been under cultivation for only a little over fifty years, and has been used industrially for only one hundred years. British possessions, Malaya, Ceylon, India and Borneo, and the Dutch East Indies are the world's rubber producing centers today.

Rubber was first brought to the attention of European civilization when Columbus reputedly brought back crude bouncing balls fashioned out of it by West Indian natives. Later, Brazilian natives were found waterproofing footwear with coats of latex. It was not until the middle of the eighteenth century that French explorers discovered the source of rubber in South America to be the now famous Brazilian rubber tree. The early French name for rubber was "caoutchouc," a French rendition of the Indian "cahuchu" or weeping tree, so called because of its tear-like exudations of latex. The present day term rubber 
was applied by the British chemist Priestley, in 1770, after he had found it useful in rubbing out, or erasing, lead pencil marks. Although rubber articles, and clothing waterproofed with rubber solutions, were used somewhat, it was the accidental discovery of rubber vulcanization by the American, Goodyear, that led to the widespread usefulness of rubber today. Until the stabilization of rubber by vulcanization, or heating in the presence of sulphur, was developed, rubber was stiff and brittle when cold, soft and sticky when warmed. Vulcanized rubber is not as subject to changes with variations in temperature or moisture. Today widely different types of rubber articles are manufactured, their hardness or softness predetermined by the amount of sulfur added and the degree of heat to which the compound is subjected. The United States is the world's leading rubber user, importing about $70 \%$ of the annual rubber production to supply our rubber industry. The rnanufacture of automobile tires and tubes, the last phase of the rubber industry to develop, uses almost nine-tenths of the crude rubber imported by the United States. Other uses include the manufacture of rubber boots and shoes, druggists sundries such as hot water bottles, rubber gloves, etc., electrical goods, hard rubber goods, and other uses too numerous to mention.

\section{The Brazilian Rubber Tree}

Of the multitude of rubber-yielding plant species common to the hot, damp forests of South America and Africa, one-the BRAZILIAN or PARA RUBBER tree-stands out far beyond all others in importance. It is a member of the Spurge Family, which also includes Ceara and Intisy rubber plants; but the Para rubber tree produces about $95 \%$ of the world's rubber supply today. In addition to being the chief wild source in its South American jungle home, it is the most common tree used for planting in the extensive rubber plantations of the British and Dutch East Indies. In South America the tree attains heights of over one hundred feet with diameters of three feet, living to an age of two hundred years. The small, inconspicuous flowers are in marked contrast to the giant, three-parted leaves (fig. 237). 
Rubber production in South America differs considerably from production on East Indian plantations even though the same tree is used in both instances. In South America, collection is almost entirely from wild trees in the jungles of the Amazon region. They are linked by trails, and native collectors tap the trees and collect the latex. Trees are tapped in the early morning by cutting a diagonal notch in the bark with a small hand axe, and the exuding latex is collected in a small tin cup attached below the wound. Several cuts may be made on the same tree, and the operation is repeated twice weekly for six months or more, after which the trees are allowed a resting period of several

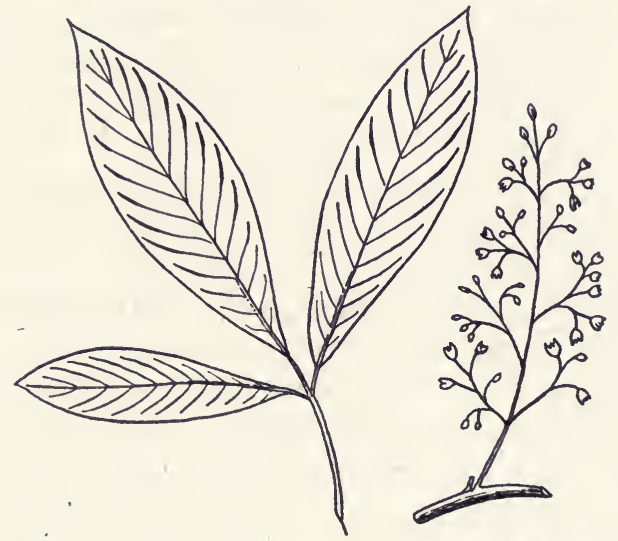

FIg. 237.-The Brazilian rubber tree has inconspicuous flowers in contrast with large three-parted leaves.

seasons during which time the bark is renewed. With proper care, trees may produce for fifty years or more. Coagulation of the collected latex is accomplished by repeatedly dipping a stick or paddle into the latex and then rotating the film in a dense, oily smoke made by burning the fruits of a palm, or other plant materials. This is continued until a large ball of rubber, weighing one hundred pounds or more, has been formed. It is sold to rubber buyers in this form. Rubber gathered in this manner is rather impure, due to lack of care in collection and coagulation, and contains about $15 \%$ water.

The Brazilian rubber tree is now grown extensively under plantation conditions, where it dominates the world's rubber 
market with its produce. In fifty years, the plantation rubber industry had developed from the experimental confines of botanical gardens to cover over six million acres of former tropical jungle. Plantations are established by planting the cleared jungle areas with seedling trees which have been started in nurseries. Growth is rapid, and with care a plantation will be ready for its first tapping five to seven years after the trees have been set out, at which time the young trees measure about six inches in diameter. The cost of establishing and maintaining a rubber plantation, until the first returns from rubber are forthcoming, varies from $\$ 200$ to $\$ 400$ per acre.

Tapping is much more carefully done on plantation trees; a sharp knife is used to make a narrow diagonal cut in the bark about half way around the tree, care being taken not to injure the underlying growing tissues. The tree is retapped, always early in the morning, every other day; if properly carried out, this removes only about an inch of bark per month from the tree. This is sometimes continued throughout the year, at other times for only two to eight weeks, depending upon the demand for rubber. The length of life and amount of yield of rubber trees under plantation care is definitely favored by the highly intelligent class of native labor available. The oldest plantationsforty years or more old-are still in active production. These plantations are usually part of a large rubber estate, each of which has its own factory to which the collected latex is taken for coagulation. Here the latex is sieved to remove any debris and then left, with the adding of a weak acid solution, to coagulate over night. In the morning the coagulated rubber cake is removed, rolled flat, ribbed, or creped, and dried for a week or more after which it is packed for shipment. For some types of manufacture, it is better to have the rubber in a liquid form, known as liquid latex. This is produced by adding ammonia to the strained latex to keep it from coagulating, and shipping in large tank containers.

Final manufacture of rubber into the thousands of useful articles of present day civilization is accomplished at factories near to the consuming areas. In the United States, Akron, Ohio is one of the leading rubber manufacturing centers. 


\section{Other South and Central American Latex-producing Plants}

Of the many latex yielding plants other than the Brazilian rubber tree found in the tropical Americas, only four furnish products which are of sufficient economic importance to warrant discussion here.

Panama, or Caucho, Rubber comes from several large trees belonging to the Mulberry Family. These are found in Mexico, Central America, and the Amazon valley of South America. Due to former extremely destructive methods of collecting the latex, which involved felling the tree and tapping by means of girdling cuts around the trunk, the more important of these species were almost exterminated. Today' however, more conservative methods, much like those involved in the case of the Brazilian rubber tree, are practiced and plantations of these trees in Central America are yielding very satisfactorily. Latex is collected from tapped trees in cups, or in shallow holes scooped out of the ground. Coagulation is effected by exposure to air, boiling, or by the addition of plant juices or alum. Due to the methods of collecting latex, the resulting rubber is highly impure and does not command the price possible with a more carefully prepared product. This rubber will probably never compete successfully with that of the Para rubber tree, but its importance may well increase considerably with added care in exploiting and preparing the product.

CEARA rubber comes from a small tree of the Spurge Family, native to the desert regions of Brazil. This yields a good grade of latex which is coagulated by air or smoke, after which the crude rubber is exported in blocks, or flat cakes. The Ceara rubber tree is very rapid growing, and does well in dry, rocky soils not suitable to the production of other rubbers. In plantations of India, Ceylon, and other tropical countries, the trees are tapped when only four or five years old.

BALATA is a non-elastic rubber much like gutta-percha, and comes from a large tree of the Soapberry Family native to Trinidad and South America. The wood of the tree, being hard and durable, is also much in demand. The trees, tapped about three times a year, yield a latex which flows freely and coagulates 
readily upon exposure to air, after which it is cleaned and molded into cakes. Bâlata rubber is used for machine beltingssince it grips tightly and does not stretch; as a substitute for chicle in the manufacture of chewing gum; and for insulation, pipe stems, golf balls, and adhesives.

Chicle, a gum produced by the sapodilla or naseberry, also of the Soapberry Family, is the basis of the chewing-gum industry. The tree - a fine, tall hardwood with evergreen leaves - is indigenous to Mexico and Central America, but is cultivated elsewhere in tropical America and Florida for its edible fruit. The latex is obtained by tapping the tree with zig-zag gashes up to a height of thirty to fifty feet, and directing the latex flow to a cup or hollow in the earth at the base of the tree. The flow of latex lasts for several hours, but the trees can be tapped only at intervals of two or three years, hence plantations of the species, though being started on a limited scale are not very practicable. The chicle is collected and taken to a central camp where it is boiled and molded into blocks for shipment.

Chicle has been chewed locally for hundreds of years, but its manufacture into a chewing-gum was not practiced until some time late in the nineteenth century. From a crude beginning about seventy years ago, the United States chewing-gum industry has grown until it imports almost $\$ 5,000,000$ worth of raw chicle annually, which is almost the entire output of this product. Upon reaching the manufacturer the blocks of chicle are broken up and purified by washing with chemicals, after which processes of sterilization, compounding with sugar and flavoring materials, and cutting, wrapping, and packaging are all carried out by machinery.

\section{African Latex-producing Plants}

The number of latex-yielding plants in Africa is considerable, but in spite of this the future outlook for rubber production in Africa is very dark, the most valuable rubber-producing African trees and shrubs having been practically exterminated by the barbarous methods used in collection of the latex, not to mention the human savagery resorted to by some countries in the exploi- 
tation of African rubber. African natives are said to be the world's worst rubber collectors, and seem incapable of learning better methods. There are three leading kinds of African rubber, one of which may come to be of some economic interest, if properly developed.

LANDOLFIA RUBBER comes from several African woody vines of the Dogbane Family. These yield a latex which is coagulated by plant juices, by heat from the sun, or from native bodies on which it is often smeared for coagulation. The plants are cut down, chopped into pieces, and the latex allowed to exude and coagulate as described above. The climbing habit of this plant precludes its use in plantations; in its native habitat it reaches the tops of the tall jungle trees by means of hook-tendrils, much like wild grapes of our temperate regions.

LAGOS RUBBER comes from a large tree of tropical west Africa, also of the Dogbane Family. Undiscovered until 1894, it was then exploited so wastefully that near extermination followed its discovery. It is now being cultivated in Africa, but is not competing seriously with Para rubber plantations in the same area. At the time of discovery, the Lagos rubber tree was plentiful, but trees were either felled or tapped to such heights that they were killed. The extracted latex is hardened by boiling, the bark is then peeled and macerated, and the remaining rubber is worked into balls.

INTISY RUBBER comes from an almost leafless, cactus-like plant of the Spurge Family, inhabiting desert regions of Madagascar, which at one time supplied a considerable amount of rubber. Intisy, like other African rubber-producing plants, was almost rendered extinct by destructive exploitation. The latex exudes and hardens into strands on the surfaces of the plant, from which it is removed and rolled into balls of high grade, elastic, rubber. This plant, along with several rubber-yielding vines native to the same region, is being experimentally grown in parts of our own southwestern desert region, where there are thousands of acres of unproductive, arid lands. Intisy, by virtue of water storage tissues in the roots, can withstand long periods of drought, so may be well adapted to growth in such regions as those above. 


\section{Asiatic Latex-producing Plants}

In addition to the Brazilian rubber tree so widely used in the Asiatic rubber plantations, there are three native Asiatic latex plants that are deserving of mention. These are India rubber, gutta-percha, and jelutong.

INDIA RUBBER or ASSAM RUBBER, as it is sometimes called, comes from a large tree of the Mulberry Family-in which occurs also Panama rubber-found in northern India and Malaya

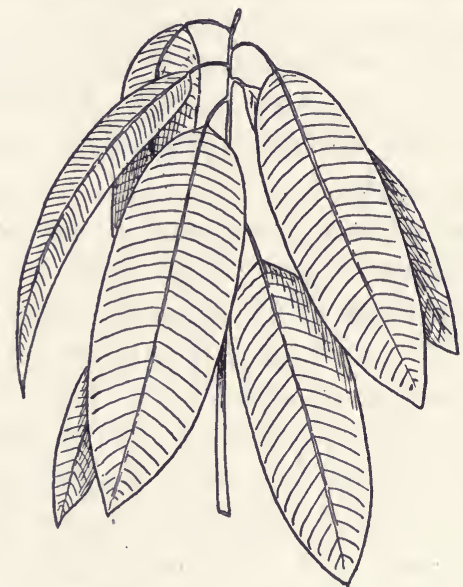

Fig. 238.-India rubber comes from a tree in the Mulberry Family.

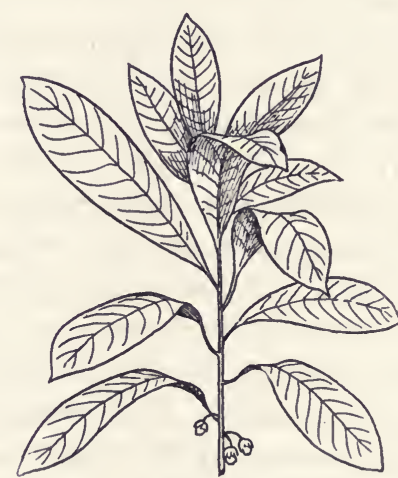

Fig. 239.-Gutta percha is derived from the latex of several trees and shrubs native to the Malay region.

(fig. 238). It is often grown as an ornamental, known simply as "rubber plant," in greenhouses and homes. The massive, widespread crown is supported by prop roots which are tapped along with the trunks proper. The latex is collected on bamboo mats and on the tree trunks where it coagulates, later to be scraped off, cleaned and dried. Some plantations of India rubber now exist although the yield is low, the quality inferior, and the trees are slow in maturing.

GutTA-PERCHA is a non-elastic rubber derived from the latex of several trees and shrubs native to Malaya and adjacent regions (fig. 239). They, like chicle and balata, are members of 
the Soapberry Family and contain latex in both stems and leaves. From the stem it is secured either by making gashes from which the latex exudes very slowly or by the more usual method of felling the tree and removing inch-wide strips of bark, about a foot apart, from which the latex is caught in shells or large leaves. This product is purified by boiling and washing to give the commercial gutta-percha which is hard at ordinary temperatures, softening at 77 degrees Fahrenheit and melting at a temperature slightly above the boiling point of water. This type of guttapercha exploitation is very destructive to the trees, and is being replaced by a plantation system which utilizes the leaves of a shrubby variety of the gutta-percha plant. Leaves are harvested and converted into a pulp while they are still fresh, after which a treatment with boiling water washes out dirt and debris, leaving the gum which is pressed into blocks. Gutta-percha is extremely resistant to salt water and for this reason is, with its substitute balata, irreplaceable as an insulator in the manufacture of submarine cables. It is widely used in surgery and dentistry, and in the manufacture of telephone receivers, pipes, golf balls, electrical connections, and adhesives.

JeLutong comes from the coagulated latex of several large tree species belonging to the Dogbane Family and has been used as an inferior substitute for rubber, gutta-percha, and chicle. It is found growing in the swampy jungles of Malaya and Borneo, and is utilized mainly in these regions. The trees are tapped in much the same manner as those of the Para rubber tree, and yield an amazingly large amount of latex. Unfortunately, the latex consists of $70-80 \%$ resinous material and only $20-25 \%$ of rubber. Jelutong was exploited as a source of rubber from 1910 to 1915 , but with the rapid growth of rubber plantations it has been practically neglected. More recently, development of refining processes have led to its limited use as a substitute for chicle in chewing gum manufacture.

\section{North American Rubber-producing Plants}

Commercial rubber, as may be seen from the foregoing discussion, is practically all produced by large tropical trees and woody vines. Several rubber containing species exist in the flora 
of North America, but these are mostly herbaceous plants, and exploiting them for their rubber necessitates destruction of the plant. However, studies on a number of the most promising of these have been under way for a number of years, and since most of these species are plants of arid or semi-desert climates, they may constitute a profitable use for now unproductive regions. They may be of no great commercial importance in the near future, with plantation rubber developed to such a high degree, but in the event of removal of plantation rubber from the reach of the American rubber industry by war embargoes, such a domestic source would be of utmost importance.

GUAYULE is the leading source of rubber in temperate regions at the present time, Mexico exporting several million pounds of guayule rubber yearly. Guayule is a low semi-shrubby plant which grows in arid parts of the southern United States and Mexico, and is treated as a crop plant, maturing in about four years to yield about $15 \%$ of its weight in rubber. The rubber occurs as tiny granules scattered through the tissues; they are removed by a milling process which consists of reducing the plants to pulp in a water medium and then skimming off the rubber particles which rise to the surface. The crude rubber obtained in this way is cleaned, rolled into sheets, and dried. Rubber produced from guayule is dark gray in color and inferior to Brazilian rubber for most purposes, although it is said to excel the latter for certain uses in the manufacture of automobile tires. Most of the experimental work on guayule has been done in the United States, where attempts are being made to develop varieties of increased rubber content. Studies on the growth, care, and harvesting of the crops are likewise being carried on.

DeserT MILKWEED, an herbaceous plant of the arid southwest, is under experimental cultivation at the present time as a possible commercial rubber source. The stems of this plant yield $2 \%$ to $6 \%$ of their weight in a low-grade rubber; after extraction of the rubber, the pulpy residue has been manufactured into paper. Studies at the present time are for the purpose of determining the proper age at which to harvest, methods of curing to favor higher rubber content, most efficient methods of extraction, and 
crossing of species and varieties in attempts to get a higher yield and higher grade of rubber.

In recent years several goldenrods have been experimentally grown for rubber production. Thomas Edison was working on this problem when he died, and his experiments are being continued. As in guayule, the rubber occurs in the form of tiny granules which must be extracted from the tissues containing them.

SYNTHETIC RUBBERS always command popular interest; the idea of man producing in a test tube, or under his own controlled conditions, a material for which he has been dependent upon nature, is very fascinating. Synthetic rubbers have been most highly developed commercially in Germany and Russia, especially during the World War when Germany was cut off from natural sources of rubber. After the war, this expensive commercial production went out of use. An American chemical company is now manufacturing an artificial rubber which is said to be more wear-resistant than natural rubber, but less elastic. The principal objection to artificial rubber is its cost in comparison to that of plantation rubber. 


\section{Chapter 22}

\section{DRUG PLANTS}

Man, in.common with other animals, is afflicted with a large number of diseases, due either to attack of his body by parasitic agencies, or to an upsetting of the normal functioning of his body by other environmental factors. From the very beginning of man's existence there have been these disease-producing agencies, and man has always fought against them so that he might have a more enjoyable life. Knowing nothing about microorganisms, and little more about human anatomy and physiology, primitive man attributed disease to the presence of an evil spirit in the body of the afflicted. The best way to cure, he believed, was to drive the evil spirit from the body, and he employed various means to this end, among them the use of foul-tasting plant substances which were supposed to make the body a hostile residence for such evil spirits.

So it came about that various plants were used thousands of years ago, in a very different manner from that in which they are used today. Many drugs were in use in China as long ago as 5000 B.C.; the Hebrews, Egyptians, Babylonians and Greeks were all familiar with many of our present day drugs. Dioscorides, a Roman writer, compiled a treatise on the nature of all medicinal plants known in 77 B.C.; this remained in use for fifteen hundred years. Later, in the sixteenth century, the peculiar "Doctrine of Signatures" came into being. According to this, every plant was endowed by the Creator with some sign of its intended use. Thus plants having a part of their body shaped like the lobes of the liver should be good for ailments of that part of the human body; plants having heart-shaped leaves should be beneficial to an ailing heart, and so on for all parts and organs of the body. This belief is still mirrored in the common names of many plants, such as heart's ease, liver leaf, heal-all, etc. 
When North America was settled by white men, a flora with many new plants unlike those used in European "remedies," confronted them. The physiological effects of countless species of plants have been tabulated from experimental or accidental use, until today there is scarcely a known genus of plants which has not been tried out in medicine. Even today, the science of medicine is not an exact one; the same drug does not affect all human organisms in precisely the same way, but a more exact knowledge of the nature and properties of plant drugs is at hand now, and is being better used than ever before. In fact, present day medicine is no longer content with plant drugs in their original form, but seeks through the aid of chemistry, to refine these substances in such a way as to discard portions which have an undesirable physiological effect, while retaining or even strengthening the beneficial portions of the compound.

The most valuable of the plant drugs have been standardized by the United States Government to prevent harmful adulteration of them. Only a few species of drug plants are cultivated, most of them growing wild in sufficient quantity at the present time. They are scattered all over the world, especially in the tropics. Their medicinal value is due to presence in the tissues of chemical substances that bring about definite physiological reactions in the human body. Under normal body conditions such substances are unnecessary, but when disease causes the upsetting of some particular function, then medicines help to restore such a condition of normality. The most important plant drugs are chemical substances known as alkaloids, which are made up of carbon, hydrogen, oxygen, and nitrogen. There are many ways in which to group plant drugs for discussion. Such grouping might be made on the basis of their chemical nature or the medicinal effect of the substances; or with regard to the natural relationships of the plant sources. Still another is based upon the part of the plant which is used as the drug source.

\section{Drugs Obtained from Flowers and Fruits}

OpIum is the dried.juice or latex of the opium poppy, native in western Asia but now occurring in most countries as a weed. 
It is an annual plant with large white flowers which give rise to large capsules one to two inches in diameter (fig. 240). Cuts are made on the sides of these when they are full sized but not yet ripe, and the latex exudes and partially hardens on the capsule. It is then scraped off and molded into cakes, wrapped, and sent to the world's markets.

Crude opium contains a number of alkaloid substances, chief among which are MORPHINE and CODEINE. It is refined to yield these and other derivatives which are used in medicine to relieve

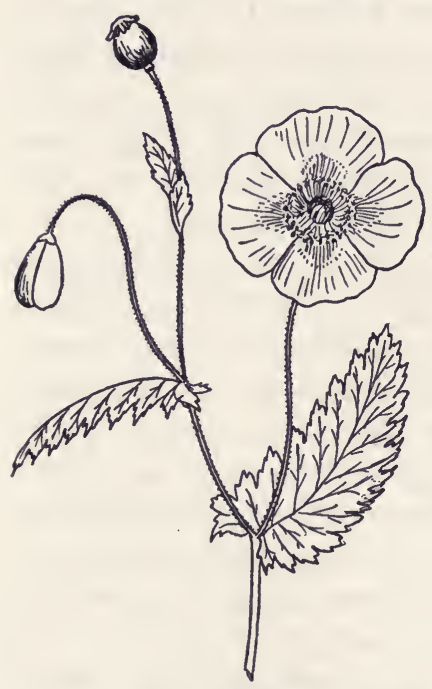

Fig. 240.-Opium comes from an annual species of poppy native to western Asia. pain and induce sleep. Because of the habit forming nature of these drugs, their use, production, and transportation is carefully regulated in most countries. In other countries, notably China and India, opium is widely smoked or eaten to produce a semi-conscious condition on the part of the user. Continued use of this, or its derivatives, results in physical and mental breakdown. Most of the medicinal opium comes from Turkey; India and China produce large amounts of a lower grade opium which is used for non-medicinal purposes.

Chaulmoogra oil is a fatty oil obtained by pressing the large seeds of a tall jungle tree known as the chaulmoogra tree. This tree is native to Burma, and other southeastern Asiatic regions, where its seeds and oil have long been used by the natives as remedies for skin diseases. Experiments with this oil as a possible cure for leprosy have resulted in the chemical refining of the crude oil to yield certain acids, or alcoholic extracts of such compounds, which are successful in curing the disease. Treatment with these derivatives is likewise much less painful than that using the crude oil. Thus chemistry and medicine have rendered curable one of the most dreaded and heretofore uncurable diseases of man. 
Croton oil is another fatty oil, secured from the seeds of a small tree or shrub cultivated in Ceylon and India, though native in larger areas of southeastern Asia. Indian natives use the crushed flowers and leaves as a fish poison, but the oil extracted from Croton seeds is used in medicine as a very powerful purgative. It is one of the most powerful of such drugs known, and should be used only upon the advice of a physician, since an overdose could be a violent, and probably fatal, poison.

The Nux Vomica tree of southeastern Asia and Australia, produces hard, bitter seeds yielding the very valuable drugs

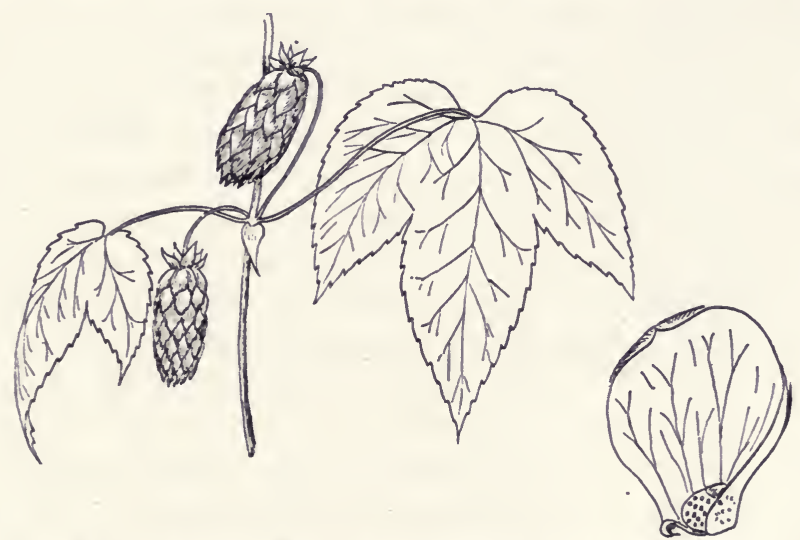

Fig. 241.-Hop plants are climbing perennials producing a bitter narcotic substance.

STRYGHNINE and BRUCINE. In very small doses, strychnine is a stimulant and tonic, and is used also in the treatment of nervous and paralytic disorders. In large doses, it is a virulent and quickkilling poison, and is widely used in the control of rodents and predatory animals such as coyotes and wolves.

PSYlLium SEED, from a European species of plantain known as fleawort, constitutes a mild laxative. Used locally in Europe for about fifty years, it has arisen as an important drug in the world's markets within the last few years. The seed may be eaten with breakfast foods or taken with water giving an effect comparable to that of agar and mineral oil-helpful in overcoming conditions of constipation resulting from the increasing inactivity 
in certain classes of the human race. The plant is now cultivated for its seed in France and Spain.

The HOP PLANT, native to the north temperate regions of both hemispheres has been known since the time of the Roman Empire, and has been cultivated in parts of Europe since the ninth century. Hops are perennial climbing herbaceous plants with male and female flowers borne on separate plants (fig. 241). The female flowers contain several bitter, narcotic substances, of which the most important is LUPULIN. When cultivated, as is done in the United States, England, and Germany, the plants are grown on poles and the hops are picked and dried in the early fall. Their principal use is in the manufacture of beer, to which they are added for their bitter flavor and to prevent bacterial decomposition. They are used in medicine for their soothing, sleep-producing effects; also as a digestive tonic, and sometimes in the form of a poultice.

The dried flowers of снамоміL, a daisy-like plant native to Eurasia but widely cultivated, contain a volatile or essential oil which is useful in overcoming stomach disorders, and as a tonic.

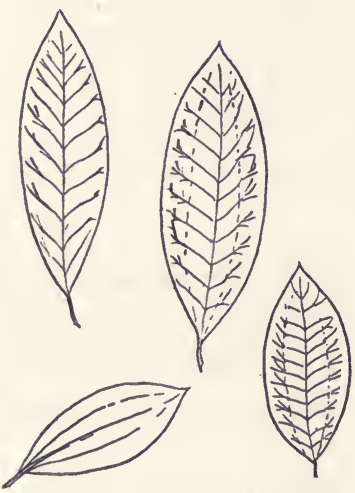

FIG. 242.-Cocaine comes from the leaves of a South American shrub.

The flower heads are dried and ground, or broken up, and used to prepare an infusion, or "tea" as it is often called. Chamomile tea formerly was a staple home remedy to relieve colic in young babies.

\section{Drugs Obtained from. Plant Leaves}

The drug cocaine is derived from the leaves of certain tropical shrubs cultivated since prehistoric times in Peru and Bolivia (fig. 242). The leaves have long been chewed by South American Indians, and its use enables the user to resist hunger and fatigue for long periods of time although habitual use leads to physical and mental breakdown and even death. The plant is widely cultivated in South America, Java, India, and Formosa. Coca leaves mature in three or four years, and crops are then 
gathered every three or four months. They are carefully dried and baled for shipment to manufacturing centers where the alkaloid cocaine, which makes up about $1 \%$ of the leaf's weight is extracted. In medicine, this drug is particularly important as a local anaesthetic, but is also used as a tonic for the nervous and digestive systems.

The dried leaves of the FOxGLOve, a biennial herbaceous plant, yield the valuable drug, DIGITALIS. Foxglove is native to Southern and Central Europe, but is widely cultivated elsewhere including the United States, as an ornamental plant. During times of war, this plant has found a place among our cultivated drug plants, but under ordinary conditions the drug can be purchased from abroad cheaper than it can be grown in the United States. Digitalis being a powerful heart stimulant, improving the rhythm and completeness of the beat, is widely used in the treatment of heart disorders.

OIL OF EUGALYPTUS is obtained from the leaves of one of the world's tallest trees. Eucalyptus trees are native to Australia, but are widely cultivated in the warmer parts of the world; in the United States they are grown chiefly in California (fig. 243). They have been widely used in soil reclama-

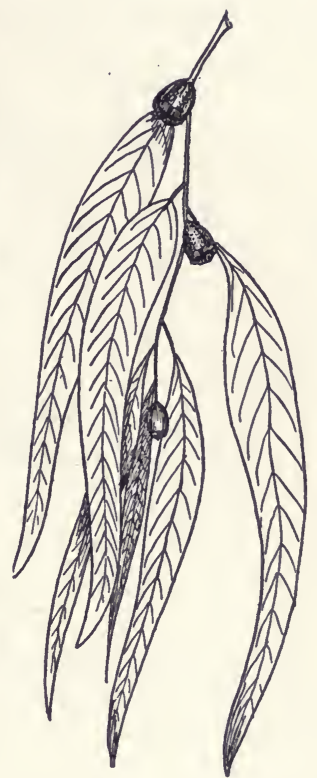

FIG. 243.-Eucalyptus trees have narrow lance-shaped leaves and aromatic fruits. tion work since it is fast growing and has an extensive root system. The oil is light yellow or colorless, and is widely used in the treatment of mucous membrane inflammations such as accompany respiratory infections and fevers.

The small, annual, blue flowered InDian товACGo plant of North America yields the drug LOBELIA. Indian tobacco is one of our poisonous plants, although cases of poisoning by this species are almost unheard of since it is an inconspicuous plant with dry, uninviting seed-pods. The drug, which is obtained from the 
dried leaves and tops, is used to induce vomiting and to promote discharge of mucus from the lungs and throat.

The important drugs BELLADONNA and ATROPINE are yielded by a coarse, herbaceous plant native to Southern and Central Europe and Asia Minor. This plant is now widely cultivated in

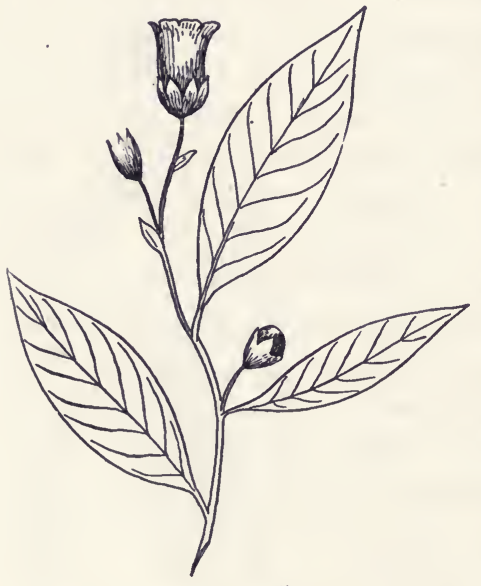

Fig. 244.-Belladonna and atropine come from the leaves of a European plant. the United States, Europe, and India. The leaves, tops, and to a limited extent the roots, are collected at about the time the plant is flowering and dried (fig. 244). The drugs obtained from belladonna leaves are used in the relief of coughs, excessive perspiration, to dilate the pupil of the eye in making examinations of that organ, and externally to relieve pain.

Aloes are stemless tropical plants with basal clusters of thick fleshy, often spiny edged, leaves. They grow native in the western and southern parts of Africa, and in the West Indies; and are grown under cultivation in Florida and California. The leaves are cut and placed in troughs, where the resinous juice gradually exudes. This is collected and evaporated to the point of solidification. The principal medicinal use of aloes is as a purgative, although some recent use of it is being made in the treatment of inflammation of nerve tissues such as exists in neuritis.

\section{Tobacco}

TовAcco, although not used as a drug plant, is included here because of the narcotic content of its leaves and stems. The use of tobacco cannot be labeled a "white man's vice," since it had been practiced by the South American Indians for centuries before white men set foot on this continent. The plant was taken first to southern Europe about 1560, and the use of it has a fumi- 
tory was not very prevalent until almost thirty years later. It soon spread over Europe, Asia, and Africa, and today its cultivation and use are world wide (fig. 245). Tobacco contains a narcotic substance known as NICOTINE, which makes its way into the human system by way of the mucous membranes of the respiratory tract. Nicotine is extracted from tobacco stems and

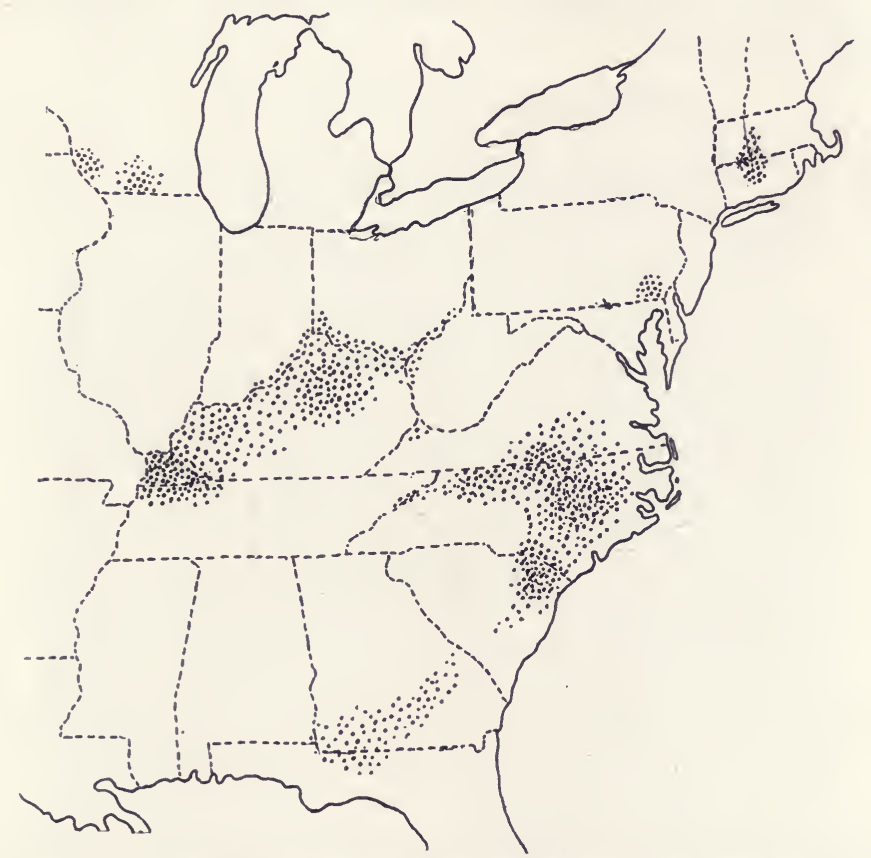

FIG. 245.-Distribution of acreage devoted to growing tobacco in 1930.

widely used as a contact insecticide, since it is powerful enough, even in dilute solutions, to kill insects upon contact.

Many types of tobacco are grown, all of which differ in their soil, moisture, and temperature requirements. Considerable care is necessary to establish and mature a tobacco crop. After the leaves, or entire plants are harvested, they are hung in sheds to cure for three to six weeks. Then they are piled and allowed to undergo another curing period of about six weeks after which 
they are sorted and aged. The United States has always led in producing the world's tobacco supply, although large amounts are produced by India, Russia, the Philippines, Turkey and other countries. Different kinds of manufactured tobacco products demand different types of tobacco. Thus tobacco, in sorting and grading, is classified as to its intended uses, such as cigar wrappers, cigar fillers, cigarette tobacco, chewing tobacco, and pipe tobacco.

\section{Drugs Obtained from Plant Stems}

The valuable alkaloid drug, EPHEDRINE, is produced by several members of the genus Ephedra, low leafless shrubs with

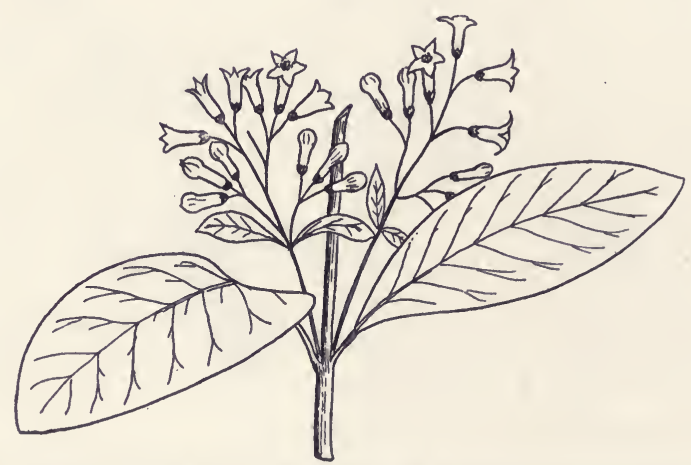

Fig. 246.-Quinine comes from the bark of cinchona trees, native to South America.

slender green stems. Although several species of this plant are found in arid parts of the United States, those producing the drug are found in Asia, notably China where it has been used for over five thousand years. Ephedrine is extracted from the entire woody plant, and has become of increasing importance as an ingredient of nose drops, for relief from nasal congestion accompanying colds, hay fever, and as an aid in the treatment of asthma.

The great importance of QUININE in the world's drug markets today is due to its specific action in killing the malarial parasites in man, thus curing the once dreaded malarial fever. Cinchona trees, the hard thick bark of which yields quinine, are natives 
of the Andes mountains of South America (fig. 246). The first recorded use of the drug was in 1638 although undoubtedly the Indians had used it long before this. Great demands were subsequently made upon the Andean supply, which was closely guarded by the natives, until finally the British and Dutch col-

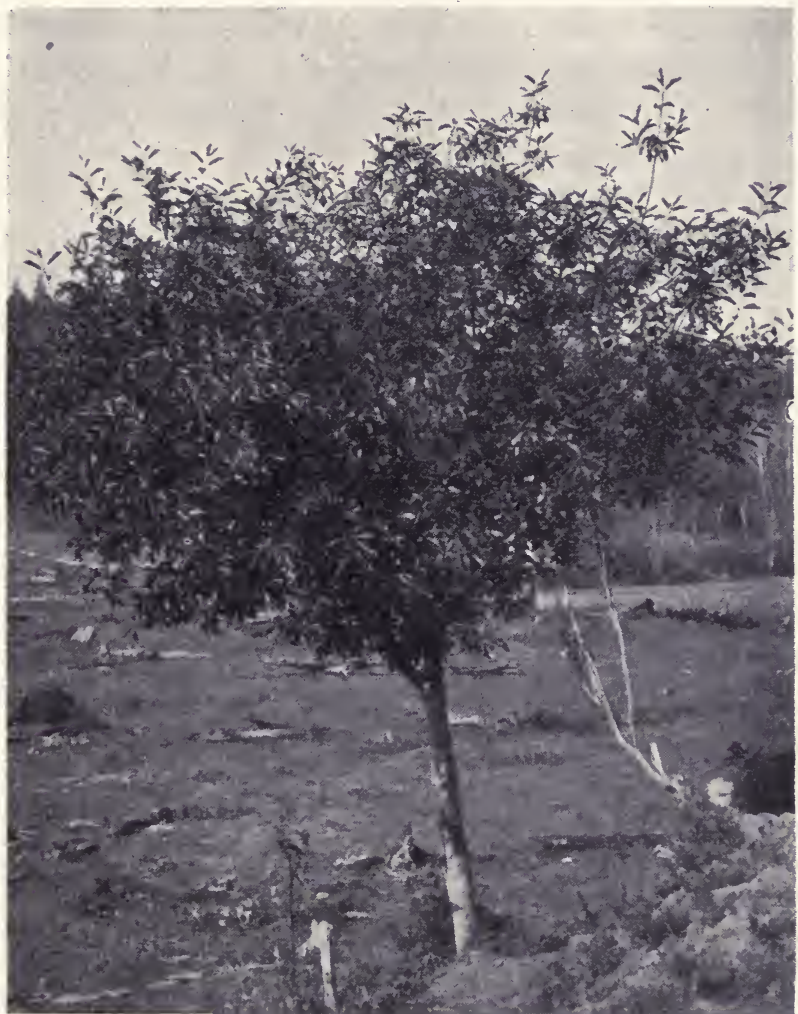

FIG. 247.- Cascara is obtained from the bark of our native buckthorn tree. (Courtesy U. S. Forest Service.)

lectors sent to South America were able to smuggle out seeds which were taken to Java and India, where most of the world's supply is now produced. The Dutch have a monopoly on the quinine that enters the world's markets today, since that produced in British India is wholly consumed within that country. 
Under cultivation, cinchona trees require rich soil and abundant moisture. Growth is rapid, and the trees are cut and peeled when about seven years old, at which time the bark will yield $5 \%$ or more of quinine. In addition to its use as a specific for malaria, quinine is used as a tonic, and for fevers in general.

CASGARA is probably the most important native drug in the United States. It is obtained from the bark of a small tree, the western buckthorn (fig. 247), native to the Pacific Northwest and Canada. The bark is peeled from the trees in the summer, and dried and seasoned for a year before it is ready for use. At the present time, the entire supply comes from wild sources, but it may be necessary at some future time, to establish plantations of buckthorn. It flourishes in a region that is fitted only for forest growth, and reproduces itself well by seed. Cascara is widely used in the United States and abroad as a laxative and tonic.

\section{Drugs Obtained from Plant Roots}

GARDEN heliotrope, a native of Eurasia but long cultivated as an ornamental in the United States, yields the drug VAlERIAN, an essential oil used in the treatment of nervous disorders such as coughing, hysteria, and pain. The dried roots, and underground creeping stem by which this perennial plant spreads, are the commercial sources of this drug.

MAy APPle, MANDRAKe, or PoDophyllum as it is known in the drug trade, occurs commonly throughout the eastern states, but is of commercial importance only in the southern Appalachian mountains. The roots and rhizomes of this spring-flowering herb yield the drug, which is used as a cathartic and to induce vomiting. Collection of the plant takes place in the spring or fall, at which time the underground portions are dug, cut into pieces, and dried. Podophyllum is not an important drug, hence no attempts at cultivation have been made.

GiNSENG is one of the most important of oriental drugs. The Chinese especially have used it for centuries as a sort of cure-all, attributing to it innumerable curative properties which research in medicine has been unable to prove. The original drug plant of this name is native to Korea and Manchuria, but the American 
ginseng has been much in demand for a number of years. These are both herbaceous plants with tuberous roots which are especially valuable, from the Oriental standpoint, if they bear any resemblance to the human body. So great have been the demands for American ginseng that the plant has been almost exterminated in its rich woodland habitats in the Eastern United States. Most of the ginseng exported now is cultivated, either under artificial shade, or in natural open woodlands. Ginseng is used to a limited extent in the United States as a mild stimulant and as stomach tonic.

The MONKSHOOD is widely cultivated as a garden plant and as a source of the plant drug ACONITE in this country, though native in the Alps and Pyrenees mountains of Europe. Aconite is extracted from the roots, which are collected and dried in the fall. Although it has long been known as a poison, aconite has only in recent years been used as a drug, externally for rheumatism and neuralgia, and internally to relieve pain and fever.

The roots and rhizomes of Goldenseal, a perennial herbaceous plant formerly common in rich woods of the eastern states, contain several alkaloid substances which are valuable in the treatment of catarrh and other mucous membrane inflammations, and as a tonic. Goldenseal has always been a favorite remedy of inhabitants of eastern North America, from the times of Indians and early white. settlers down to the present. It is no wonder, then, that it is practically exterminated from the native vegetation and must be cultivated extensively as a drug plant.

Southern Europe and Western Asia are the native homes of the LICORICE plant. Within this area it is widely cultivated, especially in Spain, Russia, and Turkey. Licorice roots are dug and dried for several months before being shipped. Large amounts are imported by the United States each year, its medical use being mainly as a soothing preparation, to induce mucus discharges from lungs and throat, and to cover up the distasteful flavor of other medicinal preparations. Most of the United States licorice imports are used as flavoring in tobacco and candy manufacture, and in the manufacture of shoe polishes. Numerous other industrial uses are being devised for licorice and its by-products. 


\section{Drugs Obtained from the Lower Plants}

All of the plant drugs mentioned above have their origin in the highest plant group, the seed plants. Of the three plant drugs discussed below, two, ergot and kelp, come from thallus plants; the other, male fern, comes from a member of the fern phylum.

Rye and other members of the grass family are attacked by a fungus disease known as ERGOT, which results in a malformation of the grain, and destruction of the food materials stored therein. When ergot is eaten with rye it causes a form of poisoning known as ergotism, which may be fatal to man or his domestic animals; but ergot as a medicine has been responsible for the saving of many human lives, since it increases the blood pressure and is used for checking hemorrhages - especially in childbirth cases. Ergot for medicinal purposes is generally produced in Northern Europe, where cheap labor is plentiful for hand-picking the infected grains.

Certain brown seaweeds, especially the large forms known as KELPS, which occur abundantly in the Pacific Ocean off the coasts of the United States and Japan, are used in medical practice as a source of certain mineral salts and vitamins which are essential to the well being of the human body. Since sea water contains, in addition to common salt, several of these salts such as those of potash and iodine, the plant bodies of the kelps are likewise high in their content of these substances.

The MALE FERN, one of a group sometimes known as shield ferns, ranges across northern North America and in Europe and Asia. Its underground stems contain a substance long used in medicine as a worm expellent. When taken into the alimentary tract, this drug causes any intestinal worms, such as tapeworms and roundworms, to relax their hold on the walls of the intestines, after which they are purged from the body by the action of a powerful cathartic. 


\section{Chapter 23}

\section{INDUSTRIAL USES OF PLANTS}

Strictly speaking, many plants used by man are the basis of industries - the textile industry dependent upon the fiber plants discussed in Chapter 20, the rubber industry supported by the latex producing plants discussed in Chapter 21, etc. There are a number of other industrial uses of plants, however, which are not of sufficient importance to justify more than a few pages of treatment in a general work of this sort, and which accordingly are grouped for discussion in this chapter. It seems quite probable that some of these plant uses are on the wane, and that others are destined for places of far greater importance than they occupy at the present time.

\section{Resins and Gums}

Resins are extremely complex chemical substances which occur as secretions in plants, generally in definite passages or cavities. They have their origin in essential oils, being oxidation products of these substances. Upon continued exposure to air, resins harden due to the further evaporation and oxidation. From the plant's standpoint, resins are probably useful in preventing decay and entrance of diseases and insects, since there generally is a copious resin flow when the plant is wounded. From man's standpoint, resins are important because they can be collected from their plant or fossil sources, dissolved in some volatile solvent such as alcohol, and spread on surfaces in the form of a varnish which gradually hardens to leave a thin, waterproof coat as the solvents and essential oils evaporate. This use of resins is no modern invention, since the ancient Chinese, Japanese, Egyptians, Greeks, and Romans were all familiar with varnishes and lacquers.

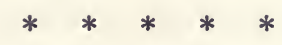


The HARD RESINS are generally solid, translucent, brittle substances lacking taste or odor, and containing little or no essential oil. Because of the latter fact, and the ease with which they dissolve in alcohol, the hard resin group contains those most important commercially, namely, the copals and damars. Copals are the hardest of the varnish resins, containing practically no essential oil and yielding a hard, elastic finish which is desirable for outdoor work. There are a number of copals, which come from widely scattered geographic areas and widely different tree species. Zanzibar copal comes from the East African coast, where it is sometimes collected from trunks and branches of living trees, but more often from fossil tree deposits. The West African copals are likewise mainly of fossil origin, although living trees yield small amounts of the commercial supply. Kauri copal is obtained from the kauri pine of New Zealand, which is the largest tree of its region. Most of this resin is dug from the ground, especially in swampy areas, although an inferior grade of resin is obtained by tapping the live pines. Other copals, somewhat softer in nature and used for interior work, come from East Indian, Malayan, Philippine, and South American tree sources.

DAmARs are softer resins than are the copals, and are used mostly in the manufacture of nitrocellulose lacquers and spirit varnishes. They are lighter in color and adhere better than the copal resins. Unlike the copals, which come from coniferous trees, the damars have their origin in Angiosperm trees of southeastern Asia; notably several species abundant in Sumatra and Malaya.

Amber is a fossil resin from an extinct pine which once flourished in the vicinity of the Baltic Sea. This resin is the hardest known, yielding a very fine varnish which is too expensive for common use. Its chief use today is for the manufacture of cigarette and cigar holders, and mouthpieces for pipes. Often found imbedded in these fossil amber deposits are insects, which lived in previous geological eras and were captured by the flow of fresh resin on the tree trunk, to be preserved for scientific scrutiny some millions of years later.

LACQUER is a natural varnish that is obtained principally as an exudate of the lacquer tree-related to our sumac-which 
is native to China and has been long cultivated there and in Japan. The milky juice hardens and darkens upon exposure to air; when applied as a varnish it is highly resistant to heat and unaffected by alcohol, acids, or alkalis. The process of lacquering was originated by the Chinese almost three thousand years ago, and is very complicated, sometimes using three to four hundred coats, and requiring several years to finish.

The oleoresins, in addition to their resin, contain considerable amounts of essential oils, which impart a definite odor and taste to them. Most important of this group are the turpentines, which originate practically entirely in coniferous trees. The production of TURPENTINE and ROSIN constitute the naval stores industry, one of the oldest forest industries, centered at the present time in the United States. Naval stores are produced from the resin, or sap, of longleaf and slash pines by chipping the surface of the tree trunk and distilling the pitch or sap which flows from the cut surfaces of the sapwood. Tar derived from the sap was formerly used in the manufacture of wooden boats, and gave the industry its name, but this product is now of minor importance. Confined to the longleaf and slash pine belts of the southern pine region this industry closely follows lumber, cotton, and other agricultural products in its importance. Timbers that have been chipped for gum are now used for sawlogs, posts, poles, etc., instead of being left in the forest to waste as in former years.

In gathering resin from the trees, chips or streaks are cut through the bark into the sapwood (fig. 248). This stimulates the production and flow of the sap, which is collected in clay or metal cups attached below the chipped area. New cuts are made, generally each week, from March to November. The resin is collected at intervals of two to five weeks and taken to centrally located distilling plants, where a large copper still is used to separate the turpentine from the residue, or rosin. These products are sold by the barrel, either to wholesalers, or through a financing company which makes loans to the operators and then sells their products at a commission. Turpentine is used mainly as a solvent and thinner for paints and varnishes, and in shoe polish 
and leather dressing. Rosin is used mainly in the paper, soap, and paint industries, and minor amounts in the manufacture of greases, printing ink, linoleum, oilcloth, etc.
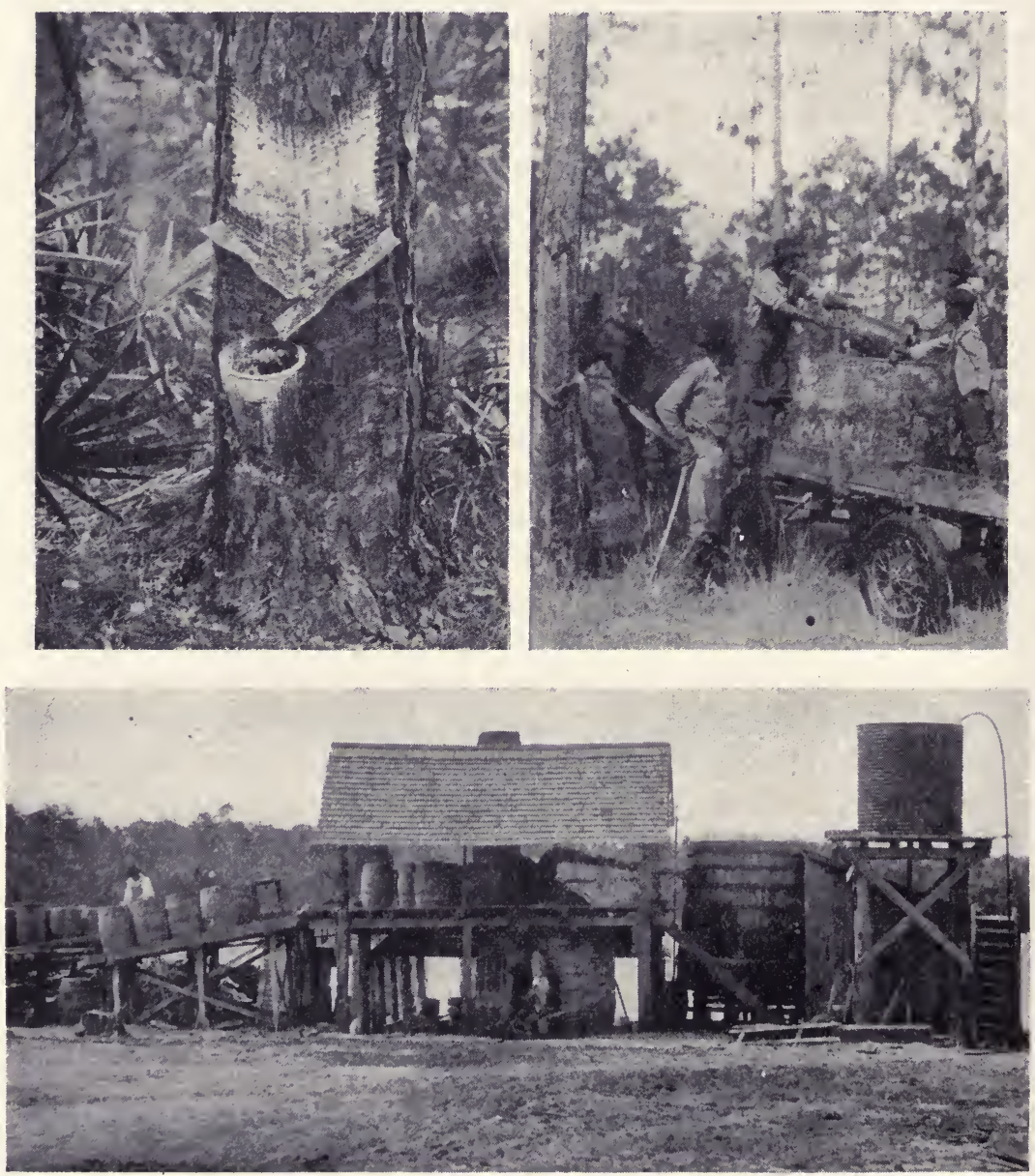

Fig. 248. - Tapping a long-leaf pine in Florida, collecting the resin and distilling the turpentine (also Florida). (Courtesy U. S. Forest Service.)

Another oleoresin of some importance is the so-called CanadA BALSAM, an exudate of the balsam fir of northeastern North America. This is collected from blisters which form on the bark, 
and is widely used as a mounting medium in the preparation of plant and animal tissues for microscopic study, and as a cement for lenses. It is used to a lesser extent as an antiseptic in medicine.

* $\quad * \quad * \quad * \quad *$

TRUE GUMS are formed as a result of internal breakdown of cellulose tissues. Unlike resins, gums are soluble in water but insoluble in alcohol. They are used in paints and candies, as adhesives, in medicine, and in textile and paper sizing. GUM ARABIC is obtained as small hardened drops or "tears" from a small species of Acacia - a tree member of the Pea Family-native to the dry regions of North Africa. Thin strips of bark are torn from the trees to stimulate gum exudation, and collections are made in three to eight weeks.

GUM TRAGAGANTH comes from a thorny shrub of Western Asia and Southeastern Europe. Gum flow is stimulated, as above, by puncturing or tearing off strips of bark, and the resultant exudate is collected, purified, and marketed. In medicine, both of these gums are used as adhesives to hold pills and lozenges together, and as emulsifying agents, to keep immiscible liquids and insoluble powders suspended.

\section{Tannins and Dyes}

The art of tanning leather to preserve it and increase its wearing qualities is by no means a development of our modern civilization, since records point to the use of such tanning materials as long as three thousand years ago by the Chinese. The American Indians used oak bark to toughen and preserve skins of buffalo and other of the animals upon which they subsisted. Oak bark was first used by early American colonists, but while it was generally preferred to that of hemlock, the latter became more widely used because of its abundant supply.

The active agent in tanning substances, itself known as TANNIN, occurs to some extent in almost all plants. Its action on animal hides makes them flexible, strong, waterproof, resistant to decay and to abrasion. It is exploited in a limited number of plant species, mostly in the form of bark, wood, fruit, and leaves. Our native American forests supply about one-half of the tanning 
materials used annually in this country. Of the native tannin producing species, chestnut is the most important present source, its wood supplying about $60 \%$ of the domestic tannins. It is followed by chestnut oak bark and eastern hemlock bark, each of which contribute to the extent of $18 \%$. In California, the tanbark oak supplies most of the material for tannin extraction. Western hemlock bark contains a higher percentage of tannin than that of the eastern hemlock, but the bark is thin, and the best stands are located in rather inaccessible areas, so that it is of no great present day importance, but may serve as a future supply of domestic tannins. Since tannins are soluble in water, they are extracted from chipped or ground wood or bark by hot water. Following extraction the extract is distilled, strained, and concentrated to the desired strength by evaporation.

The world's most important single source of tannin is the Quebracho, a hard, heavy, tropical wood from South America. About a million tons are cut annually for tanning extracts, and the yearly growth of the forests offsets the annual cut. The heartwood of this species is a more concentrated source of tannin than any other wood, yielding up to $28 \%$ of its weight in tannins.

Mangrove bark, from another tropical tree, has reached some commercial importance in the United States. Most of the present day supply comes from South America. Other foreign sources of tanning materials include myrobalan nuts which are the fruit of several tree species cultivated in India; divi-divi which is the seed pod of a small tree native to Central and South America; imported sumach from the Mediterranean region; and Valonia, the acorn from the Turkish oak of Asia Minor.

Until shortly after the Civil War most of our dyestuffs were of vegetable origin, but since then, and particularly in the last ten to twenty years, the use of synthetic dyes has increased greatly, with a corresponding decrease in the use of plant materials as sources of coloring matter. However, for certain uses, dyewoods are still in demand. Most of these are tropical woods, imported from Central and South America and the West Indies. LoGwood makes up about three-fourths of all the dyewoods imported, 
followed by fustic, Brazil-wood, sandalwood, and others of very minor importance. The most important domestic dyewood is OSAGE ORANGE, followed by QUERCITRON or the crushed bark of black oak, black walnut, butternut, sumach, yellow wood, mesquite, red gum and dogwood. These dyewoods are generally made up of $5 \%$ to $10 \%$ of their weight in true dye, which is extracted from the ground or powdered wood with a suitable solvent and then concentrated to liquid, powder, or crystal form. Most of the present day supply comes from South America.

\section{Volatile Oils}

These EsSENTIAL oILs, as they are often called, differ from the fatty or fixed oils by being volatile, or evaporating in contact with air. They possess a strong, often pleasant, odor and may be removed from their plant sources without any change in chemical composition. They occur in a large number of plant families and species, but the Mint, Aster, Myrtle, Laurel, and Parsnip Families are especially known for their aromatic species. These oils usually occur in hairlike structures or in internal glands, and may be found in any part of the plant. They are extracted from their plant sources by a variety of methods, the method used with any particular oil depending upon its stability in the presence of heat, various solvents, and the amounts present. Very delicate oils are removed by extraction with solvents, or by maceration of the oil-yielding parts with fats, after which the extracting agent is either evaporated, or in the case of fats is removed with a volatile solvent. Oils which are more stable and are present in larger amounts are removed from the ground plant parts by steam distillation. This involves heating the plant material in water until the boiling point is reached, at which time the oils are volatilized and distilled into closed containers, where they occur as an oily film on the water which has been likewise distilled from the boiling mass.

Uses of essential oils are extremely varied; the more expensive ones are used in the manufacture of perfumes and other toilet preparations. Many are used as flavorings in cooking, and candy and ice cream manufacture. Some have antiseptic properties 
which render them useful in medical practice, and still others are used industrially as solvents for paints and varnishes and in the manufacture of plastics.

$$
* \quad * \quad * \quad * *
$$

Perfumes have been in use for as long a time as man's civilization has record. In ancient times perfumes were widely used for religious purposes, as well as for personal enhancement. They were lavishly employed as a disguise for lack of personal cleanliness, at a period when the beneficial effects of soap on the human body and its clothing were unknown. The finer perfumes of the present day do not consist merely of one essential oil in a solvent, but more often are blends of several perfume oils with some heavier substance or fixative which retards evaporation of the essential oils and makes them last longer.

ROSE OIL, or ATTAR OF ROSES, is one of the principal perfume oils and has been used as such alone or in combination with other oils for a long time. Only a few of the many kinds of roses are used as a source of attar of roses, the damask rose of Bulgaria supplying most of the oil today. Thousands of acres on the southern slopes of the Balkans are devoted to the cultivation of this plant whose flowers, picked in the early morning and distilled as soon thereafter as possible, yield an essence said to be worth about $\$ 200$ per pound. The common rose water used in hand lotions and other toilet preparations consists of the water left after distillation, or else is made up by adding a few drops of rose attar to a quantity of water.

Geranium oil is distilled from the leaves of several kinds of geraniums, especially the strongly aromatic rose geranium. These are extensively cultivated in southwestern Europe and northern Africa, and have been grown experimentally in the warm parts of the United States where they may prove a valuable addition to our small list of cultivated volatile oil plants. The chief use of geranium oil is as a substitute and adulterant for attar of roses in the making of soaps and perfumes.

Cananga orl is distilled from the fully opened blossoms of the ylang-ylang tree of the Philippines and southeastern Asia. This delicately fragrant oil is used in the manufacture of almost all 
perfumes and is very valuable, being much in demand and commanding a high price.

OIL OF CITRONELLA and LEMON-GRASS OILS are imported to the United States in large quantities, chiefly from India, Ceylon, and Java, where they are distilled from the leaves of the citronella and lemon grass plants, members of the Grass Family. These oils are produced in abundance, hence inexpensive and widely used in cheap perfumes, soaps, and insect repellants. Oil of citronella contains a high percentage of GERANIOL, the essential oil derived from geraniums, and like that substance, is used as a substitute

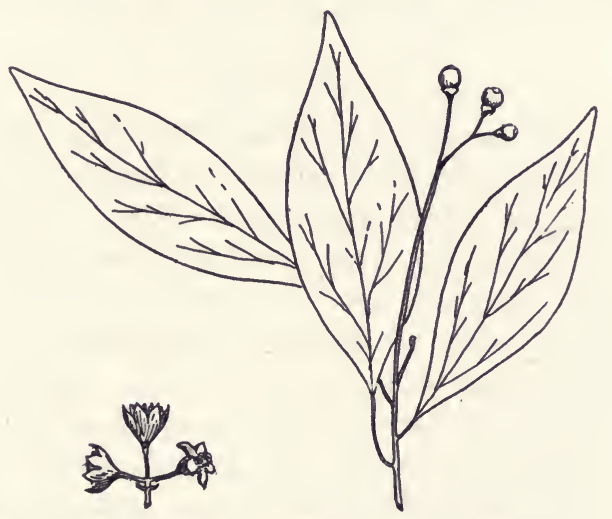

Fig. 249.-Leaves and fruit of the camphor tree.

for attar of roses. Lemon grass oil yields a substance from which synthetic violet is made, as well as being used as a flavoring and in medicine.

OIL OF VIOLET is extracted, by solvents and warm fats, from the flowers of a violet species grown in southern Europe. True violet perfume has a very delicate, sweet odor, and is very expensive and rare, having been largely replaced by synthetic violet derived from lemon grass oil.

$$
\begin{array}{llllllllll}
* & * & * & * & *
\end{array}
$$

CAMPHOR is by far the most important of the industrial essential oils. It is derived by distillation from the wood or leaves of a tree belonging to the Laurel Family (fig. 249), and native to southern China, Japan, and Formosa. The Japanese monopoly 
on natural camphor supplies has stimulated attempts at cultivation of camphor trees elsewhere in tropical regions of the world. The United States is one of the world's principal users of camphor, and is attempting to grow camphor on a large scale in southern Florida where some thousands of acres are under cultivation at the present time. In addition to being employed in a variety of medical uses and in perfumery, its most important use is in the manufacture of plastics - celluloid and other nitrocellulose products. Synthetic camphor from oil of turpentine has been a war time development in both Germany and the United States, and may rival natural camphor.

\section{Fixed Oils}

FATTY OILS, as they are also called, differ from the volatile oils in that they are incapable of being distilled or evaporated without being changed in composition. They are closely related chemically to animal fats (see p. 134), and may be liquid at ordinary temperatures, in which case they are commonly called oils, or if they are solid at ordinary temperatures they are called fats. These differences are due to the kind of acid which, with glycerin, goes to make up the compound. Fixed oils are found in many plant families, chiefly in the seeds where they constitute a light, highly concentrated form of stored food for use by the embryo plant contained within. As a rule fixed oils are lacking in strong tastes or odors, and many are used as foods by man.

In the extraction of fixed oils, the seed coats are first removed, and the kernels reduced to a meal, after which the oils are removed by solvents, or by hydraulic pressure which squeezes the oils out of the cells. Edible oils are generally extracted by the latter method; lower grades of the same oils are secured by pressure with the addition of heat which causes a somewhat higher yield but a lower quality. Such oils are used in the industries discussed later in connection with the various oils. The "cake" remaining after the oil has been removed is high in protein content, and in most cases is very valuable as a stock food. In a few instances, poisonous substances in the meal preclude their use as animal food. The fixed oils are generally classified according to their ability to absorb oxygen from the air and dry into thin, 
elastic films. Those with a high capacity for oxygen are known as drying oils, and are very important as solvents in the paint and varnish industries. The semi-drying oils absorb oxygen much more slowly, and never form as tough and elastic a film as the drying oils. The non-drying oils never undergo oxidation to form a film, hence are of no use in the paint or varnish industries but are very useful in the manufacture of soaps, as lubricants, and as foods. The plant fats and waxes are solid at ordinary temperatures, and are likewise used as foods and in the manufacture of soaps and other toilet or medical preparations.

$$
\text { * * * * * * }
$$

The list of drying oils has long been headed by LINSEED OIL, derived from the seed of the flax plant. Flax grown for its seed is a shorter, more bushy strain of the same plant that is grown for its fiber, discussed in Chapter 20. The Dakotas and Minnesota produce most of the linseed grown in the United States, which produces only a small amount of the world's total crop. Argentina leads in world production, followed by Russia, India and Uruguay. Flaxseed yields about one-third of its weight in oil, which is removed by both hot and cold pressing methods. Oil which has been heated to about $65^{\circ} \mathrm{C}$., known as boiled linseed oil, dries more rapidly than does raw oil, but the film is supposed to be less durable in the case of boiled oil. About two-thirds of the linseed oil used in the United States is consumed by the paint and varnish industries. The remainder is used in the manufacture of linoleum, oilcloth, putty, printers inks, and soaps.

Tung and CHINAwOOD oILs are produced from the nuts of two closely related Chinese trees, the tung-oil and the mu trees of the Spurge Family. The oils are widely used in waterproof varnishes, and have become so important an item of United States imports that cultivation of the trees has been started in Florida and certain other of the Gulf States. The initial plantings have been very successful and highly profitable, and further planting of the tung oil trees is being encouraged in certain localities. The trees will grow on soils unfitted to the production of other crops, but are highly sensitive to frost. In addition to being quick drying when employed in varnishes, these oils yield 
a finish which is tough, elastic, and much less liable to crack than those obtained when the copals and other hard resins are used. The oil cake left after pressing out the oils is poisonous, and unfit for use as stock food.

Numerous other drying oils are used in paints and varnishes, linoleums, oilcloths, soaps, preservatives for leather and canvas, and sometimes as illuminants. A few of these are CANDLENUT oIL and WALNUT OIL from tree sources, and POPPY OIL, PERILLA OIL, and SUNFLOWER OIL from herbaceous plants, all derived from seeds.

CotTonseed oIL, of which the United States is chief producer, is the most important of the semi-drying oils, as well as being the most abundantly produced plant oil. This has developed as a by product of the cotton industry, by which cotton seeds were regarded merely as waste prior to 1880 . Today over one hundred million gallons of oil are produced annually, and the residue, or cake remaining after expressing the oil, is an important stock food and fertilizer. Cottonseed oil is most widely used as a salad and table oil and in the manufacture of butter and lard substitutes.

SOYBEAN oll is of increasing importance in American agriculture. It is produced from the seed of the soybean, a native of eastern Asia, and long an important agricultural plant in that region. In the United States, soybean production centers in Illinois, which produces about one-half of the total soybeans grown here. In its drying characteristics, soybean oil stands midway between linseed and cottonseed oils, hence is useful in the manufacture of varnishes, printing inks and soaps, in addition to being of importance as a salad oil and for other edible purposes. Considerable use is being made of soybean oil and soybean flour as raw materials in the manufacture of certain types of molded plastics used in automobile manufacture.

CORN oIL, like cottonseed oil, was formerly a waste product, but today the embryos from corn grains are pressed for their oil which is used after refining for cooking and baking. Crude corn oil is used industrially in the manufacture of cheap paints, soaps, and rubber substitutes. 
Olive oll is the most important of the non-drying oils, as well as being the most famous edible oil in the world. It is obtained from the fleshy pulp which surrounds the seed of the olive tree, a native of Asia Minor, though cultivated extensively in the Mediterranean region and to some extent in the United States and Mexico, South Africa, and Australia. The finest grades of oil are obtained by hand pressing; lower grades obtained by machine pressing are used as lubricants and in soapmaking. Partly because of the development of native edible oils, olive oil is decreasing in importance as an American table and salad oil.

Castor oll is best known for its medicinal use which, however, accounts for only about one-sixth of the total amount used in the United States. Its principal uses are in the manufacture of some soaps, certain dyes for textiles and leather, and as a lubricant for airplane and marine engines. India leads in the world production of castor seed, although the castor plant, a low growing, short lived perennial tree, is widely grown in tropical and warm temperate regions as an ornament. Formerly some seed was produced in the United States, but the present cheapness of the Indian crop has caused abandonment of American production.

Peanut oil is expressed from the seed of the common peanut. Cold pressed oil has a light color, fine flavor, and is much used as a salad oil, as an adulterant for olive oil, for butter and lard substitutes, and as a packing oil. Hot pressed oils are used for lubricants, illuminants, and in soapmaking. The residue or cake has a higher food value than any other oil cake, and is valuable as a stock food. The United States is the chief world producer, followed by the West Indies, Africa, and India.

$$
\text { * * * * * }
$$

Coconut oIL, the most important of the plant fats, is obtained from the dried meat of the coconut, known commercially as COPRA. The coconuts are harvested, husked, and broken open to dry, after which the meat extracts readily. The former crude native methods of pressing are rapidly giving way to machine extraction which yields a better grade of oil to meet the increasing world demands for this product. The Dutch East Indies, Philippines, British Malaya and Ceylon are the principal coconut 
producing centers. Coconut oil is solid at ordinary temperatures, hence well adapted to use in butter substitutes-known as nut margarines. About three-fifths of the coconut oil consumed in the United States is used in soap manufacture-shaving soaps, hard water soaps, shampoos, and other free lathering soaps. Other uses include lard substitutes, salad dressings, and confections. Coconut oil cake is a very nutritious stock food.

The oil palm, native to West Africa, but cultivated very extensively throughout the tropics, produced two oils of interest. The nuts, borne in fibrous bunches of about two hundred, yield an oil known as PALM KERNEL OIL which is white and solid at ordinary temperatures. It is used as a butter substitute, and in the manufacture of soaps and candles, while the cake is a fine cattle food. PALM oIL is obtained by pressing the fibrous pulp which makes up the bulk of the fruit, and in which the nuts referred to above are borne. This oil is yellow to brown, tinged with red, and is used mostly in the manufacture of soaps and candles. Although inferior to palm kernel oil, it is sometimes eaten by the natives. Production centers mostly in Sumatra, Java, and West Africa.

Carnauba WAX is the most important of the plant waxes, and occurs on the leaves of the wax palm of tropical South America. Young leaves are gathered, dried, and scraped of their waxy coatings, after which the wax is refined in boiling water, skimmed, and molded into cakes for marketing. Carnauba wax is very hard, has a high melting point, and is used in the manufacture of wax varnishes, phonograph records, candles, and various toilet preparations such as cold creams.

\section{Starches in Industry}

STARGHes have been previously discussed as to their importance as plant foods and also for their importance directly as human and stock foods. The present discussion deals with their importance as a raw material for further manufacture, sometimes into human foods but more often into other commercial substances.

Corn is by far the principal commercial source of starch in the United States, furnishing about five-sixths of the starch made 
here. In Europe, large amounts of starch are extracted from potatoes, which are used also but to a much lesser extent for that purpose in the United States. Wheat and rice are of minor importance as starch producers, as are several tropical plants, the sago palm, arrowroot, and cassava. In all cases the starch is extracted from the plant tissues by first grinding to break down the cellular structure and free the starch grains, and then washing with a slow running stream of water which washes out the insoluble grains. They are allowed to settle out and are then dried in kilns after which the starch is ready for the market.

There are a number of products manufactured from the freed starch grains which are important industrially. One of these is DEXTRIN, a tasteless white solid with high adhesive qualities, which is widely used as a substitute for the natural gums. Cornstarch dextrin is the adhesive which coats the backs of United States postage stamps. Dextrins are also used for glazing papers and cards, and in the textile industry as an aid in dyeing cloths. These substances are obtained by treating starch with dilute acids often accompanied by heat, or enzymes which decompose starch into dextrins.

If this decomposition is carried far enough, starch is completely broken down into glucose, a simple sugar. In the United States this is manufactured from cornstarch, and often referred to as corn syrup. It is widely used as an infant and invalid food, since it is a sugar in its most simple and available form, and for candy making, cooking, and sweetening purposes in general.

When the insoluble starch grains are heated in water, they swell and burst, forming a paste-like substance known as soluble starch which is widely used for giving a "finish" to textiles and papers in their manufacture, and in laundry work as a stiffening agent to keep the ironed clothes fresh and free from wrinkles.

Large quantities of INDUSTRIAL ALCOHOL are manufactured from starch by first converting it into sugar by action of the enzyme diastase, and then converting the sugar into alcohol by fermentation with yeasts. This alcohol is known as ethyl, or grain alcohol, and is used in the manufacture of many other products, as well as being widely used as a solvent and anti-freeze for automobile radiators. For all these uses the alcohol is "denatured" 
or made unfit for drinking by the addition of wood alcohol or other poisonous substances. Pure ethyl alcohol is also used in medicine and surgery.

When starch is treated with nitric acid, it reacts to produce a substance known as NITROSTARCH, a high explosive which is much safer to handle than the nitrocellulose discussed later. At the end of the first World War, almost two million pounds of nitrostarch per month was being used in the manufacture of hand grenades.

\section{Cellulose Products}

From the time man first began to use plant fibers until a scant fifty years ago, the extracted fibers were regarded as the final product of the process and were used for manufacture into textiles and paper in the form provided by the plant. Today these fibers are regarded as the raw materials from which man may build other fibers, almost to his own specifications. This amazing change of outlook may well revolutionize the entire textile industry as well as the cotton growing and forest growing industries, since it is primarily from cotton and wood fiber that the cellulose is derived, to undergo chemical changes from which it emerges as any one of a variety of cellulose derivatives.

The first step in the manufacture of artificial fibers is the conversion of the cellulose into a liquid form. Then it is forced through tiny "spinnerets" in thin streams and hardened by air or chemicals into new fibers which are twisted together and spun into thread for textile manufacture. There are at least four different processes in use for the manufacture of these artificial fibers, which are known as RAYONS. The most important rayon process, known as the viscose process, consists of treating purified cellulose with caustic soda and then carbon bisulphide. This compound, with the addition of water, becomes viscose which is aged and then forced through the spinnerets into a chemical solution which hardens it into fibers. Cuprammonium rayon is produced by chemical coagulation of cellulose dissolved in ammoniacal copper hydroxide, a strong alkali solution. CELAnese, 
or cellulose acetate rayon, is prepared by spinning out the dissolved cellulose in warm air, which evaporates the solvents, chiefly acetone, and allows the fine thread of cellulose to harden.

The oldest process of rayon manufacture, which is little used now, is the cellulose nitrate process, commonly called the nitrocellulose process. This utilizes cotton linters dissolved in nitric and sulphuric acids to yield pyroxylin, which is then dissolved in a highly volatile solvent such as ether, alcohol, or acetone, and spun into the air, where it coagulates. The resulting fibers are further treated to reduce their inflammability, since they have undergone part of the same treatment applied to produce guncotton, a high explosive.

Rayon fibers take dyes more readily than do natural fibers, although their strength is not as great. Artificial fabrics tend to absorb more moisture, with a greater resultant weakening, than do fabrics of natural fibers. To overcome this a combination of natural and artificial fibers is often used. The use of such synthetic fibers is increasing, with continued research and improvement in their nature and production.

Cellulose nitrate products, of which the rayon mentioned above is one, differ according to the strength of the nitric acid employed, and the temperature and length of time that the cellulose is subjected to this nitration. Pyroxylin is one of the lower nitrates of cellulose, and is exceedingly important in industry. It is the very foundation of modern photography since all photographic film formerly consisted of a thin sheet of pyroxylin with a sensitive gelatin coating or emulsion. Pyroxylin is soluble in a variety of solvents, and can be finished into products such as celluloid, pyralin, and other plastics with the use of camphor; artificial fabrics, leather substitutes, and quick drying varnishes and paints. Guncotton, a high explosive, is produced as the result of high nitration of cellulose, and is used as a constituent of many high explosives. Smokeless powder is a mixture of guncotton with the lower nitrates; cordite, one of the high explosives, is a mixture of guncotton and nitroglycerin.

Cellulose acetate products also have many important uses, such as in safety film which is much less inflammable than the older nitrate films, varnishes, artificial glass, and artificial fabrics. 
The now famous cellophane, which encloses everything, from baby's rubber doll on the store counter to sausages in the butcher's show case, is a product of the viscose process, and is made by forcing the semiliquid viscose solution through narrow slits which result in the formation of a transparent sheet only one one-thousandth of an inch thick. 
Part Five

PLANTS AS

PARASITES 



\section{Chapter 24 \\ BACTERIA AND DISEASE}

Bacteria are probably the most universally distributed of all plants. They are especially abundant in the air where they are carried on dust particles, in water, in the alimentary tract of the human body, and in the upper layers of soils, where certain forms play an important part in soil fertility (see Chapter 5). Since bacteria are colorless plants, they must depend upon organic foods for their energy. Many species utilize dead plant or animal materials for their nourishment, but there are likewise many which attack living plants or animals, causing characteristic diseases of those organisms. These latter are known as plant, or animal, pathogens, or are referred to merely as pathogenic bacteria-meaning disease producing individuals.

If body size were a criterion of potency, the bacteria could be entirely neglected in this discussion, since they are the smallest members of the plant kingdom, the largest bacteria being about one-twenty five hundredth of an inch long and one-twenty five thousandth of an inch wide. A billion of the smaller bacteria could be contained in a single drop of water; and about one hundred and twenty five thousand, placed end to end would form a line one inch long. Bacteria are single-celled plants (see pp. 45-46) which reproduce by simple fission. They are capable, under favorable conditions, of dividing as often as once every twenty minutes. Thus an enormous bacterial population may result from a single parent cell at the end of twenty four hours. Fortunately, the bacteria poison themselves by their own waste products without reaching such numbers, but it is easy to see how food may spoil quickly, or disease strike suddenly, with the great potential reproductive capacities of these organisms.

Bacteria may be classified into three groups on the basis of shape; the rod-shaped bacteria or BAcILLI, the spherical bacteria 
or COCGI, and the spiral or corkscrew-shaped bacteria or SPIRILLA. The relative abundance of the various types is in the order above noted. Many of these bacteria are able to produce spores, or heavy walled resting structures, in which form they are very resistant to extremes of temperature and drying; some are able to withstand boiling in water for over one-half hour. Fortunately, from man's viewpoint, some of the worst disease producing forms - the typhoid, undulant fever, and tuberculosis bacteria-do not form spores, so that the heating of milk to a temperature of about $145^{\circ} \mathrm{F}$. for thirty minutes - the process known as pasteurization-renders it safe from contagion by any of these organisms.

The identification of bacteria and a knowledge of their nature and activities is essential to the understanding and treatment of disease. This can be accomplished only by the isolation of a particular bacterial organism and its growth in a pure culture, which is a growth of only one kind of individual. Of the hundreds of bacterial species, many are practically identical as to shape and size so that it is necessary to resort to tests to determine the function as well as the form of the particular bacterial cell being studied. Shape and size of bacteria is determined by staining with dyes derived from coal tar compounds; in addition to this, certain forms give characteristic staining reactions with special dyes, which permits their separation from other forms of like size and shape but giving different reactions. Bacterial function is further studied by growth of pure strains upon various types of culture substances or media, which result in varying sizes, shapes and colors of colonies produced upon agar, gelatin, potato, and milk media. Optimum temperatures for bacterial growth also give important clues as to their identity; human pathogenic bacteria grow best at a temperature near that of the human body, while soil bacteria have their optimum at a considerably lower point.

\section{Human Disease}

With large numbers of bacteria present at all times in the air, and also common in water, milk, foods, and particularly on the human hands, one often marvels at the small amount of trouble 
that they cause. The answer is found in the remarkable protective devices of the human body. To cause disease, a bacterial organism must first gain entrance into a body, and in the case of man, such a successful entrance is often very difficult. Bacteria of the air are filtered out during breathing by hairs in the nostrils, and by the mucous linings of the nose and throat so that they rarely reach the delicate network of air sacs in the lungs. Bacteria in foods have to withstand the acid of the gastric juices in the stomach, later the alkali of the bile secretions poured in from the liver and finally the ravages of other bacteria which are normal residents of the human intestines. The skin affords ample protection to the outside of the body, being dry and impenetrable to bacteria except when broken.

In spite of all these protective devices, some pathogenic bacteria do gain entrance into the tissues of the human body, where they meet a secondary line of defense which is likewise very effective. The blood contains substances which weaken most bacteria, making them easy prey for the white corpuscles which then destroy them. The strength of these defenses varies from person to person, and from time to time in the same person depending upon the physical condition. This internal resistance to attack by disease causing bacteria is known as IMMUNITY. If an individual can resist attack by certain disease bacteria, he is said to be immune to the disease; if he succumbs easily, he is said to be susceptible to the disease. Disease itself is not inherited, but immunity or susceptibility to a particular disease can be inherited. When a person is born with an immunity he is said to possess a NATURAL IMMUNITY. Thus the white race has a certain amount of natural immunity to measles, and it is relatively mild in its effects on individuals of this race, but when brought to the American Indians and natives of Greenland and Iceland it proved a very deadly disease among them. The same is true of the smallpox brought to the American Indians by European settlers.

The immunity which results from having had a particular type of disease is known as Natural ACQUiRED immunity. Such an immunity is brought about by the development in the human body of certain substances, which react against either the 
attacking organisms themselves or against the poisons, or toxins, produced by the bacteria. Thus when an individual has recovered from an attack of smallpox, measles, or scarlet fever, his body has produced such a strong immunity reaction to the microorganisms or their toxins that subsequent attacks usually do not result in a recurrence of the disease. But today it is not necessary to have had a disease to be insured against further attack; ARTIFICIALLY ACQUIRED IMMUNITY, which is just as effective as naturally acquired immunity, may be had without the risk and discomfort of having the disease. Such an immunity is brought about in several ways, one consisting of injecting into the human body cultures of the causal organism which have previously been weakened, or reduced in virulence by passing them through the body of another animal. This is done in the case of the organism causing smallpox. Calves are inoculated with the virus-supposedly a microorganism too small to be seen or isolated-which is collected in a weakened condition from pustules on the skin and manufactured into smallpox vaccine for human use. This stimulates an immunity reaction just as does the presence of the disease organism in its normal form, but without the ill effects of the latter.

Another method, used in creating immunity to typhoid fever and Asiatic cholera, is to inoculate with dead bacteria in known numbers, thus stimulating an increasing immunity reaction with increasingly larger doses of the killed bacteria. A third method of creating artificial immunity is by the use of bacterial toxins, or the poisons given off by bacterial cells. This is used in the case of immunity to diphtheria, where the bacterial cells are grown for several days in a meat.broth, then killed and the toxins filtered free of any bacterial cells and prepared for injection in a chemically modified form known as a toxoid. This has replaced the older method of inoculating a horse with the bacteria and using the serum from horse blood as an antitoxin to be administered with the toxin.

Often an individual has been exposed to a disease or is suffering from the early stages of the disease before preventive measures are taken. This is called PASSIVE IMMUNITY since instead of injecting an immunity stimulating substance into the body, the im- 
munity itself is given in the form of an antitoxin developed in the body of another animal as described above. Diseases treated in this way include diphtheria, tetanus, scarlet fever, measles, and infantile paralysis.

In addition to the immunity methods described above as being valuable in preventing disease producing organisms from causing illness, there are many public health practices which are of enormous value in checking the spread of disease bacteria. It is necessary for such organisms to travel from one host to another, since conditions for their growth in one place never remain favorable over long periods of time. Either their host dies, the body rebels against them, or their own waste materials begin to poison them. Therefore, if their pathway from one host to another can be blocked, their spread and harm will be checked. Such organisms often live in or upon some host other than man and by eliminating these secondary hosts, the spread of a particular disease can be checked. An example of this is seen in the case of bubonic plague, which is primarily a disease of rats and is transmitted by the bite of a flea. In times of severe plague among rats, the fleas take to biting humans, inflicting the plague upon them. Thus by controlling rats, the plague is kept under control.

Sanitation and general cleanliness are important in public health work, since many disease organisms are present in human excreta, and improper disposal of such refuse is likely to result in contamination of man's food supplies. With bacteria as passengers on dust particles in the air, it is wise to employ soap and water frequently, as soap is a good mild antiseptic, and the removal of excess moisture, oils and dust from the surface of the body by cleansing is one way of eliminating bacteria.

Many disease bacteria depend upon actual contact for transmission from one host to another, consequently isolation or quarantine of one known to be suffering from the disease is of great importance in safeguarding the health and lives of others. Unfortunately, some few people harbor disease producing organisms in their bodies without themselves showing any signs of the disease. Such individuals are known as "carriers" of the disease 
and should be barred from work in which they might pass their disease bacteria to others.

Milk, being an important human food, as well as an ideal medium for the growth and multiplication of many bacteria, must be adequately safeguarded. Many epidemics of septic sore throat, typhoid fever, and other diseases have been laid to faulty handling of milk. Proper dairy conditions and pasteurization of milk will make this important food source safe.

Water likewise is a great potential source of disease if not properly safeguarded, since it often comes from rivers into which

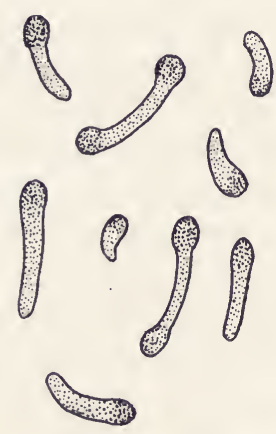

Fig. 250.-Tuberculosis bacilli are slender rodshaped cells.

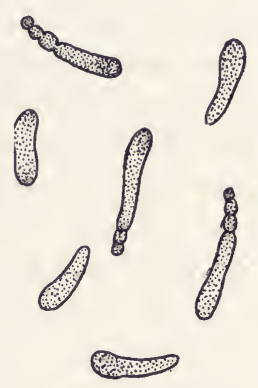

FIG. 251.-Diphtheria is caused by a slightly curved bacillus.

sewage is emptied. The use of chlorine as a disinfectant for city water supplies and the refinement of sewage disposal systems have greatly lowered the death rates of typhoid fever.

The three types of bacteria noted on page 404 all contain disease producing members, but the latter are especially found in the bacillus group which contains those species causing typhoid fever, diphtheria, tuberculosis, dysentery, leprosy and tetanus. TUBERCULOSIs is one of man's most stubborn present day diseases, caused by a slender rod shaped cell which gets into the body by way of the respiratory or intestinal tracts (fig. 250). From here it migrates to various parts of the body - the lungs being a favorite place - and multiplies to form extensive colonies which cause a 
breaking down of the tissues. With plenty of rest, good food, fresh air and sunshine, the human body is able to overcome the invasion of these organisms if their presence is detected in time. Disregarded, they will ultimately cause death of the individual attacked. In addition to man, cattle and pigs are particularly susceptible to tuberculosis. DipHTHERIA is caused by a slightly curved bacillus (fig. 251) which, in addition to producing strangulation of the victim by forming a thick membranous growth in the throat, also produces a powerful toxin which is carried in the blood stream to other parts of the body, where it weakens such vital organs as the heart and kidneys. Tetanus

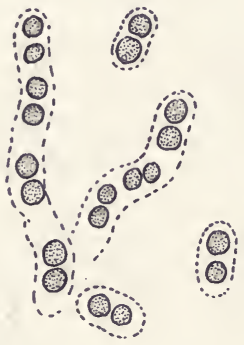

A

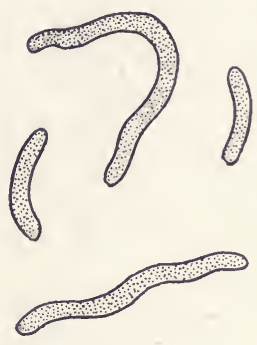

$B$

FIG. 252.-Other pathogenic bacteria include (A) pneumonia cocci, and (B) cholera spirilla.

bacilli produce the often fatal "lockjaw." These are common in soil, water, and in the intestinal tract of the horse where they live harmlessly. Introduced into the blood stream and tissues of man, generally by way of nail punctures and similar deep wounds, they multiply rapidly to produce the disease.

The spherical bacteria or cocci contain a number of the pus forming species common in boils, abscesses, and open wounds. When these organisms gain entrance to the deeper body tissues and blood stream, erysipelas results. Many of the streptococcus forms-chains of cocci-are responsible for infections of the throat and other portions of the respiratory system, as well as some types of dysentery and appendicitis. Other coccus formsknown as diplococci (fig. 252)-occur in pairs and cause pneumonia, meningitis, eye infections, pleurisy, and an often 
fatal, general inflammation of the abdominal lining known as peritonitis.

The spiral bacteria, or spirilla, are less important as disease producers than either of the other two groups. However, some diseases, notable among them cholera, result from spirillum infections. The cholera spirilla destroy the red blood corpuscles, in addition to producing extremely virulent toxins.

\section{Plant Disease}

Not so close to our personal welfare, but none the less of vital importance, are the bacterial diseases of plants. First demon-
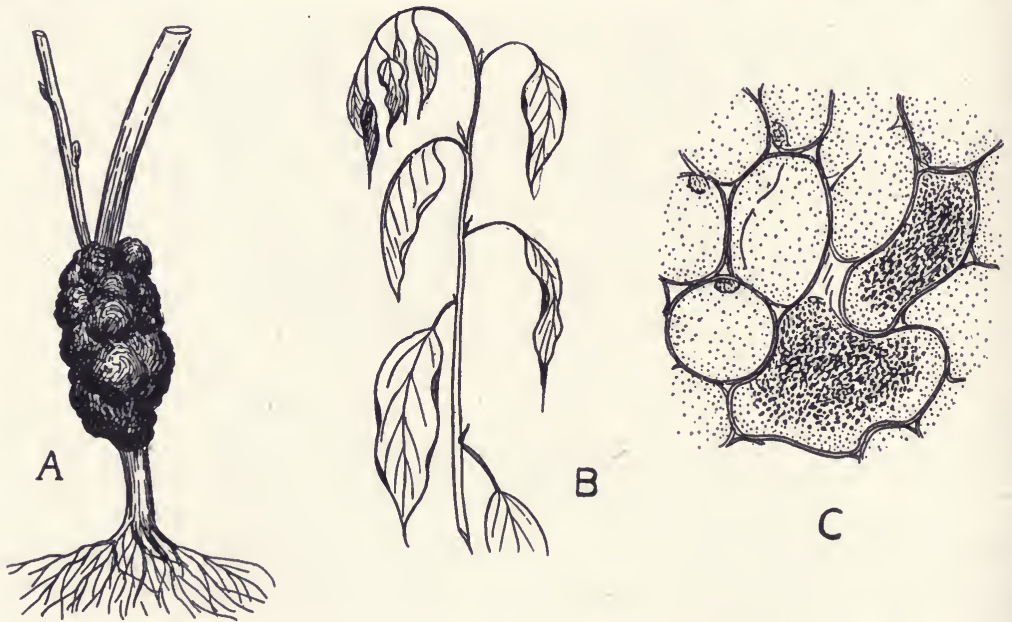

Fig. 253.-Some bacterial diseases of plants include (A) crown gall and (B) fire blight of pears and apples; $\mathrm{C}$ shows bacteria of fire blight in cells of the flower.

strated as plant pathogens only sixty years ago, bacteria today are credited with causing many serious diseases of plants, outstanding among these being the FIRE BLIGHT (fig. 253B) of pears, apples, and quinces. This disease, in addition to occurring on the hosts mentioned above, is found on many other cultivated and wild plants of the Rose Family. It was probably native to America but has spread to the Old World, outbreaks of the disease having occurred in Italy and in New Zealand. Fire blight is caused by a member of the bacillus type of bacteria, 
which flourishes especially in the soft, juicy tissues of the trees. It attacks all above ground parts of the tree, including the blossoms and fruit, gaining entrance mainly by way of the nectaries or honey secreting glands of the blossoms, or by way of the stomata in young leaves, in either case being spread by insects, wind, rain and dew, and man's activities. The bacteria overwinter in cankers, or infections on the woody parts of the trees, and are exuded in gummy masses during the spring when sap flow is resumed. These serve as sources of infection for the new growth. In some years this disease causes little loss, but in other years entire crops and even whole orchards may be wiped out. The Bartlett pear is so susceptible to fire blight that the growing of this variety has been abandoned in some sections due to the disease. During a twenty year period, fire blight destroyed almost one-third of all the full grown pear orchards in California. The best way to control fire blight is to remove infected parts of trees, thus eliminating sources of infection. Various sprays during the blossoming period are also very helpful.

BAGTERIAL BLIGHT OF BEANS occurs commonly in the more humid bean growing areas and reduces the crop yield by about $5 \%$. It is caused by several kinds of rod bacteria which overwinter in the seed or in the soil. It usually forms blackened, dead areas on the leaves, stems and pods, thus interfering with normal growth of the plant or normal development of the fruit. During the growing season the disease is spread by drops of rain or dew being blown from infected to disease free plants, and by man's cultivating and picking operations. Control of this blight is best effected by the use of disease-free seed produced in the dry parts of the country where the disease is rare, and by avoiding cultivation or picking when the foliage of the bean plants is wet with rain or dew.

There are many other bacterial plant diseases, among them the destructive POTATO SCAB which causes a loss estimated at between five and twenty four million bushels of potatoes a year, and CROWN GALL (fig. 253A) which is very destructive on apples, roses, raspberries, and other woody plants. BLACK ROT OF CRUCIFERS attacks most of our important members of the Mustard Family such as cabbage, cauliflower, turnip, radish, mustards 
and rutabagas, sometimes causing them to rot in the field and at other times developing during storage of such vegetables. A GUCURBIT WILT attacks members of this plant family such as the cucumber, squash, pumpkin, and cantaloupe. As its name suggests, the disease causes wilting and death of entire plants, sometimes destroying $75 \%$ of the crop.

From the above discussion the reader may be inclined to regard bacterial plant diseases as very important and severe plant pests. However, the real destroyers of man's cultivated plants are the fungi, a discussion of which is found in the next chapter. 


\section{Chapter 25}

\section{FUNGI AND PLANT DISEASE}

Plant diseases are nothing new to mankind. The ancient Hebrews, in their biblical writings, frequently mention rusts, mildews, and blights of their crops. Aristotle, Pliny. and Theophrastus mention diseases of the olive, fig, and grape, the most valued of the Greek's cultivated plants. In ancient times these plant maladies were attributed to the doings of some god or gods whose disfavor the people had incurred. To appease the wrath of such a diety and thus protect coming crops from damage, offerings of fruits and cereals were made at various times. Such superstitious beliefs regarding the nature and cause of plant disease persisted until the middle of the nineteenth century.

Modern plant pathology, or the study of plant disease, has found more specific causes, classifying plant diseases according to the nature of the causal organism. The invention and improvements of the microscope and methods of preparing plant tissues for microscopic examination have resulted in the gathering of much information concerning the nature, functions, and methods of attack of man's many destructive plant diseases. Information on the detection and control of these is disseminated by federal and state agricultural departments.

Fungi have existed as parasites of the green plants for many hundreds of thousands of years, exacting a yearly toll from them in the wild state long before man took them into his agriculture. By growing such plants in great numbers, man offers the fungi a great opportunity for rapid growth and reproduction, so that as he becomes more and more dependent upon cultivated crops for his food and clothing supplies, he must be ever more watchful for the invasion of plant diseases. Many historical records of misery and starvation picture the ravages of fungi. The famous ERGOT poisoning due to the eating of cereal grains, especially 
rye, which are infected with a fungus disease called ergot, caused untold suffering and famine in Italy, France, and Spain during the middle ages. France again suffered nine epidemics of this disease in the seventeenth century and seven in the eighteenth, while Germany experienced twenty one outbreaks of ergotism in the eighteenth century alone. The human disease is of two types, the one known as gangrenous ergotism which causes the body extremities - fingers, toes, nose and ears - to become gangrenous, ultimately progressing to cause death, and the other called convulsive ergotism, which affects the nervous system and brings about convulsions, delirium and finally death.

The great POTATO BLIGHT in Ireland during the years 18431845 resulted in the death of one quarter of a million people as a result of starvation and sickness, and started a fifty year emigration, totalling over one and one-half million people, to the United States. The powdery and downy mildew diseases of grapes practically extinguished the wine industries of various parts of Europe during the late nineteenth century, necessitating a complete change of farming and produce among the inhabitants of the affected regions. Within the short space of a decade a leaf disease of the coffee tree wiped out this once flourishing industry on the Island of Ceylon which is now devoted to the growing of cocoa and tea. The notorious CHESTNUT BLIGHT disease, first found in New York in 1904, has swept the range of our native American chestnut trees, and there is little hope of avoiding extinction of this once valuable and important United States timber tree. Not only do the forest owners feel the loss of this tree, but telephone and light companies who formerly used chestnut poles, as well as the tanning industry to which chestnut formerly furnished $90 \%$ of its native tanning extracts, are likewise affected. Thus these minute fungus plants become of great importance in their relation to the affairs of mankind through their effects upon his agricultural and forest products.

Although fungi cause the most destructive of plant diseases, they are not the sole causal agents. Indeed, a whole host of diseases are due not to the attack of plant or animal organisms, but rather to conditions or factors in the plant's surroundings. These diseases are generally referred to as non-parasitic maladies, 
since there is obviously no attack by a parasite. They may also be called environmental, or physiological diseases, the latter because their presence is manifest in the malfunctioning of the plant. These diseases may be likened to upsets in. the normal health of man himself, which are due not to disease organisms but rather to too much or too little of some substance or some factor in the environment. For example, sunlight is very beneficial to the human body when taken in the proper amounts, but may result in discomfort or illness when taken in too large quantities; also, certain foods are very necessary in small amounts, but cause indigestion when eaten in large portions. Plants, as living organisms, respond similarly to deficiencies or excesses in their surroundings. Thus a shortage of water may result in a dwarfing of plant growth, and an excess of water, causing a poorly aerated, waterlogged soil may produce a yellow, unhealthy growth. High temperatures, accompanied by intense sunlight, may cause death of the cambium and scorching of leaves in full grown trees, as well as a heating of dark soil surfaces to the point where they actually kill young tender seedlings by heat injury at the ground line. Low temperatures may similarly kill parts of trees, and in young seedlings may also kill indirectly by causing an injury known as "frost heave" which is an upheaval of the soil due to the freezing of soil water, which carries the young plants upward. When the soil thaws, it settles back into place but often leaves the young, practically uprooted tree seedlings to die for lack of moisture. Many chemical substances, like boron, are necessary in minute quantities for successful plant growth, but in excessive amounts cause yellowing and stunting of certain kinds of plants. The sprays and dusts which are used to kill insects or fungi, when improperly mixed or applied, or used in too high concentrations, cause injury to the very plants they were supposed to protect. In cities which have a municipal gas plant, leaks in the underground mains may cause the injury or death of valuable shade trees. Such injury may first be diagnosed as a parasitic disease, but careful examination will reveal no parasite and will sometimes be an indication of a developing gas leak. Similarly, trees along trolley lines, where overhead wires are used as a power source, are some- 
times injured-especially during wet weather-by escaping electrical charges which pass down the tree trunk to the ground, killing the cambium layer in much the same way as a small lightning charge.

In the case of parasitic diseases, some causal organism may always be located. This may be a plant, an animal, or a virus, which is an infectious principle so small as to pass through filters which will screen out bacteria, and which is invisible with an ordinary microscope. Numerous virus DISEASES of plants are known, some of the more important being peach yellows, tobacco mosaic - which causes a loss of over one million dollars per year;

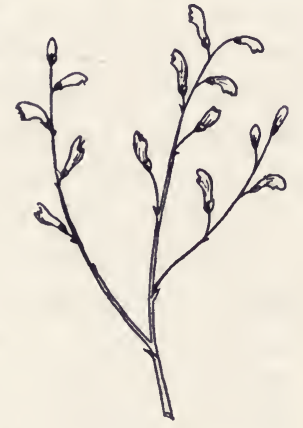

A

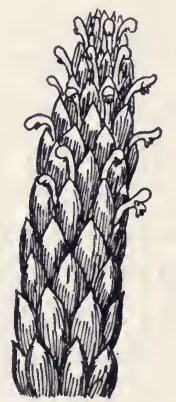

B

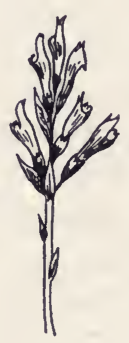

C

FIG. 254.- Root parasites include (A) beech drops, (B) squaw root and (C) broom rape.

curly top of sugar beets - which causes heavy losses in the beet growing regions of the far west; and the mosaics of potatoes, beans, and cucumbers; all of which cause large crop losses chiefly through a reduction in the yield. Protection against virus diseases is accomplished mainly through the use of disease free seed and planting stock, varieties of plants that are very resistant to attack by viruses, rotation of crops, and the controlling of insects which are known to transmit the diseases from one host plant to another by their feeding habits.

The seed plants, which themselves constitute the most highly parasitized group of the plant kingdom, include a number of parasitic forms. While these do not rank in importance with the virus, bacterial, and fungus diseases, brief mention of a few is 
included here. The so-called ROOT PARAsites (fig. 254) attach themselves to the roots or underground stems of their host plants. Some obtain in this way their entire food supply, as in the case of beech drops, squaw root, and broom rape, all completely lacking in chlorophyll. Others depend upon their host plants for water and mineral salts only; examples of the latter group are seen in the green, herbaceous cow wheat, yellow rattle, eyebright, and painted cup. STEM PARASITES attach themselves

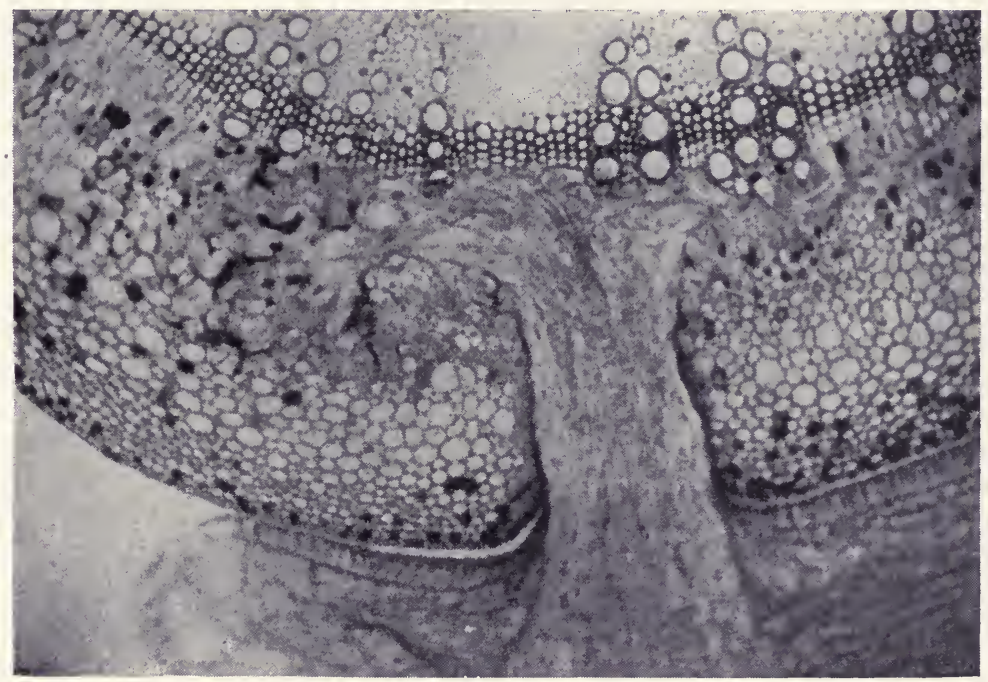

FIG. 255.-Dodder is a stem parasite, forcing an absorbing haustorium into the conducting channels of its host upon which it depends for water and food. Parasite can be seen in lower half of illustration, host plant in upper half.

to the above ground parts of their hosts. Here again there are members which are completely dependent upon the host for foods, the best known of which are the common dodders of clover and alfalfa (fig. 255). These are twining plants which encircle the host plant stems, sending into their tissues haustoria, or root-like absorbing organs which absorb foods for the parasite. Dodder seeds overwinter in the ground, or may be found contaminating clover or alfalfa seed, which is its chief method of dispersal. The dwarf mistletoes are colorless stem parasites of many coniferous trees, especially those of the arid and mountain 
regions of the western United States. They cause a swelling of the attacked portion and the development of a very bushy growth called a "witches broom." Ultimately the portion of the stem beyond the infection dies; thus young trees would be killed and other trees would suffer a reduction in growth. The green leafy mistletoe, so popular during the Christmas holiday season, is another stem parasite, but depends upon its host only for water and mineral nutrients, being able to manufacture its

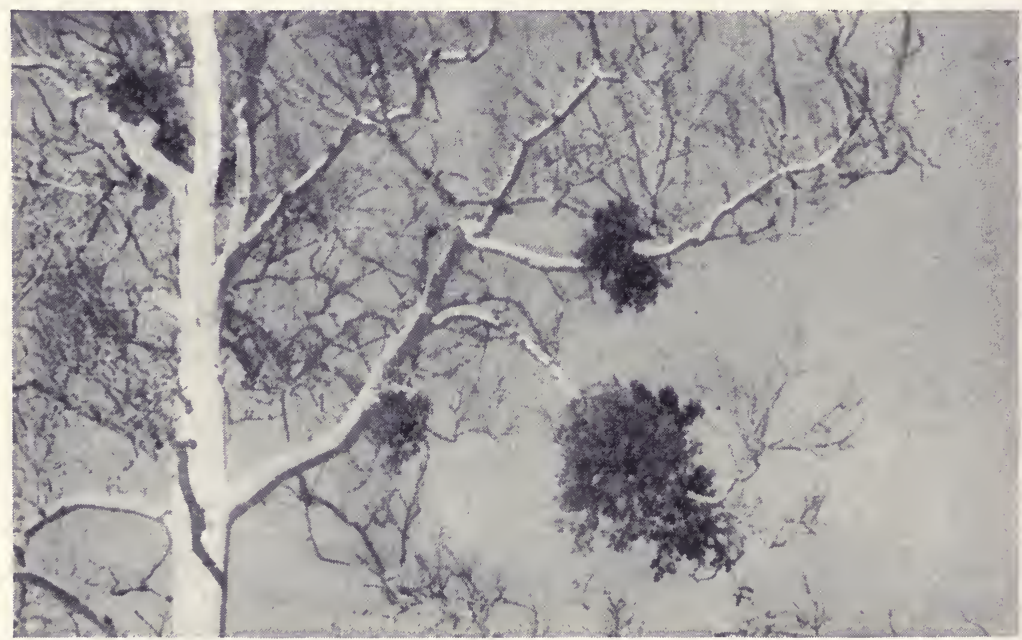

Fig. 256.-Mistletoe plants are semi-parasites, absorbing water and minerals from the host tree.

own food (fig. 256). Leafy mistletoes attack both deciduous and coniferous tree species; their chief damage is in causing a breakage of the stems and limbs due to increasing weight, since they grow from one year to another. Mistletoes all produce a fleshy fruit, which is eaten by birds. The seeds, however, are not eaten and are wiped off the birds' beaks onto the tree stem where they adhere due to a sticky surface, and germinate to produce a new mistletoe plant. Fortunately many of the more destructive mistletoes are highly specific as to their host. Thus, if the seed from a ponderosa pine mistletoe were placed upon the bark of a red alder tree, the seed would germinate, but the mistletoe 
would not be able to infect the red alder. The best control for these parasites is to remove infected trees when the forest is being logged. On shade or ornamental trees, the plants may be cut or broken out of the trees.

\section{Plant Diseases Caused by the True Fungi}

Most of the true fungi, as we have seen in Chapter 4, are grouped in three well defined classes; the Phycomycetes or algal fungi, so called because of their similarity in body form and reproductive habits, to some of the green algae; the Ascomycetes or sac fungi, whose chief reproductive structure is a sac within which the spores are produced; and the Basidiomycetes or club fungi, which bear their spores upon a basidium.

The Phycomycetes are the lowest group of true fungi, many of their members still retaining an aquatic habit and living as saprophytes or parasites upon water plants, fish, and insects. Many others live as saprophytes or parasites in a terrestrial habitat, and it is among these that some of man's most destructive plant parasites are found. The main body, or mycelium, of the Phycomycetes consists of a single cell, much branched to form cylindrical filaments known as hyphae. Everyone is familiar with the common BREAD MOLD (fig. 23) which has hyphae large enough to be seen as tiny white "threads" with the naked eye. These hyphae secrete enzymes which digest the food outside the plant body, after which it is absorbed into the filaments. It seems remarkable that these delicate hyphae can grow into seemingly hard substances such as the skins of various fruits and vegetables, woods, and even living green leaves of plants. Many of these hyphae become specialized, not only for absorbing food, but for both sexual and asexual reproduction. After the bread mold has grown for a few days, countless black dots may be observed at the tips of the hyphae. These are spore cases bearing numerous asexual spores which, if alighting on food materials, may grow into a new mold plant. If two different sexes or strains of the mold are allowed to grow into contact with each other, specialized reproductive cells are formed by each. These fuse and develop into a heavy walled resting spore which eventually germinates to produce not a new mold plant directly, but an 
asexual spore bearing stalk which produces the spores that will give rise to new plant bodies. In some of the Phycomycetes, sexual reproduction is not dependent upon the existence of two different strains of the fungus, rather both male and female gametes are produced, side by side, upon the same plant.

The bread mold discussed above is most common as a saprophyte living upon bread, cake, and even leather, but under certain conditions it may become parasitic, causing serious damage to stored vegetables and fruits, and even to young growing seedling plants. Before 1920 this organism destroyed $20-30 \%$ of the sweet potato crop each year by causing an injury known as soft rot. Through the development of improved storage conditions, and care in digging and transporting of sweet potatoes, the loss has been reduced to 5-10\%. Strawberries are likewise seriously injured by bread mold, shipments from the south sometimes being almost a total loss due to the "leak" caused by this organism. Since entrance to the fruit is gained only through breaks in the skins, care in picking and handling is essential, as well as storage in a cool, dry atmosphere. Other fruits and vegetables which may be severely damaged by rots due to bread mold include the Irish potato, peaches, pears, quinces, cherries, plums, and peas. Entire seedlings, and the leaves of mature plants, may be damaged by bread mold if moisture conditions are favorable, which occurs especially when plants are crowded in seed beds, and on greenhouse benches.

The most serious disease of seedlings is the one known as DAMPING-OFF, caused by several different pathogens which ordinarily live as saprophytes in the soil. In crowded propagating benches and seed beds, especially in greenhouses, hot beds, and nursery seed beds of forest tree species, these organisms may wipe out almost the entire stand of seedlings, necessitating replanting. The fungus attacks at the soil line, girdling the young plant stems and causing them to fall over. If the fungi are abundant in the soil, many of the young seedlings may be attacked and killed before they emerge above the soil surface. In greenhouses and nurseries, control of damping-off is effected by sterilization of the soil used in seed beds, either by the use of heat, or by sprinkling with dilute solutions of fungicidal 
chemicals. Avoidance of heavy seeding, high soil and atmospheric moisture content, and care in shading all help to reduce losses from damping off. Deep plowing, where field crops are to be grown in a soil that is known to contain the pathogens, is beneficial since the organisms live in the topmost soil layers.

The LATE BLIGHT of POtatoes (fig. 257), referred to in the opening pages of this chapter, is another disease caused by a Phycomycete. Tomatoes are also attacked severely by this disease in the presence of favorable conditions, but ordinarily escape
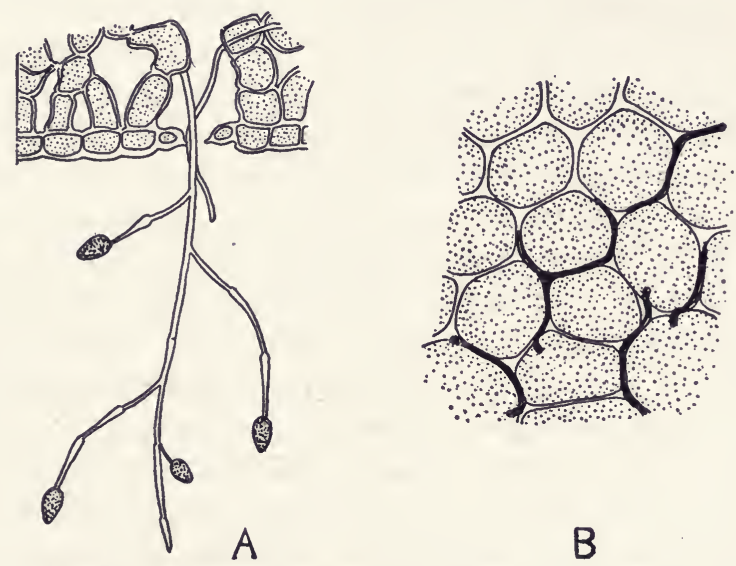

Fig. 257.-Late blight of potatoes: A shows fruiting structures extruded from stomate of leaf, and B shows hyphae of fungus in cells of the potato tuber.

serious damage. The severity of its attack on the potato crop depends upon seasonal weather conditions; a cool, rainy season providing optimum conditions for infection of both tops and tubers. Initial infection with late blight comes from diseased seed potatoes. When these are planted, the pathogen grows upward through the young sprouts, ultimately producing wind-borne spores which may infect other shoots, or be carried downward in the soil by rain to infect young developing tubers. Of course, the best way to control late blight is to use disease-free seed, thus keeping the parasite from gaining a foothold in the field. Since it is often impossible to be sure of such a freedom from attack, sprays of Bordeaux mixture- $\mathrm{a}$ fungicide consisting of lime, 
copper sulphate, and water-are advisable. If the blight is known to exist in a field, a delay in digging the tubers until after frost, and exposure of the tubers to the sun upon digging, prevents increased infection. The development of disease resistant varieties and hybrids is being carried on, and ultimately will further decrease the present large annual loss due to late blight.

DOWNY MILDEW OF GRAPE is probably native on the wild grape of the Mississippi valley. Although the native American grapes are not notably resistant to the disease, they are not so completely susceptible to its attack as are the European varieties. Downy mildew was introduced into Europe on rootstocks imported because of their resistance to attack by a root louse which likewise had been introduced to the vineyards of Europe from America. Its spread was both rapid and destructive, and had it not been for the discovery of the Bordeaux mixture referred to above, it might well have completely destroyed the grape industry of Europe. During the 1880's the disease was so destructive that many vineyards were abandoned, the owners turning to other pursuits for their livelihood. Although spraying helps greatly in combatting the disease, Germany in 1925 lost $40 \%$ of her grape crop in spite of all available precautions. Downy mildew attacks the leaves, young stems, and fruit of the grape, initial infection occurring in the summer by means of spores produced on the surfaces of infected leaves, or in the spring by similar types of spores which have arisen from heavy walled resting structures formed in the fallen leaves. The mycelium of the fungus is capable of overwintering in the buds, resuming its infection when growth of the host begins in the spring. Presence of this pathogen is easily detected by the masses of downy, white fungus growth which appear on the lower surfaces of the leaves, and on the clusters of green fruit. Like most fungus diseases, downy mildew is checked in its growth by long dry periods, and favored in its development by shaded, moist situations and humid weather. Spraying with Bordeaux mixture every two weeks during the growing season gives good control of downy mildew, and removal or plowing under of the leaves in early spring prevents infection from overwintering spores present in such refuse. The pruning off of infected plant parts is also ad- 
vised. These four diseases by no means exhaust the list of Phycomycete plant pathogens, which include such other important diseases as CLUB ROOT OF CABBAGE, the WHITE RUST OF CRUCIFERS and POWDERY SCAB OF POTATOES.

The Ascomycetes vary greatly. as to their body size and complexity, ranging all the way from the microscopic single celled yeast plant to the well known fleshy, edible, morel. They all have in common the sac like reproductive structure, or ascus, within which are borne characteristically eight ascospores. The asci are often arranged in a compact layer, either underneath the epidermis of the host plant, or in special, variable reproductive structures which may be flask, disc, or cup shaped, and situated on the surface tissues of the host. Almost one half of all known fungi belong to this group, the greater part of which are saprophytes, but which contains many plant diseases.

Perhaps the most recent Ascomycete disease to make its appearance in this country is the so called Dutch Elm DISEASE, which did not originate in Holland, but probably in China, being brought into the United States about ten years ago on elm burl logs imported from France for conversion into fancy grained veneers. The disease first gains entrance to the elm trees by way of breaks in the bark, often caused by insect borings. Two species of elm bark beetles are known to be active in spreading the disease, and it is possible that other insects, as well as birds, may transport the fungus spores from one locality to another. Within the tree, the fungus grows rapidly in the sapwood, causing a plugging of the water conducting vessels, and a subsequent wilting and drying of the green leaves beyond the point of attack. This wilting is one of the symptoms of the disease, but drought and several native diseases of minor importance produce the same external symptoms. When the limb or trunk is cut, a ring of brown spots is evident in the sapwood, but this internal symptom is true also of other wilt diseases, so that for final determination it is necessary to isolate the causal organism and grow it in the laboratory in order to secure the fruiting structures which will give its actual identity. Spores are produced on 
cut ends of infected trees, in insect tunnels, and under loose bark. The only method of control is to locate and remove all infected trees, as well as all trees weakened by drought or other causes, which serve as breeding grounds for the insect carriers of the disease. To control this disease, man power and money must be available while the disease is still confined to the restricted area within a one hundred mile radius of New York city. A few isolated infections in Ohio, Indiana, Virginia, and Mary-

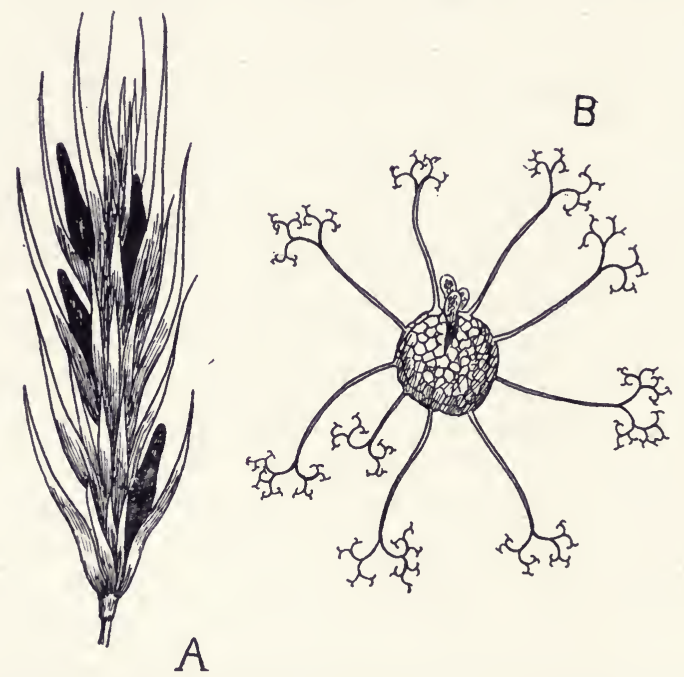

FIG. 258.-Other plant diseases include ergot of rye (A) and numerous powdery mildews (B).

land, have been supposedly eradicated. Unless controlled immediately, the elms, especially the highly prized American or white elm may suffer the same fate as that of the American Chestnut, which has been practically exterminated by another Ascomycete disease, the Chestnut blight or bark disease. This disease, referred to in the opening pages of this chapter, kills by destroying the inner bark and cambium of the tree, thus girdling it and causing death.

The ERGOT OF RYE to which reference was made in the introduction to this chapter, is another Ascomycete (fig. 258). Ergot does not seriously affect the yield of the rye and other cereal 
crops, but the blackened, fungus infected heads cause poisoning if they are present in sufficient quantity. On wheat, this disease is rarely destructive, but under certain conditions may become so. When present in only small amounts, ergot may cause rejection of wheats for manufacture into macaroni and spaghetti since the infected heads would cause black streaks in the resulting product and make it unfit for sale. The ergot fungus infects the ovary of the cereal flower, either destroying it entirely, or causing a malformation of the resultant grain. The fungus further develops to form a mycelium which completely fills the blighted grain, finally producing a black, very heavy-walled resting mass of mycelium known as a sclerotium. These sclerotia resemble mature grains in shape, but are often more elongated, and their presence is easily detected. The fungus winters in the sclerotium stage, sometimes with the seed, but often in the field. In the spring, the heavy walls of the sclerotium soften, and the mycelium develops into several spore-bearing structures which produce numerous asci. These produce the spores which cause infection in the new grain crop. Warm, wet weather favors heavy infection of a field, since it causes the flowers to remain open longer, and likewise is favorable to the development of ascospores. Control of ergot is effected by the use of disease free seed, by the rotation of crops-that is, if infection has been evident in a preceding cereal crop, some other crop should be grown in the particular field until the fungus has had an opportunity to die out-and finally by the removal of susceptible wild grasses from fence rows. Near-by pastures of susceptible grasses should be either closely grazed or mowed before flowering time to prevent infection and subsequent spread of the disease to grain fields.

BROWN ROT OF STONE FRUITS Occurs generally throughout the United States where such fruits as apricots, peaches, cherries, plums, and apples are grown, but is especially destructive to certain kinds of plums grown in the mid-west, and under favorable conditions is one of the worst diseases of the peach crop. The fungus may attack leaves, twigs, flowers, or fruit, causing at first a symptom that may be mistaken for frost. Although brown rot does cause damage to foliage and twigs by killing them, it is most destructive to the fruit, gaining entrance by natural open- 
ings or by wounds. When the fungus is inside the fruit, it spreads rapidly, causing a brown discoloration which increases with its spread until the entire fruit is discolored. In the orchard some of these rotted fruits hang on the trees, and gradually dry to produce the so-called mummies. It is in these infected fruits that the brown rot organism overwinters, renewing its growth in the early spring to produce spore bearing structures which start the infection over again. Many infected fruits likewise rot in storage or on the market, causing shipping and marketing losses. If warm, wet weather is prevalent during the ripening period, an entire crop of peaches may be destroyed within a few days time. A second kind of spore is produced during the growing season, and is spread by wind, insects and rain. The ascospores which cause initial infections from rotted fruits depend mostly upon wind for dispersal. Control therefore involves removal of such potential spore producing tissues or infected fruit and twigs. Sprays applied during flowering and fruit maturing periods will aid materially in preventing infection by the brown rot fungus.

The POWDERY MILDEWS comprise a group of Ascomycetes most of which are external parasites living as masses of cobweblike hyphae on the surfaces of plant tissues, and sending food absorbing organs-haustoria -into the plant tissues. The external mycelium soon begins to produce thin walled, light colored spores which give the whole leaf or twig surface a dusty or powdery appearance, hence their name powdery mildews. They are mainly parasites of leaves, but may grow upon stems, flowers, or fruits. Ascospores are produced in addition to the thin walled spores referred to above, though some of the fungi of this group will produce asci only upon certain host plants or under certain environmental conditions. The group is known to occur upon many host plants, among them the apple, grape, strawberry, clover, pea, cereals and grasses, cherry, lilac, pear, and quince. It is especially destructive on the first two hosts mentioned. On the apple, it causes a dwarfing and stunting of the young leaves, twigs, flower clusters, and fruits. The grape also is affected in this way, and badly infected vines may become much dwarfed in size. Powdery mildews overwinter in old leaves or in the soil, as well as in the infected buds and stems or twigs. Control therefore 
consists of removal of infected parts of the host plants, in the case of perennial species, cultivation and fertilization of soils to produce a hardy, resistant plant growth, and spraying or dusting with fungus-killing chemicals during the growing season when numerous short lived spores are being produced.

The Basidiomycetes include members which are more familiar to the average person than either of the two groups previously discussed. Two groups of these organisms, the smuts and rusts, are notorious as disease producers on our cereal crops, especially
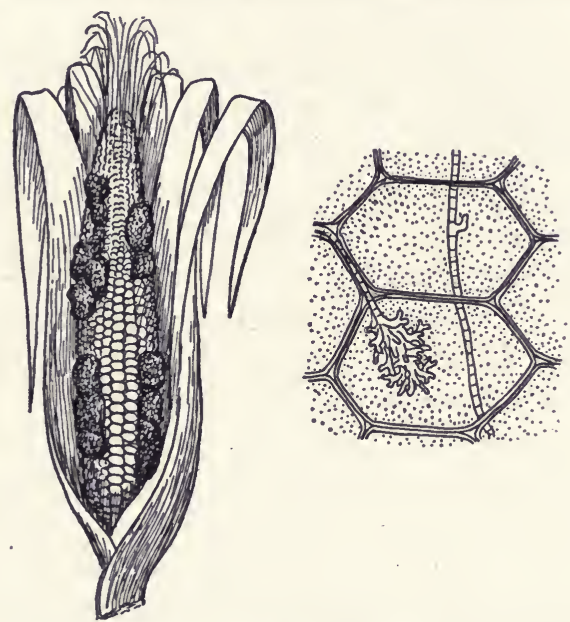

FIg. 259.- - Smuts are all internal parasites living within the tissues of the host. wheat and corn. The fleshy forms, commonly known as mushrooms, toadstools, and bracket fungi, are commonly found on living trees, fallen logs, stumps, in pastures and fields; in short, everywhere that organic matter exists in abundance, some form is likely to be present, provided there is sufficient moisture. Although the group comprises a great variety of plant forms, all display a basidium at some time during the life cycle. This is a club- or stalk-shaped reproductive structure which bears, externally, four single celled spores in most Basidiomycetes.

The sMUTs are generally held as the most primitive of the Basidiomycete group, due to their simplicity of body structure 
and life cycle. They are all parasitic, and have as their most common hosts members of the Grass Family, although they are known to attack many other herbaceous seed plants and some ferns. The smuts are all internal parasites, growing within the tissues of the host plants (fig. 259). In the majority of smuts infection is seed borne, the pathogen occurring either as a spore on the surface of the seed, as is the case in the loose and covered smuts of oats, stinking smut of wheat, and covered smut of barley; or as a resting mycelium within the seed, a condition found to exist in loose smut of wheat, brown loose smut of barley, and the loose and covered smuts of oats. In the case of the corn and onion smuts, infection results from soil or wind borne spores. Control measures must be applied in the light of this knowledge of infection sources and can be effected by cultural practices such as proper spacing in planting, rotation of crops, and by the use of resistant corn and onion varieties. In instances where spores are borne on the seeds, surface disinfection of seed by means of chemicals is effective; this method is of no avail in the case of internal seed borne smut mycelium, which must be killed by hedt, since the seed embryo can tolerate a higher temperature without injury than can the fungus mycelium.

Corn smut causes an estimated annual reduction in yield amounting to $3-5 \%$ of the total corn crops of the United States. Infection takes place early in the growing season by means of wind borne spores which are able to penetrate the host plant only by way of new tissues. Danger of infection is generally past after the plant is over eighteen inches high. The pathogen grows within the plant tissues, remaining near the spot where infection entered and stimulating the plant to produce the large galls or tumors so characteristic of smuts. Ultimately the mycelium in these galls becomes segmented and heavy walled, giving the whole mass a black, dusty appearance. These heavy-walled mycelial segments are known as chlamydospores, and function as overwintering structures in the soil or plant refuse until the next growing season, when they germinate to form the basidium stage which carries the infection to new corn plants. Control, as indicated above, is accomplished by cultural practices. 
Oat smut infects the host plants either in the seedling stage, or at flowering time, in either case becoming systemic - that is, pervading the entire plant body and sporulating in the grain or floral parts. Ordinarily oat smuts are not serious, but do result in a reduction of about $4 \%$ in the annual yield. This low figure is due to seed treatment, and the development of smut resistant oat varieties. In addition to reducing the yield, smuts create fire and explosion hazards in infected grain. The numerous spores may form a dust in grain elevators or storage places, and a spark or flame will often serve to ignite this dust with explosive violence, much the same as mine explosions underground.
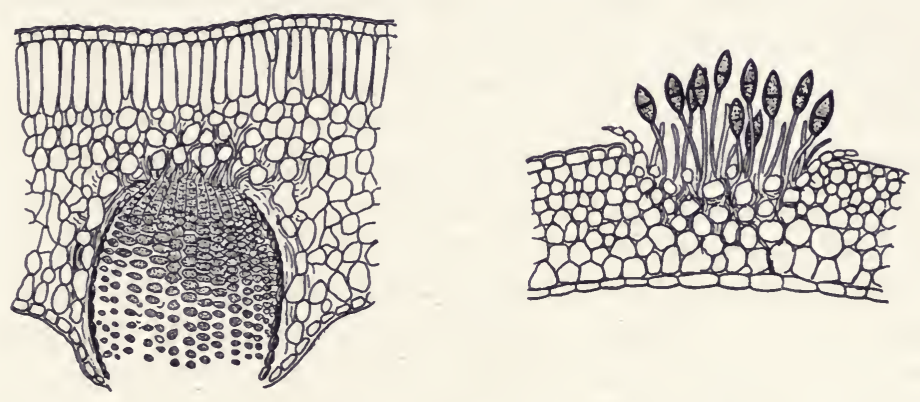

A

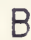

Fig. 260.-Wheat rust fungus: A, on barberry leaf; B, on wheat leaf.

Bunt, or stinking smut of wheat, likewise causes loss from decreased yield as well as from fire and explosions in threshing machines. Smutted wheat must be scoured before milling into flour. Reductions in yield vary from 1-20\%, depending upon the seasonal moisture and temperature conditions. Treatment of the seed with liquid or dry chemicals is the usual method of control for the wheat smuts.

The RUSTS constitute a Basidiomycete group whose members are characterized by the formation, during their life cycles, of from two to five different spore forms, often involving an alternate or secondary host for a given species of rust. As their name suggests, they form orange, brown, or black spore pustules which gives their host plant a rusty appearance. Typical of the group is 
wheat rust, a very common and destructive parasite of wheat crops throughout the world (fig. 260). The mycelium of this fungus ramifies throughout the tissues of the wheat plant during the growing season, erupting at intervals on the surfaces of leaves and stems to produce the red rust stage which consists of single celled, thin walled spores which spread the infection to other wheat plants. This general infection of the wheat plant results in interference with its food manufacturing activities, and a subsequent much reduced yield, from the standpoint of both quality and quantity of wheat grain produced. In late summer or autumn, another spore form is produced by the same mycelium, perhaps even on the same plant, or in threshed straw or stubble in the field. This is a heavy-walled, two-celled spore which is the overwintering form of wheat rust. In the spring, each cell germinates to form a four celled basidium, each cell of which produces one basidiospore. These basidiospores are incapable of infecting wheat plants, and will produce an infection only when they alight upon the leaves of the common barberry. Here they germinate and produce a mycelium within the barberry leaves, and here they produce two different spore forms, one of which is responsible for renewing the infection in wheat plants. By removing the common barberry plants in wheat growing regions, one source of wheat rust infection is removed. All important wheat producing states have laws forbidding the growing of common barberry. Formerly used as a hedge plant, it has been replaced by the lower growing, rust immune, Japanese barberry which is wholly as satisfactory in its growth and ornamental value: Unfortunately the disease is often not entirely eliminated by barberry eradication, due to the ability of the first mentioned "summer spore" form to withstand winter temperatures in milder parts of the wheat growing region. Likewise, these spores may be wind borne from regions of mild winters to more northern climates, since they have been collected at altitudes of several thousand feet, by means of greased plates exposed from aeroplanes.

Another important rust is the BLISTER RUST of five needle pines, which has helped to make growing of the long used white pine a hazardous undertaking. This rust enters the tree by way of the foliage, working back into the stem where it girdles the 
trunk, causing a canker or swelling, and ultimately death. Originally imported from Europe, this disease has attacked successively three of the outstanding American timber trees; the eastern white, western white, and California sugar pines. Since the fungus must spend a part of its life history upon some wild or cultivated currant or gooseberry, elimination of the alternate host makes control of the disease possible.

The CEDAR-APPLE RUST is a destructive organism on apple trees in the east and midwest, causing early leaf fall, as well as rusted, dead areas on the fruit. In addition to producing malformed fruit, the tree is weakened and rendered more susceptible to winter injury. The red cedar tree is alternate host to this pathogen, and while ordinarily less severely damaged than apples, the trees may become so heavily galled that their branches are malformed or even killed.

A third group of Basidiomycetes is known as the fleshy fungi. This includes the GILL FUNGI, of which our common edible field mushroom is an example, and the PORE FUNGI, to which belong many of the bracket or shelf fungi so common on tree trunks. Many of the organisms are saprophytic, living on dead wood and fallen leaves, but many others are very destructive wood rots of living forest trees. The saprophytic forms are important as destroyers of such manufactured wood products as railroad ties, posts, poles, mine timbers, and bridges. The preservative treatment of woods to be used in these situations aids greatly in reducing the destructiveness of fungus activity. There remains, however, the problem of reducing the losses due to wood rotting fungi in forest trees, since this is an appreciable factor in hastening depletion of American forest resources. Control measures will probably be improved upon as forest products become more valuable and as forestry practice increases in intensity.

A gill fungus known as MUSHROOM ROOT ROT, which lives as a saprophyte on logs, stumps, etc., may become parasitic, entering forest and fruit trees through wounds in the roots, and penetrating healthy underground tissues of potatoes and dahlias. Once inside the host, this organism interferes with proper root functions and ultimately results in its death. The parasite may be controlled by 
waiting three years before replanting soil areas in which it is known to occur.

BLAGK SCURF Or SGAB OF POTATOES is produced by another soil inhabiting fungus. This organism attacks tubers, stems, and roots, causing characteristic lesions and interfering with translocation and storage of foods in the tubers. The black scurf fungus also occurs in destructive form on celery, onions, beets, tomatoes, and beans, in all cases affecting mostly the underground plant parts. Control is effected mainly by long rotation of susceptible crops with those not susceptible, such as the cereals.

Prior to the enactment of the plant quarantine law of 1912, the United States was unprotected against entrance of new insect and fungus parasites of plants. This act provides for regulation of imports of nursery stocks, plants, and plant products, and gives the Secretary of Agriculture the power to establish and maintain quarantine districts for insects and diseases. Had such an act been passed fifty years previous to this date, American forestry and agriculture might have been spared the ravages of such imported diseases as chestnut blight, white pine blister rust, and asparagus rust, as well as such insect pests as San José scale, gypsy moth, and the cotton boll weevil. Properly inspected and approved bulbs, seeds, and nursery stocks are still imported from Europe and other foreign countries, so that these quarantine laws have by no means cut us off from the most desirable of the world's flowers and fruits. 
Part Six THE ENJOYMENT OF PLANT LIFE 



\section{Chapter 26}

\section{AMERICAN WILD FLOWERS}

An appreciation of plant life involves more than an understanding of how plants live and their relations with man in terms of their economic importance. We live in the midst of a green world, populated by living organisms which are our neighbors in life. We drive along streets shaded by trees, relax in gardens made restful by ornamental plants, travel over plains and mountains whose scenic value is greatly enhanced by the vegetation covering them; we camp, hunt, fish and hike in countless national and state parks where the trees, shrubs and wild flowers add interest to the drab earth. To know a few of the common plant neighbors who live in these various environments which touch upon ours, to be able to recognize them by name as old friends, to understand their distribution and origin-all make for a fuller and richer life.

In previous pages, we have become acquainted with some of the trees which make up the forest vegetation of the United States. There are, however, many smaller herbaceous plants whose flowers add an interesting touch to our fields and woodlands; all of these belong to the Angiosperm group of the Seed Plants. It is impossible within the compass of a single chapter to do more than suggest a few of the more common families of wild flowers whose representatives should be familiar to Americans. These families are grouped into the two main subdivisions (see p. 103) of the Dicots and Monocots. The Dicot families have broad leaves characterized, in most cases, by netted venation, and possess flowers whose perianth, when present, usually consists of four, five or an indefinite number of petals or sepals. The Monocot families, on the other hand, have flowers whose perianth, when present, consists of three or six parts, and leaves which are usually narrow and long, with parallel venation. Arranged 
in progressive order of flower complexity, representative Dicot families include the Buttercup, Poppy, Mustard, Violet, Saxifrage, Pea, Rose, Cactus, Mallow, Evening Primrose, Heath, Indian Pipe, Figwort, Mint and Thistle families. Common Monocot families, fewer in number, include the Arum, Lily, Amaryllis, Iris and Orchid families.

\section{The Buttercup Family}

The Buttercup Family (Ranunculaceae) is considered the most primitive of all the Angiosperm families since its flowers have
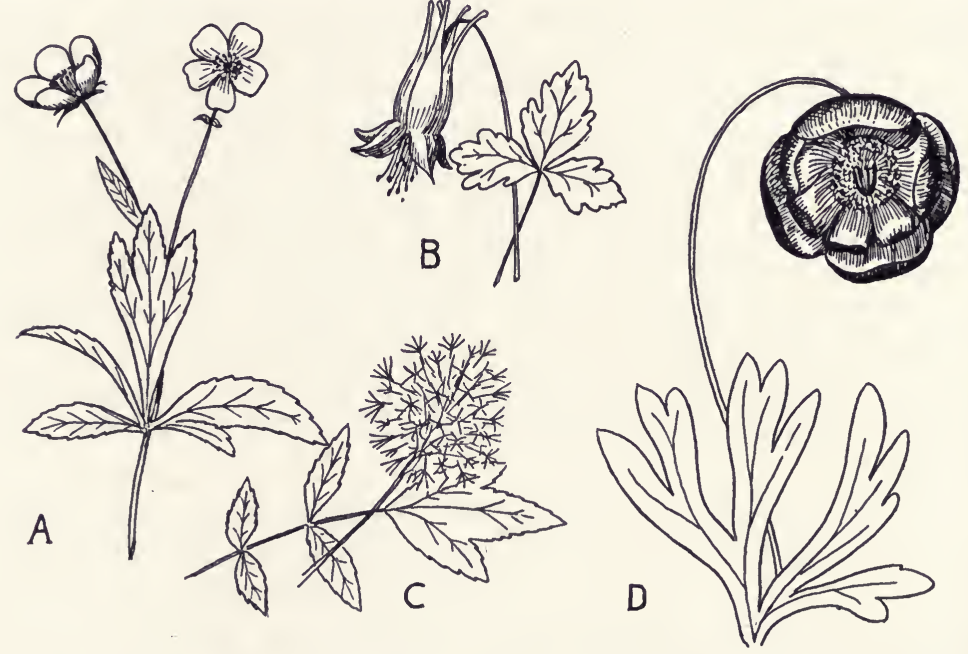

Fig. 261.-The Buttercup Family includes some species with both petals and sepals in the flower; typical are buttercups (A), columbine (B), baneberry (C) and peony (D).

separate petals and sepals, often of an indefinite number; in some of the genera the flowers lack petals and in such cases the sepals are like petals in appearance. Many of the species prefer wet habitats. Some are among our most widespread wild flowers.

Both petals and sepals are characteristic of the buttercup, columbine, baneberry, peony and larkspur genera (fig. 261). There are a dozen or more species of BUTTERGUPS native to the United States. The leaves are usually divided into narrow lobes, and the flowers have five sepals and five petals, the latter in some 
species being white or red in addition to the better known yellow color. Columbine is one of the most beautiful of our wild flowers, a representatively American plant in that it grows in almost every part of the United States. The common eastern columbine has scarlet nodding flowers, each consisting of five petal-like sepals between which the petals project backwards as long spurs. As in the buttercup the leaves are divided into segments and lobed. BANEBERRY species are found from coast to coast; they have compound leaves and globular clusters of small white flowers, each

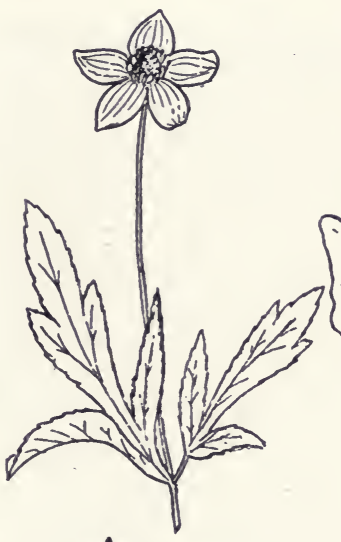

A

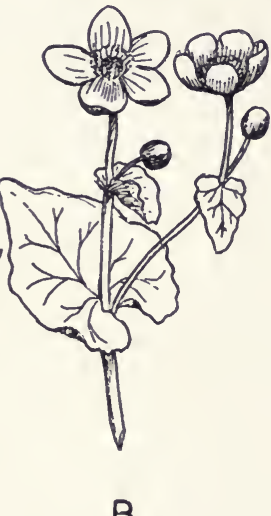

B

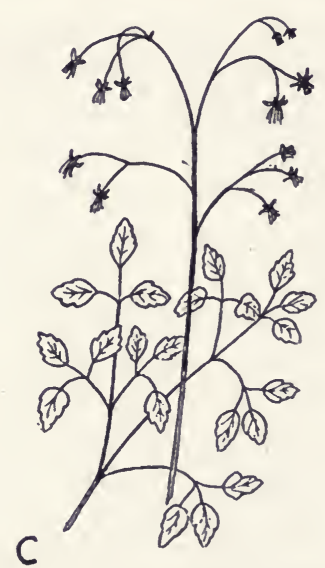

FIG. 262.-Other flowers in the Buttercup Family lack petals; such include the anemones (A), marsh marigold (B), meadow rue (C).

with three to five sepals which fall off and leave a flower of narrow petals and conspicuous white stamens. The PEONIES are predominantly European and Asiatic plants but there is one species native of the Pacific coast. This western peony has compound leaves and flowers which bear little resemblance to the largeflowered garden peonies; each flower consists of five or six greenish red sepals and a similar number of reddish brown petals. The LARKSPURS are a large genus of plants common to the north temperate zone; like other members of the Buttercup Family the leaves are lobed or divided into segments. The flowers occur in showy terminal clusters, each flower with five sepals, one of which forms a spur, and petals of which the posterior ones are 
also spurred. Most of our native species are found in the South and the West; the flowers are white, scarlet or blue.

Other genera of the Buttercup Family have flowers which lack petals, so that the sepals are the colored part of the flower; in this group we find meadow rue, hepatica, anemone, marsh marigold and Pasque flower (fig. 262). MEAdow RUE is a rather bushy plant with pendant flowers whose long stamens are more conspicuous than the four or five small greenish sepals; the early meadow rue common to rocky woods throughout the entire eastern states has compound leaves with small lobed leaflets. A taller fall meadow rue found in wet meadows is recognized by its large clusters of purplish or white flowers. Hepatica, also known as LIVERLEAF, is one of the earliest spring flowers of the eastern states; its leaves are three-lobed, and its flowers characterized by six to twelve blue, lavender, pink or white sepals. On the prairies of our central states grows the PASQUE FLOWER or WILD CROGUS which, like the hepatica, is a low-growing plant; however it has compound leaves and solitary flowers, each with five to seven blue or white sepals. Anemones include a great number of species growing in the mountainous regions of the northern states; their compound leaves are segmented or lobed, and the flowers are showy even though there are no true petals. In the woods of our northeastern states is found the tall anemone or thimbleweed whose white flowers may reach a diameter of an inch or more. Other eastern species include the smaller Canada anemone, and the even smaller wood anemone whose flowers have four to nine purple-tinted white sepals. On dry western mountain slopes we find the western windflower, while in the prairie states are numerous species of anemones which are common in wet meadows. MARSH MARIGOLD or COWSLIP is a familiar spring flower in swampy woods of northeastern United States where its clusters of golden yellow flowers provide a cheery note amid the neutral browns of the late winter vegetation. Cowslips have large coarse leaves and stout stems which bear flowers with five to fifteen large colored sepals.

\section{The Poppy Family}

The Poppy Family (Papaveraceae) is characterized by plants with a milky or colored sap and showy flowers. BLOOD ROOT shares 
with hepatica the distinction of being one of the earliest spring flowers of northeastern United States, where it grows in moist open woods. Its name is due to the fact that the root stocks contain an orange-red juice. The large leaves are palmately lobed and surround the solitary white flowers consisting of two sepals and eight to twelve petals (fig. 263). Celandine is an escaped European species which has become a common wild flower; its stout stems contain a yellow sap and the leaves are compound. Celandine flowers occur in clusters, each flower made up of two

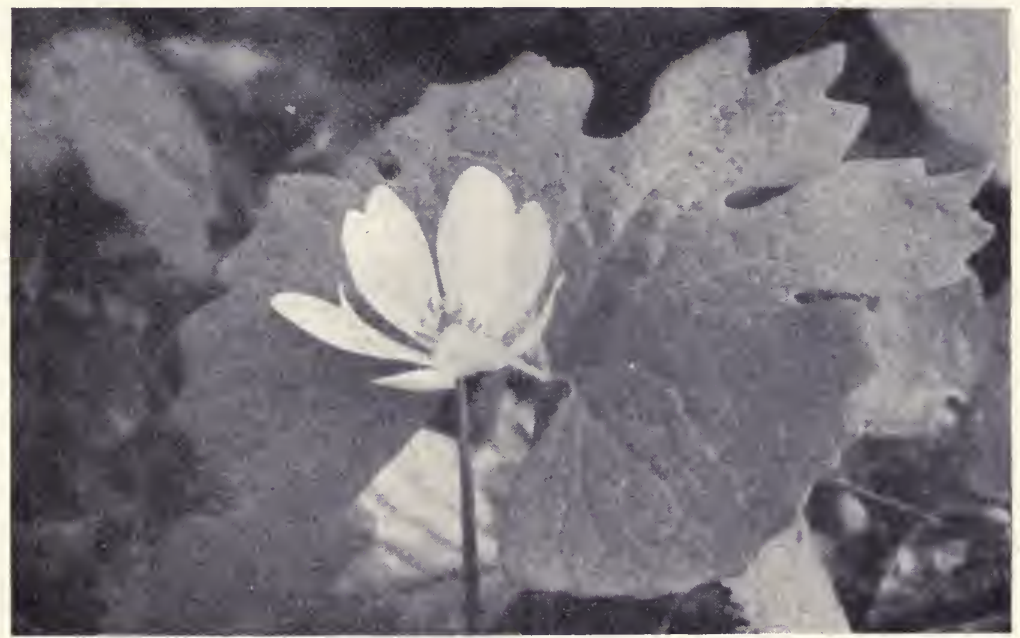

Frg. 263.-Blood root is often surrounded by its single large palmately-lobed leaf.

sepals and four small yellow petals. Cream-Gups is a western genus common among the California foothills, with grass-like leaves and weak stems which bear cup-shaped flowers consisting of white or yellowish petals. Most of our native POPPIES are found in the western part of the United States (fig. 264). The prickly poppy is a western species with orange colored sap, prickly stems and foliage, and white flowers. Several of the western poppies grow to be tall and bushy; the Matilija poppy bears a profusion of large white flowers each with six papery petals, the entire flower often being four or five inches in diameter. The tree poppy, of more restricted range in the Southwest, bears bright yellow 
flowers each with four broad petals. The best known of our native poppies is the orange-yellow California poppy which with five related species populates grassy hillsides and arid slopes from California to Arizona and Utah. The two sepals of the flower

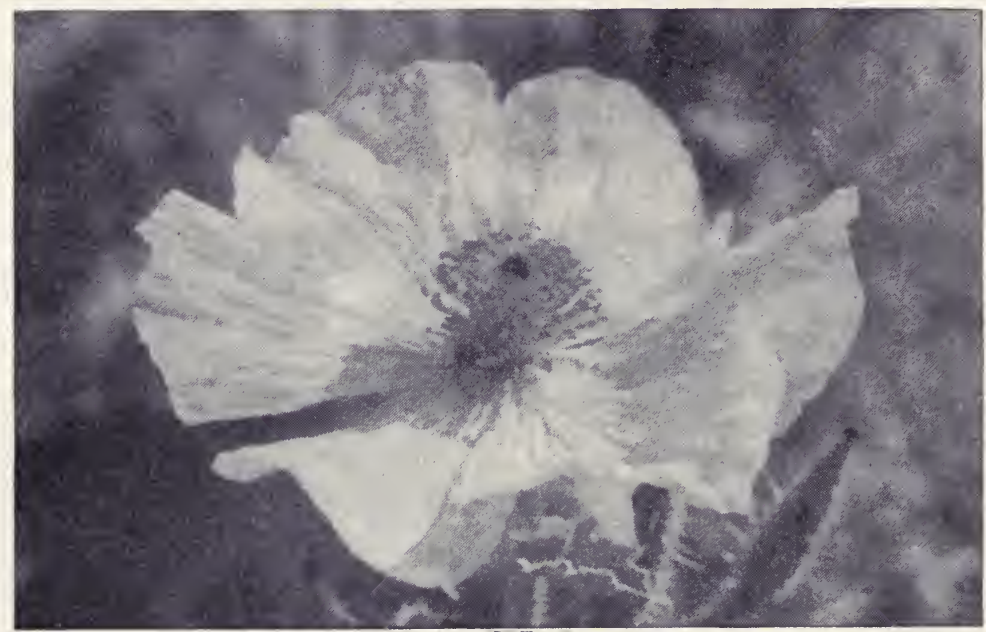

FIG. 264.-The western prickly poppy has large papery petals.

form a pointed cap which is soon pushed off by the four large petals.

\section{The Mustard Family}

Most of the species of the Mustard Family (Cruciferae) are characterized by inconspicuous and relatively unattractive flowers; a great number of them have become common weeds in various parts of the United States (fig. 265). PEPPERwort is a common roadside weed with entire or compound leaves and terminal clusters of small flowers which may be white, red or yellow; the flower, like that of other members of the family, consists of four petals arranged in the form of a cross. BLADDERPOD is a low growing plant with basal leaves and yellow flowers; in the midwestern states it thrives on dry plains, and in the far West is found on mountainsides and in the deserts. Shepherd's PURSE is better known for its peculiar pods than for its small flowers; the latter are white and are borne in clusters. This is 
another European species which has made itself at home in waste places. Wild GANDYTUFT or ROCKGRESS, a plant especially abundant in the prairie states and on western mountain slopes, has white, yellow, pink or purple flowers in terminal or axillary clusters. Sea Rocket is a bushy plant common to both the Pacific and Atlantic coasts; the fleshy stems produce lobed leaves and clusters of purple or white flowers. The PRAIRIE ROCKET is a yellow- or brown-flowered species found on the central plains.
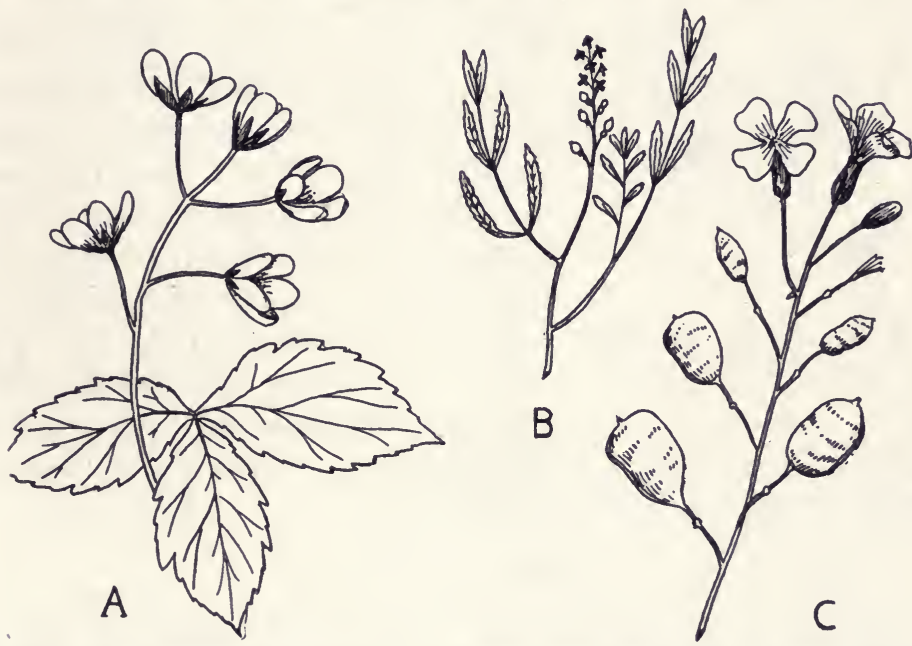

Fig. 265.-The Mustard Family includes toothwort (A), rocket (B), and moonwort (C).

The most attractive flowers of the Mustard Family are toothwort, crinkleroot and wall flower. TоoтнwORT has compound leaves and a terminal cluster of relatively large white flowers; it grows in moist woodlands of the eastern states. Crinkleroot, found in the same area, has fewer flowers which are usually white or pink and borne in a cluster above a pair of lobed leaves. WALlFlower is native to western United States, with stout stems and terminal clusters of showy yellow or orange flowers.

\section{The Violet Family}

The Violet Family (Violaceae) includes about eighty different species of violets distributed throughout the United States, found 
in a variety of habitats from sandy plains to rich woods and wet meadows. Similar species occur from the Atlantic coast to the

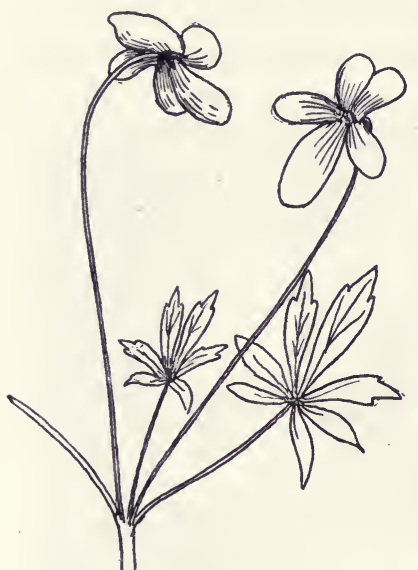

Fig. 266.-Birdsfoot violet is one of our most attractive violets.

Mississippi Valley, and different members of the genus are found west of the Rocky Mountains. Violets are unusual in having both sterile and fertile flowers; the familiar violet, which consists of five sepals and five unequal-sized petals, is sterile (fig. 266). The less conspicuous fertile flowers bear rudimentary petals, but are fertilized without the opening of the flower; it is from these that seeds are produced. Many of the familiar violets are'stemless and bear white or blue flowers; those with branching and leafy stems include the white Canada violet of the eastern states, the blue Pacific coast violet, and the smooth yellow violet or wild pansy found in woodlands from the Atlantic coast to Texas.

\section{The Saxifrage Family}

The flower of the Saxifrage Family (Saxifragaceae) has five sepals and five petals; beneath these the stem is usually enlarged to form a saucer-shaped or bell-shaped receptacle (fig. 267). Alum ROOT is a stout-stemmed plant with broad leaves and terminal clusters of small white, green, yellow or purple flowers. Many different species are found in our woods from coast to coast. MITREWORT is a slender plant of eastern woodlands with a pair of leaves beneath the terminal cluster of small white flowers, each of which resembles a tiny bell with a fringed margin. FOAMFLOWER Or FALSE MITREWORT grows in rich rocky woods of northeastern United States; the terminal clusters of white flowers do not have the fringed petals characteristic of the true mitrewort. Grass of Parnassus, found in swampy habitats of our eastern and far western states, has a basal cluster of leaves above which rises the flowering stalks bearing white flowers with green- 
veined petals. Prairie star or wOOdLAND STAR is a midwestern and Pacific coast plant with white or pink bell-shaped flowers grouped in terminal clusters. Several hundred species of the saxifrages thrive in temperate regions; the name means "rock breaker," a fitting appellation since the plants usually grow in the crevices of rocks. SAxifrages are low growing plants with basal
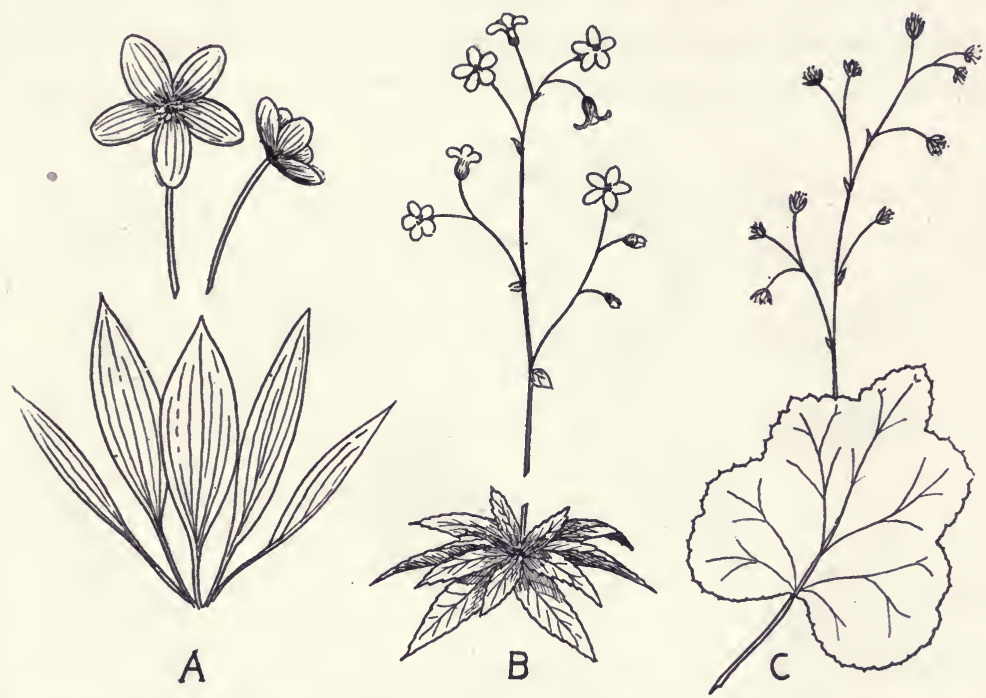

Fig. 267.-In the Saxifrage Family we find grass of Parnassus (A), saxifrage (B), and alum root $(\mathrm{C})$.

rosettes of leaves and terminal clusters of small white flowers each with a five-lobed calyx and five petals.

\section{The Pea Family}

The Pea Family (Leguminosae) is one of the largest, including some twelve thousand species widely distributed throughout the temperate and subtropical regions of the world. Most genera of this family have compound leaves, an irregular flower with a corolla of five petals of which the uppermost is the largest and two lowermost ones are united to form a boat-shaped portion of the flower (fig. 268). PARTRIDge PEA or wild Sensitive Plant is found in sandy soils throughout the eastern states; small 
clusters of yellow flowers are produced in the axils of the leaves. WILD INDIGO or HORSEFLY WEED is a plant of similar sandy habitats in our eastern and prairie states; the compound leaves consist of only three leaflets, a contrast to the twelve to forty leaflets of a partridge pea leaf. The yellow flowers are grouped in compact terminal clusters. RAtтLEBox, so called because of the inflated pod with loose seeds, is a common genus of the southeastern states with yellow flowers of the usual pea type. GoATs' RUE, common to the eastern and southern states, has nine to twenty five

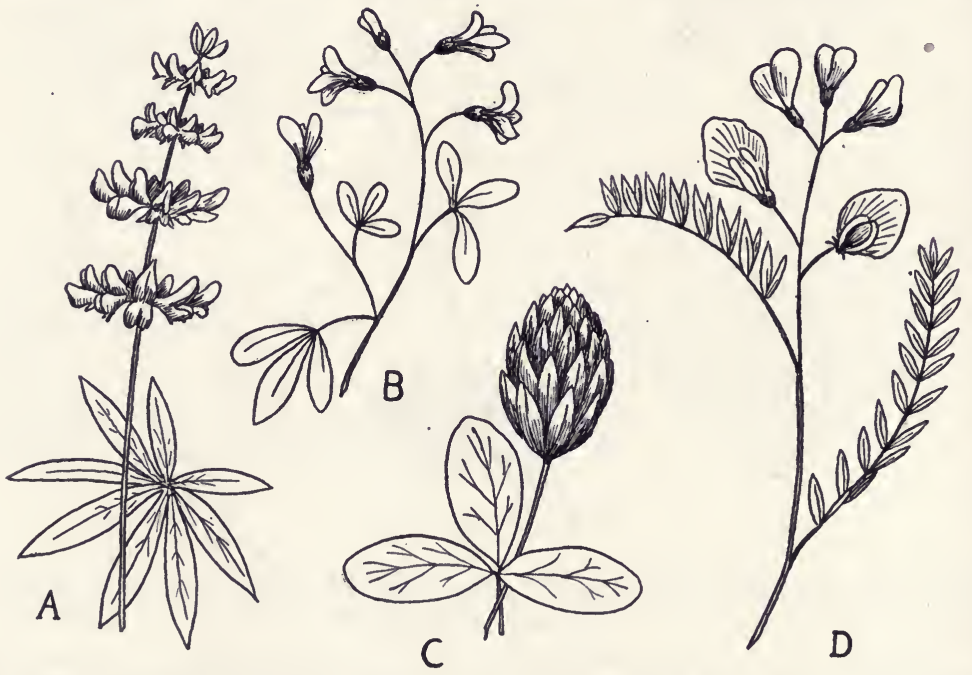

Frg. 268.-The Pea Family includes lupine (A), wild indigo (B), clover (C) and goats rue (D).

leaflets in each leaf, and clusters of red or yellow flowers. The BUSH GLOVERs, found in central and eastern United States, have compound leaves divided into three leaflets, and pink, purple, yellow or white flowers in axillary clusters. Our native species of true clover is known as BUfFAlo clover, found in the northeastern states and recognized by its globular flower clusters. PRAIRIE TURNIP and PRAIRIE GLOVER are common in the central and western parts of the United States; the former has clover-like leaves, spikes of white or purple flowers, and a tuberous starchy root; the latter has pinnately compound leaves and spikes of 
flowers which may be white, yellow, red or purple. LOCOwEed includes a great number of species abundant in arid regions of central and western United States; the scarlet, cream-colored or white flowers are grouped in erect spikes. LuPINE flowers are blue, purple, red, white or yellow. The common lupine of northeastern United States prefers sunny and sandy habitats. The California lupines form a large part of the annual "wild flower show" which transforms miles of grassy slopes of the California hills into a sea of blue and purple.

\section{The Rose Family}

The Rose Family (Rosaceae) includes several common wild flowers. We have already seen (see p. 193) that a great number of
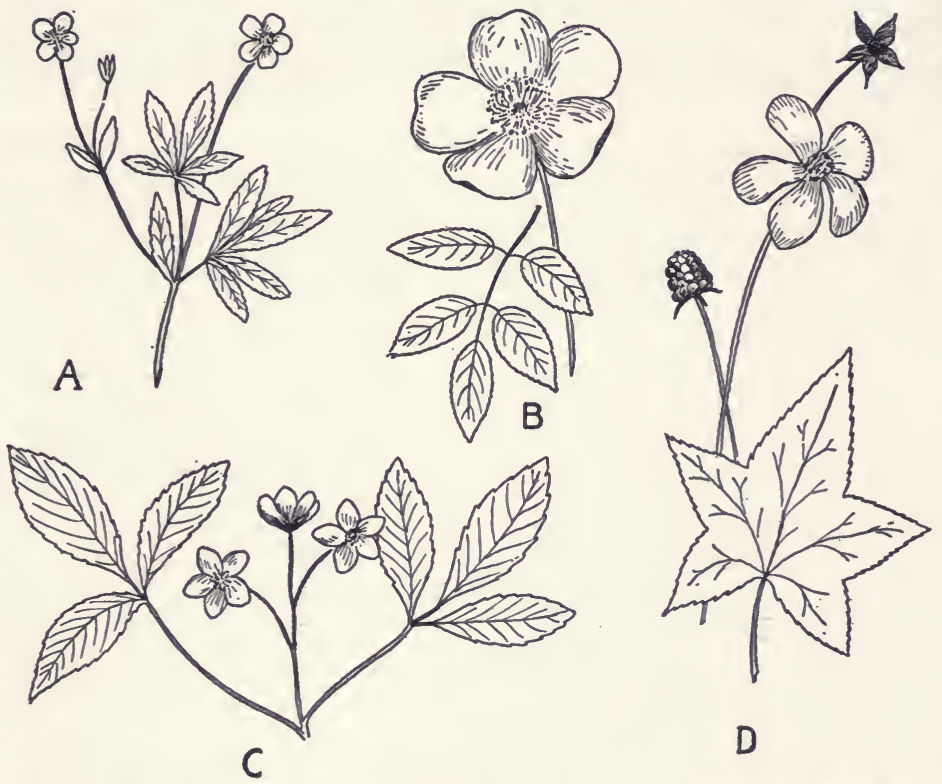

Fig. 269.-The Rose Family includes five finger (A), wild rose (B), wild strawberry (C), and thimbleberry (D).

our orchard fruits belong to this family. The flower of a typical member of the Rose Family is made up of five sepals and five petals attached to the rim of a cup-shaped receptacle (fig. 269). FiveFINGER or CINQUEFOIL is a genus of temperate and subarctic 
regions; of our forty native species the majority are found in the West. Their name comes from the fact that each compound leaf is made up of five leaflets spreading out like the fingers of a hand. The flowers are usually yellow. Meadowsweet and STEePlebush are two common shrubby species found in fields of our eastern states, and to a lesser extent in the West. The rose-pink or white flower clusters of meadowsweet are spreading; while steeplebush has more compact spikes of rose-purple flowers. DEwDROP or FALSE VIOLET is one of the few members of the Rose Family with simple leaves, which in this case are broadly heart-shaped. It is a white flowered creeping plant of our northeastern woods. Likewise characterized by simple leaves is the THIMBLEBERRY, a shrubby wild flower of the eastern and central states with conspicuous white, pink or purple flowers. Roses are shrubby or vine-like plants of open sunny places, particularly abundant in the prairie states although there are numerous eastern and far western members of the genus. The common prairie rose has thorny stems, pink or white flowers and compound leaves with three to five leaflets. WILD STRAWBERRY is a low growing member of the family with white flowers, found from coast to coast in sunny habitats.

\section{The Cactus Family}

The most fantastic of our native plants are found in the Cactus Family (Cactaceae). These leafless plants have adapted themselves to the arid wastes of western United States, being found from California to Texas, and northward and eastward in diminishing numbers. The cacti native to the United States number somewhat over two hundred species most of which occur in Arizona, California and New Mexico.

The PRICKLY PEAR CACTI- the most widely distributed members of the family-are characterized by jointed stems divided into green flattened sections or "pads" and protected by rosettes of spines which are an efficient defense against herbivorous animals (fig. 270). The flowers, large and unusually beautiful, consist of eight or more petals which vary in color from red and purple to yellow. The GANE CACTUS and the GHOLLA are close relatives of 

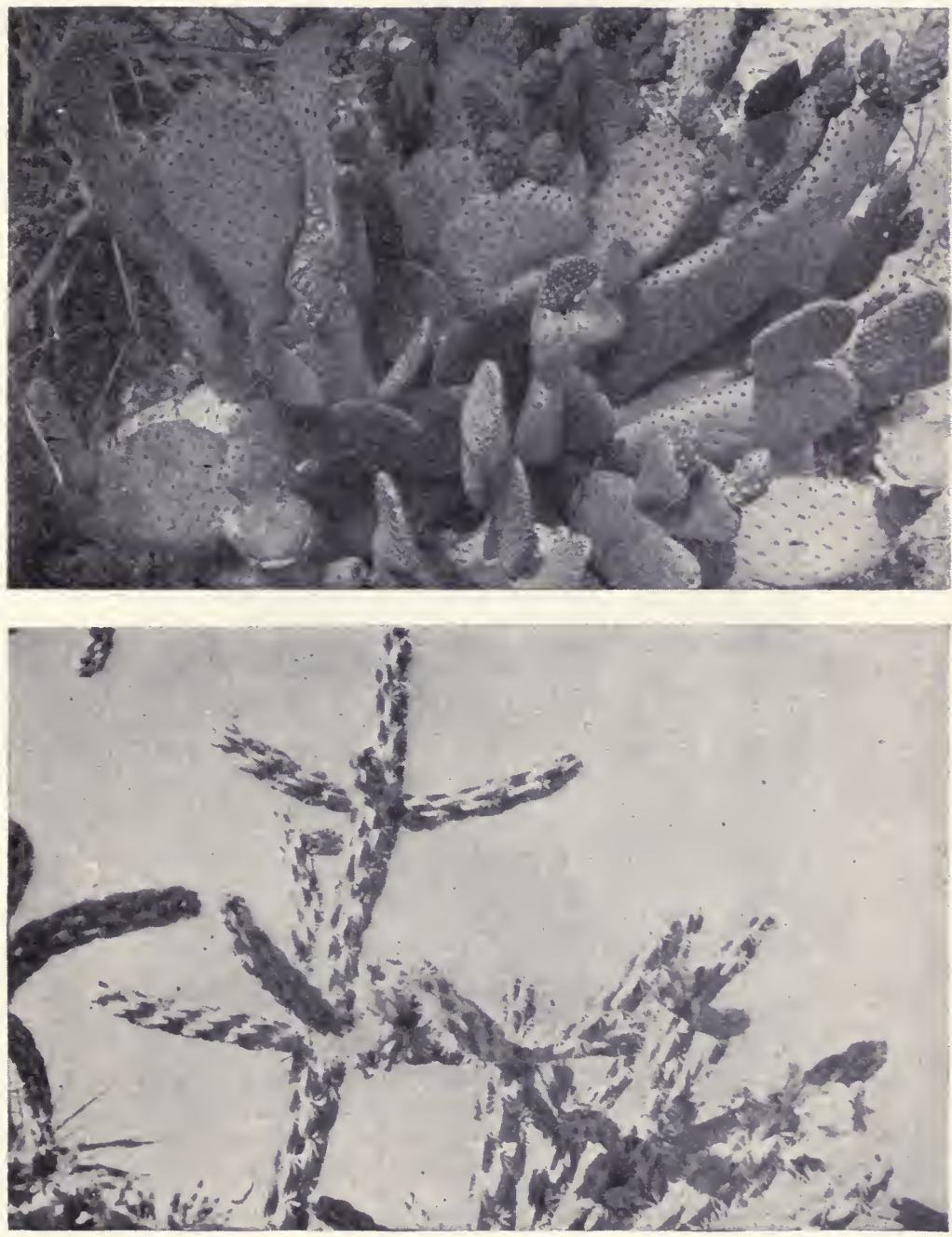

FIG. 270.-The prickly pear cacti (above) and cane cacti (below) have jointed, swollen or flattened, stems which are green and take the place of leaves. 
the prickly pears differing from them by having cylindrical rather than flattened stems.

The smallest of the cacti are the globular PINCUSHION CACTI which rarely grow more than a few inches in height; each individual is marked by rows of spirally arranged tubercles, bearing

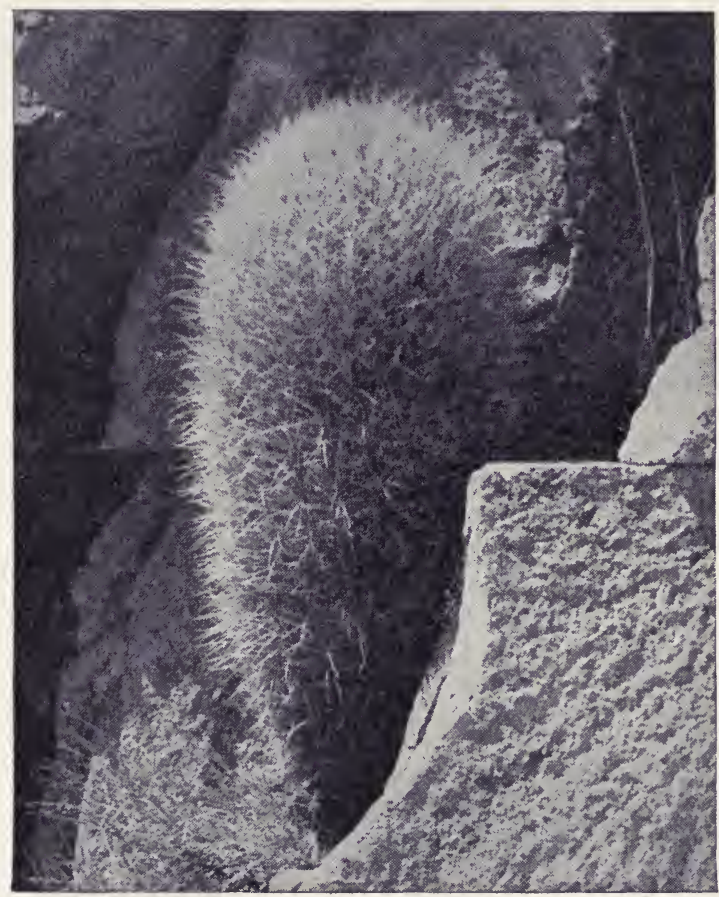

FIG. 271. - The barrel cactus of California often grows to a height of six feet, and to a diameter of a foot or more.

spines. The flowers are white, cream, purple or rose; various species are known as fish-hook cacti or devil's pincushions.

The HEDGEHOG GACTI are larger plants with ribbed cylindrical stems, armed with clusters of long spines; the purple or red flowers often attain an inch or more in diameter. Related species include the delicately spined lace cactus common in Texas. Larger than the hedgehog cacti are the BARREL GACTI of the California and Nevada deserts; species may reach a height of 
eight feet and a diameter of one foot (fig. 271). Each plant is marked with twenty or more longitudinal ribs, armed with stout reddish or yellowish spines which completely protect the surface of the plant; the flowers are usually yellow, with purplish sepals.

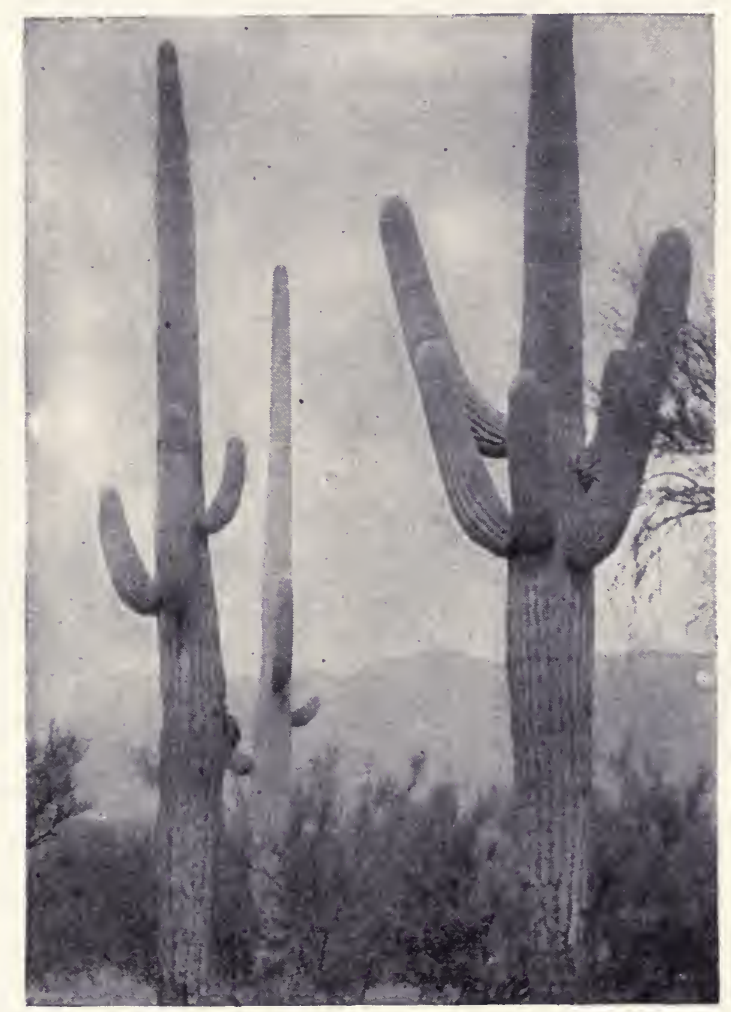

Fig. 272.-The sahuaro cactus of southern Arizona, which grows to tree size, is our most spectacular native plant.

Most spectacular of our native cacti are the TORCH CACTI or CEREUS GAGTI, columnar and fluted plants which grow to a height of thirty or forty feet. The largest species is the giant SAHUARO (fig. 272) whose massive succulent stem is divided into longitudinal ridges separated by deep furrows. Waxy white flowers, made up of numerous petals and thousands of stamens, are produced at the tops of the trunks; each funnel-shaped flower 
is about four inches in length and blooms for a single night. These tree cacti are abundant in southern Arizona where an extensive forest of them is preserved in the Sahuaro National Monument.

\section{The Mallow Family}

Unlike many of the preceding families, the Mallow Family (Malvaceae) is predominately a warm temperate and tropical group. Members of the family usually have lobed leaves and large showy flowers with five partly-fused sepals and five large petals

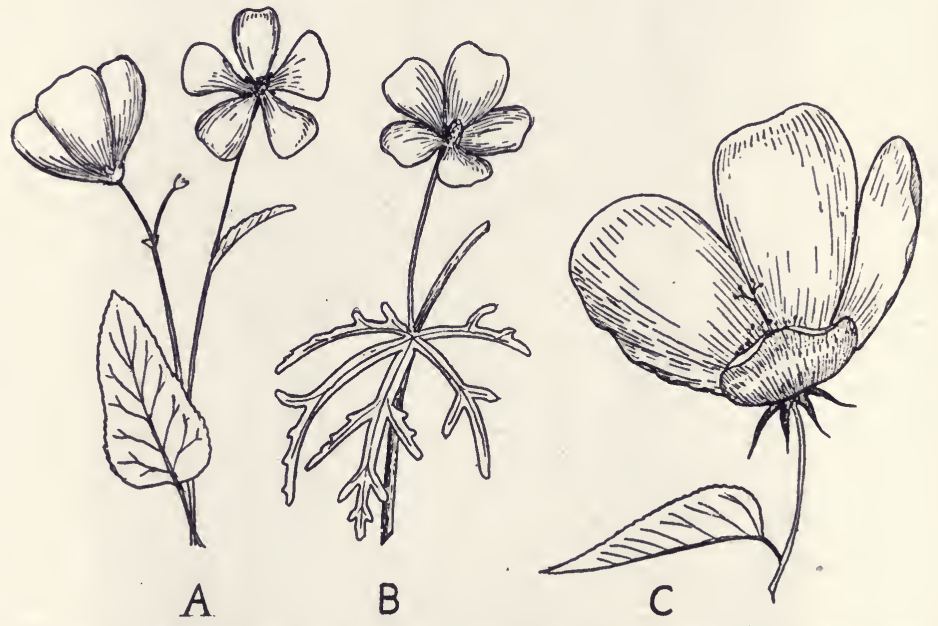

Fig. 273.-In the Mallow Family are found poppy mallows (A), musk mallows (B) and rose mallows $(\mathrm{C})$.

(fig. 273). The DWARF MALlow, with trailing stems and pale lavender flowers, is found throughout eastern and western United States. Also found throughout the country is the muskmallow with its deeply lobed leaves and rose or white flowers. Numerous species of FALSE MALLOWS with yellow or orange flowers occur in the Gulf region. The POPPY MALlows, with deep purple flowers, grow in our southeastern woodlands as well as in the prairies. The GLOBE MALLOWS or WILD HOLLYHOCKS, with pink or red flowers, are found in our midwestern and Pacific coast states. The most striking flowers of the family are in the ROSE MALLOws 
which are closely related to the cultivated Hibiscus and rose of Sharon. These plants, found in swamps of our eastern and southern states, produce rose-pink or white flowers which often reach a diameter of seven inches. In the far West is the California rose mallow, also with pink or white flowers.

\section{The Evening Primrose Family}

The Evening Primrose Family (Onagraceae) is characterized by flowers in which the four sepals are often fused at the base to form a tubular calyx beneath the corolla of four petals (fig. 274).

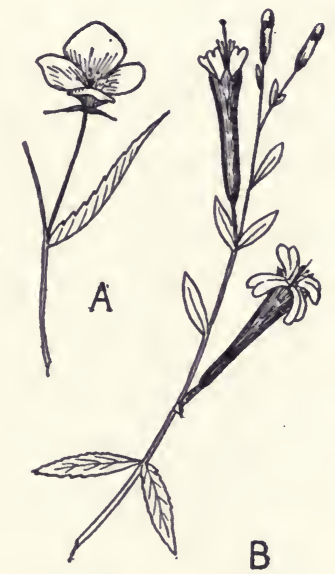

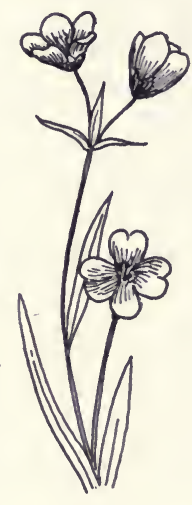

C

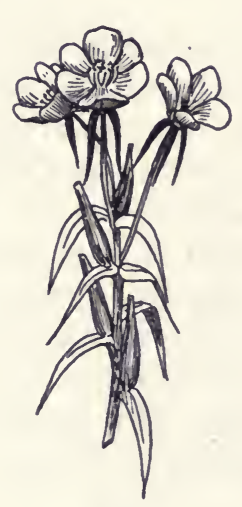

D

FIG. 274. - The Evening Primrose Family includes farewell-to-spring (A), California fuchsia (B), sundrops (C) and evening primrose (D)

The EVEning PRIMrose is a stout plant of eastern United States with terminal clusters of bright yellow flowers. In the prairie region grows a WHITE-FLOWERED PRIMROSE, and in the far West are several dozen additional species most of which have yellow flowers. The DESERT PRIMROSE is one of the daintiest blooms of the arid Southwest, producing large pure white flowers. Sundrops are shrubby plants with clusters of large yellow flowers, common to sunny habitats in our eastern states. FirEweEd or willowHERB, which ranges throughout the entire United States, is a rank growing plant with conspicuous spikes of purple or lavender flowers. The PRIMrose wILlOws, with willow-like leaves and 
axillary yellow flowers, are common in wet locations throughout the central states.

There are numerous species of the family which are peculiar to the West. FAREwELL-TO-SPRING, found on hillsides of the Pacific coast, has lavender, purple or white flowers, each with four petals in the form of a shallow cup. RED RIBBONS, found from California to Washington, has flowers characterized by recurved sepals and four narrow rose-purple petals. CALIFornia FUCHSIA, a species partial to dry slopes, has flowers with a scarlet funnelshaped calyx and four small petals.

\section{The Heath Family}

In the preceding families of Dicots, the flowers typically consist of separate sepals and petals, a condition considered primitive among Angiosperms. As a result of progressive specialization for insect pollination, there has occurred a fusion of sepals or petals (or both) to form a tubular calyx or corolla. This sympetalous condition is characteristic of the remaining families of Dicots, from the Heath Family to the Composites. The Heath Family (Ericaceae) includes many plants frequenting the northeastern boggy woodlands (fig. 275). Checkerberry, trailing arbutus and bearberry are herbaceous plants of the family; while azalea, rhododendron, laurel and manzanita are shrubby members of the group.

Checkerberry or teAberRy (cf. fig. 175) grows in evergreen woods of our northeastern states; the leaves are dark green and shiny, the urn-shaped flowers of white or pink are borne in the axils of the leaves. Trailing ARbUtus or MAyflower is a creeping plant with oval evergreen leaves and clusters of fragrant pink flowers each with a broad five-lobed corolla; it grows in woods throughout eastern United States. BEARBERRY is likewise a trailing evergreen plant with narrow leaves and white flowers in terminal clusters. Western species of the same genus, known as MANZANITA, become shrubs with smooth red bark, gray-green foliage and white or pink urn-shaped flowers.

Azaleas are shrubs with deciduous leaves and fragrant pink or white flowers, each with a funnel-shaped corolla of partly united petals and projecting stamens. They are especially 
abundant in the southeastern states. The RHODODENDRON genus consists of shrubs or trees which grow to a greater size and have evergreen leaves; in addition the flowers have a shorter tubular corolla. The species known as ROSE-BAY, abundant throughout the Allegheny Mountains, is one of our most magnificent native shrubs, with large showy clusters of pink or white flowers. The

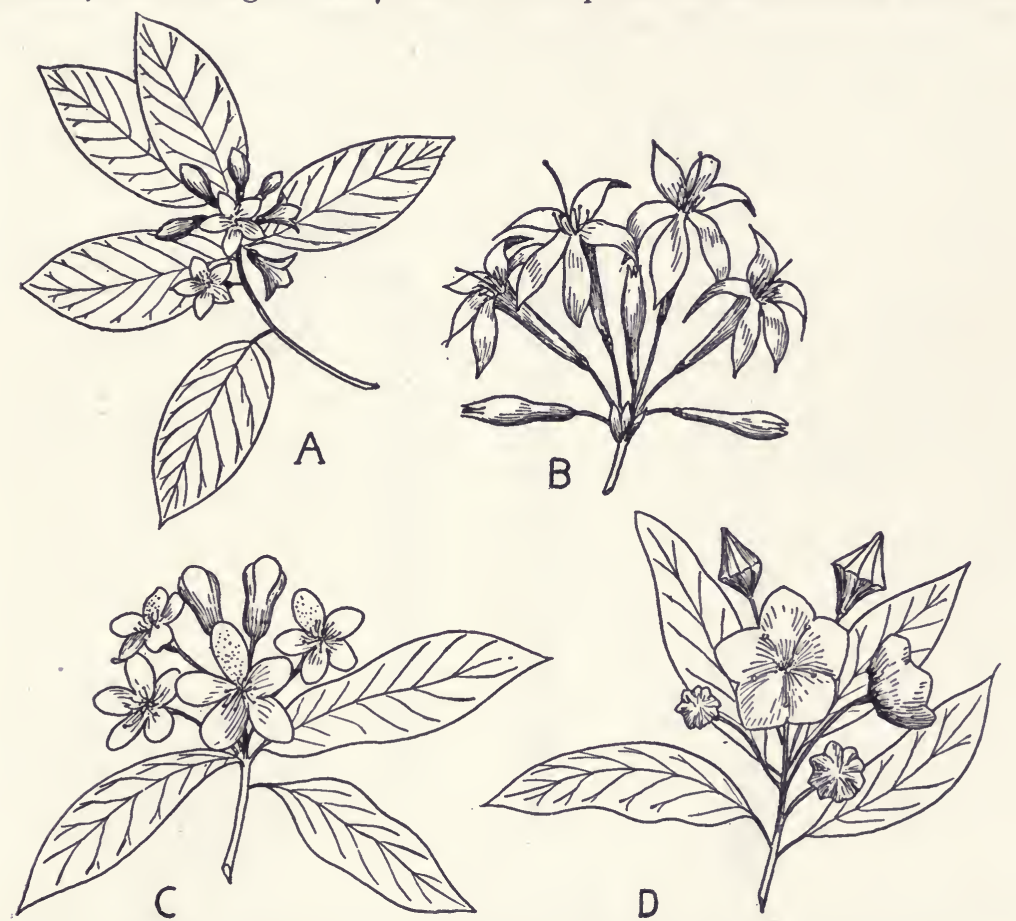

Fig. 275.-The Heath Family includes trailing arbutus (A), azalea (B), rhododendron (C), laurel (D).

California rose-bay with purplish flowers is found in the redwood forests of the Pacific coast. The laurels, also evergreen shrubs, produce flowers with a wheel-shaped and five-lobed corolla. Mountain LAUREL often forms dense thickets in the woods from New England to Louisiana; its flowers are white or pink in color. Sheep LAUREL is a smaller plant with rose-pink flowers; it grows in pastures and swamplands of our eastern coast states. 


\section{Indian Pipe Family}

The Indian Pipe Family (Monotropaceae) is made up of unusual plants which have lost their chlorophyll and are therefore either saprophytes or parasites; it is related to the Wintergreen and Heath Families (fig. 276). INDIAN PIPES are frequently mistaken for fungi because the whole plant is white in color; they bear white leaf scales and solitary terminal flowers with six white or
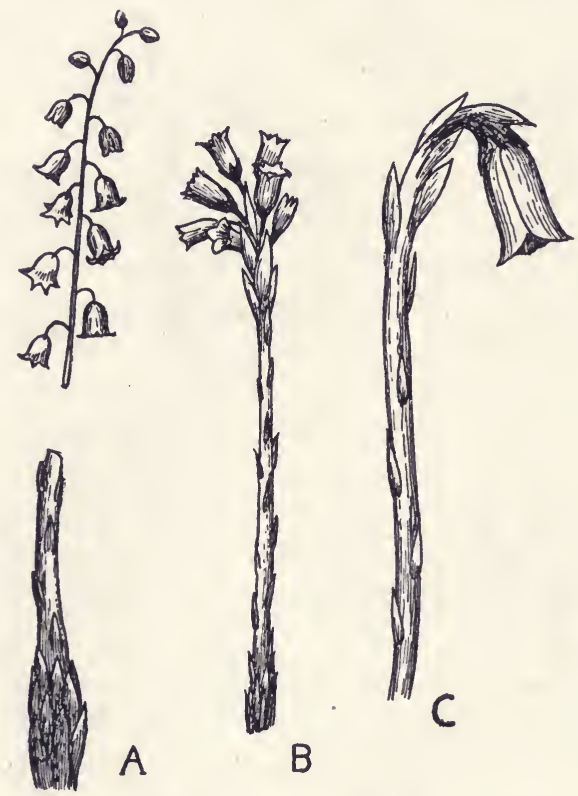

B

FIG. 276.-In the Indian Pipe Family are such chlorophyll-deficient plants as pinesap (A), pinedrops (B) and Indian pipes (C).

pink petals. Like other members of the family Indian pipes are found in damp shaded woods. Pinesap is a yellowish brown or pink plant with a nodding one-sided cluster of red or yellow flowers; pinesap is found in the Atlantic coastal region. PineDROPS is a stouter and clammy plant with brownish stems and nodding white flowers; this member of the family is common along the Pacific coast where it lives as a parasite upon pine roots. Likewise western in its distribution is the bright red sNOw 
PLANT, a scarlet saprophyte especially abundant in conifer forests of the Sierras; the fleshy stem is almost entirely covered with numerous five-lobed flowers in a thick head. Similar appearing heterotrophic plants occur in the Broom-rape Family (Orobanchaceae), which includes broom-rape, squawroot and beechdrops.

\section{The Mint Family}

In the Mint Family (Labiatae), we find a great number of aromatic and square-stemmed plants with opposite or whorled

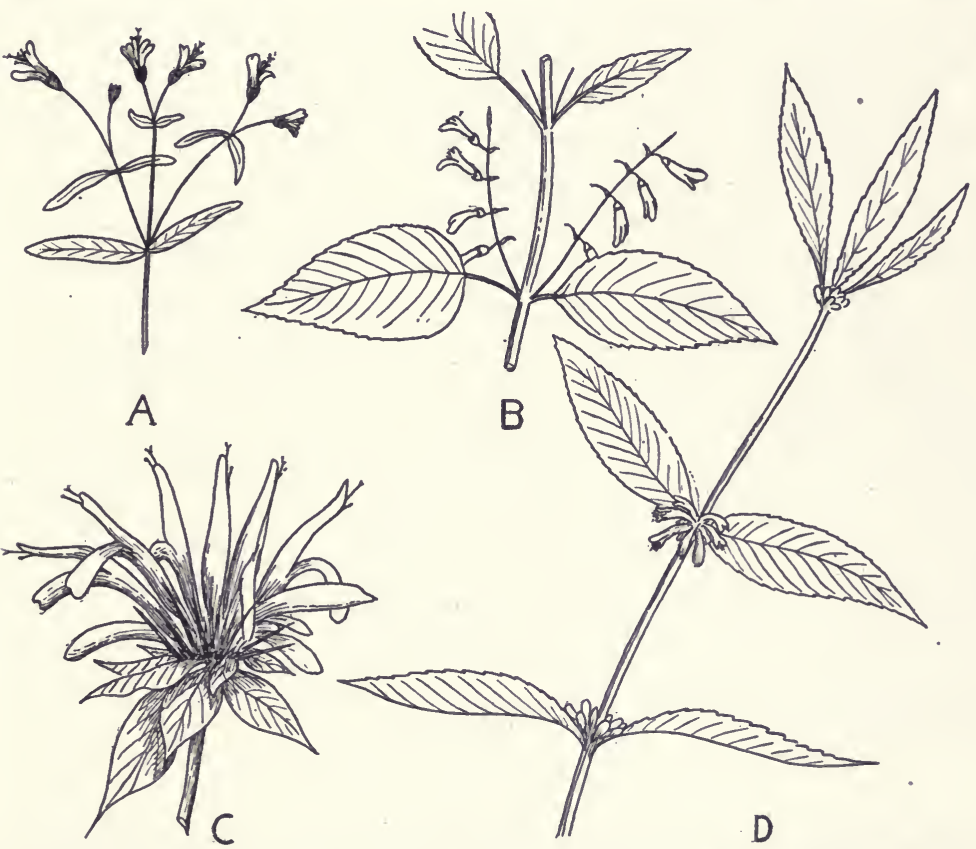

Fig. 277.- The Mint Family includes blue curls (A), skull cap (B), wild mint (D) and bee balm (C).

leaves; the flowers are characteristically two-lipped, with the upper lip divided into two lobes and the lower into three (fig. 277).

HAIRY GERMANDER, thriving in moist woods from New England to the Mississippi valley, produces terminal clusters of 
purplish flowers. A western species, found from Texas to California, has pale blue flowers clustered in the axils of the leaves. BLUE GURLS is a more slender plant with bell-shaped flowers whose upper lobes are longer than the lower ones; it grows in sandy fields from New England to Texas. A related blue-flowered species known as VINEGAR WEED is found in dry fields from California to Washington. SkullaAP is a rather large genus of plants partial to marshy habitats; the common blue skullcap has coarsely toothed leaves and small blue flowers clustered in the axils of the leaves, while hooded skullcap has larger blue flowers which are solitary in the axils of the upper leaves. Western species found on the Pacific coast are yellow or white in color as well as blue.

The s.trongly aromatic sages produce whorls of flowers surrounded by leafy bracts - each flower with an erect upper lip and a three-lobed lower one. The THISTLE SAGE common to dry western fields has lavender flowers grouped into terminal heads-the middle lobe of each lower lip is delicately fringed and each flower is surrounded by spine-like bracts. Other western species have crimson, blue or purple flowers. OsWEGO TEA or BEE BALM is an eastern plant of open woods and roadsides with heads of scarlet flowers above reddish bracts. Related species of central and eastern United States include WILD BERGAMOT, with yellow or lilac colored flowers, PURPLE BERGAMOT with purplish red flowers; and HORSEMINT with yellow flowers, spotted with purple. The mint genus includes many species with aromatic and fragrant foliage; the common WILD MINT, found in moist habitats from New England to Nebraska, has whorls of small lavender or white flowers in the axils of the leaves.

\section{The Figwort Family}

The Figwort Family (Scrophulariaceae) is characterized by flowers with four or five sepals - which may or may not be united - and corolla of five united petals with a lobed or hooded upper lip and a three-lobed lower one (fig. 278).

Monkey flower is a genus found from New England to California. A common eastern species of wet habitats has opposite leaves and blue flowers; the western monkey flower displays a corolla of bright yellow spotted with red. TurtLeneAd is a 
swamp dwelling plant of eastern United States; its white flowers strikingly resemble a turtlebeak in profile. BEARDTONGUE is a genus of attractive flowers, more frequently met with west of the Rocky Mountains than in the East; from the tubular corolla of each nodding flower projects a bearded stamen simulating the tongue which gives to the plant its common name. Eastern and midwestern species are usually blue or purple in color. A Californian species known as SGARLET BUGLER bears bright red flowers. INNOCENCE, flowering in moist woods of the central
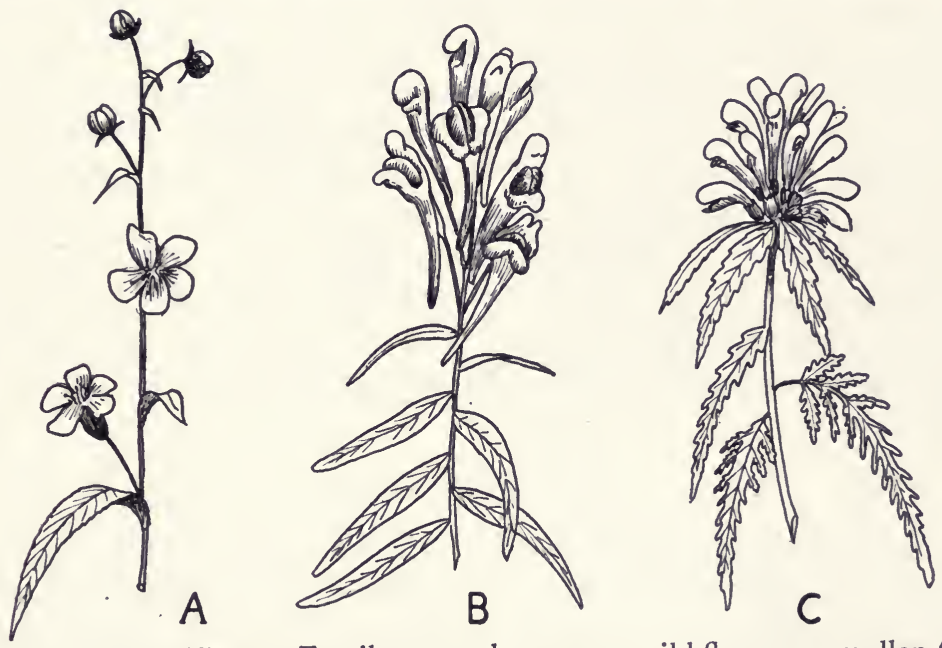

FIG. 278. - In the Figwort Family are such common wild flowers as mullen (A), butter and eggs $(B)$ and wood betony $(\mathrm{C})$.

states, has two-lipped white, pink or blue corollas; the middle of the lower lip forms a sac which encloses the stamens. A western species known as CHINESE HOUSEs has whorls of flowers with a white or lavender upper lip and a violet lower one. SPEedwell or AMERICAN BROOKLIME inhabits wet locations from coast to coast; its blue or white flowers, often striped with purple, grow in clusters in the axils of the leaves. The FALSE Foxgloves, common to eastern United States, have deeply toothed or fern-like leaves and yellow funnel-shaped flowers in axillary clusters.

Among the brightly colored wild flowers of early summer few are more conspicuous than INDIAN PAINTBRUSH Or PAINTED CUP, 
of which the greater number of species occur in the central and western states. Small leaves immediately beneath the flowers are tipped with red or yellow. The eastern painted cup, a plant of moist meadows, has yellowish green flowers, while the western species has showy red flowers. OwL's clover is a Pacific coast species in which the upper leaves, like those of Indian paintbrush, are colored; each flower is yellow or purple, with purple spots on the inflated lower lip. WoOD BETONY is an eastern species with basal clusters of pinnately lobed fern-like leaves; the small yellowish brown flowers are grouped in compact heads, each corolla having an arched upper lip and a three-lobed lower one.

Two very common members of the figwort family are Eurasian species which have become firmly established along roadsides and in waste places. Mullein is a tall plant with basal woolly leaves and tall flowering stalks bearing clusters of white or creamcolored flowers. ButTER-AND-EGGS, also known as TOADFLAX, produces its flowers in smaller elongated clusters; the upper lip of the corolla is yellow and erect, and the lower lip, also yellow, possesses an orange colored fold which closes the throat of the flower.

\section{The Thistle Family}

It has already been pointed out that the culmination of evolution among Dicot flowers is the small sympetalous flower, aggregates of which form a compact head; this condition is typical of the families commonly known as Composites. In the flower of a typical Composite the calyx is an inconspicuous scaly or bristly portion of the flower. The tubular corolla is of two kinds; one type with no projections from its margin, is known as a disc flower, and since it produces stamens and pistils, is usually fertile. Another type, known as a ray flower, is characterized by a flattened or strap-shaped projection of the corolla rim, which resembles the petal of a simple flower. In many Composites (see fig. 44) the ray flowers are arranged around the outer edge of the flower head, and function only for attracting insects, since they lack stamens or pistils. The Composites are the most successful of all Dicot families from the viewpoint of their reproductive adaptations; the number of species in this group has been 
variously estimated at from fifteen to twenty thousand. The Thistle Family (Carduaceae) is the largest family in the group, with some ten thousand widely distributed species.

For convenience, members of this family may be separated into two groups depending upon the types of flowers found in the head. Disc flowers only are found among the ironweed, boneset, pearly everlasting, burdock, thistle and basket flower genera (fig. 279). Ray and disc flowers both occur in the asters, goldenrods, sunflowers, black-eyed Susan, desert gold, firewheel, yarrow, white daisy and sagebrush (fig. 280).

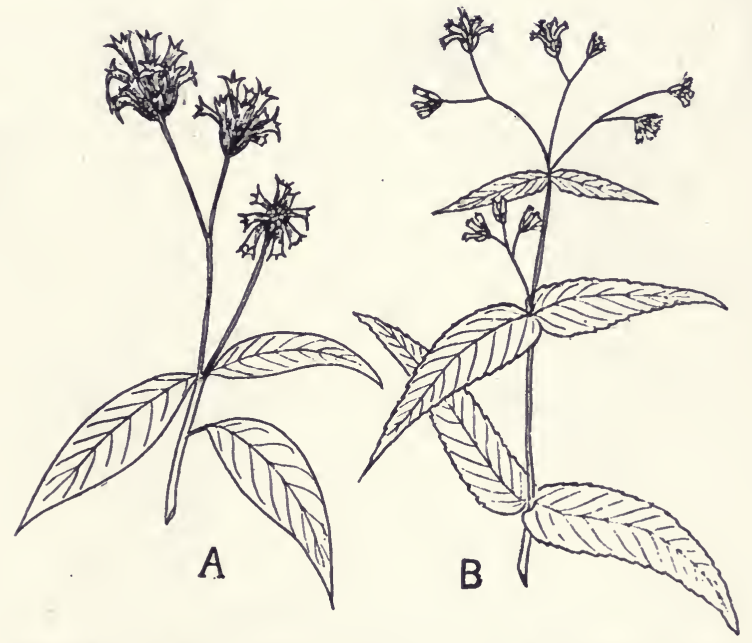

FIG. 279.-Members of the Thistle Family with disc flowers only in the flower head include ironweed (A) and boneset (B).

IRONWEED, of the eastern and southern states, is a tall plant with narrow leaves and heads made up of thirty or more small purple flowers. BONESET is also a stout stemmed plant, inhabiting wet meadows of eastern United States; each flower head consists of a dozen or more grayish white flowers. JOE-PYE WEED, a related species with purplish flowers, grows in moist places from New England to Texas. Pearly everlasting is a familiar silvery white flower found in sunny fields throughout the United States; the central mass of white tubular flowers is surrounded by many pearly white bracts. Pussy toes is a somewhat similar genus with 
whitish flowers. BuRDOCK is a European immigrant which has adapted itself as a roadside weed; the bushy plants have large heart-shaped leaves and small purple disc flowers grouped in a spherical head and provided with sharply barbed bracts. The common THISTLE is well known for its spiny foliage and flower heads; most of our species are introduced European plants. The small flowers vary in color from white to purple. BASKET FLOWER, found from the Mississippi valley to Kansas and Arizona, is closely related to the cultivated bachelor's button;
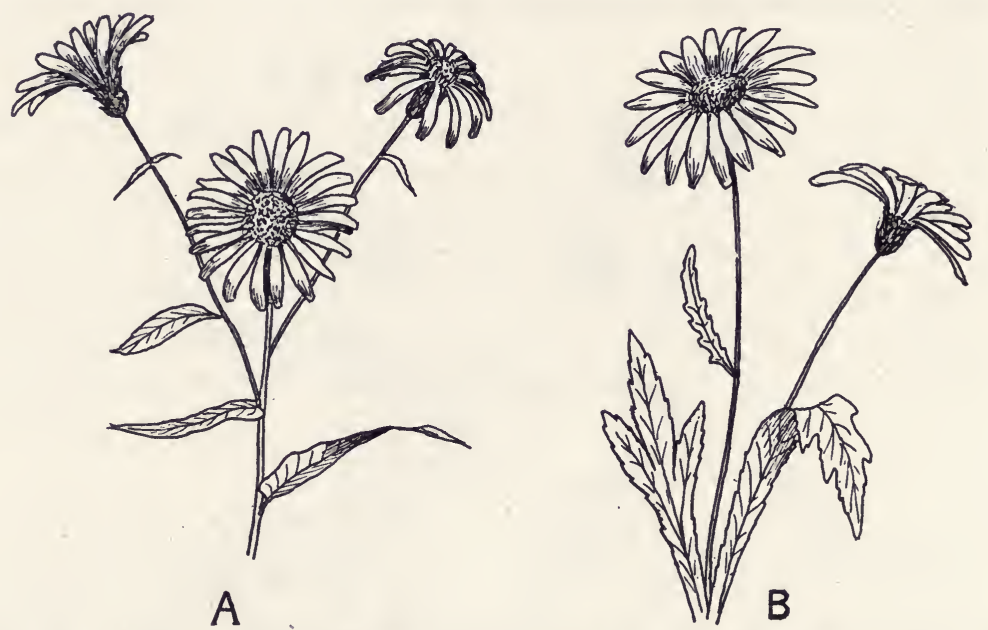

FIG. 280 -Members of the Thistle Family with both ray and disc flowers in the flower head include asters (A) and daisies (B).

the spherical flower head lacks spiny bracts and is made up of rose colored flowers with fringed lobes.

Asters are the most numerous and colorful of our autumn wild flowers. Some fifty species are found in the northeastern, and over a hundred in the southern, states; the number of species decreases as one goes westward. Asters have heads made up of an outer series of blue, pink or white ray flowers, and a central mass of golden yellow fertile disc flowers. One of the most beautiful eastern species is the New England aster found in rich fields from New England to Kansas, whose flower heads often reach a diameter of an inch or more, each fringed with forty to fifty 
purple ray flowers. The calico aster and the mountain aster are two eastern species with white ray flowers. The lavender desert aster is a delicate species which has made itself at home on the southwestern deserts.

GoldENRODS together with the asters create the royal purple and gold which characterize the eastern fields in autumn. This widespread genus, which includes almost a hundred American species, is especially abundant in the eastern states. The entirely yellow flower heads are smaller than those of the asters, and are frequently borne in plume-like clusters. The most showy member of the genus is the Canada goldenrod of our eastern and central states. An exception to the typical yellow color is found in the SILVERROD which develops flower heads with white ray flowers and whitish bracts; this species grows in dry soil from New England to Georgia and Minnesota.

Sunflowers (fig. 281) are coarse-stemmed and tall plants with showy flower heads made up of conspicuous yellow ray flowers and purplish brown disc flowers. Of some hundred American species, almost half occur in the southern and eastern states. The common sunflower, which under cultivation reaches a height of ten feet or more and develops a flower head a foot in diameter, belongs to the central states. The eastern woodland sunflower is a more slender plant of moderate height with smaller flower heads. BLACK-EYED SUSAN or CONEFLOWER grows in the prairies but has spread also throughout the eastern states; the rough hairy stems bear flower heads made up of orange colored ray flowers and a central cone of purplish brown disc flowers. DESERT GOLD, a low growing and gregarious western member of the family, displays heads of bright yellow ray and disc flowers; the abundance of these small Composites colors acres of sandy fields from the Mexican border to Oregon. Firewheel or GailLARDIA, inhabits our central states; its solitary heads are made up of showy yellow and red ray flowers surrounding a mass of purple disc flowers.

Yarrow and the common white daisy are two European plants which have become naturalized throughout the United States. YARROw has fern-like leaves and flat topped clusters of small flower heads, each made up of a few white ray flowers and pale 

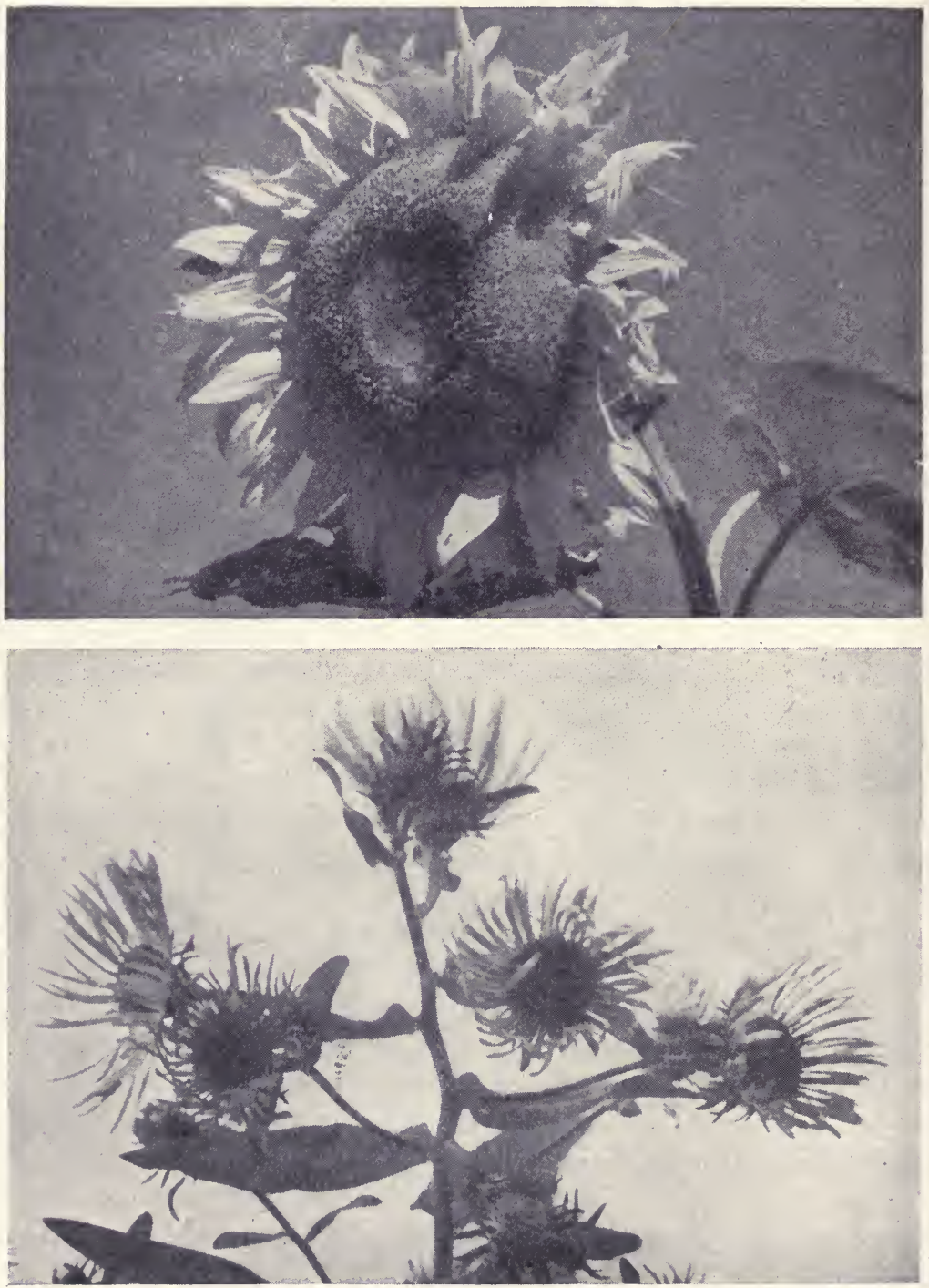

FIG. 281.-Composites have showy heads of many small flowers. Sunflower (above) has conspicuous yellow ray flowers, smaller purplish disk flowers. Aster (below) has smaller heads, similarly made up of ray and disc flowers. 
yellow disc flowers. The common wHITE DAISY is, like the yarrow, a familiar summer flower of fields and roadsides; each flower

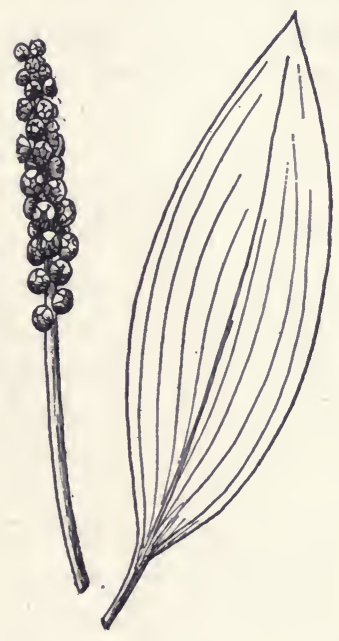

A

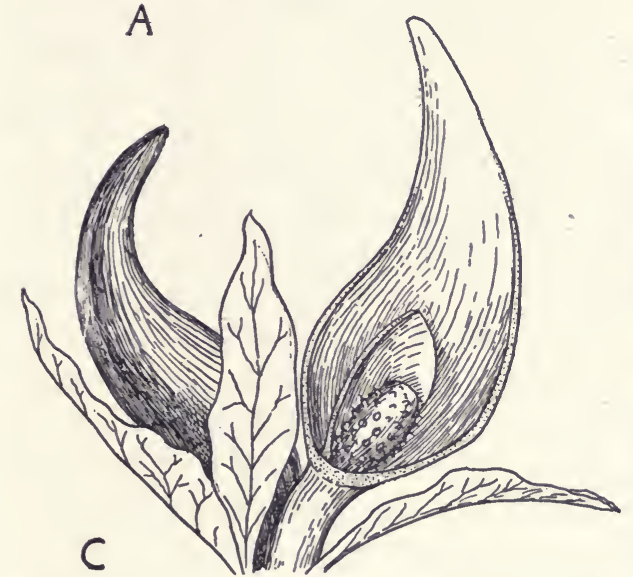

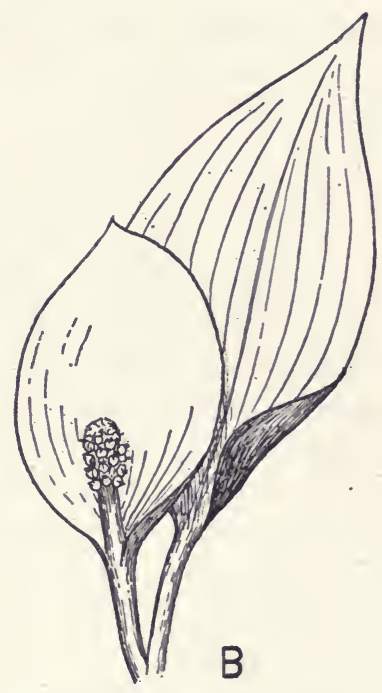

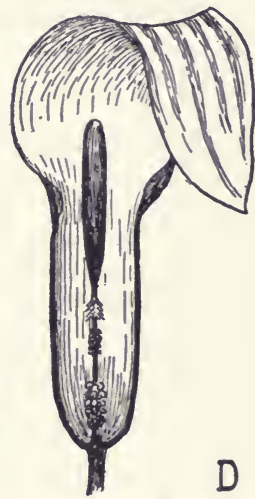

Fig. 282.- In the Arum Family we find such early spring flowers as skunk cabbage (C) and Jack in the pulpit (D); as well as the less common sweet flag (A) and water arum (B).

head consists of white ray flowers and a central mass of disc flowers. 
On the western plains we find an aromatic shrub of the thistle family-sagebrush. SAGEBRUSH, which includes a great number of species common to the central and western states, has foliage of a gray-green color. The sagebrush flowers are grouped in small yellow or purple heads. This is one of the few. wind-pollinated genera of the family.

\section{The Arum Family}

The Arum Family (Araceae) includes plants which show a marked preferance for wet and swampy habitats; typical of this Monocot family are the numerous small flowers without sepals or petals, clustered on a fleshy axis which is often surrounded by a large and showy spathe (fig. 282). One of the most familiar members of the family is the earliest of the spring pioneers - the SKUNK CABBAGE whose purplish green spathes form conical hoods over the floral axis. After the appearance of the flowers, the coarse large leaves appear. Skunk cabbage is common throughout eastern swamplands. JAGK-IN-THE-PULPIT, also known as INDIAN TURNIP because of its starchy and tuberous root stock, produces several compound leaves and an erect purple or dark green spathe which surrounds and arches over the "jack" - the fleshy axis bearing the small flowers. Jack-in-the-pulpit also grows in moist woods throughout eastern United States. SwEET FLAG is a semi-aquatic plant found from New England to Texas; it has long tapering leaves, some of which function as an open spathe and surround the axis with its small yellowish flowers. GoLDEN CLUB, likewise partial to wet habitats over the same area, has long narrow leaves and a leaf-like spathe beneath the compact mass of golden flowers which suggests the common name. WATER ARUM Or WILD CALLA is found in cold swamps and along lake margins in our northeastern states; the leaves are large and heart-shaped, and a white spathe forms a conspicuous portion of the inflorescence.

\section{The Lily Family}

Some of the most attractive flowers found in the Monocot group are included in the Lily Family (Liliaceae). Many of the 
species produce underground stems known as bulbs, and the majority have narrow tapering leaves with parallel venation. The perianth of the flower consists of three sepals and three petals which look alike and thus form a six-parted perianth.
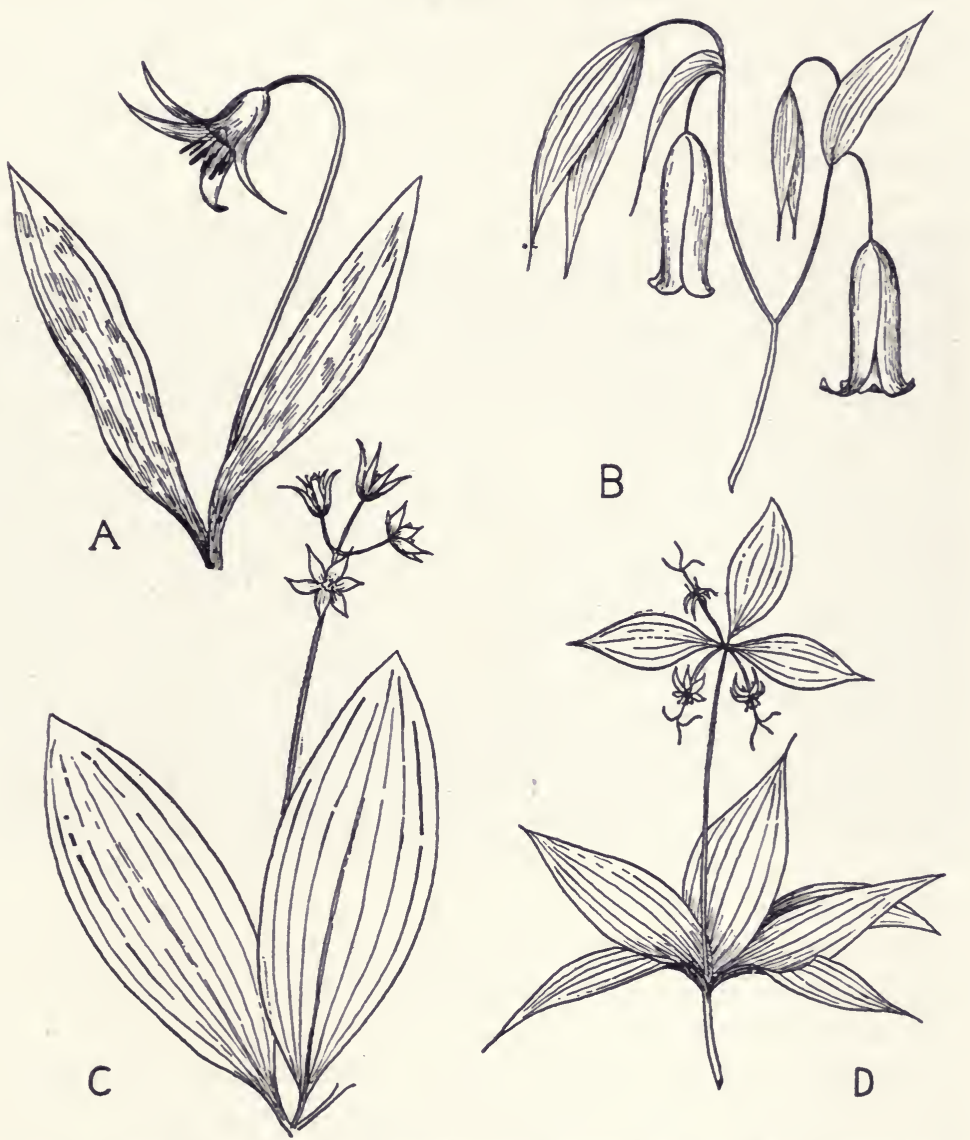

FIG. 283. - The Lily Family includes dog's tooth violet (A), bellwort (B), dogberry (C) and Indian cucumber root (D).

Mountain ASPHODEL, growing in sandy woods of the Atlantic coast states, has a basal cluster of wiry leaves and an erect flowering stalk terminated by a cluster of small white flowers. On the 
Pacific coast a related species with creamy white flowers is known aS ELK GRASS Or FIRE LILY.

A companion of skunk cabbage in eastern swamplands is INDIAN POKE Or FALSE HELLEBORE, a coarsely growing plant with pleated leaves and large terminal clusters of small yellowish green flowers. WESTERN FALSE HELLEBORE or GORN LILY is a related species growing in wet meadows in our far western states.

BELLWORT, a frail member of the family, bears inconspicuous drooping flowers which are bell-shaped and yellow; it prefers the rich woods of our eastern and plains states (fig. 283). DoG'sTOOTH VIOLET or ADDER's TONGUE is also a familiar eastern flower, often found in company with hepatica. The several basal leaves are marked with brownish spots, and above them nod light yellow flowers with recurved segments. On the Pacific coast there is a related species with yellowish white flowers, known as FAwN LILY.

Solomon's SEAL has pendant greenish bell-shaped flowers, occurring in pairs in the axils of the leaves; it is found on rocky hillsides throughout the eastern and central states (fig. 293). FALSE SOLOMON'S SEAL or FALSE SPIKENARD is a stouter plant with a zigzag stem bearing a terminal bushy cluster of small white flowers; it is found in moist habitats throughout the eastern United States. Two-Leaved Solomon's Seal or Canada mayFLOWER is one of the smallest members of the Lily Family; small white flowers, each made up of four segments, are borne in a terminal cluster on a short zigzag stem. It prefers moist woodlands of our northeastern states. TWISTED STALK is characterized by forking stems which bear greenish white or rose colored bellshaped flowers in the axils of the leaves; several species occur in our northern states.

Dogberry or Clintonia can be identified by its large oval basal leaves, and erect flowering stalk terminated by several drooping flowers each with six narrow segments; the species found in northeastern United States has yellow flowers while one of the southern Appalachians (known as the SPECKLED wOOD LILY) has white flowers spotted with green or purple. INDIAN GUCUMBER ROOT, found in the same region as the dogberry, has two whorls of leaves, the uppermost one immediately beneath 
the several yellowish green flowers with recurved segments and prominent pistils.

The Trilliums (fig. 284) include a great number of species common to rich woodlands of northeastern United States. The plants bear a whorl of three leaves above which appear the flowers, each of which consists of three green or brown sepals and three colored petals. Some species have purplish red petals, others have white petals, and a showy species known as painted trillium has white petals whose bases are streaked with red and purple.

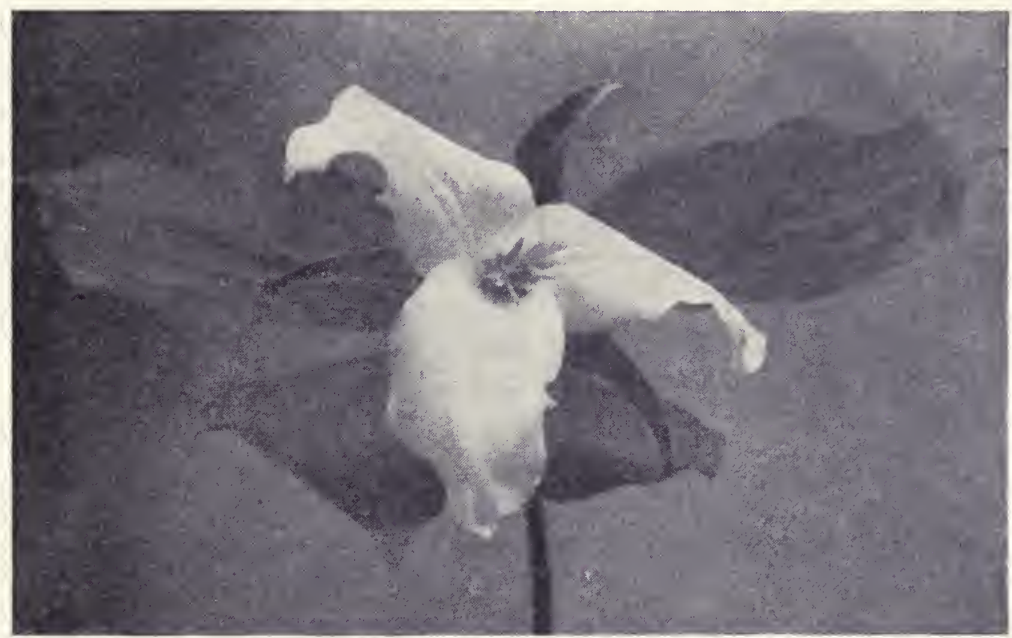

FIG. 284.-Trillium is a small but attractive member of the Lily Family.

The true lilies comprise a great number of showy flowered species found throughout the United States (fig. 285). Eastern lilies include the wOOD LILY with erect orange-red flowers; the southeastern LEOPARD LILY with solitary scarlet flowers; the TURK's GAP LILY with nodding orange flowers made up of recurved segments; and the CANADA LILY with nodding yellow flowers spotted with brown. The numerous western species of true lilies include the WASHINGTON LILY of California and Oregon, with pure white fragrant flowers somewhat like those of the Easter lily; the spotted yellow LEMON LILY, found on the western mountains; the tall HuмвоLт LILY, with nodding orange- 
red flowers, of the southern California mountains; and the REDWOOD LILY, a white flowered species growing in the redwood forests of California.

Many other genera of plants are popularly known as lilies. The western SAND LILY has a basal tuft of grass-like leaves from which grow erect fragrant white flowers; this genus is found in the mountains from Nebraska to Oregon. The GHOcolate LiLy or MISSION BELLS, found on grassy hillsides of California, has nodding brownish purple flowers. The MARIPOSA LILY is a

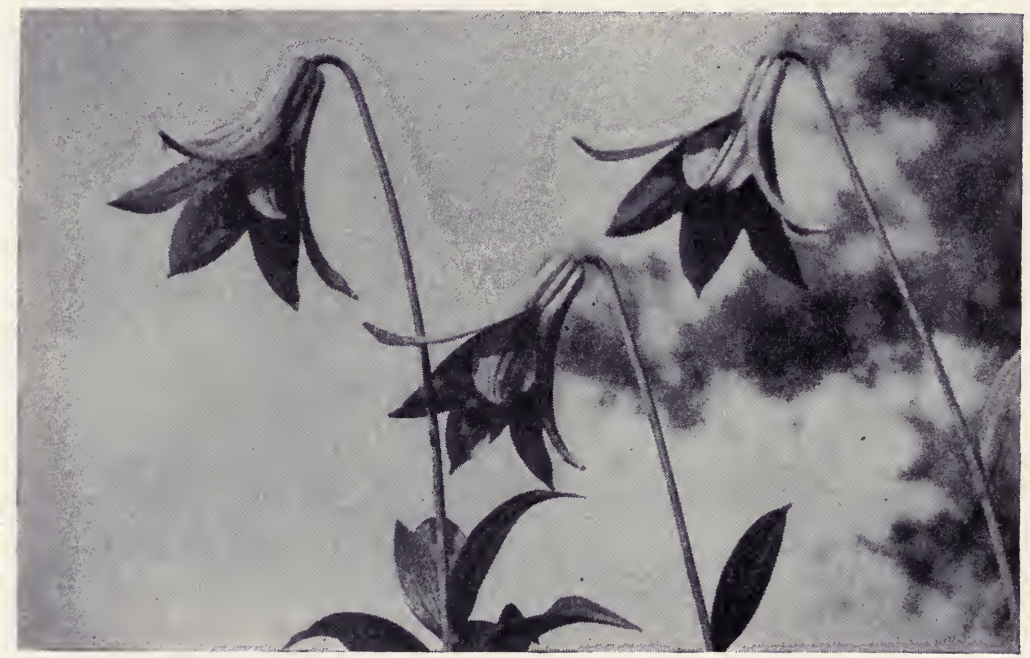

Frg. 285.-The lilies are among our most beautiful wild flowers.

delicately tinted member of the family growing on dry mountain slopes of the western states; each plant has a basal cluster of narrow leaves and slender stems terminated by solitary flowers, each with three green sepals and three white petals marked with rose and yellow at their base.

Some members of the Lily Family are restricted to the midwestern and far western states. SAND GORN is predominantly a plant of the western sage-brush and grassland areas; it has narrow grass-like leaves and clusters of green or white flowers. SOAP PLANT likewise has grass-like leaves; it produces a terminal cluster of white flowers veined with purple; this species occurs 
in California and Oregon. Camas or Wild Hyacinth found from Texas westward has clusters of blue flowers. BrodiaEA is a well known wild flower of the Pacific coast region with narrow basal leaves and tall flowering stalks bearing small clusters of starshaped flowers whose color varies from golden yellow, blue and purple to scarlet.

One of the most unusual genera of the lily family is the predominantly western YUCGA, some species of which become bushy shrubs as well as trees, but all characterized by slender pointed sword-like leaves. BEAR GRASS is a southeastern species with a basal rosette of leaves and a flowering stalk five feet or more in height bearing a huge cluster of white flowers. In the same general area, Spanish Bayonet inhabits sandy soils where it produces its rosettes of sharply pointed leaves and clusters of flowers with a reddish tinge. More typical of the Southwest are the species known as SPANISH DAGGER and DESERT CANDLE (fig. 286) whose flowering stalks -often six and eight feet tall-produce giant clusters of creamy white flowers which are conspicuous features on the dry hillsides of California. The largest member of the genus is the grotesque JOSHUA TREE of the southwestern deserts.

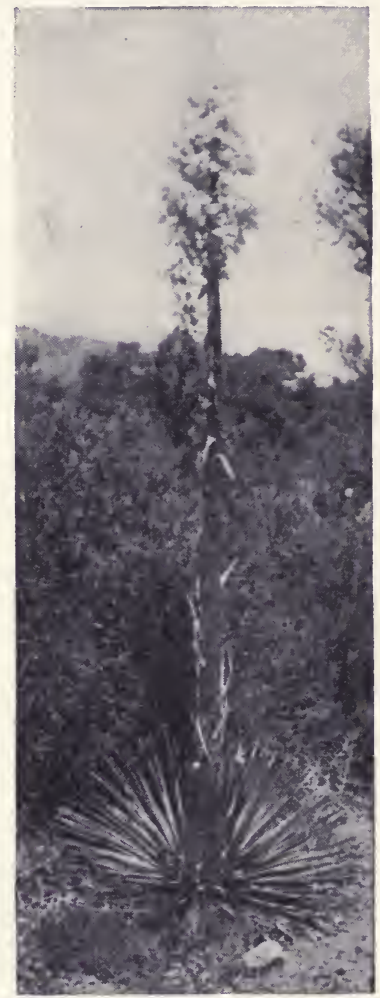

Fig. 286.-Desert candle is a $r u c c a$ species which produces a huge flower cluster.

\section{The Amaryllis Family}

The Amaryllis Family (Amaryllidaceae) is closely related to the Lily Family, being distinguished from it chiefly by having the ovary of the flower attached to the calyx, rather than entirely free. The perianth, consisting of six segments, usually has a partly united and tubular base. 
Yellow STAR GRASS, as the name implies, has grass-like leaves amid which rise slender flowering stalks bearing small yellow flowers; it grows on open hillsides throughout eastern United States. Colrc ROOT is also a small plant; above its basal cluster of leaves rise the yellow bell-shaped flowers; it is found in

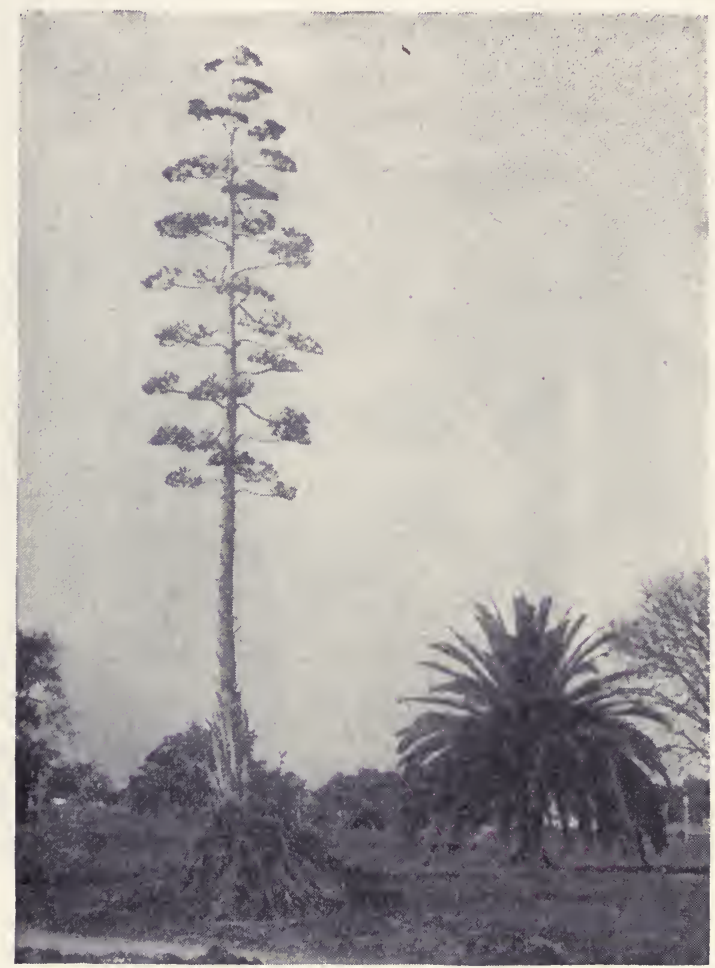

FIG. 287.-Century plant produces a tree-like inflorescence after a decade or more of vegetative growth.

the pinelands of our coastal plains states. Two members of the family are especially typical of our southeastern states. SwAmP LILY has narrow tapering leaves in a basal cluster, and a slender stalk bearing several large white fragrant blossoms. SPIDER LILY has similar leaves and white flowers. Both of these are found in wet and swampy habitats. A companion of the yuccas and cacti 
on our southwestern deserts is the CENTURY PLANT (fig. 287) or FALSE SISAL from whose basal rosette of pointed succulent leaves, thicker than those of a yucca, rises a flowering stalk often ten feet in height, terminated by a cluster of bright yellow flowers.

\section{The Iris Family}

The Iris Family (Iridaceae) is also a close relative of the Lily Family, with flowers similar to those of the Amaryllis family but with three stamens instead of six. BLUE FLAG or WILD IRIS is found in wet places throughout the entire United States; above its long slender leaves arise the clusters of showy flowers with recurved sepals and erect petals. Other species have yellowish brown flowers or yellow flowers marked with lavender. BLuEEYED GRASS is a smaller member of the family, with grass-like leaves and smaller purplish blue flowers with spreading petals and sepals.

\section{The Orchid Family}

The Orchid Family (Orchidaceae) represents the culmination of floral evolution in the Monocots just as the thistle family does for the Dicots. The family consists of some ten thousand species most of which are tropical epiphytes; the temperate species which include most of our native orchids are terrestrial plants of forests and woodlands. The orchid flower (fig. 288) is very complex as a result of specialization for insect pollination; it is characterized by three sepals - often colored, and resembling petals - and three petals, one of which forms a conspicuous lip which assumes a variety of shapes.

LADY'S SLIPPERS can be recognized by the sac-like lip of the flower. The most familiar species, with basal oval leaves, include the MOCGASIN FLOWER of our northeastern woods and bogs; each flower consists of narrow purplish sepals and two narrow brown petals with pink sac-like lip. Other lady's slippers are yellow, white or colorfully striped. The CALIFORnIA LADY's SLIPPER found along the northern Pacific coast has yellowish green flowers with white lips.

In some genera of the Orchid Family the lip is lobed or fringed. The ROUND-LEAVED ORCHIS of our northern states has 


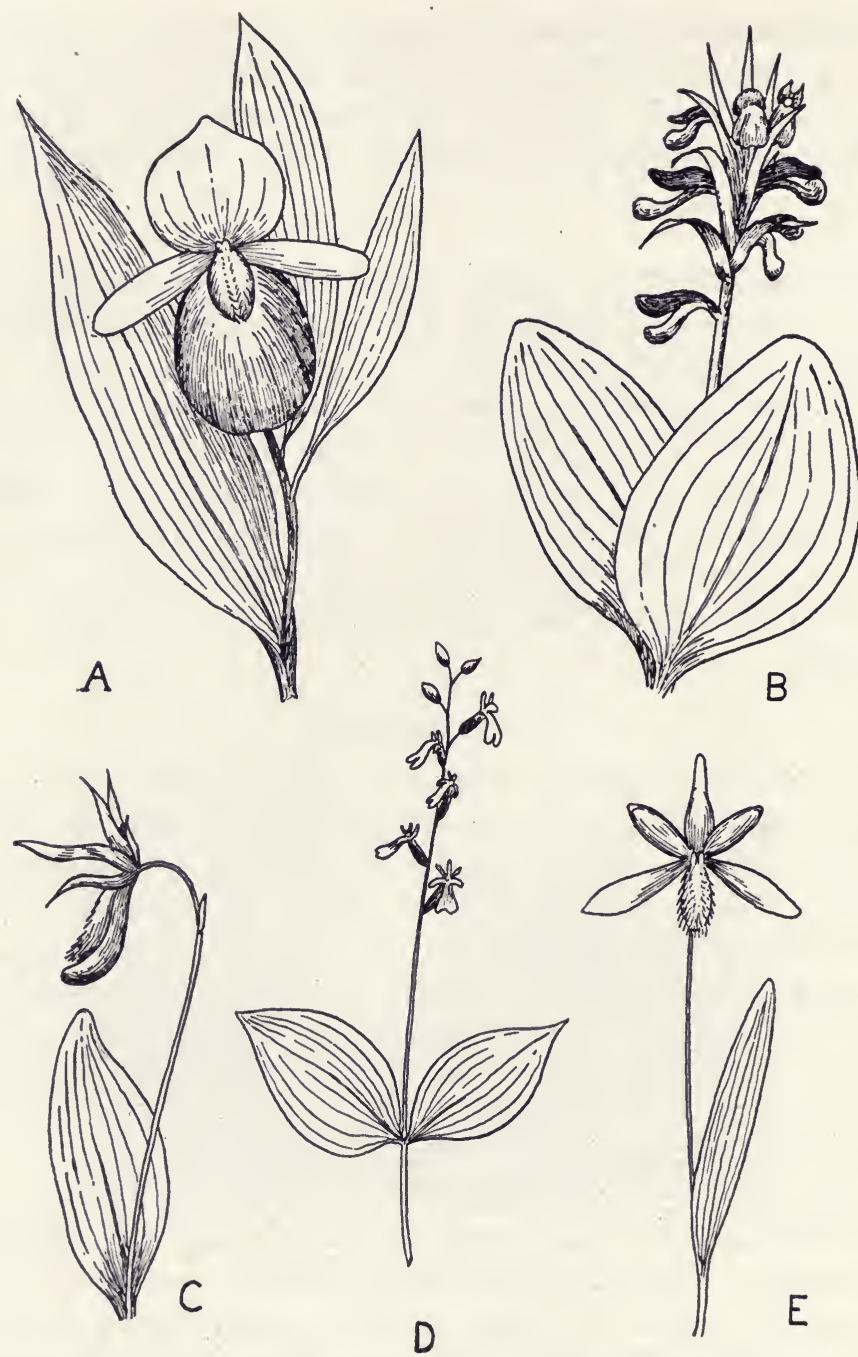

Fig. 288. - The Orchid Family includes lady's slipper (A), showy orchis (B), calypso (C), twayblade (D) and pogonia (E). 
a single basal leaf and an erect cluster of small rose colored flowers with a white lip. The sHowy orchis, found from New England to Nebraska, has a pair of basal leaves and several conspicuous purplish flowers with white lips. The LEAFY GREEN ORCHIDS are stouter plants with narrow stem leaves and a terminal spike of yellowish green flowers. The FRINGED ORCHIDS include a number of northern and eastern species; some are bright orange while others are white, green, lavender or purple. In all cases the lip of the flower is divided into segments.

The TWAYBLADES are the smallest members of the Orchid Family, flourishing in wet meadows and bogs of our eastern and central states. The small flowers may be greenish purple, greenish yellow or greenish white in color with very small sepals and petals. LADIES' TRESSES, another group of inconspicuous orchids, has grass-like leaves and small whitish flowers, each with a fringed margin. Pogonia or snakemouth is a showy flowered plant of small size bearing solitary nodding rose colored white or pink flowers with a crested and fringed lip. Calypso, one of the rarest of our native orchids, produces rounded basal leaves and solitary purple, pink and yellow flowers whose petals and sepals spread out above the crested purple lip.

* $\quad * \quad * \quad * \quad *$

Such are a representative few of the families of flowering plants which constitute our native flora. There are numerous other flowers, in isolated families or of local occurrence, which have by necessity been omitted. But perhaps enough have been presented to open new vistas in the plant world, and to make the latter a more intelligible assemblage of plants grouped together into families on the basis of similarities of flower structure, rather than a heterogeneous mixture of individual species. 


\section{Chapter 27 \\ ORNAMENTAL PLANTS}

An acquaintance with the native trees, shrubs and flowers described in previous chapters of this book is of little value when encountering the exotic ornamental plants found in American homes, gardens and parks. Few of our native trees and shrubs and scarcely any of our herbaceous flowering plants have been "domesticated" and adapted for ornamental purposes. These are a strange assemblage of foreign plants which have become adapted to our climate and soils; they come from distant homes in China, India and Japan; from Africa and the Mediterranean region; from South America, Central America and Mexico. In some cases related plants of the same family occur in our native flora, but in others there are not even family relatives belonging to the United States. Most of these introduced species are grown for their flowers, but in some cases the fruit, foliage or even the general habit, make the plant of ornamental value.

\section{Ornamental Trees}

With the exception of the palms, the majority of our common ornamental Angiosperm trees belong to the Dicot group. In temperate portions of the United States broad-leaved trees which are cultivated for their flowers, berries or for their foliage include the magnolia, redbud, dogwood, horsechestnut, hawthorn, mountain ash and varieties of cherry, apricot and almond. In the warmer portions of the United States grow also the acacia, eucalyptus and palms.

The magnolia, related to the buttercups, belongs in a family (Magnoliaceae) which has such eastern relatives as the cucumber tree and the tulip tree. Our native species of magnolia or bay tree are found from North Carolina south to Florida and west to Texas (cf. fig. 212). Magnolias have glossy dark green leaves (ever- 
green, in our southern states) and unusually large white or pink flowers with showy petals.

The REDBUD is also a native eastern tree, of smaller size than the magnolia; it is frequently grown for its colorful clusters of rose colored flowers. Together with the locusts and the acacias, it is a member of the Pea Family and in fall is covered with pods typical of the legumes.

The Rose Family has contributed the hawthorn, mountain ash, and the various flowering peaches, cherries and almonds to

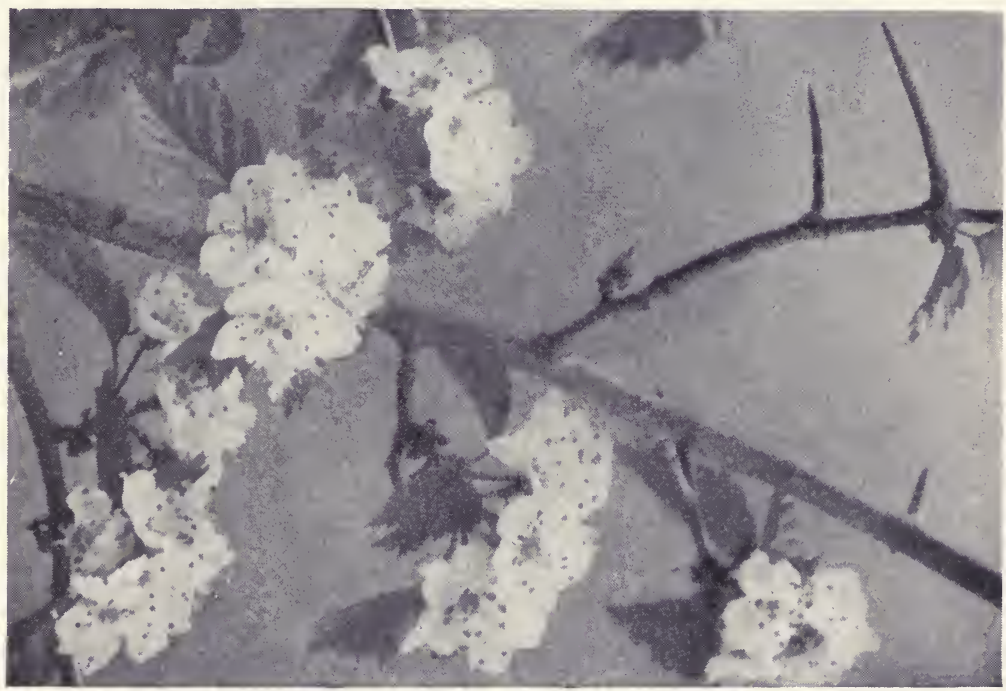

FIG. 289.-Hawthorns are shrubby ornamentals with spiny twigs and apple-like blossoms.

our stock of ornamental trees. HAwTHORns (fig. 289) are shrubby trees abundant throughout eastern and southern United States. The twigs, armed with thorns, are covered with white or pink flowers of typical rose structure, in fall producing red fruits which resemble small apples. MountaIN ASH (fig. 290) is a small tree of eastern and far western United States characterized by pinnately compound leaves and flat topped clusters of small white flowers which produce colorful orange-red fruits. Numerous species of ornamental APRICOTS, CHERRIES and ALMONDS are grown 
for their showy white or pink flowers for which they have been introduced into this country from their native homes in China, Japan and the Mediterranean region.

Among our most ornamental flowering trees are the various species of dogwood. Dogwoods (cf. fig. 221) are shrubs and small trees common to the northeastern and Pacific coast states; beneath each cluster of small yellowish green flowers are four conspicuous white or pink bracts which resemble petals. The HORSECHESTNUT, likewise a conspicuously flowered tree, has its

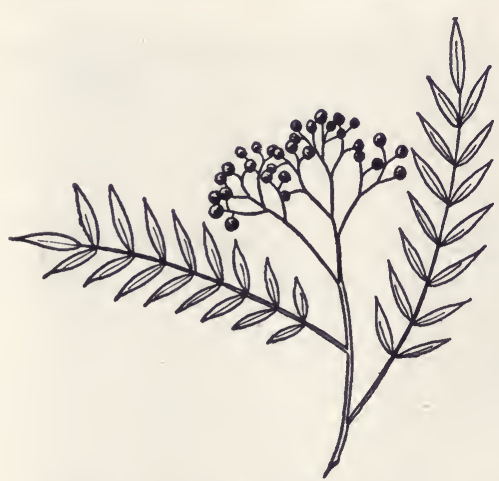

FIG. 290.-Mountain ash is a small tree with pinnately compound leaves and clusters of orange-red fruits. native home in Greece; it is grown as an ornamental because of its large erect clusters of white flowers. Related species include the buckeyes, common to our central and western states.

The AGAaia is a member of the Pea Family which is often cultivated as an ornamental in the warmer portions of the United States. A great number of the species used as ornamentals come from Australia. The majority have delicate pinnatelycompound foilage and globular clusters of small golden yellow flowers. Eucalyptus or Australian gum (fig. 291) of the Myrtle Family is another Australian tree which has become a common street tree in California. The leaves, narrow and tapering, hang in graceful clusters. The aromatic flowers have a fused perianth which forms a lid over the stamens and pistils; when this lid falls off the yellow or scarlet stamens become the most conspicuous part of the flower.

The Palm Family has contributed a great number of exotic trees which are grown along the streets and in the gardens of our southern and southwestern cities. Some have feather-like and pinnately-compound leaves of huge size which form terminal clusters at the top of the unbranched trunk. Such are the COCONUT PALMS (cf. fig. 150) probably native to South America 
and now characteristic trees of southern Florida; the ROYAL PALM, considered by some botanists to be indigenous to Florida, and used frequently as a street tree in that state; and the DATE PALM, native to Africa, but now grown commonly in Florida, the Gulf states and California as an ornamental. Other palms

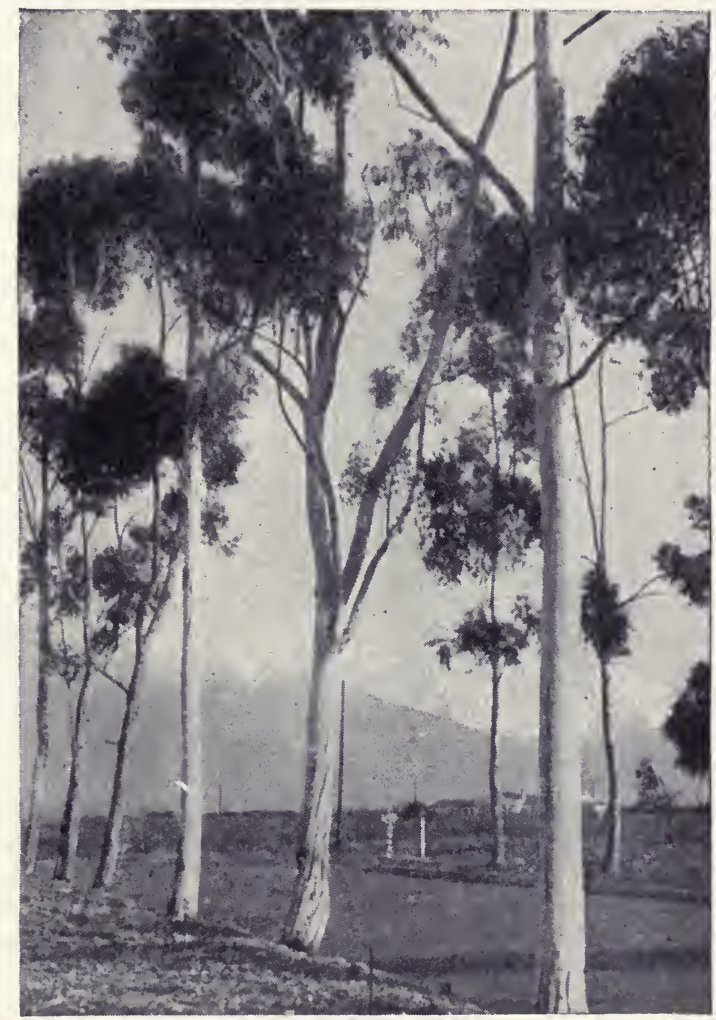

Fig. 291.-The Eucalyptus of Australia has become a common ornamental tree in California.

have fan-shaped and palmately compound leaves. This type is represented by the WASHINGTON FAN PALMS (fig. 292) of which a few wild groves occur in Palm Canyon and adjacent areas in southern California. This tall and often ungainly tree bears the accumulation of previous year's foliage as a protective covering 
over its trunk. These are the characteristic palms of California. The most abundant and widely distributed of all our eastern palms is the GABBAGE PALM of PALMETTO which grows from North Carolina through the Gulf states to Texas.

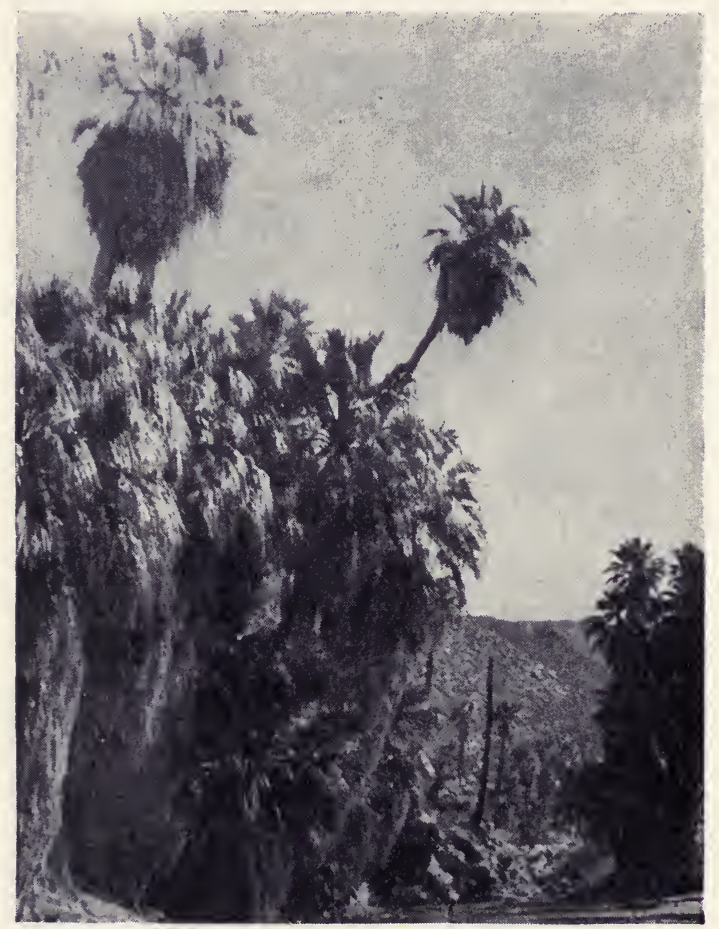

Fig. 292. - The California or Washington palm is commonly used as a street tree in California. Palm Canyon possesses a fine stand of these trees.

\section{Ornamental Shrubs}

Numerous woody Dicots are familiar as ornamental shrubs. In the temperate portions of the United States we find barberry, hydrangea, azalea, Forsythia and lilac; while in the warmer southern portions of the country Scotch broom and oleander are also cultivated.

The cultivated BARBERRY (fig. 293) is a European shrub with spiny twigs, rosettes of small leaves and clusters of small drooping 
yellow flowers which give rise to the familiar red berries. A related species is native to eastern United States where it has earned a notorious reputation by being the host of the wheat rust fungus. Hydrangea (fig. 294) is a shrubby member of the Saxifrage Family with conspicuous flower clusters. Cultivated varieties come from China and Japan although native species occur in our southern coastal plain states. Each flower of the cluster has four or more sepals and petals which may be white,

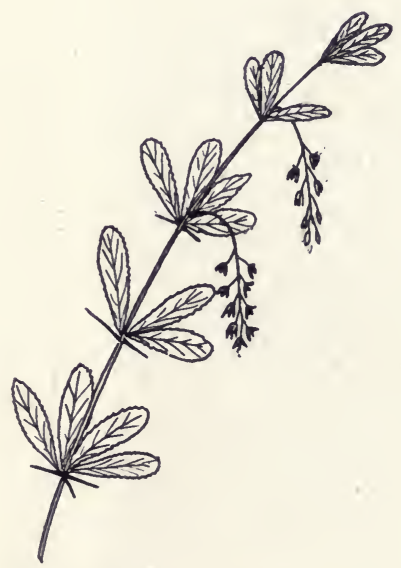

Fig. 293.-Barberry has spiny twigs and rosettes of small leaves.

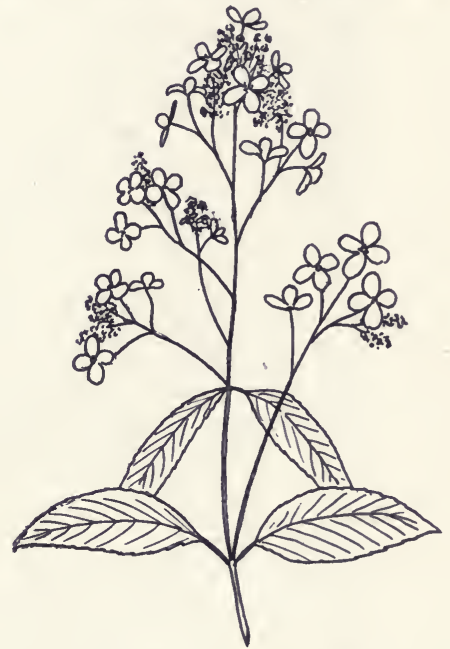

FIG. 294.-Hydrangea is a shrubby ornamental of the Saxifrage Family.

pink or blue in color. The AZALEAS and RHODODENDrons are among the few native shrubs which are grown for ornamental purposes. The flame azalea, with yellow or orange colored flowers, belongs to our southeastern woodlands. Some of the more brilliantly colored varieties have been evolved from Chinese or Japanese species.

The Olive Family, which includes our native ashes as well as the introduced olive trees, furnishes our gardens with privet, lilac and Forsythia (fig. 295). Privet is an Eurasian shrub with small opposite leaves and white or green flowers with funnelshaped corollas; due to the dense production of branches and 
foliage, privet serves admirably as a hedge plant. ForsythiA is a favorite flowering shrub of early spring which produces masses of golden yellow flowers each with a deeply four-parted corolla. Most of the species come from China and Japan. Lilac, a native of Eurasia, has long been a familiar and favorite shrub of eastern gardens; the white or purple flowers, each with a funnel-shaped and four-lobed corolla, are grouped in large pyramidal clusters.
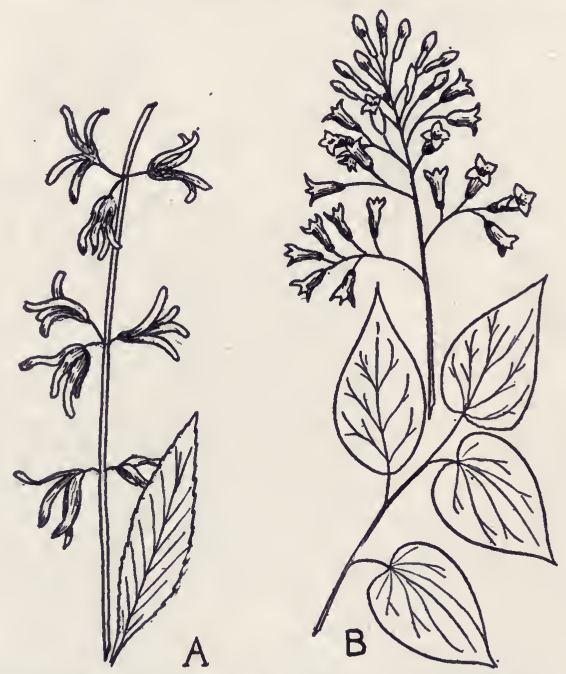

FIG. 295. -The Olive Family includes such ornamental shrubs as Forsythia (A) and lilac (B).

Sсотсн вRоOм is an Old World member of the Pea Family cultivated as a shrub in the warmer portions of the country. The leaves are inconspicuous and transitory, while the stems are green and carry on photosynthesis. During the flowering season the stiff stems are covered with yellow pea-like blossoms. Oleanders, members of the Dogbane Family, come from the Mediterranean and Asiatic regions; they are warm-climate shrubs bearing large clusters of red, white or yellow flowers.

\section{Ornamental Vines}

A few vine-like plants are common as ornamentals. Familiar to inhabitants of temperate United States are clematis, wistaria, 
woodbine, English ivy and honeysuckle. In the warmth of our southern states additional vines include bougainvillea and trumpet creeper. Clematis (fig. 295A) includes numerous native species of eastern United States with clusters of small white flowers and, in late summer, silky masses of fruits. Cultivated species are Japanese or Chinese in ancestry and have larger

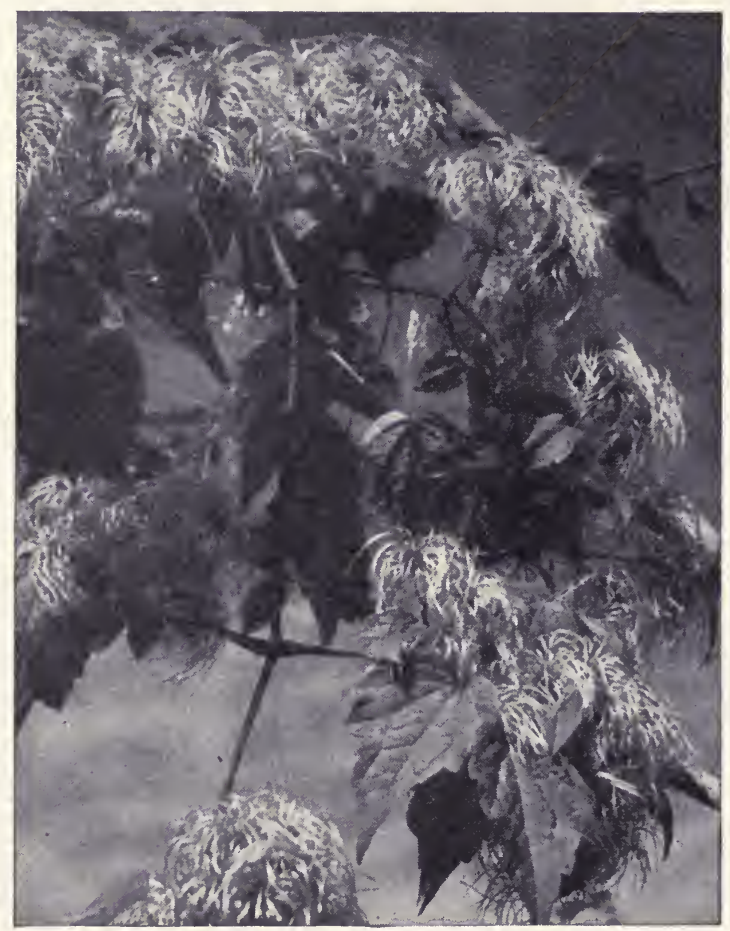

FIG. 295A.-Clematis produces masses of silky-haired fruits.

flowers with purplish sepals. Clematis is a member of the Buttercup Family. Wistaria, a vigorously growing vine of the Pea Family with compound leaves, bears drooping clusters of white, light blue or purple flowers (fig. 296). Native species are found from Kentucky to Texas; but the cultivated varieties are derived from Chinese and Japanese species. The Grape Family includes numerous genera of woody vines many of which are native to the 
United States. Woodbine or Virginia GREePer is a genus found in eastern United States, with compound leaves divided into five leaflets, and clusters of small green flowers which give rise to blue berries (fig. 297). ENGLISH IVY, an Eurasian member of the

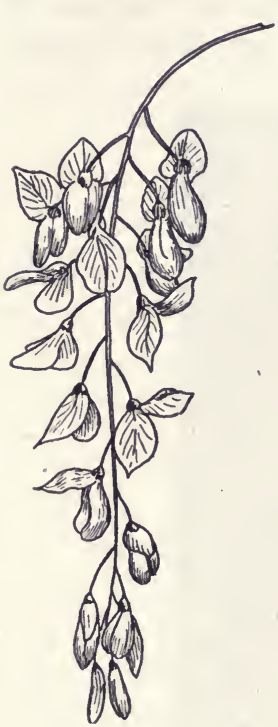

FIG. 296.-Wistaria bears drooping clusters of white or blue flowers.

Ginseng Family, is the most frequently used ornamental.vine; among the lobed leaves appear clusters of small greenish flowers which produce black berries. English ivy forms an effective wall cover because of the aerial roots which are adapted to fasten themselves to smooth surfaces.

The Honeysuckle Family, which includes our native elderberries and viburnums, comprises a variety of woody vines from China and Japan commonly used as porch and trellis plants. The showy flowers, usually white or creamy yellow in color, have a tubular corolla. Native species of HONEYSUCKLES are common shrubs in our central and eastern woodlands.

Bougainvillea is a bushy vine which thrives in our southern states, where it has been introduced from its South American home. The inconspicuous individual flowers are surrounded by showy purplish red bracts which are frequently mistaken for petals. Likewise common in the warmer portions of the country is the TRUMPET CREEPER native of tropical America with pinnately compound leaves and large yellow flowers.

\section{Ornamental Dicot Flowers}

The countless variety of garden and house plants which are grown for their flowers originate in a number of Dicot and Monocot families, with by far the greater number belonging to the Dicot group. Such ornamental Dicots are found chiefly in the Pink, Buttercup, Poppy, Mustard, Violet, Pea, Rose, Mallow and Thistle Families.

Common wild flowers in the Pink Family are the chickweeds, sandworts and catchflies; this family also includes, however, one 


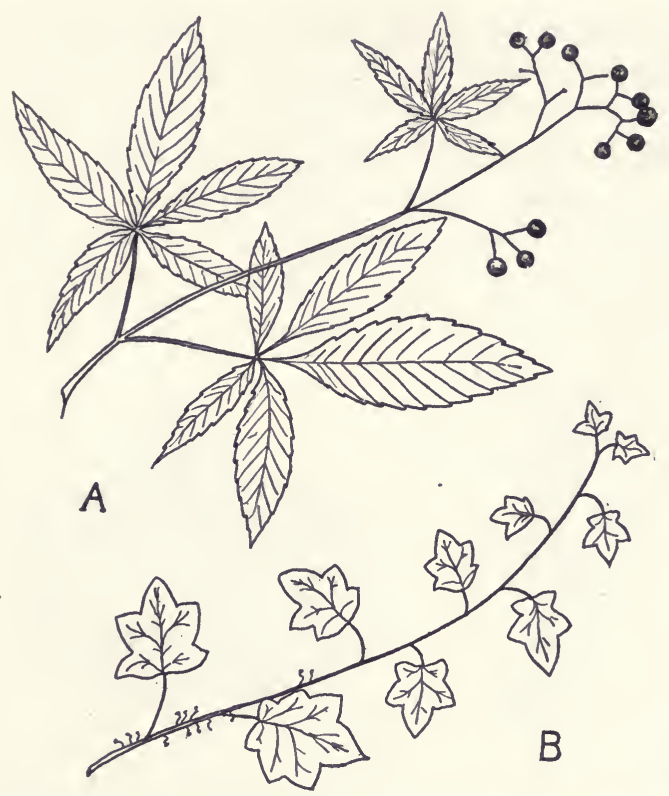

Fig. 297.-Woodbine (A) and English ivy (B) are two ornamental climbing plants.
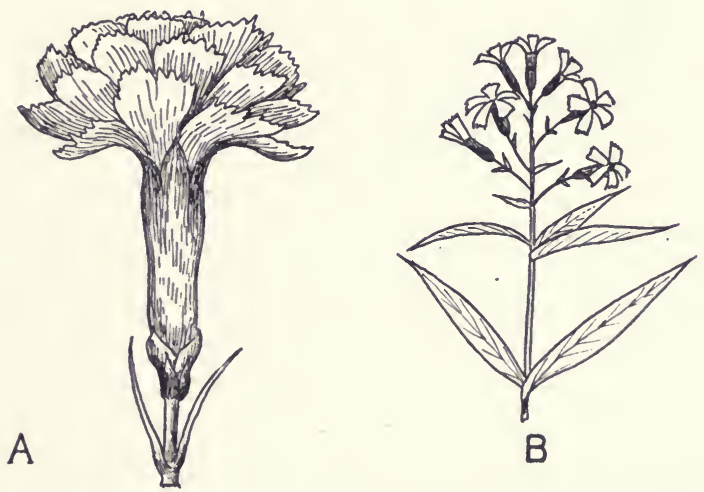

Fig. 298.-Carnation (A) and sweet william (B) are ornamental species of the Pink Family 
of the most ancient of cultivated flowers - the GARNATION (fig. 298), which has become a favorite cut flower as well as outdoor ornamental. Native to the Mediterranean region, carnations may be white, pink or red in color, each flower with an elongated calyx and five broad fringed petals. In many varieties a doubling of the flower parts has resulted in a flower with more numerous petals. Sweet William is a related species with structurally similar but smaller flowers in flat topped clusters.
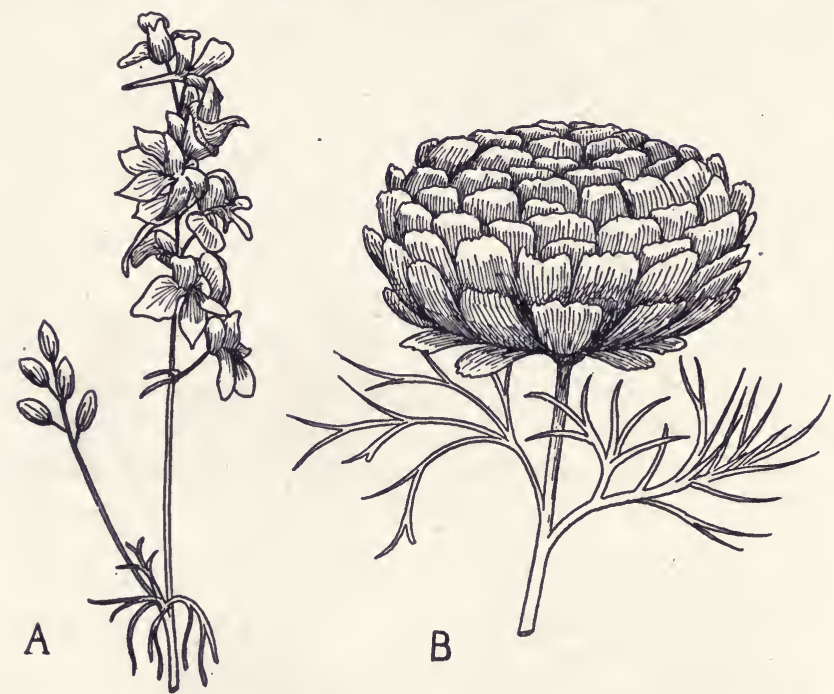

FIG. 299.-Ornamentals in the Buttercup Family include larkspurs (A) and peonies (B).

The Buttercup Family (see p. 436) of which there are so many native wild flowers, contributes larkspurs, delphiniums and peonies to our list of garden plants (fig. 299). LARKSPURS are native flowers but the related garden delphiniums are natives of Europe and Siberia. The garden forms of PEONIEs are all derived from European or Asiatic species; their flowers-white, yellow, orange, pink, purple or red-are characteristically very large and colorful, often with numerous petals as a result of the doubling of the floral parts.

Ornamental flowers in the Poppy Family include the numerous species of true poppies (fig. 300). The ICELAND POPPY is a 
hardy plant with basal leaves and orange, red or white flowers. The Oriental POPPy, native of Persia and the Mediterranean region, has stiff hairy stems and large scarlet flowers, each petal marked with black at its base. The CORN POPPY of Europe, with finely lobed leaves, produces smaller red, white or purple flowers. The OPIUM POPPY of Greece and the Orient is a tall plant with white, pink or red flowers.
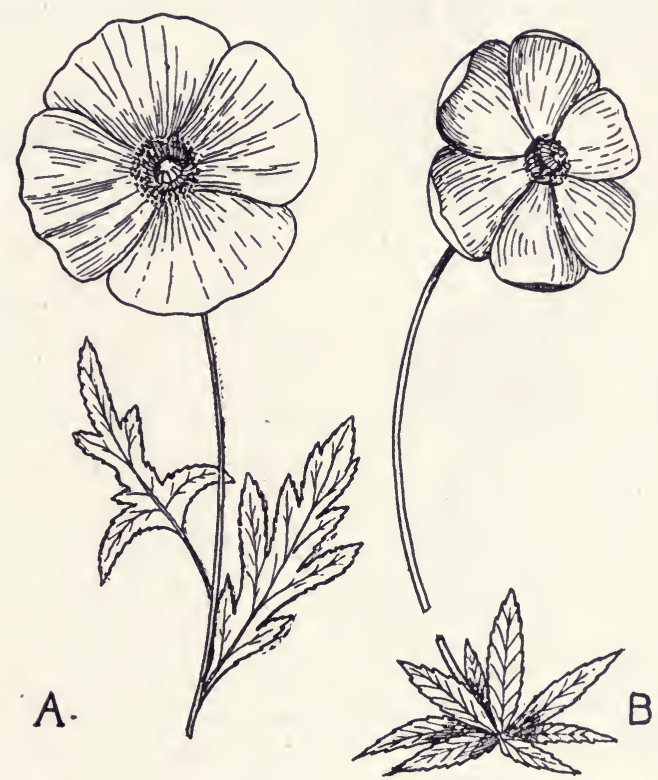

FIG. 300.-Ornamental poppies include corn (A) and Iceland (B) poppies.

The Mustard Family consists of plants typically with small flowers with a characteristic arrangement of four petals in the form of a cross (see p. 440). Yet this family has contributed to our gardens sweet alyssum, stock, candytuft and wallflower (fig. 301). SweEt AlySSUm is a low growing European plant with grayish green leaves and clusters of small white or yellowish flowers. Stock, a taller plant native to the Old World, has terminal clusters of white or purple flowers. WALLFLOWER, of which there are several native western species, is a stout plant with flowers in terminal clusters; ornamental varieties with 
yellow or purple flowers have been introduced from the Mediterranean region. CandyTuFT is a low growing Eurasian plant with compact clusters of small white flowers, each with two of the four petals larger than the others.

The Violet Family has contributed one of the most familiar garden flowers - the pansy. A PANSY is in reality a large-flowered
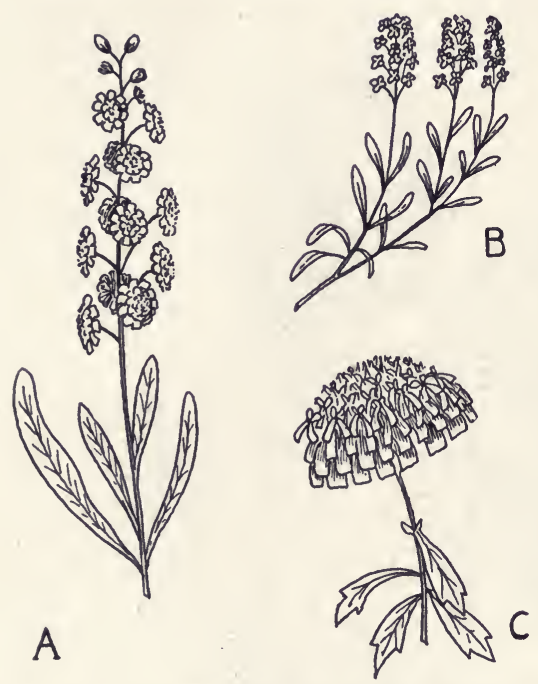

Fig. 301.-The Mustard Family includes such ornamental flowers as stock (A), sweet alyssum (B), and candytuft (C). violet derived from the wild pansy or heartsease of Europe. As a result of centuries of breeding a number of varieties of pansies in single and mixed colors-chiefly yellow, white, blue and purple-have been produced.

The Pea Family, in addition to furnishing us with numerous attractive wild flowers and food plants, includes the ornamental lupine and sweet pea. In spite of the fact that there are numerous native Lupines (see p. 445), the garden varieties come from European species; these are ordinarily yellow, blue or white in color. The SWEET PEA is a Mediterranean species which produces flowers in numerous shades of blue, red and yellow as well as white.

Roses, like carnations, are garden plants of great antiquity. The usual five petals of the rose flower is increased in the double flowered varieties by the transformation of stamens into petals. The majority of our ornamental varieties are of European or Oriental ancestry. Sweet briar or eglantine roses are pink flowered European species; and from Europe also comes the white flowered musk rose. The familiar rambler rose with white, pink or red flowers is a native of China and Japan; and from China comes also the delicately tinted tea roses. A common 
single flowered variety is the white Cherokee rose, native to the Orient.

The GERANIUM, so frequently used both as an indoor and outdoor ornamental, is a South African plant (fig. 302). Geraniums have irregular flowers with two petals larger than the others. The Geranium Family (Geraniaceae) includes a few native wild flowers such as wild geranium, herb Robert and storksbill.

The Spurge Family (Euphorbiaceae), in which we find the important para rubber tree (see p. 360), includes Poinsetria, a

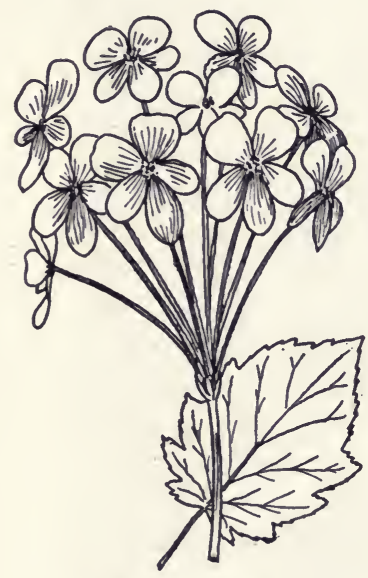

Fig. 302.-Geranium is a South African plant with showy clusters of slightly irregular flowers.

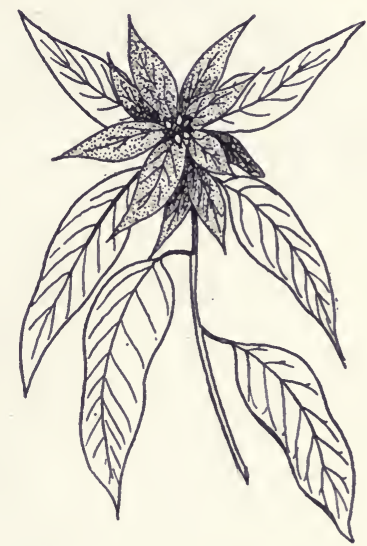

FIG. 303.-Poinsettia is a Mexican plant with small flowers surrounded by showy red bracts.

Mexican plant which has become very popular within recent years (fig. 303). Poinsettias have small and inconspicuous flowers which are surrounded by conspicuously colored red leaves. Poinsettias are outdoor shrubs in Florida and California, and are grown, in the northern states, in greenhouses for Christmas trade.

One of the most brilliantly flowered members of the Mallow Family is the Hibiscus, which comes from China and Japan. It is cultivated out-of-doors in our southern states where it becomes a tall shrub with showy large red flowers, each with a projecting scarlet column of pistil and stamens. ROSE of SHARON is also 
an Asiatic species, related to Hibiscus, with smaller white, pink or purple bell-shaped flowers. A member of the family more familiar to residents of temperate United States is the HolLyHOCK, introduced from China, which produces the tall terminal spikes of large white or rose-pink flowers usually seen in eastern old fashioned gardens (fig. 304).

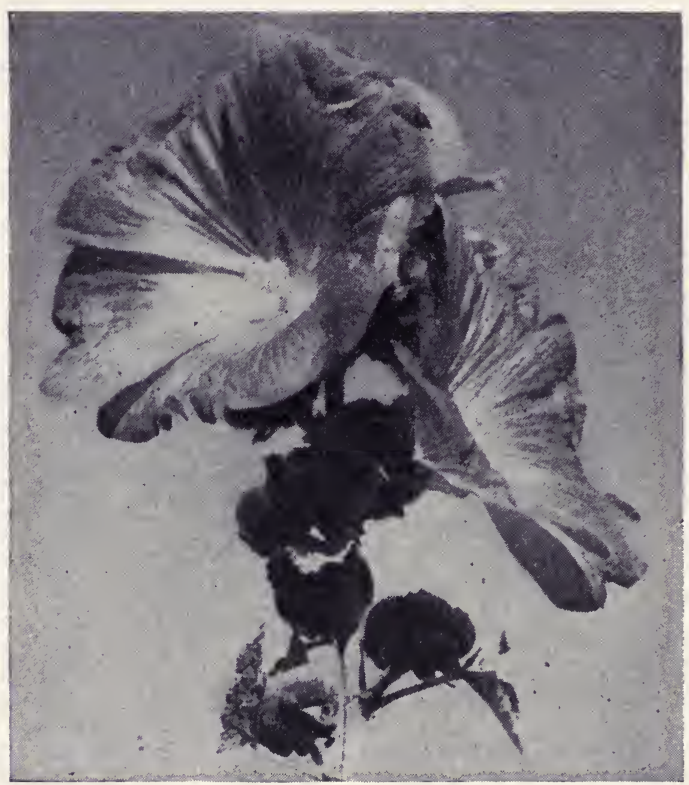

Fig. 304.-The hollyhock is an ornamental member of the Mallow Family.

In the Potato Family we find the Petunia, a South American and Mexican genus; each flower-which may be pink, white or purple - has a five parted calyx and an elongated tubular corolla which widens to form a five lobed margin.

The Thistle Family has contributed a great number of ornamental species to our American gardens. Because of the grouping ot hundreds of flowers into a single head, members of this and other Composite families are characterized by unusually attractive inflorescences (fig. 305). Zinnias, natives of Mexico and tropical America, have yellow ray flowers and yellow or orange 
disc flowers. Types with ray flowers in a wide range of tints and, in the double varieties, lacking disc flowers entirely, have been produced. Cosmos is a bushy garden flower from the same region, with showy flower head made up of various colored ray flowers and yellow disc flowers. The DAHLIA is another Mexican plant which grows taller and more vigorously than most Composites; the ray flowers are usually red or purple in color and in

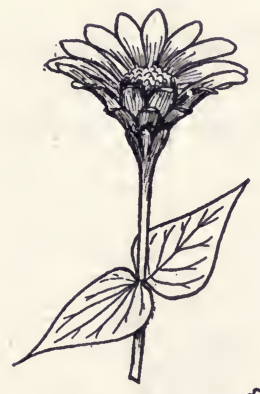

A

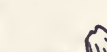

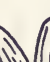
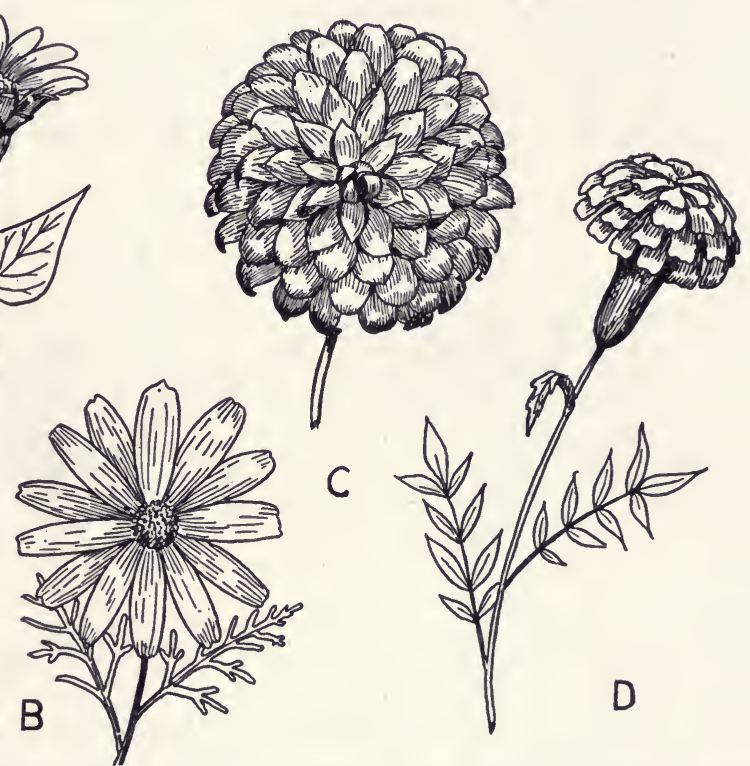

FIG. 305.-The Thistle Family has given man many beautiful garden flowers, among them zinnia (A), cosmos (B), dahlia (C), and marigold (D).

the original species the disc flowers are yellow. In many varieties the disc flowers have been transformed into ray flowers. The MARIGOLDS are another genus of tropical American plants, typically with strongly scented foliage and a small flower head of yellow or orange ray flowers and disc flowers. Most showy of all the ornamental Composites is the CHRYsanthemum, a genus cultivated in the Orient for the past thousand years. Ornamental garden varieties number into the thousands, in many cases double flowers resulting in huge spherical flower heads as in the pompom types. 


\section{Ornamental Monocot Flowers}

The Arum Family which includes the familiar spring flowers skunk cabbage and jack-in-the-pulpit gives us the CALlA LILY, a native of Africa which is grown as an outdoor aquatic in our southern states. The fleshy axis, with its numerous small flowers, is surrounded by a conspicuous broad spathe which may be white, pink or straw colored.

The true lilies include a number of familiar ornamental plants (fig. 306): the common EASTER LILY is a native of China and Japan, and from this same region comes the orange-red

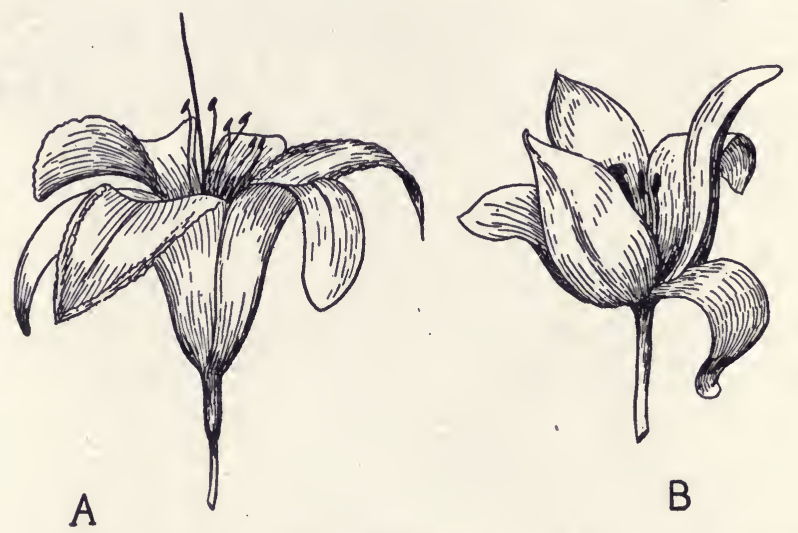

Fig. 306.-Day lilies (A) and tulips (B) are ornamentals of the Lily Family.

TIGER LILY. Other members of the lily family which are cultivated as ornamentals are the tulips and hyacinths. The TULIP genus is native of Asia, Asia Minor and the Mediterranean regions. Tulips grow from bulbs which produce basal leaves and large solitary flowers with sepals and petals alike in color. HyAcinth, whose original home is Greece and Asia Minor, also has basal leaves but produces a cluster of small flowers each with six segments to the perianth.

In the Amaryllis Family there is another familiar ornamental, the narcissus; various species are native of Europe and the Orient. Each flower has an elongated tubular basal portion and six perianth segments bearing in their throat a crown known as the 
corona (fig. 307). The PAPER NARcissus has pure white segments and a lemon yellow corona. Related species with a conspicuously elongated corona are known as DAFFODILS.
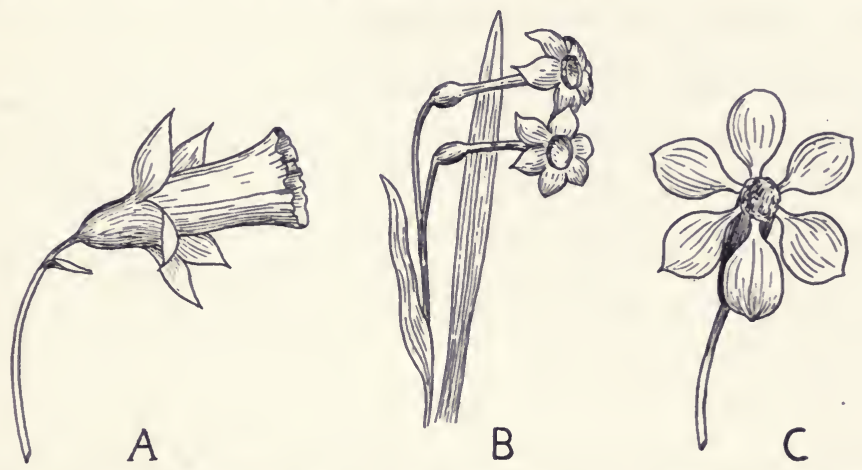

Fig. 307.-In the Amaryllis Family are daffodils (A), jonquils (B), and narcissus (C).

In the Iris Family are the cultivated varieties of Iris, Gladiolus and Crocus (fig. 308). Many of the colorful IRIS species come from Japan. The Gladiolus genus, native to Africa and western
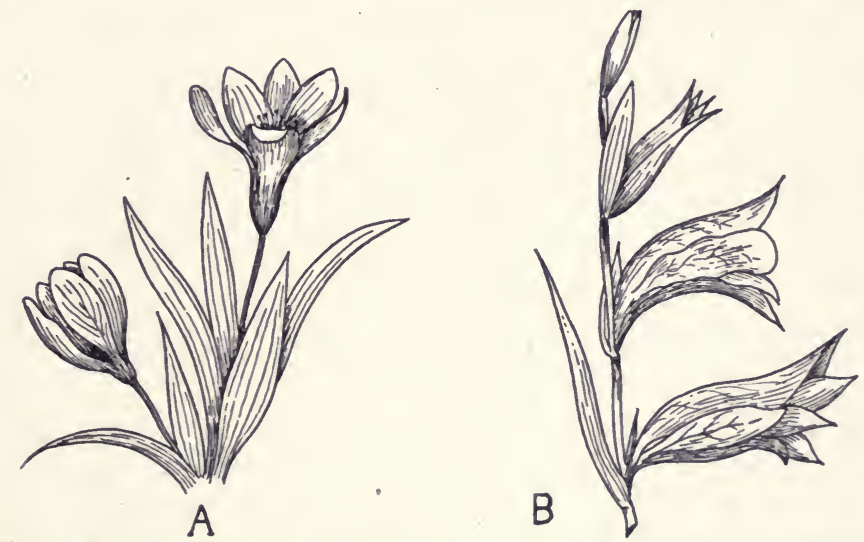

FIG. 308.-The Iris Family includes as ornamental species the familiar crocus (A) and gladiolus (B).

Asia, produces flowers in spikes, each flower funnel-shaped and with unequal segments in a variety of colors. CROCus is a smaller - stemless plant with clusters of flowers which appear early in 
spring. Most of the species are native to Europe and southwestern Asia.

These flowering members of the Dicot and Monocot groups of the Angiosperms indicate what a wide geographical range plant explorers have covered to bring us these chosen species. Many of them have been under cultivation in other parts of the world for thousands of years; but all originally were wild plants. Centuries of patient breeding, experimentation and careful cultivation have developed the latent possibilities of their natures, resulting in the variety of ornamental plants which many of us casually accept as natural members of our gardens and decorations in our homes. 


\section{GLOSSARY}

Accessory fruit.-A fruit formed chiefly by some other part of the flower than the ovary; example, apple or strawberry.

Achene.-A dry fruit containing a single seed, and not splitting open at maturity; example, buttercup, dandelion.

Aggregate fruit. - A fruit formed by the ripening of a number of separate pistils of a single flower; example, raspberry.

Aleurone grain.-Protein particles found in the outside cells of cereal grains.

Algae.-General term applied to the chlorophyll-bearing thallus plants; example, seaweeds and pondscums.

Alkaloid.-An alkaline vegetable substance, often employed as a drug; example, quinine.

Amino acid.-A simple organic compound, containing carbon, hydrogen, oxygen and nitrogen; basic constituents of proteins.

Angiosperms. - The group of seed plants (Spermatophyta) reproducing by flowers and fruits; examples, elms and roses.

Annual.-Completing the entire life cycle from seed to seed in the same year, and dying at its termination.

Antheridium.-The male sex organ of thallus plants, mosses and ferns, in which sperms are produced.

Antitoxin.-Antibodies, or chemical substances produced in animal bodies to neutralize the effects of bacterial poison, or toxins.

Aquatic.-Living in the water.

Archegonium.-The female sex organ found in thallus plants, mosses and ferns; in which an egg is produced.

Ascus.-The sac-like spore-producing structure characteristic of the sac fungi.

Autotrophic.-Pertaining to organisms or metabolism characterized by an ability to transform inorganic materials into organic ones; i.e., to be able to synthesize food.

Axil.- The junction of a leaf stalk or bud with the stem from which it arises.

Axillary.-Arising in the axils of leaves.

Bacillus.-A rod-shaped bacterial cell. 
Basidium.-The club-shaped spore-bearing structure found in the life history of all the club fungi or Basidiomycetes.

Bast fiber.- Slightly lignified sclerenchyma cells found in phloem or pericycle of some plants.

Berry.-A type of fleshy fruit formed from a single pistil; example, grape or tomato.

Biennial.-Completing the life cycle from seed to seed in two years; usually the seed grows into a plant the first year, produces flowers and fruit the second year and then dies. Example, beet.

Bract.-A leaf-like part of a flower sometimes mistaken for a petal; conspicuous in such flowers as dogwood.

Bran.-The fruit and seed coats (husks) of wheat grains, removed in making white flour.

Bulb.-The short stem surrounded by fleshy leaf bases which serves as a reproductive organ in some plants; example, onion and tulip.

Caffeine.-A stimulating alkaloid substance found in coffee and tea. Calyx.-The whorl of sepals making up the outermost part of a flower; usually green.

Cambium.-The growing tissue from which new bark and wood arise in trees and shrubs.

Cankers.- Swellings or tumors produced as the result of bacterial or fungus invasion of plant tissues.

Carbohydrate. - A compound of carbon, hydrogen and oxygen with the latter two in the proportions of 2:1; example, sugar or starch.

Carnivorous.-Flesh-eating.

Carotin.-A reddish yellow pigment chemically composed of hydrogen and carbon, abundant in carrots.

Caryopsis.-A type of achene in which the thin dry wall of the fruit adheres to the seed coat; example, corn or wheat grain.

Catkin.-A wind-pollinated, cone-like reproductive structure consisting of an axis bearing small flowers, each lacking petals and sepals; example, willow or birch.

Cell.-A unit of highly organized protoplasm surrounded by a nonliving cell wall.

Cellulose.-A complex carbohydrate substance which makes up most of the cell wall in plants.

Chlorophyll.-The green pigment found in plant cytoplasm, made up of carbon, hydrogen, oxygen, nitrogen and magnesium; essential for carrying on photosynthesis.

Chloroplast.-The cell structure containing chlorophyll, giving green plants their characteristic color. 
Chromatin.-Deeply staining material in the nucleus which becomes organized into chromosomes during cell division, and is the carrier of inherited traits.

Cilium (pl. cilia).-Whip-like or hair-like protoplasmic structure projecting from a cell and serving as a locomotor organ in unicellular organisms.

Coccus.-A spherical bacterial cell.

Collenchyma.-Temporary supporting tissue made up of cells with unevenly thickened cellulose walls.

Colloid.-A condition of matter in which minute particles of one substance are held in suspension in another substance; example, milk.

Compound leaf.-A leaf in which the blade is divided into separate leaflets; example, hickory or palm.

Cone.-The reproductive structure of a Gymnosperm, bearing pollen and ovules on exposed scales.

Coppice.-The sprouts formed by tree stumps after cutting the parent tree.

Corolla.-The whorl of petals inside the calyx of a flower, usually colored or white.

Cortex.- Region in stems and roots made up of relatively unspecialized and large parenchyma cells.

Cotton linters. - The short hairs of the cotton seed, usually too short to be manufactured into textiles.

Cotyledon.- The part of a seed which functions as an embryonic leaf, contains stored food in many Dicots.

Cuticle.-The outer waxy covering formed by the epidermis of leaves. Cytoplasm.-The portion of the protoplasm exclusive of the nucleus, in which most of the cell activities take place.

Decay.-The action of bacteria in breaking down complex organic compounds into simple inorganic ones (chiefly water and carbon dioxide).

Deciduous. - Shedding the leaves at the end of a growing season; not evergreen.

Dextrin.-A gummy substance formed from starches by acids, heat or enzymes; used in sizings and pastes.

Dialvsis.-Diffusion of a substance through a semi-permeable membrane.

Dicots (Dicotyledons).-The group of Angiosperms with two cotyledons in each embryo; examples, roses and hickories.

Diffusion.-Movement of gases or substances in solution from a place of high concentration to one of lesser concentration. 
Drupe.-A fleshy fruit containing a hard inner portion, or stone, surrounding the seed; example, cherry.

Egg.-The female gamete produced during sexual reproduction.

Elaioplasts.-Special oil-forming plastids found in some plants.

Embryo. - The undeveloped organism resulting from growth of the fertilized egg or a spore; in the flowering plants, found inside the seed and fruit.

Endosperm. - The food-storage region of a seed, outside of the embryo. Entire leaf.-A leaf with smooth margin.

Entomologist.-One who makes a specialty of studying insects and their control.

Enzyme.-A substance, found in plants or animals, which brings about some particular chemical action; an organic catalyst.

Epidermis.-The outer protective layer of cells in an organism.

Epiphyte.-A plant which lives upon another plant but derives no sustenance from it; example, lichen.

Excurrent.-Tree habit in which the trunk continues as a central axis without large diverging branches; example, pine or spruce.

Fat.-A compound of carbon, hydrogen and oxygen; with a lesser amount of oxygen than in carbohydrates.

Fertilization.-The union of sperm and egg, or male and female nuclei, with consequent fusion to form a single cell, or single nucleus. The culmination of sexual reproduction.

Fiber.-Slender and thick-walled skeletal cells found in the wood of stems and roots.

Filament.-Thread-like series of cells attached end to end; a form of body common among thallus plants.

Fission.-The simplest form of asexual reproduction, involving simple cell division; example, bacteria.

Fixed oil.-A fatty oil which can not be distilled without changing its chemical nature.

Flagellum.-Hair-like locomotor structure developed by motile cells. Flower.-The reproductive structure of the sporophyte of an Angiosperm, consisting essentially of stamens and pistils.

Fruit.-The matured and enlarged ovary of a flower, surrounding the seed and functioning for dispersal; in some cases other parts of the flower (calyx, receptacle) take part in fruit formation.

Fumitory.-Any substance burned as an inhalant, such as tobacco.

Fungi.-General term applied to the chlorophyll-deficient thallus plants which possess cells with organized nuclei. 
Gamete.-A sexual reproductive cell which must fuse with another gamete before developing into an embryo.

Gametophyte.-The plant generation reproducing sexually by gametes. Genus.-A classification unit; a group of related species.

Glucose.-A simple sugar, the most common fuel substance of organisms. Guncotton.-Cellulose which has been treated with strong nitric and sulphuric acids; sometimes called "nitrocellulose."

Gymnosperms. - The group of seed plants reproducing by cones or structures with unprotected ovules, and lacking true fruits.

Habit.-The general appearance of a plant.

Habitat.-The natural environment in which a plant is found; the kind of place in which it lives.

Haustorium (pl. haustoria).-A finger-like projection from a fungous filament into a host cell for purposes of absorbing food.

Head.-A type of inflorescence in which many small flowers are all attached at practically the same point; example, daisy or dandelion.

Heartwood.-The inner woody core of the tree trunk, generally of a darker color than the sapwood.

Herbaceous. - Characterized by soft stems which die to the ground at the end of the growing season; example, buttercup or corn.

Herbivorous.-Eating plants as food.

Heterotrophic.-Pertaining to organisms or metabolism which is dependent upon organic material as food, which is either absorbed (fungi) or ingested (animals).

Humus.-Accumulated debris of plant stems, leaves and roots forming the organic material in soil.

Hybrid.-The type of plant resulting from hybridization.

Hybridization.-Crossing two species by transferring the pollen from one to the pistil of the other; usually successful only with species of the same genus.

Hypha (pl. hyphae).-A fine, thread-like filament which makes up the vegetative part of fungus plants.

Immunity.-Condition of being able to resist the attack of a disease. Inflorescence.-A cluster or group of flowers; example, yarrow or golden rod.

Inner bark.- The layer of bark immediately surrounding the cambium layer in trees.

Invertebrate.-One of a group of animals characterized by no skeleton or an external one; example, sponge, jelly-fish, clam or insect. 
Irregular.-A term applied to a flower in which the petals are not all the same size.

Latex.-The milky juice of a number of plant species, including the rubber yielding plants.

Legume.-Term applied either to the fruit (pod), or a member, of the Pea Family.

Lenticels.-The spongy and porous portion of the bark through which gaseous exchange takes place.

Lignin.-A complex substance associated with cellulose in the cell wall structure of plants:

Lint.-The long hairs of the cotton seed; used in manufacturing of textiles.

Malt.-The partly germinated grain (usually barley) or its extract, used in the brewing of beers and ales.

Megaspore.-The large spore developed by seed plant sporophytes, germinating into a female gametophyte.

Metabolism.-The sum total of all the physical and chemical changes taking place in protoplasm during which energy (food) is taken in, transformed and utilized.

Microspore.-The small spore developed by seed plant sporophytes, germinating into a male gametophyte.

Monocots (Monocotyledons).-The group of Angiosperms with one cotyledon in each embryo; examples, grasses or lilies.

Mutant.-An organism exhibiting a mutation.

Mutation.-The appearance of a new trait in an offspring, capable of being passed on to the next generation.

Multicellular.-A characteristic of body complexity involving many cells living in organic continuity with each other.

Mycelium.-A mass of hyphae forming the vegetative body of a fungus.

Naval stores.-Turpentine, rosin and wood tar derived from the sap of the longleaf pine.

Narcotic.-A drug substance which is used to relieve pain or induce sleep.

Nitrate bacteria.-Bacteria which can change nitrites to nitrates.

Nitrite bacteria.-Bacteria which can change ammonia to nitrites.

Nitrocellulose.-Cellulose which has been "nitrated"; that is, treated with any concentration of combined nitric and sulphuric acids. More properly called cellulose nitrate. See guncotton and pyroxylin. 
Nitrogen-fixing bacteria.-Bacteria capable of changing nitrogen into nitrates, found on root nodules of plants in the Pea Family.

Nitrostarch.-A compound obtained by treating starch with nitric acid. Used in high explosives.

Nucleus.-A dense mass of protoplasm, usually found near the center of the cell, governing most of the vital activities of the cell and important in heredity as the location of chromatin.

Nut.-A modified achene with a hard shell-like covering produced by the ovary wall.

Organ.-A part of a body, made up of tissues, that carries on a special function or group of functions; example, heart, leaf.

Organic.-Pertaining to a compound containing carbon, which has been derived directly or indirectly from living activities.

Organism.-Any living individual.

Osmosis. - Passage of water or other solvent through a semi-permeable membrane from a region of low concentration of a solute to one of greater concentration.

Ovary. - The enlarged region at the base of the pistil of a flower, where the ovules are found and where fertilization takes place.

Ovule.-The sporangium of a seed plant, in which the megaspores and female gametophytes are produced; found in the ovary of a flower. Oxidation.-The union of oxygen with another substance.

Pathogen.-A plant or animal which causes disease.

Pathogenic.-Disease causing or producing.

Palmate.-A type of leaf venation or compounding in which the veins or leaflets all radiate from a common point; example woodbine or horse-chestnut.

Parasite.-A heterotrophic organism which derives its nourishment from another living organism, living on or within it.

Parasitic.-Living at the expense of another, its host. See parasite. Parenchyma.-Relatively unspecialized cells making up the fundamental or ground tissue of plants; common in leaves, flowers and fruits. Pepo.-A type of fruit with an outer rind; example, squash or melon. Perennial.-Any plant living for more than two years.

Petal.- One of the colored parts of the flower (see corolla) whose function is attraction of pollinating agents.

Phloem.-The special food-conducting channels in higher plants.

Photosynthesis. - The synthesis of carbohydrates from carbon dioxide and water, by plant cells containing chlorophyll, in the presence of sunlight. 
Phylum.-The largest classification unit; a group of classes. Examples, Bryophyta or Spermatophyta.

Piling.-Long, straight poles driven deep into the ground to act as supports for bridges, docks and buildings.

Pinnate.-A feather-like type of venation or leaf composition in which all leaflets or veins extend outward from a common midvein or midrib, which serves as a line of origin; example locust or ash.

Pistil.-The part of the flower producing ovules.

Pistillate.-The female flower cluster or flower part, containing pistils. Pith.-The central portion of the stem in Dicots.

Placenta.-The portion of the ovary to which the ovules are attached. Plastid.-Specialized parts of the cytoplasm found in plant cells, usually associated with pigments; example, green plastids such as chloroplasts.

Pod.-A dry fruit containing several seeds which splits open at maturity, characteristic of Pea and Bean Family.

Pollen.-The male gametophyte resulting from germination of the microspore.

Pollen tube.-The portion of the male gametophyte which grows out of the microspore, into the tissues of the pistil and ovule, and through which the male cell reaches the egg.

Pollination.-The transfer of microspores, or male gametophytes, to the pistil.

Pome.-An accessory fruit in which the ovary forms a core, and the receptacle and calyx form the fleshy portion; example, apple.

Protein.-Compounds made up of amino acids, chiefly composed of carbon, oxygen, hydrogen, nitrogen and sulphur.

Prothallus.-The small, often microscopic, gametophyte of a fern or a seed plant.

Protoplasm.-The living substance which is the physical basis of life; chiefly a mixture of proteins in the colloidal state.

Protozoa.-The group of unicellular animals; examples, Amoeba, Paramecium.

Pure stand.-A forest, or community of trees, made up of a single species, such as a pure white pine stand.

Pustule.-A small blister-like elevation on the surface of a plant part. It ultimately bursts to release the spores lying beneath it's covering. Pyroxylin.-A cellulose nitrate compound produced by partial nitration of cellulose.

Radial section.-A section of a tree trunk or of wood, which is cut along the radius of a circle formed by the end of the trunk, or cut on a line from the center of the trunk to the outside. 
Receptacle.-The end of a floral stem to which the calyx and corolla are attached.

Resin.-The raw sap of the longleaf pine.

Respiration.-The oxidation of carbon compounds in the cell, as a part of metabolism, necessary for the liberation of the energy in food. Rhizoid.-The filamentous absorbing structures of thallus plants and mosses.

Rhizome.-An underground creeping stem from which arise flowers and leaves.

Root hair.-Outgrowth of an epidermal cell of the root, specializing in absorption of water and dissolved minerals.

Rosin.-The hard residue left after distilling turpentine from resin.

Saprophyte.-A heterotrophic organism depending upon dead organic material for food.

Saprophytic.-Deriving organic materials from remains or products of organisms (see saprophyte).

Saw logs.- Logs of sufficient size to be sawed into lumber.

Sawtimber.-Trees, or timber of large enough size to be made into saw logs.

Sapwood.-The outer cylinder of the tree's woody stem, immediately surrounding the heartwood and gradually changing into it as growth progresses.

Sclerotium.-A mass of very heavy-walled hyphae, capable of withstanding cold and drought.

Sclerenchyma.-Highly specialized supporting tissue, represented by the fibers of hardwoods.

Seed.- The ripened ovule containing the embryo and stored food.

Sepal.-One of the green parts of the flower (see calyx) whose function is to support and protect the corolla.

Shelterbelt. - A belt-like planting of trees, placed at right angles to the prevailing winds for the purpose of protecting fields or homes.

Simple leaf.- - A leaf composed of a single blade, in contrast with the condition found in compound leaves (q.v.); example, elm or violet.

Slash.-The debris-tops, limbs, etc.-left after felling and removing timber from the forest.

Spathe.-A showy leaf, or bract; occurring below the fleshy floral axis of members of the Arum Family; example, calla lily.

Species. - The smallest classification unit: a group of related individuals which are able to breed with each other.

Sperm.-The motile male gamete produced during sexual reproduction. Spirillum.-A spiral or corkscrew-shaped bacterial cell.

Sporangium.-A structure in which spores are produced. 
Spore.-A specialized asexual reproductive cell.

Sporophyte.-The plant generation reproducing asexually by spores.

Stamen.-The part of a flower producing the pollen.

Staminate.-The male flower cluster or male parts of the flowers, containing stamens.

Starch.-A complex carbohydrate, the most common form of storage food in plants.

Stomate.-Minute opening in the epidermis of leaves, permitting exchange of gases.

Sucrose.-A more complex sugar than glucose, commonly known as cane sugar or beet sugar.

Sympetalous. - Having the petals united or fused with each other; example, morning glory or honeysuckle.

Tannin.-An astringent substance which forms an insoluble compound with proteins.

Terrestrial.-Living on land.

Thallophyte.-General term applied to all the thallus phyla; including fission plants, algae and fungi.

Thallus.-A plant body made up of many cells or a few tissues, but not definite and complex organs; examples, algae and fungi.

Theobromine.-The mildly stimulating alkaloid substance present in cocoa beans and cola nuts.

Tissue.-A group of cells alike in structure and function.

Toddy.-The sweet juice obtained by tapping the unopened flower clusters of several kinds of sugar palms.

Toxin.-A poisonous substance produced by bacteria.

Tracheid.-An elongated cell with slightly thickened and lignified walls, capable of functioning both for conduction and support; conspicuous in conifer wood.

Transpiration.-The loss of water through the stomates of leaves, by vaporization.

Tuber.-An underground stem functioning as a storage organ; example, white potato.

Turgidity.-The swollen condition of cells due to absorption of water and consequent distension of cell walls.

Vacuole.-A cavity in the protoplasm of a cell, usually filled with water or oil, or materials in solution.

Vascular.-Pertaining to the conductive processes, whereby materials are carried from one portion of an organism to another. 
Vegetative.-Pertaining to the part of the plant concerned with metabolism and maintenance of the life of the individual.

Venation.-The pattern formed by the veins in a leaf.

Vessel.- - Long tube-like structure found in the wood of higher plants, serving for conduction of water.

Virus.-An infectious substance, the exact nature of which is not well known, since it is invisible under the best microscopes, but which is capable of causing disease in plants and animals.

Volatile oil.-An essential oil which is highly volatile and can be distilled from plant tissues without being changed chemically.

Vulcanization.-The process of heating rubber in the presence of sulphur to render it a stable substance.

Whorl.-A circle of structures, such as petals or sepals, in a flower.

Wood.-The supporting cells of higher plants, constituting the bulk of the root and stem of perennial species.

Wood fiber.-Heavily lignified sclerenchyma cells found in xylem of Dicots.

Xanthophyll.-A yellow pigment, composed chemically of hydrogen, carbon and oxygen.

Xylem.-The water-conducting element of vascular plants.

Zoospore.-A swimming spore. 



\section{INDEX}

Page numbers in bold-faced type indicate location of illustrations.

Abacá, 351

Acacia, 387, 476

Accessory fruit, 168

Achene, 167, 168

Aconite, 381

Acorn, 168

Agar, 91

Agave, 352

Aggregate fruit, 168

Alcohol, 240, 397

Ale, 243

Aleurone, 170

Alder, 285

Algae, 5, 9, 10

blue-green, 15, 86, 87, 107

brown, 28-30, 88, 89, 90

green, $86, \mathbf{8 8}, 108$

red, 90, 91, 108

Algae-like fungi, 91, 92

Allspice, 229

Almond, 145, 200, 201

Aloes, 376

Alternate host, 407

Alternation of generations, 56, 57,

$$
60,63,66,81
$$

Alum root, 442, 443

Amaryllidaceae 469

Amaryllis Family, 469, 490, 491

Amber, 384

Amino acid, 135

Amorphophallus, 107

Anemone, 437, 438

Angiosperm, 67, 100-102, 108

Anise, 231
Annual ring, 43, 249, 252

Antheridium, 55, 56, 57, 58

Anthocyan, 137

Apple, 145, 194, 196

acreage, 195

life history of, 72, 81

Apricot, 147, 200

Araceae, 463, 464

Arbor vitae, 273, 274

Archegonium, 55, 56, 57, 58

Arrowroot, 397

Arum Family, 107, 109, 463, 464, 490

Ascomycetes, 92, 423-427

Ascus fungi, 92, 423-427

Asexual reproduction, 20, 50

Ashes, 77, 307, 308, 309, 324, 328, 332

Asparagus, 159, 160

Aspen, 282

Aster, 460, 462

Atropine, 376

Attar of rose, 390

Autotrophic, 13

Auxiliary pigments, 87

Avocado, 149, 188

Azalea, 148, 330, 452, 453, 479

Bacilli, 46, 403, 408

Bacteria, 5, 14, 45, 46, 51, 86, $107,113-116,403-412$

Bamboo, 354

Banana, 147, 207, 208

Baneberry, 436, 437 
Barberry, 478, 479

Bark, 40, 41

Barley, 144, 178

Basidiomycetes, 427-432

Basidium fungi, 93, 427-432

Basket flower, 460

Basswood, 302, 318, 324, 328

Bast fiber, 251, 252

Bean, 75

blight of, 411

broad, 144, 180

kidney, 149, 181

lima, 149, 181, 182

soy, 146, 180, 181

Bear grass, 469

Bearberry, 452

Beard tongue, 457

Bee balm, 455, 456

Beech, 287, 288, 314, 320, 322, $324,331,332$

Beech Family, 104, 108

Beechdrops, 416, 417

Beer, 242

Beet, 144, 155, 219, 220

Beggar tick, 78

Begonia, 146

Belladonna, 376

Bellwort, 465, 466

Bergamot, 456

Berry, 79, 80, 183

Beverages, 234

Big tree, 269, 270

Birch Family, 104

Birches, 283, 284, 285, 320, 322, $324,327,331,332$

Blackberry, 148, 189

Black-eyed Susan, 461

Bladderpod, 440

Blister rust, 340,430

Bloodroot, 438, 439
Blue curls, 455, 456

flag, 471

Blueberry, 148, 187

Blue-eyed grass, 471

Boneset, 459

Bougainvillea, 71, 482

Boxes, 324, 325

Bract, 72

Brandy, 243

Brazil-wood, 389

Bread mold, 419

Breadfruit, 213

Broccoli, 164

Brodiaea, 469

Broom rape, 416, 417

Broom Rape Family, 455

Broomcorn, 355

Broomroot, 355

Brown rot, 425

Brucine, 373

Brussels sprouts, 163, 164

Bryophyta, 86, 95, 108

Buckeye, 305, 306

Buckthorn, 379, 380

Buckwheat Family, 104, 158

Bulb, 165

Bunt of wheat, 429

Burbank, 153, 162

Burdock, 460

Burr, 78

Butter and eggs, 457, 458

Buttercup, 436

Buttercup Family, 104, 109, 436, 484

Butternut, 286

Cabbage, 144, 163, 164

Cacao, 149, 239

Cactaceae, 446

Cactus, barrel, 448

cane, 446, 447 
Cactus, Cereus, 449

cholla, 446

hedgehog, 448

pincushion, 448

prickly pear, 446, 447

sahuaro, 449

torch, 449

Cactus Family, 36, 104, 109, 446

Calla lily, 490

Calypso, 472, 473

Calyx, 69, 71

Camas, 469

Cambium, 42

Camphor, 391

Canada balsam, 386

Candytuft, 441, 486

Cantaloup, 146

Caraway, 231

Carbohydrates, 130, 131

Carbon cycle, 114

dioxide, 16, 113, 114 synthesis, 14

Carduaceae, 459

Carnation, 146, 483, 484

Carnauba wax, 396

Carotin, 137

Carrot, 144, 156, 157

Carrot Family, 231

Caryopsis, 167, 168

Cascara, 379, 380

Cassava, 397

Catalpas, 309, 315

Catkin, 68, 104

$$
\text { trees, 280-292 }
$$

Cat-tail Family, 105

Cauliflower, 163, 164

Cedars, 64, 272, 273, 274, 275, $276,277,314-316,333$

Celandine, 439

Celanese, 398

Celery, 144, 159
Cell, 5, 6

division, 50

wall, 6

Cellophane, 400

Cellulose, 114, 120, 132, 317, 398

Central cylinder, 38, 39

Century plant, 470, 471

Cereals, 168-179

Chamomile, 374

Chard, 162

Checkerberry, 231, 452

Chemical derivatives, 317

Cherry, 145, 198, 299, 327

Chestnut, 288, 289, 314, 315, 388 blight, 340, 414

Chicle, 364

China grass, 348

Chinese houses, 457

Chives, 165

Chlorophyll, 15, 136

Chlorophyta, 86, 88, 108

Chloroplast, 6, 25, 27, 32, 38

Chocolate, 238

Cholera, 410

Chrysanthemum, 147, 489

Cider, 243

Cinchona, 378

Cinnamon, 227

Citron, 147, 205, 206

Citrus fruit, 201

Class, 84

Classification, 107

Clematis, 77, 481

Clove, 228

Clover, 444

Clubmoss, 34, 59, 97, 108

Coal, 121

Coca, 374

Cocaine, 374

Cocci, 404, 409

Cocoa, 238, 239 
Coconut, 211

Codeine, 372

Coffee, 146, 234, 235

Coir, 355

Cola, 240

Colic root, 470

Collenchyma, 250

Colloid, 4

Colorless plants, 44

Columbine, 436, 437

Composite, 70, 71, 458

Composite Family, 105, 109, 158, 162

Cone, 64, 65

Conifer, 101, 108, 256, 257

Construction materials, 312

Cooperage, 323

Copal, 384

Copra, 395

Cork; 40, 329

Corn (see maize), 75,103,168, 396 lily, 466 pop, 176 syrup, 397

Cornel, 306

Corolla, 69, 70

Cortex, 38, 39, 40-42

Cosmos, 489

Cotton, 146, 149, 348, 349, 350

Cottonwood, 283, 324

Cotyledon, 75

Cranberry, 148, 187

Crates, 325

Creamcups, 439

Creeping pine, 98

Crinkleroot, 441

Crocus, 491

Cross ties, 314

Crown gall, 410, 411

Cruciferae, 440

Crucifers, black rot of, 411
Cucumber, 146, 190, 191 tree, 295, 296

Cucurbit wilt, 412

Currant, 145, 186

Currants, 185

Cuticle, 36

Cycad, 100, 101, 108

Cypress, 270, 271, 272, 274, 275, 314-316, 333

Cypress Family, 101

Cytoplasm, 6, 7

Daffodil, 491

Dahlia, 149, 489

Daisy, 460, 463

Damars, 384

Damping off disease, 340,420

Dandelion, 77

Date, 79, 145, 208, 209

Decay, 112

Deciduous habit, 279

Deliquescent, 257

Delphinium, 146

Desert candles, 469 gold, 461

Desmid, 24, 25

Dewdrop, 446

Dextrin, 131, 133, 397

Diatoms, 122

Dicot, 75, 102, 103, 108, 435 families, 104, 105

Digitalis, 375

Dill, 231

Dimension stock, 328

Dioscoreaceae, 158

Diphtheria, 408, 409

Diplococci, 409

Disc flower, 71

Disease, damping off, 340, 420

Dutch elm, 340, 423

forest tree, 339 
Disease, human, 404-410

$$
\text { leaf, } 341
$$

physiological, 415

plant, 410-432

seedling, 340

stem, 340

virus, 416

Distillation products, 322,323

Divi-divi, 388

Dodder, $\mathbf{4 1 7}$

Dogbane Family, 480

Dogberry, 465, 466

Dog's tooth violet, 465, 466

Dogwoods, 306, 307, 476

Douglas fir, 264, 265, 314, 317, $320,324,328,330,333$

Downy mildew, 422

Drugs, 370-382

Drupe, 80

Duckweed Family, 105

Dulse, 91

Dyes, 388-389

Easter lily, 148

Egg, 54 plant, 185

Elaioplast, 134

Elk grass, 466

Elm Family, 108

Elms, 292, 293, 294, 324, 328, 332

Endive, 160

Endosperm, 75

English ivy, 482, 483

Ephedrine, 378

Epidermis, 8, 10, 32, 35, 36

Ergot, 382, 413, 424

Ericaceae, 452

Erosion control, 123

Eucalyptus, 375, 476, 477

Euphorbiaceae, 487

Evening primrose, 451
Evening Primrose Family, 451

Evergreen habit, 258

Excelsior, 328

Excurrent, 257

False foxglove, 457 hellebore, 466

Solomon's seal, 466

Family, 84

Farewell-to-spring, 451, 452

Fats, 131, 133

Fawn lily, 466

Fence posts, 315

Ferns, 34, 57, 58, 59, 60, 96, 97, 108,330

Fertilization, 54, 74

Fertilizers, 139

Fetter bush, 330

Fiber board, 320

Fibers, 119, 251, 345, 355

Fig, 145, 212, 213

Figwort Family, 456, 457

Fir balsam, 319, 330, 331, 332

Fire blight, $\mathbf{4 1 0}$

Fireweed, 451

Firewheel, 461

Firs, 64, 267, 268, 330, 333

Fission, 50, 86

Five finger, 445

Flavorings, 230

Flax, 146, 345, 346, 393

Florida moss, 214

Flower, 67, 69

Flowering plants, 11

Foam flower, 442

Food, 129

Forest areas, 332, 333, 334-337

Forests, extent of, 331

fires of, 337

fungus diseases of, 339-341

insect pests of, 338-339 
Forests, products of, 312 protection of, 337-341 recreational value, 343 reproduction, 334-335

Forsythia, $\mathbf{4 8 0}$

Foxglove, 375

Fructose, 130

Fruit, 76, 77, 78-80, 119, 193

Fuchsia, 451, 452

Fucoxanthin, 137

Fuel, 120

$$
\text { wood, } 328
$$

Fungi, 10, 413-432

Furniture, 326

Fustic, 389

Gamete, 52, 53, 55, 56

Gametophyte, 57, 58, 62, 64, 65,

$$
74
$$

Garlic, 165

Genus, 84

Geranium, 146, 487

Geranium Family, 487

Gill fungi, 431

Gin, 243

Ginger, 227, 228

Ginseng, 380, 381

Gladiolus, 491

Glucose, 16, 25, 37, 129, 130, 397

Glucoside, 137

Goat's rue, 444

Golden club, 464

Goldenrod, 461

Goldenseal, 381

Gooseberry, 145, 146, 186

Gourd, 190

Gourd Family, 105, 190

Grape Family, 104, 184, 481

Grapefruit, 147, 204

Grapes, 79, 145, 184, 185

Grass, 105, 109
Grass Family, 105, 106

Grass of Parnassus, 442, 443

Grazing, 343

Ground pine, 97

Growth, 18, 43

Guarana, 240

Guava, 213, 214

Guayule, 368

Gum, 31, 133, 303, 314, 320, 326, 387

arabic, 387

black, 303

red, 294, 295, 314, 324, 327, 333

sweet, 294, 324

tragacanth, 387

Guncotton, 399

Gutta-percha, 366, 367

Gymnosperm, 64, 100, 101, 108, 256

Hairy cap moss, 33

germander, 455

Hardwood distillation, 322

Hardwoods, 279

Hawthorn, 475

Heath Family, 104, 109, 452

Heliotrope, 380

Hemlocks, 265, 266, 267, 314, $319,320,326,331,388$

Hemp, 146, 346, 347

Manila, 255, 351, 352

New Zealand, 353

Henequen, 352

Hepatica, 438

Heterotrophic, 15, 44

Hibiscus, 487

Hickories, 286, 287, 322, 328, 332, 333

Holdfast, 28, 29

Hollies, 301-302 
Holly Family, 104, 301

Hollyhock, 148, 488

Honey, 223

Honeysuckle, 70, 482

Honeysuckle Family, 482

Hop plant, 373, 374

Horse chestnut, 305, 476

Horse Chestnut Family, 104, 305

Horseradish, 145, 156

Horsetail, 34, 98, 99, 108

Huckleberry, 148, 187

Huckleberry Family, 105

Hyacinth, 490

Hybridization, 152

Hydrangea, 148, 479

Immunity, 405, 406

Indian cucumber root, 465, 466 paint brush, 457

pipe Family, 454

pipes, $\mathbf{4 5 4}$

poke, 466

tobacco, 375

Industrial alcohol, 397

Ingestion, 15

Innocence, 457

Iridaceae, 471

Iris, 491

Iris Family, 471, 491

Irish moss, 91

Iron bacteria, 14

Ironweed, 459

Istle, 352

Jack in the pulpit, $72,463,464$

Jamaica pepper, 229

Jelutong, 367

Joe-pye weed, 459

Jonquil, 491

Joshua tree, 106, 469
Juniper, 276

Jute, 347

Kale, 163

Kapok, 351

Kelp, 28, 29, 52, 89, 90, 108, 382

Kohlrabi, 163, 164

Kumquat, 147, 206, 207

Labiatae, 455

Lacquer, 384

Ladies tresses, 473

Lady's slipper, 471, 472

Laminaria, 28, 52

Larches, 262, 314, 317, 333

Larkspur, 146, 437, 484

Latex, 123, 359, 371

Laurel, 330, 453

Leaf, 32, 34, 35-37, 119, 162

Leek, 165

Legume, 180

Leguminosae, 443

Lemon, 147, 205

Lentil, 182

Lettuce, 144, 164

Leucoplast, 132

Lichen, 9, 93, 94, 118

Licorice, 381

Lilac, 146, 480

Liliaceae, 464-469

Lilies, 467, 468, 470, 490

Lily Family, 106, 109, 158, 162, 464-465

Lime, 147, 206, 207

Linden, 302

Little clubmoss, 59, 61, 62, 63

Liverwort, 30, 31, 32, 95, 96, 108

Lobelia, 375

Locoweed, 445

Locusts, 300, 301, 315, 328

Loganberry, 190 
Logging, 341

Logwood, 388

Loquat, 147

Lumber, 312, 313

Lupine, 444, 445, 486

Lupulin, 374

Mace, 229

Magnolia, 295, 474

Magnolia Family, 104, 295, 474

Magnoliaceae, 474

Maidenhair tree, 101, 108

Maize, 149, 173, 174, 175

$$
\text { acreage, } 176
$$

Male fern, 382

Mallow Family, 104, 109, 450, 487

Mallows, 450

Maltose, 130

Malvaceae, 450

Mandrake, 380

Mangrove bark, 388

Manila hemp, 351, 352

Manzanita, 452

Maple Family, 104, 303

$$
\text { sugar, } 221
$$

syrup, 221

Maples, 34, 77, 303-305, 314, $320,322,324,326,328$, 331,332

Marchantia, 30, 31, 32

Marigold, 489

Marsh marigold, 437, 438

Mass culture, 151

May apple, 380

Mead, 243

Meadow rue, 437, 438

Meadowsweet, 446

Megaspore, 61, 62

Melon, 190, 191

Membrane, 6, 7, 17

Metabolism, 12, 13
Microspore, 61, 62, 73

Mildew, 92, 108, 422, 426

Millet, 144

Mine timbers, 316

Mint, 455, 456

Mint Family, 105, 109, 232, 455

Mistletoe, 417, 418

Mistletoe Family, 104, 417

Mitrewort, 442

Moccasin flower, 471

Mockernut, 287

Molasses, 219

Mold, 9, 10, 46, 47, 108, 419, 420

Monkey flower, 456

Monkshood, 381

Monocot families, 105

Monocots, 75, 102, 103, 109, 435

Monotropaceae, 454

Moonwort, 441

Morel, 92

Morning Glory Family, 105, 155

Morphine, 372

Moss, 33, 54-56, 95, 108

Mountain ash, 475, 476 asphodel, 465

Mulberry, 145, 315

Mulberry Family, 213

Mullein, 457, 458

Multicellular organism, 7

Mushroom, 9, 47, 48, 93, 108, 118,125

root rot, 431

Mustard, 226

Mustard Family, 104, 155, 162, 440, 441, 485

Mycophyta, 86, 91, 108

Myrobalan nuts, 388

Myrtle Family, 476

Narcissus, 491

Naval stores, 385, 386 
Nightshade Family, 226

Nitrates, 25, 115

Nitrocellulose, 399

Nitrogen, 115, 140 cycle, $\mathbf{1 1 5}$

Nitrostarch, 398

Nucleus, 6, 27

Nut, 167, 168

Nutmeg, 229

Nutrient solution, 140

Nux vomica, 373

Oaks, 289-291-292, 314-316, 322, $324,326,328,329,332$, $333,388,389$

Oats, 144,179

Oedogonium, 53, 54

Oil, 133

cananga, 390
candlenut, 394
castor, 395
chaulmoogra, 372
chinawood, 393
citronella, 391
coconut, 395
corn, 394
cottonseed, 394
croton, 373
drying, 393
essential, 389
eucalyptus, 375
fatty, 392
fixed, 392
geraniol, 391
geranium, 390
lemon grass, 391
linseed, 393
non-drying, 393, 395
olive, 395
palm, 396
peanut, 395

Oil, poppy, 394

rose, 390

sage, 232

soy bean, 394

sunflower, 394

tung, 393

violet, 391

volatile, 389

walnut, 394 .

wintergreen, 231

Oleander, 480

Oleoresin, 385

Olive, 145, 214

Olive Family, 479

Onagraceae, 451

Onion, 144, 146, 165

Opium, 371, 372 poppy, 371, 372

Orange, 147, 202, 203

Orchid Family, 106, 109, 471, 472

Orchidaceae, 471

Orchids, 149, 473

Orchis, 471, 472, 473

Order, 84

Organ, 10, 11, 12

Orobanchaceae, 455

Osage orange, 315, 389

Ovule, 64, 65, 73

Owl's clover, 458

Oxygen, 16, 112

Palm, cabbage, 478 coconut, 210, 211, 355, 476 date, 208, 209, 477

hat, 353

royal, 477

sago, 101, 397

Washington, 477, 478

Palm Family, 106, 109, 208, 476

Panama hat, 353

Pansy, 146, 486 
Papaveraceae, 438

Paper, 320, 321

Paprika, 186

Parasite, 45, 57

Parasitism, 116

Parenchyma, 8, 10, 36

Parsley, 145, 164, 231

Parsley Family, 155, 158, 162

Parsnip, 145, 157

Partridge Pea, 443

Pasque flower, 438

Pea, 145, 182, 486

Pea Family, 104, 109, 443, 444, $475,480,486$

Peach, 80, 147, 199 acreage, 199 yellows, 416

Peanut, 182, 183

Pear, 145, 196

Pearly everlasting, 459

Peat moss, 95, 120, 121

Pecan, 287

Pectin, 133

Pedigree culture, 151

Peony, 148, 436, 437, 484

Pepper, 225, 226

Pepper Family, 104

Peppermint, 232

Peppers, 149, 186

Pepperwort, 440

Perfume, 390

Persimmon, 148, 214

Petal, 69, 70

Petroleum, 122

Petunia, 149, 488

Phaeophyta, 86, 88, 89, 108

Phloem, 40, 41, 42

Phosphorus, 140

Photosynthesis, 16, 23, 26

Phycocyanin, 138

Phycoerythrin, 138
Phycomycetes, 419-423

Phylum, 84

Pigments, 136, 287

Pignut, 287

Pigweed Family, 155, 162

Piling, 314, 315

Pine family, 101, 258

life history, 64, 65, 66

Pineapple, 149, 215

Pineapple Family, 214

Pinedrops, 454

Pines, 64, 258, 259, 260, 261, 278, $314,316,317,318,319$, $323,324,326,328,330$, $332,333,385,386$

Pinesap, 454

Pink Family, 104, 108, 482

Pistil, 68, 69, 73

Plane tree, 298

Plant fibers, 345

Plastics, 322

Plastid, 7

Plum, 80, 145, 197

Plumule, 75

Plywood, 324, 325

Pod, 168

Podophyllum, 380

Pogonia, 472, 473

Poinsettia, 149, 487

Poison ivy, 125

Poisonous plants, 125, 126

Poles, 314

Pollen, 8, 64, 73 tube, 73,74

Pollination, 74

Pome, 194

Pondscum, 10, 27, 108

Pondweed Family, 105

Poplar, yellow, 296, 326, 332, 333

Poplars, 282, 283, 320 
Poppies, 146, 371, 372, 439, 440, Quince, 145, 197

\section{$485 \quad$ Quinine, 378}

Poppy Family, 104, 438, 484, 485

Pore fungi, 431

Porphyra, 91

Potassium, 140

Potato, black scurf of, 432

blight of, 414, 421

scab of, 411, 432

sweet, 149, 157, 158

white, 149, 160, 161, 397

wild, 70

Potato Family, 105, 158, 488

Powdery mildew, 424, 426

Prairie star, 443

Primrose, 451

Primrose Family, 105

Primrose willow, 451

Primus berry, 190

Privet, 479

Proteins, 4, 115, 134, 135, 136

Prothallus, 57, 58, 59

Protococcus, $\mathbf{5 0}$

Protoplasm, 3, 14

Protozoa, 5

Prune, 198

Psyllium, 373

Pteridophyta, 86, 96, 108, 121

Pulp, groundwood, 319

mills, 318

soda, 320

sulphate, 319

sulphite, 319

wood, 317

Pulque, 243

Pumpkin, 149, 190

Pussy toes, 459

Pyroxylin, 399

Quebracho, 388

Quercitron, 389

Radicle, 75

Radish, 144, 146, 156

Raisin, 185

Ramie, 348

Ranunculaceae, 436

Raspberry, 148, 189

Rattan, 354

Rattlebox, 444

Ray flower, 71

Rayon, 320, 398, 399

Red ribbons, 452

Redbud, 475

Redwood, 269, 314, 315, 316, 333

Redwood Family, 101, 314

Reforestation, 335

Reproduction, characteristics of, 85

forest, 334, 335

types of, 49

Resins, 383, 384

Respiration, 13, 26

Rhizoid, 31, 32, 33, 58, 59

Rhododendron, 330, 453, 479

Rhodophyta, 86, 90, 91, 108

Rhubarb, 159

Rice, 146, 176, 177, 397 acreage, 177

Rocket, 441

Root, 32, 35, 38, 39, 118, 154

cap, 38

hair, 39, 40

parasites, 417

Rosaceae, 445, 475

Rose Family, 104, 109, 193, 445, 475

Rose of Sharon, 487

Roses, 70, 146, 147, 445, 446, 486

Rosin, 385 
Rubber, 149, 359

assam, 366

balata, 363

Brazilian, 360

caucho, 363

ceara, 363

desert milkweed, 368

guayule, 368

India, 366

intisy, 365

Lagos, 365

Landolfia, 365

Panama, 363

Para, 360-362

synthetic, 369

Rue Family, 104, 201

Rum, 243

Rusts, 341, 429-431

Rye, 144, 178, 179

Sage, 232

Sagebrush, 464

Sago palm, 101, 397

Saké, 243

Sand corn, 468

Sandalwood, 389

Saprophyte, 45

Sapwood, 41

Sargasso Sea, 90.

Saxifragaceae, 442

Saxifrage, 443

Saxifrage Family, 104, 442, 443

Sawdust, 328

Scarlet bugler, 457

Schizophyta, 86, 87, 107

Sclerenchyma, 250, 251

Scotch broom, 480

Scouring rush, 98

Scrophulariaceae, 456

Seaweed, 10, 28, 54, 108
Seed, 60, 66, 67, 75, 76

plants, 100

Selaginella, 61

Selection, 150, 151

Sepal, 69, 71

Sequoia, 18, 19, 269, 270

Sex organ, 54, 55

Sexual reproduction, 20, 53

Shavings, 328

Shepherd's purse, 440

Shingles, 315

Sieve tube, 8

Silverrod, 461

Sisal, 255, 352, 353

Skullcap, 455, 456

Skunk cabbage, 463, 464

Smuts, 427, 428, 429

Snow plant, 454

Soap plant, 468

Softwood distillation, 323

Solomon's seal, 466

Soluble starch, 397

Sorghum syrup, 222

Soy bean, 146, 180, 181

Spanish bayonet, 469

dagger, 469

Spathe, 72

Spearmint, 232

Species, 83

Speedwell, 457

Sperm, 54

Spermatophyta, 86, 99, 100, 108

Sphagnum, 120, 121

Spices, 224-225

Spinach, 145, 163

Spirilla, 404, 409, 410.

Spirogyra, 27, 52, 88

Sporangium, 52, 58, 62, 65, 66

Spore, 20, 51, 58

Sporophyte, 57, 59 
Spruces, 64, 263, 278, 318, 319, Tetanus, 409

$$
320,326,330-333
$$

Spurge Family, 487

Squash, 149, 190

Squawroot, 416, 417

Stalk, 28, 29

Stamen, 68, 69, 72, 73

Starch, 131, 132, 396, 397

Steeple bush, 446

Stem, 32, 35, 40, 41, 119, 158,

$$
\text { 252, } 254
$$

parasites, 417

Stock, 485, 486

Stomate, 35, 36

Stone cell, 250

Strawberry, 145, 148, 188, 189, 445,446

leak, 420

Streptococcus, 409

Strychnine, 373

Sucrose, 130, 216

Sugar acreage, 216

beet, 219, 220

cane, 217

maple, 221

palm, 222, 223

Sundrops, 451

Sunflower, 461, 462

Supporting tissues, 10, 253, 254

Sweet alyssum, 485, 486

flag, 463, 464

pea, 486

William, 483, 484

Sycamore, 297, 298

Symbiosis, 93

Tamarack, 262, 314

Tannin, 138, 387, 388

Tape-grass Family, 105

Tea, 146, 236, 237
Thallophyte, 9, 10, 86

Thallus, 9, 10 plants, 9, 117

Thimbleberry, 445, 446

Thistle, 460 sage, 456

Thistle Family, 458-460, 488, 489

Tick trefoil, 78

Timber harvesting, 341, 342 supplies, 333, 334

Tissue, 8, 10

Tobacco, 149, 376-378

acreage, 377

mosaic, 416

Tomato, 79, 149, 185

Toothwort, 441

Touch-me-not, 77, 78

Tracheid, 248, 249

Trailing arbutus, 452, 453

Transpiration, 36

Trees, Angiosperm, 279

deciduous, 279

evergreen, 258

Gymnosperm, 256

Trillium, 467

Truffles, 92

Trumpet creeper, 482

Tuberculosis, 408

Tulip, 146, 490 tree, 296

Tung oil, 393

Tupelo, 303, 314, 324, 333

Turgidity, 247

Turnip, 144, 155

Turpentine, 385, 386

Turtlehead, 456

Twayblade, 472, 473

Twisted stalk, 466 
Ulothrix, 51, 52, 53, 88

Unicellular organisms, 4 plants, 5, 24, 51

Vacuole, 6

Valerian, 380

Valonia, 388

Vanilla, 230

Vascular, 8, 10

Vegetable acreage, 166

Vegetables, 119, 154-166

Vegetative organs, 118

Veneers, 324, 325

Vessel, 8, 42

Vinegar weed, 456

Violaceae, 441

Violet, 442

Violet Family, 104, 441, 486

Virus, 416

Vodka, 243

Wallflower, 441, 485

Walnut Family, 104, 108, 285

Walnuts, 285, 286, 327, 332

Water arum, 463, 464

hyacinth, 105

lily, 104

Watermelon, 145, 191, 192

Watershed protection, 342

Wax, 134

Wheat, 144, 169, 170-173, 397 acreage, 171

Whisky, 243
Wild geranium, 78 hyacinth, 469 indigo, 444 life, 343

Willow Family, 104, 280

Willows, 68, 280, 281

Wine, 241

Wintergreen, 231

Wistaria, 148, 481, 482

Witches broom, 418

Wood, 42, 113

betony, 457, 458

containers, 323

fibers, 8, 42, 251

pulp, 317

rot, 341

waste, 311

Woodbine, 482, 483

Xanthophyll, 137

Xylem, 40, 42

Yam, 158

Yarrow, 461

Yeast, 92

Yellow star grass, 470

Yerba maté, 240

Yew, 277

Yew Family, 101, 277

rucca, 280, 469

Zinnia, 488, 489

Zoospore, 51, 52 



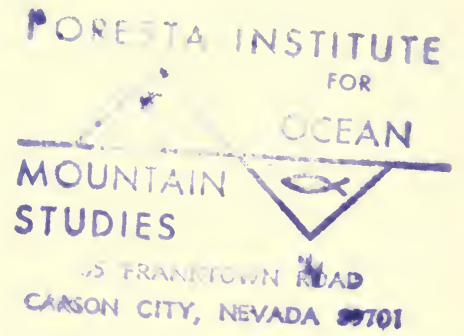


